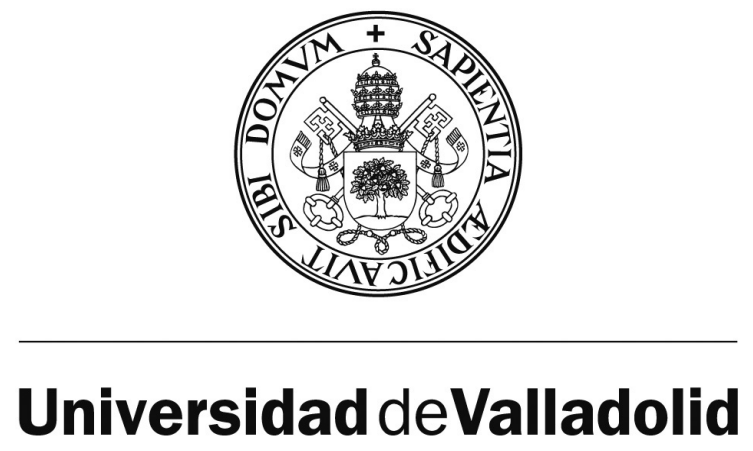

ESCUELA TÉCNICA SUPERIOR DE INGENIERÍAS AGRARIAS

DEPARTAMENTO DE INGENIERÍA AGRÍCOLA Y FORESTAL

TESIS DOCTORAL:

\title{
CARACTERIZACIÓN Y MEJORA TECNOLÓGICA DE LA MADERA DE POPULUS X EURAMERICANA I-214 (DODE) GUINIER, AUSTRAL Y BOREAL, CON FINES ESTRUCTURALES
}

Presentada por Eleana María SPAVENTO para optar al grado de doctora por la Universidad de Valladolid

\author{
Dirigida por: \\ Dr. Luis ACUÑA RELLO \\ Dra. Ma. Teresa de TROYA FRANCO
}




\section{AGRADECIMIENTOS}

Deseo expresar mí agradecimiento a todas aquellas personas que de una forma u otra me han ayudado y apoyado durante este camino.

Al programa Eurotango ERASMUS MUNDUS por el financiamiento de la instancia de máster y parte de la instancia doctoral.

A la Universidad de Valladolid por el grato acogimiento durante esta instancia y muy especialmente al Grupo de Investigación en Estructuras y Tecnologías de la madera.

Al Instituto Nacional de Investigación y Tecnología Agraria y Alimentaria, INIA, Centro de Investigación Forestal, CIFOR, por su grato acogimiento y muy especialmente al grupo que comprende el Laboratorio de Protección de Maderas.

A la Facultad de Ciencias Agrarias y Forestales por el apoyo para la realización de la instancia de máster y doctorado en España.

A la Unidad de Cambio Rural, UCAR, Componente Plantaciones Forestales Sustentables, Ministerio de Agricultura, Ganadería y Pesca, Argentina (BIRF 7520-AR), por el gran apoyo económico brindado para la compra de todo el material de procedencia argentina, equipamiento/materiales de laboratorio y viajes para la realización de la instancia internacional, con especial mención para la Ing. Florencia Reca y el Ing. Martín Aguerre por su buena predisposición para atender y darle respuestas a mis necesidades.

A la Universidad Nacional de La Plata por el apoyo económico otorgado para poder culminar mi instancia doctoral en España.

Al Laboratorio de Estudios de Materiales y Estructuras para la Ingeniería Civil, Facultad de Ingeniería, Universidad Nacional de La Plata, especialmente Jorge Anille y Teodoro Galván por su buena predisposición para la realización de los ensayos mecánicos.

A mi director, Dr Luis Acuña Rello, sin cuyo inestimable apoyo, conocimientos y enseñanzas, este trabajo no hubiese sido posible ni tampoco hubiese sido tan ameno.

A mi co-directora, Dra María Teresa de Troya Franco, por su incondicional apoyo, enseñanzas y consejos.

A mi tutor académico, M. Sc. Gabriel Keil, por su inconmensurable apoyo, conocimientos y palabras de aliento en cada paso recorrido, desde y en Argentina.

A mi compañera Milagros Casado por el apoyo y buena predisposición y por haberme hecho sentir como en casa desde el primer día

A mis compañeras Mercedes Refort y Carla Taraborelli por su gran apoyo para la realización de los ensayos en Argentina y por alentarme para que esta etapa llegara a su fin. 
A mi compañera Mónica Murace por su apoyo en los temas de durabilidad en Argentina.

Al Ing. Agr. Miguel Ángel Barberis perteneciente al área de Fruticultura del Ente de Desarrollo de la zona de General Conesa (EN.DE.CON), Gerenal Conesa, Río Negro, por aportarme los datos meteorológicos de la zona de procedencia del material de ensayo y por estar siempre dispuesto a mis consultas.

Al Ing. Agr. Norberto Serventi por sus gestiones para conseguir el material de ensayo de Argentina y por brindarme sus vastos conocimientos en los temas foresto-industriales.

A mi familia que nunca deja de apoyarme en todo lo que emprendo, aunque eso muchas veces signifique largos tiempos sin vernos.

A mis amigos, los de siempre, los nuevos, los de aquí y de allí, por el apoyo incondicional y la compresión en mis largos tiempos de ausencia.

A Miguel, mi gran compañero de vida, por ayudarme y por acompañarme en cada paso de mi crecimiento personal y profesional.

Y por último, a todas aquellas personas, que fueron muchas y sería una lista extensa para mencionar, que de una forma u otra formaron parte de la realización de esta tesis, sumándole un granito de arena a esta etapa. 


\section{ÍNDICE DE CONTENIDOS}

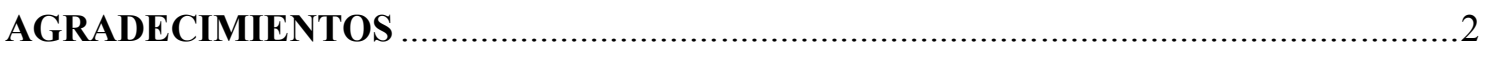

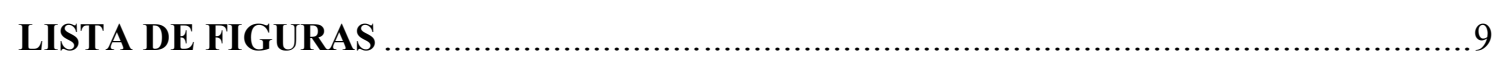

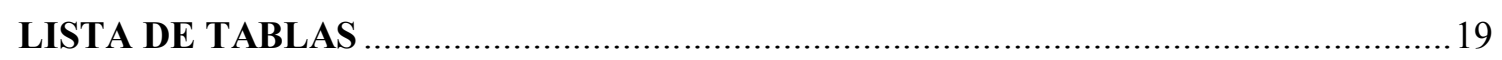

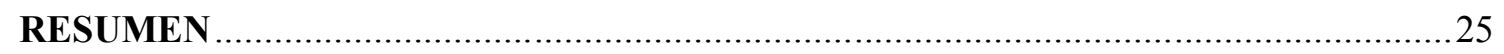

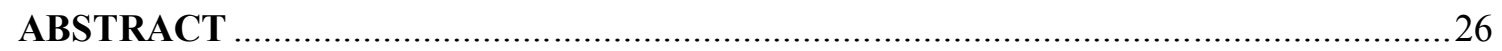

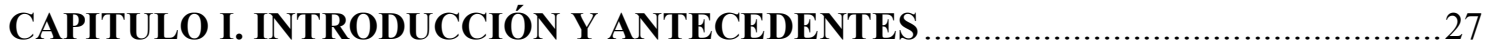

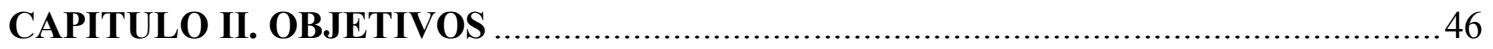

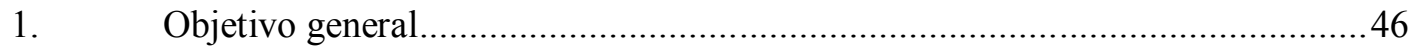

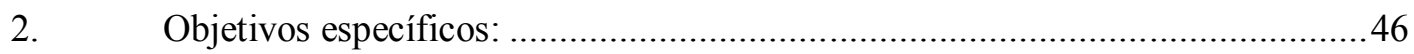

2.1. Caracterización de madera maciza...............................................................46

2.1.1. Probetas de pequeñas dimensiones y libre de defectos ....................................46

2.1.2. Piezas macizas semi-estructurales (escala 1:5) ................................................46

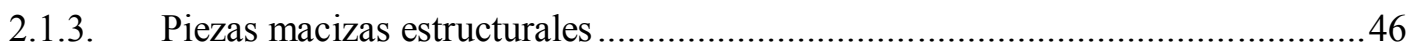

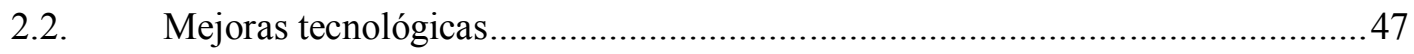

2.2.1. Probetas de pequeñas dimensiones y libre de defectos ...................................47

2.2.2. Piezas macizas semi-estructurales (escala 1:5) ...............................................4

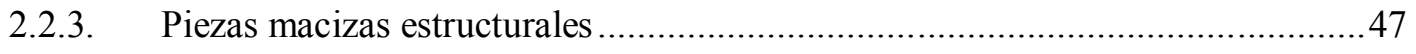

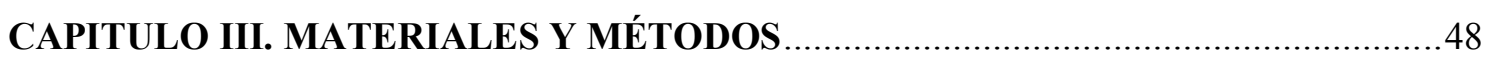

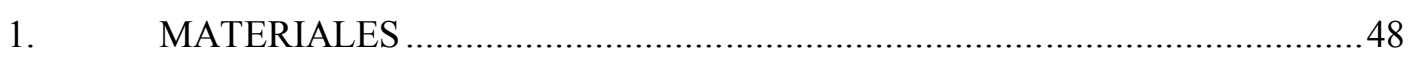

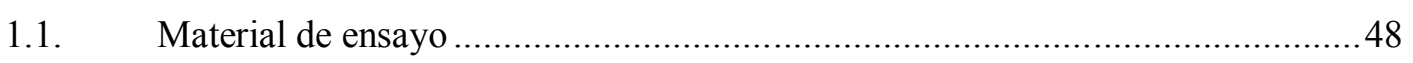

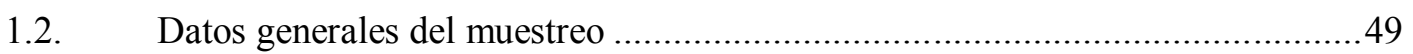

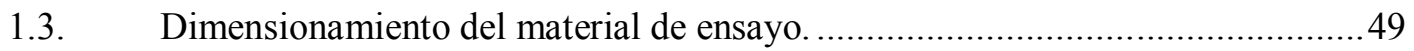

1.3.1. Material macizo de pequeñas dimensiones. ..................................................50

1.3.2. Material macizo semi-estructural (escala 1:5) ...............................................50

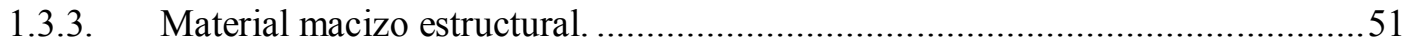

1.3.4. Material encolado: piezas dúo y trío. ………...............................................5

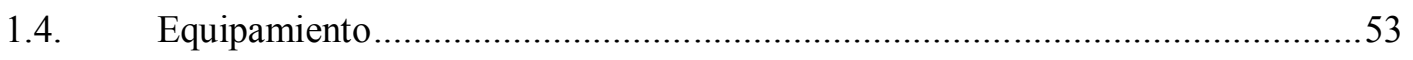

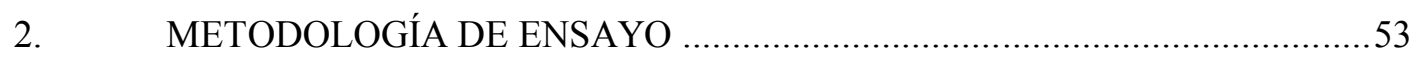

2.1. SECCIÓN I: Caracterización de madera maciza ……........................................53

2.1.1. Probetas de pequeñas dimensiones y libres de defectos....................................53

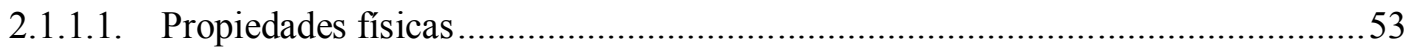

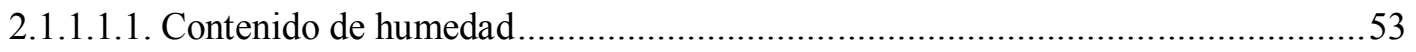

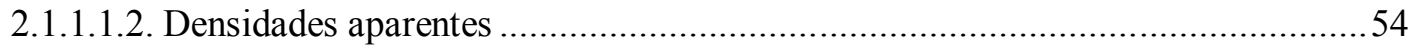

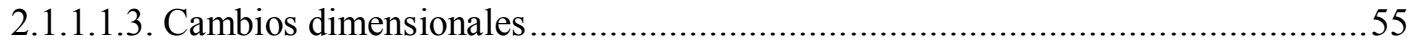




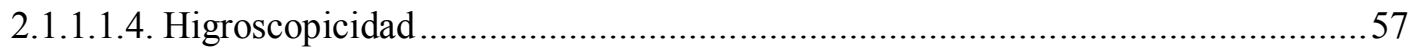

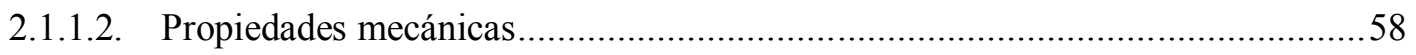

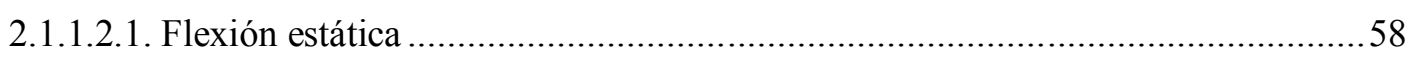

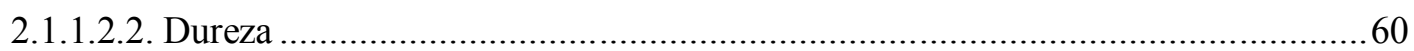

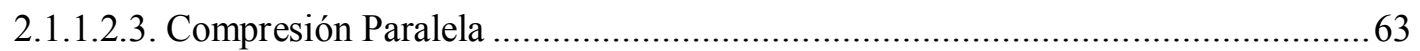

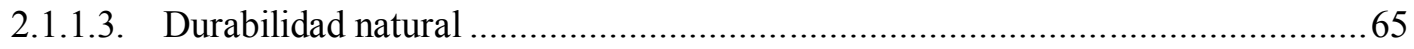

2.1.1.3.1. Determinación de la durabilidad frente a hongos basidiomicetos xilófagos .......65

2.1.1.3.2. Determinación de la durabilidad frente a hongos ascomicetos e imperfectos .....67

2.1.1.3.3. Determinación de la durabilidad frente a Termitas ............................................69

2.1.2. Piezas macizas semi-estructurales (escala 1:5) y piezas macizas estructurales...71

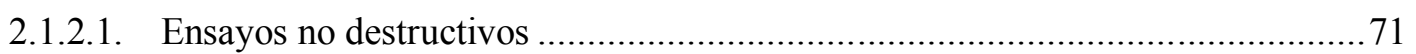

2.1.2.1.1. Inspección-medición de singularidades y clasificación visual ............................71

2.1.2.1.2. Técnicas de ensayo no destructivas (NDT) ….................................................77

2.1.2.1.3. Efectividad de las NDT en la estimación de las clases resistentes .....................79

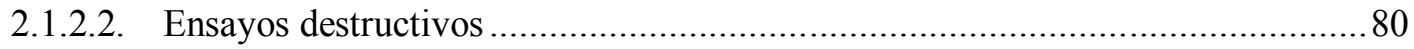

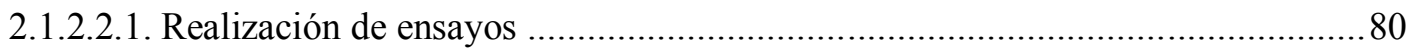

2.1.2.2.2. Determinación de valores característicos (EN 384:2010) ................................83

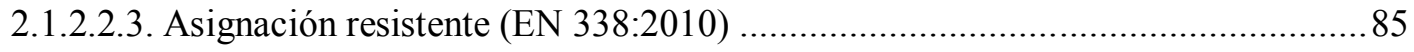

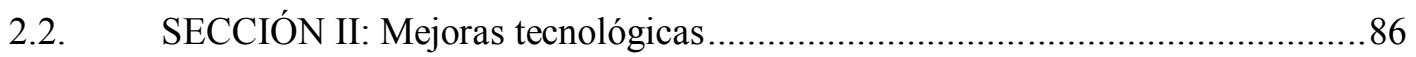

2.2.1. Probetas de pequeñas dimensiones y libres de defectos...................................86

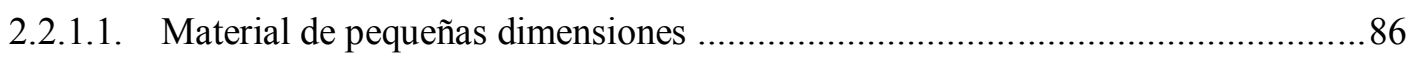

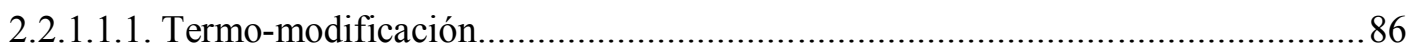

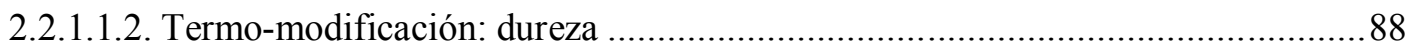

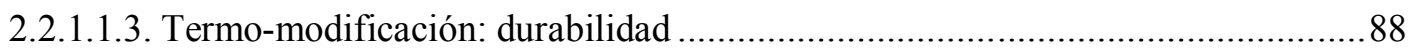

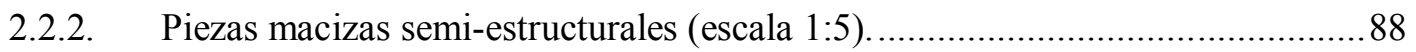

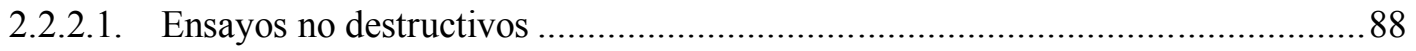

2.2.2.1.1. Determinación del MOE a través de la frecuencia propia de vibración en piezas

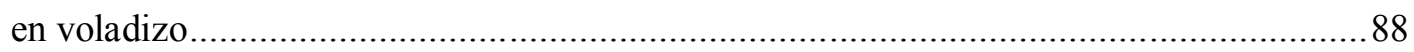

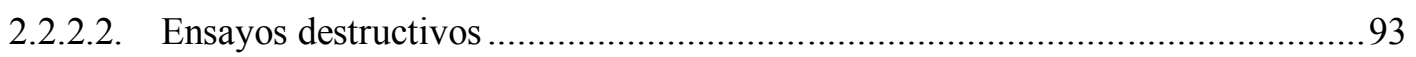

2.2.2.2.1. Evaluación elasto-resistente en piezas dúos y tríos........................................93

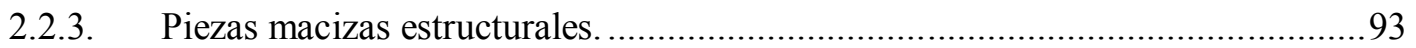

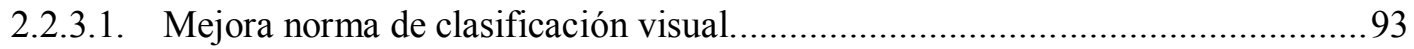

2.2.3.2. Procedimiento para control triboluminiscente de sobrecarga en madera

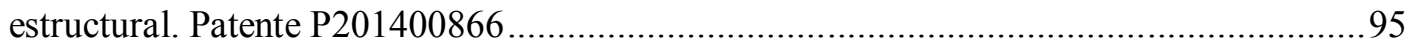

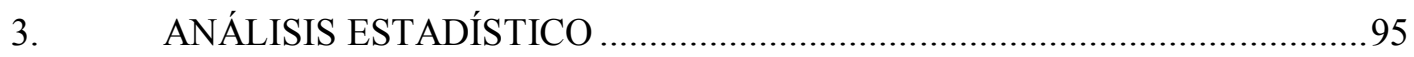


CAPITULO IV. RESULTADOS Y DISCUSIÓN 104

4. SECCIÓN I: Caracterización de madera maciza .. 104

4.1. Probetas de pequeñas dimensiones y libres de defectos. 104

4.1.1. Propiedades físicas. 104

4.1.1.1. Contenido de humedad $(\mathrm{CH})$. 104

4.1.1.2. Densidades aparentes 106

4.1.1.3. Cambios dimensionales 109

4.1.1.3.1. Parámetros dimensionales lineales 109

4.1.1.3.2. Parámetros volumétricos 113

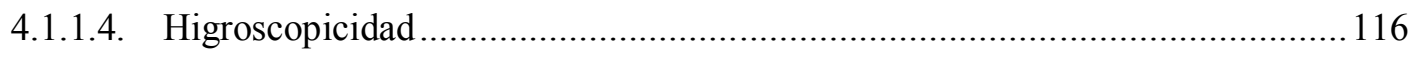

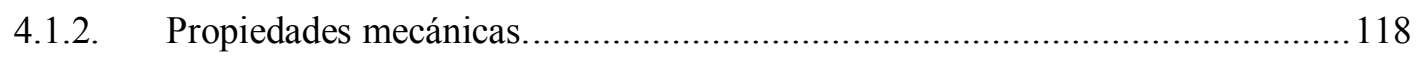

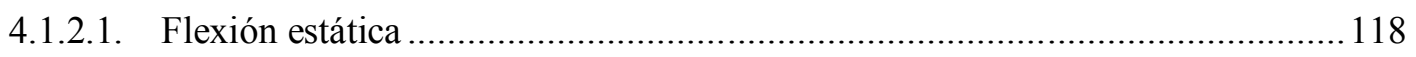

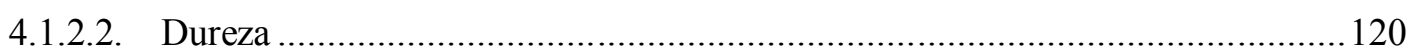

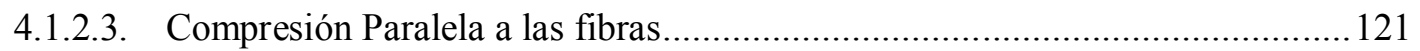

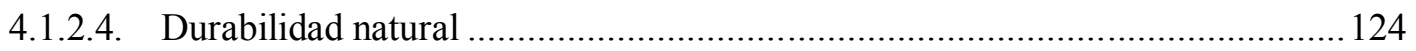

4.1.2.4.1. Determinación de la durabilidad frente a hongos basidiomicetos xilófagos ..... 124

4.1.2.4.2. Determinación de la durabilidad frente a hongos ascomicetos e imperfectos ... 129

4.1.2.4.3. Determinación de la durabilidad frente a termitas

4.2. Probetas de pequeñas dimensiones y libres de defectos: consideraciones generales 134

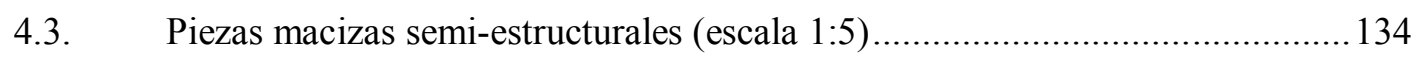

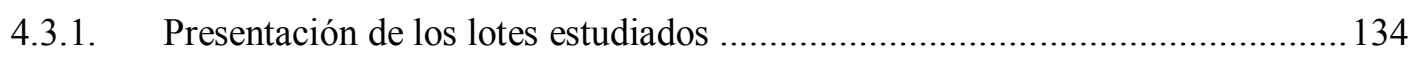

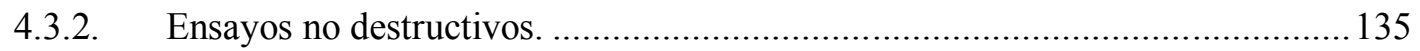

4.3.2.1. Inspección-medición de singularidades y clasificación visual. ......................... 135

4.3.2.2. Comportamiento clasificatorio de la norma de clasificación visual................... 135

4.3.2.3. Determinación de parámetros dinámicos mediante ensayos no destructivos .... 137

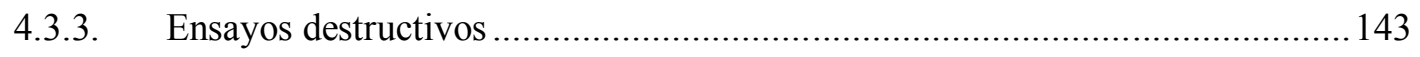

4.3.3.1. Influencia de defectos naturales en el Módulo de elasticidad (MOE)................ 147

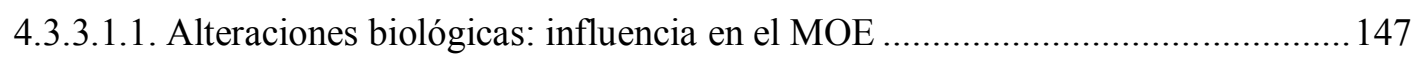

4.3.3.2. Influencia de defectos naturales en el Módulo de rotura (MOR)...................... 148

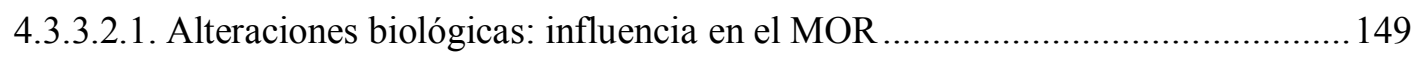

4.3.3.3. Predicción de variables elasto-resistentes a partir de NDT ............................... 150

4.4. Piezas macizas semi-estructurales (escala 1:5): consideraciones generales ....... 155

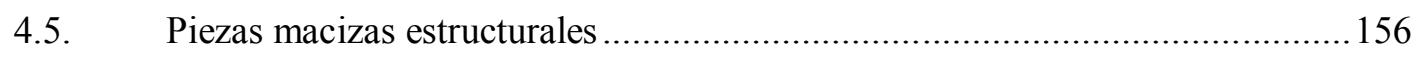

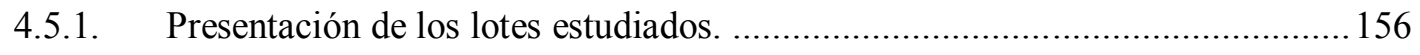




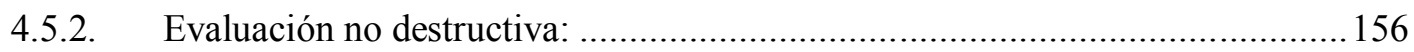

4.5.2.1. Inspección-medición de singularidades y clasificación visual .......................... 156

4.5.2.2. Comportamiento clasificatorio por norma de clasificación visual.....................157

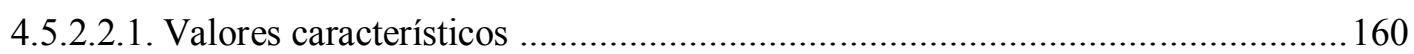

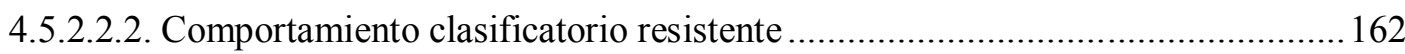

4.5.2.2.3. Comportamiento comparativo entre clases visuales y clases resistentes: Aciertos, Subestimas y Sobreestimas. 169

4.5.2.3. Comportamiento clasificatorio mediante metodología de ensayo no destructiva 173

4.5.2.3.1. Determinación de parámetros dinámicos mediante NDT................................. 173

4.5.2.3.2. Efectividad de los NDT en la estimación de las clases resistentes ....................176

4.5.2.4. Influencia de las singularidades en las variables estudiadas............................. 179

4.5.2.4.1. Influencia de defectos en el Módulo de elasticidad (MOE) .............................. 180

4.5.2.4.1.1. Defectos naturales: influencia en el MOE ............................................... 180

4.5.2.4.1.2. Defectos de aserrado: influencia en el MOE ........................................... 186

4.5.2.4.1.3. Defectos de secado: influencia en el MOE ............................................... 189

4.5.2.4.2. Influencia de defectos en el Módulo de Rotura (MOR) ................................... 192

4.5.2.4.2.1. Defectos naturales: influencia en el MOR .............................................. 192

4.5.2.4.2.2. Defectos de aserrado: influencia en el MOR ............................................ 198

4.5.2.4.2.3. Defectos de secado: influencia en el MOR ................................................ 201

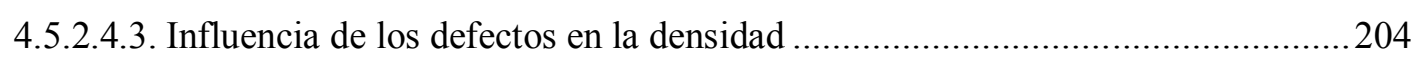

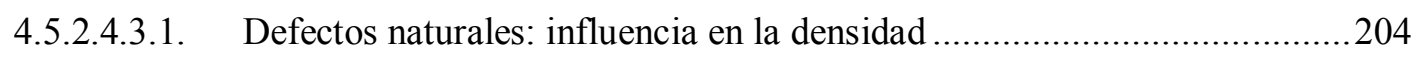

4.5.2.4.3.2. Defectos de aserrado: influencia en la densidad ......................................209

4.5.2.4.3.3. Defectos de secado: influencia en la densidad .......................................213

4.5.2.4.4. Influencia de los defectos (agrupados por tipo) en la predicción de las variables

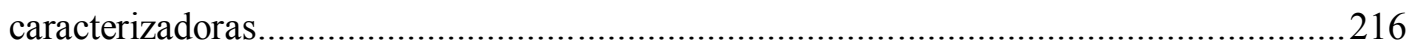

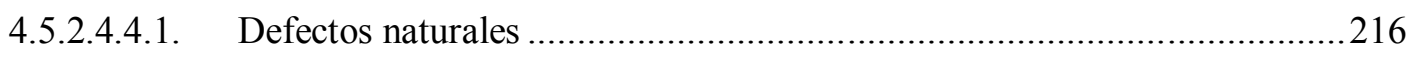

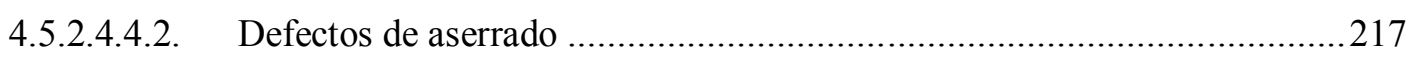

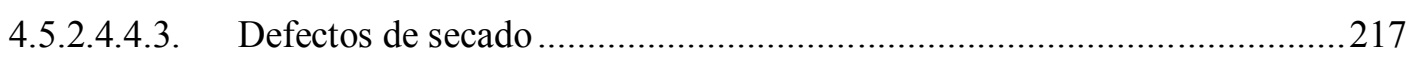

4.5.2.4.5. Influencia de los parámetros no destructivos en la predicción de las variables

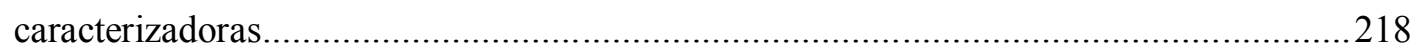

4.6. Piezas macizas estructurales: consideraciones generales ................................219

4.7. Caracterización de madera maciza: consideraciones finales. ….......................221

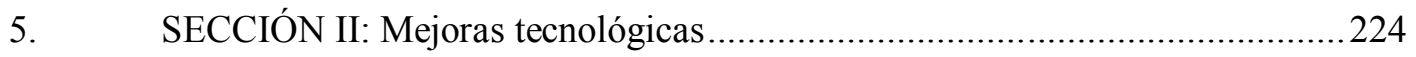

5.1. Probetas de pequeñas dimensiones y libres de defectos.................................224 


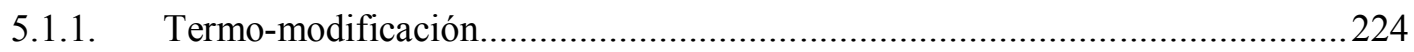

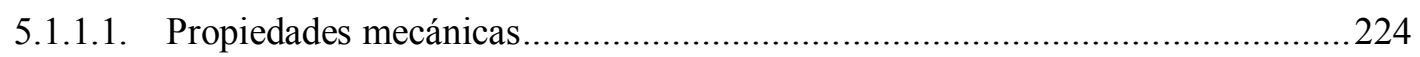

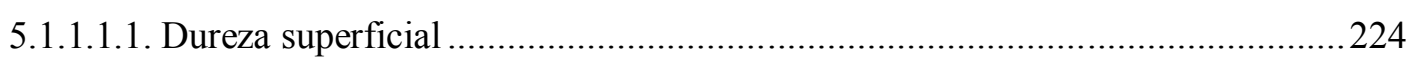

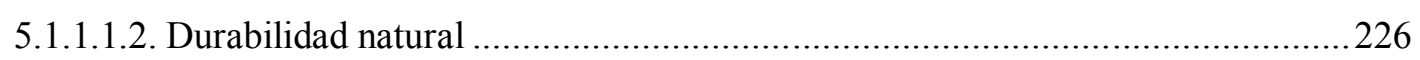

5.1.1.1.2.1. Determinación de la durabilidad frente a hongos basidiomicetos xilófagos 226

5.1.1.1.2.2. Determinación de la durabilidad frente a termitas ..................................223

5.2. Piezas macizas semi-estructurales (escala 1:5) ............................................235

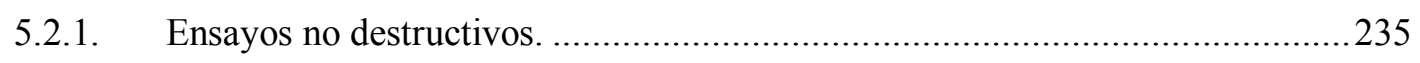

5.2.1.1. Determinación del MOE a través de la frecuencia propia de vibración en piezas

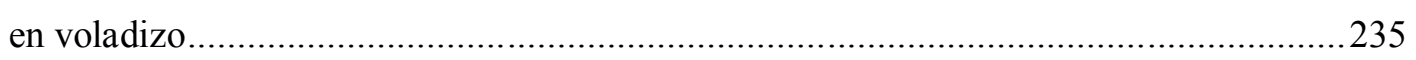

5.2.1.2. Predicción del MOE a partir del ensayo de vibración libre en voladizo ............240

5.2.2. Ensayos destructivos: piezas dúo y trío...........................................................241

5.2.2.1. Valores elasto-resistentes del material encolado reagrupado por clases visuales 251

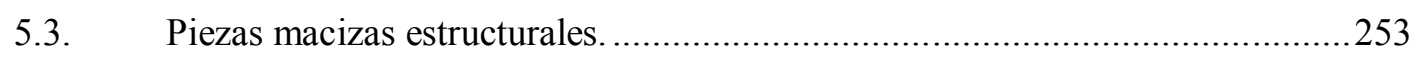

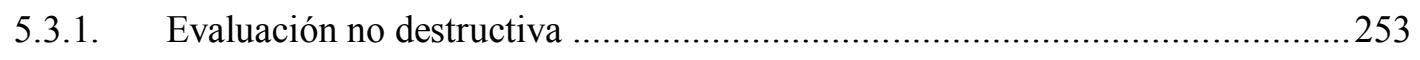

5.3.1.1. Propuesta de mejora de norma de clasificación visual ....................................253

5.3.1.2. Procedimiento para control triboluminiscente de sobrecarga en madera

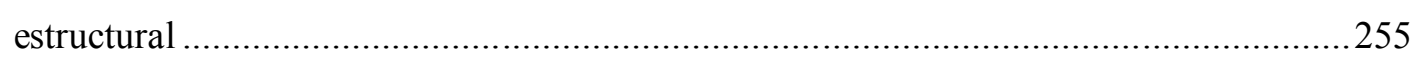

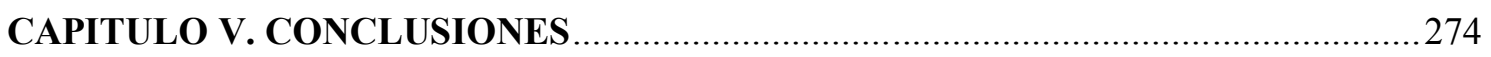

CAPITULO VI. REFERENCIAS BIBLIOGRÁFICAS …............................................22

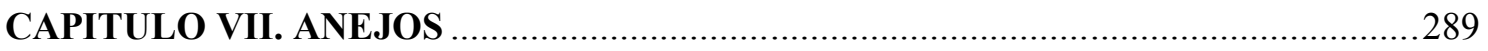




\section{LISTA DE FIGURAS}

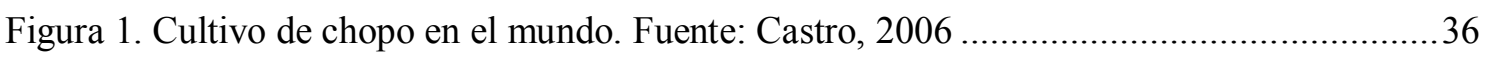

Figura 2. Climodiagrama deWalter y Lieth: Villafer - León - España: período 1938-1970 .......48

Figura 3. Climodiagrama deWalter y Lieth: General Conesa - Río Negro - Argentina: período 2009-2014

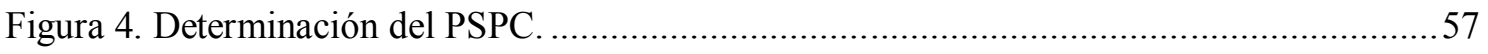

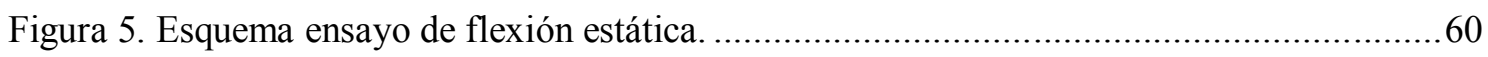

Figura 6. Gráfico carga - deformación con línea de tendencia (en rojo) en 10\% - 40\% de carga

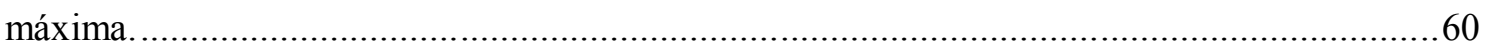

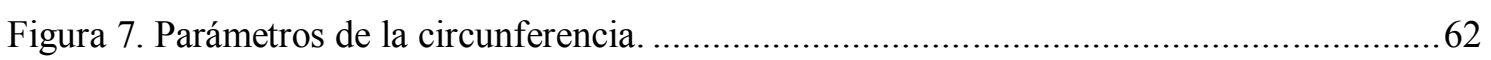

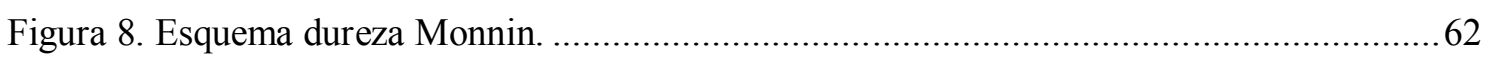

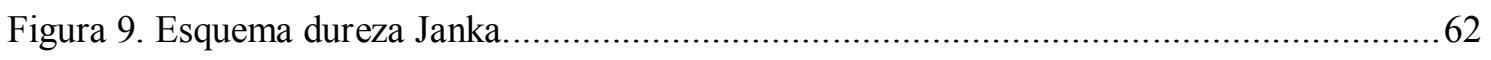

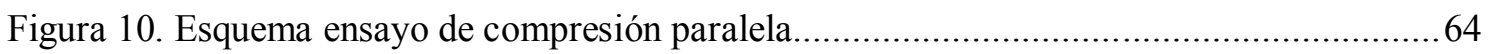

Figura 11. Anchura de anillos de crecimiento: medición. ........................................................ 72

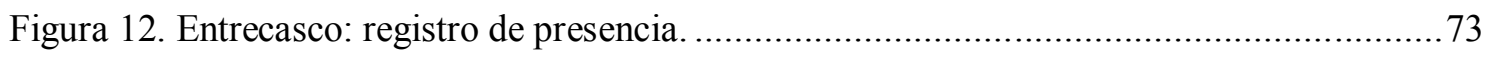

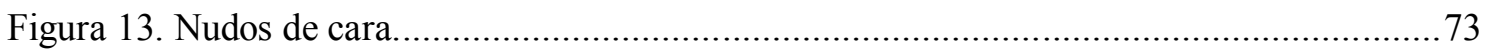

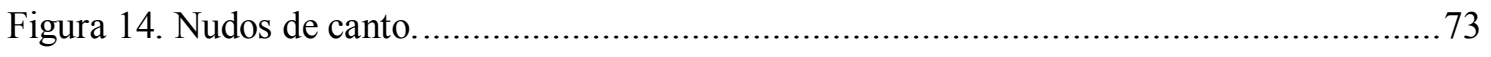

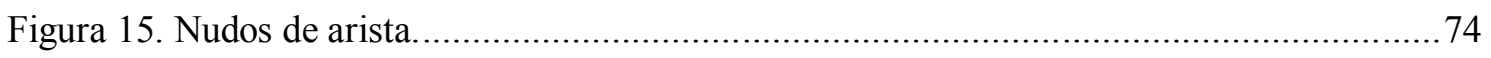

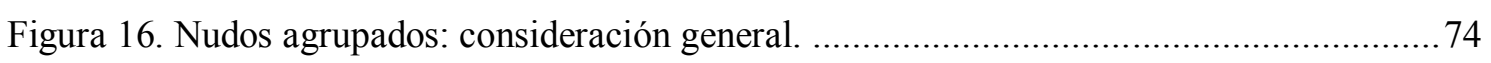

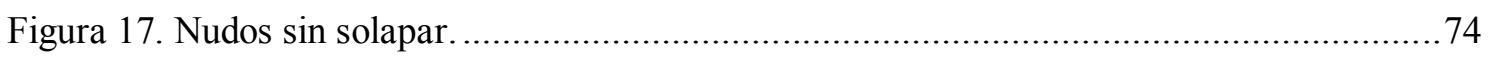

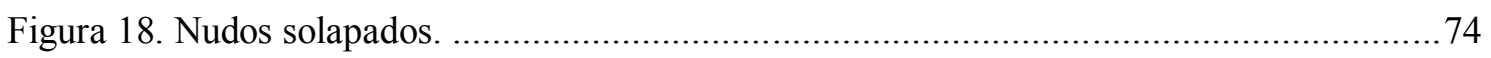

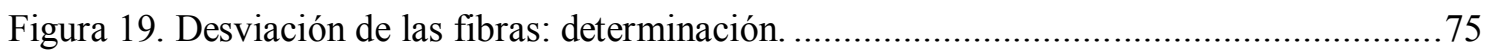

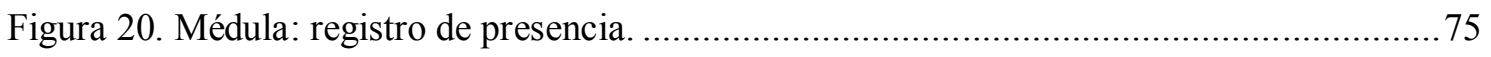

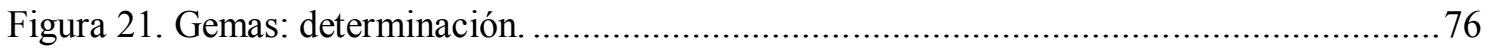

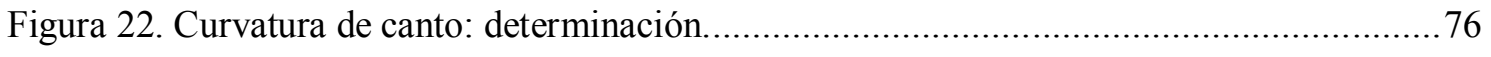

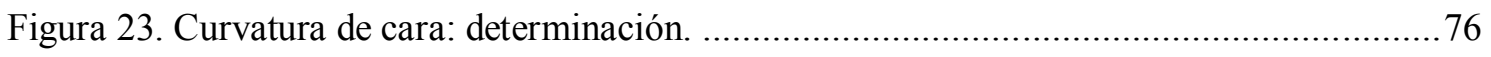

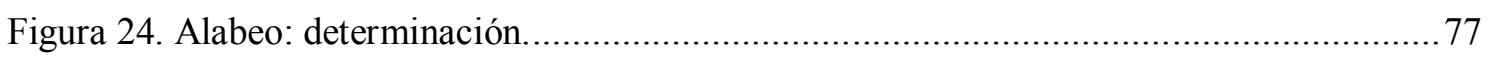

Figura 25. Esquema representativo del ensayo de ultrasonidos (Sylvatest $\AA^{8}$ ). .........................78

Figura 26. Esquema representativo ensayo de vibraciones inducidas.....................................79

Figura 27. Esquema de ensayo de flexión estática (EN 408:2011+A1:2012). ............................. 82

Figura 28. Carga - deformación dentro de los márgenes de deformación elástica.......................82

Figura 29. Esquema de pieza en voladizo: sujeción, longitud inicial y longitud final................90

Figura 30. Esquema de pieza en voladizo: posición vertical (V).............................................90

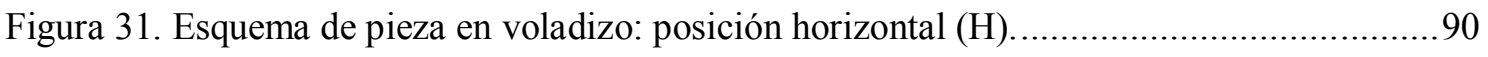


Figura 32. Viga en voladizo: representación cartesiana y escuadrías. ......................................91

Figura 33. Piezas encoladas dúo. Fuente: Basterra, 2011 .....................................................93

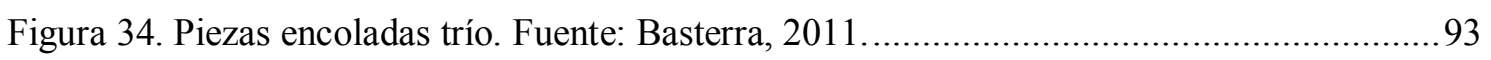

Figura 35. Gráfico de Caja y Bigote: medidas de centralidad y dispersión.................................96

Figura 36. Gráfico de Dispersión de Residuos: ejemplo de ajuste no lineal o curvilíneo. Fuente:

Vilar Fernández, 2006.

Figura 37. Gráfico de Dispersión de Residuos: ejemplo de heterocedasticidad. Fuente: Vilar

Fernández, 2006. . .98

Figura 38. Singularidades ligadas a la anatomía de la madera..............................................101

Figura 39. Singularidades ligadas al proceso de aserrado..................................................... 102

Figura 40. Singularidades ligadas al proceso de secado: deformaciones. ................................ 103

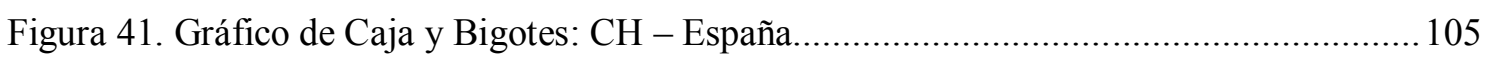

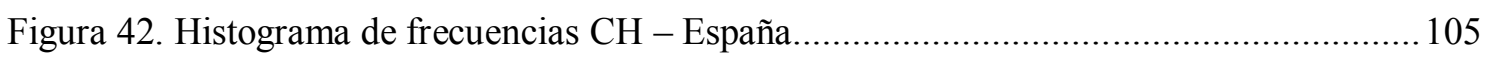

Figura 43. Gráfico de Caja y Bigotes: CH - Argentina ............................................................ 105

Figura 44. Histograma de frecuencias $\mathrm{CH}-$ Argentina ....................................................... 105

Figura 45. Gráfico de medias e IC 95\% Tukey HSD: CH (\%) por procedencia ....................... 105

Figura 46. Gráfico de Caja y Bigotes: Do - España ........................................................ 106

Figura 47. Histograma de frecuencias: Do - España ...................................................... 106

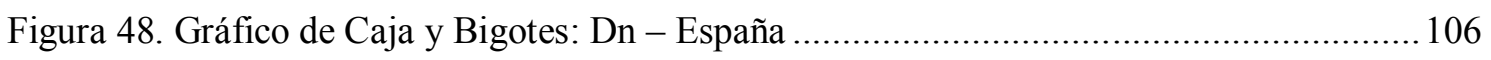

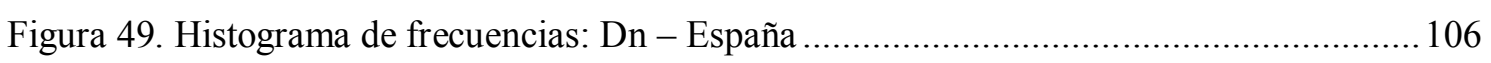

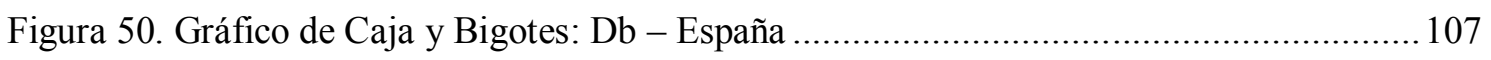

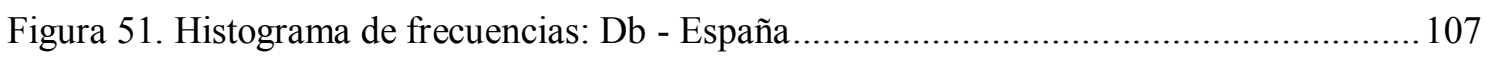

Figura 52. Gráfico de Caja y Bigotes: Do - Argentina.............................................................. 107

Figura 53. Histograma de frecuencias: Do - Argentina ......................................................... 107

Figura 54. Gráfico de Caja y Bigotes: Dn - Argentina.......................................................... 107

Figura 55. Histograma de frecuencias: Dn - Argentina ........................................................ 107

Figura 56. Gráfico de Caja y Bigotes: Db - Argentina.......................................................... 107

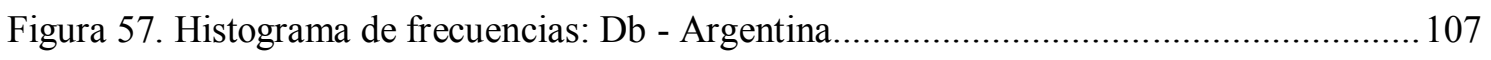

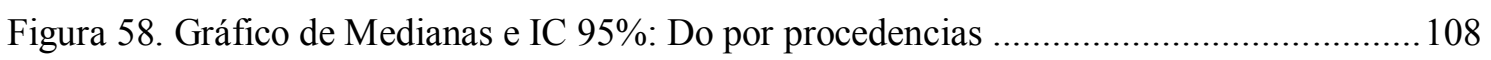

Figura 59. Gráfico de Medias e IC 95\% Tukey HSD: Dn por procedencias ............................. 108

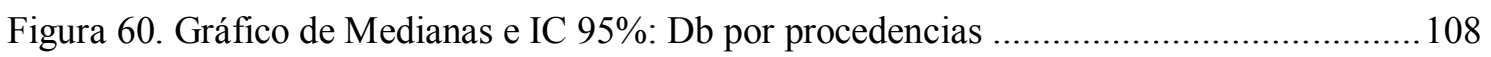

Figura 61. Gráfico de Caja y Bigotes: CnmáxL (\%) - España................................................. 109

Figura 62. Histograma de frecuencias: CnmáxL (\%) - España................................................. 109

Figura 63. Gráfico de Caja y Bigotes: CnmáxRd (\%) - procedencia España........................... 110

Figura 64. Histograma de frecuencias:CnmáxRd (\%) - procedencia España........................... 110 
Figura 65. Gráfico de Caja y Bigotes: CnmáxTg (\%) - procedencia España ............................ 110

Figura 66. Histograma de frecuencias: CnmáxTg (\%) - procedencia España ............................110

Figura 67. Gráfico de Caja y Bigotes: T/R - procedencia España. .......................................... 110

Figura 68. Histograma de frecuencias: T/R - procedencia España. ......................................... 110

Figura 69. Gráfico de Caja y Bigotes: CnmáxL (\%) - procedencia Argentina........................... 110

Figura 70. Histograma de frecuencias: CnmáxL (\%) - procedencia Argentina.........................110

Figura 71. Gráfico de Caja y Bigotes: CnmáxRd (\%) - procedencia Argentina........................ 111

Figura 72. Histograma de frecuencias:CnmáxRd (\%) - procedencia Argentina........................111

Figura 73. Gráfico de Caja y Bigotes: CnmáxTg (\%) - procedencia Argentina........................ 111

Figura 74. Histograma de frecuencias: CnmáxTg (\%) - procedencia Argentina.......................111

Figura 75. Gráfico de Caja y Bigotes: T/R - procedencia Argentina....................................... 111

Figura 76. Histograma de frecuencias: T/R - procedencia Argentina..................................... 111

Figura 77: Chopo España: Evolución de las contracciones normales (\%) con el CH (\%) .........112

Figura 78: Chopo Argentina: Evolución de las contracciones normales (\%) con el CH (\%) ....112

Figura 79. Gráfico de Medianas e IC 95\%. CnmáxL por procedencias.................................... 113

Figura 80. Gráfico de Medianas e IC 95\%. CnmáxRd por procedencias.................................. 113

Figura 81. Gráfico de Medianas e IC 95\%. CnmáxTg por procedencias................................. 113

Figura 82. Gráfico de Medianas e IC 95\%. T/R por procedencias. ......................................... 113

Figura 83. Gráfico de Caja y Bigotes: CnV (\%) - procedencia España. ................................... 114

Figura 84. Histograma de frecuencias: $\mathrm{CnV}(\%)$ - procedencia España. ...................................114

Figura 85. Gráfico de Caja y Bigotes: V (\%) - procedencia España......................................... 114

Figura 86. Histograma de frecuencias: V (\%) - procedencia España.......................................... 114

Figura 87. Gráfico de Caja y Bigotes: CnV (\%) - procedencia Argentina.................................114

Figura 88. Histograma de frecuencias: $\mathrm{CnV}(\%)$ - procedencia Argentina. .............................. 114

Figura 89. Gráfico de Caja y Bigotes: V (\%) - procedencia Argentina. .................................... 114

Figura 90. Histograma de frecuencias: V (\%) - procedencia Argentina. .................................. 114

Figura 91. Gráfico de Medias e IC 95\% Tukey HSD: CnV - procedencias............................. 115

Figura 92. Gráfico de Medias e IC 95\% Tukey HSD: V - procedencias. .................................. 115

Figura 93. Gráfico de Caja y Bigotes: hi - procedencia España.............................................. 116

Figura 94. Histograma de frecuencias: hi - procedencia España. ........................................... 116

Figura 95. Gráfico de Caja y Bigotes: hi - procedencia Argentina.............................................. 117

Figura 96. Histograma de frecuencias: hi - procedencia Argentina....................................... 117

Figura 97. Gráfico de medias e IC95\% Tukey HSD: hi - procedencias. ................................117

Figura 98. Gráfico de Caja y Bigotes: MOE por procedencias. .............................................. 118

Figura 99. Gráfico de Caja y Bigotes: MOR por procedencias. ............................................. 118 
Figura 100. Histograma de frecuencias MOE - España....................................................... 119

Figura 101. Histograma de frecuencias MOR - España. ......................................................... 119

Figura 102. Histograma de frecuencias: MOE - Argentina. ..................................................... 119

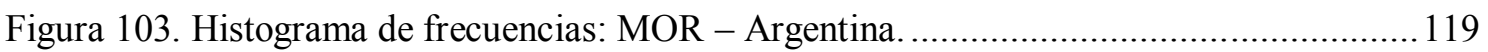

Figura 104. Gráfico de Medianas e IC 95\%: MOE por procedencias........................................ 120

Figura 105. Gráfico de Medias e IC 95\% Tukey HSD: MOR por procedencias....................... 120

Figura 106. Gráfico de Caja y Bigotes Dureza Monnin (UNE)............................................. 121

Figura 107. Histograma de frecuencias Dureza Monnin (UNE). .......................................... 121

Figura 108. Gráfico de Caja y Bigotes Dureza Janka (IRAM).............................................. 121

Figura 109. Histograma de frecuencias Dureza Janka (IRAM) ............................................. 121

Figura 110. Gráfico de Caja y Bigotes: MOE por norma (España)........................................ 122

Figura 111. Gráfico de Caja y Bigotes: MOE por procedencia (IRAM). ................................. 122

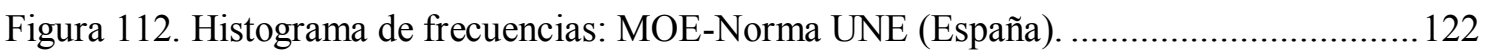

Figura 113. Histograma de frecuencias: MOR-Norma UNE (España).................................... 122

Figura 114. Histograma de frecuencias: MOE-Norma IRAM (España).................................. 122

Figura 115. Histograma de frecuencias: MOR-Norma IRAM (España).................................122

Figura 116. Histograma de frecuencias: MOE-Norma IRAM (Argentina) ............................. 122

Figura 117. Histograma de frecuencias: MOR-Norma IRAM (Argentina)............................... 122

Figura 118. Gráfico de Medianas e IC 95\%: MOE por norma de ensayo (España). ................. 123

Figura 119. Gráfico de Medianas e IC 95\%: MOR por norma de ensayo (España). ................. 123

Figura 120. Gráfico de Medianas e IC 95\%: MOR (norma IRAM) por procedencia................ 124

Figura 121. Gráfico de Caja y Bigotes: Pp (\%) Trametes versicolor - secciones....................... 125

Figura 122. Gráfico de Caja y Bigotes: Pp (\%) Coniophora puteana -................................... 125

Figura 123. Gráfico de Caja y Bigotes: Pp (\%) Chopo (Argentina) - cepas fúngicas................126

Figura 124. Gráfico de medias e IC 95\% Tukey HSD: Pp (\%) T. versicolor - Chopo (España) secciones.

Figura 125. Gráfico de medias e IC 95\% Tukey HSD: Pp (\%) C. puteana - Chopo (España) secciones.

Figura 126. Gráfico de medias e IC 95\% Tukey HSD: Pp (\%) Chopo (Argentina) - agente de deterioro

Figura 127. Gráfico de medias e IC 95\% Tukey HSD: Pp (\%) T. versicolor - Chopo procedencias

Figura 128. Gráfico de medias e IC 95\% Tukey HSD: Pp (\%) C. puteana - Chopo -

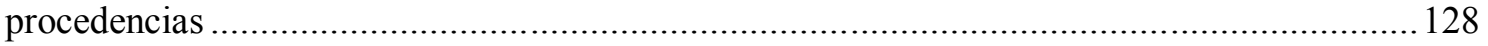

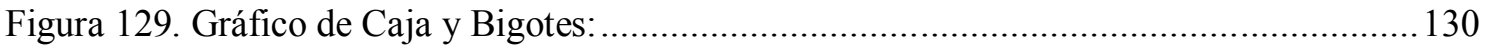


Figura 130. Gráfico de medias e IC 95\% Tukey HSD: Pp (\%) Pudrición blanda - Chopo (España) sección. 130

Figura 131. Gráfico de Caja y Bigotes: TS (\%) - Chopo(España) - secciones 132

Figura 132. Gráfico de Caja y Bigotes: Pp (\%) - Chopo (España) - secciones 132

Figura 133. Gráfico de Caja y Bigotes: TS (\%) - Chopo (sección interna) - procedencias ..... 132

Figura 134. Gráfico de Caja y Bigotes: Pp (\%) - Chopo (sección interna) - procedencias....... 132

Figura 135. Gráfico de Medias e IC 95\% Tukey HSD: TS (\%) Chopo (España) - secciones... 133

Figura 136. Gráfico de Medias e IC 95\% Tukey HSD: TS (\%) - Chopo - procedencias. 133

Figura 137. Gráfico de Medias e IC 95\% Tukey HSD: Pp (\%) Chopo (España) - secciones. .. 133

Figura 138. Gráfico de Medianas e IC 95\% Tukey HSD: Pp (\%) - Chopo - procedencias

Figura 139. Representación porcentual de la clasificación visual UNE-56544:2011(ChopoEspaña). 136

Figura 140. Representación porcentual de la clasificación visual UNE-56544:2011 (ChopoArgentina)...... 136

Figura 141. Gráfico de Caja y Bigotes: Chopo (España) - Densidad. 138

Figura 142. Histograma de Frecuencias: Chopo (España) - Densidad. 138

Figura 143. Gráfico de Caja y Bigotes: Chopo (España) - Fr (VI). ....................................... 138

Figura 144. Histograma de Frecuencias: Chopo (España) - Fr (VI). ..................................... 138

Figura 145. Gráfico de Caja y Bigotes: Chopo (España) - Vel (Ult). ...................................... 138

Figura 146. Histograma de Frecuencias: Chopo (España) - Vel (Ult). .................................. 138

Figura 147. Gráfico de Caja y Bigotes: $E_{\mathrm{d}}-$ VI Chopo (España). ......................................... 138

Figura 148. Histograma de Frecuencia: $E_{\mathrm{d}}-$ VI Chopo (España).......................................... 138

Figura 149. Gráfico de Caja y Bigotes: $E_{\mathrm{d}}-$ Ult. Chopo (España)............................................ 139

Figura 150. Histograma de Frecuencia: $E_{\mathrm{d}}-$ Ult. Chopo (España). ....................................... 139

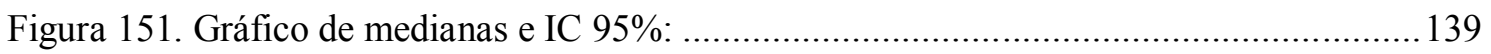

Figura 152. Gráfico de Caja y Bigotes: Densidad-Chopo (Argentina). .................................... 140

Figura 153. Histograma de Frecuencia: Densidad-Chopo (Argentina)................................... 140

Figura 154. Gráfico de Caja y Bigotes: Frecuencia VI-Chopo (Argentina)............................. 140

Figura 155. Histograma de Frecuencia: Frecuencia VI-Chopo (Argentina). ........................... 140

Figura 156. Gráfico de Caja y Bigotes: Velocidad Ult-Chopo (Argentina). ............................ 141

Figura 157. Histograma de Frecuencia: Velocidad Ult-Chopo (Argentina).............................. 141

Figura 158. Gráfico de Caja y Bigotes: Ed-VI-Chopo (Argentina)........................................... 141

Figura 159. Histograma de Frecuencia: $E_{d-}$ VI-Chopo (Argentina) ......................................... 141

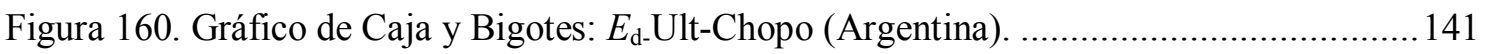

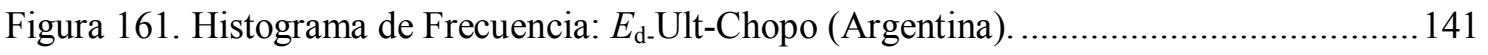


Figura 162. Gráfico de medias e IC 95\% HSD de Tukey: $E_{d}$-NDT Chopo (Argentina)............ 142

Figura 163. Gráfico de medianas e IC 95\%: Fr (VI) - Procedencias. ....................................... 142

Figura 164. Gráfico de medianas e IC 95\%: $E_{\mathrm{d}}(\mathrm{VI})$ - Procedencias. ......................................... 142

Figura 165. Gráfico de medianas e IC 95\%: Velocidad (Ult.) - Procedencias. .......................... 143

Figura 166. Gráfico de medianas e IC 95\%: $E_{\mathrm{d}}(\mathrm{Ult})$ - Procedencias. ........................................ 143

Figura 167. Gráfico de Caja y Bigotes: Densidad-Chopo (España). ........................................ 144

Figura 168. Histograma de Frecuencia: Densidad-Chopo (España)....................................... 144

Figura 169. Gráfico de Caja y Bigotes: MOE - Chopo (España) ............................................. 144

Figura 170. Histograma de Frecuencia: MOE - Chopo (España) ............................................ 144

Figura 171. Gráfico de Caja y Bigotes: MOR - Chopo (España). ............................................ 144

Figura 172. Histograma de Frecuencia: MOR - Chopo (España)........................................... 144

Figura 173. Gráfico de Caja y Bigotes: Densidad - Chopo (Argentina). ..................................145

Figura 174. Histograma de Frecuencia: Densidad - Chopo (Argentina)................................... 145

Figura 175. Gráfico de Caja y Bigotes: MOE - Chopo (Argentina). .......................................... 145

Figura 176. Histograma de Frecuencia: MOE - Chopo (Argentina)....................................... 145

Figura 177. Gráfico de Caja y Bigotes: MOR - Chopo (Argentina)........................................ 145

Figura 178. Histograma de Frecuencia: MOR - Chopo (Argentina)...................................... 145

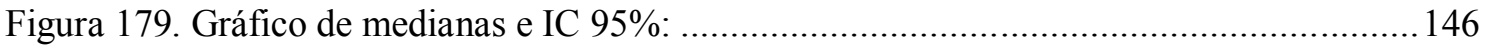

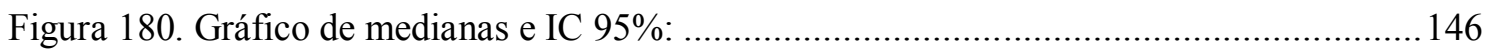

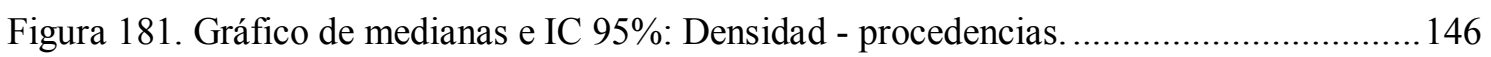

Figura 182. Gráfico de medias e IC 95\% HSD de Tukey: MOE - Rechazos B/NB................. 148

Figura 183. Gráfico de medias e IC 95\% HSD de Tukey: MOR - "Lugar de rotura". .............. 150

Figura 184. Regresión Simple: MOE - Frecuencia VI............................................................ 151

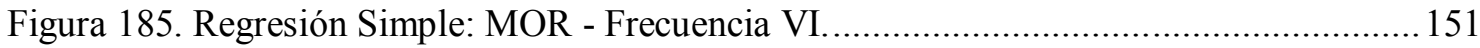

Figura 186. Regresión Múltiple MOE - Fr (VI)-Densidad..................................................... 151

Figura 187. Regresión Múltiple MOR - Fr (VI)-Densidad. .................................................. 151

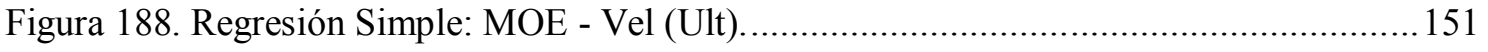

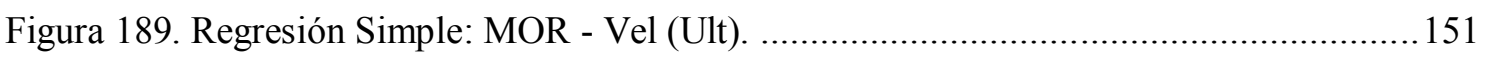

Figura 190. Regresión Múltiple MOE - Vel (Ult). - Densidad................................................... 152

Figura 191. Regresión Múltiple: MOR - Vel (Ult). - Densidad. ............................................... 152

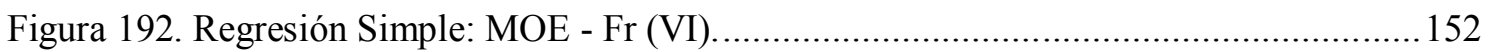

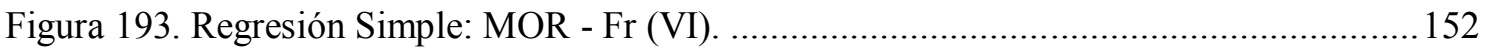

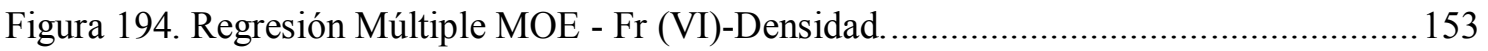

Figura 195. Regresión Múltiple: MOR - Fr (VI)-Densidad. …….......................................... 153

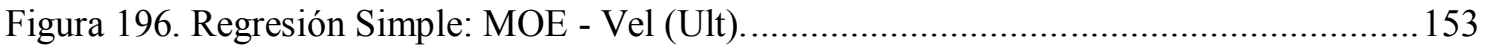




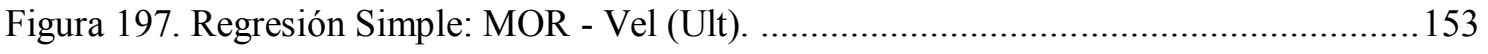

Figura 198. Regresión Múltiple MOE - Vel (Ult) - Densidad. ................................................ 153

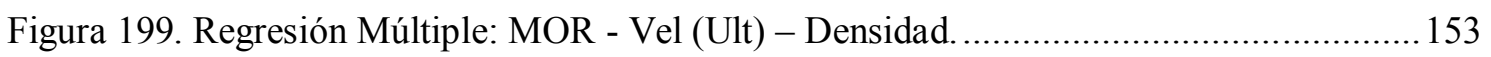

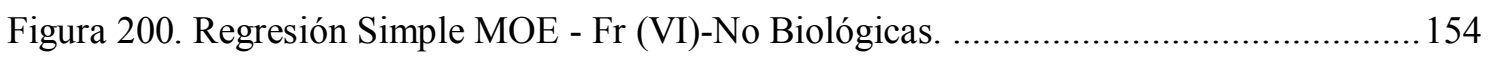

Figura 201. Chopo Argentina. Regresión Simple MOE - Fr (VI)-Biológicas............................ 154

Figura 202. Regresión Simple MOE - Vel (Ult). - No Biológicas. Chopo Argentina. ...............154

Figura 203. Regresión Simple MOE - Vel (Ult). -Biológicas. Chopo Argentina. ..................... 154

Figura 204. Regresión Simple MOR - Fr (VI)-No Biológicas. Chopo Argentina...................... 155

Figura 205. Regresión Simple MOR - Fr (VI)-Biológicas. Chopo Argentina............................ 155

Figura 206. Regresión Simple MOR - Vel (Ult). - No Biológicas. Chopo Argentina. ............... 155

Figura 207. Regresión Simple MOR - Vel (Ult). - Biológicas. Chopo Argentina. .................... 155

Figura 208. Representación porcentual según clases UNE-56544: 1997................................. 158

Figura 209. Representación porcentual según clases UNE-56544: 2011 _................................ 158

Figura 210. Representación porcentual según clases NF B52-001: 2007................................ 158

Figura 211. Representación porcentual según clases DIN 4074-5: 2008_............................... 159

Figura 212. Representación porcentual según clases NCh 1970/1:1988_.................................159

Figura 213. Histograma de frecuencia: LOG(MOE), MOR y 1/Densidad............................... 161

Figura 214. Gráfico de Caja y Bigotes: variables caracterizadoras clases UNE 56544: 1997. . 163

Figura 215. Gráfico de Caja y Bigotes: variables caracterizadoras clases UNE 56544: 2011 .. 164

Figura 216. Clasificación resistente: EN-338: 2010 - UNE 56544: 1997-2011 ........................ 164

Figura 217. Gráfico de Caja y Bigotes: variables caracterizadoras clases NF B52-001: 2007. 165

Figura 218. Clasificación resistente: EN-338: 2010 - NF B52-001:2007.................................. 166

Figura 219. Gráfico de Caja y Bigotes: variables caracterizadoras clases DIN 4074-5:2003 ... 167

Figura 220. Clasificación resistente: EN-338: 2010 - DIN 4074-5:2003 ............................... 167

Figura 221. Gráfico de Caja y Bigotes: variables caracterizadoras clases Ch 1970-1:1988 .... 168

Figura 222. Clasificación resistente: EN-338: 2010 - Norma Ch1970/1:1988......................... 169

Figura 223. Comportamiento clasificatorio: normas de clasificación visual - norma clase

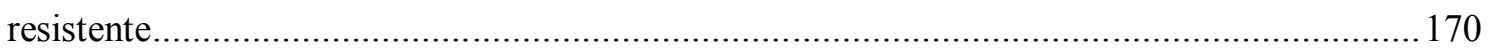

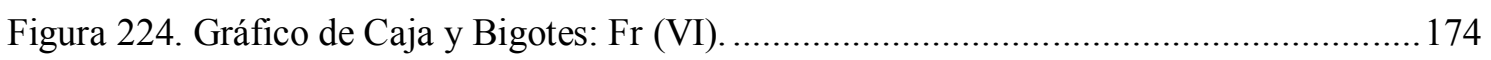

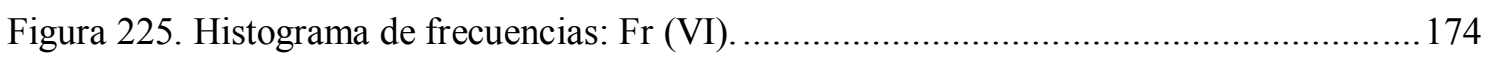

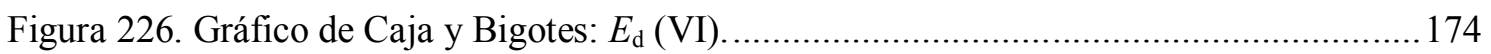

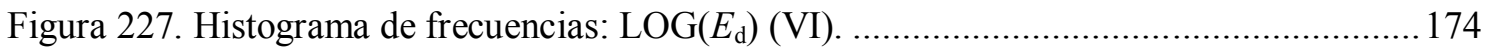

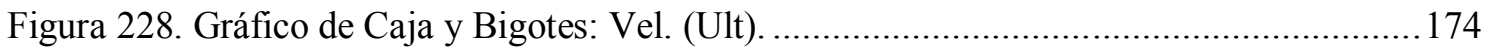

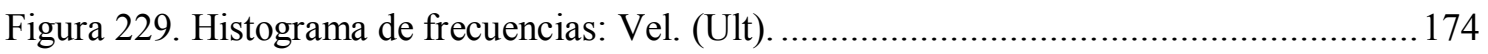

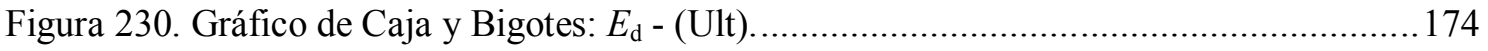




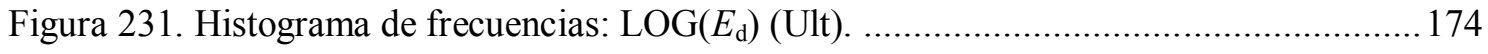

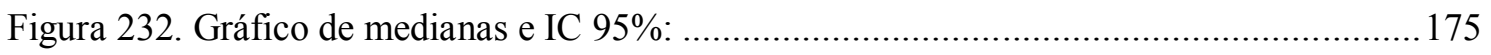

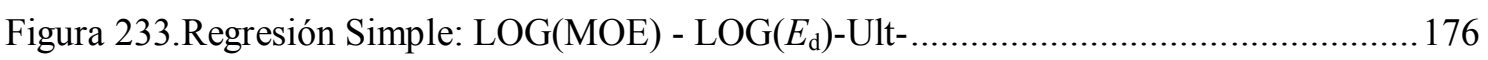

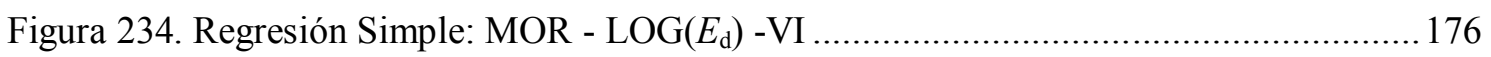

Figura 235. Clasificación según evaluación no destructiva de Ultrasonidos............................. 177

Figura 236. Clasificación según evaluación no destructiva de vibraciones inducidas...............178

Figura 237. Comportamiento clasificatorio: Clases Resistentes (EN 338:2010) - Clases NDT.

Figura 238. Gráfico de medianas e IC 95\%: LOG(MOE) - Presencia nudos de cara. .............. 181

Figura 239. Gráfico de medianas e IC 95\%: LOG(MOE) - Presencia nudos de canto. ............ 182

Figura 240. Gráfico de medianas e IC 95\% LOG(MOE) - "Nudos"....................................... 183

Figura 241. Gráfico de medias e IC 95\%: LOG(MOE) - Tamaño nudos de cara (Unequal N

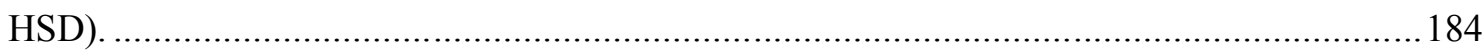

Figura 242. Gráfico de medias e IC 95\%: LOG(MOE) - Tamaño de nudo de canto..................184

Figura 243. Gráfico de medias LOG(MOE) - Grupo desviación (Unequal N HSD)................ 185

Figura 244. Gráfico de medianas e IC 95\%: LOG(MOE) - Entrecasco................................... 186

Figura 245. Gráfico de medianas e IC 95\%: LOG(MOE) - "Grupo anchura de gema". ..........187

Figura 246. Gráfico de medias e IC 95\%: LOG(MOE) - "Grupo longitud de gema" (Unequal N

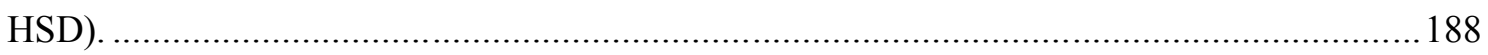

Figura 247. Gráfico de medianas e IC 95\%: LOG(MOE) - Médula....................................... 189

Figura 248. Gráfico de medias e IC 95\% Unequal N HSD: LOG(MOE) - Grupo curvatura de cara...

Figura 249. Gráfico de medias e IC 95\% Tukey HSD: LOG(MOE) - Grupo curvatura de cara.

Figura 250. Gráfico de medias e IC 95\%: LOG(MOE) - Grupo Curvatura de canto (Unequal N HSD).

Figura 251. Gráfico de medias e IC 95\% (Unequal N HSD): LOG(MOE) - Grupo alabeo..... 192

Figura 252. Gráfico de medias e IC 95\% Tukey HSD: LOG(MOE) -Grupo alabeo. ............... 192

Figura 253. Gráfico de medias e IC 95\% Tukey HSD: MOR - Presencia nudos de cara......... 194

Figura 254. Gráfico de medias e IC 95\% (Unequal N HSD): (MOR) - "Presencia nudos de canto". 194

Figura 255. Gráfico de medias e IC 95\% Tukey HSD: MOR - "Nudos”................................ 195

Figura 256. Gráfico de medias e IC 95\%: MOR - "Tamaño nudo de cara”............................. 196

Figura 257. Gráfico de medias e IC 95\%: MOR - "Tamaño nudo de canto”. .......................... 197

Figura 258. Gráfico de medias e IC 95\% Tukey HSD: MOR - “Grupo desviación”................ 197 
Figura 259. Gráfico de medias e IC 95\% Tukey HSD: MOR - "Entrecasco". ......................... 198

Figura 260. Gráfico de medias e IC 95\% Tukey HSD: MOR - "Grupo anchura de gema". ....199

Figura 261. Gráfico de medias e IC 95\% Tukey HSD: MOR - Grupo longitud de gema. ........200

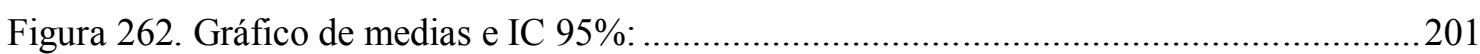

Figura 263. Gráfico de medianas: MOR - Grupo curvatura de cara. .......................................202

Figura 264. Gráfico de medianas: MOR - Grupo curvatura de canto......................................203

Figura 265. Gráfico de medianas: MOR - Grupo alabeo.......................................................203

Figura 266. Gráfico de medianas: 1/Densidad - Presencia nudos de cara. ...............................205

Figura 267. Gráfico de medianas: 1/Densidad - Presencia nudos de canto...............................205

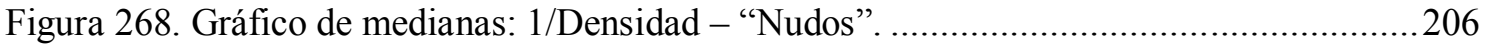

Figura 269. Gráfico de medianas: 1/Densidad - Tamaño nudo de cara...................................207

Figura 270. Gráfico de medianas e IC 95\%: 1/(Densidad) - Tamaño nudo de canto................208

Figura 271. Gráfico de medianas e IC 95\%: 1/(Densidad) - "Grupo desviación”. ....................208

Figura 272. Gráfico de medianas: 1/(Densidad) - Entrecasco. .................................................209

Figura 273. Gráfico de medianas e IC 95\%: 1/Densidad - "Grupo Anchura de gemas"..........211

Figura 274. Gráfico de medianas e IC 95\%: 1/(Densidad) - "Grupo Longitud de gemas". .....211

Figura 275. Gráfico de medianas e IC 95\%: 1/(Densidad) - Médula.......................................212

Figura 276. Gráfico de Medianas e IC 95\%: Densidad - "Grupo curvatura de cara". ..............214

Figura 277. Gráfico de Medianas e IC 95\%: 1/(Densidad) - "Grupo curvatura de canto".......214

Figura 278. Gráfico de Medianas e IC 95\%: 1/(Densidad) - "Grupo alabeo". ..........................215

Figura 279. LOG(MOE), MOR y 1/Densidad - Tipo de corte. Chopo (España)......................220

Figura 280. MOE, MOR y Densidad - Tamaño de pieza. Chopo (España)...............................222

Figura 281. MOE, MOR y Densidad - Tamaño de pieza. Chopo (Argentina). .........................222

Figura 282. Variación dureza por tiempo a diferentes temperaturas. ......................................225

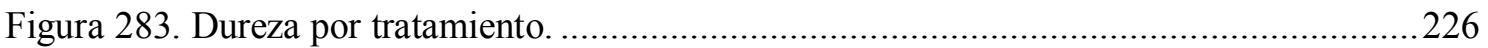

Figura 284. Gráfico de caja y bigotes: Pp (\%) - tratamientos................................................228

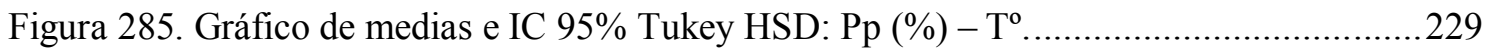

Figura 286. Gráfico de caja y bigotes: Pp (\%) - TM...........................................................231

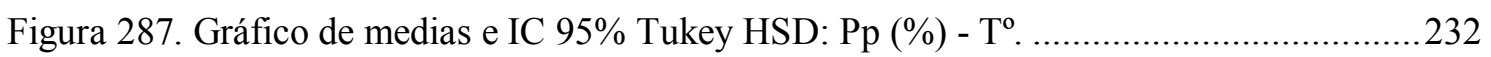

Figura 288. Gráfico de medias e IC 95\% Tukey HSD: Pp (\%) - Tiempos..............................232

Figura 289. Gráfico de caja y bigotes: TS - tratamiento. Chopo (España)................................223

Figura 290. Gráfico de medias e IC 95\% Tukey HSD: TS (\%) - T TM. ..............................235

Figura 291. Gráfico de caja y bigotes: frecuencia de vibración - longitud libre.....................237

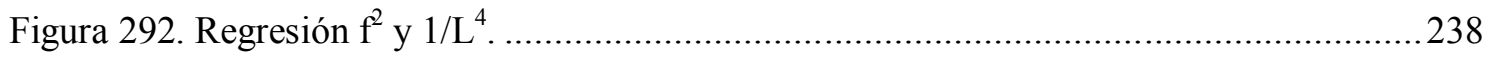

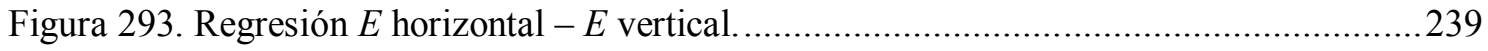




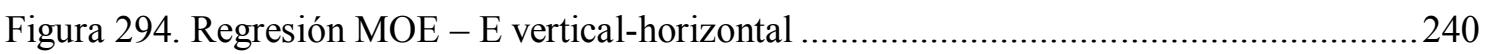

Figura 295. Gráfico de Caja y Bigotes MOE, MOR y densidad. Piezas Dúos (España)...........242

Figura 296. Histograma de Frecuencias MOE, MOR y densidad. Piezas Dúos (España). ........242

Figura 297. Gráfico de Caja y Bigotes MOE, MOR y densidad. Piezas Tríos (España)..........243

Figura 298. Histograma de Frecuencias MOE, MOR y densidad. Piezas Tríos (España). .......243

Figura 299. Gráfico de Caja y Bigotes MOE, MOR y densidad. Piezas dúos (Argentina).......244

Figura 300. Histograma de Frecuencias MOE, MOR y densidad. Piezas dúos (Argentina).....244

Figura 301. Gráfico de Caja y Bigotes MOE, MOR y densidad. Piezas tríos (Argentina). ......245

Figura 302. Histograma de Frecuencias MOE, MOR y densidad. Piezas tríos (Argentina). ....245

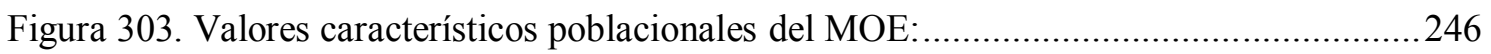

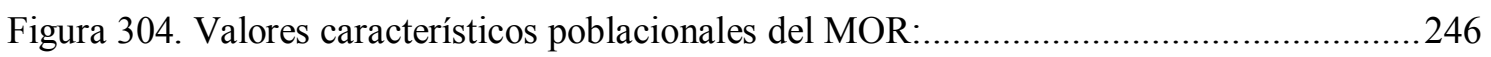

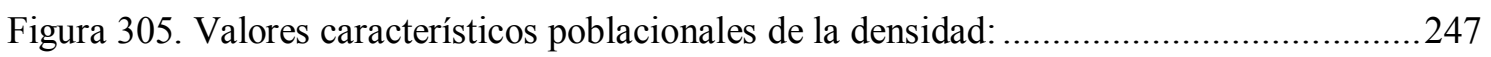

Figura 306. Gráfico de medianas e IC 95\%: MOE. Piezas dúos - Procedencias........................249

Figura 307. Gráfico de medias e IC 95\%: MOR. Piezas dúos - Procedencias. ...........................249

Figura 308. Gráfico de medianas e IC 95\%: MOE. Piezas Tríos - Procedencias. ......................250

Figura 309. Gráfico de medias e IC 95\%: MOR. Piezas tríos - Procedencias............................250

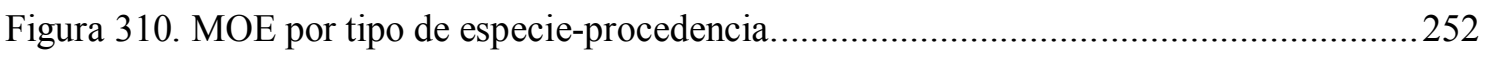

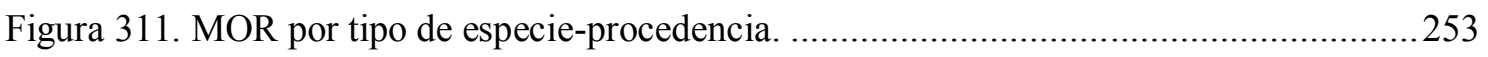




\section{LISTA DE TABLAS}

Tabla 1. Probetas de pequeñas dimensiones: normas de ensayos, número de individuos, dimensiones y procedencia del material ensayado.

Tabla 2. Material semi-estructural (escala 1:5): ensayos, normativas, número de individuos, dimensiones y procedencia.......

Tabla 3. Material estructural: dimensiones nominales del material de ensayo

Tabla 4. Material estructural: normas de ensayo y procedencia del material.

Tabla 5. Piezas dúo: normas, número de individuos, dimensiones y procedencia del material. .52

Tabla 6. Piezas trío: normas, número de individuos, dimensiones y procedencia del material...53

Tabla 7. Clase de durabilidad frente al ataque de hongos basidiomicetos según el coeficiente $\mathrm{x}$.

Tabla 8. Clase de durabilidad frente a de hongos xilófagos ascomicetos e imperfectos según x.

Tabla 9. Clase de durabilidad frente al ataque de termitas según nivel de ataque medio. ...........71

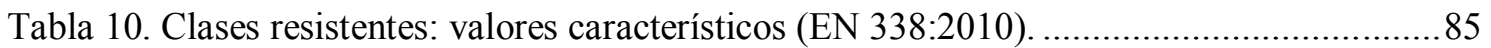

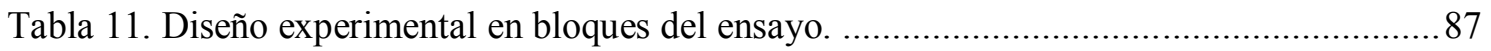

Tabla 12. Valores de $C n$ según modo de vibración. .................................................................92

Tabla 13. Norma UNE 56544: 2011: criterios de clasificación visual.......................................94

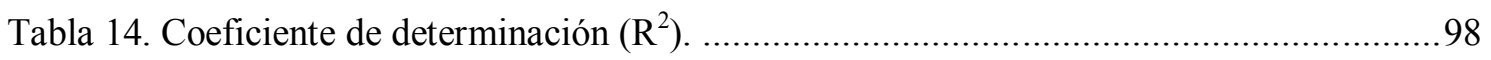

Tabla 15. Coeficiente de correlación de Pearson/Spearman....................................................99

Tabla 16. Grupos de singularidades e intervalos clasificatorios. ............................................. 100

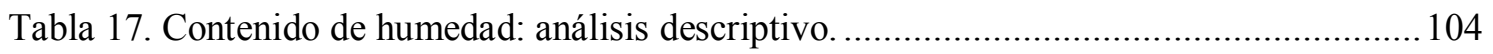

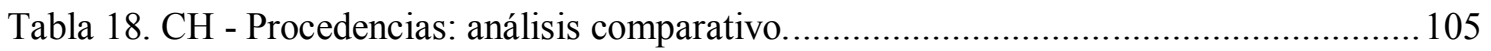

Tabla 19. Densidades aparentes: resultados discriminados por procedencias. .......................... 106

Tabla 20. Densidades aparentes: análisis comparativo entre procedencias.............................. 108

Tabla 21. Parámetros dimensionales lineales: análisis descriptivo .......................................... 109

Tabla 22. Parámetros dimensionales: análisis comparativo. ................................................... 112

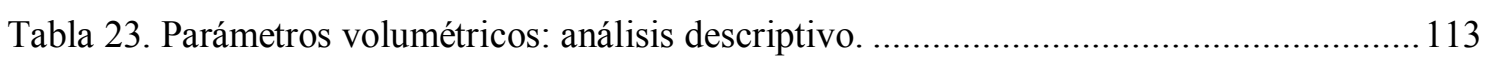

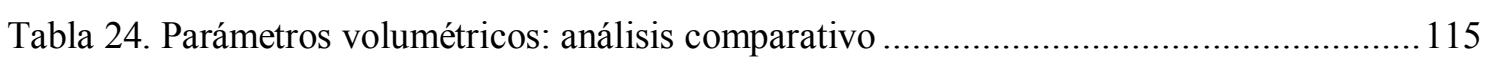

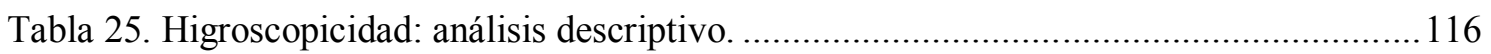

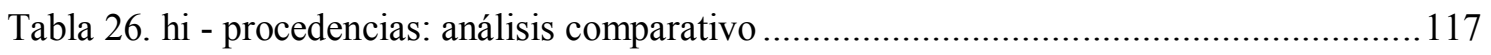

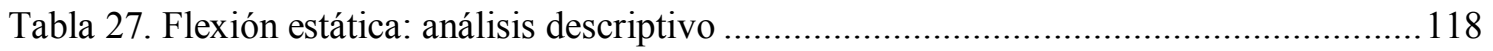

Tabla 28. Flexión estática: análisis comparativo por procedencias. ........................................119

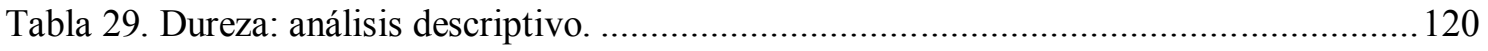


Tabla 30. Compresión paralela a las fibras: análisis descriptivo. 121

Tabla 31. MOE - MOR Chopo (España): análisis comparativo (Kruskal-Wallis). 123

Tabla 32. MOR (compresión paralela) - Procedencias: análisis comparativo. 124

Tabla 33. Pp (\%) - cepa fúngica: análisis descriptivo. 125

Tabla 34. Pp (\%) - cepa fúngica: análisis descriptivo. . 126

Tabla 35. Pp (\%) - secciones - Chopo España: análisis comparativo. 126

Tabla 36. Pp (\%) - procedencias: análisis comparativo. 127

Tabla 37. Pp (\%) - procedencias: análisis comparativo. 128

Tabla 38. Pp (\%) - sección - Chopo España: análisis descriptivo. 130

Tabla 39. Pp (\%) - sección - Chopo España: análisis comparativo. 130

Tabla 40. Valoración del daño causado por termitas: análisis descriptivo.

Tabla 41. Pp (\%) Termitas - sección - procedencias: análisis comparativo. 133

Tabla 42. Dimensiones nominales y contenido de humedad de ambos lotes. 135

Tabla 43. Respuesta clasificatoria y causa de rechazos según norma UNE-56544:2011. 136

Tabla 44. Evaluación mediante metodología no destructiva: análisis descriptivo 137

Tabla 45. $E_{\mathrm{d}}$ - NDT Chopo (España): Análisis comparativo (Kruskal-Wallis). 139

Tabla 46. Evaluación mediante metodología no destructiva: análisis descriptivo 140

Tabla 47. $E_{\mathrm{d}}$-NDT (Chopo-Argentina): análisis comparativo.

Tabla 48. Vibraciones inducidas y Ultrasonidos - procedencias: Test de Kruskal-Wallis. ..... 142

Tabla 49. Evaluación mediante metodología destructiva: análisis descriptivo.

Tabla 50. MOE, MOR y Densidad - procedencias: análisis comparativo (Kruskal-Wallis). ... 146

Tabla 51. MOE - Defectos naturales: Correlación Ordinal de Spearman. 147

Tabla 52. MOE-Rechazos por causas biológicas-no biológicas: análisis comparativo. 148

Tabla 53. Correlación Ordinal de Spearman MOR - Defectos naturales 149

Tabla 54. MOR-Rechazos por causas biológicas-no biológicas (Chopo - Argentina): análisis comparativo. 149

Tabla 55. MOR-Rechazos por "Lugar de rotura": análisis comparativo. 150

Tabla 56. Capacidad predictiva de NDT en las variables caracterizadoras. 151

Tabla 57. Capacidad predictiva de NDT en las variables caracterizadoras. 152

Tabla 58. Capacidad predictiva de NDT en las variables caracterizadoras. 154

Tabla 59. Dimensiones nominales y contenido de humedad de los lotes. 156

Tabla 60. Homologaciones clases resistentes vs clases asignadas por clasificación visual 157

Tabla 61. Comportamiento clasificatorio de las normas de clasificación visual. 157

Tabla 62. Causa de rechazos por norma. 160

Tabla 63. Resumen descriptivo del material estructural en estudio. 161 
Tabla 64. Rangos de valores característicos: correspondencia calidad - clases resistentes........ 162

Tabla 65. Análisis descriptivo: Densidad, MOE y MOR por clases.......................................... 162

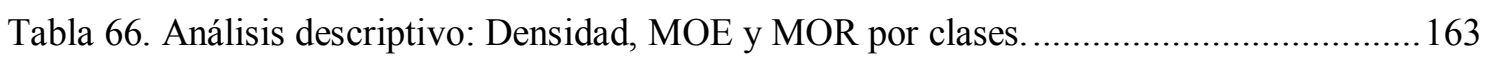

Tabla 67. Análisis descriptivo: Densidad, MOE y MOR por clases ......................................... 165

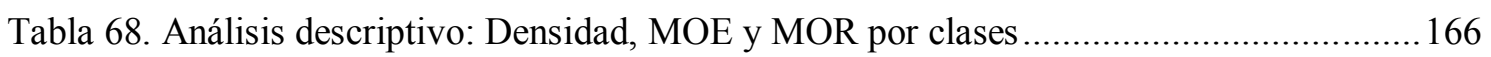

Tabla 69. Análisis descriptivo: Densidad, MOE y MOR por clases ......................................... 168

Tabla 70. Comportamiento de las normas de clasificación visual con respecto a la norma EN-

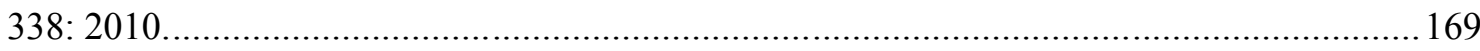

Tabla 71. Tabla referencial para lectura de comportamiento clasificatorio de Tabla 70. .........170

Tabla 72. Comportamiento clasificatorio: Norma EN 338: 2010 - Norma UNE-56544: 1997.170

Tabla 73. Comportamiento clasificatorio: Norma EN 338: 2010 - Norma UNE-56544: 2011.171

Tabla 74. Comportamiento clasificatorio: Norma EN 338: 2010 - Norma NF B52-001: 2007172

Tabla 75. Comportamiento clasificatorio: Norma EN 338: 2010 - Norma DIN 4074-5: 2003.172

Tabla 76. Comportamiento clasificatorio: Norma EN 338: 2010 - Norma NCh 1970/1: 1988.172

Tabla 77. Variables dinámicas NDT - Material estructural: Análisis descriptivo...................... 173

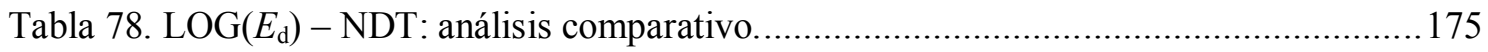

Tabla 79. Capacidad predictiva de NDT en las variables caracterizadoras.............................. 175

Tabla 80. Correspondencia Clases NDT-Clases resistentes................................................... 176

Tabla 81. Contraste Clase Resistente (EN 338: 2010)-Clase NDT (Ultrasonido) ...................... 177

Tabla 82. Contraste Clase Resistente (EN 338: 2010)-Clase NDT (V. inducidas).................... 178

Tabla 83. Aciertos, subestimas y sobreestimas: Clasificación: visual - NDT vs resistente...... 179

Tabla 84. LOG(MOE) - Defectos naturales: correlación Ordinal de Spearman. ....................... 180

Tabla 85. LOG(MOE) - Presencia de nudos de cara: análisis comparativo. ............................... 181

Tabla 86. LOG(MOE) - Presencia de nudos de canto: análisis comparativo. ...........................181

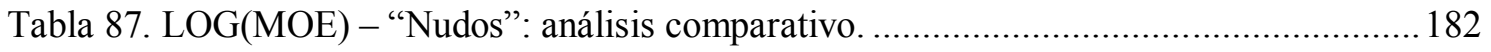

Tabla 88. LOG(MOE) - Tamaño nudos de cara: análisis comparativo. ................................... 183

Tabla 89. LOG(MOE) - "Tamaño nudo de canto”: análisis comparativo................................... 184

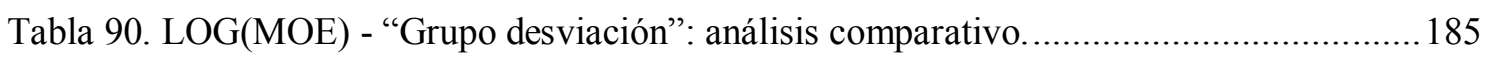

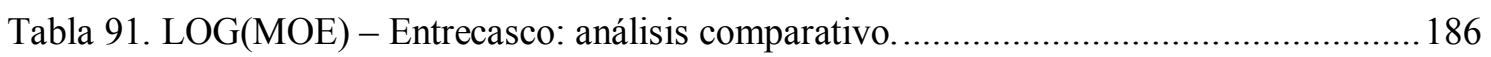

Tabla 92. LOG(MOE) - Defectos de aserrado: correlación Ordinal de Spearman. ................... 186

Tabla 93. LOG(MOE) - Grupo anchura de gema: análisis comparativo................................... 187

Tabla 94. LOG(MOE) - Grupo longitud de gema: análisis comparativo................................... 188

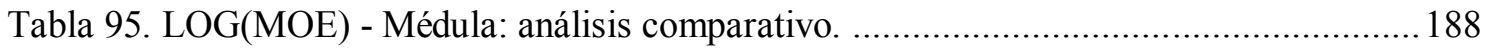

Tabla 96. LOG(MOE) - Defectos de secado: correlación ordinal de Spearman. ....................... 189

Tabla 97. LOG(MOE) - Grupo Curvatura de cara: análisis comparativo. ................................ 190 
Tabla 98. LOG(MOE) - Grupo Curvatura de canto: análisis comparativo. .............................. 191

Tabla 99. LOG(MOE) - Grupo Alabeo: análisis comparativo. ................................................. 192

Tabla 100. MOR - Defectos naturales: Correlación ordinal de Spearman. ............................... 193

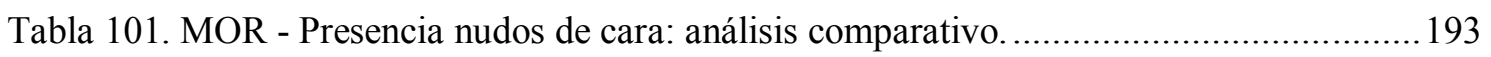

Tabla 102. MOR - Presencia nudos de canto: análisis comparativo.......................................... 194

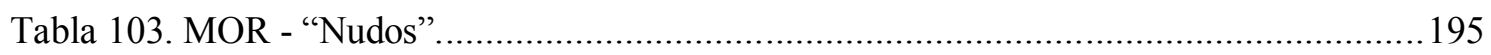

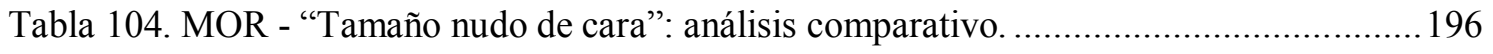

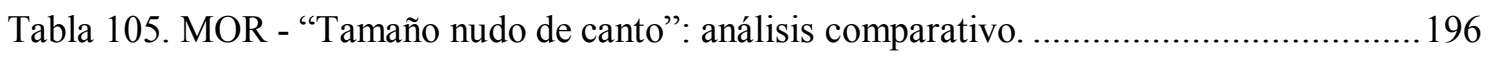

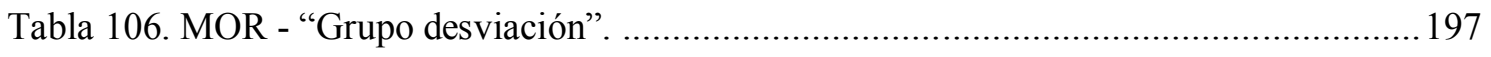

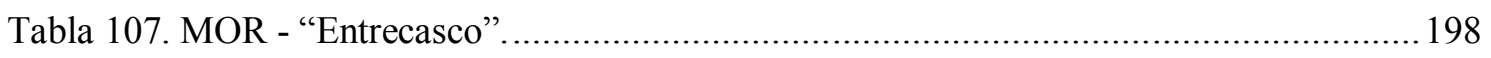

Tabla 108. MOR - Defectos de aserrado: Correlación Ordinal de Spearman. .......................... 198

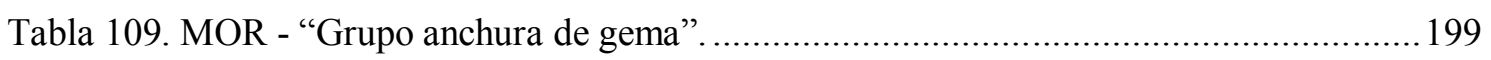

Tabla 110. MOR - Grupo longitud de gema: análisis comparativo. …....................................200

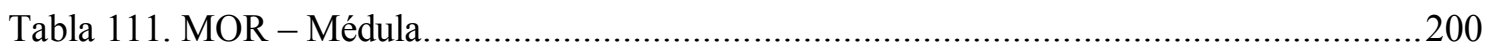

Tabla 112. MOR - Defectos de secado: Correlación Ordinal de Spearman. .............................201

Tabla 113. MOR - Grupo curvatura de cara: análisis comparativo. ........................................202

Tabla 114. MOR - Grupo curvatura de canto: análisis comparativo........................................202

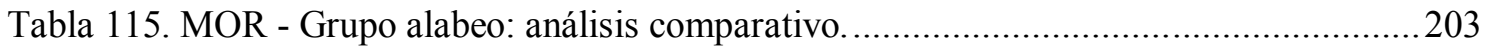

Tabla 116. 1/(Densidad) - Defectos naturales: Correlación Ordinal de Spearman. ..................204

Tabla 117. 1/(Densidad) - Presencia de nudos de cara: análisis comparativo. ...........................205

Tabla 118. 1/(Densidad) - Presencia de nudos de canto: análisis comparativo. ........................205

Tabla 119. 1/(Densidad) - "Nudos": análisis comparativo.......................................................206

Tabla 120. 1/(Densidad) - "Tamaño nudos de cara”: análisis comparativo. ..............................207

Tabla 121. 1/(Densidad) - Tamaño nudo de canto: análisis comparativo..................................207

Tabla 122. 1/(Densidad) - “Grupo desviación”: análisis comparativo......................................208

Tabla 123. 1/(Densidad) - Entrecasco: análisis comparativo. ...................................................209

Tabla 124. 1/(Densidad) - Defectos de aserrado: correlación Ordinal de Spearman. ................210

Tabla 125. 1/(Densidad) - "Grupo anchura de gema”: análisis comparativo. ...........................210

Tabla 126. 1/(Densidad) - "Grupo longitud de gema": análisis comparativo............................211

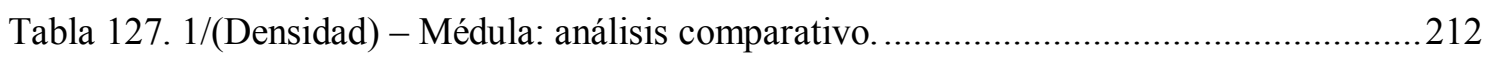

Tabla 128. 1/Densidad - Defectos de secado: Correlación Ordinal de Spearman. .....................213

Tabla 129. 1/(Densidad) - "Grupo curvatura de cara": análisis comparativo. ...........................213

Tabla 130. 1/(Densidad) - "Grupo curvatura de canto": análisis comparativo...........................214

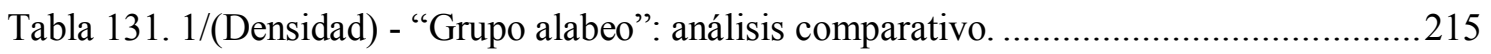


Tabla 132. Influencia de los defectos naturales en la determinación de las variables caracterizadoras. 216

Tabla 133. Influencia de los defectos de aserrado en la determinación de las variables caracterizadoras.

Tabla 134. Influencia de los defectos de secado en la determinación de las variables caracterizadoras.

Tabla 135. Influencia de los parámetros NDT (Vibraciones inducidas) en las variables caracterizadoras.

Tabla 136. Influencia de los parámetros NDT (Ultrasonidos) en las variables caracterizadoras.

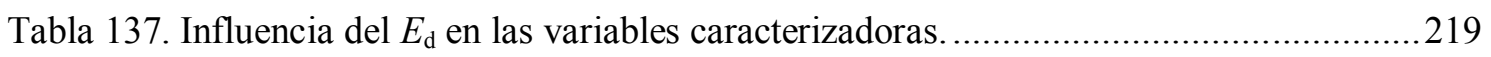

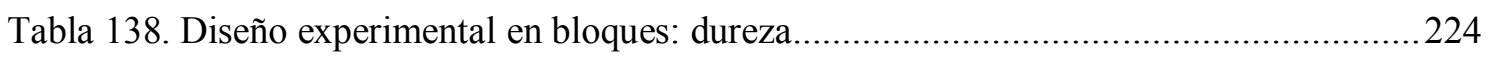

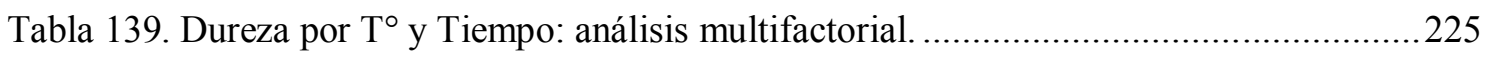

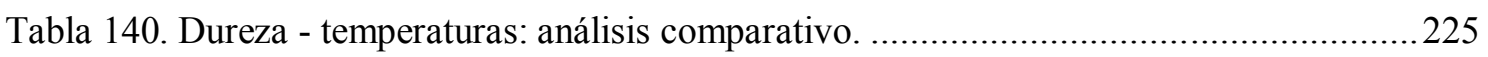

Tabla 141. Deterioro causado por T. versicolor: diseño experimental en bloques. ...................227

Tabla 142. Pp (\%) por temperatura - tiempo: análisis multifactorial.......................................228

Tabla 143. Pp (\%) por temperatura - tiempo: test de Tukey HSD..........................................229

Tabla 144. Deterioro causado por C. puteana: diseño experimental en bloques......................230

Tabla 145. Pp (\%) por temperatura - tiempo: análisis multifactorial......................................231

Tabla 146. Pp (\%) por temperatura - tiempo: test de Tukey HSD........................................231

Tabla 147. Deterioro causado por $R$. grassei: diseño experimental en bloques. ......................233

Tabla 148. TS (\%) por temperatura - tiempo: análisis multifactorial. .....................................234

Tabla 149. TS (\%) por temperatura - tiempo: test de Tukey HSD. ..........................................235

Tabla 150. Frecuencia - longitudes libres: orientación vertical. …….....................................236

Tabla 151. $E$ en vibración libre y MOE en máquina Universal: resumen descriptivo..............239

Tabla 152. MOE: análisis predictivo a partir del ensayo de vibración en piezas en voladizo... 240

Tabla 153. Dimensiones nominales y contenido de humedad de ambos lotes. ..........................241

Tabla 154. Propiedades estructurales de los diferentes tipos de piezas. ..................................242

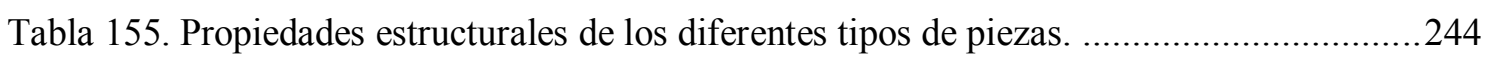

Tabla 156. Análisis comparativo: MOE - Tipo de pieza (España)........................................247

Tabla 157. Análisis comparativo: MOR - Tipo de pieza (España).........................................248

Tabla 158. MOE - tipo de pieza: análisis comparativo (Argentina).........................................248

Tabla 159. MOR - tipo de pieza: análisis comparativo (Argentina). .....................................248

Tabla 160. MOE: piezas dúos - procedencia: análisis comparativo.......................................249

Tabla 161. MOR: piezas dúos - procedencia: análisis comparativo......................................249 
Tabla 162. MOE: Piezas tríos - procedencia: análisis comparativo. 250

Tabla 163. MOR: Piezas tríos - procedencia: análisis comparativo. 250

Tabla 164. Piezas dúos-tríos: respuesta clasificatoria y causa de rechazos, norma UNE56544:2011.

Tabla 165. Análisis descriptivo: MOE y MOR por clases. .252

Tabla 166. Criterios de clasificación propuestos en la norma de clasificación visual. .254

Tabla 167. Comportamiento de la norma de clasificación propuesta. .254

Tabla 168. Análisis descriptivo de la norma de clasificación visual propuesta. 255 


\section{RESUMEN}

El recurso forestal de Populus $x$ euramericana I-214 disponible en España y Argentina, ha permitido el uso de su madera dentro de un nicho de mercado aún no profundizado, por lo que resulta de fundamental importancia contar con información sobre aquellas propiedades físicas, mecánicas y de durabilidad natural que permitan su uso más eficientemente; a partir de su estudio, se podrán plantear alternativas de mejoras en aquellas propiedades que resulten de interés para uso estructural y no estructural. Para ello, en este trabajo se recogen los resultados del proceso de caracterización llevado a cabo, según las normativas correspondientes, en madera maciza de dicho clon, proveniente de España y Argentina, considerando para ello tres tamaños de muestra: piezas de pequeñas dimensiones libres de defectos, piezas semi-estructurales y piezas estructurales. Sobre el primer tipo de piezas se realizó la caracterización física, mecánica y de durabilidad natural. Sobre los otros dos tamaños de piezas se realizó una caracterización no destructiva: visual y mediante técnicas de ensayos no destructivos, y una caracterización mecánica destructiva mediante ensayos de flexión estática en máquina universal. Una vez caracterizado el material, se plantearon alternativas de mejoras, tendentes a un aprovechamiento más adecuado del recurso, trabajando para ello en los tamaños de piezas antes mencionados. En las probetas de pequeñas dimensiones libres de defectos se trabajó sobre la mejora en las propiedades de dureza y durabilidad; en las piezas de tamaño semi-estructural se trabajó sobre la aplicación de la técnica de vibración libre para estimar el módulo de elasticidad a partir su frecuencia de vibración, como también sobre la fabricación de material encolado, dúo y trío, con el fin de evaluar la respuesta elasto-resistente respecto al material macizo. En cuanto a las piezas de tamaño estructural, las líneas de mejora estuvieron enfocadas a la inclusión de este clon en la normativa de clasificación visual, para lo cual se establecieron modificaciones e incorporaciones en la norma actual española, a fin de adaptar el rendimiento clasificatorio de la misma para esta especie. Por último, se planteó un método de control de sobrecarga en madera estructural en servicio, en el marco de una patente. De acuerdo con los resultados obtenidos, se logró una extensa base de información para este clon en ambas procedencias y se obtuvieron alternativas de mejoras tecnológicas que permiten establecer un punto de partida para futuros trabajos, pudiendo contribuir al uso más eficiente de este recurso forestal actualmente disponible en el mercado español y argentino.

PALABRAS CLAVE: propiedades físico-mecánicas; durabilidad natural; técnicas de ensayos no destructivas; clasificación visual; valores característicos. 


\section{ABSTRACT}

Populus x euramericana I-214 forestry resources available in Spain and Argentine, allowed the use of wood, even though their market has not been well developed, reason because is important have information about physical, mechanical and natural durability that allow more efficient use properties. From this information, it is possible proposes alternatives for improvement those properties that are interest to structural and non-structural use. In this work to collect the results of characterization in according to corresponding standard, I-214 clone solid wood, from Spain and Argentine, considering three piece sizes: small and without defects, semi-structural and structural pieces. In the small pieces, realized physical, mechanical and natural durability characterization. In semi-structural and structural pieces has been made non-destructive characterization: visual and about non-destructive testing, and destructive characterization in static bending in Universal machine. Later, the improvement alternatives to tend resource suitable useful, were proposed. In the small pieces and free defects worked about hardness and durability properties improvement; in the semi-structural pieces worked about modulus of elasticity estimation since free vibration frequency, and as well as on manufacturing glued wood, duo and trio, to improvement with respect the elastic and resistant solid wood. In the structural pieces, the improvement focused in the I-214 clone incorporation current Spanish standard to adapt the qualifying performance for this specie. Also, a method about the overload control of structural wood in service, which resulted in a patent, was proposed. In according to the results, won an extensive database information for this clone in both sources, as well as, establishment technological improvement alternatives that could be started point for future works, contributing to efficient use of this forestry resource available in spanish and argentine markets.

KEY WORDS: physical-mechanical properties; natural durability; non-destructive testing technique; visual grading; characteristic values. 


\section{CAPITULO I. INTRODUCCIÓN Y ANTECEDENTES}

En un contexto de preocupación mundial sobre las influencias del cambio climático, y el impacto de los gases de efecto invernadero en el medio ambiente, la madera ha cobrado cada vez más protagonismo. Las masas forestales de donde proviene este material tienen la capacidad de reducir las fuentes de dióxido de carbono de diversas formas: minimizando el uso de energía para su producción, sustituyendo otros materiales tradicionales como el acero, hormigón, etc, ahorrando energía durante su vida útil (eficiencia energética), sustituyendo, al final de su vida útil, la energía proveniente de combustibles fósiles (en caso de que no pueda reutilizarse o reciclarse) y aumentando los sumideros de carbono (Guy-Quint, 2009).

Asimismo, la creciente demanda de madera de calidad, ha ido en detrimento de grandes masas boscosas representadas por especies de crecimiento lento con buenas propiedades físicomecánicas, propiciando el uso de madera de especies de crecimiento rápido, que permiten la obtención de mayor volumen de madera en un corto período de tiempo (Troya et al., 1995; Mora et al., 2006), especies de las que, en ocasiones, no se conoce bien su comportamiento.

La caracterización de la madera sólida hace referencia a la determinación de una serie de propiedades físicas y mecánicas del material relacionadas con su comportamiento estructural. Este proceso puede ser llevado a cabo mediante la utilización de probetas de pequeñas dimensiones libre de defectos, como así también mediante la utilización de piezas de madera de tamaño estructural "real" y con singularidades/defectos propios de este material biológico. En el primer caso, los datos sirven fundamentalmente con fines de investigación para determinar el potencial mecánico de la madera, sin embargo, es la caracterización del material en tamaño estructural la que brinda valores reales de la misma (Rodrigo et al., 2013).

En este aspecto, hasta mediados de los años 70 aproximadamente, la caracterización mecánica de la madera se realizaba básicamente mediante ensayos con probetas de pequeñas dimensiones libres de defectos. Los métodos de cálculo de estructuras de madera seguían el formato de las tensiones admisibles del material, las cuales se obtenían a partir de un percentil (normalmente el $5^{\circ}$ ) de la distribución normal de la resistencia, al que se aplicaban una serie de ajustes por duración de la carga, humedad, altura de la sección, calidad y coeficiente de seguridad global (Íñiguez-González, 2007).

En este sentido, las investigaciones sobre el comportamiento resultante, se centraron en las diferencias producidas entre este tipo de material y el real (influencia del "efecto tamaño"). En base a ello, se llegó a la conclusión de que no era factible una predicción correcta de la resistencia de madera estructural a partir de un material tan diferente, como es la madera libre de defectos. Fue ante este comportamiento diferencial, que a comienzos de los años 70 se 
comenzó a trabajar en la línea de la determinación de las propiedades mecánicas de la madera, mediante el ensayo de piezas de tamaño real incorporando todas las singularidades que le son propias al material (Hermoso, 2001).

A comienzos del siglo XX, se comenzaron a vislumbrar los primeros métodos de ensayo no destructivos, entendiéndose por tal cualquier tipo de prueba practicada a una pieza de madera u otro material, que no altere de forma permanente sus propiedades físicas, químicas, mecánicas o dimensionales. Estas técnicas permiten una evaluación integral del material y estiman sus propiedades resistentes (densidad, módulo de elasticidad -MOE- y módulo de rotura -MOR-), sin que se tenga necesidad de alterar la pieza, por lo que resulta una técnica rápida y versátil (Íñiguez-González, 2007). Dichos métodos, clasificados en función de su naturaleza, se pueden dividir en: métodos visuales, mecánicos, acústicos, electromagnéticos y nucleares. En términos generales, consisten en el registro de un parámetro físico y la clasificación del material en función de la relación existente entre ese estimador y las propiedades resistentes. De este modo, cuanto más fácil de medir sea el estimador y mayor sea dicha relación, mejor será la técnica (Íñiguez-González et al., 2007).

De este modo, empezaron a surgir las primeras normas de clasificación visual de madera estructural, siendo la primera de ellas desarrollada y publicada por el Forest Products Laboratory de Madison (USA), en el año 1923. Hacia 1950, en Europa empezó el desarrollo normativo, sobre todo en Alemania (Deutsches Institut für Normung, DIN), Inglaterra (British Standards Institution, BSI) y Francia (Association Française de Normalisation, AFNOR) (Fernández-Golfín et al., 2001). Actualmente, existen numerosas normas de clasificación que difieren en las singularidades consideradas $\mathrm{y} / \mathrm{o}$ en la forma de medirlas, que recogen experiencias propias de cada país o región, y que se orientan a determinadas especies y/o procedencias. Básicamente, la evaluación compara el tamaño de las singularidades respecto a las dimensiones de la pieza evaluada, cuyo resultado es la clasificación del material en calidades visuales asociables con parámetros mecánicos conocidos que se detallan también en normativas específicas (Carballo-Collar et al., 2009). Entre este tipo de normas, en la actualidad pueden mencionarse la norma Española, UNE 56544: 2011, la norma alemana DIN 4074-5: 2008, la norma francesa NF B52-001: 2007. Todas ellas tienen en común la correlación existente entre las singularidades de la madera y su comportamiento de rigidez, resistencia y densidad.

Jayne (1959) propuso que la energía almacenada y disipada en las propiedades de materiales leñosos, podía ser medida de forma no destructiva, dado que dichos comportamientos se asemejarían con las propiedades estáticas elásticas y resistentes, y podían ser alcanzables mediante análisis de regresión estática (Hearmon, 1966). A partir de ese momento se generó un amplio desarrollo en la fabricación de equipos de técnicas no destructivas, para evaluar la 
calidad de diversos productos de madera y mejorar la precisión de dichas normas (Ross et al., 1991). Como ejemplo se pueden mencionar las máquinas de clasificación, MSR, que permiten evaluar parámetros no percibidos visualmente, y que confieren mayor precisión y velocidad al proceso (Glos and Diebold, 1994; Glos, 1995b).

En la actualidad, los avances en este campo están relacionados principalmente con la presencia de equipos más pequeños, versátiles y menos costosos, comparados con la máquina convencional de clasificación visual, MSR. Aunque los resultados encontrados con las nuevas metodologías no sean tan prometedores como los obtenidos con la MSR, proporcionan gran precisión con respecto a la más primitiva utilizada tradicionalmente, la clasificación visual, lo cual ha sido descrito por diversas autores, (Moslemi,1967; Ross et al.,1991; Halabe et al., 1995; Schad et al., 1995; Haines et al., 1996; Sánchez-Beitia and Barallo, 2000; Fernández Golfín et al., 2001; Burdzik and Nkwera, 2002; Ilic, 2003; Castro and Zanuttini, 2004; Álvarez, et al., 2005; Casado et al., 2005; Divos and Tanaka, 2005; Ross et al., 2005; Basterra et al., 2006; Acuña, et al., 2007; Wang et al., 2008; Basterra et al., 2009; Casado et al., 2009; Divos and Sismandy Kiss, 2010; Arcidiácono et al., 2011; Calderón et al., 2011; Casado et al., 2011; Casado et al., 2012; Wang et al., 2012; Hunt et al., 2013; Baradit, et al., 2013; Keil et al., 2014, entre otros). Los requisitos para el empleo de los métodos de ensayo no destructivo como medios de clasificación mecánica se establecen en las normas EN 14081: 1, 2 y 3.

Hoy en día, se dispone de diversas metodologías de este tipo de ensayos que permiten determinar las propiedades elasto-resistentes de la madera con mayor o menor precisión (Esteban-Herrero, 2003).

A principios de los años noventa, cuando se comenzó el libre comercio de los productos dentro del espacio europeo, el concepto de calidad del material que se tenía en ese momento, fue derivando en la búsqueda de patrones que constituyesen una idea de calidad común. Sumado a ello, la heterogeneidad de las diferentes especies madereras y la incorporación de diferentes procedencias para una misma especie, dieron lugar a diversas controversias provocadas por el desconocimiento de sus características específicas. En consecuencia, fueron surgiendo diversas normativas regulatorias para lograr un material competitivo, y establecer lotes de madera más homogéneos (Hermoso, 2001). Actualmente, esa tendencia se mantiene e incluso se potencia, acompañado por el interés creciente en el uso de materiales renovables para fines estructurales, como la madera y sumado a los modernos conceptos de diseño estructural. Todo ello, ha llevado a unificar los criterios internacionales en el uso de los diversos materiales utilizados en la construcción, entre los que cabe destacar la madera.

En Europa, el Comité Europeo de Normalización (CEN) es el que se encarga, a través de los Comités Técnicos (TC) de establecer las normas de calidad en cada campo y de proteger 
los intereses de los usuarios (Hermoso, 2001). Particularmente, el comité CEN/TC 250 es el responsable de todos los "Eurocódigos Estructurales", del que surgió el mencionado "Eurocódigo 5", que establece una serie de criterios para la correcta implementación de estructuras de madera en concordancia con las normas internacionales relacionadas al respecto. Dicho código se aplica en el cálculo de estructuras de madera maciza, aserrada, cepillada o en forma de rollizo, y de madera laminada encolada o tableros derivados de madera unidos entre sí mediante encolado o fijaciones mecánicas y establece los requisitos relativos a la resistencia mecánica, condiciones de servicio y de durabilidad de las estructuras (ENV 1995-1-1:1997).

A nivel nacional, en España, este seguimiento lo realiza Asociación Española de Normalización y Certificación (AENOR). En esta línea, en el seno del comité AEN/CTN 56: "Madera y Corcho", se estandarizan las dimensiones preferentes y tolerancias mediante la norma EN 336, las clases resistentes mediante la norma EN 338, el método de cálculo para los valores característicos mediante la norma EN 384, los métodos de ensayo de las propiedades mecánicas y físicas mediante la norma EN 408 permitiendo la comparación entre países y procedencias, los requisitos necesarios para la clasificación visual a través de la norma UNE 56544 o por máquina mediante la norma EN 14081, entre otros. Estas normas establecen diferentes parámetros de ensayos en madera estructural, donde en la mayoría de los casos, el principal "cuello de botella" está representado por los valores de rigidez determinados mediante el MOE, y por los valores de resistencia determinados a través del MOR, los cuales a su vez presentan una estrecha relación con las singularidades presentes en la madera. Al respecto, sumadas a las limitantes estructurales que pueda presentar la madera, en lo que respecta a la normativa de clasificación visual existente en España, UNE 56544: 2011, la misma no incluye al Populus sp dentro de su alcance, si bien fue incluida en su versión del año 1999. Asimismo, la norma UNE 56546: 2013, referente a la clasificación visual de especies de frondosas, sólo se limita a la madera aserrada de Eucalyptus globulus Labill y de Castanea sativa Mill, de procedencia española. En este sentido, al momento de establecer clasificaciones teniendo en cuenta los defectos del material, se trabaja sobre una base normativa incierta con las consecuencias de importantes pérdidas de eficiencia o rendimientos clasificatorios. Junto a ello, la falta de regulación en los mercados madereros, hace que el comprador se encuentre con un lote de calidades heterogéneas, cuando debería existir una clasificación por calidades que permitan comprar y pagar por lo que realmente se necesita.

En Argentina, el marco regulatorio de madera estructural lo lleva a cabo el Centro de Investigación de los Reglamentos Nacionales de Seguridad para las Obras Civiles (CIRSOC) como un Centro del Sistema de Centros de Investigación del Instituto Nacional de Tecnología Industrial (INTI), el cual fue creado en el año 1978. Actualmente, mediante la creación del 
Reglamento Argentino de Estructuras de Madera CIRSOC 601, aprobado en el año 2013, se regulan los métodos generales a emplear en el diseño y construcción de estructuras para edificaciones y obras civiles con madera aserrada, laminada encolada y productos derivados de la madera; se consideran los requisitos relacionados con el comportamiento mecánico de dichos productos, así como la durabilidad de las estructuras, los métodos a emplear en el diseño y la fabricación de uniones simples y múltiples; todo ello basado en las especies madereras de origen nacional utilizadas en construcción (Araucaria angustifolia, Eucalyptus grandis y Pinus taeda/elliottii). Si bien esto representa un panorama positivo para el sector, aún queda mucho por hacer en lo referente a normativas que regulen los requisitos de clasificación visual de madera aserrada maciza, las propiedades físico-mecánicas en material estructural, los valores característicos de los mismos, entre otros avances. El organismo competente para estas acciones es el Instituto Argentino de Normalización y Certificación (IRAM).

Cabe destacar que en ambos países (España y Argentina), existen normativas de ensayo para caracterización de madera de pequeñas dimensiones y libres de defectos, pero estos ensayos son básicamente empleados para fines de investigación e identificación del material, y como punto de partida para una caracterización en tamaño real a posteriori.

La caracterización física se lleva a cabo en probetas de pequeñas dimensiones y libres de defectos. A su vez, al ser la madera un material anisótropo, las determinaciones relacionadas con los cambios dimensionales, se realizan en tres direcciones: longitudinal, radial y tangencial. Mediante estas determinaciones es posible inferir el comportamiento de la madera frente al proceso de secado. La determinación de la densidad se encuentra regulada también en normativas referentes a ensayos estructurales, dado que es un parámetro considerado dentro de la clasificación resistente de la madera.

La caracterización mecánica puede realizarse en probetas de pequeñas dimensiones y libres de defectos o en piezas de tamaño estructural "real". En este último caso, pueden plantearse dos alternativas: técnicas no destructivas y técnicas destructivas.

En la predicción de las propiedades de la madera a través de técnicas de ensayo no destructivo (NDT), el método más tradicional y ampliamente utilizado es el de clasificación visual, donde básicamente, la evaluación compara el tamaño de las singularidades respecto a las dimensiones de la pieza evaluada, según se especifica en norma. El resultado de la evaluación es la clasificación del material en calidades asociables con características mecánicas conocidas, cuya efectividad real será dependiente de la correlación existente entre dichas singularidades y las propiedades resistentes (Hermoso, 2001; Esteban-Herrero, 2003; Íñiguez-González et al., 2007; Carballo-Collar et al., 2009). Sin embargo, las principales desventajas de las normas de clasificación visual radican en que están diseñadas para especies, procedencias y tamaños muy 
concretos, dejando normalmente fuera de clasificación a la madera de gran escuadría o a especies madereras de interés (Íñiguez-González, 2007).

En cualquier caso, aunque este tipo de técnicas aportan información pertinente sobre el comportamiento o condición del material, la madera aserrada maciza y aserrada encolada destinada para usos estructurales, es clasificada en función de los valores elasto-resistentes (MOE-MOR) y de densidad "reales" determinados mediante ensayos destructivos, cuyas condiciones de ensayo y de material son estipuladas en la norma EN 408. Posteriormente, mediante la norma EN 384 a partir de esos parámetros se determinan los valores característicos del material, correspondiendo a la media poblacional y al $5^{\circ}$ percentil de la población, para el MOE y para el MOR y la densidad, respectivamente. Con estos valores característicos, a partir de la norma EN 338, se establecen las clases resistentes del material, las cuales son distinguidas entre clases resistentes de coníferas y de frondosas, cuya razón de ser se basa en las diferentes estructuras anatómicas entre ambas que hacen que su comportamiento, también sea distinto; por ejemplo, la densidad de las frondosas es alta, pero no se corresponde con propiedades resistentes y elásticas como cabría esperar. Los chopos son las únicas frondosas que tienen relaciones densidad-resistencia similares a las coníferas, y por tanto, se les aplican las mismas clases resistentes que a éstas (Hermoso, 2001).

Culminada esta etapa es cuando la eficiencia clasificatoria de las normas de clasificación visual cobra verdadero sentido, ya que aquellas que permitan obtener una estimación confiable de las clases reales resistentes, serán más efectivas como método único de clasificación, de forma que las normas que presentan un gran número de aciertos, un número intermedio de subestimas y un número mínimo de sobreestimas, serán las más eficientes. Los aciertos indican que lo establecido con las normas de clasificación visual, es coincidente con lo obtenido mediante la clasificación resistente. Las subestimas muestran que lo obtenido mediante clasificación visual, es inferior a lo realmente obtenido por clasificación resistente, hecho que brinda seguridad al cliente siendo ineficiente para el productor, ya que comercializa un material con calidad resistente superior que la establecida por la norma de clasificación visual. Este último punto, supone una de las principales razones por la que esta técnica se comenzó a emplear junto con otros métodos no destructivos de estimación resistente (Hermoso, 2001). Finalmente, un alto porcentaje de piezas sobreestimadas supone un riesgo para el comprador, pero conlleva mejores ganancias para el productor.

En esta línea, aquellas NDT que permitan obtener una estimación confiable de los valores resistentes reales de un lote, serán más apropiadas como métodos de clasificación, pudiendo considerarse su inclusión dentro de normativas de clasificación (Casado et al., 2009; 2011; 2012; Hermoso, 2001; Íñiguez-González, 2007; Basterra et al., 2009). 
Considerando el factor económico, para lograr mejores rendimientos y mayor productividad mediante una clasificación por resistencia, una población de madera debe dividirse en clases o grupos de distinta calidad, sobre la base de una inspección no destructiva individual. Dicha inspección, visual o mecánica, tiene en cuenta el nivel de singularidades consideradas y, en función de los límites establecidos en cada norma, se realiza la asignación de cada elemento a una determinada clase resistente. Una población de madera aserrada sin clasificar, conduce a la obtención de valores característicos muy bajos, como consecuencia de la alta dispersión natural de sus propiedades. Por el contrario, la división de la población original en clases, que constituyen sub-poblaciones de características más homogéneas, permite sacar provecho de las piezas de mayor calidad, y a su vez trabajar con mayor confianza, por lo que razones técnicas y económicas son entonces, las que justifican la clasificación por resistencia de la madera (Glos, 1995b; Blaß \& Görlacher, 1996; Glos and Lederer, 2000).

Por otro lado, el uso de la madera implica su exposición a situaciones propicias para la degradación que pone en riesgo su tiempo/vida útil. De acuerdo con la normativa europea EN 350-1, la durabilidad natural se define como la resistencia intrínseca que presentan las maderas a la degradación por organismos vivos (hongos, termitas, coleópteros y perforadores marinos). Conocer esta propiedad permite definir la situación de uso del material más apropiada o bien, precisar su conservación ante la necesidad de utilizarla en situaciones de riesgo (clases de uso) para las que no presenta aptitud, tal como queda especificado en las reglas generales de diseño de estructuras de madera establecidas en el "Eurocódigo 5". La norma 350-2 presenta una lista de las frondosas de mayor importancia en el ámbito de la construcción europea, con sus correspondientes clases de resistencia a los distintos tipos de daño biológico, en la cual el género Populus está representado por las especies P. canescens, P. nigra, P. alba y por el grupo $P$. hybrid. Cabe destacar que ambas partes de la norma EN 350, han sido unificadas en marzo del 2015 y se encuentran en etapa de aprobación.

Dentro de las frondosas más productivas de crecimiento rápido, se encuentran diversas especies e híbridos del género Populus, cuyo cultivo ha sido impulsado mundialmente con el fin de obtener madera para uso estructural, carpintería y reprocesado industrial, con los beneficios socioeconómicos y ambientales que conlleva (Castro and Fragnelli, 2006).

De acuerdo con esto, a continuación se detalla la clasificación taxonómica, las propiedades generales y el uso de la madera de Populus sp, como así también su situación en un contexto mundial. 


\section{El género Populus}

El género Populus sp, vulgarmente conocido como "Chopo" o "Álamo", comprende unas 40 especies entre árboles y arbustos, típicas de zonas templadas y frías septentrionales. Taxonómicamente, según Engler (1964) se clasifica según se indica a continuación:

Subdivisión: Angiospermae

Clase: Dicotyledoneae

Subclase: Archychlamydeae

Orden: Salicales

\section{Familia: Salicaceae}

\section{Género: Populus}

\section{Populus sp: propiedades generales de su madera}

La madera de "Chopo" presenta una escasa diferenciación entre albura y duramen.

Según la disposición de los vasos, su porosidad es difusa, con vasos de diámetro similar, dispuestos uniformemente en el anillo de crecimiento.

La composición volumétrica es dominada por una alta proporción de fibras (53-60\%), seguida por elementos de vaso (28-34\%), radios celulares (11-14\%) y una despreciable proporción de parénquima axial (0,1-0,3\%) (Balactinecz et al., 2001).

El promedio de la longitud de las fibras se encuentra entre 1,3 a $1,4 \mathrm{~mm}$, siendo inferiores a las "fibras papeleras" (traqueidas) de las coníferas (3-4 mm), mientras que el promedio de la longitud de los elementos de vaso en la madera madura, se encuentra en el rango de 0,58 a $0,67 \mathrm{~mm}$. La diferencia entre la longitud de las fibras explica por qué la pulpa de las coníferas presenta mejores propiedades de resistencia al rasgado, explosión y longitud de rotura; mientras que los elementos de vaso de los álamos mejoran significativamente la suavidad y opacidad del papel, siendo muy apropiado para la fabricación de papel de impresión (Balactinecz et al., 2001). Tanto para los híbridos, como para las especies naturales, la longitud de las fibras se incrementa con la edad y posición en el árbol (Koubaa et al., 2005).

La composición química de la madera de chopo se caracteriza por altos contenidos de polisacáridos (aproximadamente $80 \%$ de holocelulosas: $50 \%$ celulosa y $30 \%$ de hemicelulosa), y bajo contenido de lignina (alrededor de $20 \%$ o menos).

Desarrollan con bastante facilidad madera de tensión, denominada madera de reacción para las latifoliadas (Balactinecz et al., 2001). Dicha madera es aquella que se forma en la parte superior de la inserción de las ramas o en las ramas inclinadas. Anatómicamente, se caracteriza por la falta de lignificación de la pared celular y a menudo, por la presencia de una capa 
gelatinosa en las fibras; en relación con la madera normal presenta mayor proporción de celulosa y cenizas pero menor proporción de lignina y hemicelulosa (Balactinecz et al., 2001).

\section{Populus sp: usos de su madera}

La madera de chopo es muy preciada a nivel mundial debido a su alta versatilidad y a sus principales propiedades, tales como liviandad, color claro, facilidad para ser descortezada, encolada y todas aquellas tareas de remanufactura final (Castro, 2006).

En términos generales, según Calderón (2006), sus usos se pueden resumir en:

\section{- Usos rurales}

- Construcciones rurales

○ Postes

- Usos industriales

- Madera para aserrado

Carpintería, cajonería, vigas laminadas, lápices, etc.

○ Madera debobinada

Contrachapados, embalajes livianos, fósforos, palitos para helados, palitos para arroz, etc.

- Madera triturada

Tableros aglomerados, OSB, pasta para papel

- Virutas de madera

\section{- Usos medioambientales}

- Tratamiento y reutilización de aguas residuales

○ Fitorremediación

○ Estabilización de riberas

○ Dunas

○ Retención de carbono

- Usos energéticos

- Sistemas agroforestales

- Otros usos

○ Ornamental y forrajera

\section{Populus sp: la madera en el contexto mundial}

A nivel mundial, Figura 1, el género Populus se puede encontrar tanto en bosques nativos, en el hemisferio norte, como en plantaciones en latitudes templadas de ambos hemisferios, establecidas como macizos, cortinas o como pequeños grupos de árboles aislados o 
incluidos en sistemas silvopastorales, según cuál sea el objetivo (Dickmann, 2006; Pincemin et al., 2007).

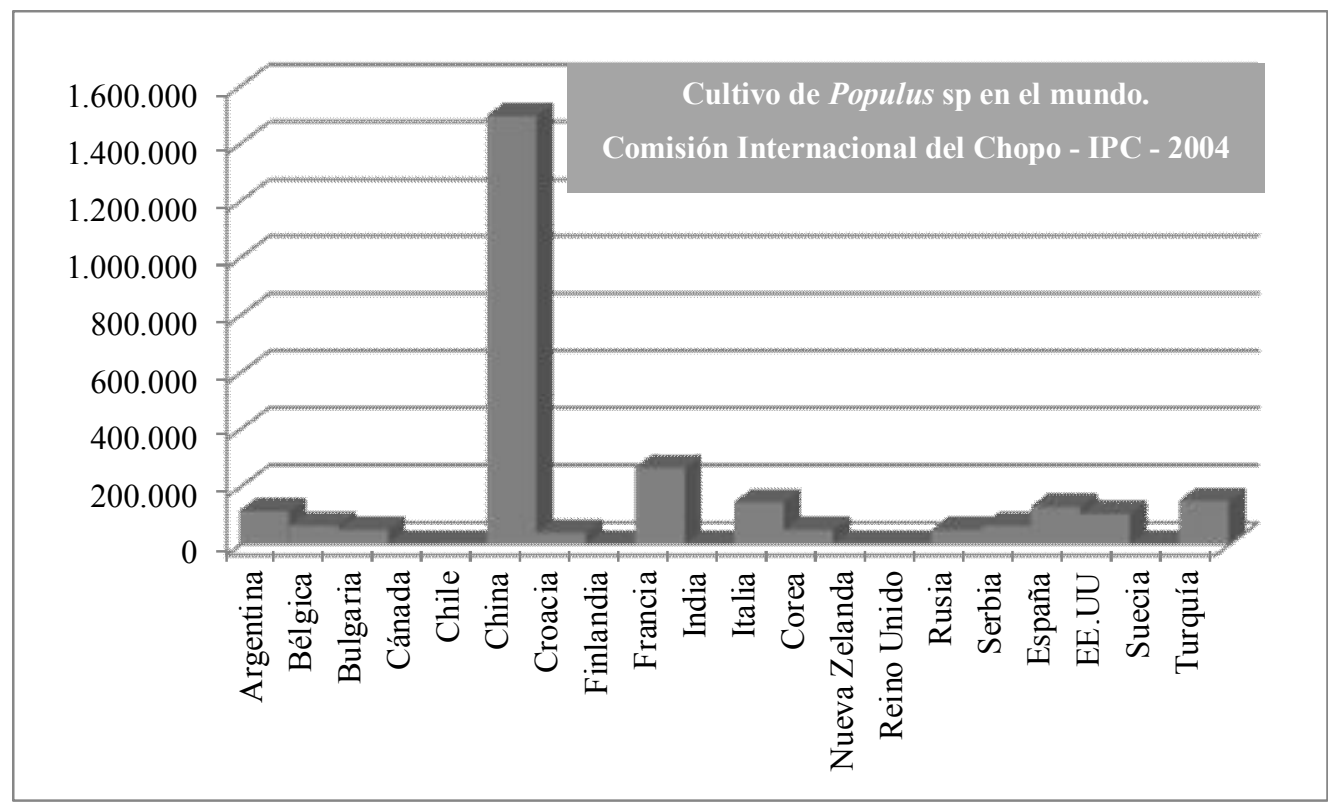

Figura 1. Cultivo de chopo en el mundo. Fuente: Castro, 2006

El chopo ocupa más de 80 millones de hectáreas en todo el mundo, siendo China el país con mayor representación, donde se pueden encontrar forestaciones en un rango de altitudes que van desde los $500 \mathrm{msnm}$ hasta $4500 \mathrm{msnm}$. El destino principal de la materia prima obtenida de estas plantaciones es la industria del contrachapado (Confemadera, 2010; Wan, 2010).

En Europa, Francia e Italia se encuentran entre los principales productores de chopo. Francia, cuenta con una superficie de 240.000 ha dedicadas a la populicultura, donde la industria del contrachapado y de embalajes y pallets es el destino principal aunque, con un creciente interés en su introducción para fines estructurales en la construcción (Confemadera, 2010). Italia, cuenta sólo con el 1,3\% de su área forestada total, destinada a la populicultura, sin embargo, representa cerca del $45 \%$ de la madera rolliza producida en el país para uso industrial, que se concentra en la industria de tableros contrachapados destinado sobre todo al sector del mueble, donde su liviandad es muy apreciada y prácticamente imposible de alcanzar con otros productos (Castro, 2006).

En España, según la Encuesta sobre Superficies y Rendimientos Cultivos, ESYRCE (2014), del total de 50.593.546 ha de superficie geográfica española, 19.013.972 ha se corresponde con superficie forestal arbolada, lo que supone alrededor del $38 \%$ del territorio nacional. De esa superficie, 134.770 ha son ocupadas por especies del género Populus, de las cuales, alrededor del $65 \%$ se encuentran ubicadas en Castilla y León. Este desarrollo ha 
incentivado a la investigación y al desarrollo de nuevos clones, como a la puesta a punto de técnicas de cultivo acordes y tendientes a la mejora de dicha calidad (García-Caballero, 2011).

Actualmente, de la producción total de chopo $\left(600.000 \mathrm{~m}^{3}\right)$, un $50 \%$ aproximadamente se destina a la industria del desenrollo para la producción de chapa y tablero contrachapado, principalmente utilizados en la industria de envases y embalajes horto-frutícolas. Igualmente, en menor medida se destina a otros sectores como el de la construcción, mueble, juguete, entre otros (Confemadera, 2010).

Entre las especies más representativas, el clon I-214 de la variedad euramericana, ocupa $70 \%$ de las choperas españolas, cuyo destino principal es la industria del debobinado; entre los requerimientos exigibles para este sector se consideran las características físicas de la madera, la morfología del tronco (excentricidad, conicidad y curvaturas relativas al eje longitudinal de la pieza) y la ausencia de corazón negro o falso duramen, entre las más importantes. La madera de corazón negro presenta un contenido de humedad en estado verde, superior al del resto de la madera, aunque sin diferencias apreciables en cuanto a la densidad (Baonza and Gutiérrez, 1997), siendo más susceptible al colapso durante las primeras etapas de secado (Álvarez and Fernández-Golfín, 1997; Confemadera, 2010).

En otros países europeos, al igual que en Canadá y Estados Unidos, esta madera se utiliza con fines estructurales. Allí, la madera sólida frecuentemente es sustituida de modo ventajoso con productos derivados de la madera denominados "ingenieriles".

Por otra parte, a través de los años, la utilización del chopo ha ido aumentando con el desarrollo de la industria de tableros, con un nivel actual tan alto que existe la preocupación en algunos países como Estados Unidos y Canadá, de que la corta supere el crecimiento (Balactinecz et al., 2001). Cabe destacar que estos países junto con Rusia presentan la mayor superficie natural de chopo (Confemadera, 2010).

En lo que respecta a América del sur, las superficies datadas de plantaciones de chopo más abundantes, se encuentran en Chile y Argentina.

En Chile, se ha generado un creciente interés en el potencial forestal de las especies e híbridos del género Populus; cuenta con aproximadamente 6.500 hectáreas de plantaciones de híbridos entre los que se encuentran los clones I-214 e I-488 de Populus x euramericana, distribuidos principalmente en las regiones del Maule y Libertador General Bernardo O’Higgins. Sin embargo, desde el año 1999 se han ido introduciendo diferentes híbridos, lo que ha significado un aumento en la diversidad genética de este género (Rubio-Meléndez et al., 2011). La producción de estas maderas está orientada principalmente a la obtención de rollizos y a la producción de madera de calidad inferior con destino cajonería y mueblería (Spavento, 2011). 
En Argentina, la superficie de bosques implantados, se estima en 1.200 .000 ha aproximadamente, de las cuales, un 10\% están representadas por salicáceas (Populus sp y Salix sp), con un valor destacado en la producción forestal, ya que constituyen el tercer cultivo de importancia, en cuanto a volúmenes extraídos anualmente, por debajo del género Pinus sp. y Eucalyptus sp.; según las estadísticas del Ministerio de Agricultura, Ganadería y Pesca de la Nación (MAGyP, 2010), la extracción de productos forestales totales de bosques implantados en Argentina puede dividirse en: $60 \%$ pertenecientes a especies de coníferas, $32 \%$ a latifoliadas del género Eucalyptus, 7\% a latifoliadas pertenecientes a Salicáceas y 1\% a la extracción de otras especies. Del total del consumo aparente de rollizos de bosques implantados, aproximadamente el $50 \%$ tiene como destino la elaboración de pasta celulósica, el $30 \%$ la industria de la madera aserrada y el resto se distribuye entre la producción de chapas de madera mediante corte a la plana (faqueado) - desenrollo (debobinado) y la producción de tableros. Entre las especies del género Populus, la variedad deltoides y los cultivares de la variedad euramericana son los más representativos (Marquina et al., 2006; MAGyP, 2014).

Atendiendo a la disponibilidad de material correspondiente al clon I-214, a continuación, se detallan las especies utilizadas para obtener la hibridación euramericana así como los recursos forestales existentes, los usos actuales de su madera y las cuestiones técnicas de caracterización, tecnología y regulaciones a nivel mundial.

\section{Populus $x$ euramericana: su historia}

El Populus $x$ euramericana (Dode) Guinier, es una hibridación espontánea entre un chopo americano (Populus deltoides Bartr. ex Marsh.) y un chopo euroasiático (Populus nigra L.). Este híbrido se conoce también bajo la denominación de Populus $x$ canadensis Moench, pero la Comisión Internacional del Álamo (IPC), la sustituyó por euramericana Guinier (Boom, 1967). Sin embargo, los cambios de nomenclatura han sido ampliamente discutidos. Al respecto, Boom (1967) en un trabajo publicado en el Acta Botánica Neerlandica, permite aclarar un poco esta cuestión, y describe que los "Chopos/Álamos de Canadá" ó "Canadien Poplars", como mundialmente suele conocerse a estos híbridos, no se introdujeron en Europa desde Canadá ni desde América del Norte, sino que son híbridos originados a partir del Populus deltoides de origen americano introducido espontáneamente en Francia a mediados del siglo XVIII, y del Populus nigra de origen euroasiático, lo que ocasionó el cambio de canadensis a euramericana, oportunamente. Si bien existen contradicciones o diferencias de opiniones entre algunos autores (Jalas and Suominen, 1976; Soriano, 1993; Vanden Broeck, 2003; Cotrell et al., 2005) la Comisión Internacional del Álamo (2004), recomendó el uso de la terminología 
canadensis, por lo que actualmente es común encontrar ambas nomenclaturas como sinonimias sin que se especifique claramente cuál es la correcta.

\section{Populus $x$ euramericana I-214: su historia}

El clon I-214, es uno de los híbridos euroamericanos más difundidos en las forestaciones a nivel mundial; es clon femenino de origen italiano (de ahí su identificación "I" en la mención del cultivar), desarrollado en el año 1929 en el antiguo Istituto di Sperimentazione per la Pioppicoltura (actualmente Unità di ricerca per le Produzioni Legnose fuori Foresta), situado en Casale Monferrato (De la Cruz-Callejas, 2005). Este clon, de crecimiento muy rápido, presenta características intermedias a las de sus parentales, siendo el Populus deltoides (madre) quien aporta sus mejores cualidades tecnológicas y el Populus nigra (padre) quien aporta su facilidad para el estaquillado y su mejor adaptación al medio, aunque en términos generales prefiere de un suelo fértil y no muy turboso o gravoso, siendo bastante sensible al fototropismo, a heladas precoces y a vientos fuertes.

En cuanto a sus características fenotípicas puede observarse que posee una copa bastante amplia, un fuste ligeramente tortuoso y es bastante exigente en cuanto a prácticas de poda, a fin de lograr mejor calidad del material aserrado.

En lo que a su madera se refiere, si bien presenta una calidad discutible, será el objeto de estudio de este trabajo, y se debatirá oportunamente con el desarrollo del mismo.

\section{Populus x euramericana I-214: recurso forestal disponible en España y Argentina}

De acuerdo con lo manifiesto en la $1^{\mathrm{a}}$ Conferencia Internacional del Futuro del Cultivo de Chopo (2003), gracias a su facilidad de cultivo y crecimiento, el chopo está llamado a representar un papel muy importante en todo el mundo (Álvarez-Moreno, 2004).

En España, se pueden considerar tres zonas productoras de chopo, diferenciadas por método de cultivo y aprovechamiento (Comisión Nacional del Chopo, 2010):

$\checkmark$ Zona del Duero: donde el sistema más utilizado de plantación es el de raíz profunda, con un turno de corta promedio de 15 años.

$\checkmark$ Zona del Valle Medio del Ebro y Cataluña: donde las plantaciones se realizan a raíz superficial con riego y turno de corta de 12 años

$\checkmark$ Zona de Andalucía (Granada): principalmente el Valle del Genil y del Darro, con plantaciones bajo riego y con turnos de aprovechamiento entre 8 y 10 años. 
En la zona del Duero, según datos aportados por la Confederación española de empresarios de la madera (2010), la Comunidad de Castilla y León es la que presenta mayor superficie dedicada a la producción de chopo con 82.627 ha (ESYRCE, 2014) correspondiéndose a un $65 \%$ de las superficies nacionales, lo que la posiciona como la principal productora de esta madera en España.

En la zona del Valle Medio del Ebro, la producción de La Rioja, Aragón y Navarra, donde se concentra la populicultura de esta zona, se encuentra regulada bajo los designios de la Confederación Hidrográfica del Ebro (CHE). De acuerdo con los datos ofrecidos por ESYRCE (2014), esta zona cuenta con 17.366 ha cultivadas con chopos. En lo referente a Cataluña, la superficie forestada con especies de Populus se cifra en 6.334 ha (ESYRCE, 2014).

En Andalucía las plantaciones de chopo ocupan aproximadamente 7.158 ha, de las cuales 5484 ha se concentran en la provincia de Granada (ESYRCE, 2014), principalmente en el Valle del Genil y del Darro (López, 2002; Ripoll-Morales et al., 2009).

En cuanto al material vegetal, en las tres zonas descritas, la populicultura se sustenta sobre un reducido número de clones, que garantizan crecimientos aceptables y cierta plasticidad bajo diferentes condiciones ambientes. En términos generales, las plantaciones son fundamentalmente monoclonales puras y representadas por el clon Populus x euramericana I214. La preponderancia de este clon se basa en su alta plasticidad para ser empleado en los distintos tipos de terrenos y condiciones climáticas, sumado a su elevada tasa de crecimiento y a la buena calidad de su madera. Sin embargo, existen algunos inconvenientes inherentes a él, entre los que cabe destacar: la sensibilidad a ciertos agentes patógenos, las pérdidas volumétricas de madera ocasionadas por la tortuosidad de su tronco, o por la presencia de defectos relacionados a la deficiencia y/o carencia de eventuales procesos de poda (Padró, 1992; López, 2002).

Según el informe tetra-anual de la Comisión Nacional del Chopo, España (2012), la populicultura está enfocada a cuatro vías principales de explotación:

$\checkmark$ Elaboración de productos de madera con calidades diferenciales: si bien, en dicho compendio se cita un proyecto sobre caracterización de la madera de los clones 'Luisa Avanzo' y 'MC' de Populus $x$ euramericana con destino a la industria del desenrollo, no existe registro referente a la caracterización y estudio de la madera maciza procedente de las plantaciones disponibles del clon I-214, que es el más difundido en la península. Por su parte, externamente a dicho informe, se han encontrado estudios relacionados al mismo, fundamentalmente llevados a cabo por el Grupo de 
Investigaciones en Estructuras y Tecnología de la Madera de la Universidad de Valladolid.

$\checkmark$ Fuente renovable de energía (bioenergía): la superficie dedicada a cultivos energéticos basados en especies de chopos, se cifra en torno a 3.500 ha. Entre los principales cultivares utilizados se encuentra el clon 'I-214'.

$\checkmark$ Usos ambientales: se usa tanto como mitigador del cambio climático, en donde se destaca la presencia del clon 'I-214', como de barrera de protección para cultivos hortofrutícolas y fruti-vinícolas.

$\checkmark$ Fitorrecuperadores de suelos y aguas contaminadas: esto viene dado por el gran potencial extractivo y metabólico del género Populus sp.

En Argentina, se pueden considerar tres grandes zonas productoras de chopo diferenciadas por método de cultivo y aprovechamiento:

$\checkmark$ Delta del Río Paraná (Buenos Aires y Entre Ríos): donde las plantaciones se realizan principalmente sobre albordones, con turnos de cortas de 12 a 16 años y con crecimientos promedios de 20-25 $\mathrm{m}^{3} / \mathrm{ha} /$ año (Spavento, 2011).

$\checkmark$ Patagonia norte (zona del Valle medio de Río Negro): donde los recursos madereros están disponibles en sistemas bajo riegos, como cortinas de protección para cultivos horto-frutícolas (con distanciamientos de 2 × 2 m) ó como plantaciones en macizos en sistemas silvopastorales con distanciamientos superiores ( $6 \times 6 \mathrm{~m}, 6 \times 4 \mathrm{~m}$ o $5 \times 5 \mathrm{~m})$, con turnos de corta entre 13 - 15 años y con un crecimiento promedio anual de 25-30 $\mathrm{m}^{3} / \mathrm{ha} / \mathrm{año}$, rendimiento altamente diferencial con respecto a las coníferas regionales (Cortizo, 2011; Beale and Ortíz, 2013).

$\checkmark$ Región de Cuyo (Mendoza): el sistema de plantación bajo riego está representado básicamente por cortinas protectoras de cultivos de vid, principal actividad productiva de la provincia (Spavento, 2011; Beale and Ortíz, 2013), y por plantaciones en macizos bajo sistema silvopastoral con distanciamientos preponderantes de $8 \mathrm{~m} \times 2 \mathrm{~m}$; los turnos de corta están comprendidos entre los 12-15 años, con rendimientos que rondan los 20$30 \mathrm{~m}^{3} /$ ha/año.

En la región del Delta del Río Paraná, la superficie forestal supera las 100.000 ha de las cuales, cerca del $50 \%$ corresponden a Salicáceas ubicadas en su mayoría en el Delta del río Paraná perteneciente a la provincia de Buenos Aires; en la región del Delta de Entre Ríos, los recursos de salicáceas se cifran en 12.000 ha aproximadamente (Beale and Ortíz, 2013). 
La región patagónica (provincias de Neuquén, Río Negro, Chubut y Santa Cruz), está representada por 75.900 ha, las que a su vez se dividen en dos regiones que presentan sistemas selviculturales muy diferentes. Por un lado, la zona de regadío del Valle de Río Negro con una superficie forestal de unas 20.000 ha, representadas básicamente por Salicáceas implantadas en cortinas de protección de los vientos zonales (conocidas como "cortinas rompevientos"), ó en el cada vez más difundido, sistema silvopastoral en macizo. Este sistema le otorga al productor una retribución económica intermedia antes del aprovechamiento final de la plantación. En esta región, el cultivo de chopos en particular, ha estado históricamente relacionado a barreras de protección para la producción horto-frutícolas con la finalidad de proteger a los cultivos de los vientos característicos de la región; posteriores repoblaciones en macizo se han relacionado con la producción de madera de mejor calidad, destacándose para ello los clones 'I-214', 'I-488', 'Conti 12' y 'Guardi', de las variedades euramericana (Cancio and Thomas, 2011). Asimismo, la finalidad de estas maderas está orientada hacia el abastecimiento de aserraderos locales y regionales para la elaboración de paneles contrachapados (compensados), y productos de bajo valor añadido (agregado), aun desconociendo si el material puede presentar mejores prestaciones (Thomas and Garcés, 2011).

Por otra parte, en la Patagonia Andina, se cuenta con más de 55.000 ha forestadas, las cuales están representadas principalmente por Pinus ponderosa y Pseudotsuga menziesii (Cortizo, 2011; Beale and Ortíz, 2013).

En cuanto a la Región de Cuyo, específicamente la provincia de Mendoza, de acuerdo con los datos del Censo Nacional Agropecuario, la superficie aproximada considerando macizos y cortinas, es de 8.000 ha. Según valores aportados por la Facultad de Agronomía (Cátedra de Dasonomía), Universidad Nacional de Cuyo, la superficie rondaría las 12.000 ha. De todos modos, del total estimado, un $94 \%$ está representado por Populus sp, seguido por una mínima existencia de cultivo de Salix sp y menor proporción aún, por Eucalyptus sp y Pinus sp. Asimismo, este porcentaje representa el 2,76\% de las 290.000 ha cultivadas bajo riego, de las cuales sólo el cultivo de vid abarca 150.000 ha, siendo esta la principal actividad productiva de la provincia (Spavento, 2011; Beale and Ortíz, 2013).

En términos generales, los clones más representativos son Populus deltoides y Populus $x$ euroamericana. Asimismo, el primero de ellos es más representativo de la zona del Delta del Río Paraná y de la Región de Cuyo (provincia de Mendoza), mientras que los cultivares euroamericanos son más específicos de la zona del Valle medio de Río Negro, preponderando entre ellos las variedades I-214, junto con I-488, Conti-12 y Guardi. Con representación similar en las tres regiones se encuentra el Populus nigra. Mientras que en la zona del valle medio es posible encontrar también forestaciones de Populus trichocarpa. 
Al igual que lo mencionado para España, según el informe tetra-anual de la Comisión Nacional del Álamo, Argentina (2012), la populicultura Argentina enfocada según las cuatro vías de explotación antes descritas, se puede resumir de la siguiente manera:

$\checkmark$ Elaboración de productos de madera con calidades diferenciales: al respecto se han mencionado, entre algunas consideraciones referentes a la industria del debobinado que escapan del alcance de este trabajo, estudios tecnológicos básicos realizados en cultivares de Populus nigra y de Populus trichocarpa, pero al igual que en el panorama español, no se mencionan estudios registrados referentes a la caracterización y estudio de la madera maciza procedente de las plantaciones disponibles del clon I-214. No obstante, externamente a este informe, se encontraron trabajos recientes referentes a la caracterización del clon I-214, y más concretamente en la zona del Valle medio de Rio Negro, llevados a cabo por el Laboratorio de Investigaciones en Maderas de la Universidad Nacional de La Plata.

$\checkmark$ Fuente renovable de energía (bioenergía): parcelas establecidas en el año 2006 (Mendoza) con álamos y sauces se encuentran en fase de análisis y evaluación; los cultivares de chopo reportados pertenecen a la variedad euramericana.

$\checkmark$ Usos ambientales: fundamentalmente relacionado a la creación de cortinas rompevientos para la protección de cultivos horto-frutícolas.

$\checkmark$ Fitorrecuperadores de suelos y aguas contaminadas: en una fase incipiente de evaluación, las plantaciones comerciales de Populus sp. irrigadas con aguas provenientes de efluentes domiciliarios, han presentado buenos resultados.

Según Serventi and García (2004), se estima que la superficie de chopos en esta región se va a mantener, e incluso a incrementar, debido a la existencia de áreas con condiciones ecológicas y de suelo aptos para producir madera de calidad con altos rendimientos por ha.

\section{Populus $x$ euramericana I-214: mejoras y optimización tecnológicas}

Tal como se ha mencionado en puntos anteriores, la madera de chopo está cobrando mayor importancia en el sector industrial. Concretamente el clon I-214, ampliamente distribuido y disponible a nivel mundial, supone un recurso maderero, del que no se conoce exhaustivamente sus características. El análisis profundo relacionado a la caracterización de su madera con fines estructurales, es un nicho sin cubrir y representa un paso fundamental para tomar las decisiones adecuadas que cambien el destino de esta madera, o bien que hagan de ella un uso más eficiente. A continuación se detallan algunas alternativas de mejora de la madera de este clon entre las que cabe destacar, además de su obligada inclusión en la normativa nacional 
correspondiente, su optimización de uso a partir de fabricación de piezas encoladas y el termotratamiento. No se mencionan otros tratamientos como los químicos tradicionalmente utilizados, ya que su uso y aplicación depende de la estandarización de cada país.

\subsection{Populus $x$ euramericana I-214: inclusión en normas}

Para poder lograr un equilibrio entre la creciente necesidad de madera con clases resistentes apropiadas y diferenciadas para usos específicos, es necesario contar con estudios y normativas que regulen su uso. Para ello, este clon debe presentar una identidad tecnológica reconocida para que pueda ser utilizado de forma correcta y homologada. Si bien existe una amplia variedad de normas generales que regulan el correcto uso de la madera, debe partirse de aquellas que no consideran al chopo dentro de su alcance. En este sentido, la incorporación de este clon dentro de las normas de durabilidad, como así también, dentro de la norma que regule su clasificación visual es uno de los aspectos de mejoras y optimización que se plantean dentro del alcance de este trabajo.

\subsection{Populus $x$ euramericana I-214: fabricación de piezas encoladas dúo y trío como alternativa de estructuras livianas}

Con la finalidad de buscar alternativas de uso a la madera de chopo disponible en mercados madereros locales (españoles y argentinos), resulta de interés encaminar los estudios en torno a la fabricación de productos con mayor valor añadido (agregado), como es el caso del material macizo encolado, estudio realizado dentro del proyecto "Fabricación y caracterización de vigas de madera reforzadas con fibras", VI Plan Nacional de Investigación Científica, Desarrollo e Innovación Tecnológica 2008-2011 (Universidad de Valladolid).

Las vigas dúos o tríos consisten en la unión, por medio de encolado, de piezas de madera de formatos superiores a las láminas corrientes de vigas laminadas. Esta unión se realiza de forma que las piezas queden con la superficie de encolado en posición vertical, logrando que las caras con los anillos de crecimiento más externo queden en el interior de la viga, y las caras que se sitúan más interiormente queden vistas hacia fuera en la viga.

Aunque no existe ninguna norma propia para vigas dúo y trío, en Alemania su uso estructural está regulado mediante "Allgemeine bauaufsichtliche Zulassung, Z-9.1-440" (2) del "Deutsches Institut für Bautechnik", donde se definen las características de las vigas dúo y trío, la producción, marcado y control de las mismas.

Las ventajas son múltiples. Desde el punto de vista visual los cortes internos presentan menos nudos y son éstos los que aparecen en la cara exterior en el sistema dúo. Desde el punto de vista de la geometría de las vigas, las deformaciones de las mismas son menores, y el 
fendado lateral casi inexistente. En cuanto a las propiedades mecánicas, se consigue una optimización en el uso de la madera de costeros del tronco originario de una mayor resistencia, uniéndose para conformar piezas de mayor escuadría (Ahvenainen and García Barbero, 2007).

En términos generales, al igual que en otros productos de madera maciza encolados, las principales ventajas (Castro, 2006) radican en los siguientes puntos:

$\checkmark$ Optimización del comportamiento físico-mecánico y reducción de la variabilidad natural de la madera, lograda a través de una selección de la materia prima y una recomposición controlada, con la finalidad de obtener productos más isotrópicos y homogéneos.

$\checkmark$ Aumento de la durabilidad del producto elaborado, logrado a través de mecanismos químicos y/o físicos (por ejemplo, mediante la elección de adhesivos apropiados).

\subsection{Populus $x$ euramericana I-214: termo-modificación como alternativa de mejora de} dureza y durabilidad de su madera

El interés por el uso de termo-tratamiento para modificar las propiedades de la madera data de hace varias décadas (Tiemann, 1920; Kollman, 1936; Seborg et al., 1945; Stamm et al., 1946; Seborg et al., 1953; Kollmann and Schneider, 1963; Kollman and Fengel, 1965; Fengel, 1966 I, II, II; D’Jakonov and Konepleva, 1967; Nikolov and Encev, 1967; Burmester, 1973, 1975; Rusche, 1973a,b; Giebeler, 1983; Hillis, 1984). Más recientemente se ha renovado el interés por este proceso debido, principalmente, a la creciente escasez de maderas de características tecnológicas apropiadas, al incremento de la demanda de materiales constructivos sostenibles, a la alta tasa de deforestación, especialmente de especies tropicales y a las crecientes regulaciones gubernamentales para el uso de productos químicos (Boonstra, 2008).

En términos generales, los primeros estudios, se centraron en las ventajas que conllevaba este proceso en el comportamiento de la madera en relación al contenido de humedad de equilibrio higroscópico, los cambios dimensionales, la durabilidad y las propiedades mecánicas; sin embargo, este proceso supone ciertos inconvenientes en la madera como su variación de color y sus transformaciones químicas (Tiemann, 1920; Kollman, 1936; Seborg et al., 1945; Kollman and Schneider, 1963; Kollman and Fengel, 1965; Fengel, 1966 a, b; D’Jakonov and Konepleva, 1967; Nikolov and Encev, 1967; Burmester, 1973; Rusche, 1973 a, b; Giebeler, 1983; Hillis, 1984; Militz, 2002; Mazela et al., 2003; Esteves et al., 2007 a, b; Shi et al., 2007; Boonstra, 2008; Esteves and Pereira, 2009, entre otros). 


\section{CAPITULO II. OBJETIVOS}

\section{Objetivo general}

Caracterizar la madera maciza de Populus $x$ euroamericana I-214, Austral (perteneciente al Valle Medio de Río Negro, Argentina) y Boreal (perteneciente a Castilla y León, España), y proponer mejoras tecnológicas para un aprovechamiento más adecuado de este recurso, con especial énfasis en usos estructurales.

\section{Objetivos específicos:}

A fin de lograr un mejor entendimiento de este estudio, los objetivos específicos (y en consecuencia vendrá reflejado a tal fin en "Materiales y Métodos" y "Resultados y Discusión") se plantean dentro de dos secciones, tal como se detalla a continuación.

\subsection{Caracterización de madera maciza}

\subsubsection{Probetas de pequeñas dimensiones y libre de defectos}

$\checkmark$ Caracterización del material de ambas procedencias mediante el estudio de las propiedades físico-mecánicas y de durabilidad natural frente a hongos xilófagos y termitas.

$\checkmark$ Evaluación de similitudes y/o diferencias de comportamiento tecnológico entre procedencias.

\subsubsection{Piezas macizas semi-estructurales (escala 1:5)}

$\checkmark$ Clasificación visual de las piezas mediante aplicación de la norma española.

$\checkmark$ Evaluación elasto-resistente del material mediante la aplicación de metodología de ensayo no destructivo (NDT).

$\checkmark$ Caracterización del material mediante densidad y comportamiento mecánico a flexión estática.

$\checkmark$ Evaluación del rendimiento/eficiencia clasificatorio (acierto, subestima y sobreestima) entre los valores visuales y los valores "reales" elasto-resistentes y de densidad.

\subsubsection{Piezas macizas estructurales}

$\checkmark$ Clasificación visual de las piezas mediante aplicación de diferentes normativas.

$\checkmark$ Evaluación elasto-resistente del material mediante la aplicación de metodología de ensayo no destructivo (NDT).

$\checkmark$ Determinación de los valores mecánicos característicos de rigidez (Módulo de elasticidad, MOE) y resistencia (Módulo de rotura, MOR) mediante ensayo destructivo de flexión estática. 
Evaluación de la capacidad de los métodos de ensayo no destructivos (clasificación visual y NDT) para predecir las clases resistentes reales del material.

$\checkmark$ Evaluación del rendimiento/eficiencia clasificatorio (acierto, subestima y sobreestima) entre los valores visuales y los valores "reales" elasto-resistentes y de densidad.

\subsection{Mejoras tecnológicas}

\subsubsection{Probetas de pequeñas dimensiones y libre de defectos}

$\checkmark$ Aplicación de tratamientos de termo-modificación, como alternativa menos nociva para mejorar la dureza y durabilidad natural de la madera.

\subsubsection{Piezas macizas semi-estructurales (escala 1:5)}

$\checkmark$ Determinación de vibración libre en voladizo como alternativa para la estimación del módulo de elasticidad del material.

$\checkmark$ Elaboración de piezas semi-estructurales encoladas constituidas por 2 o 3 láminas de madera (piezas dúo y trío, respectivamente) como alternativa de mejora de las propiedades elasto-resistentes del material de ambas.

\subsubsection{Piezas macizas estructurales}

$\checkmark$ Establecimiento de una propuesta de mejora en la norma de clasificación visual actualmente vigente en España que incluya al clon I-214 dentro de su alcance.

$\checkmark$ Planteamiento de un procedimiento para el control triboluminiscente de sobrecarga en madera estructural: patente.

Mediante la realización de estos objetivos se pretende:

$\checkmark$ Contribuir al conocimiento más profundo de la madera sólida de Populus $x$ euroamericana I-214 disponible en el mercado español y argentino, de forma tal de generar una base de datos confiable que caracterice al clon de ambas procedencias y que pueda contribuir a una homologación de este material mediante su incorporación en normativas de ensayo con especial énfasis en aquellas de madera estructural.

$\checkmark$ Contribuir con propuestas de mejoras u optimización para el uso de este clon en productos de mayor valor añadido. 


\section{CAPITULO III. MATERIALES Y MÉTODOS}

\section{MATERIALES}

\subsection{Material de ensayo}

Teniendo en cuenta el recurso de Populus x euramericana I-214 disponible, así como la extensa tradición en el uso de su madera para aplicaciones de bajo valor añadido, tal como se ha mencionado en los objetivos, se ha utilizado madera de dicho clon considerando dos regiones geográficas:

$\checkmark$ Plantación comercial de 20 años de edad de España (Quintanillas de Sollamas, Comunidad Autónoma de Castilla y León: 42³6'24”N; 549'10”O)

$\checkmark$ Plantación comercial de 15 años de edad Argentina (Pomona, provincia de Río Negro: 39²9'40,74”S; 65³5'28,01”O).

Las características climáticas (temperatura y precipitación media anual) se representan en los climodiagramas de Walter y Lieth presentados en la Figura 2 (España) y en la Figura 3 (Argentina). En España, se trabajó con los datos meteorológicos correspondientes a la zona de Villafer, (León), para un período de años comprendidos entre el año 1938 y 1970 mientras que para Argentina se consideraron los datos meteorológicos correspondientes a la zona de General Conesa (Río Negro) y para un período comprendido entre el año 2009 y 2014.

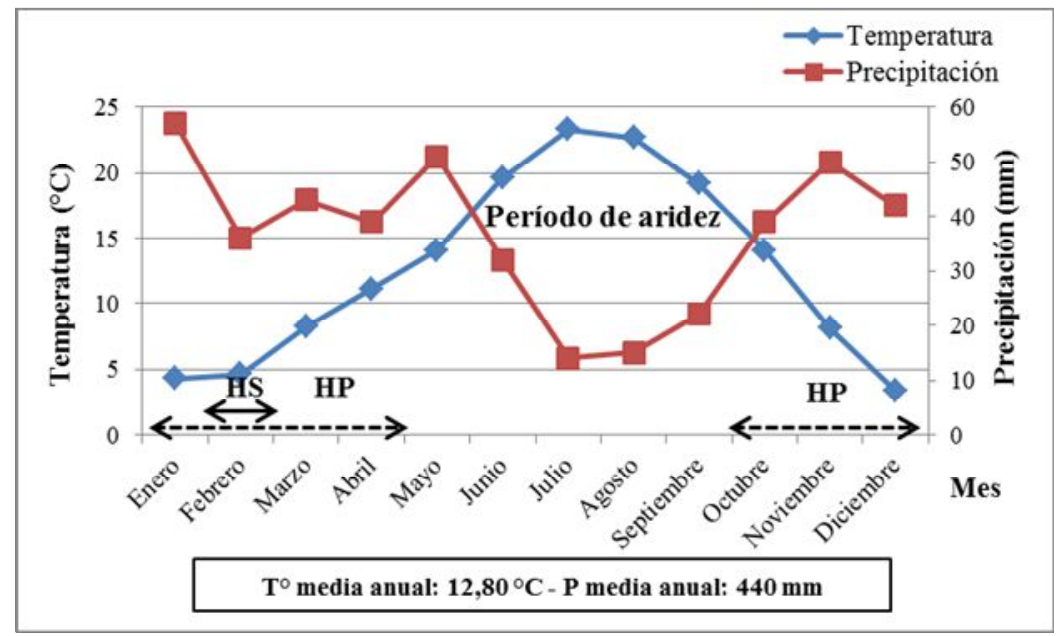

Figura 2. Climodiagrama deWalter y Lieth: Villafer - León - España: período 1938-1970 


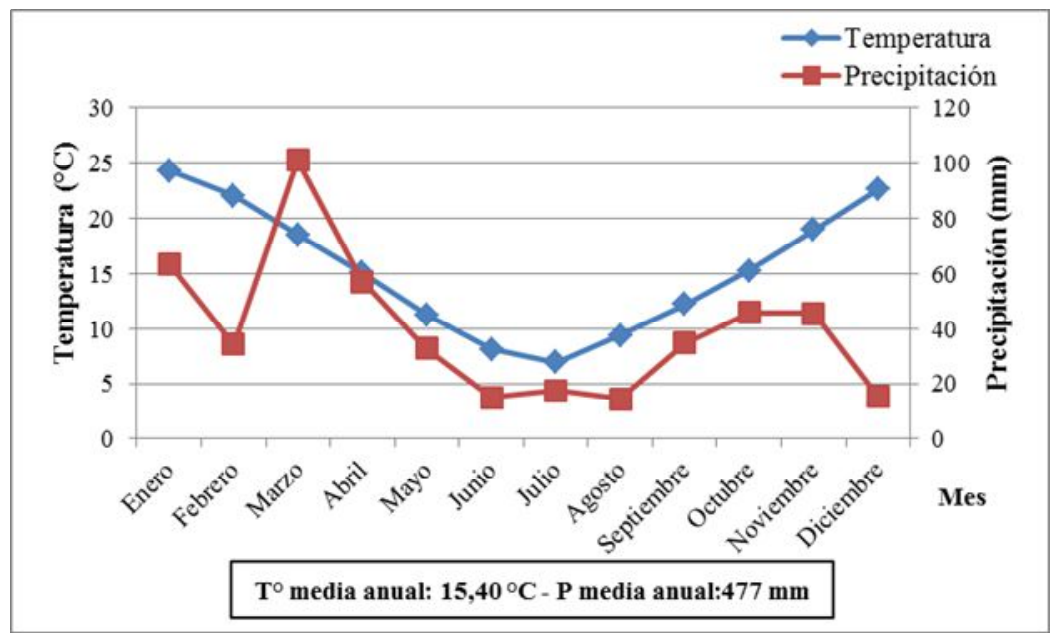

Figura 3. Climodiagrama deWalter y Lieth: General Conesa - Río Negro - Argentina: período 2009-2014

La temperatura promedio y las precipitaciones son similares en ambas zonas, aunque en España, se observa una zona seca bien delimitada en los meses de verano (junio-septiembre) y en Argentina dicha delimitación no es tan marcada, dado que se presentan precipitaciones considerables en la época de verano (diciembre-marzo).

\subsection{Datos generales del muestreo}

El muestreo del material en campo (selección de árboles) fue llevado a cabo acorde a las especificaciones del mercado en lo referente a las pautas de representatividad dentro la población, evitando muestreos en zonas con diferencias muy marcadas de densidad de plantación y tasa de crecimiento, como así también evitando el efecto borde en las parcelas.

Las trozas obtenidas se procesaron en tablones de $50 \mathrm{~mm} \times 150 \mathrm{~mm} \times 3000 \mathrm{~mm}$, que fueron identificados, enrastrelados (estibados) y secados hasta humedad de equilibrio higroscópico -HEH-, hecho constatado mediante xilohigrómetro digital (Testo 606-1, España; Hydromette HT 85, de la marca GANN, Argentina).

\subsection{Dimensionamiento del material de ensayo.}

Los tablones originales, fueron re-dimensionados y acondicionados, de acuerdo a las normativas de ensayo correspondientes, en piezas de diferentes tamaños (pequeñas dimensiones, piezas semi-estructurales y vigas estructurales) y para distintas condiciones de uso (macizoencolado), Tabla 1. 


\subsubsection{Material macizo de pequeñas dimensiones.}

La selección del material de ensayo, y posterior obtención-acondicionamiento de las probetas de pequeñas dimensiones, se realizó según lo establecido en la norma UNE 56528:1978. Las dimensiones, el número de individuos empleados y las procedencias del material se muestran en la Tabla 1.

Tabla 1. Probetas de pequeñas dimensiones: normas de ensayos, número de individuos, dimensiones y procedencia del material ensayado.

\begin{tabular}{|c|c|c|c|c|c|}
\hline \multicolumn{2}{|c|}{ Ensayo } & Norma & $\mathbf{n}^{*}$ & $\begin{array}{c}\text { Dimensión } \\
(\mathrm{mm})\end{array}$ & $\begin{array}{c}\text { Procedencia del } \\
\text { material }\end{array}$ \\
\hline \multicolumn{2}{|c|}{ Contenido de humedad } & $\begin{array}{c}\text { UNE } \\
56529: 1977\end{array}$ & $20-30$ & $20 \times 20 \times 25$ & $\begin{array}{c}\text { España - } \\
\text { Argentina }\end{array}$ \\
\hline \multicolumn{2}{|c|}{ Higroscopicidad } & $\begin{array}{c}\text { UNE } \\
56532: 1977\end{array}$ & $25-100$ & $20 \times 20 \times 25$ & $\begin{array}{c}\text { España - } \\
\text { Argentina }\end{array}$ \\
\hline \multicolumn{2}{|c|}{ Densidades aparentes } & $\begin{array}{c}\text { UNE } \\
56531: 1977\end{array}$ & $20-30$ & $20 \times 20 \times 25$ & $\begin{array}{c}\text { España - } \\
\text { Argentina }\end{array}$ \\
\hline \multicolumn{2}{|c|}{ Cambios Dimensionales } & $\begin{array}{c}\text { UNE } \\
56533: 1977\end{array}$ & $75-40$ & $20 \times 20 \times 40$ & $\begin{array}{l}\text { España - } \\
\text { Argentina }\end{array}$ \\
\hline \multicolumn{2}{|c|}{ Flexión estática } & $\begin{array}{c}\text { UNE } \\
56537: 1979 \\
\text { IRAM 9542. } \\
1977\end{array}$ & 75 & $20 \times 20 \times 300$ & $\begin{array}{l}\text { España } \\
\text { Argentina }\end{array}$ \\
\hline \multirow{2}{*}{ Dureza } & Monnin & $\begin{array}{c}\text { UNE } \\
56534: 1977\end{array}$ & 320 & $20 \times 20 \times 60$ & España \\
\hline & Janka & $\begin{array}{c}\text { IRAM } \\
9570: 1971\end{array}$ & 42 & $50 \times 50 \times 150$ & Argentina \\
\hline \multirow{2}{*}{\multicolumn{2}{|c|}{ Compresión paralela }} & $\begin{array}{c}\text { UNE } \\
56535: 1977\end{array}$ & 170 & $20 \times 20 \times 60$ & España \\
\hline & & $\begin{array}{c}\text { IRAM } \\
9551: 1985\end{array}$ & 70 & $50 \times 50 \times 200$ & Argentina \\
\hline \multicolumn{2}{|c|}{$\begin{array}{c}\text { Hongos xilófagos } \\
\text { (pudrición blanca y parda) }\end{array}$} & $\begin{array}{c}\text { CEN/TS 15083- } \\
1: 2005\end{array}$ & $220-140$ & $25 \times 50 \times 15$ & $\begin{array}{c}\text { España - } \\
\text { Argentina }\end{array}$ \\
\hline \multicolumn{2}{|c|}{$\begin{array}{l}\text { Hongos xilófagos } \\
\text { (pudrición blanda) }\end{array}$} & $\begin{array}{c}\text { CEN/TS 15083- } \\
2: 2005\end{array}$ & 90 & $5 \times 10 \times 100$ & España \\
\hline \multicolumn{2}{|c|}{ Termitas } & EN 117:2012 & $60-60$ & $25 \times 50 \times 15$ & $\begin{array}{l}\text { España - } \\
\text { Argentina }\end{array}$ \\
\hline \multicolumn{2}{|c|}{ Termo-modificación } & $\begin{array}{c}\text { UNE } \\
\text { 56534:1977 } \\
\text { CEN/TS 15083- } \\
1: 2005 \\
\text { EN 117:2012 }\end{array}$ & 160 & $20 \times 20 \times 60$ & España \\
\hline
\end{tabular}

*n: número de individuos para España y Argentina, respectivamente.

\subsubsection{Material macizo semi-estructural (escala 1:5).}

A fin de poder encontrar relaciones resistencia-tamaño más cercanas a las reales, minimizando el consumo de madera, en este trabajo se ha incorporado un tamaño intermedio de pieza, denominado semi-estructural, respetando la relación de dimensiones establecida en la norma EN 408:2010+A1:2012: longitud superior a 19 veces la altura/espesor de la sección. 
El tipo de ensayo realizado, las normativas, número de individuos, dimensiones y procedencias empleadas se especifican en la Tabla 2.

Tabla 2. Material semi-estructural (escala 1:5): ensayos, normativas, número de individuos, dimensiones y procedencia.

\begin{tabular}{|c|c|c|c|c|c|}
\hline $\begin{array}{l}\text { Técnica de } \\
\text { evaluación }\end{array}$ & Ensayo & Norma & $\mathbf{n}^{*}$ & $\begin{array}{l}\text { Dimensión } \\
(\mathbf{m m})\end{array}$ & $\begin{array}{l}\text { Procedencia } \\
\text { del material }\end{array}$ \\
\hline \multirow{4}{*}{$\begin{array}{c}\text { No } \\
\text { destructiva }\end{array}$} & $\begin{array}{c}\text { Clasificación } \\
\text { visual }\end{array}$ & UNE 56544:2011 & $149-92$ & $40 \times 60 \times 1200$ & $\begin{array}{c}\text { España - } \\
\text { Argentina }\end{array}$ \\
\hline & $\begin{array}{c}\text { Vibraciones } \\
\text { inducidas } \\
\text { (longitudinales) }\end{array}$ & & $149-92$ & $40 \times 60 \times 1200$ & $\begin{array}{l}\text { España - } \\
\text { Argentina }\end{array}$ \\
\hline & $\begin{array}{l}\text { Ultrasonidos } \\
\text { (longitudinales) }\end{array}$ & & $149-92$ & $40 \times 60 \times 1200$ & $\begin{array}{c}\text { España - } \\
\text { Argentina }\end{array}$ \\
\hline & $\begin{array}{c}\text { Vibraciones } \\
\text { inducidas } \\
\text { (transversales) }\end{array}$ & & 12 & $40 \times 60 \times 1200$ & España \\
\hline Destructiva & $\begin{array}{l}\text { Flexión estática } \\
\text { y densidad }\end{array}$ & $\begin{array}{c}\mathrm{EN} \\
408: 2010+\mathrm{A} 1: 2012\end{array}$ & $149-92$ & $40 \times 60 \times 1200$ & $\begin{array}{l}\text { España - } \\
\text { Argentina }\end{array}$ \\
\hline
\end{tabular}

\subsubsection{Material macizo estructural.}

Se ensayaron lotes de madera representados por diferentes dimensiones nominales, Tabla 3, entendiéndose por "lote" a la madera de una misma especie, procedencia y tamaño, clasificada en un turno de trabajo (EN 14081-1:2006+A1:2011).

Tabla 3. Material estructural: dimensiones nominales del material de ensayo.

\begin{tabular}{cccccccc}
\hline Procedencia & Dimensiones & \multicolumn{5}{c}{ Lotes } & \\
\hline \multirow{3}{*}{ España } & Espesor $(\mathrm{mm})$ & 50 & 52 & 80 & 80 & 100 & \multirow{2}{*}{ Total } \\
\cline { 2 - 7 } & Ancho $(\mathrm{mm})$ & 150 & 135 & 120 & 150 & 200 & \\
\cline { 2 - 7 } & Largo $(\mathrm{mm})$ & 3050 & 2600 & 3100 & 3100 & 4100 & \\
\cline { 2 - 7 } & $\mathrm{n}^{*}$ & 430 & 122 & 40 & 277 & 80 & 949 \\
\hline
\end{tabular}

*n: número de individuos.

Las diferentes normas utilizadas sobre el material estructural se indican en la Tabla 4. 
Tabla 4. Material estructural: normas de ensayo y procedencia del material.

\begin{tabular}{|c|c|c|c|}
\hline $\begin{array}{l}\text { Técnicas de } \\
\text { evaluación }\end{array}$ & Ensayo & Norma & Procedencia del material \\
\hline \multirow{7}{*}{ No destructiva } & \multirow{5}{*}{ Clasificación visual } & EN 56544:2011 (España) & España \\
\hline & & EN 56544:1997 (España) & España \\
\hline & & $\begin{array}{c}\text { NF B52-001:2007 } \\
\text { (Francia) }\end{array}$ & España \\
\hline & & $\begin{array}{c}\text { DIN 4074-5:2003 } \\
\text { (Alemania) }\end{array}$ & España \\
\hline & & NCh1970-1:1988 (Chile) & España \\
\hline & Vibraciones inducidas & & \multirow{2}{*}{ España } \\
\hline & Ultrasonidos & & \\
\hline Destructiva & $\begin{array}{c}\text { Flexión estática y } \\
\text { densidad }\end{array}$ & EN 408:2010+A1:2012 & España \\
\hline
\end{tabular}

\subsubsection{Material encolado: piezas dúo y trío.}

Las vigas dúos o tríos son aquellas constituidas por dos o tres piezas de madera, "piezas parte", respectivamente, encoladas entre sí. La diferencia entre estas vigas y las vigas laminadas radica en una consecuencia de la norma EN 386, reemplazada por EN 14080: 2013, la cual determina que para constituir una viga laminada, sus piezas constitutivas no deben superar los $45 \mathrm{~mm}$ de espesor en clases de servicio 1 y 2 . Las vigas dúos y tríos sobrepasan esta especificación, pudiendo extenderse hasta $80 \mathrm{~mm}$ de espesor. Asimismo, otra diferencia radica en que cada tabla es encolada en posición vertical y con la zona de mejor calidad hacía el exterior, evitando de este modo la aparición de fendas y otras singularidades del material.

Para la realización de las piezas dúos y tríos se trabajó con el material clasificado visualmente, pero seleccionado al azar, a fin de evaluar la influencia de las singularidades en el comportamiento de la pieza encolada; las normas, número de individuos, dimensiones y procedencias se establecen en la Tabla 5 y Tabla 6 para piezas dúos y tríos, respectivamente.

Tabla 5. Piezas dúo: normas, número de individuos, dimensiones y procedencia del material.

\begin{tabular}{|c|c|c|c|c|c|}
\hline Evaluación & Ensayo & Norma & $n^{*}$ & $\begin{array}{c}\text { Dimensiones } \\
(\mathbf{m m})\end{array}$ & Procedencia \\
\hline \multirow{2}{*}{$\begin{array}{c}\text { No } \\
\text { destructiva* }\end{array}$} & \multirow{2}{*}{$\begin{array}{c}\text { Singularidades } \\
\text { /Clasificación } \\
\text { visual }\end{array}$} & \multirow{2}{*}{$\begin{array}{c}\text { EN 1310:1997 - EN } \\
56544: 2011\end{array}$} & 160 & $20 \times 60 \times 1200$ & España \\
\hline & & & 160 & $20 \times 60 \times 1200$ & Argentina \\
\hline Destructiva* & $\begin{array}{c}\text { Flexión } \\
\text { estática y } \\
\text { densidad }\end{array}$ & $\begin{array}{c}\text { EN } \\
408: 2010+\mathrm{A} 1: 2012\end{array}$ & 80 & $40 \times 60 \times 1200$ & $\begin{array}{l}\text { España- } \\
\text { Argentina }\end{array}$ \\
\hline
\end{tabular}


Tabla 6. Piezas trío: normas, número de individuos, dimensiones y procedencia del material.

\begin{tabular}{cccccc}
\hline Evaluación & Ensayo & Norma & n* & $\begin{array}{c}\text { Dimensiones } \\
(\mathbf{m m})\end{array}$ & Procedencia \\
\hline $\begin{array}{c}\text { No } \\
\text { destructiva* }\end{array}$ & $\begin{array}{c}\text { Singularidades/ } \\
\text { Clasificación } \\
\text { visual }\end{array}$ & $\begin{array}{c}\text { EN-1310:1997 - EN } \\
56544: 2011\end{array}$ & 135 & $13 \times 60 \times 1200$ & España \\
\cline { 5 - 6 } Destructiva* & $\begin{array}{c}\text { Flexión estática } \\
\text { y densidad }\end{array}$ & $\begin{array}{c}\mathrm{EN} \\
408: 2010+\mathrm{A} 1: 2012\end{array}$ & $45-80$ & $40 \times 60 \times 1200$ & $\begin{array}{c}\text { España- } \\
\text { Argentina }\end{array}$ \\
\hline
\end{tabular}

*la evaluación no destructiva fue realizada en "piezas parte"; la evaluación destructiva fue realizada en las piezas encoladas; $n$ : número de individuos.

\subsection{Equipamiento}

Para facilitar la lectura de este documento, la infraestructura y equipos utilizados, se ha detallado a lo largo del desarrollo de la metodología de ensayo.

\section{METODOLOGÍA DE ENSAYO}

Este apartado se presenta en dos secciones: "Caracterización de madera maciza" y "Mejora tecnológica".

\subsection{SECCIÓN I: Caracterización de madera maciza}

\subsubsection{Probetas de pequeñas dimensiones y libres de defectos.}

\subsubsection{Propiedades físicas}

La obtención y acondicionamiento de las probetas se realizó de acuerdo con la norma UNE 56528:1978; el dimensionamiento del material para cada ensayo fue realizado según las normas indicadas en la Tabla 1.

\section{Equipamiento empleado:}

$\checkmark \quad$ Material de carpintería (sierra sin fin o de banda, sierra de mesa, metro, etc).

$\checkmark$ Equipos manuales de medición (xilohigrómetro de resistencia, calibre de $0,01 \mathrm{~mm}$ de precisión, balanza electrónica de $0,001 \mathrm{~g}$ de precisión).

$\checkmark$ Equipos para secado (estufa con circulación de aire $\left(103^{\circ} \mathrm{C} \pm 2^{\circ} \mathrm{C}\right.$ ), desecador).

$\checkmark$ Otros materiales menores (pinzas, recipientes, etc).

\subsection{Contenido de humedad}

Los valores físico-mecánicos se expresan a un contenido de humedad $(\mathrm{CH})$ del $12 \%$ (normal), por lo que es necesario conocer el contenido de humedad inicial de la madera o 
contenido de humedad de equilibrio higroscópico (CHEH) y luego, referenciar los resultados a dicho valor de referencia normal.

Procedimiento empleado (UNE 56529:1977):

Obtenida las probetas según lo indicado en la Tabla 1, se procedió tal como se describe a continuación:

Identificación y acondicionamiento del material discriminado por procedencias.

$\checkmark$ Determinación del peso de las probetas a un contenido de humedad "h" (inicial) en balanza analítica de $0,001 \mathrm{~g}$ de precisión.

$\checkmark$ Secado de las probetas en estufa a $103^{\circ} \mathrm{C} \pm 2^{\circ} \mathrm{C}$ hasta peso constante (constatado cuando dos pesadas consecutivas difirieron en menos de $1 / 200 \mathrm{~g}$ de la anterior).

$\checkmark$ Reposo de las probetas en desecador hasta estabilización de la temperatura.

$\checkmark$ Determinación del peso anhidro de las probetas.

$\checkmark$ Determinación del contenido de humedad mediante la fórmula (1):

$$
\mathrm{CH}(\%)=\frac{\mathrm{Ph}-\mathrm{Po}}{\mathrm{Po}} \times 100
$$

Dónde:

CH: contenido de humedad de la probeta, en $\%$.

$\mathrm{Ph}$ : peso de la probeta en estado "h", en $\mathrm{Kg}$.

Po: peso de la probeta en estado anhidro, en $\mathrm{Kg}$.

NOTA: el contenido de humedad " $h$ " hace referencia a la humedad inicial que contiene la madera estabilizada y seca al aire en la condiciones de humedad relativa y temperatura de laboratorio.

\subsection{Densidades aparentes}

Procedimiento empleado (UNE 56531:1977):

Luego del dimensionado de las probetas, Tabla 1, se procedió como se indica a continuación:

Identificación y acondicionamiento del material discriminado por procedencias.

$\checkmark$ Determinación del peso de las probetas a un contenido de humedad "h" en balanza analítica de $0,001 \mathrm{~g}$ de precisión. 
Determinación de las dimensiones de las probetas a un contenido de humedad "h" mediante calibre (precisión 0,01 $\mathrm{mm}$ ).

$\checkmark$ Secado de las probetas en estufa a $103^{\circ} \mathrm{C} \pm 2^{\circ} \mathrm{C}$ hasta peso constante (constatado cuando dos pesadas consecutivas difirieron en menos de $1 / 200 \mathrm{~g}$ de la anterior).

$\checkmark$ Reposo de las probetas en desecador hasta estabilización de la temperatura.

$\checkmark$ Determinación del peso anhidro de las probetas de madera.

$\checkmark$ Determinación de las dimensiones anhidras de las probetas.

$\checkmark$ Determinación las densidades aparentes según se indica a continuación:

\section{Densidad aparente a contenido de humedad " $h$ "}

$$
\rho_{\mathrm{h}}\left(\mathrm{Kg} / \mathrm{m}^{3}\right)=\frac{\mathrm{Ph}}{\mathrm{Vh}}
$$

\section{$\underline{\text { Densidad aparente anhidra }}$}

$$
\rho_{\mathrm{o}}\left(\mathrm{Kg} / \mathrm{m}^{3}\right)=\frac{\mathrm{Po}}{\mathrm{Vo}}
$$

Dónde:

$\rho$ : densidad aparente a un contenido de humedad inicial "h" ó anhidro "0" respectivamente, en $\mathrm{Kg} / \mathrm{m}^{3}$.

P: peso de la probeta a un contenido de humedad inicial "h" ó anhidro "0" respectivamente, en Kg.

V: volumen de la probeta a un contenido de humedad inicial "h" ó anhidro "0" respectivamente, en $\mathrm{m}^{3}$.

\subsection{Cambios dimensionales}

Las alteraciones dimensionales producidas con las variaciones en el $\mathrm{CH}$ de la madera, son desarrolladas en este apartado.

Procedimiento empleado (UNE 56533:1977):

Con las probetas dimensionadas acorde a lo presentado en la Tabla 1, se procedió como se indica a continuación:

$\checkmark$ Identificación y acondicionamiento del material discriminado por procedencias.

$\checkmark$ Inmersión de las probetas en agua a temperatura ambiente hasta saturación.

$\checkmark$ Medición con calibre (precisión 0,01 mm) de las dimensiones de las probetas en condición saturada; obtención del volumen saturado.

$\checkmark$ Determinación del peso de las probetas en condición saturada empleando balanza analítica de $0,001 \mathrm{~g}$ de precisión. 
Reposo de las probetas en condiciones de laboratorio hasta estado de equilibrio higroscópico (CH "h") comprobado realizando pesadas sucesivas - en intervalos de $24 \mathrm{~h}$-, hasta que dos de ellas no superasen el 1/200 de la primera de ellas.

$\checkmark$ Medición de las dimensiones de las probetas en intervalos de $24 \mathrm{~h}$.

$\checkmark$ Determinación de CH (\%) y obtención de las contracciones normales en cada uno de los intervalo de $\mathrm{CH}(\%)$ tomados, a fin de determinar gráficamente, el punto de saturación de la pared celular (PSPC).

$\checkmark$ Medición de las dimensiones de las probetas a CH "h"; obtención de volumen húmedo.

Secado en estufa $\left(103^{\circ} \mathrm{C}+2^{\circ} \mathrm{C}\right)$ hasta estado anhidro.

$\checkmark$ Determinación del peso anhidro en balanza analítica de precisión $0,001 \mathrm{~g}$.

$\checkmark$ Determinación de las dimensiones anhidras; obtención del volumen anhidro.

$\checkmark$ Determinación de los siguientes parámetros dimensionales:

\section{Contracción lineal}

$$
\mathrm{Cn}_{\text {máx }}(\%)=\frac{\mathrm{Lv}-\mathrm{Lo}}{\mathrm{LV}} \times 100
$$

Siendo:

$\mathrm{Cn}_{\text {máx }}(\%)$ : contracción normal máxima, en $\%$.

Lv: longitud de la probeta en estado saturado, en $\mathrm{mm}$.

Lo: longitud de la probeta en estado anhidro, en mm.

\section{Contracción volumétrica}

$$
\mathrm{CV}_{(\%)}=\frac{\mathrm{Vs}-\mathrm{Vo}}{\mathrm{Vs}} \times 100
$$

Dónde:

Cv: contracción volumétrica total, en \%.

Vs: volumen de la probeta en estado saturado, en $\mathrm{m}^{3}$.

Vo: definido en fórmula (3).

\section{Coeficiente de contracción volumétrica}

$$
\mathrm{v}=\frac{\mathrm{Vh}-\mathrm{Vo}}{\mathrm{Vo} \times \mathrm{h}} \times 100
$$

Dónde:

v: coeficiente de contracción volumétrica, en \%.

Vh: definido en fórmula (2).

Vo: definido en fórmula (3).

h: definido en la sección 2.1.1.1.1: Propiedades físicas: Contenido de humedad. 


\section{Punto de saturación de la pared celular}

Para la obtención del punto de saturación de la pared celular (PSPC), también conocido como punto de saturación de las fibras (PSF), la evolución de las contracciones (longitudinales, radiales y tangenciales) con respecto a las variaciones en el contenido de humedad, determinadas en cada intervalo de tiempo (24-48 hs), se ha recogido en la Figura 4, donde el PSPC quedó definido mediante la intersección de la línea de tendencia con el eje de las abscisas (x), el cual se puede corroborar mediante la relación del punto de intercepción en la ordenada y la pendiente de la recta; en el caso del ejemplo 8,0539/0,2959.

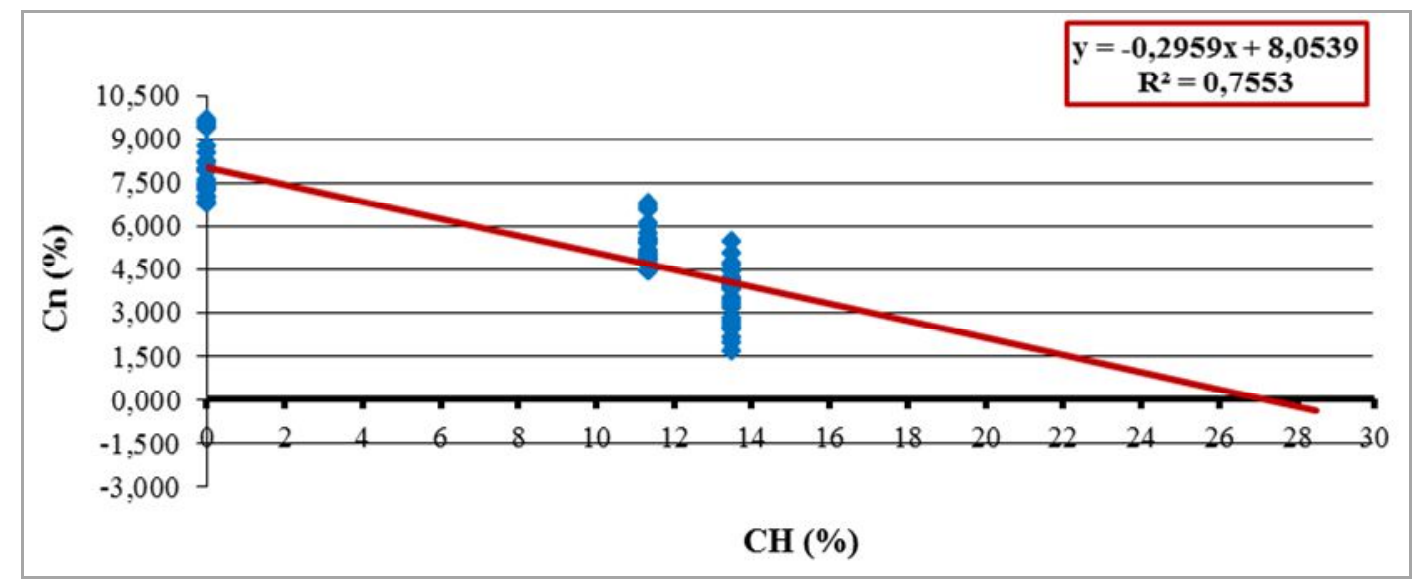

Figura 4. Determinación del PSPC.

\subsection{Higroscopicidad}

El valor medio de higroscopicidad fue determinado a partir de los valores de densidad y de coeficiente de contracción volumétrica hallados en cada probeta según fórmula (7), norma UNE 56532:1977.

$$
\text { hi }\left(\mathrm{Kg} / \mathrm{m}^{3}\right)=\frac{(1-\mathrm{v}) \mathrm{x} \rho_{12}}{100}
$$

Dónde:

hi: higroscopicidad, en $\mathrm{Kg} / \mathrm{m}^{3}$.

v: definido en fórmula (6); determinado según norma UNE 56533:1977.

$\rho_{12}$ : densidad al $12 \%$ de contenido de humedad, en $\mathrm{Kg} / \mathrm{m}^{3}$. 


\subsubsection{Propiedades mecánicas}

La obtención y acondicionamiento de las probetas se realizó de acuerdo con la norma UNE 56528: 1978; el dimensionamiento del material para cada ensayo fue realizado según las normas indicadas en la Tabla 1.

\section{Equipamiento empleado:}

$\checkmark \quad$ Material de carpintería (sierra sin fin o de banda, sierra de mesa, metro, etc)

$\checkmark$ Equipos manuales de medición (xilohigrómetro de resistencia, calibre de 0,01 mm de precisión).

$\checkmark$ Máquinas Universales de Ensayo (con los respectivos implementos de ensayo): España: modelo ELIB - $100 \mathrm{~W}$ de la marca IBERTEST; Argentina: modelo ALFRED J. AMSLER \& Co, Schaffouse - Suisse 7928 de $50 \mathrm{kN}$ para los ensayos de flexión estática y dureza Janka; modelo ALFRED J. AMSLER \& Co, Schaffouse - Suisse 7928 de $250 \mathrm{kN}$ para los ensayos de compresión paralela.

NOTA: los ensayos mecánicos fueron realizados con madera al contenido de humedad " $h$ " $y$ posteriormente referenciados al $12 \% \mathrm{de} \mathrm{CH}$.

\subsection{Flexión estática}

Obtenidas las probetas de acuerdo con las dimensiones especificadas en la Tabla 1, se realizó el ensayo según se detalla a continuación:

Procedimiento empleado (UNE 56537:1979; IRAM 9542:1977):

$\checkmark \quad$ Identificación y acondicionamiento del material discriminado por procedencias.

$\checkmark \quad$ Medición de las dimensiones de las probetas con calibre de precisión 0,01 $\mathrm{mm}$.

$\checkmark$ Realización del ensayo de flexión estática siguiendo las especificaciones indicadas en las normas de ensayo. En ambos casos, norma UNE y norma IRAM, el ensayo se inició colocando la probeta sobre un implemento previsto por apoyos cilíndricos de ejes paralelos separados entre sí $240 \mathrm{~mm}$ (luz). La carga fue aplicada/transferida mediante otro implemento superior y centrado a los apoyos (Figura 5). Dado que la norma UNE no estipula la determinación del MOE, a fin de obtener dicho valor, se consideró la carrera de la máquina (recorrido del cabezal durante la compresión de la probeta) para estimar la deformación. En el caso de la norma IRAM se empleó un deflectómetro (linear variable differential transformer, LVDT), colocado mediante imán en la parte inferior y en el centro de luz de la probeta y mediante la escala graduada del 
implemento, se determinaron las deformaciones generadas ante la aplicación de la carga. Dicho procedimiento se realizó hasta el punto de máxima elasticidad (P), el cual fue estimado de ensayos de referencia anteriores, momento en el que se quitó el implemento. Posteriormente a esta etapa, en ambas normativas, se prosiguió el ensayo hasta evidencia de rotura en el material.

$\checkmark$ Realización de las gráficas de Carga vs. Deformación para la determinación de los valores de elasticidad, Figura 6.

$\checkmark$ Determinación del valor elástico. Para ello, en la gráfica hallada se trazó una línea de tendencia con los datos comprendidos entre el 10\% y el $40 \%$ de la fuerza máxima; de la ecuación de regresión obtenida, se tomó la pendiente de la recta como la relación elástica que posteriormente fue empleada para la determinación del módulo de elasticidad. Para estas determinaciones sólo fueron consideradas las gráficas que presentaron un $\mathrm{R}^{2}$ igual o superior a 0,99; Figura 6.

$\checkmark$ Determinación de los parámetros elasto-resistentes, según fórmulas:

$$
\operatorname{MOE}(\mathrm{MPa})=\frac{\mathrm{L}^{3}}{4 \mathrm{bh}^{3}} \times \frac{\mathrm{P}}{\Delta}
$$

Siendo:

MOE: módulo de elasticidad, en MPa.

$\mathrm{P} / \Delta$ : pendiente de la curva carga vs deformación, en el rango elástico, en $\mathrm{kN} / \mathrm{mm}$.

L: distancia entre apoyos o luz de la probeta, en $\mathrm{mm}$.

b: ancho de la probeta, en $\mathrm{mm}$.

h: altura de la probeta, en $\mathrm{mm}$.

$$
\operatorname{MOR}(\mathrm{MPa})=1.5 \times \frac{\mathrm{Q} \mathrm{L}}{\mathrm{b} \mathrm{h}^{2}}
$$

Siendo:

MOR: módulo de rotura, en MPa.

Q: carga de rotura, en $\mathrm{kN}$.

L, b y h: definidos en la fórmula (8).

$\checkmark$ Corrección al $12 \%$ de $\mathrm{CH}$ de los valores elasto-resistentes obtenidos, según se indica en la siguiente fórmula (corrección tomada de la norma EN384:2010):

$$
\mathrm{X}=\mathrm{X}_{1}\left[1+\mathrm{A}\left(\mathrm{CH}-\mathrm{CH}_{1}\right)\right]
$$

Siendo:

$\mathrm{X}$ : MOE o MOR, expresado en MPa

$\mathrm{X}_{1}$ : MOE o MOR calculado, expresado en MPa

A: 1\% para corrección de MOE; MOR sin corrección según lo indicado en la norma EN 384:2010.

$\mathrm{CH}$ : media de contenido de humedad "h", expresado en $\%$.

$\mathrm{CH}_{1}$ : contenido de humedad de referencia (12), expresado en $\%$. 


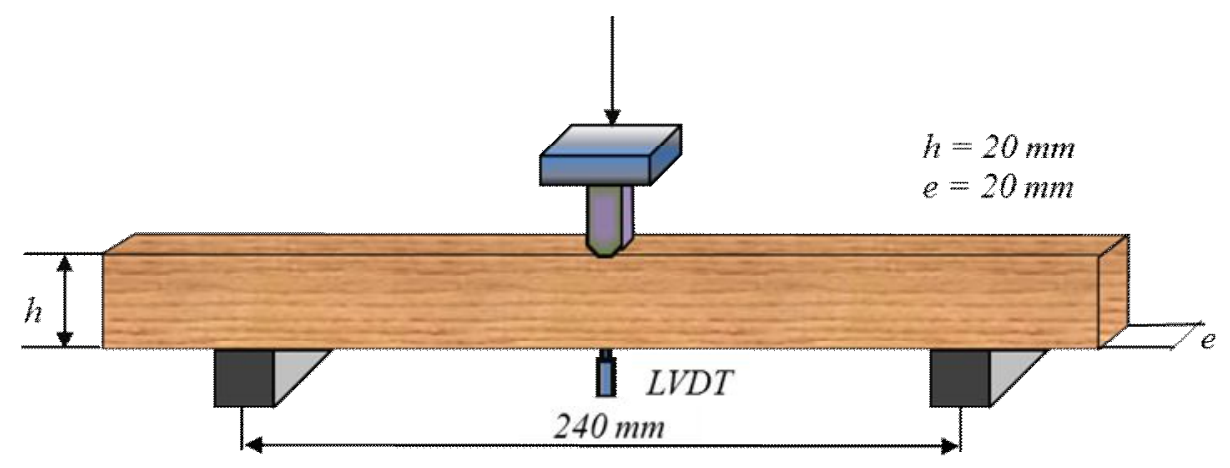

Figura 5. Esquema ensayo de flexión estática.

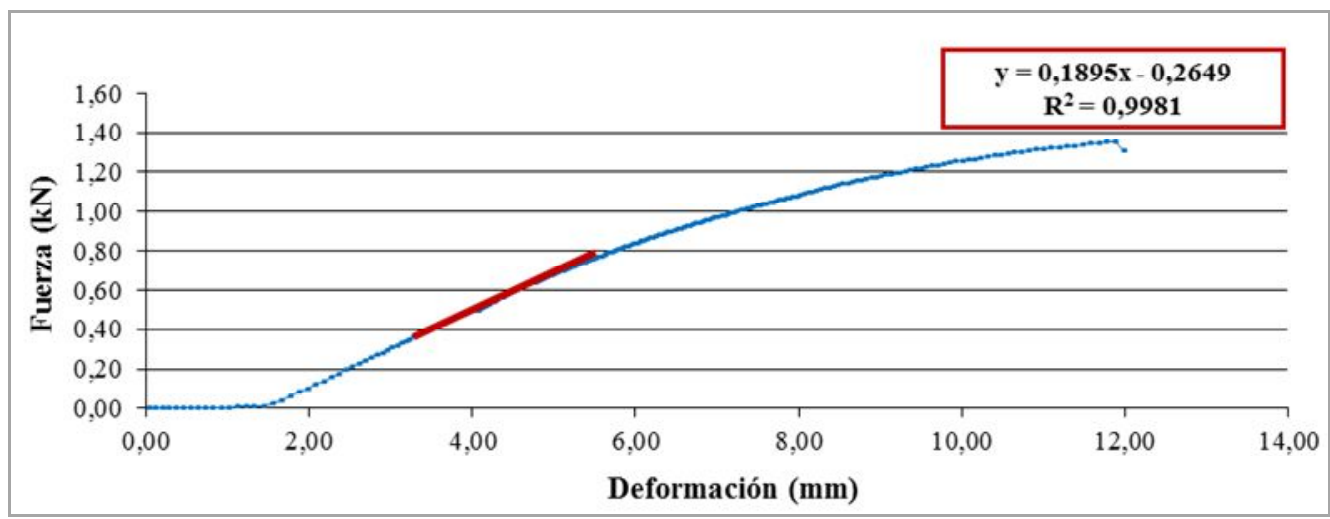

Figura 6. Gráfico carga - deformación con línea de tendencia (en rojo) en $10 \%$ - $40 \%$ de carga máxima.

\subsection{Dureza}

La determinación de los valores iniciales de dureza de este clon fue llevada a cabo con la finalidad de caracterizarlo, y también como punto de referencia para la evaluación de tratamientos de mejora de dureza superficial mediante termo-modificación, sección 2.2.1.1.2.

Los métodos para evaluar la dureza en la madera pueden dividirse en dos grupos: aquellos que miden el área de contacto producida por el indentador en la superficie de la madera aplicando una una fuerza constante y aquellos que miden la fuerza necesaria para realizar una penetración determinada con un elemento indentador. En este estudio, ambos grupos fueron analizados utilizando dos normativas representativas $\mathrm{y}$, consecuentemente, dos métodos de determinación: norma UNE 56534:1977 (España), método Monnin ó Chalais Meudon y noma IRAM 9570:1971 (Argentina), método Janka. Para el primer caso, el indentador estuvo constituido por un cilindro de acero de $30 \mathrm{~mm}$ de diámetro y la determinación de la huella fue realizada aplicando una carga constante de $1 \mathrm{kN}$ de fuerza, mientras que para el segundo caso el indentador estuvo constituido por una esfera de acero de $11,3 \mathrm{~mm}$ de diámetro con la cual se obtiene una impronta de $100 \mathrm{~mm}^{2}$ al hacerla penetrar hasta la mitad de su diámetro. 
En ambos casos, el ensayo fue realizado en la dirección radial de la pieza, por ser la más limitante.

Procedimiento empleado (UNE 56534:1977; IRAM 9570:1971):

Una vez obtenidas las probetas según el dimensionamiento detallado en la Tabla 1, se procedió a la:

$\checkmark \quad$ Identificación y acondicionamiento del material discriminado por procedencias.

$\checkmark$ Medición de la anchura de la probeta con calibre de precisión de $0,01 \mathrm{~mm}$.

$\checkmark$ Realización del ensayo de dureza propiamente dicho, mediante los dos procedimientos antes mencionados: Dureza Monnin ó Chalais Meudon (normativa Española) y Dureza Janka (normativa Argentina).

$\checkmark$ Cálculo del valor de dureza utilizando la expresión general representada por la relación:

$$
\text { Dureza }=\frac{F}{S}
$$

Siendo:

Dureza: valor expresado en MPa

F: fuerza, en $\mathrm{kN}$

S: superficie, en $\mathrm{mm}^{2}$.

Para el ensayo de dureza Monnin ó Chalais Meudon, S quedó determinada por la superficie de la huella dejada por el cilindro metálico de $30 \mathrm{~mm}$ de diámetro; el cálculo de la superficie es expresado mediante la siguiente ecuación:

$$
\mathrm{S}=\mathrm{L} \times \mathrm{B}
$$

Dónde:

S: superficie de la huella, en $\mathrm{mm}^{2}$.

L: longitud del arco de la circunferencia, en $\mathrm{mm}$

B: base de la probeta, en mm.

Para la obtención de la longitud del arco de la circunferencia (L), previamente se calcula el ángulo $\alpha$ que la determina, Figura 7. Este ángulo se obtiene por la relación trigonométrica que queda representada en la fórmula (13). 


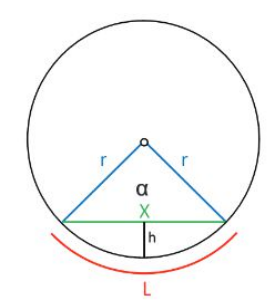

Figura 7. Parámetros de la circunferencia.

$$
\alpha=2 * A \cos \left(\frac{\mathrm{r}-\mathrm{h}}{\mathrm{r}}\right)
$$

Siendo

$\alpha$ : ángulo, en radianes.

r: radio: $15 \mathrm{~mm}$

h: penetración dejada por del indentador, en $\mathrm{mm}$.

Posteriormente se calcula la longitud del arco de circunferencia mediante la aplicación de la fórmula (14):

$$
\mathrm{L}=\mathrm{r} * \alpha
$$

Siendo

L: longitud del arco de la circunferencia, en $\mathrm{mm}$.

r: definido en fórmula (13).

h: definido en fórmula (13).

Con este dato y la base de la probeta se calculó la superficie de la huella, según la fórmula 12 .

Para el ensayo de dureza Janka, S quedó determinada por la impronta dejada por la esfera metálica de 11,3 mm de diámetro, penetrada hasta la mitad del mismo, sobre la superficie de la madera.

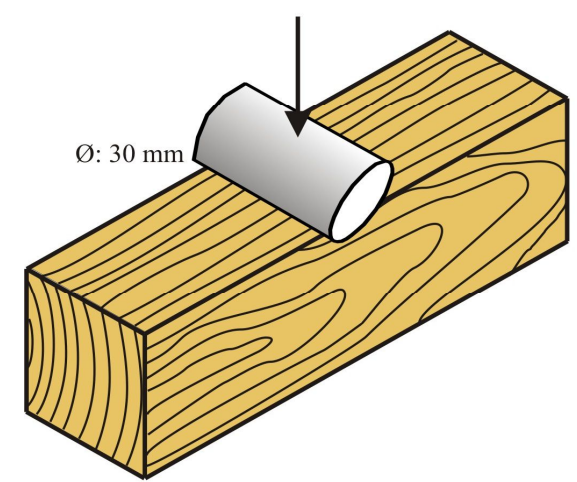

Figura 8. Esquema dureza Monnin.

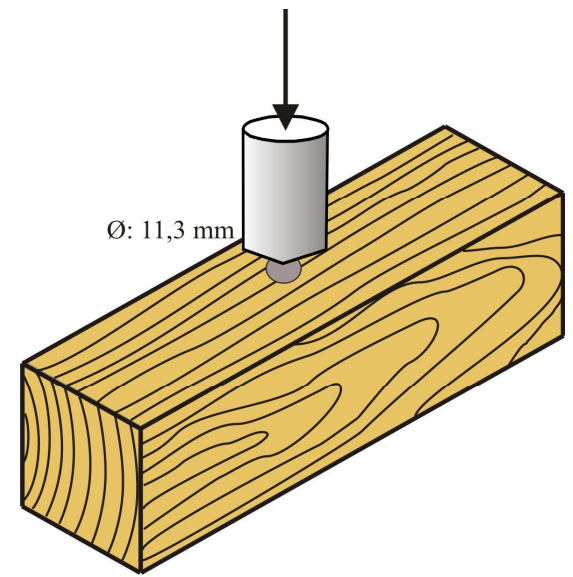

Figura 9. Esquema dureza Janka. 


\subsection{Compresión Paralela}

Procedimiento empleado (UNE 56535:1977; IRAM 9551: 1985):

Dimensionado el material según lo indicado en la Tabla 1, fue realizado el ensayo como se detalla a continuación:

$\checkmark \quad$ Identificación y acondicionamiento del material discriminado por procedencias.

$\checkmark$ Determinación de las dimensiones de las probetas con calibre de precisión 0,01 mm. A fin de evaluar el comportamiento de los parámetros de compresión paralela empleando diferentes metodologías, en el material de procedencia española se trabajó con dos tamaños de probetas: probetas de $20 \mathrm{~mm}$ x $20 \mathrm{~mm}$ x $60 \mathrm{~mm}$, estipulado por la norma UNE-56535: 1977 y probetas de 50mm x 50mm x 200mm, estipulado por la norma IRAM 9551: 1985. En el material de procedencia Argentina, dada la imposibilidad de acople a la máquina, el ensayo sólo pudo realizarse con probetas de 50mm x 50mm x 200mm según IRAM 9551: 1985.

Colocación de las probetas en sentido vertical (con el eje en sentido paralelo a la dirección de las fibras) sobre un plato metálico.

$\checkmark$ En ambos casos, norma UNE y norma IRAM, el ensayo se comenzó aplicando, sobre la probeta, una carga constante (velocidad aproximada de $200 \mathrm{kN} / \mathrm{s}$ ), transmitida mediante un plato metálico superior unido a un cabezal. Dado que la norma UNE no estipula la determinación del MOE, a fin de obtener un valor de comparación con respecto a los datos obtenidos mediante normativa Argentina, se consideró la carrera de la máquina (recorrido del cabezal durante la compresión de la probeta) como valor de deformación. Por su parte, la norma IRAM estipula la determinación del MOE, por lo que, para la estimación de los valores elásticos, se utilizó un deflectómetro (LVDT) a fin de determinar las deformaciones en la zona comprendida entre abrazaderas, $135 \mathrm{~mm}$, Figura 10. Dicho procedimiento se realizó hasta el punto de máxima elasticidad (P), obtenido en ensayos de referencia, momento en el que se procedió a quitar el implemento. Posteriormente, en ambos casos se procedió a continuar el ensayo hasta la evidencia de rotura en el material o hasta la obtención de una carga máxima también estipulada mediante ensayos de referencia anteriores.

$\checkmark$ Determinación de los parámetros elásticos (MOE) y resistentes (MOR), de acuerdo con las siguientes fórmulas: 


$$
\operatorname{MOE}(\mathrm{MPa})=\frac{\mathrm{LP}}{\mathrm{A} \Delta}
$$

Siendo:

MOE: módulo de elasticidad, en MPa.

L: longitud total de la probeta, en $\mathrm{mm}$.

$\mathrm{P}$ : carga máxima aplicada en el límite elástico, en $\mathrm{kN}$.

A: sección transversal de la probeta, en $\mathrm{mm}^{2}$.

$\Delta$ : acortamiento total de la probeta, en $\mathrm{mm}$.

$$
\operatorname{MOR}\left(\mathrm{kN} / \mathrm{mm}^{2}\right)=\frac{\mathrm{Q}}{\mathrm{A}}
$$

Siendo:

MOR: módulo de rotura, en MPa.

Q: carga de rotura, en $\mathrm{kN}$.

A: definido en fórmula (15).

$\checkmark$ Corrección (al 12\% de $\mathrm{CH}$ ) de los valores elasto-resistentes obtenidos, según fórmula (10) considerando como factor de corrección "A": 1\% para corrección de $\mathrm{MOE}$ (corrección tomada de la norma EN 384:2010) y 4\% para corrección de MOR (corrección tomada de la norma UNE 56532:1977).

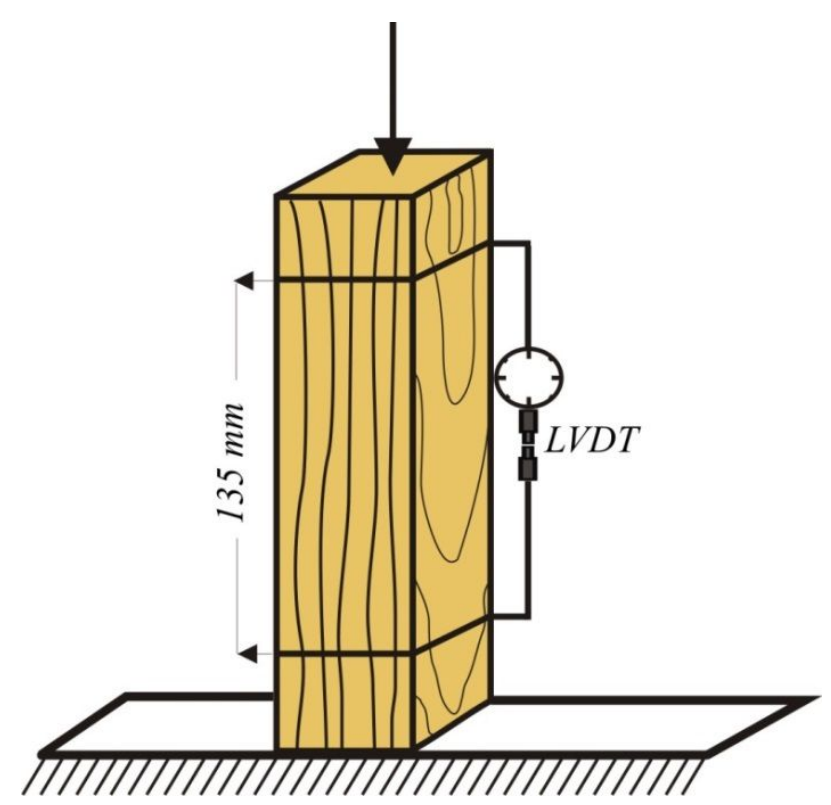

Figura 10. Esquema ensayo de compresión paralela. 


\subsubsection{Durabilidad natural}

El término durabilidad hace referencia a la resistencia intrínseca de la madera a los ataques por organismos destructores (EN 350-1:1995). Esta norma establece los criterios para evaluar la durabilidad en cada grupo de maderas (frondosas y coníferas) y frente a diferentes organismos xilófagos, determinados de acuerdo con las metodologías establecidas en las normas específicas. En este trabajo, dichas metodologías, para cada grupo de organismos xilófagos, han sido las siguientes:

$\checkmark$ CEN/TS 15083-1: 2005 frente a hongos basidiomicetos xilófagos.

$\checkmark$ CEN/TS 15083-2: 2005 frente a hongos ascomicetos e imperfectos xilófagos.

$\checkmark$ EN-117: 2012 frente a termitas.

\section{Equipamiento empleado:}

Infraestructura y material ordinario de uso común propio de un laboratorio de Patología y Protección de madera:

$\checkmark$ Entomología (criadero de termitas, estufas de incubación, material de vidrio, etc).

$\checkmark$ Microbiología (micoteca, cámaras de cultivos, placas Petri, material de vidrio, etc). Tratamiento (cámara de acondicionamiento, estufa de secado, balanzas, desecadores, etc).

\subsection{Determinación de la durabilidad frente a hongos basidiomicetos xilófagos}

La determinación de la durabilidad frente a hongos basidiomicetos xilófagos, se realizó de acuerdo con la metodología indicada en la norma CEN/TS 15083-1: 2005, empleando las cepas de obligado cumplimiento para las frondosas (Trametes versicolor (Linnaeus) Quelet, cepa CTB 863 A y Coniophora puteana (Schumacher ex Fries) Karsten, cepa BAM Ebw.15, como organismos de pudrición fibrosa/blanca y cúbica/parda, respectivamente).

\section{Procedimiento general empleado (CEN/TS 15083-1: 2005)}

Se cortaron probetas del clon I-214 de las dimensiones detalladas en la norma, Tabla 1, e identificadas como madera próxima y alejada a la médula (referenciada como sección interna y externa, respectivamente), utilizando como especie sensible de referencia Fagus sylvatica L. (Haya). 
Para no explicar exhaustivamente la norma, a continuación se describe brevemente la metodología utilizada:

$\checkmark \quad$ Identificación y acondicionamiento del material de ensayo (ME) y de referencia (MR) según procedencias y secciones.

$\checkmark$ Preparación del medio de cultivo agar-malta (agar 1,5\%, malta 3\%).

$\checkmark \quad$ Reparto del medio de cultivo en placas Petri (dos placas Petri: una por cepa fúngica a cultivar) y en frascos de vidrio de $350 \mathrm{ml}$ de capacidad. Para el material procedente de España se emplearon 55 frascos en total para cada cepa fúngica: 20 por sección de ME y 15 para MR; para el material de procedencia Argentina se emplearon 35 frascos por cepa fúngica: 20 frascos de ME (sección interna) y 15 de MR.

$\checkmark$ Esterilización de las caja Petri y los frascos en autoclave durante 20 minutos a $1 / 2$ atm. de presión y posterior reposo de los mismos hasta consolidación del medio.

$\checkmark$ Cultivo axénico de cada una de las cepas en las placas Petri.

$\checkmark$ Logrado el crecimiento del micelio en las placas Petri, repique del mismo en los frascos de cultivo.

Colocación de los frascos en cámara de acondicionamiento $\left(20^{\circ} \mathrm{C} \pm 2{ }^{\circ} \mathrm{C}\right.$ y $65 \pm 5 \%$ de HR), hasta el desarrollo del hongo en la superficie del medio de cultivo (los frascos con escaso o mal establecimiento del hongo o contaminados, fueron descartados).

$\checkmark$ Determinación del peso anhidro (estufa a $103^{\circ} \mathrm{C} \pm 2^{\circ} \mathrm{C}$ hasta peso constante) del ME y del MR.

$\checkmark \quad$ Una vez logrado el cubrimiento del medio por parte del micelio del hongo, fueron colocados los soportes de plástico estériles en los frascos seleccionados y posteriormente fueron incorporadas las probetas de ensayo -ME- (2 por frascos); dicho procedimiento fue llevado a cabo en condiciones estériles en cámara de flujo laminar.

$\checkmark$ Incubación de los frascos de ensayo en cámara acondicionada a $22^{\circ} \mathrm{C} \pm 2{ }^{\circ} \mathrm{C}$ y $70 \%$ $\pm 5 \%$ de HR, durante un período de 16 semanas.

$\checkmark$ Transcurrido dicho período se dio por finalizado el ensayo.

$\checkmark$ Extracción, limpieza (para eliminar excedente de micelio y/o sustrato) y colocación de las probetas de haya - MR - en estufa a $103^{\circ} \mathrm{C} \pm 2^{\circ} \mathrm{C}$ hasta peso constante (peso anhidro final: Pof).

$\checkmark$ Evaluación gravimétrica de los daños (pérdida de peso) en el MR, mediante la fórmula:

$$
P p(\%)=\frac{P o(i)-P o(f)}{P o(f)} \times 100
$$


$\checkmark$ Análisis de validez de los resultados: pérdida de peso del material de referencia igual o superior al $20 \%$ y $30 \%$ para la $T$. versicolor y C. puteana, respectivamente.

$\checkmark$ Constatada la validez del ensayo, se procedió a extraer y limpiar todo el material de chopo -ME- identificado por procedencias/secciones y a colocarlo en estufa hasta constatación de peso constante (Pof). Del mismo modo que para el MR, con el Poi y el Pof se determinó la pérdida de peso de cada probeta de chopo en condiciones anhidras según fórmula (17).

$\checkmark$ Determinación de la clase de resistencia (clase de durabilidad) a la degradación fúngica causada por hongos xilófagos basidiomicetos mediante el coeficiente $\mathrm{x}$ expresado en la fórmula (18) y su correspondiente clasificación indicada en la Tabla 7.

$\checkmark \quad$ Estimación de la vida útil esperable en servicio según norma EN 335:2013.

$$
\mathrm{x}=\frac{\mathrm{Pp}(\%) \text { del material de ensayo }}{\mathrm{Pp}(\%) \text { del material de referencia }}
$$

Tabla 7. Clase de durabilidad frente al ataque de hongos basidiomicetos según el coeficiente $x$.

\begin{tabular}{|c|c|c|}
\hline \multirow{2}{*}{ Clase de durabilidad } & \multirow{2}{*}{ Descripción } & $\begin{array}{l}\text { Resultados de ensayos de laboratorio expresados } \\
\text { en función de } \mathrm{x}\end{array}$ \\
\hline & & $\begin{array}{c}\text { Basidiomicetos } \\
\text { EN 350-1:1995) } \\
\end{array}$ \\
\hline 1 & Muy durable & $\mathrm{x} \leq 0,15$ \\
\hline 2 & Durable & $>0,15 x<0,30$ \\
\hline 3 & Medianamente durable & $>0,30 x \leq 0,60$ \\
\hline 4 & Poco durable & $>0,60 \mathrm{x} \leq 0,90$ \\
\hline 5 & No durable & $>0,90$ \\
\hline
\end{tabular}

\subsection{Determinación de la durabilidad frente a hongos ascomicetos e imperfectos}

La estimación de la resistencia frente al ataque de hongos ascomicetos e imperfectos fue llevada a cabo de acuerdo con la norma europea CEN/TS 15083-2: 2005, la cual emplea como fuente de inóculo a la microbiota del suelo: ascomicetos y hongos imperfectos como así también aquellos microorganismos que puedan estimular su desarrollo (otros hongos -mohos y basidiomicetos- $\mathrm{y}$ bacterias).

\section{Procedimiento empleado (CEN/TS 15083-2: 2005)}

Se cortaron probetas del clon I-214 de las dimensiones detalladas en la norma, Tabla 1, utilizando como especie sensible de referencia Fagus sylvatica L. (Haya).

Para no explicar exhaustivamente la norma, a continuación se describe brevemente la metodología utilizada: 
Identificación y acondicionamiento de las probetas (MR y ME) según especie y secciones.

$\checkmark$ Constitución del sustrato: $20 \%$ de suelo natural (representando la microflora natural) y $80 \%$ de suelo fértil hortícola (esterilizado en autoclave a $1 / 2 \mathrm{~atm}$. de presión durante 20 minutos y con capacidad de retención de agua (WHC) comprendida entre el 25 y $60 \%)$.

$\checkmark$ Colocación de dicho sustrato en tres recipientes de ensayo (contenedores de plástico de $0,025 \mathrm{~m}^{3}$ con tapas perforadas para permitir las condiciones aerobias durante el ensayo), en cantidad tal que cubriese aproximadamente $120 \mathrm{~mm}$ de la profundidad de cada uno de ellos.

$\checkmark$ Determinación del peso anhidro (estufa a $103^{\circ} \mathrm{C}+2{ }^{\circ} \mathrm{C}$ hasta peso constante) del conjunto de las probetas (MR y ME).

$\checkmark$ Colocación aleatoria, en cada recipiente, de 20 probetas de chopo (ME) correctamente identificadas por sección y 10 probetas de haya (MR) separadas entre sí $20 \mathrm{~mm}$ y enterradas hasta un $20 \%$ de su longitud aproximadamente.

$\checkmark$ Colocación de los recipientes, previa determinación de su peso inicial, en cámara acondicionada a $27^{\circ} \mathrm{C} \pm 2{ }^{\circ} \mathrm{C}$ y $70 \% \pm 5 \% \mathrm{HR}$ (en condiciones de oscuridad), durante un período de 16 semanas.

$\checkmark$ Con la finalidad de mantener la capacidad de retención de agua adecuada, cada semana se inspeccionó la humedad del sustrato y, ante apariencia de sequedad, se adicionó el agua faltante correspondiente a la diferencia entre el peso inicial de los recipientes y el determinado al momento de la evaluación.

Transcurridas las 16 semanas, se procedió a la extracción aleatoria y limpieza (para eliminar restos de sustrato) de 10 probetas de haya (MR) para la determinación de su peso anhidro (estufa a $103^{\circ} \mathrm{C} \pm 2{ }^{\circ} \mathrm{C}$ hasta peso constante) y posterior determinación de su pérdida de peso, fórmula (17). Verificado visualmente el daño ocasionado y validado el ensayo mediante la obtención de una $\mathrm{Pp}$ en el MR superior al 20\%, se dio por finalizado el ensayo, tal como se indica en la normativa correspondiente.

$\checkmark$ La totalidad de las probetas (ME y el resto de MR) fueron extraídas de los recipientes, se limpiaron y se evaluaron visualmente para la detección de daños; posteriormente fueron colocadas en estufa a $103^{\circ} \mathrm{C} \pm 2{ }^{\circ} \mathrm{C}$ hasta peso constante.

$\checkmark$ Determinación de los valores de $\mathrm{Pp} \%$, según fórmula (17) y del coeficiente $\mathrm{x}$ de acuerdo con la fórmula (18) para estimar la clase de resistencia a la degradación fúngica -clase de durabilidad-, CEN/TS 15083-2:2005, según se indica en la Tabla 8 y, a partir de ella, la clase de uso para este material, EN 335:2013. 
Tabla 8. Clase de durabilidad frente a de hongos xilófagos ascomicetos e imperfectos según $x$.

\begin{tabular}{ccc}
\hline & & $\begin{array}{c}\text { Resultados de ensayos de laboratorio expresados } \\
\text { en función de } \mathrm{x}\end{array}$ \\
\cline { 2 - 3 } Clase de durabilidad & Descripción & $\begin{array}{c}\text { Ascomicetos e imperfectos } \\
\text { CEN/TS 15083-2 (2005) }\end{array}$ \\
\hline 1 & Muy durable & $\mathrm{x} \leq 0,10$ \\
\hline 2 & Durable & $>0,10 \mathrm{x} \leq 0,20$ \\
\hline 3 & Medianamente durable & $>0,20 \mathrm{x} \leq 0,45$ \\
\hline 5 & Poco durable & $>0,45 \mathrm{x} \leq 0,80$ \\
\hline
\end{tabular}

NOTA: este ensayo fue llevado a cabo sólo con madera de procedencia española.

\subsection{Determinación de la durabilidad frente a Termitas}

La durabilidad frente a termitas subterráneas se evaluó aplicando la norma EN-117 (2012), utilizando la especie Reticulitermes grassei (Clément) procedente del criadero del INIA.

\section{Procedimiento general empleado (EN-117: 2012)}

Se cortaron probetas del clon I-214 de las dimensiones detalladas en la norma (Tabla 1), utilizando como especie sensible de referencia fueron empleadas probetas de pino (Pinus sylvestris Linnaeaus).

Para no explicar exhaustivamente la norma, a continuación se describe brevemente la metodología utilizada:

$\checkmark \quad$ Identificación y acondicionamiento de las probetas (MR y ME) según especie y secciones.

$\checkmark \quad$ Preparación del sustrato en frascos de vidrio $(350 \mathrm{ml})$ : arena de mar humedecida (proporción 1 volumen de agua en 8-10 volúmenes de arena) constituyendo una capa de 40-60 $\mathrm{mm}$ de espesor.

$\checkmark$ Colocación de 0,5 g aproximadamente de madera de cría (Pinus sp) -fuente inicial de alimento de las colonias- distribuida uniformemente sobre la capa arenosa.

$\checkmark \quad$ Introducción, dentro de cada frasco, contra una de sus paredes (y a la mitad de la misma), de un anillo de vidrio ( $1 \mathrm{~mm}$ de espesor, $20 \mathrm{~mm}$ de altura y $20 \mathrm{~mm}$ de diámetro aproximadamente), utilizado como apoyo de las probetas, de forma tal que parte de él sobresaliese de la superficie del sustrato.

$\checkmark$ Constitución de las colonias: 250 obreros (eliminando aquellos en período de muda -de abdomen más blanquecino-, heridos o inmóviles) junto con un número de ninfas y 
soldados correspondiente a una proporción de 1 a $5 \%$, con respecto a su existencia en las colonias de las que fueron tomados los obreros.

$\checkmark$ Colocación de dichas colonias en los recipientes de ensayos, cierre (no hermético) de los mismos y colocación en cámara de cría bajo condiciones controladas de $26^{\circ} \mathrm{C} \pm$ $2^{\circ} \mathrm{C}$ y $70 \%+5 \%$ HR por un período de 2-4 días hasta constatación de distribución uniforme y animada de la colonia en todo el volumen del sustrato; aquellos frascos en los que no se pudieron constatar dichas condiciones fueron descartados y reemplazados.

$\checkmark$ Instalación, por cada frasco, de una probeta de madera (ME ó MR) esterilizada (autoclave a $1 / 2 \mathrm{~atm}$. de presión durante 20 minutos), ubicada de canto sobre el anillo de vidrio, evitando el contacto directo con el sustrato; los frascos de este modo preparados fueron tapados (cierre no hermético) y colocados en cámara de cría en condiciones controladas de $26^{\circ} \mathrm{C} \pm 2{ }^{\circ} \mathrm{C}$ y $70 \% \pm 5 \% \mathrm{HR}$, durante un período de 8 semanas.

$\checkmark$ Revisión periódica de las condiciones de humedad del sustrato; ante cambio de coloración, como indicador de sequedad, se re-humidificaron mediante el agregado de pequeños aportes de agua.

$\checkmark$ Transcurrido el período de contacto, las probetas se extrajeron y limpiaron cuidadosamente (para eliminar cualquier partícula o sustancia adherida a su superficie) y se procedió al examen final de cada una: se contabilizó el número de individuos vivos (obreros, ninfas y soldados) y se realizó una evaluación visual del grado de ataque según la escala establecida en la norma EN 117:2012: 0: ningún ataque; 1: tentativa de ataque; 2: ataque ligero; 3: ataque medio y 4: ataque fuerte. Mediante el número de obreros iniciales y el número de obreros sobrevivientes, se estimó la Tasa de Supervivencia.

$\checkmark$ Constatación de la validez de ensayo: la misma fue llevada a cabo mediante evaluación (nivel 4 de ataque) y recuento de sobrevivientes de obreros (tasa de supervivencia: $50 \%$ ).

Adicionalmente (no contemplado en la norma) fue evaluada la pérdida de peso en base anhidra mediante la fórmula (17), para lo cual, culminado el ensayo, todas las probetas (ME y MR) fueron colocadas en estufa a $103^{\circ} \mathrm{C} \pm 2^{\circ} \mathrm{C}$ hasta peso constante (peso anhidro final: Pof).

$\checkmark \quad$ Para la determinación de la resistencia al deterioro (clase de durabilidad) causado por termitas, se utilizó la valoración media, por sección, según se indica en la Tabla 9, EN 350-1:1995; la clase de uso para el chopo fue estimada de acuerdo con la norma EN 335:2013. 
Tabla 9. Clase de durabilidad frente al ataque de termitas según nivel de ataque medio.

\begin{tabular}{ccc}
\hline Clase de durabilidad & Descripción & $\begin{array}{c}\text { Valoración media según nivel de ataque } \\
\text { EN 350-1:1995 }\end{array}$ \\
\hline 1 & Durable & $0-1$ \\
\hline 2 & Medianamente durable & 2 \\
\hline 3 & Sensible & $3-4$ \\
\hline
\end{tabular}

\subsubsection{Piezas macizas semi-estructurales (escala 1:5) y piezas macizas estructurales.}

En este apartado se detallan conjuntamente los ensayos realizados en las piezas de tamaño semi-estructural y estructural (apartado 1.3.2 y 1.3.3, respectivamente).

\subsubsection{Ensayos no destructivos}

\subsection{Inspección-medición de singularidades y clasificación visual}

\section{Equipamiento empleado:}

$\checkmark \quad$ Material de carpintería (sierra sin fin o de banda, sierra de mesa, metro, etc).

$\checkmark$ Equipos manuales de medición (xilohigrómetro de resistencia, calibre de 0,01 mm de precisión, balanza electrónica de $0,01 \mathrm{~g}$ de precisión).

$\checkmark$ Equipos para secado (estufa con circulación de aire $\left(103^{\circ} \mathrm{C} \pm 2^{\circ} \mathrm{C}\right.$ ), desecador).

$\checkmark$ Software/equipos de ensayo no destructivo: Vibraciones Inducidas: FFT Analyzer; Ultrasonidos: Fakopp y Sylvatest ® Dúo y trío.

\section{Procedimiento empleado (para el material semi-estructural y estructural):}

Determinación del $\mathrm{CH}$ de las piezas mediante xilohigrómetro digital. Al respecto se trabajó atendiendo las consideraciones de la norma UNE 56544:2011, donde se estipula que la evaluación de las singularidades ligadas a los procesos de secado (fendas y deformaciones) como así también la densidad de un lote de madera en proceso de clasificación visual resistente, debe efectuarse con un contenido de humedad promedio igual o inferior al $20 \%$.

$\checkmark$ Determinación de las dimensiones de las piezas (espesor, ancho y largo)

$\checkmark$ Determinación del peso de las piezas

$\checkmark$ Determinación de la densidad de cada pieza a partir de sus dimensiones (y cálculo de volumen a partir de ellas) y de su peso, según fórmula (2).

$\checkmark$ Inspección y medición de las singularidades, controlando sus dimensiones y su posición. Fueron evaluadas únicamente aquellas singularidades comprendidas en el tercio central de la pieza de madera. 


\begin{abstract}
$\checkmark$ Clasificación de cada pieza de madera mediante los criterios de calidad establecidos en las normas de clasificación visual, Tabla 4. Todas las piezas fueron clasificadas en tres categorías: "Clase Estructural Superior (CS)" para la mejor categoría visual, "Clase Estructural Inferior (CI)" para la peor categoría y Rechazo (R), para aquel material sin calidad visual apropiada para fines estructurales. Las piezas semiestructurales (escala 1:5) fueron clasificadas adaptándose únicamente a la normativa española vigente establecida para material de tamaño estructural (UNE-56544:2011). En el caso de las piezas de tamaño estructural, las piezas fueron clasificadas mediante la utilización de varias normas, Tabla 4, teniendo en cuenta las siguientes consideraciones: para la clasificación según norma DIN4074-5 se utilizó la clase LS7 y LS10 como clase inferior y superior, respectivamente; para la clasificación según norma NCh-1970-1 se utilizó la clase $\mathrm{N}^{\mathrm{o}} 2$ y $\mathrm{N}^{\mathrm{o}} 4$ como clase superior e inferior, respectivamente. En ambos casos, las clases más altas se evitaron por ser muy restrictivas respecto al material estudiado (clase S13 y clase $\mathrm{N}^{\circ} 1$ para la norma DIN 4074-5 y NCh 1970-1, respectivamente).
\end{abstract}

Las singularidades tenidas en cuenta en este estudio, agrupadas en categorías según la causa de su aparición (ligadas a la anatomía, al aserrado y al secado de la madera) se detallan a continuación:

$\underline{\text { Singularidades ligadas a la anatomía de la madera. }}$

Anchura de anillos: se determinó en el segmento recto más largo que pudo trazarse perpendicularmente a los anillos de crecimiento y que atravesó más transversalmente a la pieza. La medida comenzó en el extremo más cercano a la médula determinándose el valor medio de la anchura de los primeros 5 anillos de crecimiento, Figura 11.
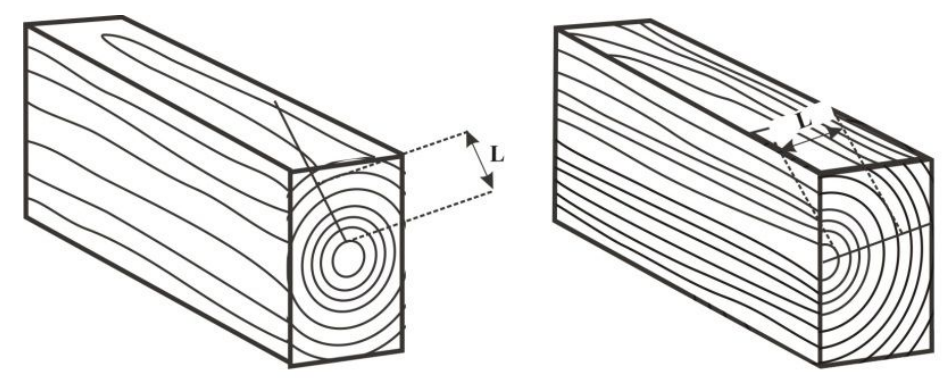

Figura 11. Anchura de anillos de crecimiento: medición.

Entrecasco: se registró únicamente su presencia (Sí) ó ausencia (No). 


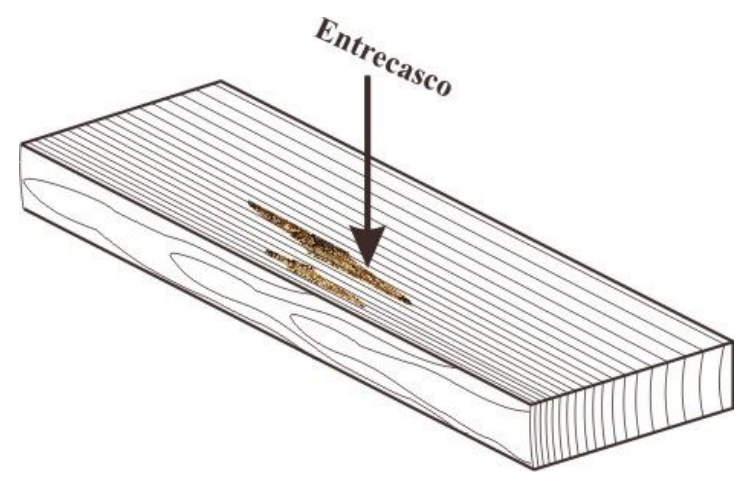

Figura 12. Entrecasco: registro de presencia.

Nudos: para esta determinación se empleó el método alternativo de medición planteado en la norma EN 1310:1997 y avalado por la norma UNE 56544:2011, mediante el cual se estipula la medición de los nudos perpendicularmente al eje longitudinal de la pieza. De todas maneras, para el dimensionamiento final del nudo se consideró la manera de cálculo del método general realizando la media entre la dimensión menor y la dimensión mayor de cada nudo.

Los nudos con dimensión inferior o igual a $10 \mathrm{~mm}$, fueron despreciados; sólo fueron considerados en el caso de nudos pasantes, tal como lo establece la normativa correspondiente. La corteza presente alrededor del nudo fue considerada como parte del mismo; las irregularidades de las fibras presentes cerca del nudo y no discernibles de él fueron consideradas como parte del mismo.

Los nudos presentados en las caras fueron evaluados como la dimensión del nudo en relación a la anchura de la pieza $(\mathrm{d} / \mathrm{h})$, mientras que los nudos presentados en el canto fueron evaluados como la dimensión del nudo en relación con el grosor (espesor) de la pieza (d/b).

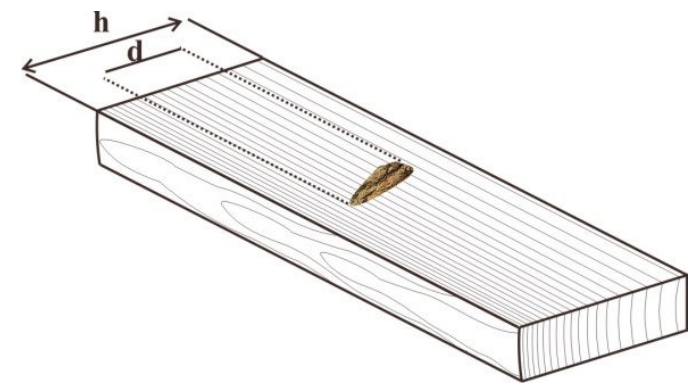

Figura 13. Nudos de cara.

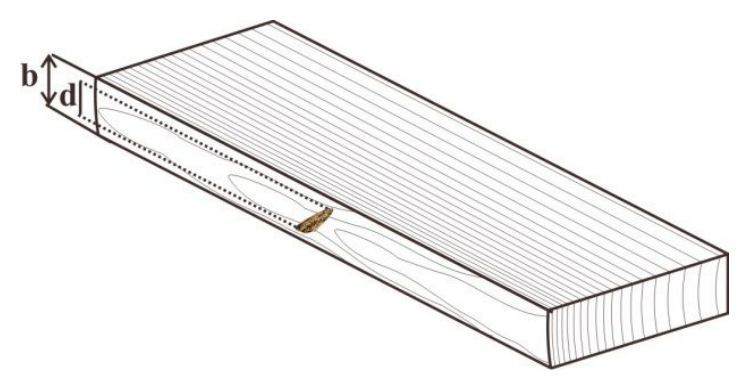

Figura 14. Nudos de canto.

En el caso de los nudos de arista -aquellos que se presentan en superficies contiguas de cara y canto- se evaluaron los que se presentaron cortados más perpendicularmente; en el caso de dudas, se consideró la relación más desfavorable (nudo mayor); Figura 15. 

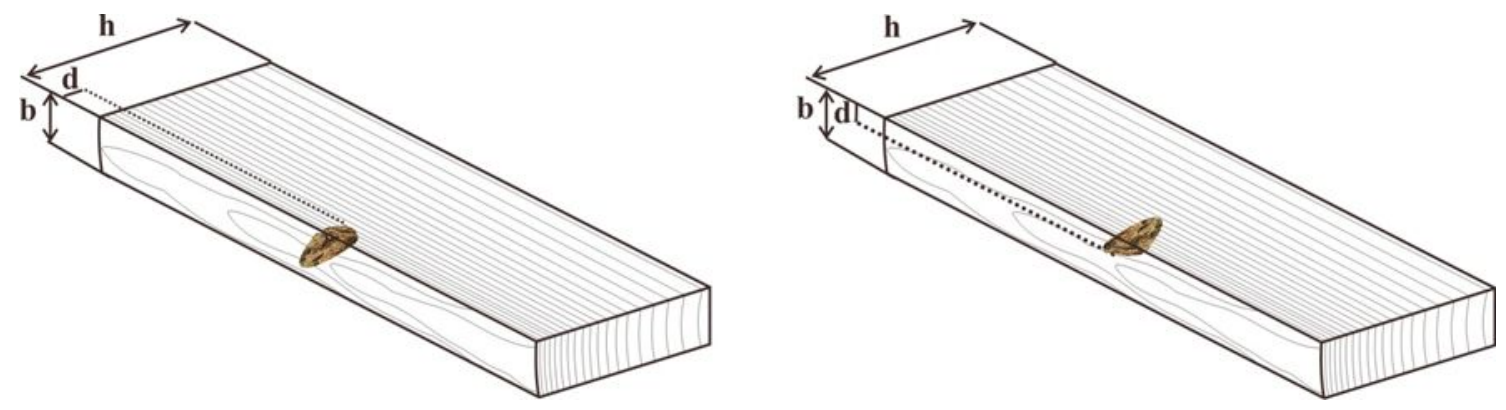

Figura 15. Nudos de arista.

Ante la presencia de nudos agrupados -aquellos cuyos centros, considerados en el eje longitudinal de la pieza, fuese igual o menor a $150 \mathrm{~mm}$ ó menor o igual a la anchura de la pieza cuando esta fue menor a $150 \mathrm{~mm}$-, Figura 16, se consideraron dos alternativas: cuando no se solaparon sobre la dirección transversal al eje longitudinal de la pieza, se sumaron los diámetros de cada nudo individual, Figura 17; cuando se solaparon, se tomaron como una unidad a la que se le determinó la dimensión menor, la mayor y luego se obtuvo su promedio, Figura 18.

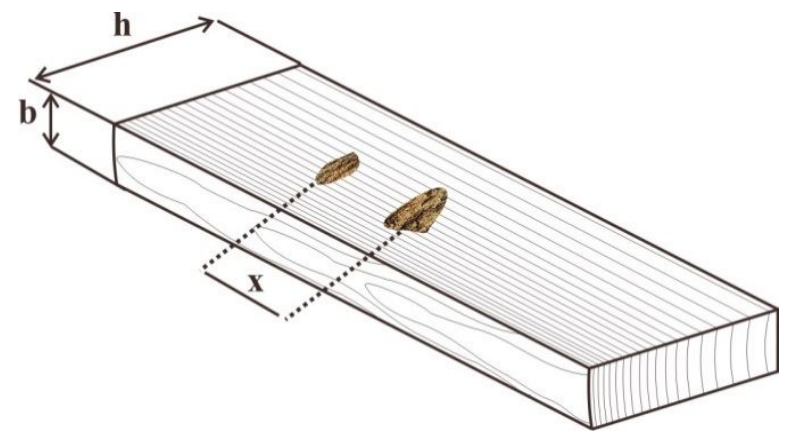

Figura 16. Nudos agrupados: consideración general.

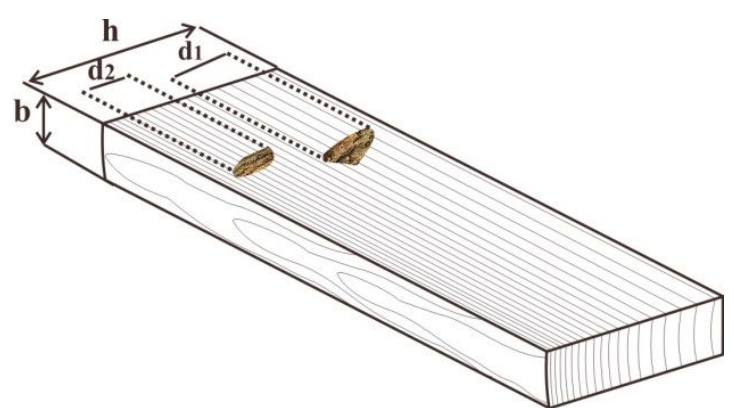

Figura 17. Nudos sin solapar.

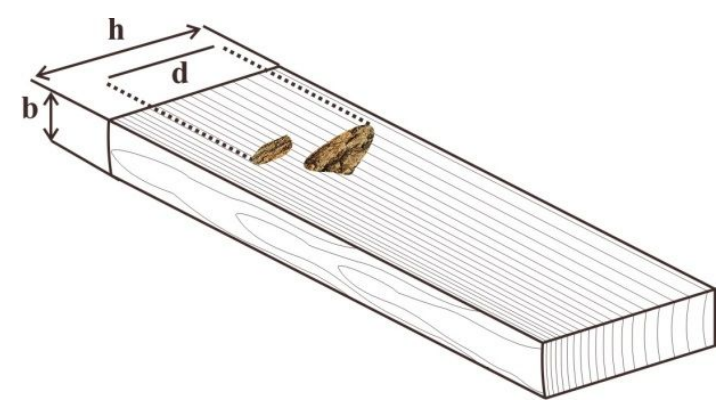

Figura 18. Nudos solapados.

Desviación de las fibras/grano inclinado: desviación media de la fibra con respecto al eje longitudinal de la pieza; dicha desviación fue evaluada sobre una longitud de $1 \mathrm{~m}$ en la zona más desfavorable de la pieza y quedó definida por la relación y/x, Figura 19. Esta singularidad 
no fue considerada en las piezas de tamaño semi-estructural dado que el largo total de las piezas fue de 1,20 metros.

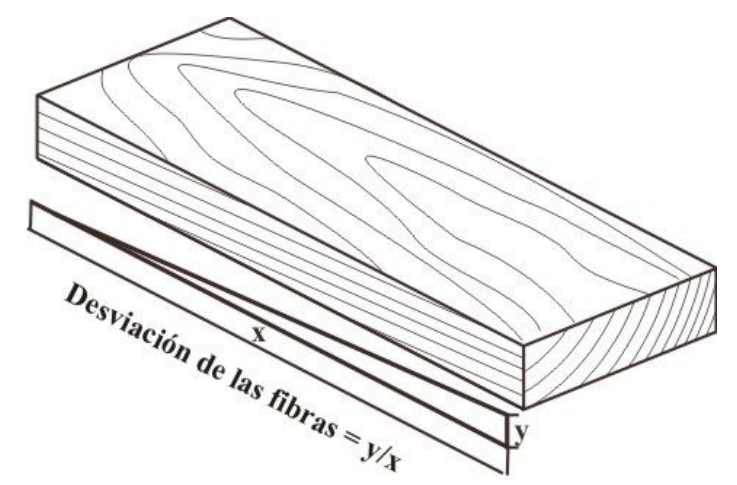

Figura 19. Desviación de las fibras: determinación.

$\underline{\text { Singularidades ligadas al proceso de aserrado. }}$

Médula: zona situada en el interior del primer anillo de crecimiento constituido principalmente por tejido blando (EN 844-7:1997); se registró su presencia "Sí" ó ausencia "No", Figura 20.

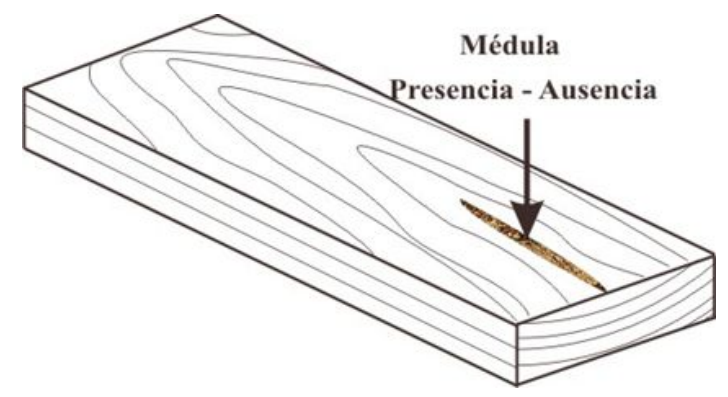

Figura 20. Médula: registro de presencia.

Gemas: superficie redondeada original de un tronco (con o sin corteza) que se manifiesta sobre las aristas de las piezas de madera aserrada. Para su evaluación se determinó la longitud de la gema en relación con la longitud de la pieza -1/L- (Longitud de gemas) y su anchura $y / o$ espesor en relación con las dimensiones de la pieza -anchura y espesor- $h_{1} / h, b_{1} / b$, respectivamente (Anchura de gemas). A los efectos de la longitud, ante la presencia de gemas en más de un sector de las aristas de la pieza, las mismas fueron sumadas. 


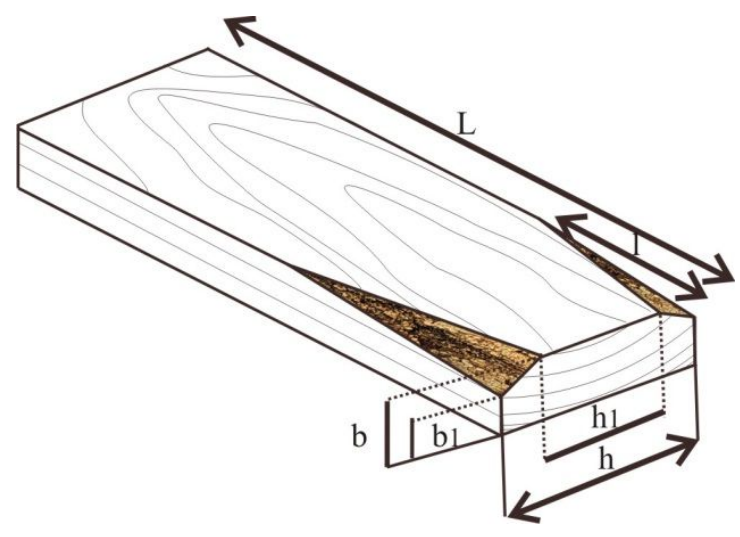

Figura 21. Gemas: determinación.

$\underline{\text { Singularidades ligadas al proceso de secado: deformaciones. }}$

Curvaturas: representadas por la flecha (a) producida entre la superficie curva y la línea recta trazada entre los extremos de la pieza; de acuerdo con lo establecido en la norma EN 1310:1997esta determinación se realizó sobre una longitud de $2 \mathrm{~m}$, por lo tanto el resultado es expresado en mm por cada $2 \mathrm{~m}$ de longitud. En la Figura 22 y Figura 23 se presenta la curvatura de cara y de canto, respectivamente.

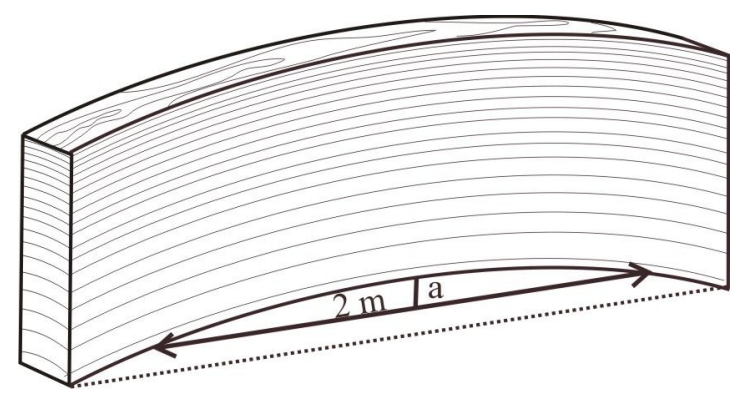

Figura 22. Curvatura de canto: determinación.

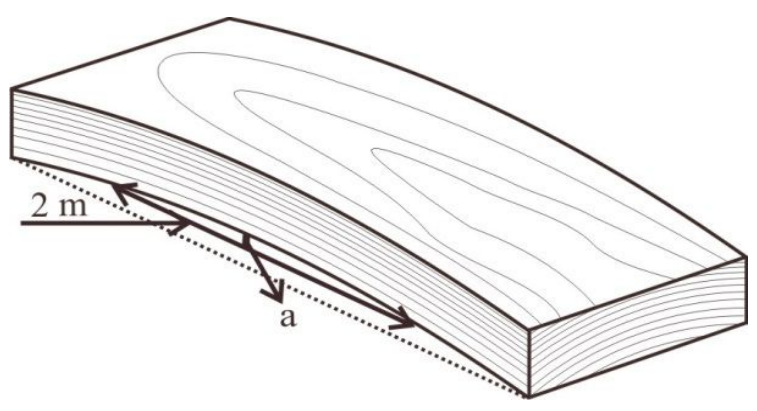

Figura 23. Curvatura de cara: determinación. 
Alabeo: es la deformación máxima de la superficie de una pieza de madera aserrada, sobre una longitud representativa de $2 \mathrm{~m}$. Según la norma EN 1310:1997, el resultado se expresa en mm por cada $25 \mathrm{~mm}$ de anchura.

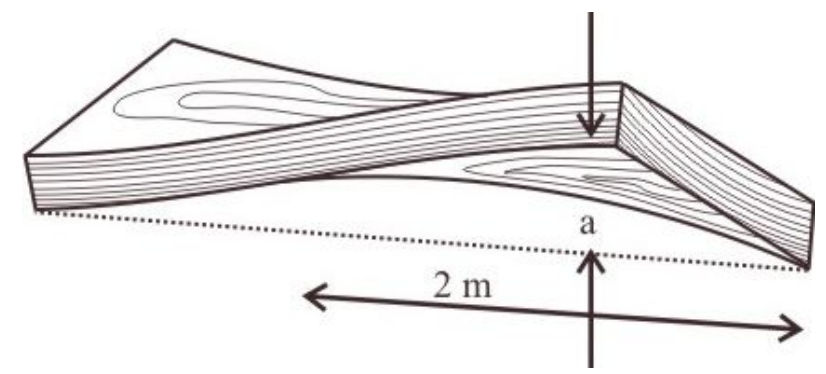

Figura 24. Alabeo: determinación.

Cabe aclarar que dado que la longitud máxima de las piezas de tamaño semi-estructural es de 1,20 metros, estas singularidades no fueron determinadas en dicho material.

Nota: fueron detalladas únicamente aquellas singularidades obtenidas en el material ensayado y no todas las consideradas en norma.

\subsection{Técnicas de ensayo no destructivas (NDT).}

Posteriormente, tras la determinación y medición de las singularidades, se realizó la evaluación no destructiva de todas las piezas (material semi-estructural y estructural) utilizando las técnicas que se detallan a continuación.

Técnica de ultrasonidos: mediante esta técnica se determina la velocidad de propagación de una onda ultrasónica que atraviesa longitudinalmente una pieza de madera. Dependiendo del equipo utilizado, la onda es generada mecánicamente mediante un impacto de martillo, equipo Fakoop o eléctricamente, equipo Sylvatest ${ }^{\circledR}$. En ambos casos, la onda es generada en un palpador emisor ubicado en un extremo de la pieza y recepcionada en un palpador receptor en el otro extremo de la pieza, registrándose en la estación del equipo, el tiempo ( $\mu \mathrm{s})$ que tarda la onda ultrasónica en llegar desde el palpador emisor hasta el palpador receptor. Para la realización de estos ensayo se empleó el equipo "Microsecond Timer" de Fakopp, en piezas de tamaño semi-estructural y los equipos Sylvatest $\circledR^{\circ}$ Dúo y Sylvatest ${ }^{\circledR}$ Trío, en las piezas de tamaño estructural, cuyos datos fueron utilizados indistintamente (Anejos 6.2.1.1).

Procedimiento empleado:

Determinadas las dimensiones, peso y densidad acorde a lo indicado en la sección 2.1.2.1.1, se realizaron unos orificios de $5 \mathrm{~mm}$ de diámetro y de $10 \mathrm{~mm}$ de profundidad 
para la correcta colocación de los captadores del equipo Sylvatets ${ }^{\circledR}$; en el caso del Microsecond Timer de Fakopp, los palpadores presentan extremos aguzados (tipo púa) para insertarse con facilidad en la madera.

$\checkmark$ Cada pieza, colocada sobre dos apoyos, fue ensayada longitudinalmente, con la mayor dimensión de la escuadría en sentido vertical (V). El ensayo propiamente dicho fue realizado impartiendo un golpe de martillo en el palpador emisor ubicado en un extremo de la pieza; el impacto fue recibido en el palpador receptor y el tiempo que tardó la onda desde el emisor hacía el receptor fue registrado por el equipo, Figura 25; la velocidad de paso de la onda surge de relacionar la longitud de cada pieza con el tiempo obtenido mediante el ensayo, en $\mathrm{m} / \mathrm{seg}$. En los equipos Sylvatest ${ }^{\circledR}$ Dúo y Trío las ondas son generadas a 30 y $22 \mathrm{~Hz}$, respectivamente. .

$\checkmark$ Determinación del módulo de elasticidad dinámico:

$$
E_{d}=(V)^{2} \times \rho
$$

Dónde:

$E_{d}$ : Módulo Dinámico, en MPa.

$\mathrm{V}$ : velocidad de paso de la onda, en $\mathrm{m} / \mathrm{seg}$.

$\rho$ : Densidad de la pieza de madera, en $\mathrm{Kg} / \mathrm{m}^{3}$.

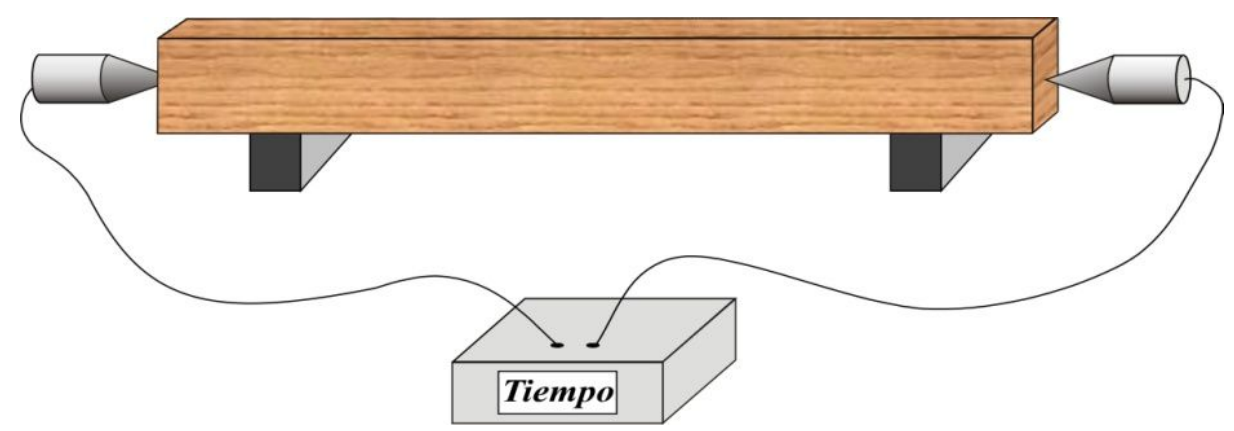

Figura 25. Esquema representativo del ensayo de ultrasonidos (Sylvatest ${ }^{\circledR}$ ).

Técnica de vibraciones inducidas: esta técnica implica la excitación de una pieza de madera mediante un impacto mecánico, generado por un martillo, en un extremo de la misma, mientras que en el otro extremo, un detector de señal lo recibe y a través de un analizador de onda, registra la frecuencia vibratoria. Dependiendo dónde se aplique el impacto, en un extremo de la pieza o en su cara transversal, se obtiene la frecuencia de vibración longitudinal o transversal, respectivamente. 


\section{Procedimiento empleado:}

$\checkmark$ Determinadas las dimensiones, peso y densidad acorde a lo indicado en la sección 2.1.2.1.1, las piezas fueron colocadas sobre dos apoyos libres (sin sujeción) y se establecieron las condiciones de ensayo: rango de frecuencia: $7350 \mathrm{~Hz}$; nivel de ruidos y ecos: 10\%; LDD: 400 .

$\checkmark$ Cada pieza fue ensayada longitudinalmente y ubicada con la mayor dimensión de la escuadría en sentido vertical (V). El ensayo propiamente dicho fue realizado impartiendo un golpe de martillo en un extremo de la pieza; el impacto fue registrado mediante un captador de señal, ubicado en el otro extremo de la pieza, y a través de un analizador de ondas (FFT Analyzer) desde un ordenador se obtuvo la frecuencia propia de vibración $(f)$ de cada pieza, Figura 26.

$\checkmark$ Determinación del módulo de elasticidad dinámico:

$$
E_{d}=(2 \times \mathrm{L} \times f)^{2} \times \rho
$$

Dónde:

$E_{d}$ : Módulo Dinámico por vibración longitudinal, en MPa.

L: Longitud total de la pieza, en $\mathrm{mm}$.

$f$ : Frecuencia de la vibración longitudinal, en Hz.

$\rho$ : Densidad de la pieza de madera en $\mathrm{Kg} / \mathrm{m}^{3}$.

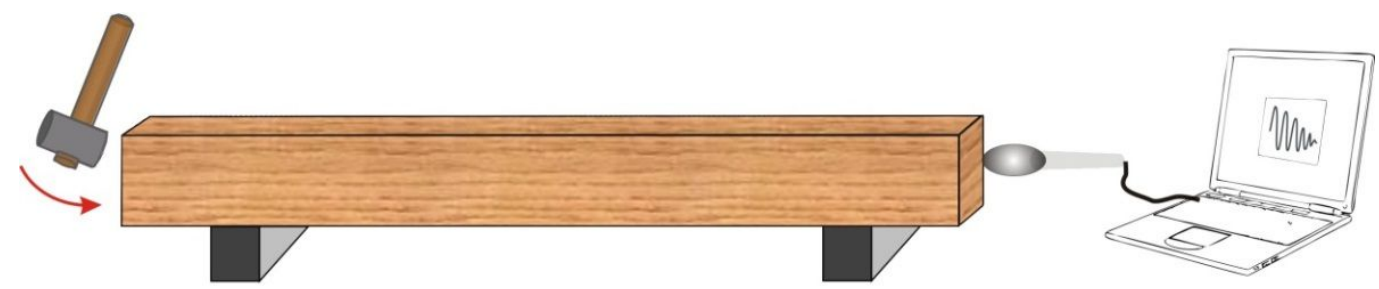

Figura 26. Esquema representativo ensayo de vibraciones inducidas.

\subsection{Efectividad de las NDT en la estimación de las clases resistentes}

Para llevar a cabo este procedimiento, se consultaron las normas EN 140811:2006+A1:2011; 2:2010 y 3:2012. En primer lugar se consideraron únicamente dos clases: "Clase Estructural" y "Clase No Estructural".

En ambas metodologías, vibraciones inducidas y ultrasonidos, para determinar los valores de "corte" de las variables no destructivas, velocidad y frecuencia de vibración, se realizó un análisis de regresión considerando la predicción del MOE estático (sin transformar), a partir de dichas variables. Debido a que dichas predicciones arrojaban bajos valores de ajustes ( $\mathrm{R}^{2}$ ajustados), se incorporó la variable densidad (sin transformar) también como variable 
predictora, mediante lo cual se lograron ajustes algo superiores y más aceptables teniendo en cuenta la heterogeneidad del material de estudio.

Con la ecuación de regresión obtenida se buscó la velocidad que representara un MOE de $7000 \mathrm{MPa}$ (valor de MOE límite C-14, según la norma EN 338:2010), utilizando como densidad para dicha determinación un valor de $320 \mathrm{Kg} / \mathrm{m}^{3}$, afectando de esta manera, a todas las piezas por un valor constante.

\subsubsection{Ensayos destructivos}

\subsection{Realización de ensayos}

La última etapa en la caracterización del material macizo de tamaño semi-estructural (escala 1:5) y estructural fue la realización del ensayo de flexión estática y la determinación de la densidad en material extraído de las piezas ensayadas.

\section{Equipamiento empleado:}

$\checkmark \quad$ Material de carpintería (sierra sin fin o de banda, sierra de mesa, metro, etc)

$\checkmark$ Equipos manuales de medición (xilohigrómetro de resistencia, calibre de 0,01 mm de precisión).

$\checkmark$ Máquinas Universales de Ensayo (con los respectivos implementos de ensayo): España: modelo ELIB - $100 \mathrm{~W}$ de la marca IBERTEST; Argentina: modelo ALFRED J. AMSLER \& Co, Schaffouse - Suisse 7928 de $50 \mathrm{kN}$ para los ensayos de flexión estática.

NOTA: los ensayos mecánicos fueron realizados con madera al contenido de humedad " $h$ " $y$ posteriormente referenciados al $12 \% \mathrm{de} \mathrm{CH}$.

Procedimiento empleado (EN 408:2010+A1:2012):

$\checkmark$ Determinadas las dimensiones, peso y densidad de cada pieza y finalizada la evaluación no destructiva (inspección y medición de las singularidades: sección 2.1.2.1.1; 2.1.2.1.2) se procedió a la evaluación destructiva en las mismas piezas.

$\checkmark$ Las piezas de madera fueron colocadas en la máquina Universal de ensayo siguiendo las especificaciones de la norma EN 408:2011+A1:2012, esto es, apoyadas sobre dos puntos simétricos con una luz de 18 veces la altura de la pieza tal como se indica en la Figura 27. 
$\checkmark$ La deformación de cada pieza fue determinada mediante un deflectómetro (LVDT) colocado en la parte inferior y en el centro de luz de la pieza, tal como es indicado en la Figura 27. Realización del ensayo aplicando una carga constante e inferior a $0,003 * \mathrm{~h}(\mathrm{~mm} / \mathrm{s})$ y perpendicular al eje longitudinal de la pieza. La misma es aplicada sobre dos puntos, tal como se indica en la Figura 27, hasta el $40 \%$ de la carga máxima, momento en el que se retira el deflectómetro y se continúa el ensayo hasta la rotura de la pieza (carga máxima).

$\checkmark$ Obtención de las gráficas/curvas Carga vs Deformación, a fin de obtener (mediante regresión) los correspondientes incrementos de carga (en $\mathrm{kN}$ ) y de deformación (en $\mathrm{mm}$ ) en los márgenes de deformación elástica (parte recta de dicha curva) estipulada entre el $10 \%$ y $40 \%$ de la carga máxima, Figura 28; las piezas con coeficiente de correlación inferior a 0,99 , no fueron consideradas para el análisis.

$\checkmark$ Determinación del módulo de elasticidad estático aplicando los parámetros obtenidos en la expresión de cálculo del MOE:

$$
M O E=\frac{3 \mathrm{al}^{2}-4 \mathrm{a}^{3}}{2 \mathrm{bh}^{3}\left(\frac{\mathrm{W}_{2}-\mathrm{w}_{1}}{\mathrm{~F}_{2}-\mathrm{F}_{1}}\right)}
$$

Siendo:

MOE: módulo de elasticidad, en MPa.

a: distancia entre un punto de carga y el apoyo más próximo, en $\mathrm{mm}$.

1: luz, en mm.

b: anchura o menor dimensión de la sección transversal, en mm.

h: altura o mayor dimensión de la sección transversal, en mm.

F2 - F1: incremento de carga sobre la línea de regresión, con un coeficiente de correlación de 0,99 o superior, en kN, Figura 28.

w2 - w1: incremento de la deformación correspondiente a F2 - F1, en mm, Figura 28.

$\checkmark$ Determinación de la resistencia a la flexión de acuerdo con la siguiente fórmula:

$$
M O R=\frac{3 \mathrm{Fa}}{\mathrm{bh}^{2}}
$$

Siendo:

MOR: resistencia a la flexión, módulo de rotura, en MPa.

$\mathrm{F}$ : carga, en $\mathrm{kN}$.

a, b y h: definidos en la fórmula (21).

$\checkmark$ Obtención de cada pieza, de una probeta libre de defectos para la determinación de su densidad. Dichas probetas fueron extraídas de la zona cercana a la rotura de la 
pieza, durante el ensayo de flexión estática y presentaron las mismas escuadrías y una longitud de $100 \mathrm{~mm}$.

$\checkmark$ Determinación de las dimensiones y peso inicial de cada probeta.

$\checkmark$ Secado de las probetas en estufa a $103^{\circ} \mathrm{C} \pm 2{ }^{\circ} \mathrm{C}$ hasta peso constante (constatado cuando dos pesadas consecutivas difierieron en menos de 1/200 $\mathrm{g}$ de la anterior).

$\checkmark$ Reposo de las probetas en desecador hasta estabilización de la temperatura.

$\checkmark$ Determinación del peso anhidro de las probetas.

$\checkmark$ Obtención del contenido de humedad según lo especificado en la norma EN 131831:2002 y de acuerdo con la fórmula (1), UNE 56529:1977.

$\checkmark$ Obtención de la densidad de cada pieza según lo indicado en la norma EN 408:2011+A1:2012 y de acuerdo con la fórmula (2), UNE 56531:1977.

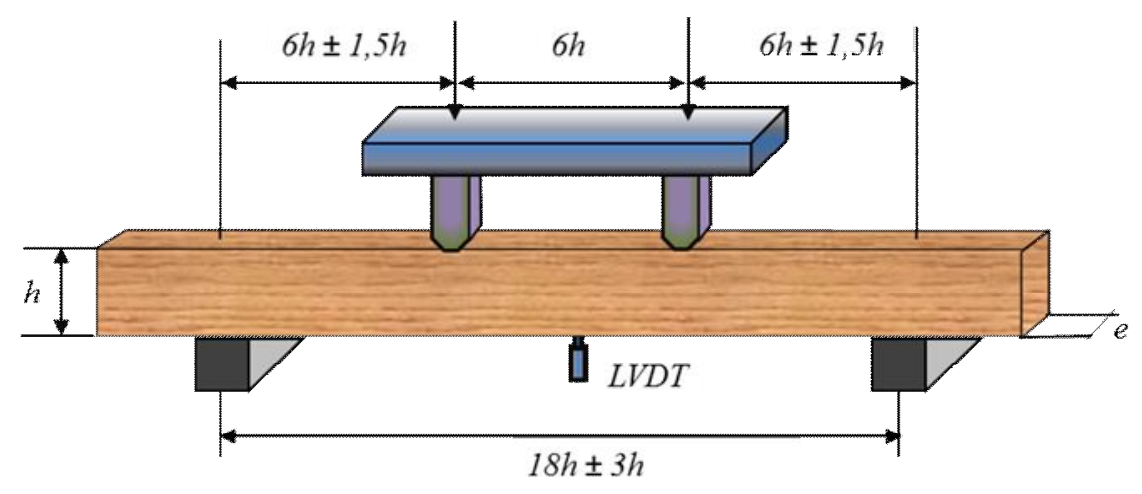

Figura 27. Esquema de ensayo de flexión estática (EN 408:2011+A1:2012).

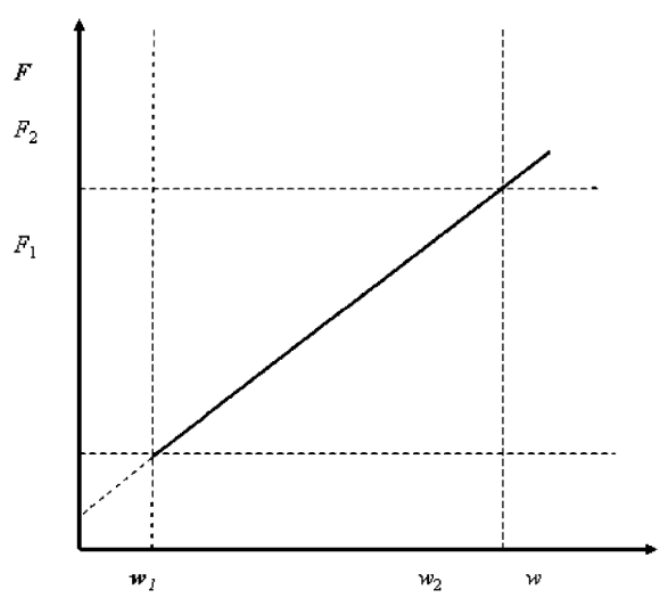

Figura 28. Carga - deformación dentro de los márgenes de deformación elástica. 


\subsection{Determinación de valores característicos (EN 384:2010)}

Se entiende por valor característico a aquel valor correspondiente a un fractil de la distribución estadística de una propiedad de la madera. Según lo especificado por la norma EN 384: 2010, el valor característico del MOE queda representado por su valor medio, mientras que para el MOR y la densidad, dicho valor queda representado por el $5^{\circ}$ percentil.

Para la determinación del valor medio característico del MOE, se estipula una corrección por contenido de humedad $(\mathrm{CH})$ : corrección del 1\%, por cada variación del 1\% del contenido de humedad. El valor medio de la población queda representado por:

$$
\operatorname{MOE}_{(12 \%)}=\operatorname{MOE} *(1+0,01 *(\mathrm{CH}-12))
$$

Siendo:

$\operatorname{MOE}_{(12 \%)}$ : módulo de elasticidad corregido por $\mathrm{CH}$, en MPa.

MOE: valor de módulo de elasticidad determinado mediante el ensayo, en MPa.

Y a su vez, se estipula la corrección respecto al módulo de elasticidad en flexión pura:

$$
\operatorname{MOE}_{12 \%(\text { fexión pura })}=\left[\frac{M O E_{12 \%}}{n i}\right] * 1,3-2690
$$

Siendo:

$\mathrm{MOE}_{12 \% \text { (flexión pura): }}$ módulo de elasticidad corregido por $\mathrm{CH}$ y flexión pura, en MPa

$\mathrm{MOE}_{12 \%}$ : definido en fórmula (23).

ni: el número de piezas que compone la i-ésima muestra.

Corregido el valor de MOE a las condiciones de referencia, el valor característico poblacional se obtiene como media ponderada de los valores característicos:

$$
\operatorname{MOE}_{(0, \text { medio })}=\frac{\sum \operatorname{MOE}_{12 \%(\text { flexión pura })} * n i}{\sum n i}
$$

Siendo:

$M O E_{(0, \text { medio) }}$ : valor característico medio del MOE, en MPa.

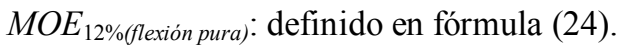

$n i$ : definido en fórmula (24).

En lo referente al MOR, el análisis de los datos comienza con el cálculo del $5^{\circ}$ percentil en cada muestra determinándose mediante un método no paramétrico consistente en ordenar los resultados en orden creciente, y elegir el dato que deja por debajo el $5 \%$ de los valores. En caso de no corresponderse con una posición real, se interpola entre los datos inmediatamente superior 
e inferior. A su vez, los cálculos deben realizarse bajo ciertas condiciones, que en caso de no cumplirse, deben aplicarse los correspondientes factores de corrección.

Para la resistencia a la flexión, se considera una altura de cara de referencia de $150 \mathrm{~mm}$ y unas proporciones de ensayo tal como se especifican en la Figura 27, por lo cual, el $5^{\circ}$ percentil de la resistencia debe corregirse atendiendo a la relación expresada como:

$$
k_{(h)}=\left(\frac{150}{\mathrm{~h}}\right)^{0,2}
$$

Dónde:

$\mathrm{k}_{(\mathrm{h})}$ : factor de corrección del MOR si h es distinto a $150 \mathrm{~mm}$.

h: altura de la cara expresada en $\mathrm{mm}$.

De este modo, es posible comparar piezas de diferentes alturas de cara y trabajar con ellas como si se tratase de una única dimensión.

El valor característico medio poblacional de la resistencia a la flexión es determinado mediante la siguiente expresión:

$$
\operatorname{MOR}_{(0, \text { medio })}=\sum\left(\frac{\operatorname{MOR}_{\left(5^{\circ}\right. \text { percenti) }} * n_{\mathrm{i}}}{\mathrm{n}_{\mathrm{i}}}\right)
$$

Siendo:

$\mathrm{MOR}_{(0, \text { medio) }}$ : valor característico medio del MOR, expresado en MPa.

$n i$ : definido en la fórmula (24).

La norma EN 384:2010 establece que las correcciones por contenido de humedad no son necesarias para la resistencia a la flexión; del mismo modo, contempla otras correcciones por longitud y por número y tamaño de las muestras, las cuales no fueron aplicadas en las muestras de este estudio.

Para el caso de la densidad, las mediciones deben realizarse de acuerdo con el apartado 6.1 de la Norma ISO 3131:1975, con las correspondientes correcciones respecto al 12\% de contenido de humedad: si el $\mathrm{CH}$ es superior al $12 \%$, la densidad debe disminuirse un $0,5 \%$ por cada variación del $1 \%$ del contenido de humedad, y si es inferior al $12 \%$, la densidad debe aumentarse un $0,5 \%$ por cada $1 \%$ de variación del contenido de humedad. Esta forma de proceder se basa en la hipótesis de que la masa y el volumen se miden al contenido de humedad de ensayo.

$$
\rho_{(12 \%)}=\rho *(1-0,005 *(\mathrm{CH}-12))
$$

Donde

$\rho_{(12 \%)}$ : densidad corregido por $\mathrm{CH}$, en $\mathrm{Kg} / \mathrm{m}^{3}$. 
Para el cálculo del $5^{\circ}$ percentil de la densidad se procede del mismo modo que lo indicado para el MOR.

La densidad característica queda definida como:

$$
\rho_{(0, \text { medio })}=\frac{\sum \rho_{\left(5^{\circ} \text { percentil }\right)^{*}} n_{i}}{\sum n_{i}}
$$

Donde

$\rho_{(0, \text { medio) }}$ : valor medio característico de la densidad, en $\mathrm{Kg} / \mathrm{m}^{3}$.

$\rho_{\left(5^{\circ} \text { percentil }\right):} 5^{\circ}$ percentil de la densidad.

$n i$ : definido en fórmula (24).

\subsection{Asignación resistente (EN 338:2010)}

Con los valores característicos de las propiedades mecánicas y de la densidad obtenidos, EN 384:2010, se acudió a la norma EN 338:2010, que especifica para cada clase resistente, cuáles son sus valores característicos y proporciona los criterios de asignación de las poblaciones de madera. En la Tabla 10 se presentan las clases resistentes y valores característicos establecidos en la norma EN 338:2010 para el chopo, recogiendo únicamente los valores de las parámetros de flexión estática (MOR y MOE) y de densidad empleados en este estudio.

Tabla 10. Clases resistentes: valores característicos (EN 338:2010).

\begin{tabular}{|c|c|c|c|c|c|c|c|c|c|c|c|c|c|}
\hline & \multicolumn{13}{|c|}{ Coníferas y chopo } \\
\hline \multicolumn{2}{|c|}{ Clases resistentes } & C14 & C16 & $\mathrm{C18}$ & $\mathrm{C20}$ & $\mathrm{C22}$ & $\mathrm{C24}$ & C27 & C30 & $\mathbf{C 3 5}$ & $\mathbf{C 4 0}$ & $\mathbf{C 4 5}$ & $\mathbf{C 5 0}$ \\
\hline \multicolumn{14}{|c|}{ Propiedades resistentes (valores característicos dado en N/mm²) } \\
\hline \multirow{7}{*}{ Flexión } & $\mathrm{MOR}_{(0, \text { medio })}$ & 14 & 16 & 18 & 20 & 22 & 24 & 27 & 30 & 35 & 40 & 45 & 50 \\
\hline & \multicolumn{13}{|c|}{ Propiedades de rigidez (valores medios y característicos dados en $\mathrm{N} / \mathrm{mm}^{2}$ ) } \\
\hline & $\mathrm{MOE}_{(0, \text { medio })}$ & 7 & 8 & 9 & 9,5 & 10 & 11 & 11,5 & 12 & 13 & 14 & 15 & 16 \\
\hline & $\mathrm{MOE}_{(0,05)}$ & 4,7 & 5,4 & 6,0 & 6,4 & 6,7 & 7,4 & 7,7 & 8,0 & 8,7 & 9,4 & 10,0 & 10,7 \\
\hline & \multicolumn{13}{|c|}{ Densidad $\left(\mathrm{Kg} / \mathrm{m}^{3}\right)$} \\
\hline & $\rho_{(0,05)}$ & 290 & 310 & 320 & 330 & 340 & 350 & 370 & 380 & 400 & 420 & 440 & 460 \\
\hline & $\rho_{\text {(medio) }}$ & 350 & 370 & 380 & 390 & 410 & 420 & 450 & 460 & 480 & 500 & 520 & 550 \\
\hline
\end{tabular}

Finalizados todos los ensayos correspondientes a la SECCIÓN I: Caracterización de madera maciza: probetas de pequeñas dimensiones libres de defectos, piezas de tamaño semi- 
estructural y piezas de tamaño estructural, se procedió al análisis de los resultados tal como se detallará en el apartado 3.

\subsection{SECCIÓN II: Mejoras tecnológicas}

En base a los resultados hallados en la Sección I: Caracterización de madera maciza, a continuación se exponen los procedimientos empleados a fin de lograr una mejora y optimización tecnológica en la madera de Populus euramericana I-214.

\subsubsection{Probetas de pequeñas dimensiones y libres de defectos.}

\subsubsection{Material de pequeñas dimensiones}

\subsection{Termo-modificación}

En este trabajo, bajo el término termo-modificación o termo-tratamiento se hace referencia a la aplicación de diferentes temperaturas en diferentes intervalos de tiempo, sin tener en cuenta para ello una atmósfera inerte.

Este proceso fue llevado a cabo a fin de evaluar la posibilidad de una mejora significativa y "ecológica" en las propiedades de dureza y de durabilidad natural, como alternativa de reemplazo a los productos más nocivos para el medio ambiente actualmente empleados para tal fin.

\section{Equipamiento empleado:}

$\checkmark \quad$ Material de carpintería (sierra sin fin o de banda, sierra de mesa, metro, etc)

$\checkmark \quad$ Equipos manuales de medición (xilohigrómetro de resistencia, calibre de 0,01 mm de precisión).

$\checkmark$ Máquina Universal de Ensayo (con el correspondiente implemento de ensayo): modelo ELIB - $100 \mathrm{~W}$ de la marca IBERTEST.

Otros materiales menores (pinzas, recipientes, etc).

Las probetas, dimensionadas como se indica en la Tabla 1 para los ensayos de dureza y durabilidad, fueron ensayadas acorde al diseño experimental planteado se muestran en la Tabla 11; el procedimiento que se detalla a continuación fue aplicado únicamente al material de procedencia española. 
Tabla 11. Diseño experimental en bloques del ensayo.

\begin{tabular}{cccccc}
\hline $\begin{array}{c}\text { TM } \\
\text { Tiempo* } \\
\text { (minutos) }\end{array}$ & 80 & 120 & 160 & 200 & Repeticiones* \\
\cline { 2 - 5 } & $10+2$ & $10+2$ & $10+2$ & $10+2$ & $40(8)$ \\
45 & $10+2$ & $10+2$ & $10+2$ & $10+2$ & $40(8)$ \\
90 & $10+2$ & $10+2$ & $10+2$ & $10+2$ & $40(8)$ \\
135 & $10+2$ & $10+2$ & $10+2$ & $10+2$ & $40(8)$ \\
180 & $40(8)$ & $40(8)$ & $40(8)$ & $40(8)$ & $160(32)$ \\
\hline
\end{tabular}

*TM 80-45: termo-tratamiento realizado a $80^{\circ} \mathrm{C}$ durante 45 minutos, y así sucesivamente; número de individuos: 10 probetas destinadas a cada tratamiento +2 probetas destinadas a la constatación de contenido de humedad por cada tratamiento.

Procedimiento empleado:

$\checkmark \quad$ Identificación de las probetas por tratamiento acorde a lo indicado en la Tabla 11.

$\checkmark$ Determinación del contenido de humedad (32 probetas) según lo indicado en el apartado 2.1.1.1.1, con la salvedad de que el peso final de la muestra fue tomado al finalizar cada tratamiento.

$\checkmark \quad$ Para el termo-tratamiento propiamente dicho se procedió calentando la estufa a cada temperatura de tratamiento, comenzando con la temperatura de $80^{\circ} \mathrm{C}$ y así sucesivamente. Lograda la temperatura deseada, fueron colocadas todas las probetas destinadas al tratamiento (40 probetas).

$\checkmark$ Cumplidos los 45 minutos de ensayo, fueron retiradas las 10 probetas pertenecientes a ese termo-tratamiento (por ejemplo: TM 80-45: $80^{\circ} \mathrm{C}$ durante 45 minutos) y las 2 probetas destinadas a la determinación del contenido de humedad; a los 45 minutos siguientes (90 minutos total), se retiraron las siguientes 10 probetas de ensayo (TM 80-90) y las 2 pertenecientes a la evaluación de $\mathrm{CH}$; así sucesivamente hasta terminar el ensayo retirando las últimas 12 probetas $(10+2$ de $\mathrm{CH})$ expuestas a la temperatura indicada durante un período de 180 minutos.

$\checkmark$ Este procedimiento fue realizado para las 4 combinaciones de temperatura/tiempo planteadas.

$\checkmark$ Culminado cada tratamiento, las probetas fueron dejadas en reposo en laboratorio y expuestas a las condiciones ambientales circundantes a fin de lograr su estabilización de temperatura y humedad (comprobado realizando pesadas sucesivas - en intervalos de $24 \mathrm{~h}$-, hasta que dos de ellas no superasen el 1/200 de la primera de ellas). 


\subsection{Termo-modificación: dureza}

En este apartado se detalla el procedimiento empleado para evaluar la modificación de la dureza de la madera a partir del material termo-tratado (apartado 2.2.1.1.1). Para ello, previamente se realizó el ensayo de dureza según lo indicado en el apartado 2.1.1.2.2 aplicando la norma UNE 56534:1977; estos valores fueron tomados como valores de referencia "testigo" del material sin tratamientos. Posteriormente se continuó como se indica a continuación:

\section{Procedimiento empleado:}

$\checkmark$ Realización del ensayo de dureza tal como se indica en el apartado 2.1.1.2.2, atendiendo a la norma UNE 56534:1977, en el material termo-modificado. .

$\checkmark$ Análisis de los resultados considerando material testigo y termo-modificado.

\subsection{Termo-modificación: durabilidad}

Para la realización de este ensayo se partió del material termo-modificado y ensayado a dureza, procediendo tal como se indica a continuación:

\section{Procedimiento empleado:}

$\checkmark \quad$ Realización de los ensayos de durabilidad según lo indicado en la sección 2.1.1.3.1 y 2.1.1.3.3 para hongos basidiomicetes y termitas, respectivamente. En este caso, como datos de referencia se emplearon los resultados obtenidos en el ensayo de durabilidad natural en madera de chopo.

$\checkmark$ Análisis de los resultados considerando material testigo y termo-modificado.

\subsubsection{Piezas macizas semi-estructurales (escala 1:5).}

\subsubsection{Ensayos no destructivos}

\subsection{Determinación del MOE a través de la frecuencia propia de} vibración en piezas en voladizo

Para la realización de estos ensayos se trabajó únicamente con material de procedencia española, con el número de piezas y dimensiones establecidas en la Tabla 2 para vibraciones inducidas transversales, procediendo tal como se indica a continuación: 


\section{Procedimiento empleado:}

$\checkmark$ Determinación de las dimensiones, peso y densidad acorde a lo indicado en el apartado 2.1.2.1.1.

$\checkmark$ Colocación de cada pieza en voladizo, esto es colocando un extremo empotrado y el otro extremo libre; para proporcionar las condiciones óptimas de rigidez las piezas fueron sujetas al soporte principal, con suplementos de madera y sujetadores, dejando libre la parte posterior a fin de permitir el desplazamiento de la pieza, tal como se indica esquemáticamente en la Figura 29.

$\checkmark$ Cada pieza fue ensayada en posición vertical (V), Figura 30, y horizontal (H), Figura 31, cuyas escuadrías, expresadas como base (b) x altura (h) fueron $40 \mathrm{~mm} \mathrm{x}$ $60 \mathrm{~mm}$ y $60 \mathrm{~mm}$ x $40 \mathrm{~mm}$, respectivamente; en cada orientación fueron realizadas 4 determinaciones (repeticiones) por longitud libre, totalizando 1008 ensayos (21 longitudes libres $\mathrm{x} 4$ repeticiones/longitud libre x 12 vigas).

$\checkmark \quad$ El ensayo se inició con una pieza ubicada de modo tal que su longitud libre inicial, Li, fuese de $500 \mathrm{~mm}$; en cada nueva posición la longitud fue aumentándose $25 \mathrm{~mm}$, d, hasta alcanzar los $1000 \mathrm{~mm}$ de longitud libre final, Lf. De este modo, cada viga fue ensayada en 21 longitudes libres diferentes.

$\checkmark \quad$ El ensayo de vibración propiamente dicho, fue realizado golpeando con un martillo perpendicularmente sobre la cara transversal de la pieza; el impacto fue registrado mediante un captador de señal, ubicado en la parte inferior del lugar del impacto, y a través de un analizador de ondas (FFT Analyzer) desde un ordenador se obtuvo la frecuencia de vibración $(f)$ de cada pieza. Previo a la realización del ensayo fueron seleccionados los parámetros de ensayo: rango de frecuencia: $7350 \mathrm{~Hz}$; nivel de ruidos y ecos: 10\%; LDD: 400.

$\checkmark$ Determinación del módulo de elasticidad dinámico, tal como se indica a continuación, y posterior análisis de resultados:

$$
\begin{gathered}
E=\left(\frac{f}{C_{n}}\right)^{2} \times \frac{\rho * \mathrm{~S} * \mathrm{~L}^{4}}{I} \\
C_{n}=\left(\frac{k_{n}}{L}\right)^{2}
\end{gathered}
$$

Dónde:

$f$ : frecuencia de vibración, en $\mathrm{Hz}$.

$C n-k n$ : factor que depende de la modalidad de vibración (mode 1: 1,875, mode 2: 4,694, mode 3: 7,855), adimensional.

E: módulo de elasticidad del material, en MPa. 
I: momento de inercia, en $\mathrm{m}^{4}$.

$\rho$ : densidad del material, en $\mathrm{Kg} / \mathrm{m}^{3}$.

$\mathrm{S}$ : área de la sección transversal, en $\mathrm{m}^{2}$.

L: longitud libre de la viga, en $\mathrm{m}$.

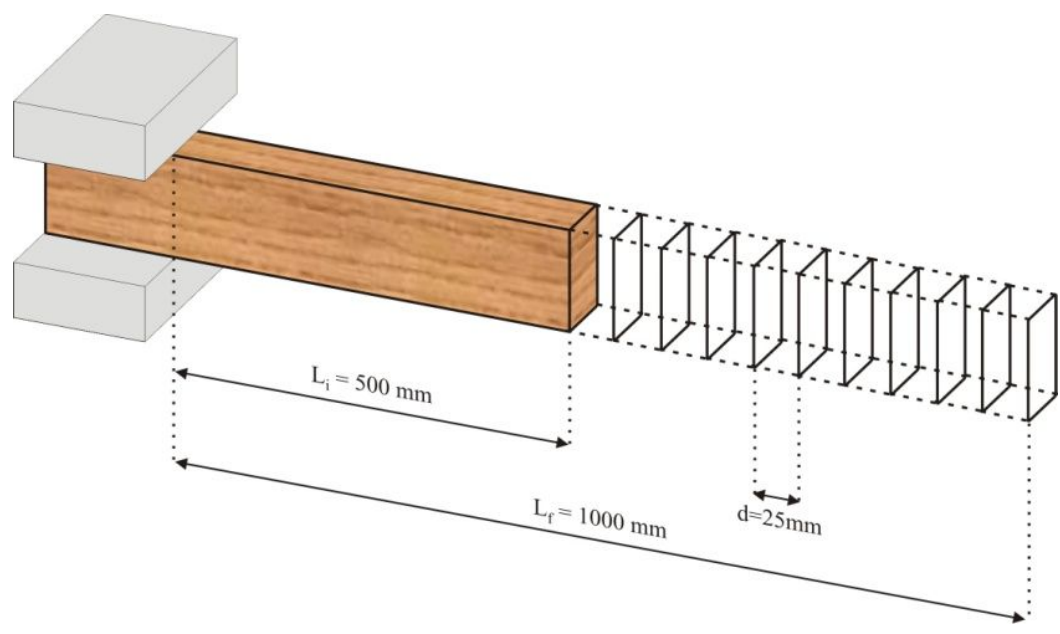

Figura 29. Esquema de pieza en voladizo: sujeción, longitud inicial y longitud final.

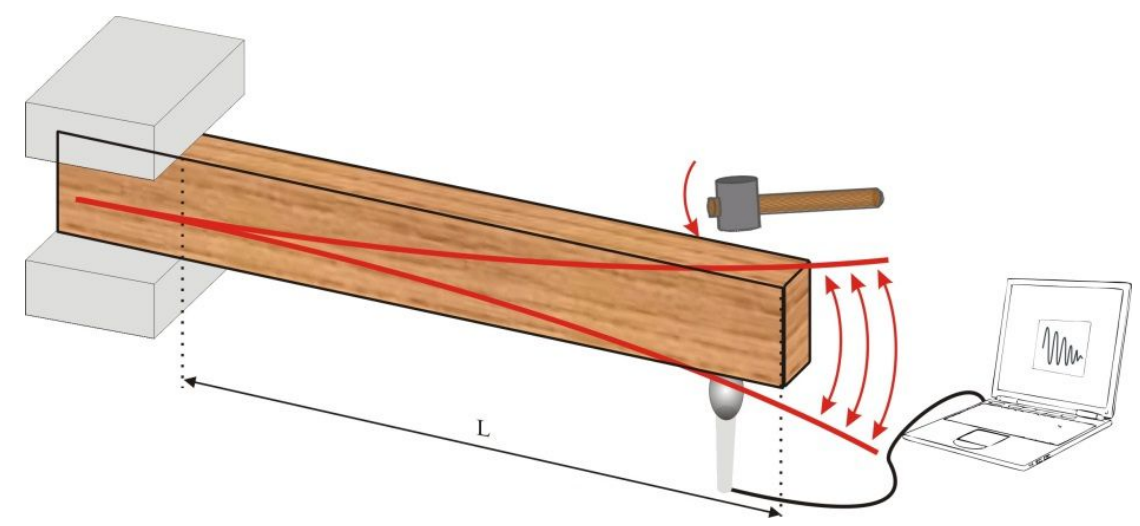

Figura 30. Esquema de pieza en voladizo: posición vertical (V).

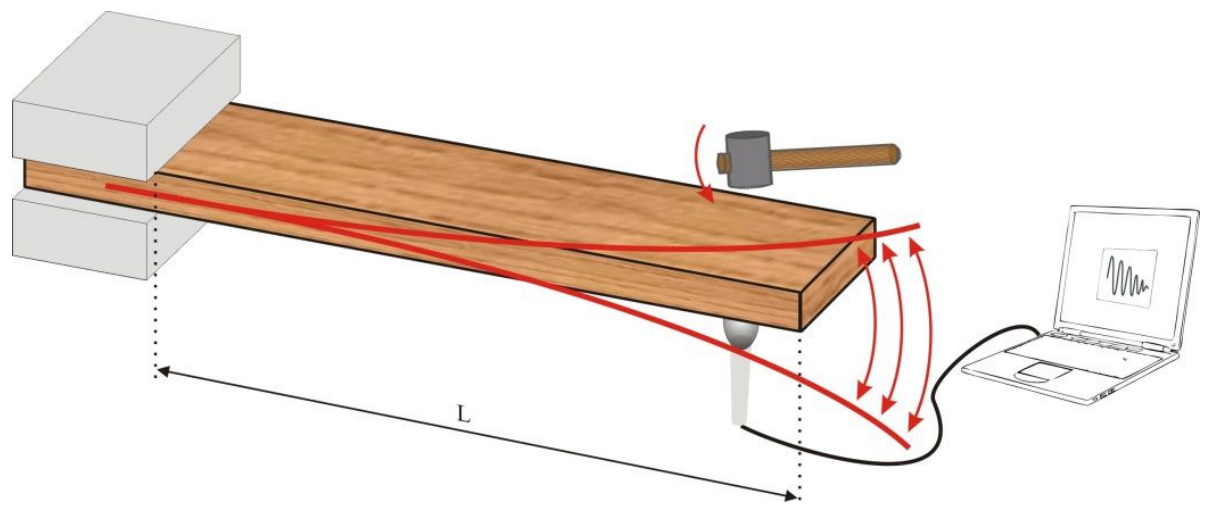

Figura 31. Esquema de pieza en voladizo: posición horizontal (H). 
Dado el inconveniente práctico presentado para conocer fehacientemente el modo de la frecuencia determinado durante el ensayo (principal, primer armónico, segundo armónico, etc), se recurrió a las herramientas de análisis modal establecidas en la bibliografía, a fin de determinar modos normales de vibración de una pieza de madera con un extremo libre. Para ello, la representación cartesiana de la pieza, indicando anchura: h, y de espesor: e, se muestra en la Figura 32.

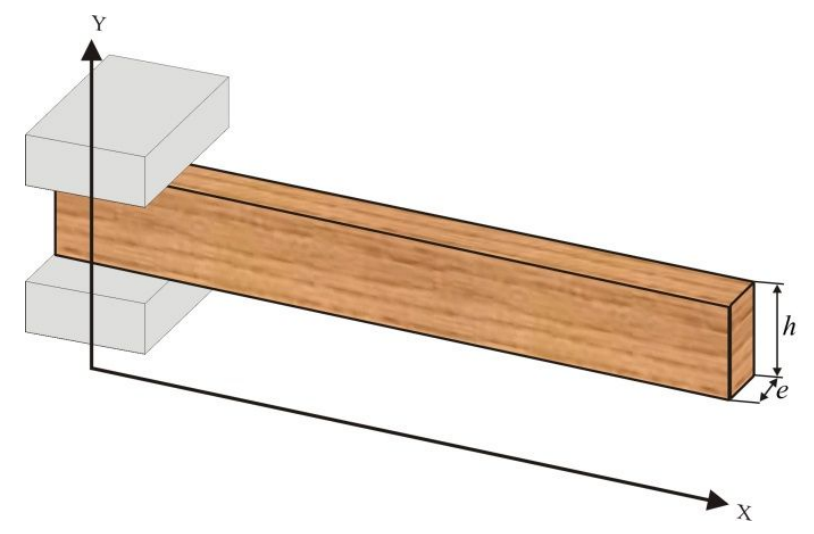

Figura 32. Viga en voladizo: representación cartesiana y escuadrías.

De esta manera, el análisis modal tiene lugar a partir de la solución general de la ecuación que describe las vibraciones de una barra, tomando en este caso, una pieza de madera

$$
\psi_{(x, t)}=y_{(x)} \operatorname{sen}(\psi t)
$$

La amplitud $y(x)$ de la vibración de los puntos " $\mathrm{x}$ " de la barra es la siguiente:

$$
y_{(x)}=A_{1} \operatorname{senh}(q x)+A_{2} \cosh (q x)+A_{3} \operatorname{senh}(q x)+A_{4} \cosh (q x)
$$

Dado que las condiciones de contorno cambian, el comportamiento también se modifica; la pieza está firmemente sujeta por su extremo izquierdo $\mathrm{x}=0$, $\mathrm{y}$ la pendiente en este punto es $d y / d x=0$, por lo que la expresión se establece como:

$$
\frac{d y}{d x}=q\left(A_{1} \cos h(q x)+A_{2} \operatorname{senh}(q x)+A_{3} \cos (q x)-A_{4} \operatorname{sen}(q x)\right)
$$

En el extremo derecho libre $\mathrm{x}=\mathrm{L}, y(L)$ y su pendiente $d y / d t$ no son cero, pero el momento y la fuerza son cero, lo que implica que $d^{2} y / d x^{2}=0$ y $d^{3} y / d x^{3}=0$, esto es:

$$
\begin{aligned}
& A_{1}(\operatorname{senh}(q L)+\operatorname{sen}(q L))+A_{2}(\cosh (q L)+\cos (q L))=0 \\
& A_{1}(\cosh (q L)+\cos (q L))+A_{2}(\operatorname{senh}(q L)-\operatorname{sen}(q L))=0
\end{aligned}
$$

Si se elimina $\mathrm{A}_{1} \mathrm{y} \mathrm{A}_{2}$, se obtiene una ecuación trascendente en $q L$ :

$$
\cosh (q L) \cos (q L)=-1
$$


Las raíces $r_{n}=q_{\mathrm{n}}{ }^{*} \mathrm{~L}$ de esta ecuación se calculan por el procedimiento numérico del punto medio, siendo sus primeros valores $r_{n}=1,875 ; 4,693 ; 7,855 ; 10,996 ; \ldots$

Conocido los valores posibles de $q_{\mathrm{n}}$ se calculan las frecuencias de vibración:

$$
\begin{gathered}
\omega_{n}=2 \pi f_{n} \\
f=\frac{r_{n}}{2 * \pi} * \sqrt{\frac{\left(E^{*} I\right)}{\rho^{*} S^{*} L^{4}}}=C_{n} * \sqrt{\frac{\left(E^{*} I\right)}{\rho^{*} S^{*} L^{4}}}
\end{gathered}
$$

Donde $f$ es la frecuencia del modo normal $\mathrm{n}$ de vibración y $C_{n}$ es un coeficiente que corresponde a este modo; en la Tabla 12 se muestra el comportamiento y los valores de $C_{n}$ en tres modos frecuenciales.

Tabla 12. Valores de $C n$ según modo de vibración.

\begin{tabular}{clll}
\hline & Modo 1* & Modo 2* & Modo 3* \\
\hline Voladizo & & $C_{2}: 3,51$ & $C_{3}: 9,82$ \\
\hline
\end{tabular}

*Modo 1: modo fundamental; Modo 2: primer armónico; Modo 3: segundo armónico...

Considerando que el coeficiente $C_{n}$ es independiente de las características de la pieza y que el término, bajo la raíz, depende del material y de las dimensiones de la pieza, si se linealiza la ecuación (30) representando $f^{2}$ en función de $1 / \mathrm{L}^{4}$, se obtiene la siguiente expresión:

$$
f^{2}=\frac{C_{n}^{2 *} E^{*} I}{\rho * S} * \frac{1}{L^{4}}
$$

Reemplazando en (39) el primer término de la ecuación $\frac{C_{n}{ }^{2 *} E^{*} I}{\rho^{*} S}$ por $\mathrm{a}_{1} \mathrm{y}$ el segundo término $\frac{1}{L^{4}}$ por $\mathrm{x}$, dicha ecuación podría resumirse como la ecuación de una recta:

$$
\begin{gathered}
f^{2}=a_{1} * x+b_{1} \\
y=a_{1} * x+b_{1}
\end{gathered}
$$

Donde $b_{1}$, puede considerarse 0 (cero).

Igualando ambas ecuaciones, se obtiene (42).

$$
E=\frac{a_{1} * \rho * S}{C_{n}{ }^{2} * I}
$$




\subsubsection{Ensayos destructivos}

\subsection{Evaluación elasto-resistente en piezas dúos y tríos.}

Para la evaluación del comportamiento de Populus $x$ euramericana I-214, como material encolado, se procedió tal como se indica a continuación:

\section{Procedimiento empleado:}

$\checkmark$ Reprocesamiento del material para la obtención de "piezas parte" dimensionadas según se especifica en el apartado 1.3.4, para piezas dúos y tríos.

$\checkmark$ Secado de las piezas en laboratorio hasta humedad de equilibrio higroscópico, evaluada mediante xilohigrómetro digital.

$\checkmark$ Inspección visual, registro/medición de las singularidades y determinación de las dimensiones y peso de cada pieza, según lo especificado en la sección 2.1.2.1.1.

$\checkmark \quad$ Encolado de las piezas partes, para lo cual se empleó adhesivo a base de resina epoxi bi-componente dispensada sobre cada pieza sujeta a encolar; dichas piezas partes fueron seleccionadas al azar y colocadas en posición vertical, Figura 33 y Figura 34. Para lograr la correcta adherencia entre partes, y consecuentemente una adecuada pieza dúo o trío, se empleó una prensa diseñada para tal fin.

$\checkmark$ Realización del ensayo de flexión estática en máquina Universal de ensayo y determinación del parámetro elástico y resistente según lo especificado en 2.1.2.2.

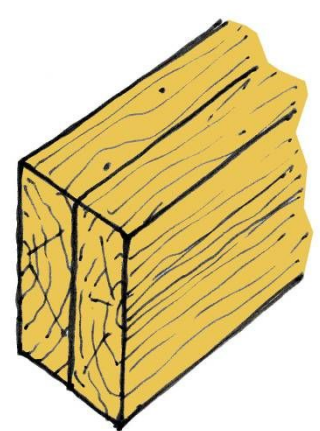

Figura 33. Piezas encoladas dúo. Fuente: Basterra, 2011.

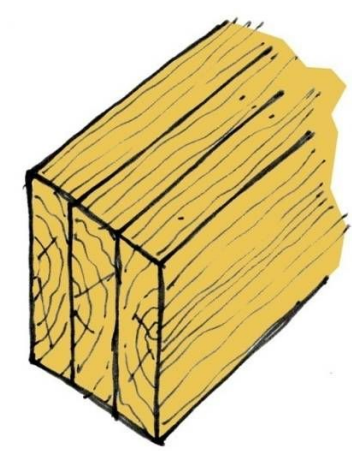

Figura 34. Piezas encoladas trío. Fuente: Basterra, 2011.

\subsubsection{Piezas macizas estructurales.}

\subsubsection{Mejora norma de clasificación visual.}

Partiendo de los datos obtenidos mediante el análisis de clasificación visual y mediante la evaluación elasto-resistente no destructiva y destructiva, se propondrá una mejora en la norma de clasificación visual española. En primer término, partiendo de la premisa de incorporar (ó reincorporar) a la especie Populus $x$ euramericana I-214 en dicha norma; luego se plantearan las 
modificaciones de los parámetros actualmente considerados en la norma de Clasificación Visual española UNE 56544: 2011, que se consideren pertinente, como así también se evaluará la incorporación de nuevos parámetros. En el primer caso, para evaluar la readaptación de los parámetros se partirá de los criterios planteados en la norma UNE 56544: 2011 vigente, Tabla 13.

Posteriormente, se realizará un análisis mediante tabulación cruzada para evaluar la respuesta clasificatoria de la norma propuesta con respecto a la norma de clase resistente. El desarrollo sobre estos análisis estadísticos se detalla en el apartado 3.

Tabla 13. Norma UNE 56544: 2011: criterios de clasificación visual.

\begin{tabular}{|c|c|c|c|}
\hline \multicolumn{2}{|c|}{ Criterios de calidad } & Clase I & Clase II \\
\hline \multicolumn{2}{|c|}{ Diámetros nudo de cara } & $\mathrm{d} \leq 1 / 5 \mathrm{de}$ "h" & $\mathrm{d} \leq 1 / 2 \mathrm{de}$ "h" \\
\hline \multicolumn{2}{|c|}{ Diámetro nudos de canto } & $\mathrm{d} \leq 1 / 2 \mathrm{de}$ "b" y d $\leq 30 \mathrm{~mm}$ & $\mathrm{~d} \leq 2 / 3 \mathrm{de}$ "b" \\
\hline \multicolumn{2}{|c|}{ Anchura de anillos ${ }^{(1)}$} & $\begin{array}{l}\leq \mathrm{a} 4-10 \mathrm{~mm} \text { (dependiendo de } \\
\text { la especie de pino considerada) }\end{array}$ & $\underline{\text { Sin limitación }}$ \\
\hline \multirow{3}{*}{ Fendas } & \multirow[b]{2}{*}{ De secado $^{(2)(3)}$} & $\mathrm{f}<2 / 5$ & $\mathrm{f} \leq 3 / 5$ \\
\hline & & \multicolumn{2}{|c|}{$\begin{array}{l}\text { Las fendas de secado sólo se consideran si su longitud es mayor que } \\
\text { la menor de las dimensiones siguientes: } 1 / 4 \text { de la longitud de las } \\
\text { piezas y } 1 \mathrm{~m} \text {. }\end{array}$} \\
\hline & Entrecasco & \multicolumn{2}{|c|}{ Se admiten si su longitud es $\leq$ a 1,5 de "h" } \\
\hline \multicolumn{2}{|c|}{ Desviación de las fibras } & $1: 10(10 \%)$ & $1: 6(16,7 \%)$ \\
\hline \multirow[b]{2}{*}{ Gemas } & Longitud & $\leq 1 / 4 \mathrm{de}^{\prime \prime} \mathrm{L} "$ & $\leq 1 / 3 \mathrm{de}^{\prime}$ "L" \\
\hline & $\begin{array}{l}\text { Dimensión } \\
\text { relativa }\end{array}$ & $\mathrm{g} \leq 1 / 4$ & $\mathrm{~g} \leq 1 / 3$ \\
\hline \multicolumn{2}{|c|}{ Médula } & $\begin{array}{l}\text { Admitida } \\
\text { No admitida si se clasifica en } \\
\text { húmedo }\end{array}$ & Admitida \\
\hline $\begin{array}{r}\text { Alterac } \\
\text { (pudrición- }\end{array}$ & $\begin{array}{l}\text { biológicas } \\
\text { ías de insectos) }\end{array}$ & \multicolumn{2}{|c|}{ No admitidas } \\
\hline \multicolumn{4}{|c|}{ Deformaciones máximas ${ }^{(2)(3)(4)}$} \\
\hline \multicolumn{2}{|c|}{ Curvatura de cara } & $\begin{array}{c}10 \mathrm{~mm} \text { para una longitud de } 2 \\
\text { metros }\end{array}$ & $\begin{array}{c}20 \mathrm{~mm} \text { para una longitud de } 2 \\
\text { metros }\end{array}$ \\
\hline \multicolumn{2}{|c|}{ Curvatura de canto } & $\begin{array}{c}8 \mathrm{~mm} \text { para una longitud de } 2 \\
\text { metros }\end{array}$ & $\begin{array}{c}12 \mathrm{~mm} \text { para una longitud de } 2 \\
\text { metros }\end{array}$ \\
\hline \multicolumn{2}{|c|}{ Alabeo } & $\begin{array}{l}1 \mathrm{~mm} \text { por cada } 25 \mathrm{~mm} \text { de "h" } \\
\text { para una longitud de } 2 \text { metros }\end{array}$ & $\begin{array}{c}2 \mathrm{~mm} \text { por cada } 25 \mathrm{~mm} \text { de h para } \\
\text { una longitud de } 2 \text { metros }\end{array}$ \\
\hline \multicolumn{2}{|c|}{ Abarquillado } & \multicolumn{2}{|c|}{ Sin limitación } \\
\hline
\end{tabular}

\footnotetext{
${ }^{(1)}$ Criterios considerados únicamente cuando se comercializa en húmedo; ${ }^{(2)}$ Criterios considerados únicamente cuando la clasificación se efectúa en húmedo; ${ }^{(3)}$ Referidas a un $20 \%$ de contenido de humedad; ${ }^{(4)}$ Pueden aceptarse deformaciones mayores siempre que no afecten a la estabilidad de la construcción (porque puedan corregirse durante la fase del montaje) y exista acuerdo expreso al respecto entre el suministrador y el cliente.
}

NOTA: solo se mencionan los factores sujetos a modificación en la propuesta de norma que se planteará en resultados y discusión. 


\subsubsection{Procedimiento para control triboluminiscente de sobrecarga en madera estructural. Patente P201400866}

Con esta patente se pretende mejorar la fiabilidad de la madera en servicio, generando un "indicador" de su estado resistente en obra. La misma pretende ser de aplicación a diversas especies madereras, con lo cual, para el caso del presente trabajo, sería adaptable al Populus $x$ euramericana I-214. En Resultados y Discusión se presentará el proyecto presentado y en Anejos el comprobante de solicitud de la misma.

\section{ANÁLISIS ESTADÍSTICO}

El análisis estadístico utilizado se realizó a través de los programas Statgraphics Centurion XVI.I y Statistica (versión 2010), ambos con licencia de la Universidad de Valladolid. El primer paso consistió en plasmar los resultados básicos a través de la Estadística Descriptiva, mediante la cual se llevó a cabo el recuento, ordenación y clasificación de los datos obtenidos de las observaciones/ensayos. Para ello, se calcularon parámetros estadísticos que permitieron caracterizar las distintas variables planteadas como así también la distribución de la población. Del mismo modo, se utilizaron tablas y gráficos que permitieron definir, resumir y simplificar la complejidad de los datos y sus distribuciones.

Las tablas resumen de cada variable analizada se constituyen por medidas de centralidad (media, mediana, percentiles, mínimos y máximos), medidas de dispersión (rango o recorrido intercuartílico, desviación estándar), medidas de forma (coeficiente de variación, curtosis estandarizada, sesgo estandarizado), medidas de relación entre variables (coeficiente de regresión, de correlación, entre otros).

Los parámetros que no se mencionan en resultados y discusión son ampliados en tablas resumen en el capítulo de Anejos.

Entre los gráficos empleados para describir la distribución de todas variables medidas, se han utilizado los gráficos de "Caja y Bigotes" ó "Box-Plot", Figura 35, los histogramas de frecuencia y los gráficos de dispersión. Los gráficos que no se presentan en resultados y discusión se presentan en el capítulo de Anejos. 


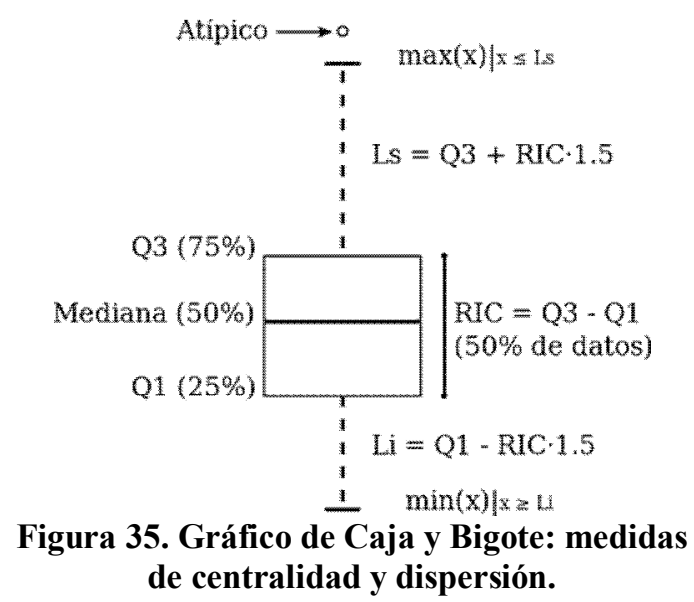

Para la verificación de las hipótesis de normalidad de los datos pertenecientes a cada variable, paso fundamental para la aplicación de los procedimientos estadísticos habituales, se realizaron las constataciones de los supuestos de independencia, normalidad y homocedasticidad. Para ello se utilizaron las pruebas de normalidad de Chi-Cuadrado, Estadístico W de Shapiro-Wilk, Valor-Z para asimetría y/o Valor-Z para curtosis, como así también las pruebas de Bondad de Ajuste de Kolmogorov-Smirnov y el apoyo gráfico del Histograma de Frecuencias. Del mismo modo, el Test de Levene fue empleado para evaluar la hipótesis de igualdad de desviaciones estándar.

En todos los casos, se trabajó con la Hipótesis Nula (Ho) de igualdad de medias, medianas y/o desviaciones estándar, con un nivel de confianza del 95\% y con un valor de probabilidad (P-valor) de 0,05\%, por debajo del cual se rechaza dicha hipótesis nula de igualdad, aceptando la hipótesis alternativa de desigualdad de medias, medianas y/o desviaciones estándar. Si bien no se profundizará más sobre este tema, en el capítulo de Anejos, se recogerán los resultados de los análisis que no son presentados en el capítulo de resultados y discusión.

Ante la no constatación de los supuestos de normalidad en las observaciones de las variables en estudio, se procedió a realizar su transformación y el posterior análisis descriptivo de las mismas, cuyos resultados generalmente serán mostrados en Anejos.

Una vez constatados los supuestos y transformadas las variables, en caso que correspondiera, se continuó con el análisis mediante Estadística Inferencial.

Para ello, cuando los supuestos estadísticos fueron aceptados, se trabajó con análisis de la varianza (ANOVA), que proporciona información sobre si las diferencias entre las medias de distintas poblaciones o grupos son significativas, esto es, superior a la variabilidad normal dentro de cada población o grupo. En este análisis, se realiza el planteamiento de la Hipótesis Nula (Ho) mediante la cual se afirma que todas las muestras proceden de la misma población, y que por lo tanto sus medias no difieren significativamente; sus diferencias se explican 
adecuadamente por el error muestral, esto es, por la variabilidad normal que es posible encontrar en cualquier grupo (García-Pérez, 2005; Ruiz-Maya Pérez, 1986; Tukey, 1977; Levene, 1960). Asimismo, el mero análisis de varianza no muestra directamente entre qué grupos se encuentra la diferencia; por lo que posteriormente se comparan los grupos, dos a dos, mediante procedimientos de contrastes. En este sentido, se utilizaron dos tipos de pruebas estadísticas: test de Tukey HSD y test Unequal N HSD, para poblaciones balanceadas o desbalanceadas, respectivamente.

El test de Tukey HSD (también denominado de "diferencia significativa honesta") determina las diferencias significativas entre pares de medias siendo un test muy conservador dado que cuando los valores promedio son muy próximos no detectan diferencias significativas que otros sí detectarían; o lo que es lo mismo, acepta menos diferencias significativas de las que realmente pudieran existir. Las diferencias se establecen para un valor de $p<0,05$, es decir, se tiene un 5\% de probabilidad de error en las conclusiones, por lo cual la probabilidad de error es baja. Dicho en otros términos, esto representa una seguridad del $95 \%$ que la asociación que estamos estudiando no sea debida al azar (Tukey, 1977).

El Test Unequal N HSD es una modificación del método de Tukey HSD y proporciona un análisis razonable, si las diferencias en el tamaño de los grupos no son muy relevantes (Winer et al., 1991).

Cuando los supuestos estadísticos no fueron aceptados, se utilizó el test no paramétrico de Kruskal Wallis, que realiza comparaciones entre pares de medianas; en este caso, la Hipótesis Nula (Ho) plantea que las medianas son iguales, o lo que es lo mismo, que las medianas no difieren entre sí. Cuando se evidenciaron diferencias significativas entre tres o más medianas, se realizó el mismo test (Kruskal-Wallis) considerando las medianas por pares para evaluar entre cuales de ellas existían diferencias significativas.

Asimismo, para evaluar el comportamiento clasificatorio de cada norma de clasificación visual (según las categorías CS, CI y rechazo) comparativamente con la norma de clase resistente (EN 338:2010), como así también el comportamiento clasificatorio según metodología no destructiva (Estructural y No Estructural) comparando con dicha normativa resistente, se utilizó la metodología de Tabulación cruzada con escala ordinal (dado que se trabajó con rangos clasificatorios) obteniendo de este modo, el correspondiente porcentaje de aciertos, subestimas y sobreestimas.

Para ajustar y relacionar las variables obtenidas mediante metodología no destructiva y destructiva, se trabajó con modelos de regresión lineal simple y/o múltiple. En términos generales en un modelo de regresión, una variable respuesta $(\mathrm{Y})$ se expresa en función de una o más variables predictoras, más un componente del error. La finalidad de dicho análisis es 
contribuir con un modelo que describa las relaciones que existen entre las variables de tal manera que sea posible predecir $(\mathrm{Y})$ para valores conocidos de $(\mathrm{X})$ y que contenga las $(\mathrm{X})$ necesarias para generar buenas predicciones. Los ajustes son evaluados acorde al coeficiente de determinación $\mathrm{R}^{2}$ ajustado, según los rangos estimados presentados en la Tabla 14.

Tabla 14. Coeficiente de determinación $\left(\mathbf{R}^{2}\right)$.

\begin{tabular}{cc}
\hline Ajuste & Coeficiente de determinación $\left(\mathrm{R}^{2}\right)$ \\
\hline Muy débil, despreciable & $0 \%-4 \%$ \\
\hline Débil, bajo & $4 \%-16 \%$ \\
\hline Moderado & $16-19 \%$ \\
\hline Fuerte, importante & $49-81 \%$ \\
\hline Muy fuerte, muy alto & $81-100 \%$ \\
\hline
\end{tabular}

Para ello, previamente se deben constatar las premisas de linealidad de las relaciones, homocedasticidad y normalidad de los residuos. Se denomina "residuos" a las diferencias entre los valores de la variable dependiente observados y los valores que se predicen a partir de la recta de regresión. En este sentido, el diagrama de dispersión -scatterplot- de residuos permite detectar curvilinealidad (Figura 36), heterocedasticidad (Figura 37) y normalidad, en este último caso apoyado también en el histograma de residuos.

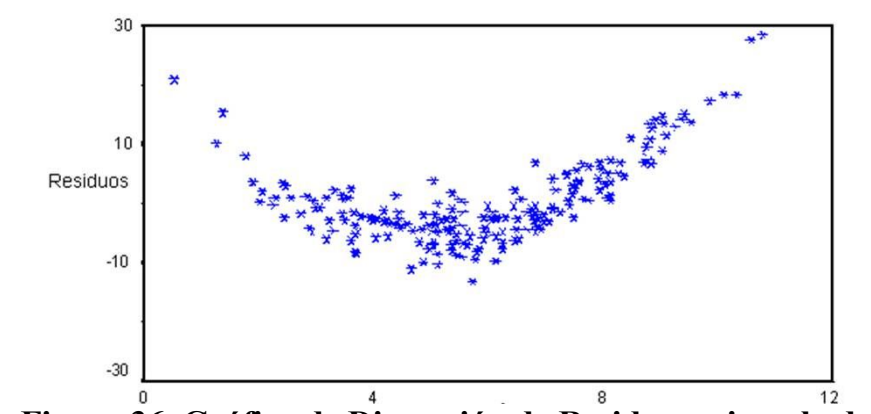

Figura 36. Gráfico de Dispersión de Residuos: ejemplo de ajuste no lineal o curvilíneo. Fuente: Vilar Fernández, 2006.

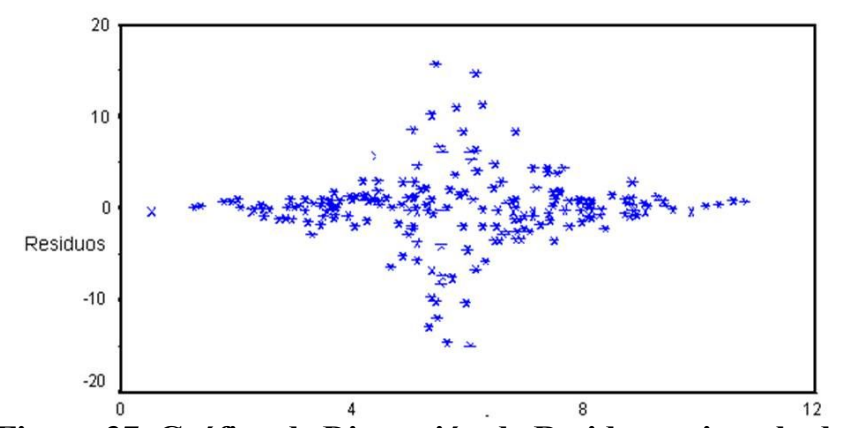

Figura 37. Gráfico de Dispersión de Residuos: ejemplo de heterocedasticidad. Fuente: Vilar Fernández, 2006.

Asimismo, los "residuos estudentizados" procuran explicar cuáles son las observaciones que están más alejadas al valor previsto o bien, qué determinaciones (valores) son erróneas. Para 
ello, cada residuo i-ésimo es dividido por la desviación estándar de todos los residuos salvo el iésimo que está siendo considerado.

Asimismo, a fin de evaluar la capacidad predictiva de las variables no destructivas en los valores resistentes establecidos por la norma EN 338:2010, se utilizó el modelo de regresión múltiple para determinar los valores de "corte" de las variables no destructivas (velocidad de ultrasonido y frecuencia vibratoria) a emplear en cada clase (Estructural y No Estructural).

Para analizar la influencia de las singularidades (factores) en las variables físicomecánicas estudiadas, se analizaron las relaciones existentes mediante la correlación Ordinal de Spearman. Dicho análisis permite medir la correlación o asociación de dos variables y es aplicable cuando las mediciones se realizan en una escala ordinal, aprovechando la clasificación por rangos. El coeficiente de correlación de Spearman se rige por las reglas de la correlación simple de Pearson, y las mediciones de este índice corresponden de $+1 \mathrm{a}-1$, pasando por el cero, donde este último significa no correlación entre las variables estudiadas, mientras que los dos primeros denotan la correlación máxima en diferentes sentidos, Tabla 15.

Tabla 15. Coeficiente de correlación de Pearson/Spearman.

\begin{tabular}{cc}
\hline Coeficiente de Pearson/Spearman (r) & Correlación \\
\hline $0-0,20$ & Muy débil, despreciable \\
\hline $0,20-0,40$ & Débil, baja \\
\hline $0,40-0,70$ & Moderada \\
\hline $0,70-0,90$ & Fuerte, importante \\
\hline $0,90-1$ & Muy fuerte, muy alta \\
\hline
\end{tabular}

Dicho coeficiente se presenta asociado a un P-valor que prueba la significancia estadística de las correlaciones estimadas: P-valores por debajo de 0,05 indican correlaciones significativamente diferentes de cero, con un nivel de confianza del 95,0\%. Es importante resaltar que en una relación, un nivel de significación bajo, no significa una asociación fuerte, sólo indica que existe una fuerte evidencia de que hay alguna asociación.

Asimismo, la existencia de una correlación no indica una relación causa-efecto ya que el coeficiente se limita a indicar la fuerza de la asociación y en qué sentido se da, mediante un único número, tratando las variables de modo simétrico.

En este sentido, de acuerdo con el incumplimiento de los supuestos estadísticos para los factores cuantitativos: diámetro relativo de nudos de cara y de canto, anchura de anillos, anchura y longitud de gemas, curvatura de cara y canto y alabeo, previo al análisis de correlación entre dichas singularidades y las variables físico-mecánicas, se establecieron los rangos clasificatorios, agrupando las singularidades, tal como se indican a continuación. 
Tabla 16. Grupos de singularidades e intervalos clasificatorios.

\begin{tabular}{|c|c|c|c|}
\hline $\begin{array}{c}\text { Grupos de } \\
\text { singularidades }\end{array}$ & Singularidades & $\begin{array}{l}\text { Tipo de } \\
\text { factor }\end{array}$ & Intervalo clasificatorio \\
\hline \multirow{5}{*}{$\frac{\text { Ligadas a la anatomía de }}{\underline{\text { la madera (Figura 38) }}}$} & Anchura de anillos (mm) & Contínuo & - \\
\hline & Entrecasco & Categórico & Sí / No \\
\hline & $\begin{array}{l}\text { Nudos de cara } \\
\left(\phi^{*} 100 / \mathrm{h}\right)^{*}(\%)\end{array}$ & Categórico & $\begin{array}{c}1:<33 \% ; 2: \text { entre } 33 \% \text { y } 66 \% ; 3: \\
>66 \%\end{array}$ \\
\hline & $\begin{array}{l}\text { Nudos de canto } \\
\left(\phi^{*} 100 / \mathrm{b}\right) *(\%)\end{array}$ & Categórico & $\begin{array}{c}1:<33 \% ; 2: \text { entre } 33 \% \text { y } 66 \% ; 3: \\
>66 \%\end{array}$ \\
\hline & $\begin{array}{c}\text { Desviación de las fibras } \\
(\%)\end{array}$ & Categórico & $\begin{array}{c}0: \text { ausencia; } 1:<7 \% ; 2: \text { entre } 7 \% \\
\text { y } 15 \% ; 3:>15 \%\end{array}$ \\
\hline \multirow{3}{*}{$\frac{\text { Ligadas al proceso de }}{\underline{\text { aserrado (Figura 39) }}}$} & Médula & Categórico & Sí / No \\
\hline & Anchura de gemas (mm) & Categórico & $\begin{array}{c}0: \text { ausencia; } 1:<33 \% ; 2: \text { entre } \\
33 \% \text { y } 66 \% ; 3:>66 \%\end{array}$ \\
\hline & $\begin{array}{l}\text { Longitud de gemas } \\
(\mathrm{mm})\end{array}$ & Categórico & $\begin{array}{c}0: \text { ausencia; } 1:<33 \% ; 2: \text { entre } \\
33 \% \text { y } 66 \% ; 3:>66 \%\end{array}$ \\
\hline \multirow{3}{*}{$\frac{\underline{\text { Ligadas al proceso de }}}{\text { secado: deformaciones }}$} & Curvatura de canto (mm) & Categórico & $\begin{array}{c}0: \text { ausencia; } 1:<10 \mathrm{~mm} ; 2: \text { entre } \\
10 \text { y } 20 \mathrm{~mm} ; 3:>20 \mathrm{~mm}\end{array}$ \\
\hline & Curvatura de cara (mm) & Categórico & $\begin{array}{c}\text { 0: ausencia; } \mathbf{1 :}<10 \mathrm{~mm} ; \mathbf{2}: \text { entre } \\
10 \text { y } 20 \mathrm{~mm} ; \mathbf{3 :}>20 \mathrm{~mm}\end{array}$ \\
\hline & Alabeo $(\mathrm{mm})$ & Categórico & $\begin{array}{c}\text { 0: ausencia; 1: < } 6 \mathrm{~mm} ; \mathbf{2}: \text { entre } \\
6 \text { y } 12 \mathrm{~mm} ; \mathbf{3 :}>12 \mathrm{~mm} .\end{array}$ \\
\hline
\end{tabular}

* $\phi=$ Diámetro; $\mathrm{h}=$ anchura; $\mathrm{b}=$ espesor.

Singularidades ligadas a la anatomía de la madera, Figura 38.

Anchura de anillos: se determinó el valor medio de los primeros 5 anillos de crecimiento más cercanos a la médula.

Entrecasco: se registró su presencia (Sí) ó ausencia (No).

Nudos (cara y canto): de acuerdo con las mediciones registradas tal como se indica en el apartado 2.1.2.1.1: Inspección y medición de singularidades, el análisis fue llevado a cabo mediante dos consideraciones generales: cualitativas y cuantitativas, Tabla 16.

\section{Consideraciones cualitativas}

Por existencia

0: "Ausencia de nudos"

1: "Presencia de nudos"

Por existencia y ubicación

Para este análisis se consideró la influencia de la presencia y ubicación de los nudos según las siguientes categorías, bajo la variable denominado "Nudos":

0: "Ausencia de nudos"

1: "Presencia solo de nudos de cara"

2: "Presencia sólo de nudos de canto"

3: "Presencia de nudos de cara y canto". 


\section{Consideraciones cuantitativas}

\section{Por tamaño}

Para ello se establecieron, para los nudos de cara, los siguientes rangos:

1: para aquellos nudos (relación entre la dimensión del diámetro (en \%) y la anchura de la pieza $\left.=\phi^{*} 100 / \mathrm{h}\right)$ que ocupan menos del $33 \%$ de la cara.

2: para aquellos nudos (relación entre la dimensión del diámetro (en \%) y la anchura de la pieza $=\phi^{*} 100 / \mathrm{h}$ ) que ocupan entre el 33 y el $66 \%$ de la cara.

3: para aquellos nudos (relación entre la dimensión del diámetro (en \%) y la anchura de la pieza $=\phi^{*} 100 / \mathrm{h}$ ) que ocupan el $66 \%$ de la cara.

Para los nudos de canto, los 3 rangos se establecieron como se indica a continuación:

1: para aquellos nudos (relación entre la dimensión del diámetro (en \%) y el espesor de la pieza $\left.=\phi^{*} 100 / \mathrm{b}\right)$ que ocupan menos del $33 \%$ del canto.

2: para aquellos nudos (relación entre la dimensión del diámetro (en \%) y el espesor de la pieza $=\phi^{*} 100 / \mathrm{b}$ ) que ocupan entre el 33 y el $66 \%$ del canto.

3: para aquellos nudos (relación entre la dimensión del diámetro (en \%) y el espesor de la pieza $=\phi^{*} 100 / \mathrm{b}$ ) que ocupan el $66 \%$ del canto.

Desviación de las fibras/grano inclinado: de acuerdo con las determinaciones planteadas en 2.1.2.1.1, se establecieron 4 categorías como se indica a continuación:

0: ausencia de desviación

1: Desviación de " $x$ " con respecto a " $y$ ", inferior al 7\%.

2: Desviación de "x" con respecto a " $y$ ", entre el 7 y el $15 \%$.

3: Desviación de " $x$ " con respecto a " $y$ ", superior al $15 \%$.

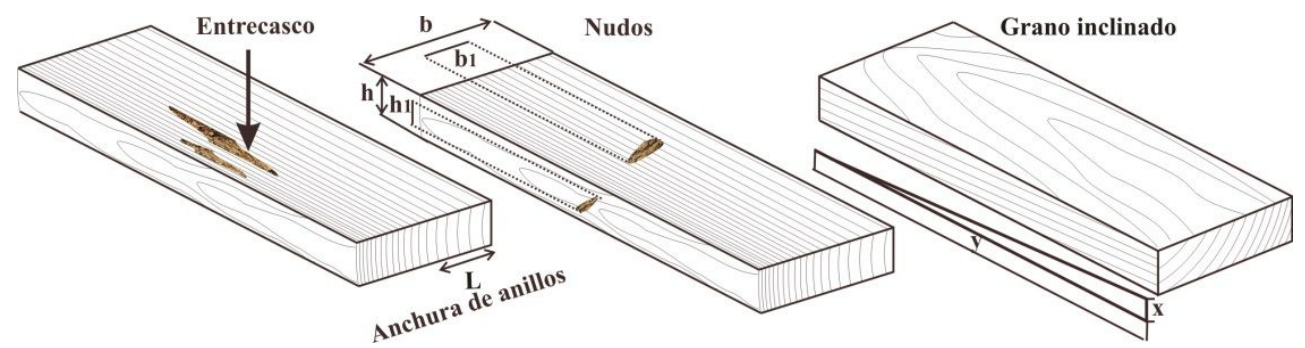

Figura 38. Singularidades ligadas a la anatomía de la madera.

Singularidades ligadas al proceso de aserrado, Figura 39.

Médula: se registró su presencia (Sí) ó ausencia (No). 
Anchura de gemas: de acuerdo con las mediciones realizadas (apartado 2.1.2.1.1: Inspección y medición de singularidades), se establecieron 4 categorías según se indica a continuación:

0: ausencia de gemas en la cara o canto.

1: relación b1/b inferior al $33 \%$ de la cara o el canto.

2: relación b1/b entre el 33 y el $66 \%$ de la cara o el canto.

3: relación b1/b superior al $66 \%$ de la cara o el canto.

Longitud de gemas: de acuerdo con las mediciones realizadas (apartado 2.1.2.1.1: Inspección y medición de singularidades), se establecieron 4 categorías según se indica a continuación:

0: ausencia de gemas en la cara o canto.

1: relación 1/L inferior al 33\% de la cara o el canto.

2: relación 1/L entre el 33 y el $66 \%$ de la cara o el canto.

3: relación 1/L superior al $66 \%$ de la cara o el canto.
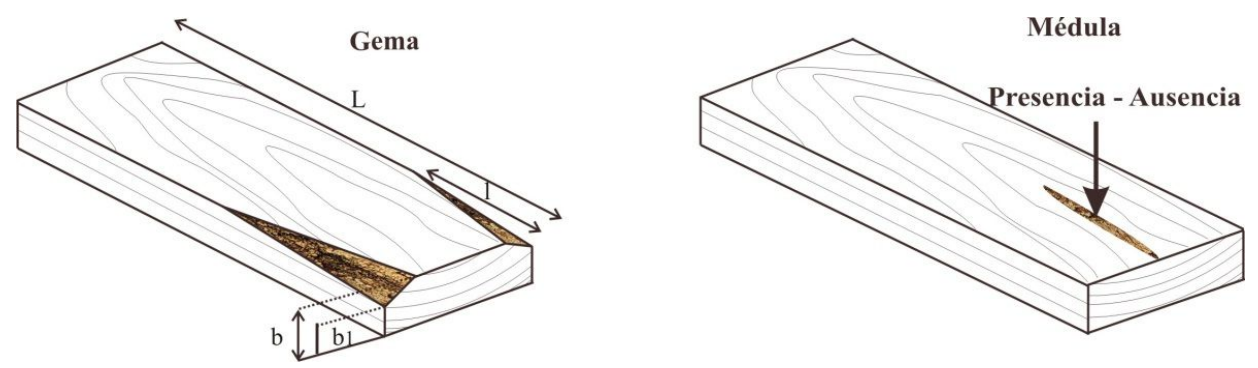

Figura 39. Singularidades ligadas al proceso de aserrado.

Singularidades ligadas al proceso de secado: deformaciones, Figura 40.

Curvatura de canto: de acuerdo con las mediciones realizadas, según lo planteado en el apartado 2.1.2.1.1: Inspección y medición de singularidades, se establecieron 4 categorías según se indica a continuación:

0: ausencia de curvatura de canto.

1: a inferior a $10 \mathrm{~mm}$.

2: a se encuentra entre $10 \mathrm{~mm}$ y $20 \mathrm{~mm}$.

3: a superior a $20 \mathrm{~mm}$.

Curvatura de cara: de acuerdo con las mediciones realizadas, apartado 2.1.2.1.1: Inspección y medición de singularidades, se establecieron 4 categorías según se indica a continuación:

0: ausencia de curvatura de cara.

1: a inferior a $10 \mathrm{~mm}$. 
2: a se encuentra entre $10 \mathrm{~mm}$ y $20 \mathrm{~mm}$.

3: a superior a $20 \mathrm{~mm}$.

Alabeo: según las mediciones realizadas acorde con lo expresado en el apartado

2.1.2.1.1: Inspección y medición de singularidades, se plantean las siguientes categorías:

0: ausencia de alabeo.

1: a inferior a $6 \mathrm{~mm}$.

2: a se encuentra entre $6 \mathrm{~mm}$ y $12 \mathrm{~mm}$.

3: a superior a $12 \mathrm{~mm}$.

Curvatura de canto

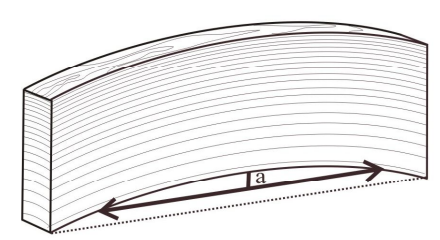

Curvatura de cara

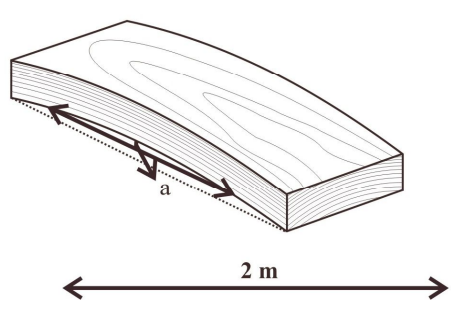

Alabeo

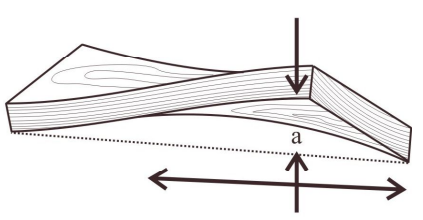

Figura 40. Singularidades ligadas al proceso de secado: deformaciones. 


\section{CAPITULO IV. RESULTADOS Y DISCUSIÓN}

"We may use wood with intelligence only if we understand wood", Wright, F.L., 1928.

\section{SECCIÓN I: Caracterización de madera maciza}

Desde el punto de vista de utilización, industrialización y uso de la madera, el conocimiento de sus características y propiedades es esencial a fin de maximizar su valor y poder destinarla a los usos adecuados. En este sentido, su calidad quedaría definida por los atributos que la hacen valiosa o apropiada para una utilización en particular (Jozsa and Middleton, 1994). En concordancia con esto, es fundamental conocer sus cualidades físicas y mecánicas, como así también su comportamiento frente a agentes de deterioro que puedan reducir su vida útil en servicio. Para ello, una caracterización exhaustiva del material es esencial como punto de partida para el posterior planteamiento de propuestas de mejoras tecnológicas en aquellas características que así lo requieran, y que la hagan más adecuada para ciertas aplicaciones (Hermoso, 2001).

A continuación se detallan los resultados obtenidos en función del tamaño de material y condición de ensayo.

\subsection{Probetas de pequeñas dimensiones y libres de defectos.}

\subsubsection{Propiedades físicas}

\subsubsection{Contenido de humedad $(\mathrm{CH})$}

\section{Análisis descriptivo por procedencias}

El resumen descriptivo del contenido de humedad de la madera de ambas procedencias, se detalla en la Tabla 17, Figura 41 a Figura 44.

Tabla 17. Contenido de humedad: análisis descriptivo.

\begin{tabular}{cccc}
\hline \multirow{2}{*}{ Procedencia } & $\mathrm{n}^{*}$ & \multicolumn{2}{c}{$\mathrm{CH}(\%)^{*}$} \\
\cline { 3 - 4 } & \multirow{2}{*}{ España } & $\begin{array}{c}\text { Media } \\
(\mathrm{CV} \%)^{*}\end{array}$ & $\begin{array}{c}\text { Mín - Máx. } \\
(\mathrm{IQR})^{*}\end{array}$ \\
\hline Argentina & 20 & $\begin{array}{c}10,08 \\
(2,32)\end{array}$ & $\begin{array}{c}9,60-10,35 \\
(0,37)\end{array}$ \\
\hline \multirow{2}{*}{30} & $\begin{array}{c}10,53 \\
(2,69)\end{array}$ & $\begin{array}{c}10,03-11,11 \\
(0,48)\end{array}$ \\
\hline
\end{tabular}

*n: número de individuos; CH: Contenido de humedad; CV: coeficiente de variación, en \%; IQR: recorrido intercuartílico. 


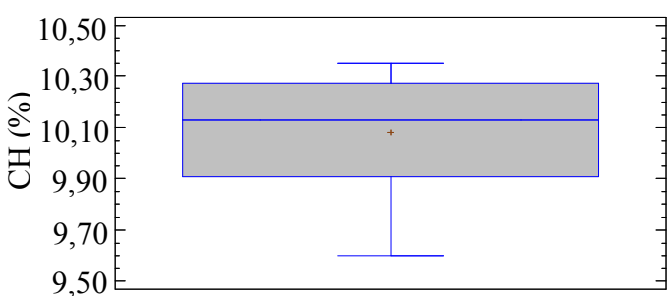

Figura 41. Gráfico de Caja y Bigotes: CH - España

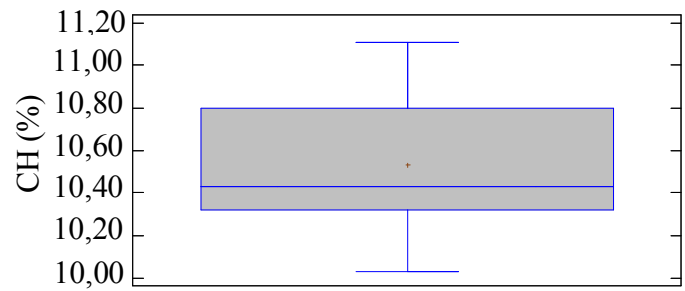

Figura 43. Gráfico de Caja y Bigotes: CH Argentina

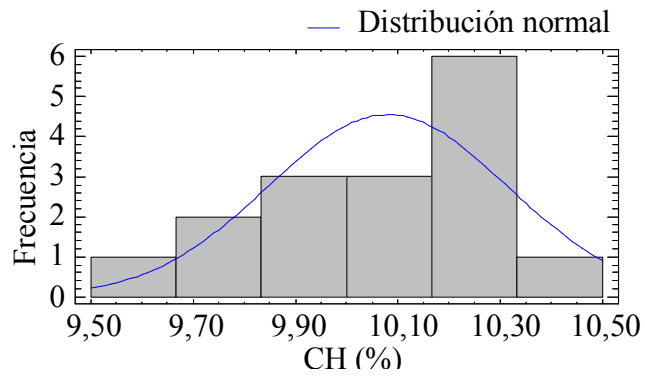

Figura 42. Histograma de frecuencias CH - España

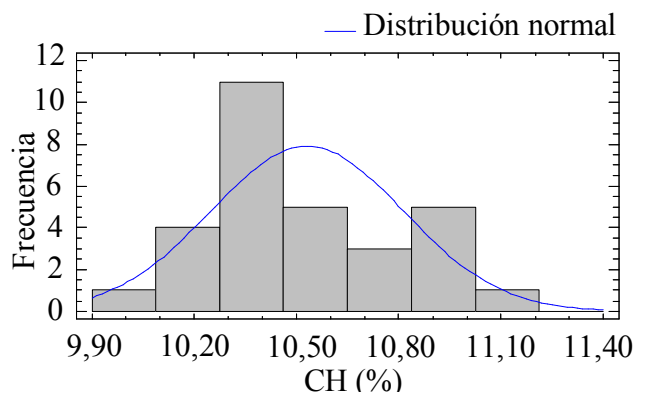

Figura 44. Histograma de frecuencias $\mathrm{CH}-$ Argentina

El CH obtenido en probetas de pequeñas dimensiones fue determinado a fin de caracterizar el material perteneciente a cada procedencia; asimismo, posteriormente todos los resultados serán referenciados al $\mathrm{CH}$ de $12 \%$, valor de referencia.

\section{Análisis comparativo entre procedencias}

En la Tabla 18, Figura 45, se detallan los resultados del análisis comparativo realizado entre los contenidos de humedad de equilibrio higroscópico obtenidos en el material de estudio.

Tabla 18. CH - Procedencias: análisis comparativo.

\begin{tabular}{cccccc}
\hline ANOVA* $^{*}$ & Razón-F & P-valor & & Procedencia & Grupos homogéneos** \\
\cline { 1 - 1 } \cline { 4 - 5 } \begin{tabular}{c} 
CH - \\
\cline { 5 - 5 } Procedencias
\end{tabular} & 29,61 & 0,00 & Tukey HSD & España & A \\
\cline { 4 - 5 } & & & Argentina & B \\
\hline
\end{tabular}

*CH: contenido de humedad; **letras diferentes denotan diferencias significativas, Tukey HSD $(\mathrm{P}<0,05)$.

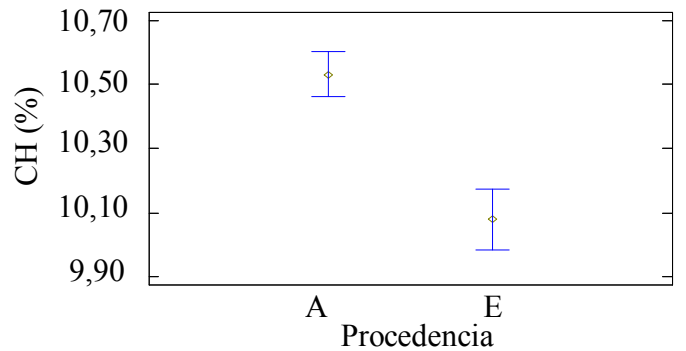

Figura 45. Gráfico de medias e IC 95\% Tukey

HSD: CH (\%) por procedencia 
Atendiendo a la clasificación establecida en la norma UNE 56540: 1978, en ambos casos se trata de madera muy seca, aunque con diferencias significativas entre ambos materiales.

\subsubsection{Densidades aparentes}

Del mismo modo que lo indicado para el $\mathrm{CH}$, los valores de densidad obtenidos en probetas de pequeñas dimensiones son indicativos a los fines de caracterización del material.

\section{Análisis descriptivo por procedencias}

En la Tabla 19, Figura 46 a Figura 57, se recogen los resultados sobre la determinación de las densidades aparentes en el material de ambas procedencias; las pruebas de normalidad de cada variable se detallan en Anejos 6.1.1.2.

Tabla 19. Densidades aparentes: resultados discriminados por procedencias.

\begin{tabular}{cccccccc}
\hline \multirow{2}{*}{ Procedencia } & \multirow{2}{*}{$\mathrm{n}^{*}$} & \multicolumn{2}{c}{$\begin{array}{c}\text { Do } \\
\left(\mathrm{Kg} / \mathrm{m}^{3}\right)^{*}\end{array}$} & \multicolumn{2}{c}{$\begin{array}{c}\text { Dn }-12 \% \mathrm{CH}- \\
\left(\mathrm{Kg} / \mathrm{m}^{3}\right)^{*}\end{array}$} & \multicolumn{2}{c}{$\begin{array}{c}\text { Db } \\
\left(\mathrm{Kg} / \mathrm{m}^{3}\right)^{*}\end{array}$} \\
\cline { 3 - 8 } & & $\begin{array}{c}\text { Media } \\
(\mathrm{CV} \%)^{*}\end{array}$ & $\begin{array}{c}\text { Mín-Máx. } \\
(\mathrm{IQR})^{*}\end{array}$ & $\begin{array}{c}\text { Media } \\
(\mathrm{CV} \%)^{*}\end{array}$ & $\begin{array}{c}\text { Mín-Máx. } \\
(\mathrm{IQR})^{*}\end{array}$ & $\begin{array}{c}\text { Media } \\
(\mathrm{CV} \%)^{*}\end{array}$ & $\begin{array}{c}\text { Mín-Máx. } \\
(\mathrm{IQR})^{*}\end{array}$ \\
\hline \multirow{2}{*}{ España } & \multirow{2}{*}{20} & $\begin{array}{c}400,66 \\
(8,36)\end{array}$ & $\begin{array}{c}343,25-466,92 \\
(49,21)\end{array}$ & $\begin{array}{c}423,97 \\
(6,51)\end{array}$ & $\begin{array}{c}371,59-476,47 \\
(35,63)\end{array}$ & $\begin{array}{c}335,56 \\
(3,61)\end{array}$ & $\begin{array}{c}308-360 \\
(15)\end{array}$ \\
\hline \multirow{2}{*}{ Argentina } & \multirow{2}{*}{30} & $\begin{array}{c}365,50 \\
(4,41)\end{array}$ & $\begin{array}{c}342-396 \\
(27)\end{array}$ & $\begin{array}{c}392,27 \\
(4,38)\end{array}$ & $\begin{array}{c}370-427 \\
(29)\end{array}$ & $\begin{array}{c}322,90 \\
(7,13)\end{array}$ & $\begin{array}{c}295-378 \\
(37)\end{array}$ \\
\hline
\end{tabular}

*n: número de individuos; Do: densidad aparente anhidra; Dn: densidad aparente normal; Db: densidad básica; CV: coeficiente de variación, en \%; IQR: recorrido intercuartílico.

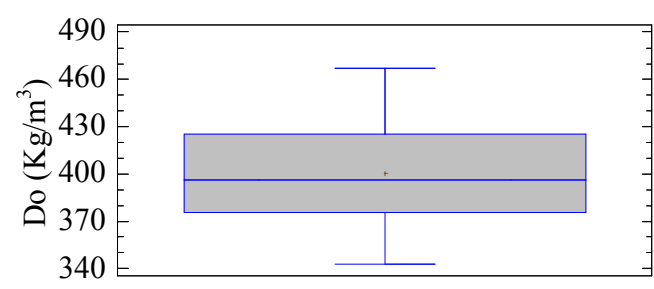

Figura 46. Gráfico de Caja y Bigotes: Do - España

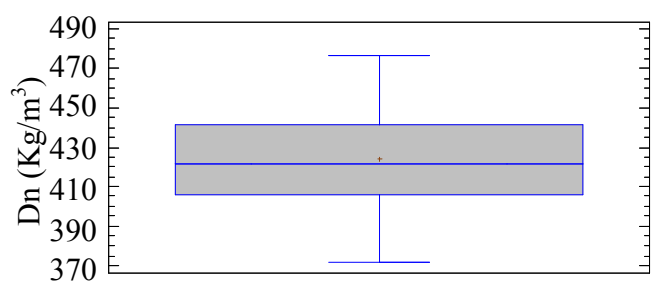

Figura 48. Gráfico de Caja y Bigotes: Dn - España

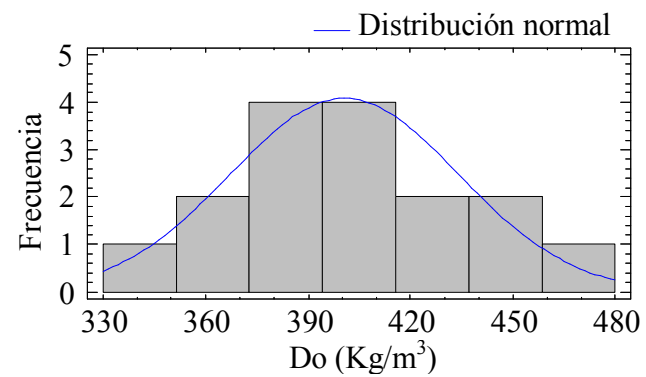

Figura 47. Histograma de frecuencias: Do - España

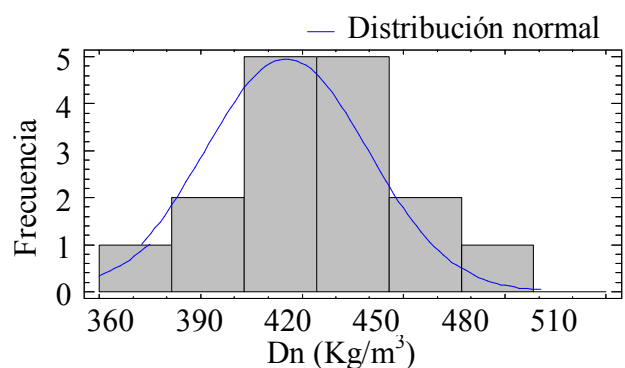

Figura 49. Histograma de frecuencias: Dn - España 


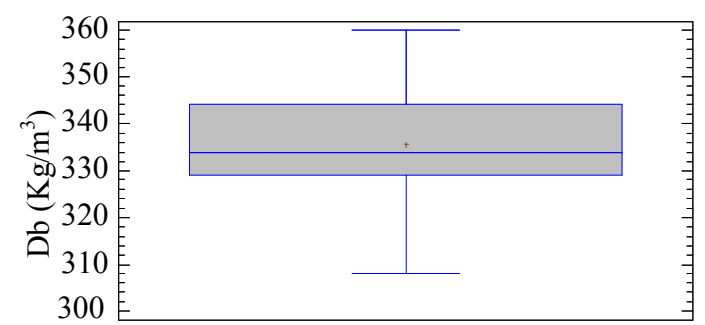

Figura 50. Gráfico de Caja y Bigotes: Db - España

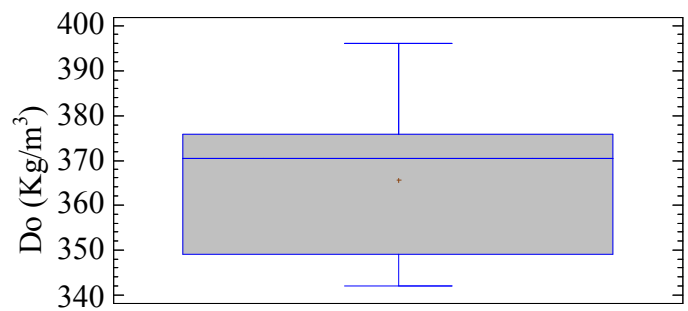

Figura 52. Gráfico de Caja y Bigotes: Do Argentina

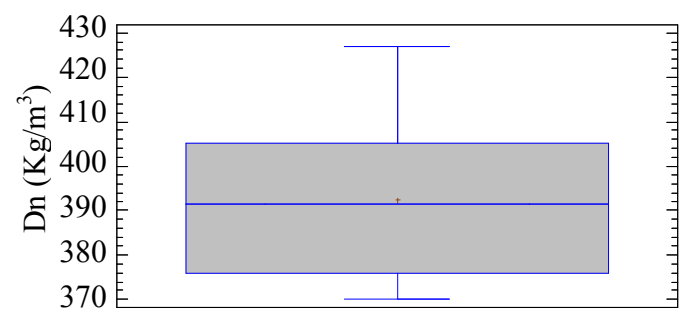

Figura 54. Gráfico de Caja y Bigotes: Dn Argentina

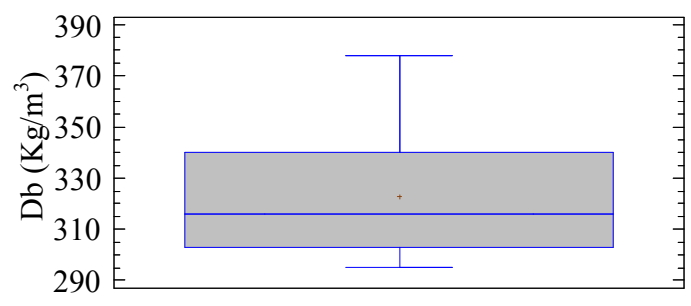

Figura 56. Gráfico de Caja y Bigotes: Db Argentina

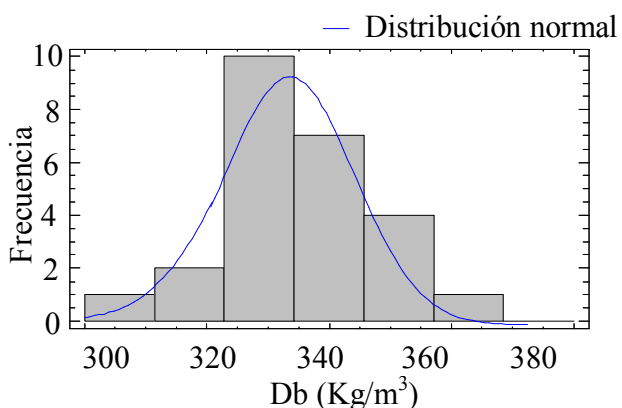

Figura 51. Histograma de frecuencias: Db - España - Distribución normal

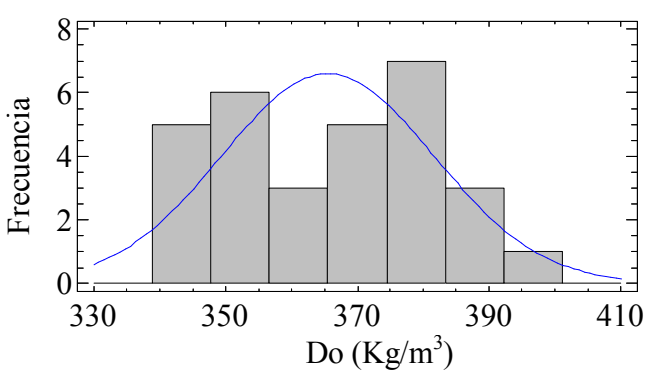

Figura 53. Histograma de frecuencias: Do Argentina

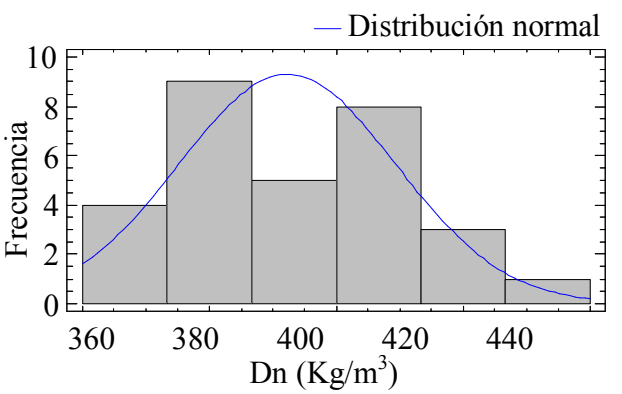

Figura 55. Histograma de frecuencias: Dn Argentina

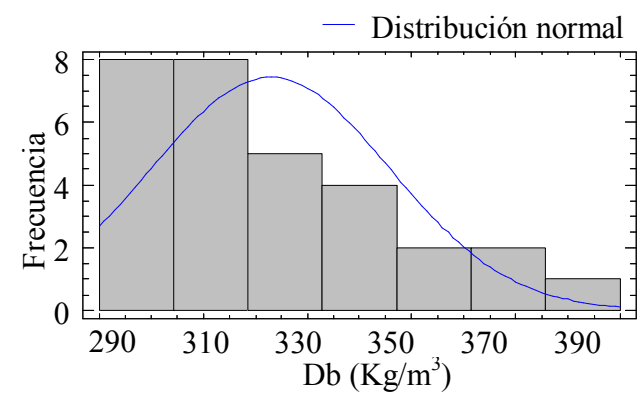

Figura 57. Histograma de frecuencias: Db Argentina 


\section{Análisis comparativo entre procedencias}

El análisis comparativo (ANOVA) empleado para evaluar el comportamiento de las densidades en el material de ambas procedencias se indica en la Tabla 20, Figura 58 a Figura 60; en Anejos 6.1.1.2 se detallan los resultados sobre la constatación de los supuestos estadísticos.

Tabla 20. Densidades aparentes: análisis comparativo entre procedencias.

\begin{tabular}{|c|c|c|c|c|c|c|c|c|}
\hline \multirow{2}{*}{ Do* } & Estad. & P-valor & \multirow{2}{*}{$\mathrm{Dn}^{* *}$} & Razón-F & P-valor & \multirow{2}{*}{$\mathrm{Db}^{* * *}$} & Estad. & P-valor \\
\hline & 12,30 & 0,00 & & 23,11 & 0,00 & & 6,78 & 0,01 \\
\hline
\end{tabular}

*Do: densidad aparente anhidra; Est.: estadístico (Test de Kruskal-Wallis); **dn: Densidad aparente normal; Razón F (Test ANOVA); ***Db: densidad básica; P-valor $<0,05$, indica diferencias significativas.

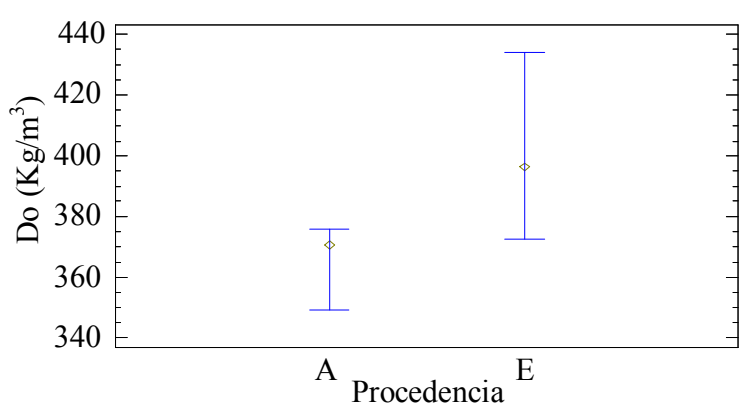

Figura 58. Gráfico de Medianas e IC 95\%: Do por procedencias

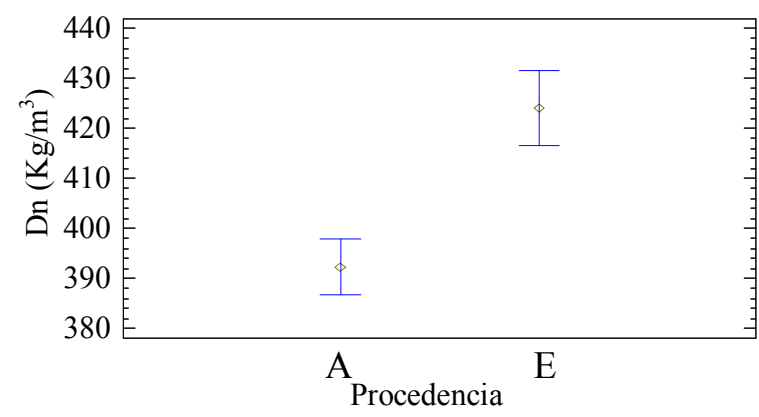

Figura 59. Gráfico de Medias e IC 95\% Tukey HSD: Dn por procedencias

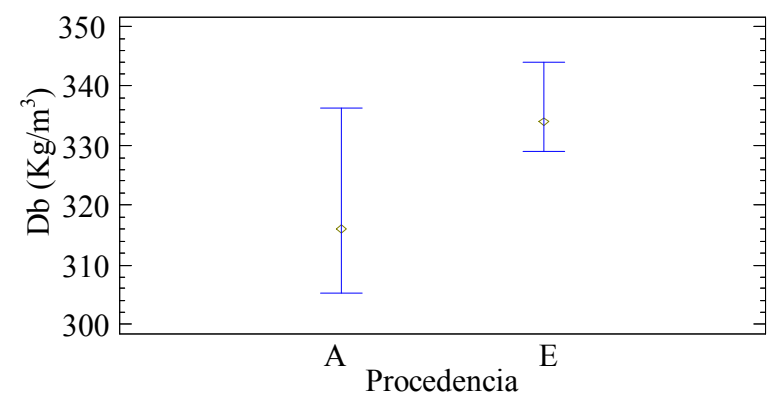

Figura 60. Gráfico de Medianas e IC 95\%: Db por procedencias 
De acuerdo con los resultados obtenidos, las densidades aparentes son significativamente diferentes entre ambas procedencias siendo, en todos los casos, estadísticamente superiores en el material de procedencia española, Figura 58 a Figura 60. En cualquier caso, atendiendo al rango de interpretación de valores de densidad establecido en la norma UNE 56540: 1978, ambas maderas son consideradas ligeras de acuerdo con los valores de Dn $-12 \% \mathrm{CH}-\left(\mathrm{Kg} / \mathrm{m}^{3}\right)$.

\subsubsection{Cambios dimensionales}

\subsection{Parámetros dimensionales lineales}

\section{Análisis descriptivo por procedencias.}

El análisis descriptivo correspondiente a los parámetros dimensionales lineales se muestra en la Tabla 21. La dispersión de los datos se muestra mediante gráficos de caja y bigotes, Figura 61 a Figura 76, para cada parámetro y procedencia. Al ser la madera un material anisótropo, las determinaciones fueron realizadas, y se indican, en las tres direcciones de estudio: longitudinal, radial y tangencial. El resumen de los análisis empleados para la constatación de supuestos estadísticos se presenta en Anejos 6.1.1.3.1.

Tabla 21. Parámetros dimensionales lineales: análisis descriptivo

\begin{tabular}{|c|c|c|c|c|c|c|c|c|c|c|}
\hline \multirow[b]{2}{*}{ Procedencia } & \multirow[b]{2}{*}{$\mathrm{n}^{*}$} & \multicolumn{2}{|c|}{ CnmáxL*(\%) } & \multicolumn{2}{|c|}{ CnmáxRd* (\%) } & \multicolumn{2}{|c|}{ CnmáxTg* (\%) } & \multicolumn{2}{|c|}{$\mathrm{T} / \mathrm{R}^{*}$} & \multirow[b]{2}{*}{$\begin{array}{c}\text { PSPC* } \\
(\%)\end{array}$} \\
\hline & & $\begin{array}{c}\text { Media } \\
(\mathrm{CV} \%)^{*}\end{array}$ & $\begin{array}{l}\text { Mín- } \\
\text { Máx. } \\
\text { (IQR)* }\end{array}$ & $\begin{array}{c}\text { Media } \\
(\mathrm{CV} \%)^{*}\end{array}$ & $\begin{array}{l}\text { Mín- } \\
\text { Máx. } \\
(\mathrm{IQR})^{*}\end{array}$ & $\begin{array}{c}\text { Media } \\
(\mathrm{CV} \%)^{*}\end{array}$ & $\begin{array}{l}\text { Mín- } \\
\text { Máx. } \\
(\mathrm{IQR})^{*}\end{array}$ & $\begin{array}{c}\text { Media } \\
(\mathrm{CV} \%)^{*}\end{array}$ & $\begin{array}{l}\text { Mín- } \\
\text { Máx. } \\
\text { (IQR*) }\end{array}$ & \\
\hline España & 75 & $\begin{array}{c}0,36 \\
(44,77)\end{array}$ & $\begin{array}{c}0,08- \\
0,82 \\
(0,24)\end{array}$ & $\begin{array}{c}4,40 \\
(14,82)\end{array}$ & $\begin{array}{c}2,65- \\
5,96 \\
(0,98)\end{array}$ & $\begin{array}{c}8,30 \\
(13,00)\end{array}$ & $\begin{array}{c}5,75- \\
10,46 \\
(1,48\end{array}$ & $\begin{array}{c}1,83 \\
(21,79)\end{array}$ & $\begin{array}{c}0,94- \\
2,63 \\
(0,43)\end{array}$ & 25,98 \\
\hline Argentina & 40 & $\begin{array}{c}0,69 \\
(53,24)\end{array}$ & $\begin{array}{c}0,12- \\
1,5 \\
(0,49)\end{array}$ & $\begin{array}{c}3,72 \\
(10,10)\end{array}$ & $\begin{array}{c}3,05- \\
4,8 \\
(0,4)\end{array}$ & $\begin{array}{c}7,69 \\
(6,66)\end{array}$ & $\begin{array}{c}6,53- \\
8,6 \\
(0,76)\end{array}$ & $\begin{array}{c}2,09 \\
(11,66)\end{array}$ & $\begin{array}{c}1,68- \\
2,57 \\
(0,34)\end{array}$ & 37,59 \\
\hline
\end{tabular}

*Cnmáx: contracción normal máxima; L, Rd y Tg: longitudinal, radial y tangencial, respectivamente; T/R: coeficiente de anisotropía, adimensional; PSPC: punto de saturación de la pared celular; CV: coeficiente de variación, en \%; IQR: recorrido intercuartílico.

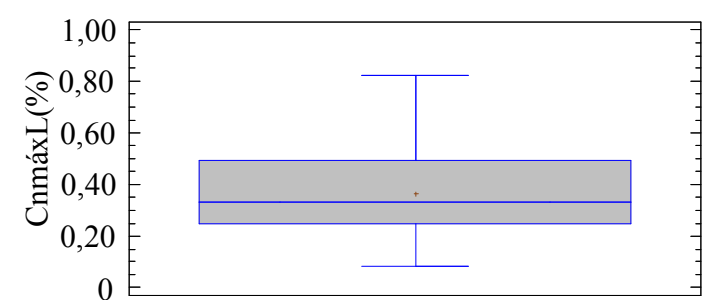

Figura 61. Gráfico de Caja y Bigotes: CnmáxL (\%) - España.

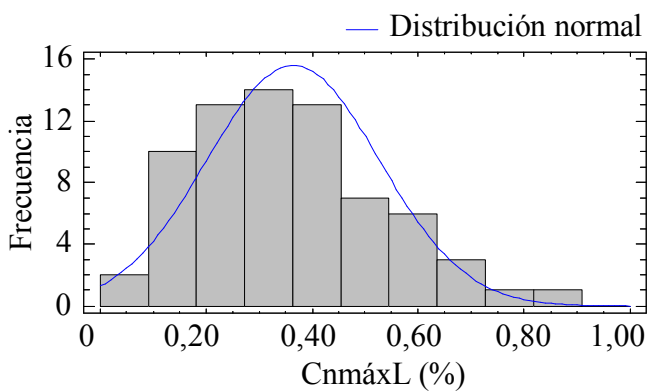

Figura 62. Histograma de frecuencias: CnmáxL (\%) - España. 


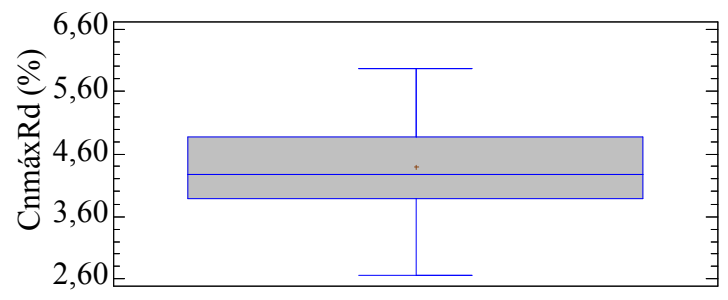

Figura 63. Gráfico de Caja y Bigotes: CnmáxRd (\%) - procedencia España.

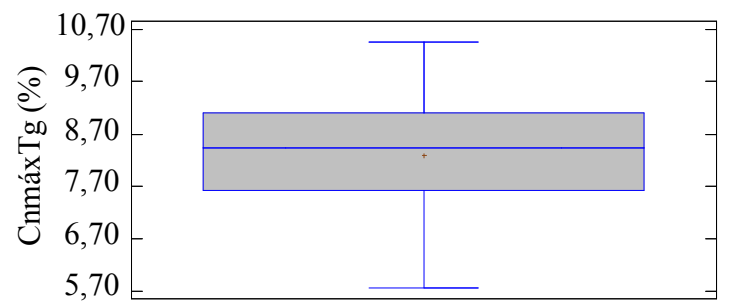

Figura 65. Gráfico de Caja y Bigotes: CnmáxTg (\%) - procedencia España

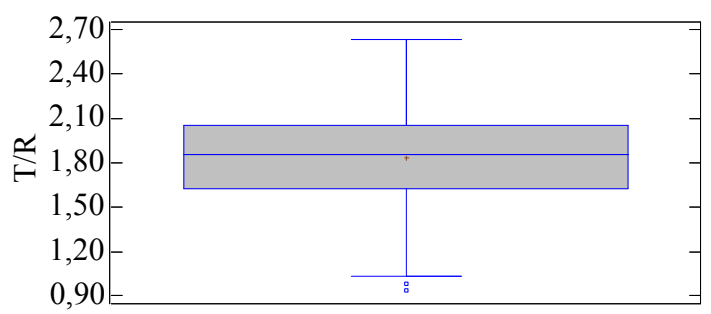

Figura 67. Gráfico de Caja y Bigotes: T/R procedencia España.

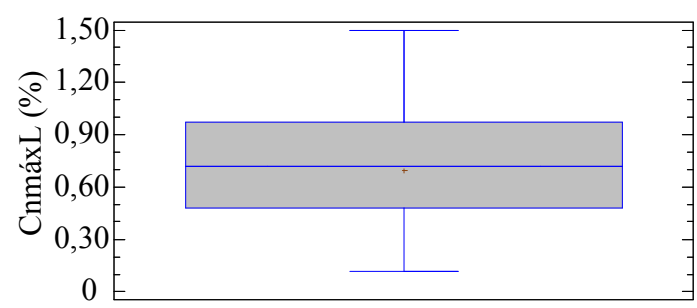

Figura 69. Gráfico de Caja y Bigotes: CnmáxL (\%) - procedencia Argentina.

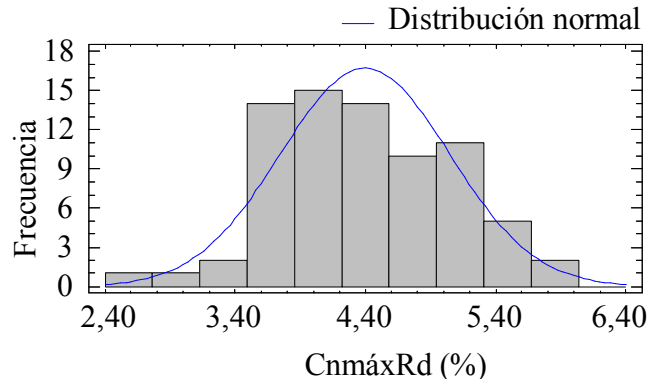

Figura 64. Histograma de frecuencias:CnmáxRd (\%) - procedencia España.

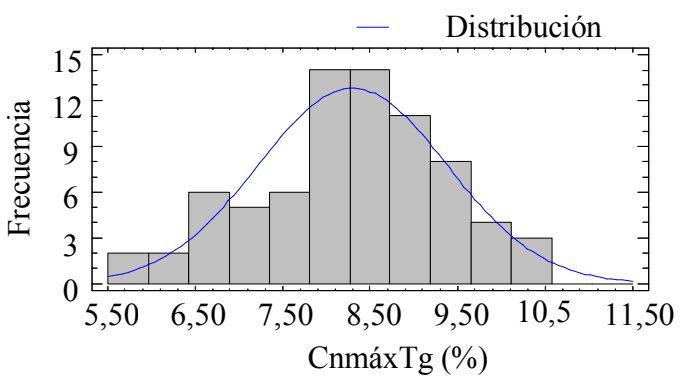

Figura 66. Histograma de frecuencias: CnmáxTg (\%) - procedencia España

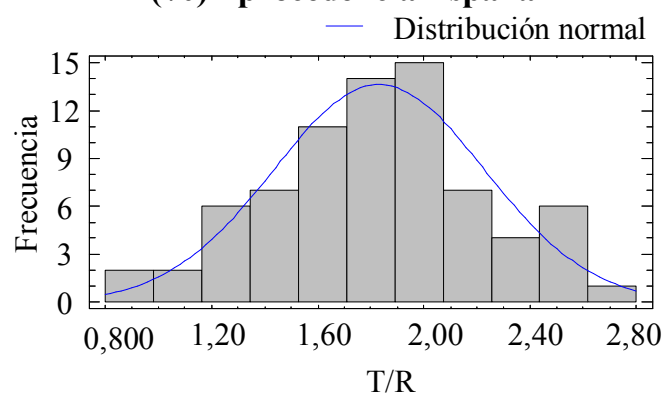

Figura 68. Histograma de frecuencias: $T / R$ procedencia España.

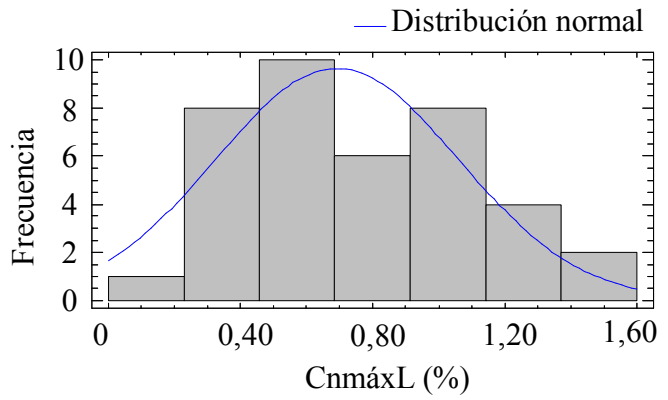

Figura 70. Histograma de frecuencias: CnmáxL (\%) - procedencia Argentina. 


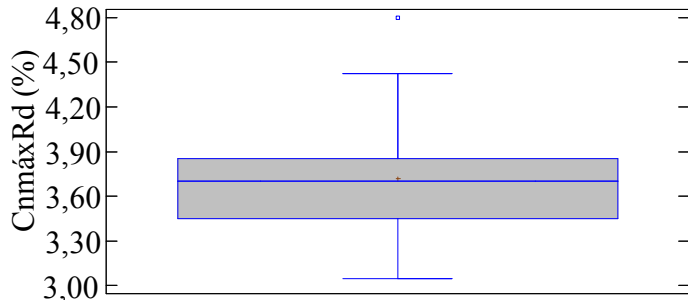

Figura 71. Gráfico de Caja y Bigotes: CnmáxRd (\%) - procedencia Argentina.

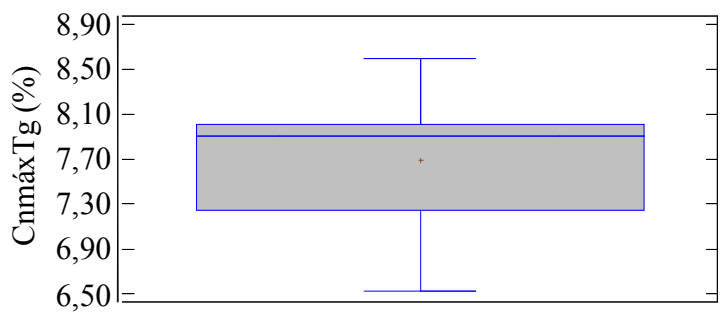

Figura 73. Gráfico de Caja y Bigotes: CnmáxTg (\%) - procedencia Argentina.

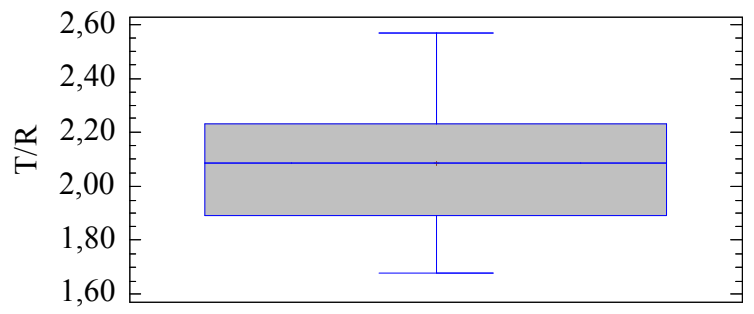

Figura 75. Gráfico de Caja y Bigotes: T/R procedencia Argentina.

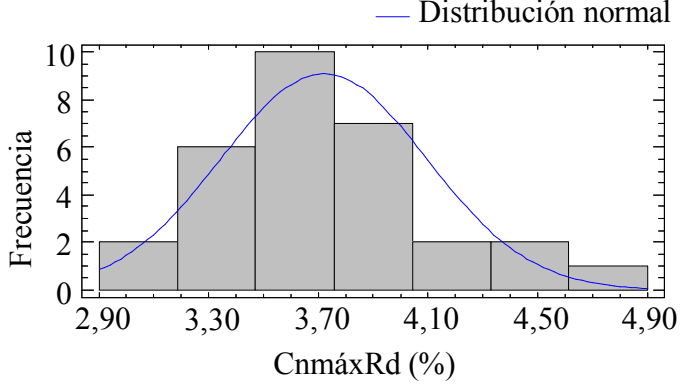

Figura 72. Histograma de frecuencias:CnmáxRd (\%) - procedencia Argentina.

- Distribución normal

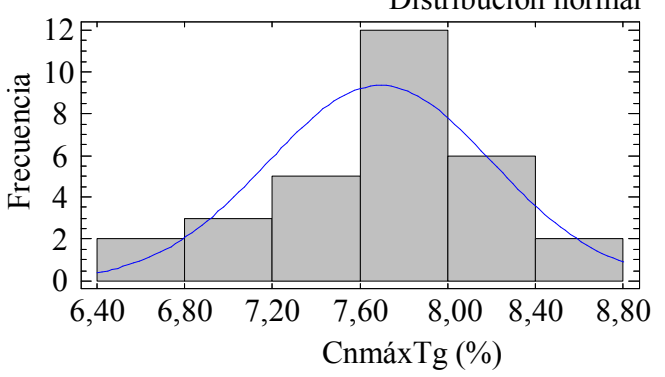

Figura 74. Histograma de frecuencias: CnmáxTg (\%) - procedencia Argentina.

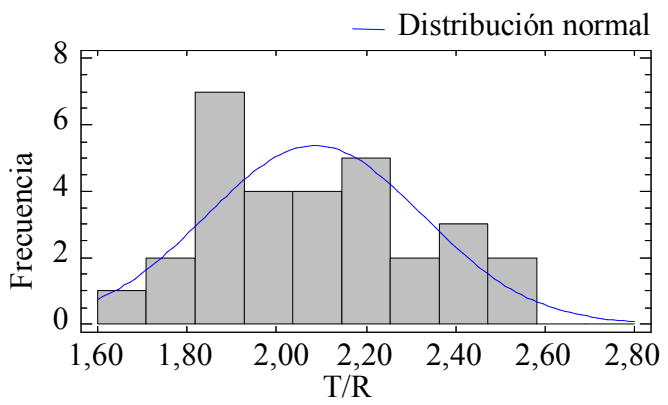

Figura 76. Histograma de frecuencias: T/R procedencia Argentina.

El punto de saturación de la pared celular (PSPC) indicado en la Tabla 21, corresponde al valor promedio de dicho parámetro obtenido gráficamente en las tres direcciones de estudio (longitudinal, radial y tangencial), tal como se muestra en la Figura 77, para el material de España, y en la Figura 78, para el material de Argentina; las ecuaciones de regresión obtenidas en cada caso se reflejan en Anejos 6.1.1.3.1. 


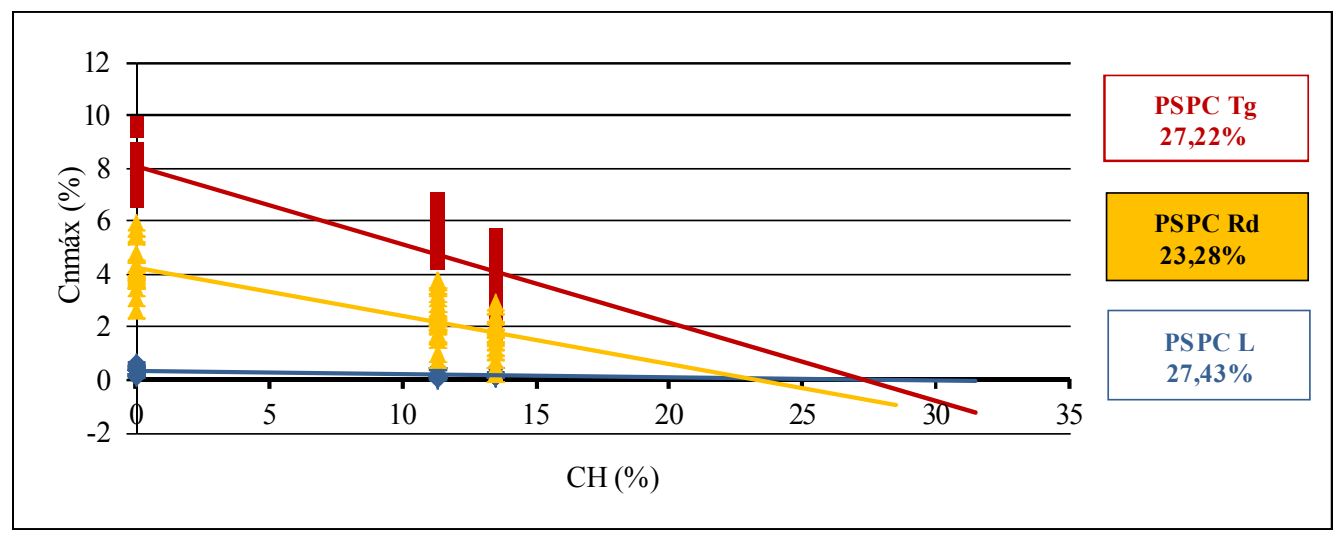

Figura 77: Chopo España: Evolución de las contracciones normales (\%) con el CH (\%)

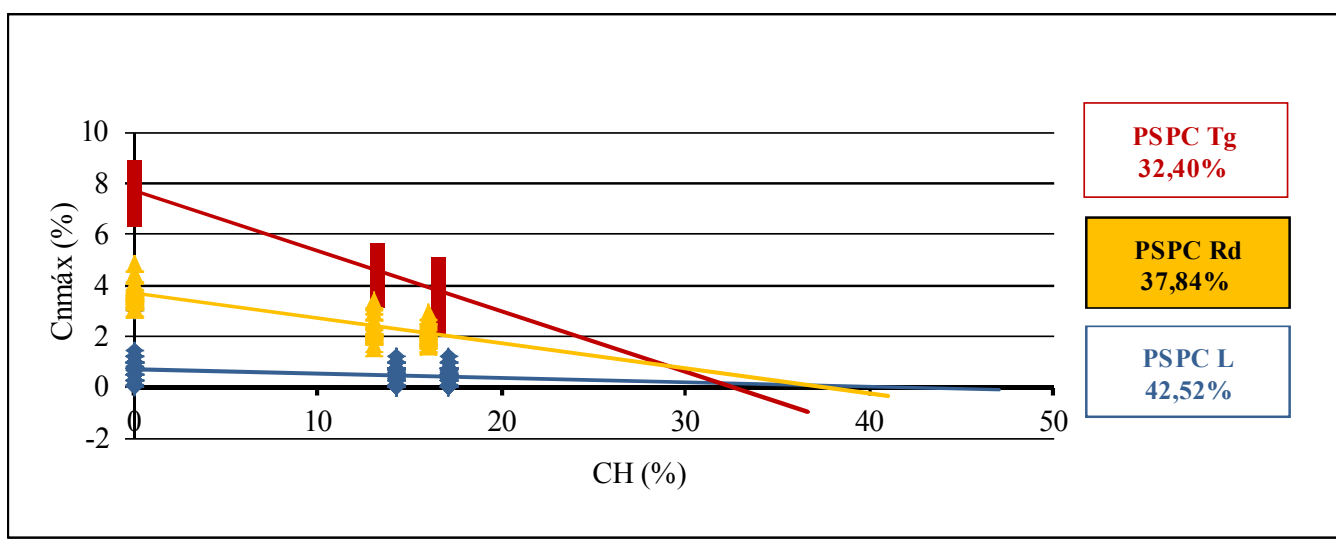

Figura 78: Chopo Argentina: Evolución de las contracciones normales (\%) con el CH (\%)

El comportamiento dimensional comparativo entre procedencias, se presenta a continuación.

\section{Análisis comparativo entre procedencias.}

Dado el incumplimiento del supuesto de homocedasticidad (Anejos 6.1.1.3.1), el análisis comparativo fue realizado mediante la aplicación del test no paramétrico de Kruskal-Wallis (comparación de medianas), Tabla 22, Figura 79 a Figura 82.

Tabla 22. Parámetros dimensionales: análisis comparativo.

\begin{tabular}{|c|c|c|c|c|c|c|c|c|c|c|}
\hline \multirow{2}{*}{ CnmáxL* } & Estad.* & $\begin{array}{c}\text { P- } \\
\text { valor }\end{array}$ & \multirow{2}{*}{ CnmáxRd* } & Estad*. & $\begin{array}{c}\text { P- } \\
\text { valor }\end{array}$ & \multirow{2}{*}{ CnmáxTg* } & Estad.* & $\begin{array}{c}\text { P- } \\
\text { valor }\end{array}$ & Estad.* & $\begin{array}{c}\text { P- } \\
\text { valor }\end{array}$ \\
\hline & 19,79 & 0,00 & & 27,26 & 0,00 & & 11,52 & 0,00 & 10,14 & 0,00 \\
\hline
\end{tabular}

*Est: estadístico; Cnmáx: contracción normal máxima; L, Rd y Tg: longitudinal, radial y tangencial, respectivamente; T/R: coeficiente de anisotropía; P-valor $<0,05$, indica diferencias significativas entre medianas. 


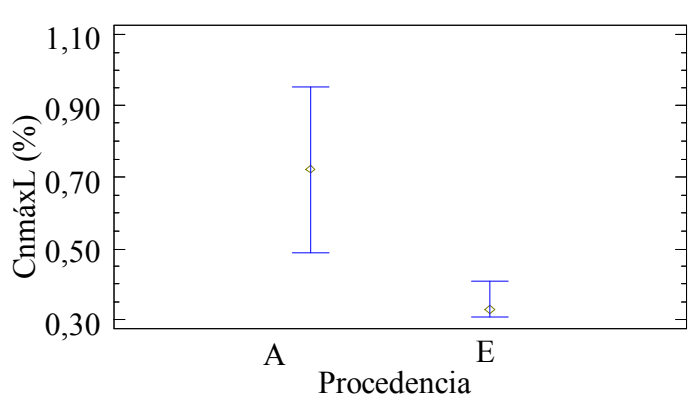

Figura 79. Gráfico de Medianas e IC 95\%. CnmáxL por procedencias.

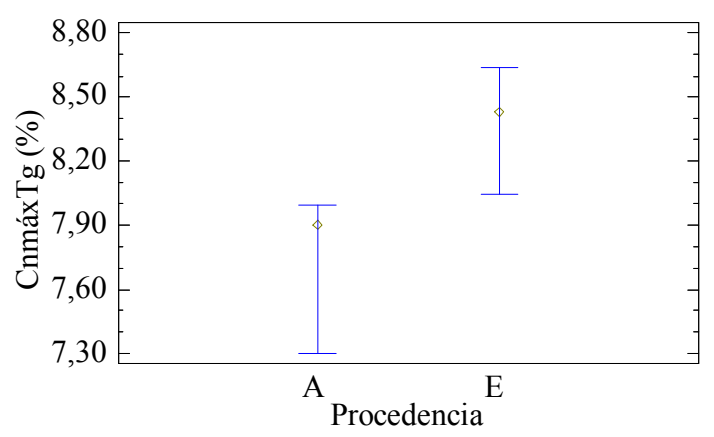

Figura 81. Gráfico de Medianas e IC 95\%. CnmáxTg por procedencias.

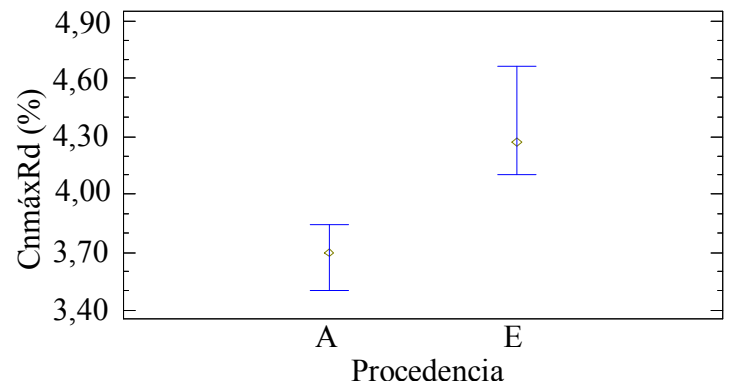

Figura 80. Gráfico de Medianas e IC 95\%. CnmáxRd por procedencias.

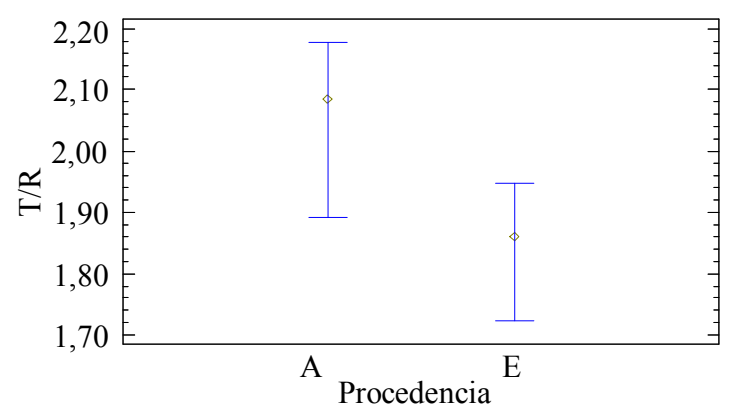

Figura 82. Gráfico de Medianas e IC 95\%. T/R por procedencias.

De acuerdo con el análisis comparativo puede observarse que el material de procedencia española presenta mayores valores de CnmáxRd y CnmáxTg, pero la relación entre ellos es significativamente inferior con respecto al material de Argentina, asimismo, este último presenta valores de CnmáxL estadísticamente superiores.

\subsection{Parámetros volumétricos}

\section{Análisis descriptivo por procedencias.}

A continuación, se presenta el análisis descriptivo, Tabla 23, correspondiente a los parámetros volumétricos del material de ambas procedencias. El resumen de los análisis empleados para la constatación de supuestos estadísticos se presenta en Anejos 6.1.1.3.2.

Tabla 23. Parámetros volumétricos: análisis descriptivo.

\begin{tabular}{|c|c|c|c|c|c|}
\hline \multirow[b]{2}{*}{ Procedencia } & \multirow[b]{2}{*}{$\mathrm{n}^{*}$} & \multicolumn{2}{|c|}{$\mathrm{CnV}(\%)^{*}$} & \multicolumn{2}{|c|}{ V $(\%)^{*}$} \\
\hline & & $\begin{array}{c}\text { Media } \\
\text { (CV\%)* }\end{array}$ & $\begin{array}{c}\text { Mín-Máx. } \\
\text { (IQR)* }\end{array}$ & $\begin{array}{l}\text { Media } \\
\text { (CV\%)* }\end{array}$ & $\begin{array}{l}\text { Mín-Máx. } \\
\text { (IQR)* }\end{array}$ \\
\hline España & 25 & $\begin{array}{l}12,15 \\
(8,61)\end{array}$ & $\begin{array}{c}10,86-14,15 \\
(1,86)\end{array}$ & $\begin{array}{c}0,43 \\
(17,71)\end{array}$ & $\begin{array}{c}0,30-0,61 \\
(0,08)\end{array}$ \\
\hline Argentina & 100 & $\begin{array}{l}12,42 \\
(9,88)\end{array}$ & $\begin{array}{c}8,86-15,34 \\
(1,40)\end{array}$ & $\begin{array}{c}0,40 \\
(22,34)\end{array}$ & $\begin{array}{c}0,19-0,67 \\
(0,12)\end{array}$ \\
\hline
\end{tabular}

*CnV: contracción volumétrica; V: coeficiente de contracción volumétrica; CV: coeficiente de variación, en \%; IQR: recorrido intercuartílico. 
Los gráficos de dispersión y de probabilidad normal para ambas variables volumétricas se indican en las siguientes figuras, Figura 83 a Figura 90.

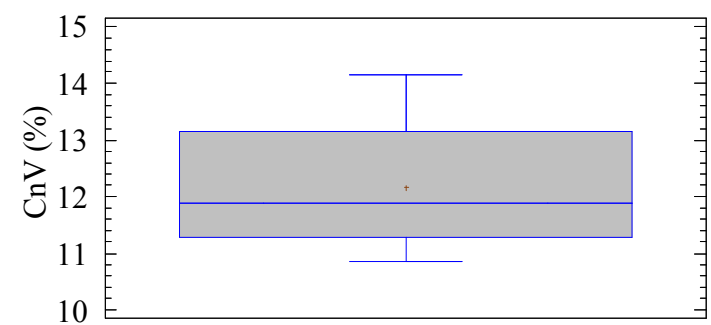

Figura 83. Gráfico de Caja y Bigotes: $\mathrm{CnV}(\%)$ procedencia España.

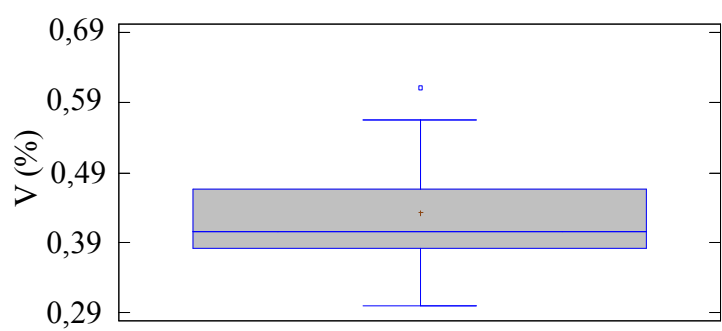

Figura 85. Gráfico de Caja y Bigotes: V (\%) procedencia España.

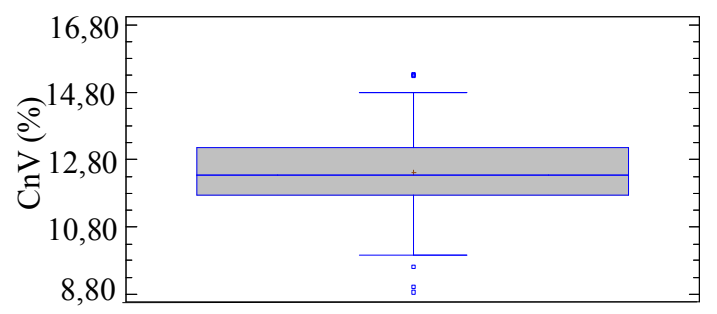

Figura 87. Gráfico de Caja y Bigotes: CnV (\%) procedencia Argentina.

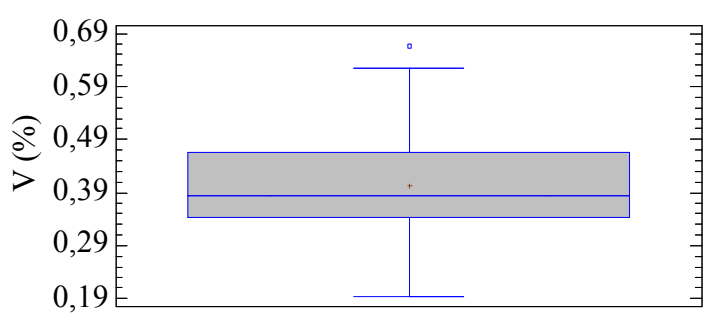

Figura 89. Gráfico de Caja y Bigotes: V (\%) procedencia Argentina.

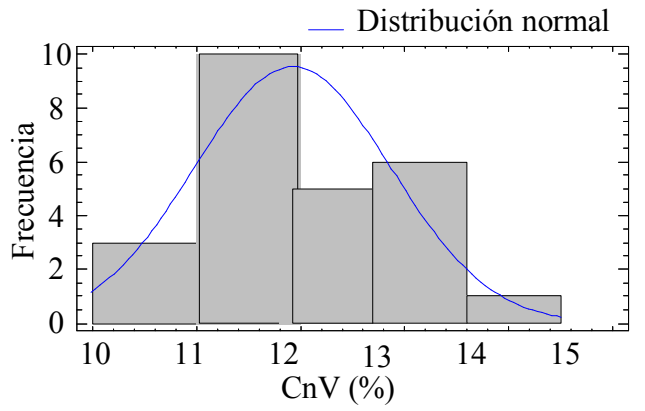

Figura 84. Histograma de frecuencias: $\mathrm{CnV}(\%)$ procedencia España.

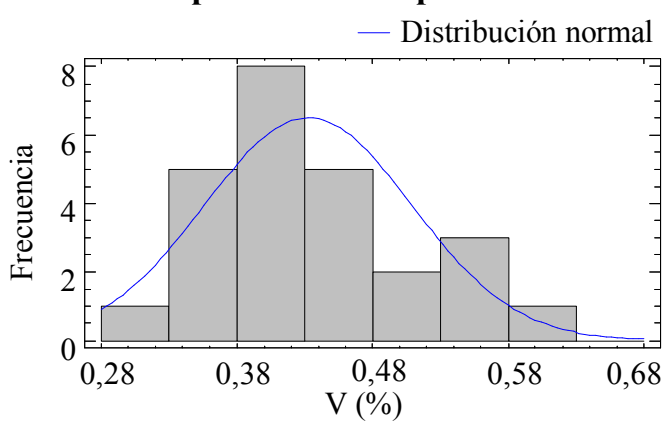

Figura 86. Histograma de frecuencias: V (\%) procedencia España.

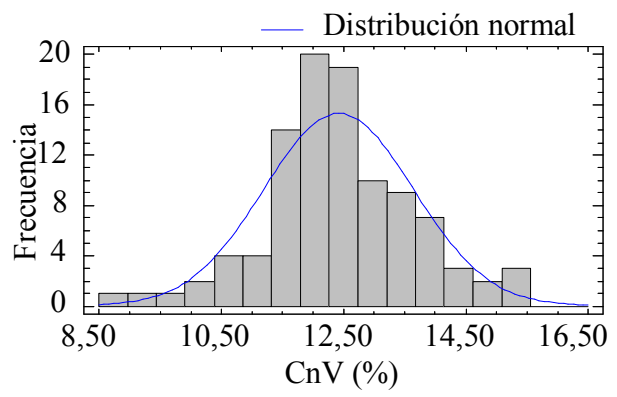

Figura 88. Histograma de frecuencias: CnV (\%) procedencia Argentina.

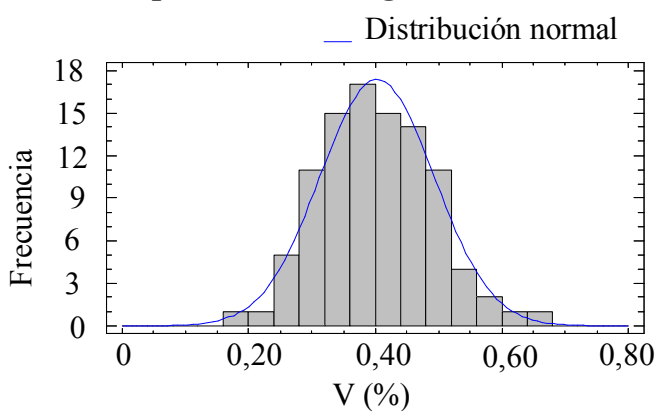

Figura 90. Histograma de frecuencias: V (\%) procedencia Argentina. 


\section{Análisis comparativo entre procedencias}

En la Tabla 24 se muestra el resumen del análisis comparativo (ANOVA) realizado con los parámetros volumétricos diferenciados por procedencias; la constatación de los supuestos estadísticos se detalla en Anejos 6.1.1.3.2.

Tabla 24. Parámetros volumétricos: análisis comparativo

\begin{tabular}{|c|c|c|c|c|c|}
\hline \multirow{2}{*}{$\mathrm{CnV}^{*}$} & Razón-F & P-valor & \multirow{2}{*}{$\mathrm{V}^{*}$} & Estad.* & P-valor \\
\hline & 1,05 & 0,31 & & 2,30 & 0,13 \\
\hline
\end{tabular}

*CnV: contracción volumétrica; V: coeficiente de contracción volumétrica; Estad.: estadístico; P-valor $<0,05$, indica diferencias significativas entre medias (ANOVA).

En la Figura 91 y Figura 92 se muestra el gráfico de medias e IC 95\% HSD de Tukey para la contracción volumétrica y el coeficiente de contracción volumétrica, respectivamente.

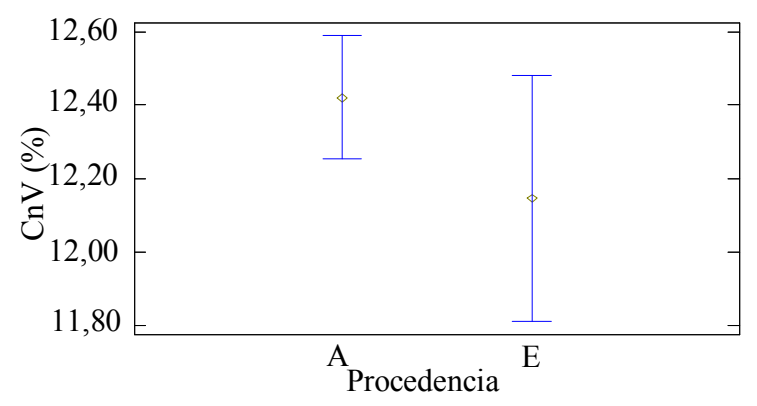

Figura 91. Gráfico de Medias e IC 95\% Tukey HSD: $\mathrm{CnV}$ - procedencias.

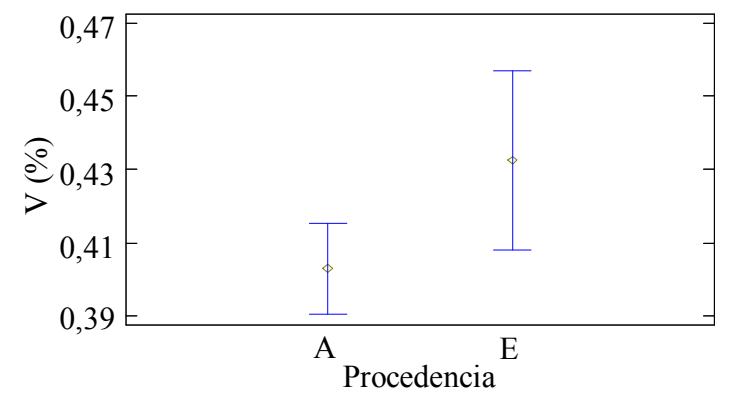

Figura 92. Gráfico de Medias e IC 95\% Tukey HSD: $\mathrm{V}$ - procedencias.

Estos resultados muestran que no existen diferencias significativas entre las medias de ambos parámetros contrastados por procedencias del material. En este sentido, considerando la clasificación planteada en la norma UNE 56540: 1978, ambas maderas presentan valores de contracción volumétrica media (rango de $\mathrm{CnV}: 10-15 \%$ ) y son consideradas medianamente nerviosas de acuerdo con los valores de V (rango de V: 0,35-0,55).

De acuerdo con la caracterización dimensional y volumétrica presentada (descriptivacomparativa), puede observarse que la madera de Populus $x$ euramericana I-214 de ambas procedencias presenta valores de contracción considerables, siendo nerviosa o inestable ante los cambios de contenido de humedad, lo cual podría generar la aparición de fendas durante el proceso de secado. En concordancia con Glass and Zelinka, (2010), las variaciones dimensionales (movimientos) en sentido longitudinal, producidos entre el estado anhidro y el punto de saturación de la fibra, fueron prácticamente despreciables en ambos materiales, aunque significativamente superior en el material de Argentina, lo cual podría tener relación con la edad de los individuos y la presencia de madera juvenil. Los movimientos en sentido radial y tangencial fueron considerables, y significativamente superiores 
en el material procedente de España aunque con una relación entre ambos, T/R, significativamente superior en el material de Argentina lo que ocasiona alabeos y torceduras de la madera durante el proceso secado. Además puede inferirse que dicha inestabilidad se hará evidente más tempranamente en el material de procedencia Argentina de acuerdo con su PSPC superior. Los parámetros volumétricos fueron consistentes con los parámetros dimensionales.

\subsubsection{Higroscopicidad}

\section{Análisis descriptivo por procedencias}

En la Tabla 25 se resumen los resultados del análisis de higroscopicidad llevado a cabo en el material de ambas procedencias; otros parámetros descriptivos como así también los test de normalidad son detallados en Anejos 6.1.1.4.

Tabla 25. Higroscopicidad: análisis descriptivo.

\begin{tabular}{cccc}
\hline \multirow{2}{*}{ Procedencia } & \multirow{2}{*}{$\mathrm{n}^{*}$} & \multicolumn{2}{c}{ hi* $^{*}$} \\
\cline { 3 - 4 } & \multirow{2}{*}{25} & $\begin{array}{c}\text { Media (adimensional) } \\
(\mathrm{CV} \%)^{*}\end{array}$ & $\begin{array}{c}\text { Mín.-Máx. } \\
(\text { IQR)* }\end{array}$ \\
\hline \multirow{2}{*}{ España } & \multirow{2}{*}{$\begin{array}{c}0,0025 \\
(13,57)\end{array}$} & $\begin{array}{c}0,0017-0,0030 \\
(0,00037)\end{array}$ \\
\hline \multirow{2}{*}{ Argentina } & \multirow{2}{*}{00} & $\begin{array}{c}0,0023 \\
(15,51)\end{array}$ & $0,0013-0,0034$ \\
& & $(0,00047)$ \\
\hline
\end{tabular}

*hi: higroscopicidad; CV: coeficiente de variación, en \%; IQR: recorrido intercuartílico.

Los gráficos de caja y bigotes y el histograma de frecuencias para la higroscopicidad se presentan en la Figura 93 y Figura 94 para el material de España, y en la Figura 95 y Figura 96 para el material de Argentina.

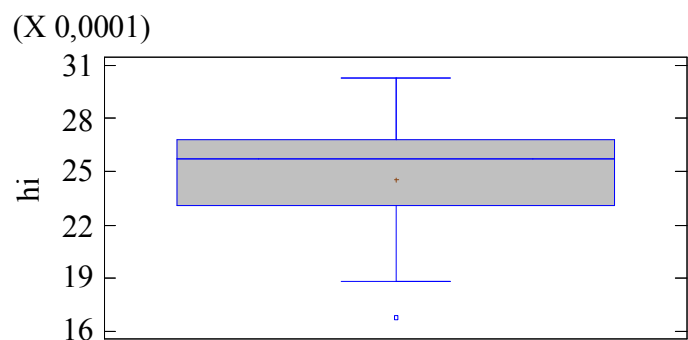

Figura 93. Gráfico de Caja y Bigotes: hi procedencia España.

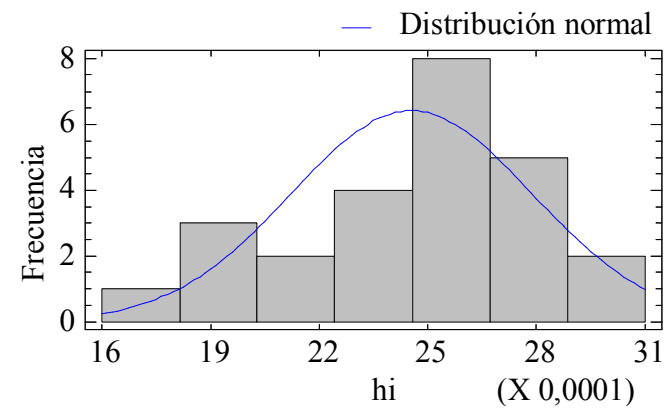

Figura 94. Histograma de frecuencias: hi procedencia España. 


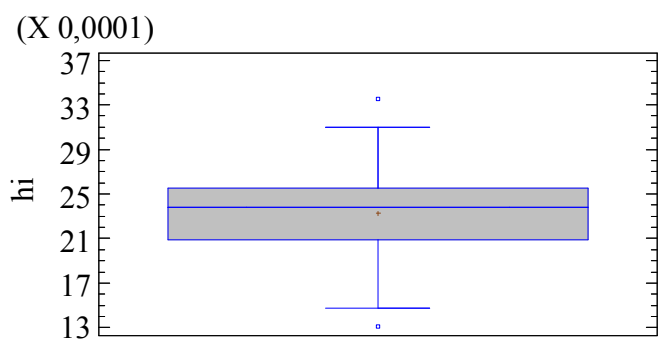

Figura 95. Gráfico de Caja y Bigotes: hi procedencia Argentina.

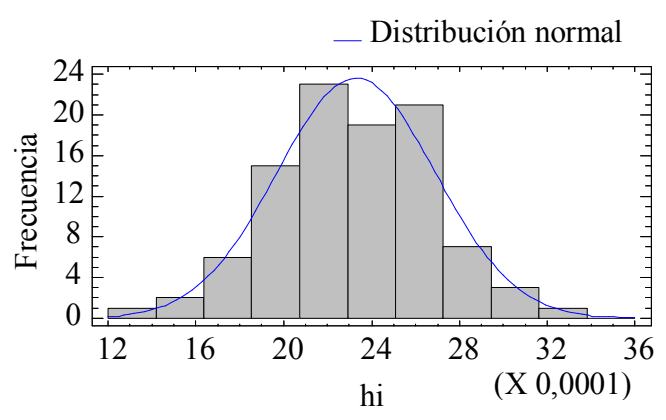

Figura 96. Histograma de frecuencias: hi procedencia Argentina.

A fin de contrastar los resultados obtenidos entre procedencias, a continuación se detalla el análisis comparativo.

\section{Análisis comparativo entre procedencias}

El análisis comparativo de hi entre procedencias se muestra en la Tabla 26; la constatación estadística se detalla en Anejos 6.1.1.4.

Tabla 26. hi - procedencias: análisis comparativo

\begin{tabular}{|c|c|c|c|c|c|}
\hline ANOVA* & Razón-F & P-valor & & Procedencia & Grupos homogéneos** \\
\hline \multirow{2}{*}{$\begin{array}{c}\text { hi - } \\
\text { Procedencias }\end{array}$} & \multirow{2}{*}{2,45} & \multirow{2}{*}{0,12} & \multirow{2}{*}{$\begin{array}{c}\text { Test de } \\
\text { Tukey HSD }\end{array}$} & España & A \\
\hline & & & & Argentina & $\mathrm{A}$ \\
\hline
\end{tabular}

*hi: higroscopicidad; **letras diferentes denotan diferencias significativas, Tukey HSD $(\mathrm{P}<0,05)$.

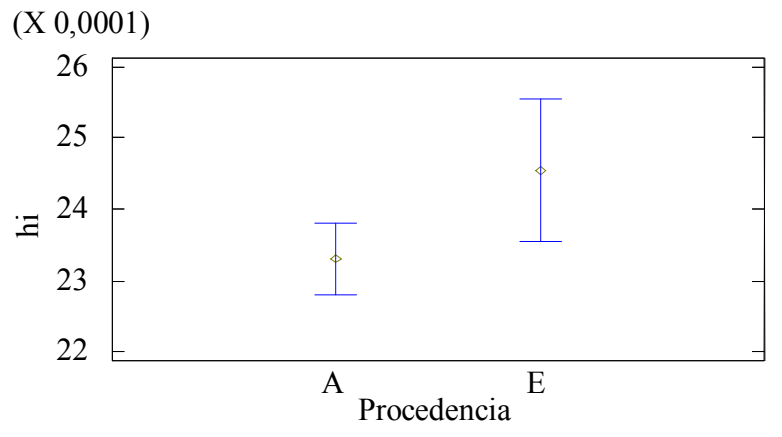

Figura 97. Gráfico de medias e IC95\% Tukey HSD: hi - procedencias.

Ambas maderas presentan una higroscopicidad débil (UNE 56540: 1978), en función de los datos de higroscopicidad obtenidos y la ausencia de significación estadística encontrada, con lo que la variación promedio de la densidad será estadísticamente similar en ambos casos, aproximadamente entre 0,0023 y 0,0025 por cada $1 \%$ de variación en el contenido de humedad. 


\subsubsection{Propiedades mecánicas.}

En este apartado se detallan los resultados de los ensayos mecánicos realizados en el material de ambas procedencias.

\subsubsection{Flexión estática}

\section{Análisis descriptivo por procedencias}

Los parámetros descriptivos del módulo de elasticidad (MOE) y de rotura (MOR) en flexión estática, se detallan en la Tabla 27.

Tabla 27. Flexión estática: análisis descriptivo

\begin{tabular}{cccccc}
\hline \multirow{2}{*}{ Procedencia } & \multirow{2}{*}{$\mathrm{n}^{*}$} & \multicolumn{3}{c}{ MOE* $^{\text {Media (MPa) }}$} & \multicolumn{2}{c}{ MOR* $^{*}$} & $\begin{array}{c}\text { Mín-Máx. } \\
(\mathrm{CV} \%)\end{array}$ & $\begin{array}{c}\text { Media (MPa) } \\
(\mathrm{IQR})\end{array}$ & $\begin{array}{c}\text { Mín-Máx. } \\
(\text { IQR })\end{array}$ \\
\hline \multirow{2}{*}{ España } & \multirow{2}{*}{75} & $\begin{array}{c}4980,1 \\
(14,92)\end{array}$ & $\begin{array}{c}3398,89-6596,73 \\
(1003,03)\end{array}$ & $\begin{array}{c}67,93 \\
(15,79)\end{array}$ & $\begin{array}{c}46,93-89,01 \\
(16,67)\end{array}$ \\
\hline \multirow{2}{*}{ Argentina } & \multirow{2}{*}{75} & $\begin{array}{c}5591,9 \\
(19,60)\end{array}$ & $\begin{array}{c}3076,04-7797,41 \\
(1721,73)\end{array}$ & $\begin{array}{c}58,20 \\
(15,97)\end{array}$ & $\begin{array}{c}38,43-77,96 \\
(14,85)\end{array}$ \\
\hline
\end{tabular}

*n: número de individuos; MOE: módulo de Elasticidad; MOR: módulo de Rotura; CV: coeficiente de variación, en \%; IQR: recorrido intercuartílico.

Los gráficos de dispersión de datos y los histogramas de frecuencias para ambas variables, diferenciados por procedencias, se muestran en la Figura 98 a Figura 103. En Anejos 6.1.2.1 se detallan otros parámetros descriptivos como así también el análisis de constatación de normalidad de las variables.

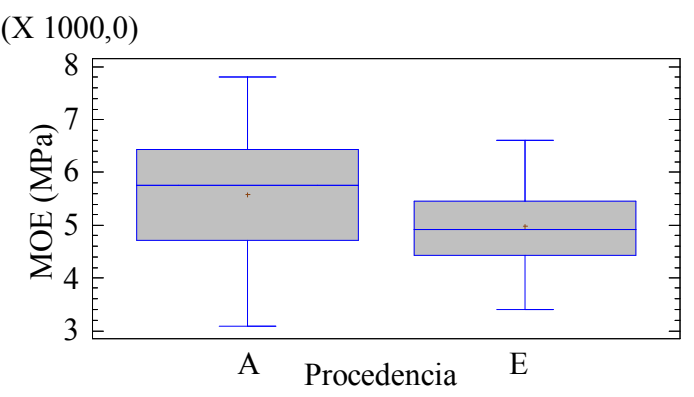

Figura 98. Gráfico de Caja y Bigotes: MOE por procedencias.

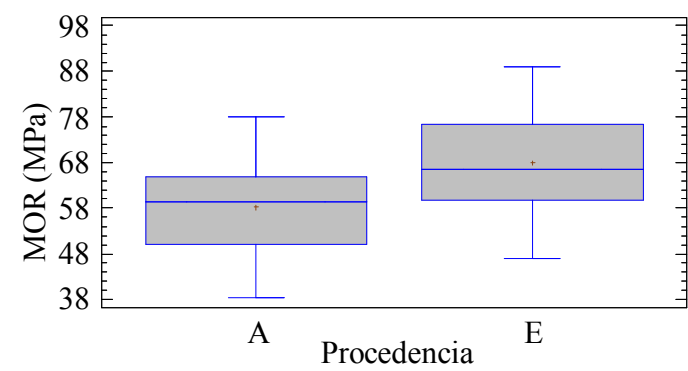

Figura 99. Gráfico de Caja y Bigotes: MOR por procedencias. 


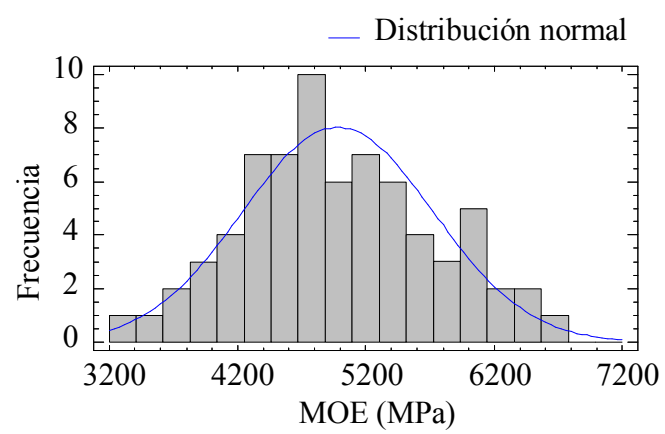

Figura 100. Histograma de frecuencias MOE España.

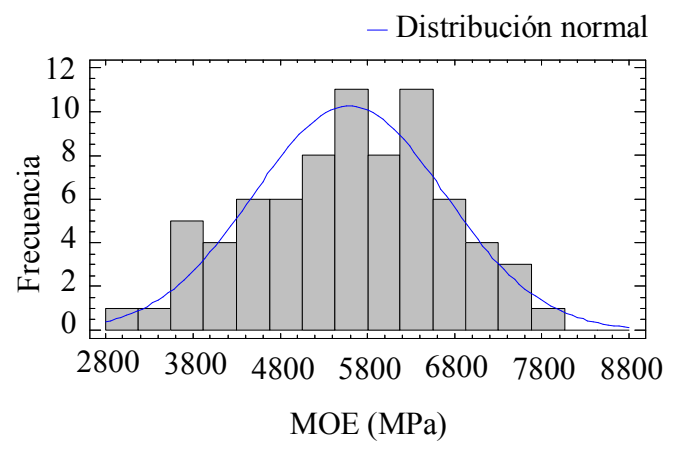

Figura 102. Histograma de frecuencias: MOE Argentina.

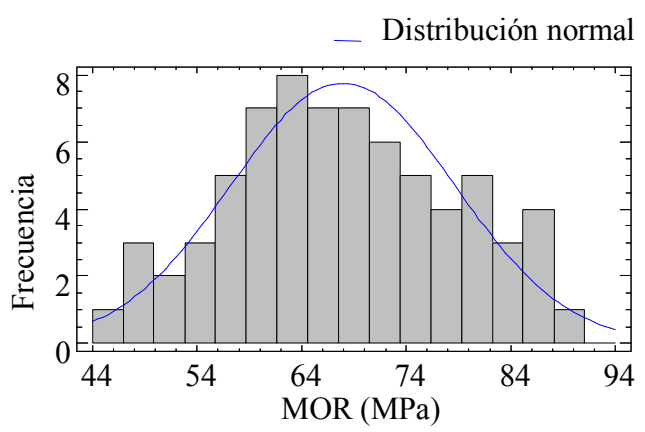

Figura 101. Histograma de frecuencias MOR España.

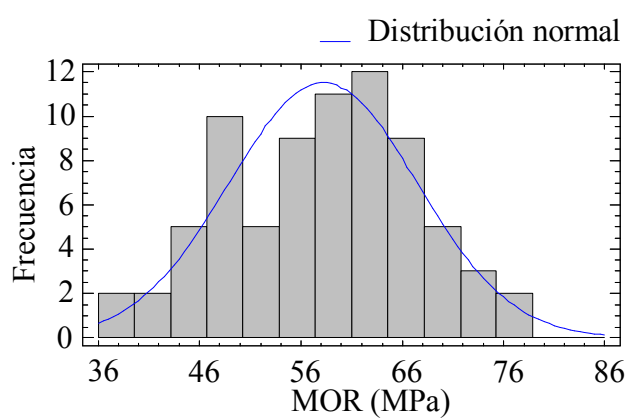

Figura 103. Histograma de frecuencias: MOR Argentina.

\section{Análisis comparativo entre procedencias}

En la Tabla 28 se presenta el análisis comparativo (prueba de Kruskal Wallis) para el MOE y MOR en flexión estática considerando ambas procedencias, mientras que los resultados de los test de comparaciones múltiples para las medianas (Kruskal Wallis) y para las medias (ANOVA) se representan en la Figura 104 y en la Figura 105, respectivamente. El incumplimiento del supuesto de homocedasticidad, corroborado mediante test de Levene, se detalla en Anejo 6.1.2.1.

Tabla 28. Flexión estática: análisis comparativo por procedencias.

\begin{tabular}{cccc}
\hline & MOE* & \multicolumn{2}{c}{ MOR** $^{* *}$} \\
\hline Estad. & P-valor & Razón - F & P-valor \\
\hline 13,56 & 0,00 & 34,42 & 0,00 \\
\hline
\end{tabular}

*Test de Kruskal-Wallis; Estad.: estadístico; **test de ANOVA. 


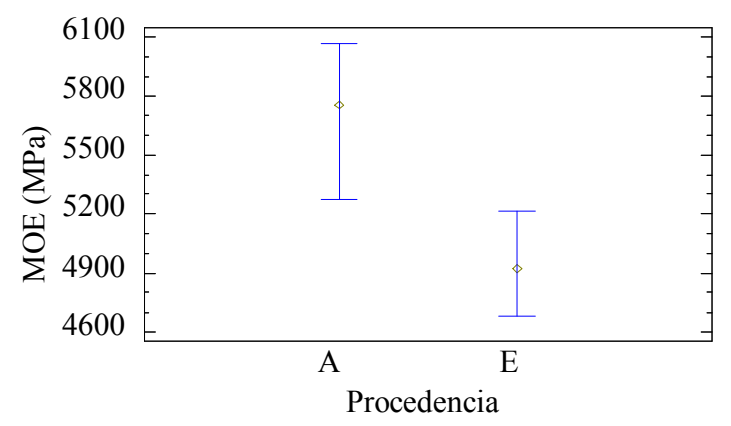

Figura 104. Gráfico de Medianas e IC 95\%: MOE por procedencias.

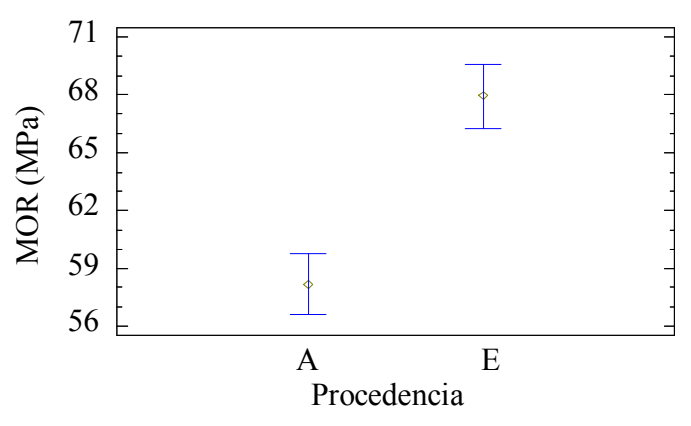

Figura 105. Gráfico de Medias e IC 95\% Tukey HSD: MOR por procedencias.

Del análisis comparativo se desprende que la mediana del MOE y la media del MOR se comportaron significativamente diferentes entre procedencias, siendo la mediana del MOE significativamente superior en el material de procedencia Argentina y la media del MOR significativamente superior en el material de procedencia España.

\subsubsection{Dureza}

La dureza, tal y como se describió en Materiales y Métodos, fue evaluada en material de ambas procedencias y empleando diferentes técnicas, acorde a las normativas nacionales vigentes en cada país: dureza Monnin (UNE 56534:1977); dureza Janka (9570:1971). Dado que son diferentes metodologías/determinaciones, el análisis comparativo no será realizado.

\section{Análisis descriptivo por procedencias}

La Tabla 29 muestra el resumen descriptivo de la dureza obtenida (Anejos 6.1.2.2) En la Figura 106 y Figura 107 se representa el gráfico de caja y bigotes y el histograma de frecuencias para el material de España, mientras que en la Figura 110 y Figura 111 se muestra ambos gráficos para el material de Argentina.

Tabla 29. Dureza: análisis descriptivo.

\begin{tabular}{cccccccc}
\hline \multirow{2}{*}{ Procedencia } & Norma & \multirow{2}{*}{ n $^{*}$} & $\begin{array}{c}\text { Dedia (MPa) } \\
\text { (CV \%)* }\end{array}$ & Mín. & Máx. & IQR* & Normalidad \\
\hline España & UNE & 320 & $\begin{array}{c}4,45 \\
(18,03)\end{array}$ & 2,49 & 6,52 & 1,14 & Sí \\
\hline Argentina & IRAM & 42 & $\begin{array}{c}17,68 \\
(19,82)\end{array}$ & 12,26 & 25,13 & 6,13 & Sí \\
\hline
\end{tabular}

*n: número de individuos; CV: coeficiente de variación, en \%; IQR: recorrido intercuartílico. 


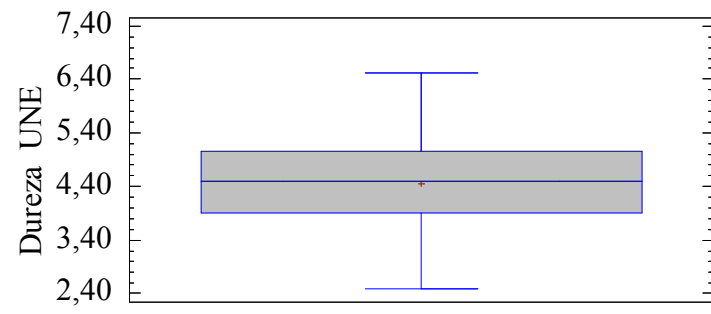

Figura 106. Gráfico de Caja y Bigotes Dureza Monnin (UNE).

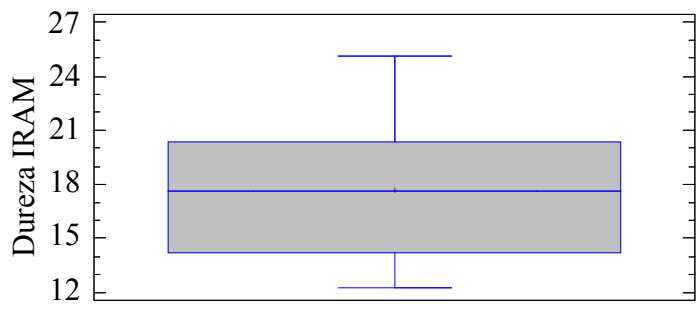

Figura 108. Gráfico de Caja y Bigotes Dureza Janka (IRAM).

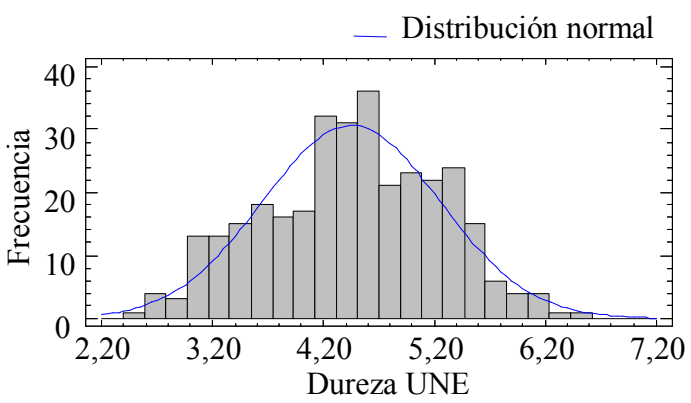

Figura 107. Histograma de frecuencias Dureza Monnin (UNE).

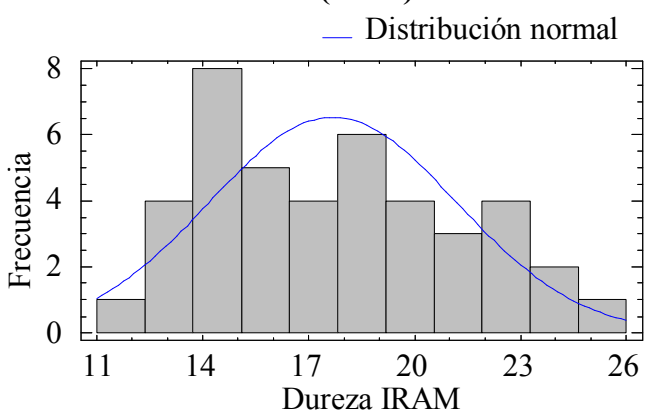

Figura 109. Histograma de frecuencias Dureza Janka (IRAM).

De acuerdo con los resultados de dureza puede observarse que la madera de ambas procedencias puede ser clasificable como blanda (UNE 56540:1978; Coronel, 1995)

\subsubsection{Compresión Paralela a las fibras}

\section{Análisis descriptivo por procedencias}

El análisis descriptivo de las variables módulo de elasticidad (MOE) y módulo de rotura (MOR) en compresión paralela a las fibras, se detalla en la Tabla 30.

Tabla 30. Compresión paralela a las fibras: análisis descriptivo.

\begin{tabular}{ccccccc}
\hline \multirow{2}{*}{ Procedencia } & \multirow{2}{*}{ Norma } & \multirow{2}{*}{ N $^{*}$} & \multicolumn{2}{c}{ MOE (MPa)* } & \multicolumn{2}{c}{ MOR (MPa)* } \\
\cline { 4 - 7 } & \multirow{2}{*}{ Media } & $\begin{array}{c}\text { Mín-Máx. } \\
(\mathrm{CQR}) *\end{array}$ & $\begin{array}{c}\text { Media } \\
(\mathrm{CV} \%)^{*}\end{array}$ & $\begin{array}{c}\text { Mín-Máx. } \\
(\mathrm{IQR}) *\end{array}$ \\
\hline \multirow{3}{*}{ España } & \multirow{2}{*}{ UNE } & \multirow{2}{*}{$\begin{array}{c}2346,62 \\
(18,21)\end{array}$} & $\begin{array}{c}1399,27-3556,19 \\
(559,97)\end{array}$ & $\begin{array}{c}37,92 \\
(11,06)\end{array}$ & $\begin{array}{c}27,99-47,94 \\
(5,98)\end{array}$ \\
\cline { 2 - 7 } & \multirow{2}{*}{ IRAM } & \multirow{2}{*}{50} & $\begin{array}{c}2863,42 \\
(6,40)\end{array}$ & $\begin{array}{c}2447,76-3251,63 \\
(235,78)\end{array}$ & $\begin{array}{c}32,87 \\
(5,06)\end{array}$ & $\begin{array}{c}28,25-36,83 \\
(1,84)\end{array}$ \\
\hline \multirow{2}{*}{ Argentina } & \multirow{2}{*}{ IRAM } & \multirow{2}{*}{55} & $\begin{array}{c}5544,44 \\
(31,65)\end{array}$ & $\begin{array}{c}2258,48-9217,28 \\
(2608,45)\end{array}$ & $\begin{array}{c}31,87 \\
(9,65)\end{array}$ & $\begin{array}{c}25,55-39,75 \\
(4,07)\end{array}$ \\
\hline
\end{tabular}

*n: número de individuos; MOE: módulo de Elasticidad; MOR: módulo de Rotura; CV: coeficiente de variación, en \%; IQR: recorrido intercuartílico.

La dispersión de los datos e histogramas de frecuencia para las variables MOE y MOR discriminados por norma y por procedencia, se representan gráficamente a continuación (Figura 110 a 
Figura 117). El resumen de otros parámetros descriptivos y los test de comprobación de normalidad de las variables es presentado en Anejos 6.1.2.3.

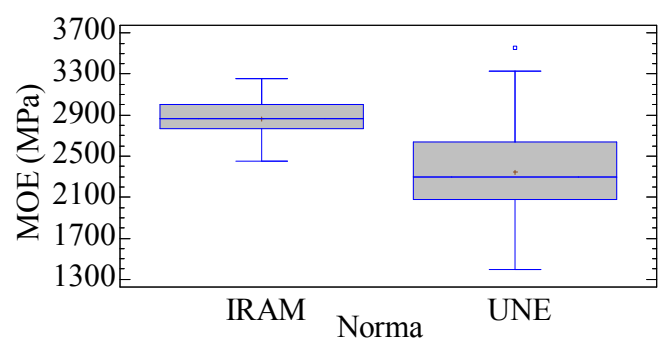

Figura 110. Gráfico de Caja y Bigotes: MOE por norma (España).

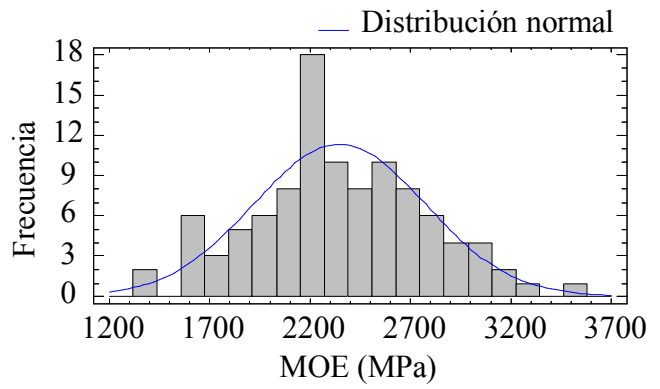

Figura 112. Histograma de frecuencias: MOENorma UNE (España).

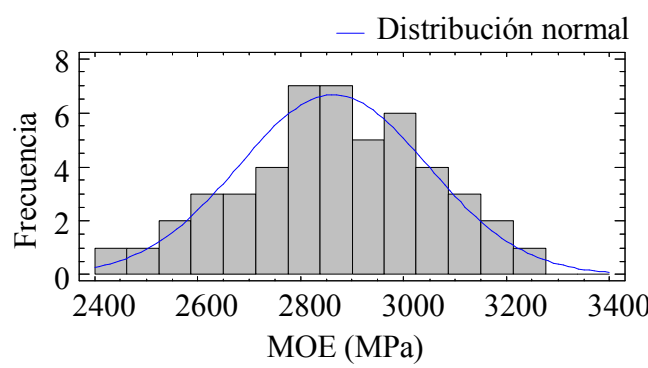

Figura 114. Histograma de frecuencias: MOENorma IRAM (España).

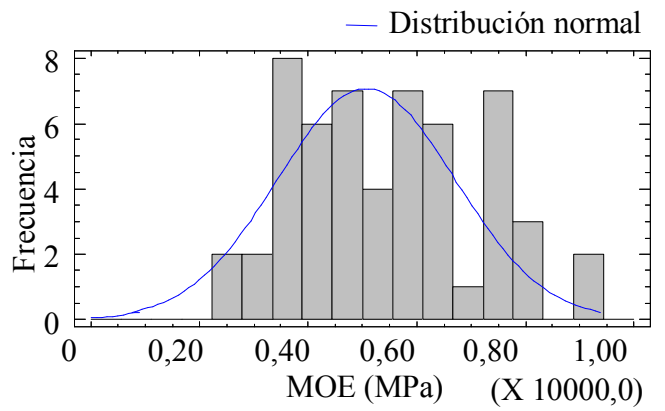

Figura 116. Histograma de frecuencias: MOENorma IRAM (Argentina).

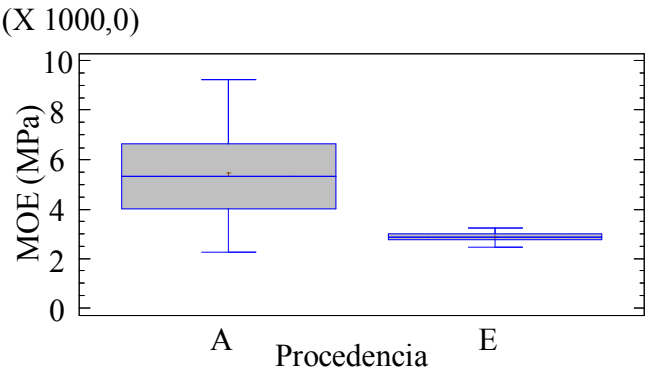

Figura 111. Gráfico de Caja y Bigotes: MOE por procedencia (IRAM).

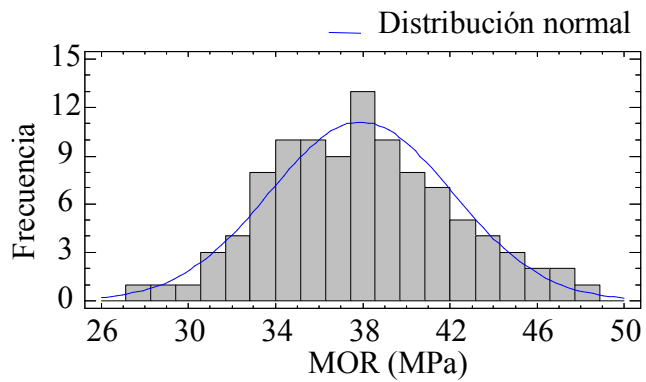

Figura 113. Histograma de frecuencias: MORNorma UNE (España).

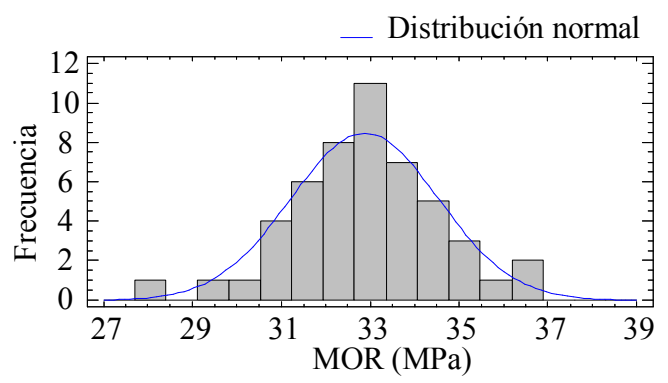

Figura 115. Histograma de frecuencias: MORNorma IRAM (España).

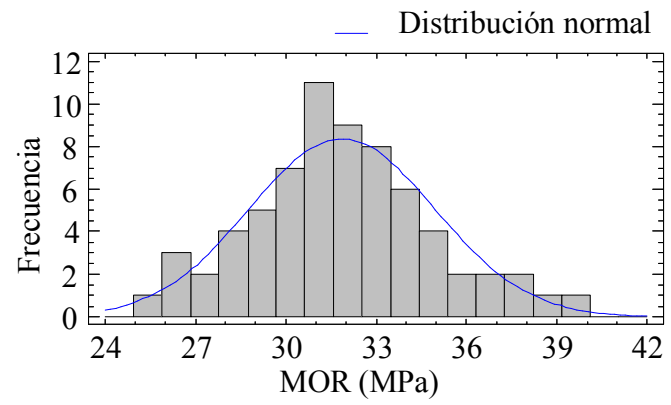

Figura 117. Histograma de frecuencias: MORNorma IRAM (Argentina). 


\section{Análisis comparativo entre normativas de ensavos: procedencia española}

El análisis comparativo (prueba de Kruskal-Wallis) para el MOE aplicando ambos procedimientos de ensayo en el material de España se muestra en la Tabla 31 y en la Figura 118 y Figura 119; el incumplimiento de los supuestos estadísticos se detalla en Anejo 6.1.2.3.

Tabla 31. MOE - MOR Chopo (España): análisis comparativo (Kruskal-Wallis).

\begin{tabular}{|c|c|c|c|c|}
\hline Procedencia & & Parámetro* & Estad. & P-valor \\
\hline \multirow{2}{*}{ España } & $\begin{array}{c}\text { Normativa de } \\
\text { ensayo }\end{array}$ & MOE & 52,21 & 0,00 \\
\hline & & MOR & 55,08 & 0,00 \\
\hline
\end{tabular}

*MOE: módulo de elasticidad; MOR: módulo de rotura; Estad.: estadístico.

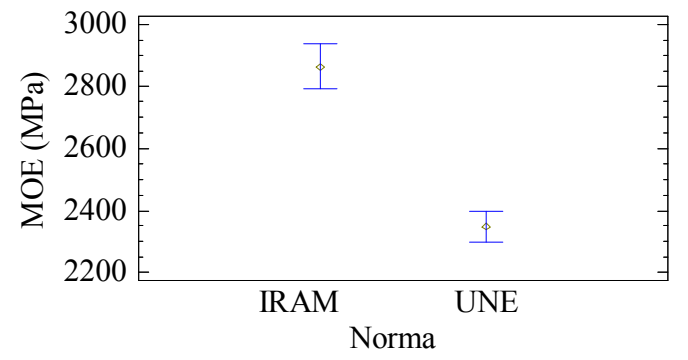

Figura 118. Gráfico de Medianas e IC 95\%: MOE por norma de ensayo (España).

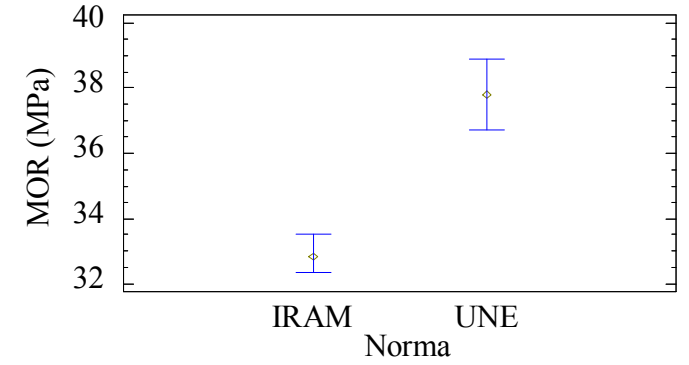

Figura 119. Gráfico de Medianas e IC 95\%: MOR por norma de ensayo (España).

De acuerdo con los datos resultantes, puede observarse que existen diferencias significativas entre las medianas del MOE y del MOR según la normativa de ensayo para el material procedente de España. Asimismo, de acuerdo a lo observado en la Figura 118 y en la Figura 119, el MOE es significativamente superior en el material dimensionado según norma IRAM, mientras que el MOR presenta el comportamiento contrario, siendo inferior en el material dimensionado según normativa IRAM, respectivamente. En concordancia con esto, el tamaño de las probetas afectaría los resultados de manera directamente proporcional para el MOE e inversamente proporcional para el MOR.

\section{Análisis comparativo por procedencias (norma IRAM).}

En correspondencia con una deficiencia en el dispositivo de ensayo, deflectómetro, empleado para determinar el acortamiento de las probetas en el material de procedencia Argentina, los valores de MOE correspondiente a dicho material presentaron una gran variabilidad, razón por la cual, el análisis comparativo fue realizado considerando únicamente los valores resistentes -MOR-, Tabla 32; Figura 120; los resultados sobre el incumplimiento de la homocedasticidad son mostrados en Anejos 6.1.2.3. 
Tabla 32. MOR (compresión paralela) - Procedencias: análisis comparativo.

\begin{tabular}{ccccc}
\hline KW & Estad. & P-valor & Procedencia & Grupos homogéneos** \\
\hline $\begin{array}{c}\text { MOR - } \\
\text { Procedencias }\end{array}$ & 5,56 & 0,02 & España & $\mathrm{A}$ \\
\cline { 3 - 5 } & & & Argentina & $\mathrm{B}$ \\
\hline
\end{tabular}

*KW: Test de Kruskal-Wallis; MOR: módulo de rotura; Estad.: estadístico; **letras diferentes denotan diferencias significativas entre medianas.

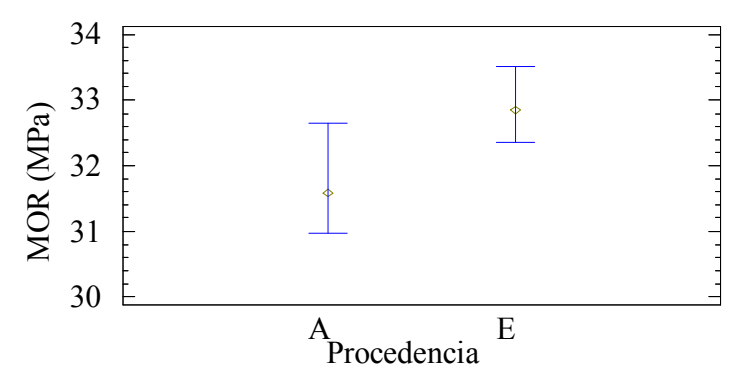

Figura 120. Gráfico de Medianas e IC 95\%: MOR (norma IRAM) por procedencia.

Puesto que el P-valor hallado fue inferior a $0,05 \%$ puede indicarse, con un nivel de $95 \%$ de confianza, que existen diferencias significativas entre procedencias para las medianas del MOR considerando el material dimensionado según normativa IRAM, comportándose estadísticamente superior el material de procedencia española, Figura 120.

El empleo de ambas metodologías permite inferir que el tamaño de la probeta es el responsable directo de los resultados del MOR, sin embargo, los valores tan dispares de MOE, del orden de 2300-2900 MPa, en material español, y de $5600 \mathrm{MPa}$ en material argentino, Tabla 30, pueden ser atribuibles a los equipos y metodologías ensayadas, según se ha descrito en Materiales y Métodos.

\subsubsection{Durabilidad natural}

Los resultados obtenidos sobre la resistencia al deterioro biológico causado por cada organismo xilófago (hongos basidiomicetos, ascomicetos y termitas) se exponen a continuación.

\subsection{Determinación de la durabilidad frente a hongos basidiomicetos xilófagos}

\section{Análisis descriptivo: material de procedencia española}

En la Tabla 33 se presentan las pérdidas de peso, Pp (\%), producidas por ambas cepas fúngicas en la madera de ensayo de Populus $x$ euramericana I-214 (ME) de procedencia española; las mismas se detallan identificadas por sección interna o próxima a la médula, y por sección externa o alejada a la médula, presentándose junto con los resultados obtenidos en la madera de referencia (MR) de Fagus sylvatica. 
Tabla 33. Pp (\%) - cepa fúngica: análisis descriptivo.

\begin{tabular}{|c|c|c|c|c|c|c|}
\hline Madera* & $\mathrm{n}^{*}$ & Cepa fúngica & Sección & $\begin{array}{l}\mathrm{Pp}(\%)^{*} \\
(\mathrm{CV} \%)^{*}\end{array}$ & $\mathrm{x}^{*}$ & $\begin{array}{l}\text { Mín.-Máx. } \\
\text { (IQR)* }\end{array}$ \\
\hline \multirow{2}{*}{$\mathrm{ME}$} & 40 & \multirow{3}{*}{$\begin{array}{l}\text { Trametes } \\
\text { versicolor }\end{array}$} & Interna & $\begin{array}{c}55,75 \\
(24,20) \\
\end{array}$ & 1,26 & $\begin{array}{c}25,11-80,86 \\
(18,40)\end{array}$ \\
\hline & 40 & & Externa & $\begin{array}{c}49,90 \\
(25,26)\end{array}$ & 1,13 & $\begin{array}{c}25,36-72,35 \\
(20,72)\end{array}$ \\
\hline MR & 30 & & & $\begin{array}{c}44,15 \\
(23,81) \\
\end{array}$ & & $\begin{array}{c}23,52-58,58 \\
(10,96)\end{array}$ \\
\hline \multirow{2}{*}{$\mathrm{ME}$} & 40 & \multirow{3}{*}{$\begin{array}{c}\text { Coniophora } \\
\text { puteana }\end{array}$} & Interna & $\begin{array}{c}26,62 \\
(22,27)\end{array}$ & 1,31 & $\begin{array}{c}20,95-37,95 \\
(8,03)\end{array}$ \\
\hline & 40 & & Externa & $\begin{array}{c}33,09 \\
(27,92)\end{array}$ & 1,63 & $\begin{array}{c}23,19-51,84 \\
(10,41)\end{array}$ \\
\hline MR & 30 & & & $\begin{array}{c}20,30 \\
(35,06)\end{array}$ & & $\begin{array}{c}13,78-35,18 \\
(7,64)\end{array}$ \\
\hline
\end{tabular}

*ME: material de ensayo: Populus x euramericana I-214; MR: material de referencia: Fagus sylvatica: n: número de individuos; Pp: pérdida de peso, en \%; CV: coeficiente de variación, en \%; x: relación pérdida de peso entre ME/MR; IQR: recorrido intercuartílico.

Los gráficos de caja y bigotes para la Pp (\%) obtenida en la madera procedente de España, diferenciada por cepa fúngica y comparada por secciones de estudio, se muestran en la Figura 121 y Figura 122. La ampliación del análisis descriptivo se detalla en Anejo 6.1.3.1.

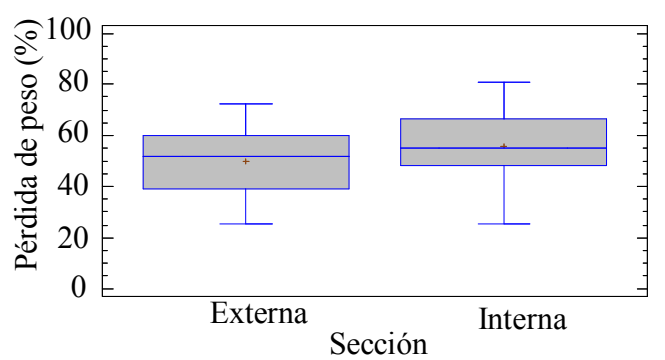

Figura 121. Gráfico de Caja y Bigotes: Pp (\%) Trametes versicolor - secciones

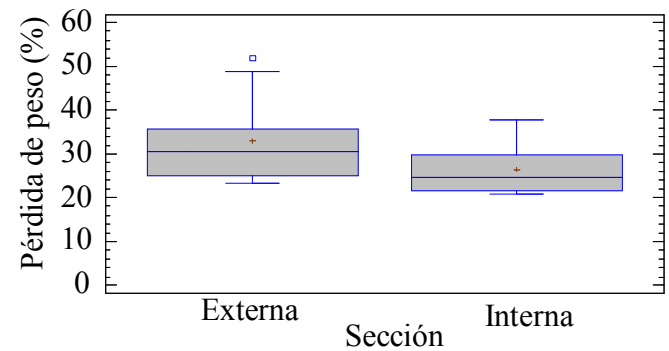

Figura 122. Gráfico de Caja y Bigotes: Pp (\%) Coniophora puteana -

\section{Análisis descriptivo: material de procedencia argentina}

La Tabla 34 muestra los resultados descriptivos en torno a la resistencia a la degradación fúngica de la madera de procedencia argentina; la Figura 123 muestra la dispersión de los datos de pérdida de peso en dicho material, considerando ambos agentes de deterioro. Tal como se indicó en materiales y métodos, y a diferencia de lo mostrado en el material procedente de España, el comportamiento de la madera de procedencia argentina fue analizado en la sección próxima a la médula. Atendiendo a la norma CEN/TS 15083-1 (2005) en todos los casos (procedencias y cepas), la validez del ensayo fue aceptada dada las Pp (\%) obtenidas en el material de referencia. 
Tabla 34. Pp (\%) - cepa fúngica: análisis descriptivo.

\begin{tabular}{|c|c|c|c|c|c|}
\hline Madera* & $\mathrm{n}^{*}$ & Cepa fúngica & $\begin{array}{l}\mathrm{Pp}(\%)^{*} \\
(\mathrm{CV} \%)^{*}\end{array}$ & $\mathrm{x}^{*}$ & $\begin{array}{c}\text { Mín.-Máx. } \\
\text { (IQR)* }\end{array}$ \\
\hline $\mathrm{ME}$ & 30 & \multirow{2}{*}{ T. versicolor } & $\begin{array}{c}38,32 \\
(28,09) \\
\end{array}$ & \multirow{2}{*}{1,21} & $\begin{array}{c}22,82-60,35 \\
(18,57)\end{array}$ \\
\hline MR & 30 & & $\begin{array}{c}31,62 \\
(23,93) \\
\end{array}$ & & $\begin{array}{c}19,95-48,88 \\
(11,67)\end{array}$ \\
\hline $\mathrm{ME}$ & 30 & \multirow{2}{*}{ C. puteana } & $\begin{array}{c}24,26 \\
(49,22) \\
\end{array}$ & \multirow{2}{*}{1,07} & $\begin{array}{c}12,23-50,5 \\
(16,43)\end{array}$ \\
\hline MR & 30 & & $\begin{array}{c}22,58 \\
(43,65)\end{array}$ & & $\begin{array}{c}12,03-40,16 \\
(15,16)\end{array}$ \\
\hline
\end{tabular}

*ME: material de ensayo: Populus x euramericana I-214; MR: material de referencia: Fagus sylvatica: n: número de individuos; Pp: pérdida de peso, en \%; CV: coeficiente de variación, en \%; x: relación pérdida de peso entre ME/MR; IQR: recorrido intercuartílico.

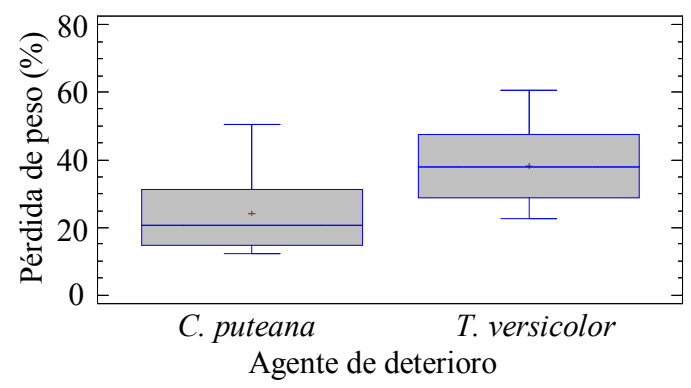

Figura 123. Gráfico de Caja y Bigotes: Pp (\%) Chopo (Argentina) - cepas fúngicas.

\section{Análisis comparativo: material de procedencia española}

En la Tabla 35 se presenta el análisis comparativo, mediante ANOVA, realizado con las Pp (\%) producidas por ambas cepas fúngicas contrastando secciones. La Figura 124 y la Figura 125 muestran los gráficos de comparación de medias e intervalos de confianza (IC) correspondiente a este análisis; los supuestos estadísticos son analizados en Anejo 6.1.3.1.

Tabla 35. Pp (\%) - secciones - Chopo España: análisis comparativo.

\begin{tabular}{cccc}
\hline Madera* & Cepa fúngica & Sección & Pp (\%)* \\
\hline \multirow{2}{*}{$\mathrm{ME}$} & T. versicolor & Interna & $55,75 \mathrm{aA}$ \\
\cline { 2 - 4 } & & Externa & $49,90 \mathrm{aA}$ \\
\cline { 2 - 4 } & C. puteana & Interna & $26,62 \mathrm{bB}$ \\
\cline { 2 - 4 } & & Externa & $33,09 \mathrm{bB}$ \\
\hline
\end{tabular}

*ME: material de ensayo: Populus x euramericana I-214; Pp: pérdida de peso, en \%; letras diferentes en minúscula indican diferencias significativas entre sección para cada cepa fúngica; letras diferentes en mayúscula indican diferencias significativas entre cepas para cada sección: test de Tukey $(\mathrm{p}<0,05)$. 


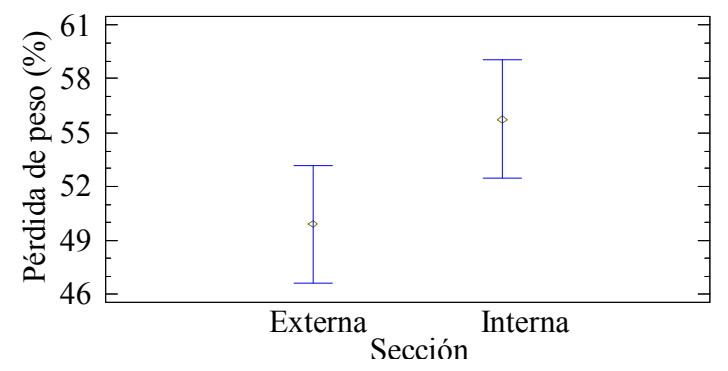

Figura 124. Gráfico de medias e IC 95\% Tukey HSD: Pp (\%) T. versicolor - Chopo (España) secciones.

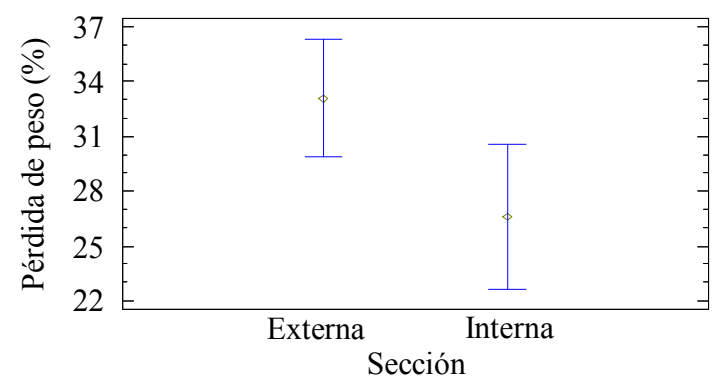

Figura 125. Gráfico de medias e IC 95\% Tukey HSD: Pp (\%) C. puteana - Chopo (España) secciones.

Mediante el análisis comparativo entre secciones, se observó que no existen valores de Pp (\%) estadísticamente diferenciables para ninguna de las cepas. Mientras que, comparando el daño producidos por los hongos en cada sección, se observaron valores estadísticamente superiores de Pp $(\%)$ en el material degradado por los hongos de pudrición blanca.

\section{Análisis comparativo: material de procedencia argentina}

En la Tabla 36 se muestra el análisis comparativo, para ambas cepas, contrastando el material correspondiente a la sección interna de procedencia argentina; en la Figura 126 se recoge el gráfico de comparación de medias e IC 95\% HSD de Tukey para T. versicolor y C. puteana, respectivamente.

Tabla 36. Pp (\%) - procedencias: análisis comparativo.

\begin{tabular}{cccc}
\hline Madera* $^{*}$ & Procedencia & Cepa fúngica & Pp (\%)* \\
\hline ME & Argentina & T. versicolor & $38,32 \mathrm{~A}$ \\
\cline { 3 - 4 } (sección interna) & C. puteana & $24,26 \quad \mathrm{~B}$ \\
\hline
\end{tabular}

*ME: material de ensayo: Populus x euramericana I-214; Pp: pérdida de peso, en \%; letras diferentes indican diferencias significativas entre cepas para el material de sección interna; test de Tukey $(\mathrm{p}<0,05)$.

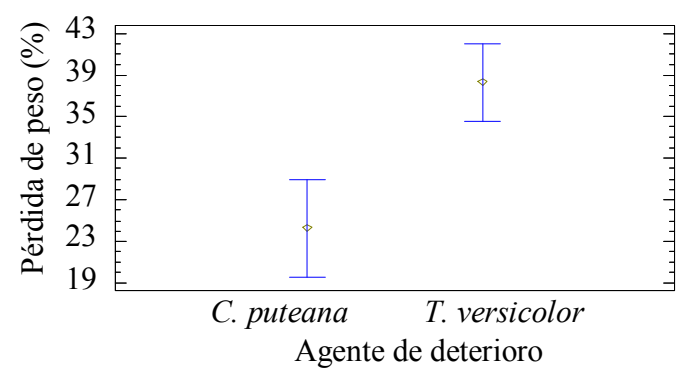

Figura 126. Gráfico de medias e IC 95\% Tukey HSD: Pp (\%) Chopo (Argentina) - agente de deterioro

\section{$\underline{\text { Análisis comparativo entre procedencias (sección interna) }}$}

En la Tabla 37 se muestra el análisis comparativo, para ambas cepas, contrastando el material correspondiente a la sección interna en las dos procedencias; en la Figura 127 y Figura 128 se recogen 
los gráficos de comparación de medias e IC 95\% HSD de Tukey para T. versicolor y C. puteana, respectivamente.

Tabla 37. Pp (\%) - procedencias: análisis comparativo.

\begin{tabular}{|c|c|c|c|}
\hline Madera* & Cepa fúngica & Procedencia & $\operatorname{Pp}(\%)^{*}$ \\
\hline \multirow{4}{*}{ ME } & \multirow{2}{*}{ T. versicolor } & España & $55,75 \mathrm{a}$ \\
\hline & & Argentina & $38,32 \mathrm{bA}$ \\
\hline & \multirow{2}{*}{ C. puteana } & España & $26,62 \mathrm{c}$ \\
\hline & & Argentina & $24,26 \mathrm{cB}$ \\
\hline
\end{tabular}

*ME: material de ensayo: Populus x euramericana I-214; Pp: pérdida de peso, en \%; letras diferentes en minúscula indican diferencias significativas entre procedencias, para cada cepa fúngica; letras diferentes en mayúscula indican diferencias significativas entre cepas para el material de sección interna, de procedencia Argentina; test de Tukey $(p<0,05)$.

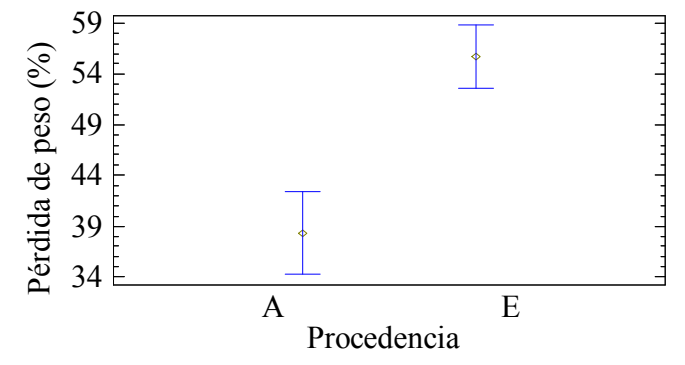

Figura 127. Gráfico de medias e IC 95\% Tukey HSD: Pp (\%) T. versicolor - Chopo - procedencias

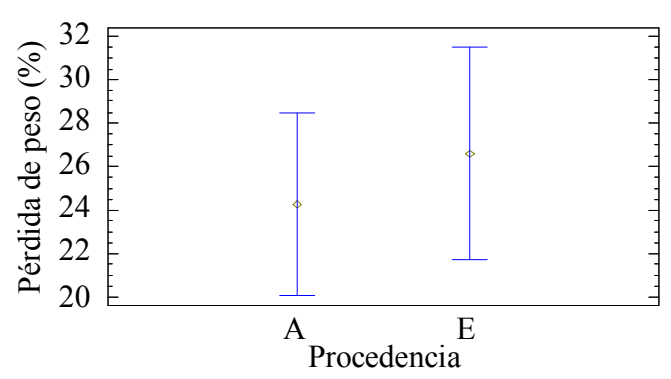

Figura 128. Gráfico de medias e IC 95\% Tukey HSD: Pp (\%) C. puteana - Chopo - procedencias

Del análisis comparativo entre procedencias considerando sección interna, puede observarse que, en presencia de $T$. versicolor (pudrición blanca), la madera de procedencia española resultó significativamente más degradada, mientras que frente a C. puteana (pudrición parda), la degradación fue estadísticamente similar entre procedencias.

Del análisis comparativo entre cepas para el material de Argentina, se observó que la pérdida de peso resultó significativamente superior en el material expuesto a hongos de pudrición blanca.

De acuerdo con el análisis sobre la resistencia a la degradación causada por los agentes xilófagos basidiomicetos, y teniendo en cuenta el rango clasificatorio establecido en la norma EN 3501:1995, puede concluirse que la madera de chopo de ambas procedencias, resultó "No Durable" frente a la acción de dichos organismos, a pesar de las diferencias significativas halladas entre las pérdidas de peso causadas por ambas cepas. Visualmente el material degradado presentó los rasgos característicos de cada tipo de pudrición: consistencia fibrosa y color blanquecino para el material expuesto a $T$. versicolor, y consistencia frágil, patrón de fractura cúbica y coloración castaño-rojiza en las probetas expuestas a C. puteana (Schwarse, 2007).

El mayor porcentaje de pérdida de peso causado por T. versicolor en todos los casos, fue el esperado dada la mayor especificidad de esta cepa para con las maderas de frondosas, relacionado a su vez, con la presencia de radicales siringilos en la lignina constituyente, la cual es considerada menos 
resistente a la acción de los hongos xilófagos (Schwarse, 2007; Schwarse et al., 2000; Scheffer and Morrell, 1998; Highley et al., 1994). Resultados similares, en cuanto a la baja resistencia al deterioro de la madera de chopo expuesta a cepas de pudrición blanca, fueron obtenidos por otros autores para Populus deltoides cv Stoneville 66 (expuesta a Pycnoporus sanguineus) y Populus nigra cv. Italica (expuesta a Trametes versicolor), de procedencia Argentina (Keil et al., 2006 y Díaz et al., 2003).

Si bien la madera de chopo resultó con igual clase de resistencia frente a ambas cepas, debe tenerse en cuenta la mayor agresividad de las pudriciones pardas; este tipo de deterioro causa una considerable pérdida de las propiedades resistentes de la madera con bajos porcentajes de pérdida de peso (Blanchette, 1995; Wilcox, 1978; Winandy and Morrell, 1993), disminuyendo así la vida útil en servicio del material expuesto a solicitaciones elasto-resistentes estructurales (Murace et al., 2010; 2014), consecuencia de la degradación de los carbohidratos constituyentes de la capa S2 de la pared celular, que es el estrato comprometido con dichas propiedades de la madera.

Para cada cepa, la falta de diferencias significativas entre secciones (indicado con letras minúsculas) en el material de procedencia española, podría deberse a la corta edad de los individuos en estudio. La misma consideración puede realizarse teniendo en cuenta la sección interna en el material degradado por la cepa de pudrición parda, comparando ambas procedencias. De acuerdo con Matyás and Pezslen (1994), alrededor del 30-40\% de la madera de ensayo podría corresponderse con madera juvenil y carecer de duramen, o bien, su presencia ser prácticamente inexistente o no diferenciable. Igualmente, si bien el factor determinante de la durabilidad natural de la madera está representado por la presencia de extractivos tóxicos en el duramen (Bamber and Fukazawa, 1985), las especies del género Populus, en general, y el clon I-214, en particular, presentan un duramen poco resistente al ataque de hongos (Martinuzzi, 2013) por su condición de madera blanca, carente de dichos extractos. Por otra parte, si bien el daño producido por la cepa de pudrición blanca fue significativamente superior en la madera de procedencia española, en ambos casos se corresponden con la misma susceptibilidad frente a la acción de dicho organismo (clase de durabilidad 5, EN 350$1: 1995)$.

\subsection{Determinación de la durabilidad frente a hongos ascomicetos e imperfectos}

\section{Análisis descriptivo: material de procedencia española}

En la Tabla 38 se muestran los porcentajes de pérdidas de peso, Pp (\%), determinados en el ME y en el MR (haya) frente a los hongos de pudrición blanda; la dispersión de los datos representado a través del grafico de caja y bigotes, se muestra en la Figura 129. 
Tabla 38. Pp (\%) - sección - Chopo España: análisis descriptivo.

\begin{tabular}{cccccc}
\hline Madera* & $\mathrm{n}^{*}$ & Sección & $\begin{array}{c}\text { Pp (\%) } \\
(\mathrm{CV} \%)\end{array}$ & $\mathrm{x}^{*}$ & $\begin{array}{c}\text { Mín.- Máx. } \\
(\mathrm{IQR} *)\end{array}$ \\
\hline \multirow{2}{*}{$\mathrm{ME}$} & 30 & Interna & $\begin{array}{c}28,46 \\
(28,63)\end{array}$ & $\begin{array}{c}12,05-45,64 \\
(13,68)\end{array}$ \\
\cline { 2 - 5 } & 30 & Externa & $\begin{array}{c}24,95 \\
(23,46)\end{array}$ & 0,81 & $\begin{array}{c}17,86-39,33 \\
(8,99)\end{array}$ \\
\hline MR & 30 & $\begin{array}{c}30,69 \\
(19,25)\end{array}$ & $\begin{array}{c}19,62-41,22 \\
(7,38)\end{array}$ \\
\hline
\end{tabular}

*ME: material de ensayo $=$ Populus $x$ euramericana I-214; MR: material de referencia $=$ Fagus sylvatica; n: número de individuos; Pp: pérdida de peso, en \%; CV: coeficiente de variación, en \%; x: relación pérdida de peso entre ME/MR; IQR: Recorrido intercuartílico.

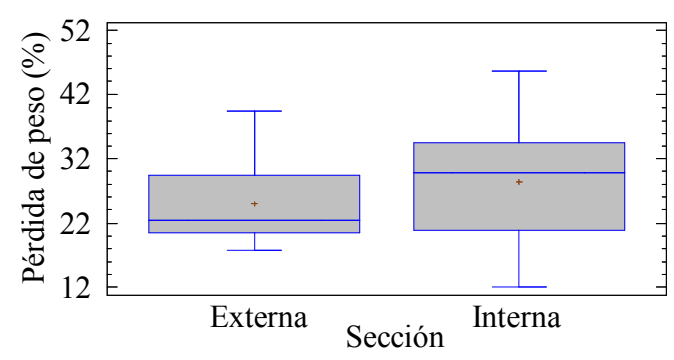

Figura 129. Gráfico de Caja y Bigotes: Pp (\%) - Chopo (España) - secciones.

\section{Análisis comparativo entre secciones: material de procedencia española}

En la Tabla 39 y en la Figura 130 se muestra el análisis comparativo entre ambas secciones. De acuerdo con el cumplimiento de los supuestos estadísticos, Anejo 4.1.2.4.2, se utilizó el análisis de la varianza para dicha comparación y el test de Tukey para la evaluación de las diferencias significativas.

Tabla 39. Pp (\%) - sección - Chopo España: análisis comparativo.

\begin{tabular}{ccccc}
\hline Madera* & Razón-F & P-valor & Sección & Pp $(\%)^{*}$ \\
\hline ME & 3,68 & \multirow{2}{*}{0,06} & Interna & $28,46 \mathrm{~A}$ \\
\cline { 3 - 5 } & & & Externa & $24,95 \mathrm{~A}$ \\
\hline
\end{tabular}

*ME: material de ensayo = Populus $x$ euramericana I-214; letras diferentes indican diferencias significativas entre secciones, test de Tukey HSD $(\mathrm{p}<0,05)$.

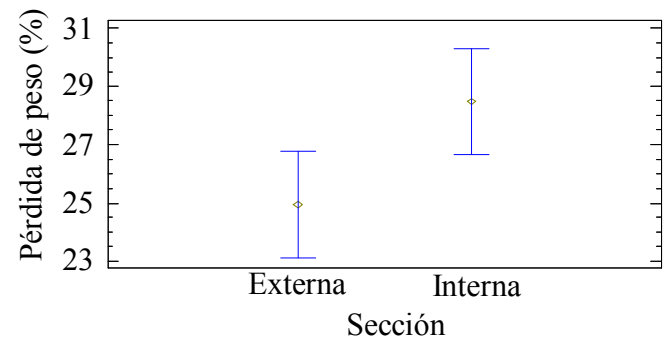

Figura 130. Gráfico de medias e IC 95\% Tukey

HSD: Pp (\%) Pudrición blanda - Chopo

(España) sección. 
De acuerdo a lo indicado en la Tabla 39 y en la Figura 130, no existen diferencias significativas entre las medias de pérdida de peso de cada sección analizada. En conclusión, la madera de Populus euramericana I-214 se clasifica como "No Durable" -CEN/TS 15083-2:2005- frente a la acción de hongos xilófagos ascomicetos e imperfectos, lo cual es estadísticamente similar entre ambas secciones de estudio (interna-externa). Visualmente el material degradado presentó los rasgos típicos de este tipo de degradación: consistencia blanda-esponjosa y coloración parda clara, producto del tipo de ataque y oxidación parcial de la lignina (Schwarse, 2007).

Estos organismos presentan un patrón de desarrollo específico y diferencial respecto al ataque causado por los hongos de pudrición blanca y parda, donde las hifas producen túneles dentro de las paredes celulares lignificadas del hospedante. En cualquier caso, químicamente, presentan similitudes de desarrollo a los generados por las cepas de pudrición parda, dado que concentran su ataque principalmente en la celulosa y hemicelulosa, mientras que la lignina es solo parcialmente modificada. En ambos casos se produce una desmetilación de los grupos metoxilos constituyentes (Schwarse, 2007). Esta similitud de comportamiento puede ser la causa de los valores absolutos semejantes que se encuentran en las $\mathrm{Pp}(\%)$ de las muestras.

Los resultados obtenidos coinciden con otros estudios, en cuanto a la baja resistencia de la albura a la degradación fúngica y la probable presencia de madera juvenil y duramen ausente o prácticamente inexistente (Scheffer and Morrell, 1998; Matyás and Pezslen, 1994).

\subsection{Determinación de la durabilidad frente a termitas}

\section{Análisis descriptivo por procedencias}

La evaluación de la durabilidad de la madera de chopo frente al ataque de termitas (Reticulitermes grassei) se recoge en la Tabla 40 (Figura 131 a Figura 134); el análisis se resume considerando la madera de ensayo -ME- (P. euramericana I-214) y de referencia -MR- (Pinus sylvestris), las procedencias y las secciones de estudio consideradas. Atendiendo a la normativa vigente (EN 117:2012), el ensayo resultó válido dado que al menos tres de las probetas de referencia de pino, se correspondieron con el nivel 4 en el examen visual y las colonias presentaron al menos el $50 \%$ de supervivientes (valores no presentados en la Tabla 40). 
Tabla 40. Valoración del daño causado por termitas: análisis descriptivo.

\begin{tabular}{|c|c|c|c|c|c|c|}
\hline Madera* & $\mathrm{n}^{*}$ & Procedencia & Sección & $\begin{array}{l}\mathrm{TS}(\%)^{*} \\
(\mathrm{CV} \%)\end{array}$ & $\begin{array}{l}\mathrm{Pp}(\%) \\
(\mathrm{CV} \%)\end{array}$ & Grado ataque \\
\hline \multirow{2}{*}{$\mathrm{ME}$} & \multirow{2}{*}{30} & \multirow{3}{*}{ España } & Interna & $\begin{array}{c}77,43 \\
(10,91)\end{array}$ & $\begin{array}{c}17,41 \\
(27,36)\end{array}$ & \multirow{2}{*}{4} \\
\hline & & & Externa & $\begin{array}{c}78,4 \\
(17,00)\end{array}$ & $\begin{array}{c}27,95 \\
(31,52)\end{array}$ & \\
\hline MR & 30 & & & $\begin{array}{c}85,25 \\
(11,90)\end{array}$ & $\begin{array}{c}11,01 \\
(4,29)\end{array}$ & 4 \\
\hline $\mathrm{ME}$ & 30 & \multirow{2}{*}{ Argentina } & Interna & $\begin{array}{c}74,77 \\
(11,65)\end{array}$ & $\begin{array}{l}13,83 \\
(9,36)\end{array}$ & 4 \\
\hline MR & 30 & & & $\begin{array}{c}71,9 \\
(4,95)\end{array}$ & $\begin{array}{l}11,63 \\
(7,82)\end{array}$ & 4 \\
\hline
\end{tabular}

*ME: material de ensayo $=$ Populus $x$ euramericana $\mathrm{I}-214 ;$ MR: material de referencia $=$ Pinus sylvestris; n: número de individuos; TS: tasa de supervivencia, en \%; Pp: pérdida de peso, en \%; CV: coeficiente de variación, en \%.

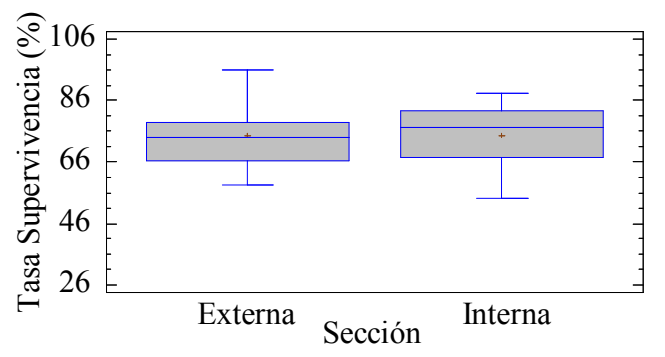

Figura 131. Gráfico de Caja y Bigotes: TS (\%) Chopo(España) - secciones

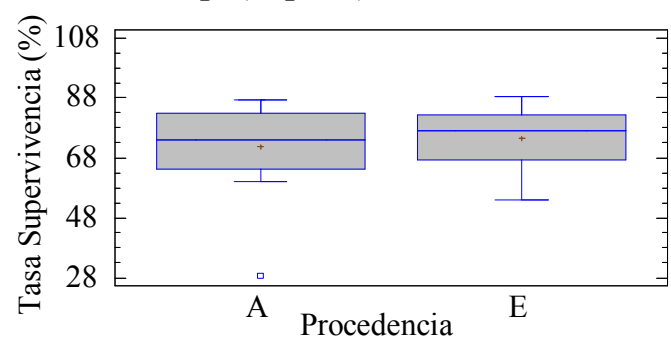

Figura 133. Gráfico de Caja y Bigotes: TS (\%) Chopo (sección interna) - procedencias

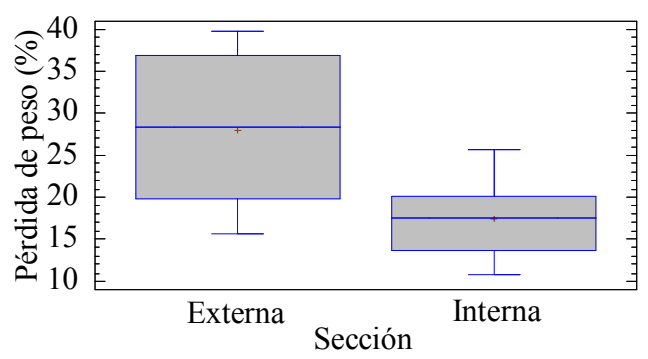

Figura 132. Gráfico de Caja y Bigotes: Pp (\%) Chopo (España) - secciones

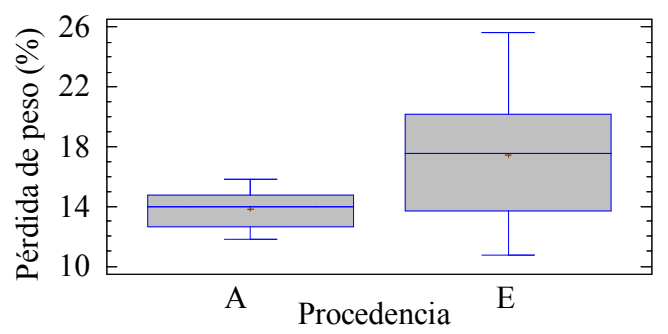

Figura 134. Gráfico de Caja y Bigotes: Pp (\%) Chopo (sección interna) - procedencias

\section{$\underline{\text { Análisis comparativo entre procedencias y secciones }}$}

En la Tabla 41, se muestra el análisis comparativo, ANOVA, de las TS (\%) y de las Pp (\%) comparando entre secciones, para la madera de procedencia española, y entre procedencias para la madera correspondiente a la sección interna. Los gráficos de medias y de medianas e IC 95\% para Pp (\%) y TS (\%), se muestran en la Figura 137 y Figura 138, respectivamente. En Anejos 6.1.3.3 se presentan los análisis de comprobación de los supuestos estadísticos. 
Tabla 41. Pp (\%) Termitas - sección - procedencias: análisis comparativo.

\begin{tabular}{|c|c|c|c|c|c|c|}
\hline Madera* & Procedencia & Sección & TS (\%) & P-valor & $\operatorname{Pp}(\%)^{*}$ & P-valor \\
\hline \multirow{3}{*}{ ME } & \multirow{2}{*}{ España } & Interna & $74,5 \mathrm{Ab}$ & \multirow{2}{*}{0,98} & $17,41 \mathrm{aA}$ & \multirow{2}{*}{0,01} \\
\hline & & Externa & $74,50 \quad b$ & & $27,95 \quad \mathrm{~B}$ & \\
\hline & Argentina & Interna & $67,76 \mathrm{~A}$ & $0,41 * *$ & $13,83 \mathrm{a}$ & $0,01 * *$ \\
\hline
\end{tabular}

*ME: material de ensayo = Populus $x$ euramericana I-214; Pp: pérdida de peso, en \%; letras diferentes en minúscula indican diferencias significativas entre secciones (chopo España); letras diferentes en mayúscula indican diferencias significativas entre procedencias (chopo sección interna); test de Tukey $(\mathrm{p}<0,05) ; *$ contraste entre procedencias (madera de sección interna).

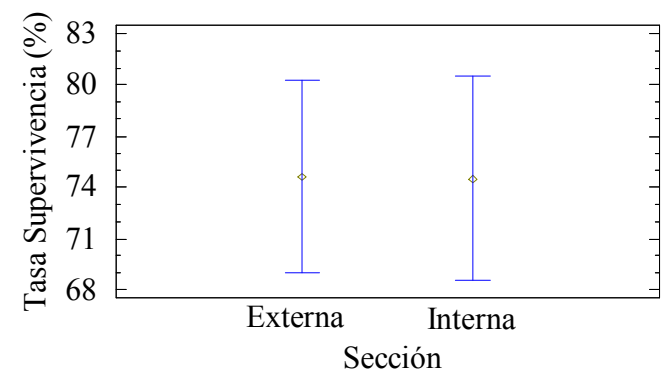

Figura 135. Gráfico de Medias e IC 95\% Tukey HSD: TS (\%) Chopo (España) - secciones.

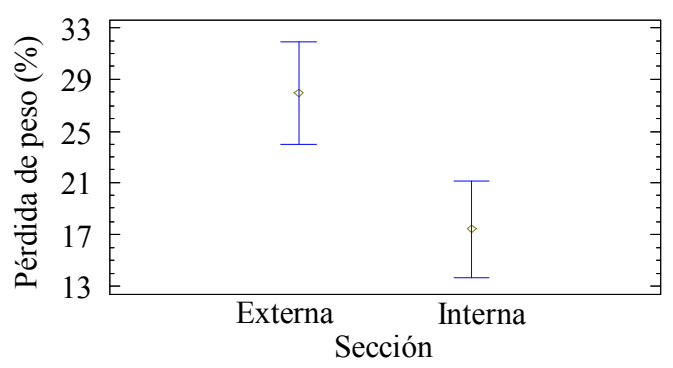

Figura 137. Gráfico de Medias e IC 95\% Tukey HSD: Pp (\%) Chopo (España) - secciones.

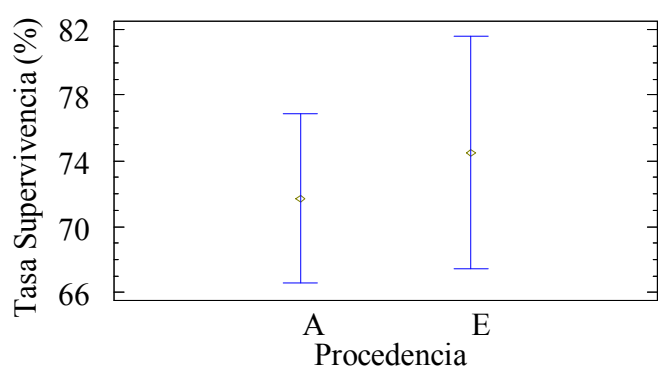

Figura 136. Gráfico de Medias e IC 95\% Tukey HSD: TS (\%) - Chopo - procedencias.

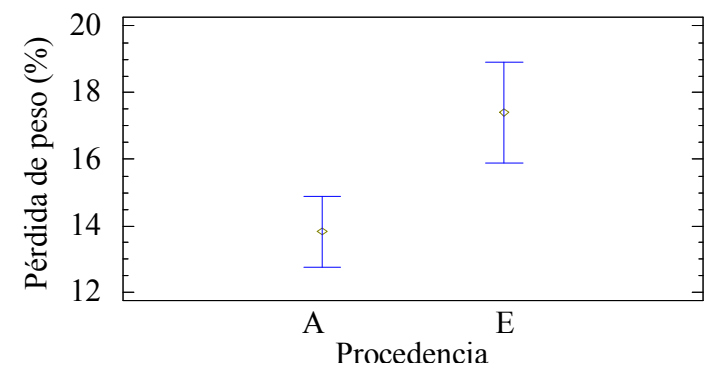

Figura 138. Gráfico de Medianas e IC 95\% Tukey HSD: Pp (\%) - Chopo - procedencias.

Del análisis comparativo puede observarse que, en cuanto a la TS (\%), no existieron diferencias significativas entre secciones ni procedencias; mientras que las $\mathrm{Pp}(\%)$ presentaron diferencias entre secciones pero no entre procedencias. Además, de acuerdo al grado de ataque indicado en la Tabla 40, único parámetro de estimación del daño indicado por la norma, el comportamiento de la madera fue igual en ambas situaciones (secciones y procedencias): "Sensible" EN 350-1:1995-, frente a la acción de termitas en ambas secciones de estudio (interna-externa). Este hecho podría indicar que el porcentaje de Pp empleado para la determinación de degradación causada por termitas no sea un valor confiable o comparable con el grado de ataque observado visualmente, y de hecho no se exige en la normativa correspondiente. Como dato de referencia puede indicarse que en un estudio realizado por Duarte et al. (2011), obtuvieron pérdidas de peso del orden del 16\% y grado de ataque 4 para madera de Fagus sylvatica, Pp del 12\% y grado de ataque 4 para madera de Pinus 
pinaster y $\mathrm{Pp}$ de 4,5\% y grado de ataque 3 para madera de Castanea sativa; valores dispares para un mismo grado visual.

Asimismo, un aspecto "criticable" de la estimación visual recomendada por la norma EN 117: 2012 puede ser su subjetividad para estimar el grado de ataque y su correspondiente aptitud de uso.

De acuerdo con los resultados hallados en torno a la resistencia a la degradación causada por los agentes xilófagos (hongos y termitas), la baja durabilidad determinada para el clon bajo estudio es coincidente con lo especificado por la Norma EN 350-2:2005 para distintas especies del género Populus. A causa de ello, el uso de la madera del clon I-214 de Populus x euramericana queda limitada a situaciones de muy bajo riesgo: uso interior, ambiente seco o bajo cubierta y al resguardo de la intemperie, y sin contacto con el suelo (Clase de uso 1-2; EN 335:2013), pudiendo estimarse una vida útil en situaciones de uso extremas -exterior en contacto con el suelo- menor a 5 años, IRAM 9600: 1998.

Si bien no se cuenta con ensayos de campo, los resultados obtenidos en laboratorio y desarrollados en esta sección, pueden ser utilizados a los fines clasificatorios normativos para Populus euramericana I-214, según lo establecido en la norma EN 350-1:1995.

\subsection{Probetas de pequeñas dimensiones y libres de defectos: consideraciones generales}

De acuerdo con el análisis realizado en el material de pequeñas dimensiones, libre de defectos puede indicarse que la madera de Populus x euramericana I-214 perteneciente a ambas procedencias, presenta características físicas y mecánicas similares: ligera o poco densa, nerviosa o inestable ante variaciones en el contenido de humedad, lo cual podría repercutir directamente en la aparición de defectos durante el proceso de secado, de baja dureza, de baja o media elasticidad y resistencia en solicitaciones longitudinales transversales a flexión y paralelas a compresión, no durable ante la acción de agentes xilófagos basidio-ascomicetos y sensible frente al ataque de termitas.

\subsection{Piezas macizas semi-estructurales (escala 1:5)}

\subsubsection{Presentación de los lotes estudiados}

Si bien la caracterización de la madera realizada en probetas de pequeñas dimensiones y libre de defectos brinda valores físico-mecánicos estimativos, al fin de su aplicabilidad, es necesario contar con datos más "reales", principalmente en lo que a comportamiento mecánico respecta. De acuerdo con esto, en este apartado se presentan los resultados obtenidos en piezas de tamaño semi-estructural, esto es, piezas dimensionadas empleando las proporciones estipuladas por la norma EN408:2011+A1:2012 para las piezas de tamaño estructural. Asimismo, en dicho material se han realizado todas aquellas determinaciones estipuladas para el material de tamaño estructural: inspección 
y medición de singularidades, comportamiento clasificatorio de la norma de clasificación visual española y determinación de parámetros no destructivos y destructivos.

\section{$\underline{\text { Análisis de centralidad y dispersión: material de ambas procedencias }}$}

En la Tabla 42 se describen los lotes de madera maciza correspondientes ambas procedencias, entendiéndose por "lote" a la madera de una misma especie, procedencia y tamaño, clasificada en un turno de trabajo (EN 14081-1:2006+A1:2011).

Tabla 42. Dimensiones nominales y contenido de humedad de ambos lotes.

\begin{tabular}{|c|c|c|c|c|c|c|c|c|c|}
\hline \multirow[b]{2}{*}{ Lotes } & \multirow[b]{2}{*}{$\mathrm{n}^{*}$} & \multicolumn{2}{|c|}{$\begin{array}{l}\text { Longitud } \\
(\mathrm{cm})\end{array}$} & \multicolumn{2}{|c|}{$\begin{array}{c}\text { Anchura } \\
(\mathrm{cm})\end{array}$} & \multicolumn{2}{|c|}{$\begin{array}{l}\text { Espesor } \\
(\mathrm{cm})\end{array}$} & \multicolumn{2}{|c|}{$\begin{array}{c}\text { Humedad } \\
(\%)\end{array}$} \\
\hline & & $\begin{array}{l}\text { Media } \\
(\mathrm{CV} \%)\end{array}$ & $\begin{array}{l}\text { Mín.- } \\
\text { Máx. } \\
\text { (IQR) }\end{array}$ & $\begin{array}{l}\text { Media } \\
\text { (CV\%) }\end{array}$ & $\begin{array}{l}\text { Mín.- } \\
\text { Máx. } \\
\text { (IQR) }\end{array}$ & $\begin{array}{l}\text { Media } \\
(\mathrm{CV} \%)\end{array}$ & $\begin{array}{l}\text { Mín.- } \\
\text { Máx. } \\
\text { (IQR) }\end{array}$ & $\begin{array}{l}\text { Media } \\
(\mathrm{CV} \%)\end{array}$ & $\begin{array}{l}\text { Mín.- } \\
\text { Máx. } \\
\text { (IQR) }\end{array}$ \\
\hline España & 149 & $\begin{array}{c}119,94 \\
(0,08)\end{array}$ & $\begin{array}{c}119,6- \\
120,1 \\
(0,10)\end{array}$ & $\begin{array}{c}6,19 \\
(0,86)\end{array}$ & $\begin{array}{c}5,71-6,29 \\
(0,02)\end{array}$ & $\begin{array}{c}4,13 \\
(1,10)\end{array}$ & $\begin{array}{c}3,97-4,43 \\
(0,02)\end{array}$ & $\begin{array}{c}7,78 \\
(8,96)\end{array}$ & $\begin{array}{l}6,57- \\
10,61 \\
(1,12) \\
\end{array}$ \\
\hline Argentina & 92 & $\begin{array}{c}120,23 \\
(0,30)\end{array}$ & $\begin{array}{c}119,00- \\
121,50 \\
(0,40)\end{array}$ & $\begin{array}{c}6,28 \\
(2,12)\end{array}$ & $\begin{array}{c}5,86-6,62 \\
(0,08)\end{array}$ & $\begin{array}{c}4,10 \\
(7,07)\end{array}$ & $\begin{array}{c}3,86-5,05 \\
(0,08)\end{array}$ & $\begin{array}{c}13,71 \\
(10,27)\end{array}$ & $\begin{array}{l}11,9- \\
18,27 \\
(1,22)\end{array}$ \\
\hline
\end{tabular}

*n: Número de individuos; CV: coeficiente de variación, en \%; IQR: recorrido intercuartílico.

Las dimensiones nominales mostradas en la Tabla 42 son aquellas correspondientes al $20 \%$ de contenido de humedad para lo cual se tuvo en cuenta lo especificado en la norma EN 336:2014 donde se menciona que por debajo del $20 \%$ del contenido de humedad las dimensiones se ven reducidas en un $25 \%$ por cada $1 \%$ de reducción del contenido de humedad en la madera. De todos modos, las dimensiones reales se ajustan a las tolerancias permitidas por la norma EN 336:2014.

\subsubsection{Ensayos no destructivos.}

\subsubsection{Inspección-medición de singularidades y clasificación visual.}

De acuerdo con la inspección y medición de las singularidades puede indicarse que en el material procedente de España se han hallado principalmente nudos de cara, nudos de canto y entrecasco. En el caso del material de procedencia Argentina, se resalta la presencia de galerías de insectos, junto a presencia de nudos de cara y canto.

\subsubsection{Comportamiento clasificatorio de la norma de clasificación visual.}

\section{Análisis descriptivo por procedencias}

En base a las singularidades halladas, en la Tabla 43 se recoge la respuesta visual clasificatoria del material correspondiente a ambos lotes. El comportamiento clasificatorio representado en clase "Estructural (ME-1 y ME-2)” y "No Estructural (Rechazo)”, como así también el comportamiento 
desglosado por clases ME-1, ME-2 y rechazo, Tabla 43, se representa en la Figura 139 y en la Figura 140 para el material de España y de Argentina, respectivamente.

Tabla 43. Respuesta clasificatoria y causa de rechazos según norma UNE-56544:2011.

\begin{tabular}{|c|c|c|c|c|c|c|}
\hline $\begin{array}{l}\text { RESPUESTA } \\
\text { CLASIFICATORIA }\end{array}$ & \multicolumn{6}{|c|}{ UNE-56544:2011* } \\
\hline \multirow{2}{*}{ Causa: } & ME-1 & ME-2 & Rechazo & ME-1 & ME-2 & Rechazo \\
\hline & $45(64,29)$ & & & $43(46,74)$ & & \\
\hline Nudos cara & & $1(1,43)$ & $5(7,13)$ & & $7(7,61)$ & $13(14,13)$ \\
\hline Nudos canto & & & $1(1,43)$ & & & $5(5,43)$ \\
\hline Nudos cara/canto & & $2(2,86)$ & $16(22,86)$ & & $1(1,09)$ & $7(7,61)$ \\
\hline Entrecasco & & & & & & $1(1,09)$ \\
\hline Galería de insecto & - & - & - & - & - & $15(16,30)$ \\
\hline $\begin{array}{l}\text { Número de individuos (n) } \\
\text { totales }\end{array}$ & & 70 & & & 92 & \\
\hline
\end{tabular}

*En cada columna se expresa: ‘número de individuos’ y (\% de representación), en ese orden.

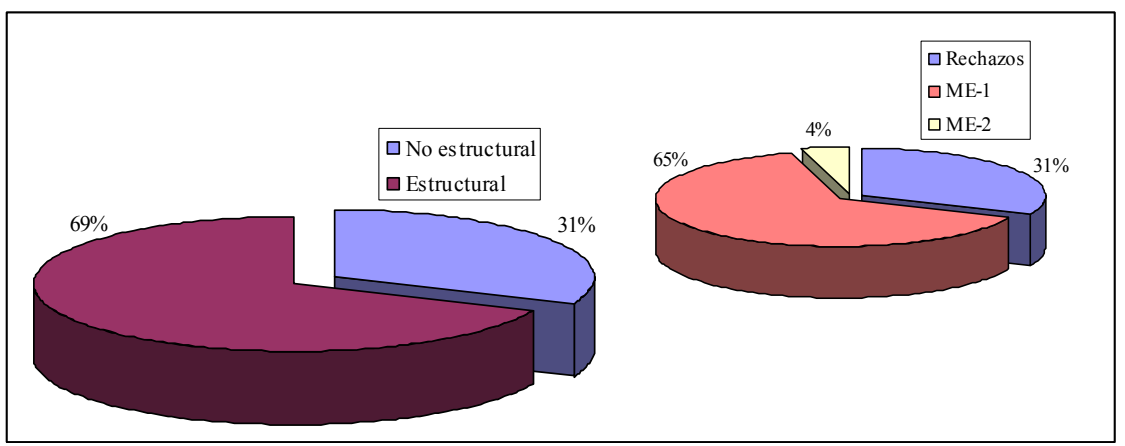

Figura 139. Representación porcentual de la clasificación visual UNE56544:2011(Chopo-España)

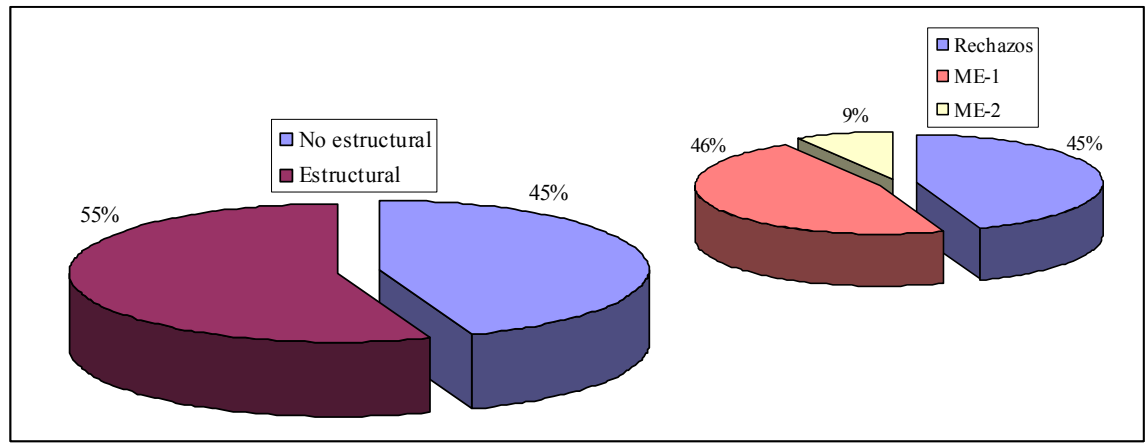

Figura 140. Representación porcentual de la clasificación visual UNE-56544:2011

(Chopo-Argentina) 
Tal como puede observarse en la Tabla 43, la causa más importante de rechazo en el material procedente de España lo marca la existencia de nudos, sin embargo, el material de procedencia Argentina si bien es altamente afectado por la presencia de nudos, es aún más "castigado" por la norma de clasificación UNE-56544:2011 a causa de los rechazos ocasionados por la presencia de daños -galerías- realizados por el taladrillo grande de los forestales (Megaplatypus mutatus $\mathrm{C}=$ Platypus sulcatus C.), una de las limitantes de las plantaciones Argentinas, actuales y potenciales, y causa de preocupaciones institucionales (Alfaro et al., 2007). Este insecto, nativo de América del Sur, perteneciente al orden Coleóptera, familia Platypodidae, forma parte de los comúnmente llamados "coleópteros o escarabajos de ambrosía", cuya característica común es el transporte de un hongo simbionte (hongo de ambrosía) dentro de pequeñas cavidades presentes en sus exoesqueletos (Alfaro, 2003). El hongo asociado a M. mutatus es Raffaelea santoroi (Guerrero, 1966), el cual crece en las paredes internas de las galerías causadas por el insecto y sirve para satisfacer las necesidades nutricionales primarias de éste; el micelio se ramifica, penetra el floema y el xilema, y esporula solamente dentro de las galerías excavadas en este último, tapizando y ennegreciendo sus paredes (Funes et al., 2013; Landi et al., 2011).

\subsubsection{Determinación de parámetros dinámicos mediante ensayos no destructivos}

A fin de continuar con la evaluación no destructiva en el material semi-estructural, a continuación se presentan los resultados obtenidos mediante la utilización de técnicas de ensayo no destructivas.

\section{Análisis descriptivo - NDT: material de procedencia española}

La presentación de los lotes descriptos a través de las variables no destructivas se muestra en la Tabla 44, Anejos 6.2.1.1.

Tabla 44. Evaluación mediante metodología no destructiva: análisis descriptivo

\begin{tabular}{ccccccc}
\hline \multirow{2}{*}{ Parámetro } & \multirow{2}{*}{$\mathrm{n}^{*}$} & \multirow{2}{*}{$\begin{array}{c}\text { Densidad } \\
\left(\mathrm{Kg} / \mathrm{m}^{3}\right)\end{array}$} & \multicolumn{2}{c}{ Vibraciones inducidas } & \multicolumn{2}{c}{ Ultrasonidos } \\
\cline { 4 - 7 } & & $\begin{array}{c}\text { Frecuencia } \\
(\mathrm{Hz})\end{array}$ & $\begin{array}{c}E_{\mathrm{d}}{ }^{*} \\
(\mathrm{MPa})\end{array}$ & $\begin{array}{c}\text { Velocidad } \\
(\mathrm{m} / \mathrm{s})\end{array}$ & $\begin{array}{c}\mathrm{E}_{\mathrm{d}}{ }^{*} \\
(\mathrm{MPa})\end{array}$ \\
\hline Media & \multirow{2}{*}{149} & $373,86-319,14^{* *}$ & 2159,88 & 9543,03 & 5021,37 & 9009,61 \\
$(\mathrm{CV} \%)$ & $(9,26)$ & $(7,01)$ & $(15,69)$ & $(5,68)$ & $(22,39)$ \\
\hline Min.-Máx. & \multirow{2}{*}{149} & $294,51-464,19$ & $1759,0-2478,0$ & $6345,97-12716,3$ & $4348,21-5702,53$ & $3147,9-13946,1$ \\
(IQR) & & $(46,57)$ & $(197,0)$ & $(1998,94)$ & $(378,75)$ & $(2152,49)$ \\
\hline *CV & & & &
\end{tabular}

*CV: coeficiente de variación, en \%; IQR: recorrido intercuartílico; n: número de individuos; $E_{\mathrm{d}}$ : módulo de elasticidad dinámico; $* * 5^{\circ}$ percentil (valor característico de la densidad, EN 384: 2010).

La dispersión de los datos de cada variable (densidad, frecuencia vibratoria, velocidad de ultrasonidos y $E_{\mathrm{d}}$ ), representada mediante gráficos de caja y bigotes y su distribución representada mediante el histograma de frecuencia, se detallan en las siguientes Figuras (Figura 141 a Figura 150). 


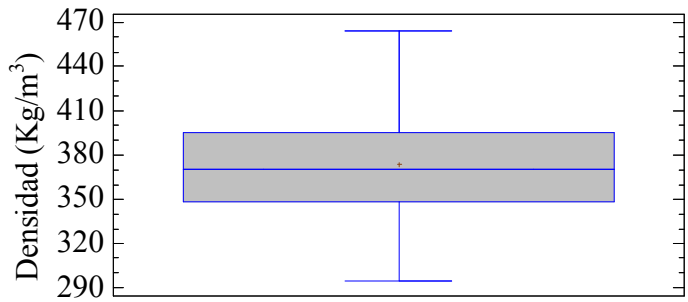

Figura 141. Gráfico de Caja y Bigotes: Chopo (España) - Densidad.

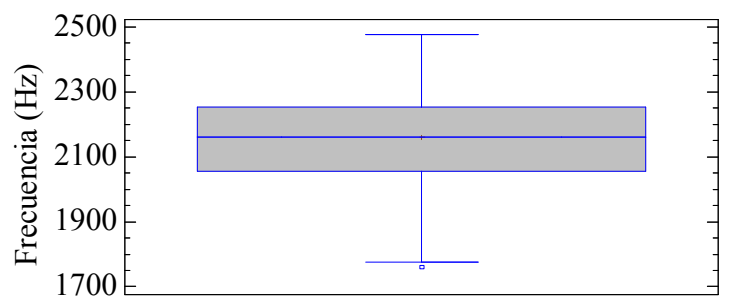

Figura 143. Gráfico de Caja y Bigotes: Chopo (España) - Fr (VI).

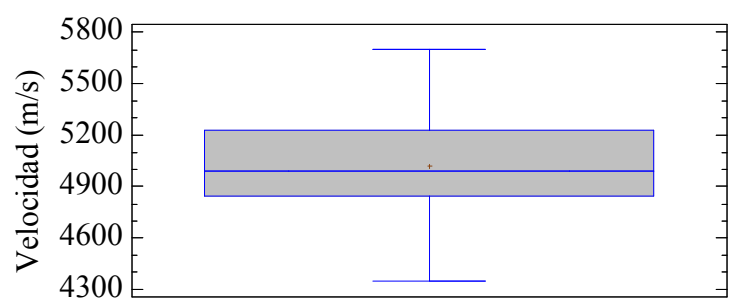

Figura 145. Gráfico de Caja y Bigotes: Chopo (España) - Vel (Ult).

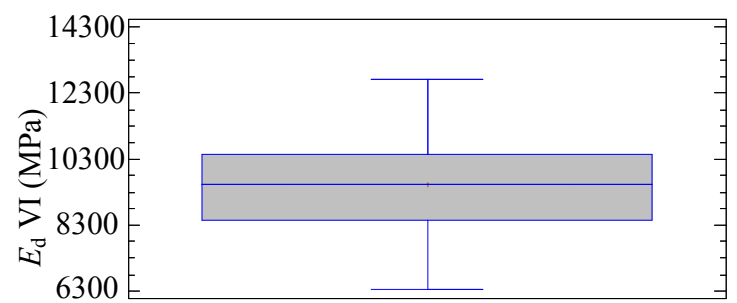

Figura 147. Gráfico de Caja y Bigotes: $E_{\mathrm{d}}-$ VI Chopo (España).

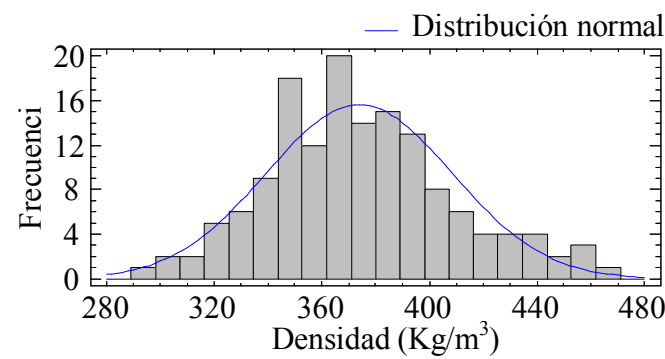

Figura 142. Histograma de Frecuencias: Chopo (España) - Densidad.

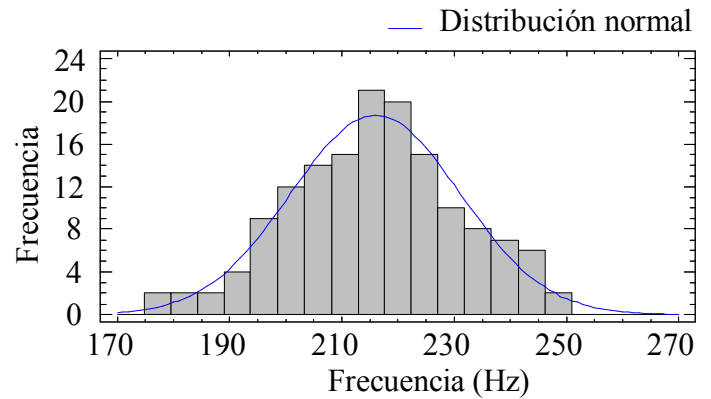

Figura 144. Histograma de Frecuencias: Chopo (España) - Fr (VI).

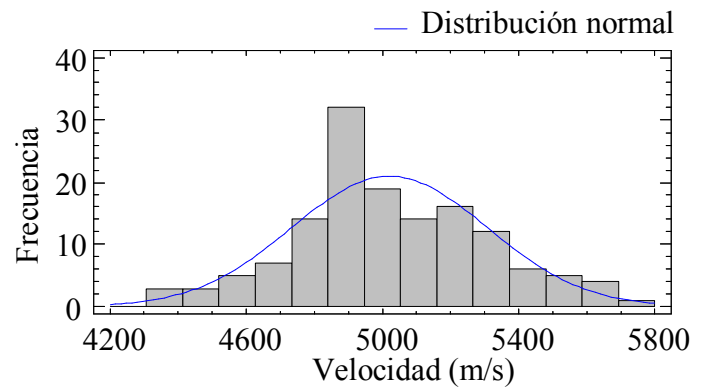

Figura 146. Histograma de Frecuencias: Chopo (España) - Vel (Ult).

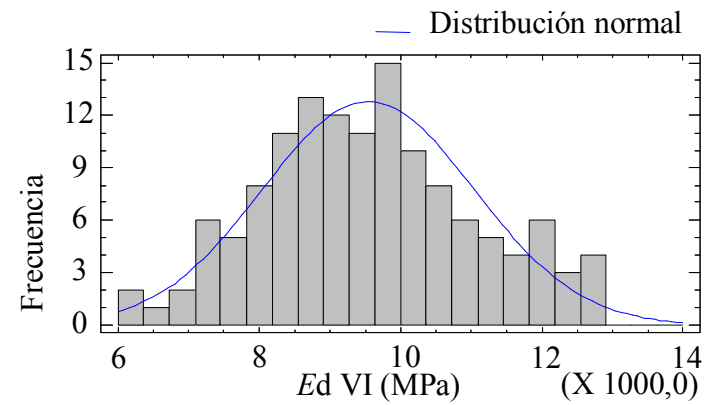

Figura 148. Histograma de Frecuencia: $E_{\mathrm{d}}-$ VI Chopo (España). 


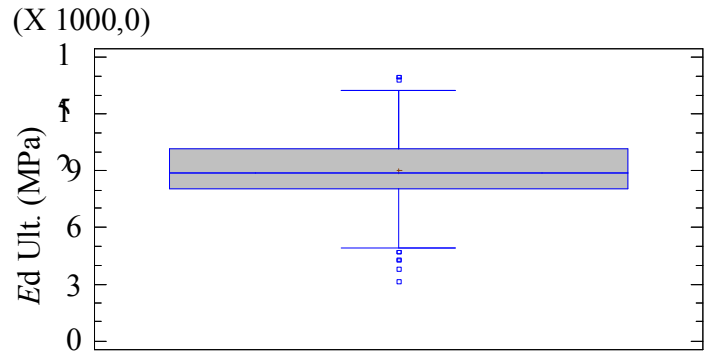

Figura 149. Gráfico de Caja y Bigotes: $E_{\mathrm{d}}-$ Ult. Chopo (España).

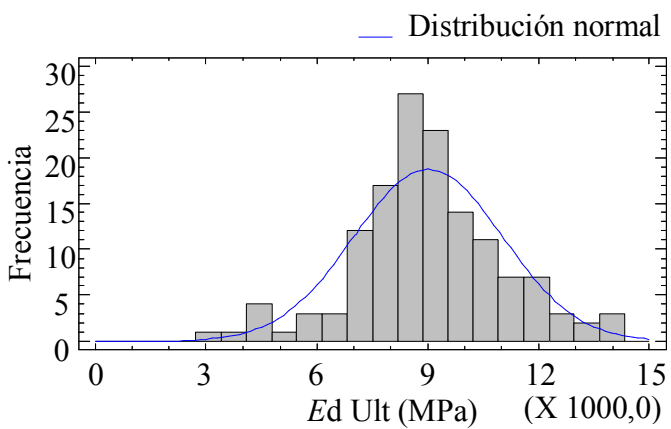

Figura 150. Histograma de Frecuencia: $E_{\mathrm{d}}-$ Ult. Chopo (España).

A fin de ampliar este primer análisis, cuya finalidad principal fue describir la población de datos correspondiente a cada variable, a continuación se presenta el análisis estadístico inferencial comparativo considerando ambas metodologías.

\section{Análisis comparativo entre NDT: material de procedencia española.}

Mediante esta comparación se evaluó la existencia de diferencias significativas entre los $E_{d}$ considerando ambas técnicas; dado el incumpliendo de las exigencias estadísticas necesarias para realizar un test paramétrico, Anejos 6.2.1.1, se trabajó con el test no paramétrico de Kruskal-Wallis a fin de evaluar la existencia de diferencias entre medianas, Tabla 45.

Tabla 45. $E_{\mathrm{d}}$ - NDT Chopo (España): Análisis comparativo (Kruskal-Wallis).

\begin{tabular}{cccccc}
\hline KW* & Estadístico & P-valor & Procedencia & NDT & $\begin{array}{c}\text { Grupos } \\
\text { homogéneos ** }\end{array}$ \\
\hline \multirow{2}{*}{$E_{\mathrm{d}}$ - NDT } & 6,24 & 0,01 & España & VI & A \\
\cline { 4 - 6 } & & & & Ult & B \\
\hline
\end{tabular}

*KW: test de Kruskal-Wallis; $E_{\mathrm{d}}$ : módulo de elasticidad dinámico; NDT: non-destructive testing; VI: vibraciones inducidas; Ult. Ultrasonidos.

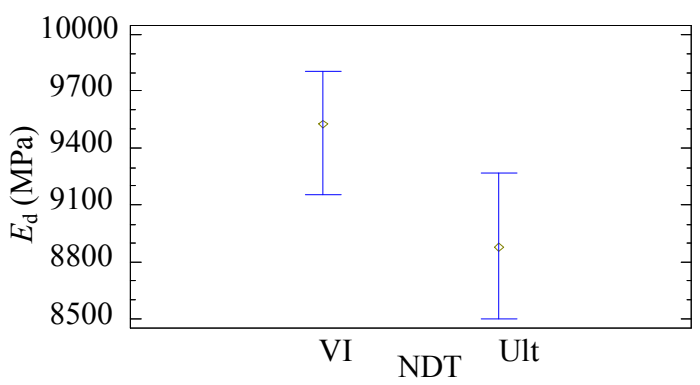

Figura 151. Gráfico de medianas e IC 95\%: $E_{\mathrm{d}}-$ END.

De acuerdo con el análisis realizado en el material de procedencia española, puede observarse que la mediana del $E_{\mathrm{d}}$ obtenida mediante la técnica de vibración longitudinal es significativamente superior a la mediana obtenida mediante la técnica de ultrasonidos. 


\section{Análisis descriptivo - NDT: material de procedencia Argentina}

La evaluación no destructiva del material de procedencia Argentina se presenta en la Tabla 46.

Tabla 46. Evaluación mediante metodología no destructiva: análisis descriptivo

\begin{tabular}{|c|c|c|c|c|c|c|}
\hline \multirow[b]{2}{*}{ Parámetro } & \multirow[b]{2}{*}{$\mathrm{n}^{*}$} & \multirow[b]{2}{*}{$\begin{array}{l}\text { Densidad } \\
\left(\mathrm{Kg} / \mathrm{m}^{3}\right)\end{array}$} & \multicolumn{2}{|c|}{ Vibraciones inducidas } & \multicolumn{2}{|c|}{ Ultrasonidos } \\
\hline & & & $\begin{array}{c}\text { Frecuencia } \\
(\mathrm{Hz})\end{array}$ & $\begin{array}{c}E_{\mathrm{d}}^{*} \\
(\mathrm{MPa}) \\
\end{array}$ & $\begin{array}{c}\text { Velocidad } \\
(\mathrm{m} / \mathrm{s})\end{array}$ & $\begin{array}{c}E_{\mathrm{d}}{ }^{*} \\
(\mathrm{MPa}) \\
\end{array}$ \\
\hline $\begin{array}{l}\text { Media } \\
(\mathrm{CV} \%)\end{array}$ & 92 & $\begin{array}{c}407,95-369,05^{* *} \\
(6,33)\end{array}$ & $\begin{array}{c}1847,41 \\
(5,93)\end{array}$ & $\begin{array}{c}8197,03 \\
(11,43)\end{array}$ & $\begin{array}{c}4726,64 \\
(4,44)\end{array}$ & $\begin{array}{c}9197,76 \\
(9,68)\end{array}$ \\
\hline $\begin{array}{l}\text { Min.-Máx. } \\
\text { (IQR) }\end{array}$ & 92 & $\begin{array}{c}354,88-464,84 \\
(39,31)\end{array}$ & $\begin{array}{c}1605,0-2067,0 \\
(176,5)\end{array}$ & $\begin{array}{c}6240,36- \\
10190,7 \\
(1380,38)\end{array}$ & $\begin{array}{l}4214,3- \\
5120,32 \\
(322,02)\end{array}$ & $\begin{array}{c}7199,53-11124,3 \\
(1175,85)\end{array}$ \\
\hline
\end{tabular}

*n: número de individuos; $E_{\mathrm{d}}$ : Módulo de elasticidad dinámico; $* * 5^{\circ}$ percentil (valor característico de la densidad según EN 384. 2010), respectivamente.

Según se desprende de la Tabla 46, la variabilidad de los datos es baja y aceptable en ambos tipos de metodologías, incluso menor que la hallada en el material de procedencia España, Tabla 44.

La dispersión de los datos de cada variable, representada por el gráfico de caja y bigotes, y la distribución de sus frecuencias, representada en histogramas, se indica a continuación, Figura 152 a Figura 161.

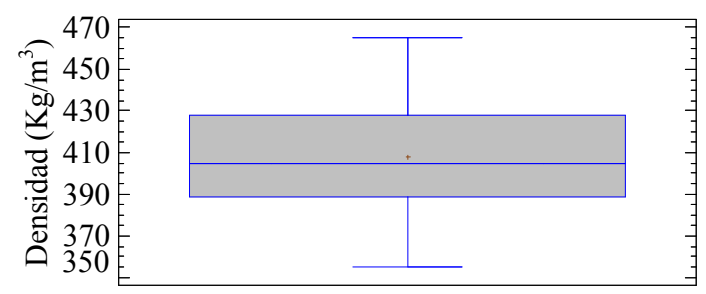

Figura 152. Gráfico de Caja y Bigotes: DensidadChopo (Argentina).

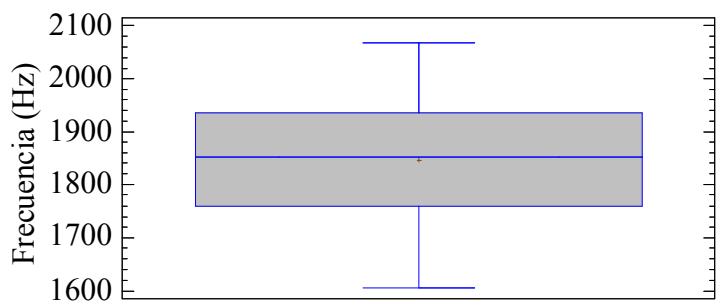

Figura 154. Gráfico de Caja y Bigotes: Frecuencia VI-Chopo (Argentina).

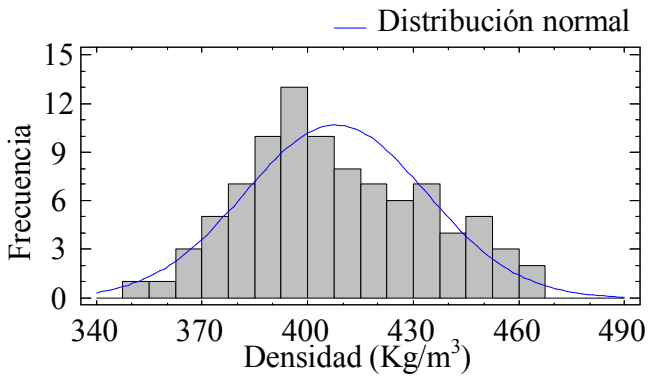

Figura 153. Histograma de Frecuencia: DensidadChopo (Argentina).

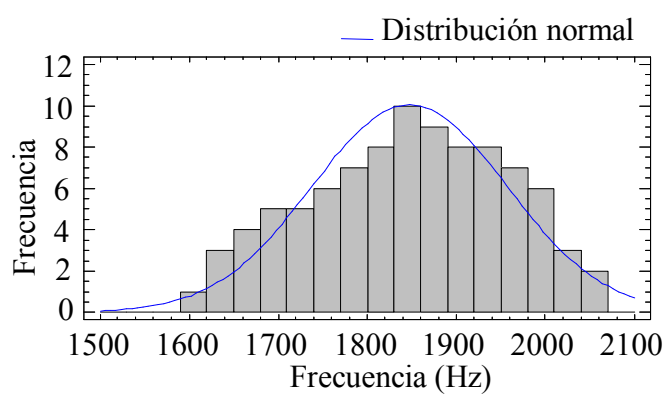

Figura 155. Histograma de Frecuencia: Frecuencia VI-Chopo (Argentina). 


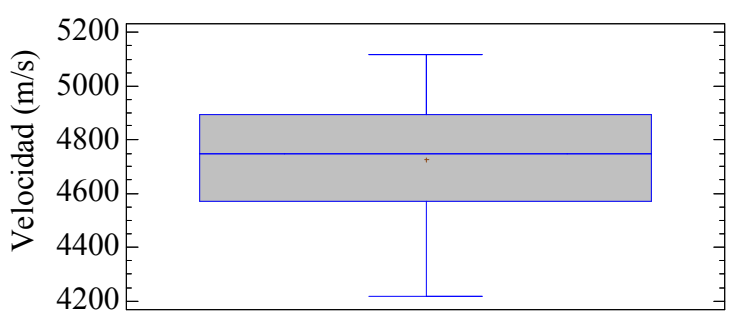

Figura 156. Gráfico de Caja y Bigotes: Velocidad UltChopo (Argentina).

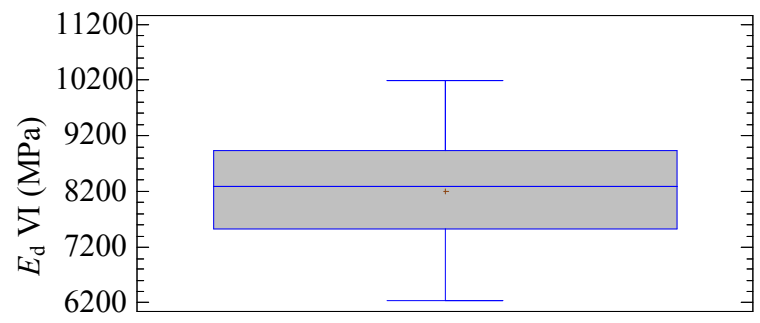

Figura 158. Gráfico de Caja y Bigotes: $\mathbf{E}_{\mathrm{d}-\text { VI-Chopo }}$ (Argentina).

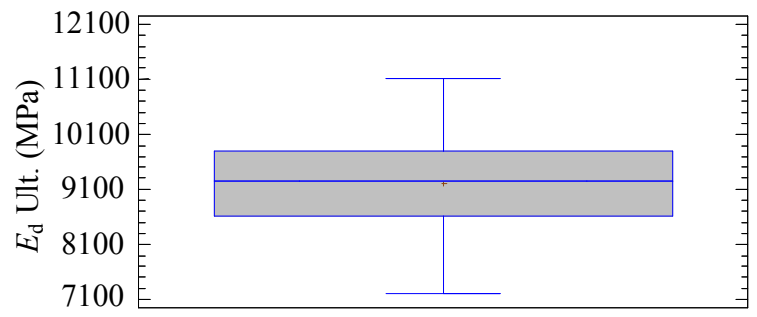

Figura 160. Gráfico de Caja y Bigotes: $E_{\mathrm{d}-\text { Ult-Chopo }}$ (Argentina).

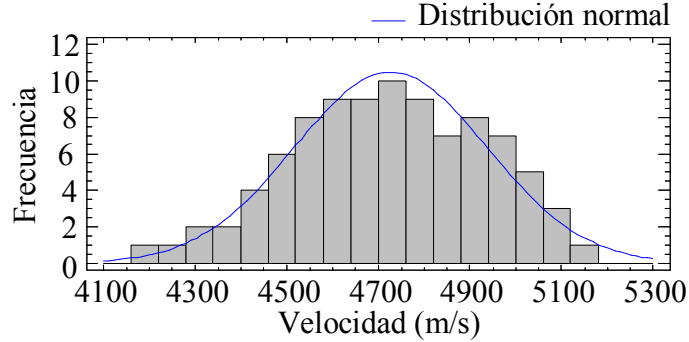

Figura 157. Histograma de Frecuencia: Velocidad Ult-Chopo (Argentina).

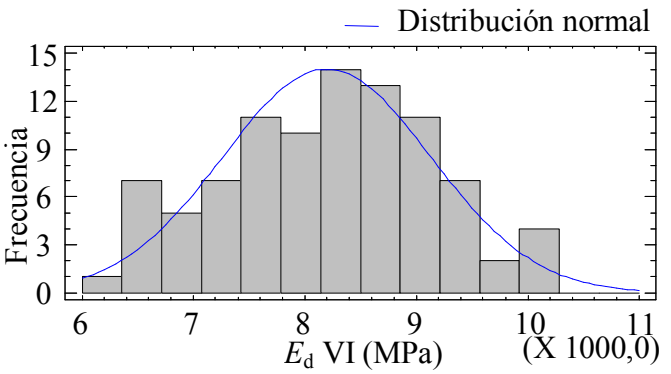

Figura 159. Histograma de Frecuencia: $\mathbf{E}_{\mathrm{d}-}$ VIChopo (Argentina).

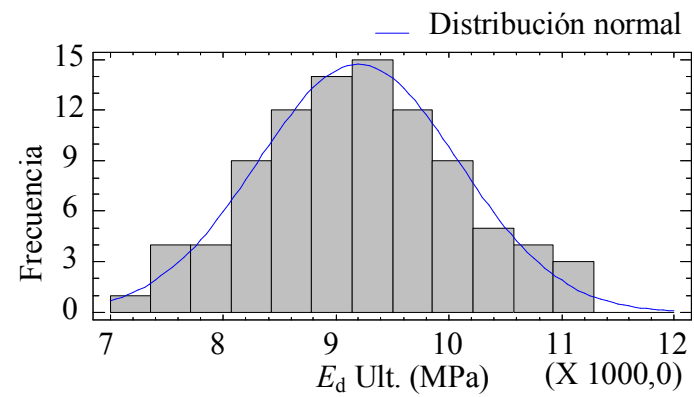

Figura 161. Histograma de Frecuencia: $E_{\mathrm{d}-}$ UltChopo (Argentina).

En Anejos 6.2.1.1 se puede ampliar la información sobre el análisis descriptivo.

\section{Análisis comparativo entre NDT: material de procedencia argentina.}

A fin de evaluar el comportamiento del módulo de elasticidad dinámico obtenido con ambas técnicas de ensayo no destructivo, en la Tabla 47 y Figura 162, se presentan los resultados del test de comparación de medias; la constatación de los supuestos estadísticos se encuentra en el Anejo 6.2.1.1.

Tabla 47. $E_{\mathrm{d}}$-NDT (Chopo-Argentina): análisis comparativo.

\begin{tabular}{|c|c|c|c|c|c|}
\hline ANOVA* & Razón-F & P-valor & & NDT & Grupos homogéneos** \\
\hline \multirow{2}{*}{$E_{\mathrm{d}}-\mathrm{NDT}$} & \multirow{2}{*}{55,13} & \multirow{2}{*}{0,00} & Test de Tukey HSD & VI & A \\
\hline & & & & Ult & B \\
\hline
\end{tabular}

${ }^{*} E_{\mathrm{d}}$ : módulo de elasticidad dinámico; NDT: non-destructive testing; **letras diferentes denotan diferencias significativas, Tukey HSD $(\mathrm{P}<0,05)$. 


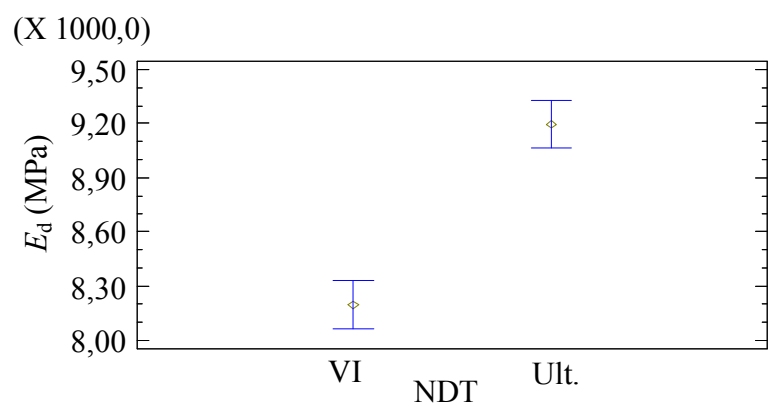

Figura 162. Gráfico de medias e IC 95\% HSD de Tukey: $E_{d}$-NDT Chopo (Argentina).

De acuerdo con los resultados hallados, y contrariamente a lo hallado en el material de procedencia española, los valores de $E_{\mathrm{d}}$ obtenidos mediante la técnica de ultrasonidos son significativamente superiores a los obtenidos mediante el método de vibraciones inducidas.

\section{Análisis comparativo - NDT vs procedencia.}

A continuación se muestra el análisis comparativo, Kruskal-Wallis, considerando cada método no destructivo contrastado por procedencia del material de ensayo; en Anejo 6.2.1.1 se presenta el análisis de evaluación de supuestos estadísticos.

Tabla 48. Vibraciones inducidas y Ultrasonidos - procedencias: Test de Kruskal-Wallis.

\begin{tabular}{cccccc}
\hline VI & Estadístico & P-Valor & Ultrasonidos & Estadístico & P-Valor \\
\hline Frecuencia & 139,12 & 0,00 & Velocidad & 57,66 & 0,00 \\
\hline$E_{\mathrm{d}}$ & 46,47 & 0,00 & $E_{\mathrm{d}}$ & 1,79 & 0,18 \\
\hline
\end{tabular}

* $E_{\mathrm{d}}$ : módulo de elasticidad dinámico; VI: vibraciones inducidas.

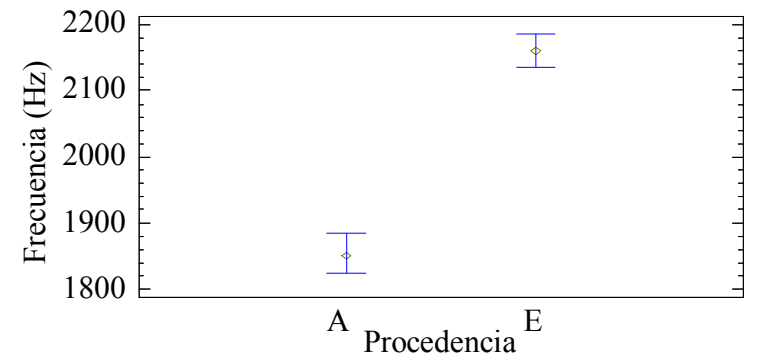

Figura 163. Gráfico de medianas e IC 95\%: Fr (VI) - Procedencias.

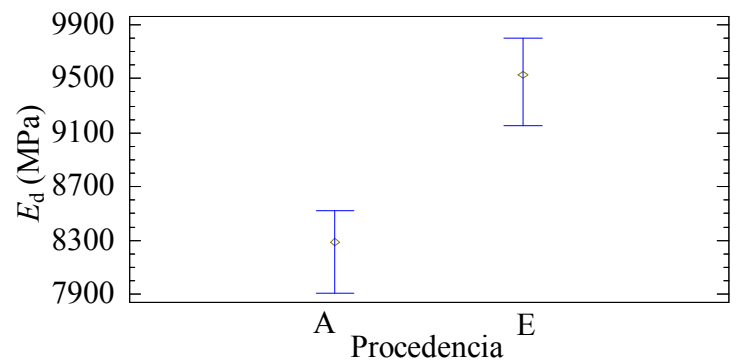

Figura 164. Gráfico de medianas e IC 95\%: $E_{\mathrm{d}}(\mathrm{VI})$ - Procedencias. 


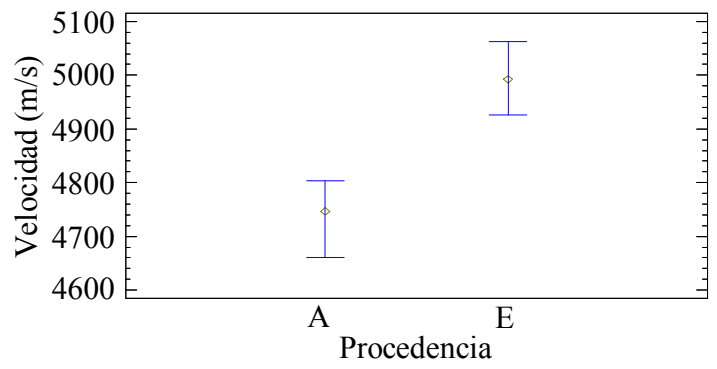

Figura 165. Gráfico de medianas e IC 95\%: Velocidad (Ult.) - Procedencias.

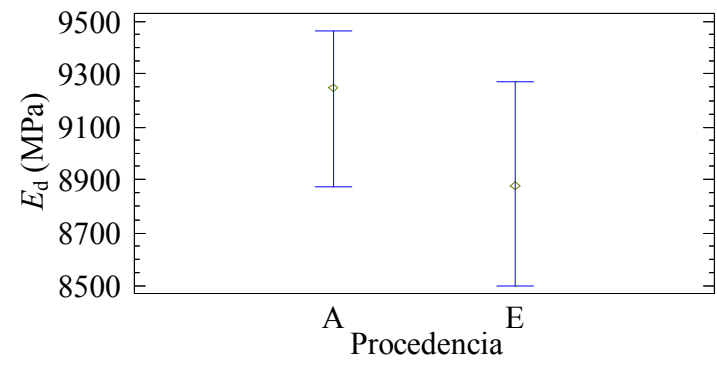

Figura 166. Gráfico de medianas e IC 95\%: $E_{\mathrm{d}}$ (Ult) - Procedencias.

De acuerdo con el análisis comparativo de los parámetros NDT entre procedencias, puede indicarse que en el caso de la metodología de vibraciones inducidas, existe una diferencia estadísticamente significativa entre las medianas de las frecuencias vibratorias y entre las medianas del $E_{\mathrm{d}}$, a favor del material procedente de España; en lo referente al método de ultrasonidos, sólo se observaron diferencias significativas, superiores en el material español, entre las medianas de las velocidades, no hallándose diferencias entre los $E_{\mathrm{d}}$.

En términos generales y en concordancia con la disparidad de comportamiento entre ambas metodologías NDT obtenidas en el material de procedencia Argentina y con los superiores valores de "paso de onda" hallados en el material procedente de España, puede inferirse que estos resultados guardan estrecha relación con la presencia de daños causados por insectos xilófagos en el material de procedencia argentina, como galerías y túneles a través del material. El fundamento de esto consiste en que, en el caso del método de ultrasonidos, cuantos más defectos tenga la pieza, más tiempo tardará la onda ultrasónica en atravesar la madera desde el palpador emisor hacía el otro extremo, palpador receptor, y por tanto, la velocidad será menor en comparación con otra pieza con menos defectos o singularidades (Hermoso, 2001); consideración aplicable al comportamiento de la frecuencia ante la presencia de singularidades en una pieza de madera.

Un panorama más claro respecto de la influencia de las singularidades en los valores elastoresistentes podrá vislumbrase mediante los análisis no destructivos presentados a continuación.

\subsubsection{Ensayos destructivos}

En primera instancia, se presenta el análisis descriptivo del material diferenciado por lotes.

\section{Análisis descriptivo por procedencias}

El resumen descriptivo de ambos lotes, indicando la variable densidad obtenida posterior a la rotura (EN 408:2011+A1:2012) y las variables elasto-mecánicas, se presenta en la Tabla 49 (Anejos 6.2.2); los gráficos de caja y bigotes e histogramas de frecuencia de cada una de ellas se indica a continuación del resumen tabular, Figura 167 a Figura 178. 
Tabla 49. Evaluación mediante metodología destructiva: análisis descriptivo.

\begin{tabular}{|c|c|c|c|c|}
\hline Procedencia & $\mathbf{n}$ & Variable & $\begin{array}{c}\text { Media - } 5^{\circ} \text { Percentil } \\
(\mathrm{CV} \%)\end{array}$ & $\begin{array}{l}\text { Mín-Máx } \\
\text { (IQR)* }\end{array}$ \\
\hline \multirow{3}{*}{ España } & \multirow{3}{*}{149} & $\begin{array}{c}\text { Densidad } \\
\left(\mathrm{Kg} / \mathrm{m}^{3}\right)\end{array}$ & $\begin{array}{c}408,77-331,73^{* *} \\
(12,11) \\
\end{array}$ & $\begin{array}{c}293,62-526,12 \\
(62,55)\end{array}$ \\
\hline & & $\begin{array}{l}\mathrm{MOE} \\
(\mathrm{MPa})\end{array}$ & $\begin{array}{c}7992,51 * *-4978,48 \\
(24,22)\end{array}$ & $\begin{array}{c}3456,93-12754,0 \\
(2426,2)\end{array}$ \\
\hline & & $\begin{array}{l}\text { MOR } \\
(\mathrm{MPa}) \\
\end{array}$ & $\begin{array}{c}45,62-26,58^{* *} \\
(24,96) \\
\end{array}$ & $\begin{array}{c}20,95-71,69 \\
(14,97)\end{array}$ \\
\hline \multirow{3}{*}{ Argentina } & \multirow{3}{*}{92} & $\begin{array}{c}\text { Densidad } \\
\left(\mathrm{Kg} / \mathrm{m}^{3}\right)\end{array}$ & $\begin{array}{c}402,93-366,13 * * \\
(6,74)\end{array}$ & $\begin{array}{c}350,03-465,36 \\
(37,88)\end{array}$ \\
\hline & & $\begin{array}{l}\mathrm{MOE} \\
(\mathrm{MPa}) \\
\end{array}$ & $\begin{array}{c}191,85 * *-5101,85 \\
(17,16) \\
\end{array}$ & $\begin{array}{c}4042,8-9798,49 \\
(1608,99) \\
\end{array}$ \\
\hline & & $\begin{array}{l}\text { MOR } \\
(\mathrm{MPa})\end{array}$ & $\begin{array}{c}33,50-20,91^{* *} \\
(20,12)\end{array}$ & $\begin{array}{c}18,29-46,03 \\
(9,92)\end{array}$ \\
\hline
\end{tabular}
384: 2010).

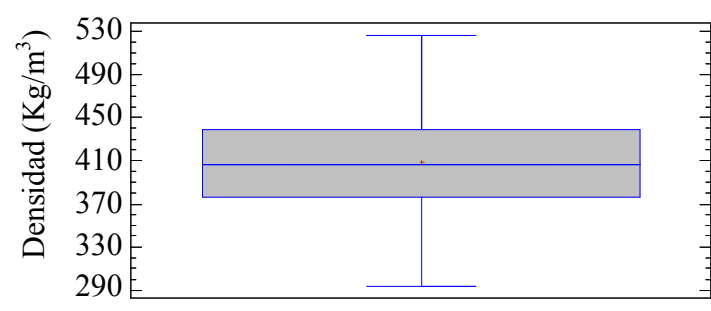

Figura 167. Gráfico de Caja y Bigotes: DensidadChopo (España).

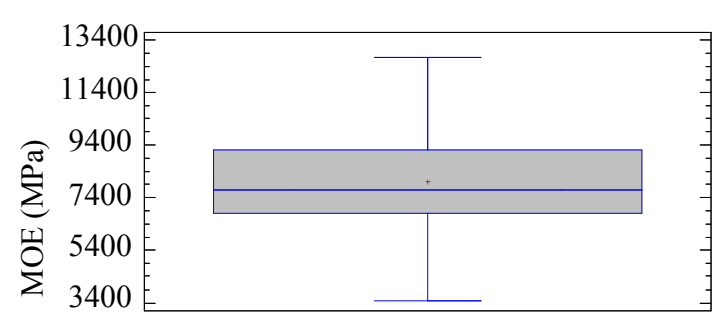

Figura 169. Gráfico de Caja y Bigotes: MOE Chopo (España)

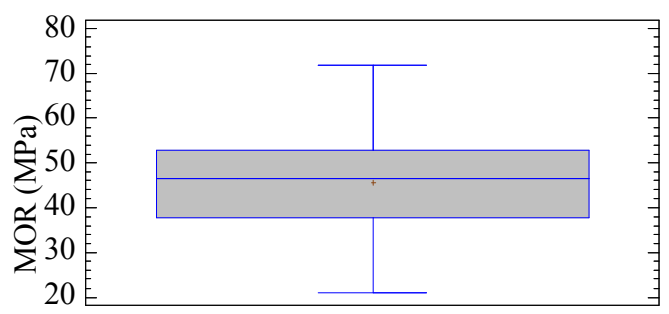

Figura 171. Gráfico de Caja y Bigotes: MOR Chopo (España).
_ Distribución normal

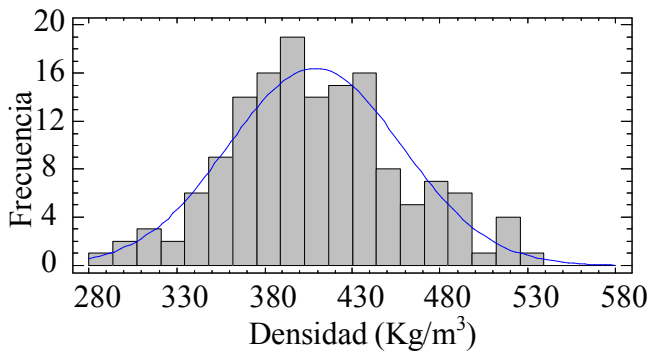

Figura 168. Histograma de Frecuencia: DensidadChopo (España).

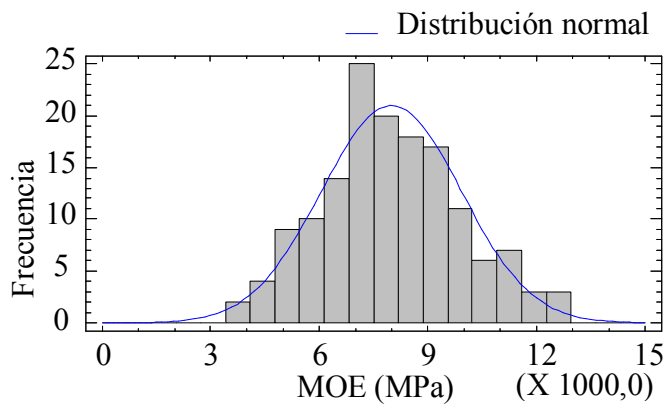

Figura 170. Histograma de Frecuencia: MOE Chopo (España)

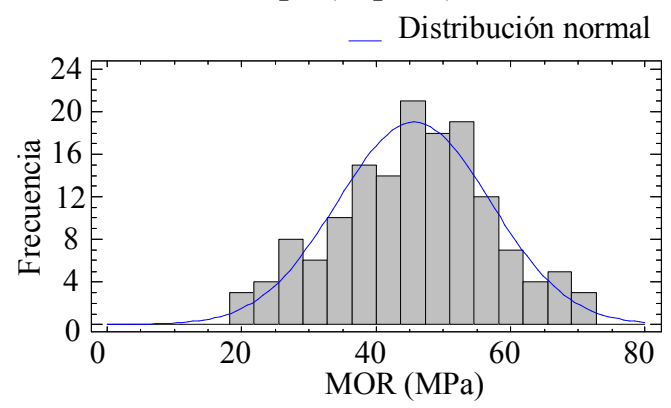

Figura 172. Histograma de Frecuencia: MOR Chopo (España). 


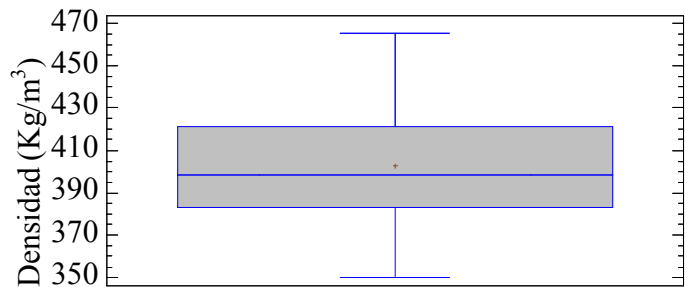

Figura 173. Gráfico de Caja y Bigotes: Densidad Chopo (Argentina).

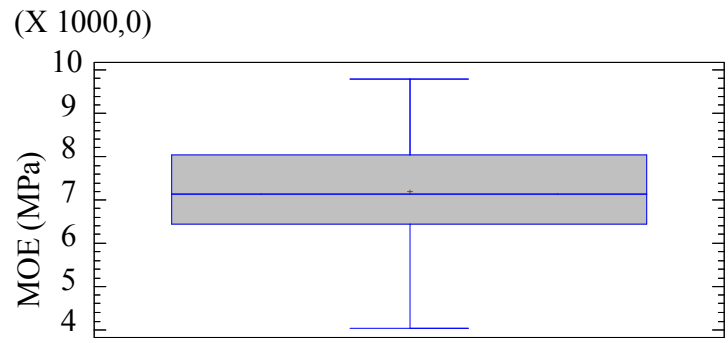

Figura 175. Gráfico de Caja y Bigotes: MOE Chopo (Argentina).

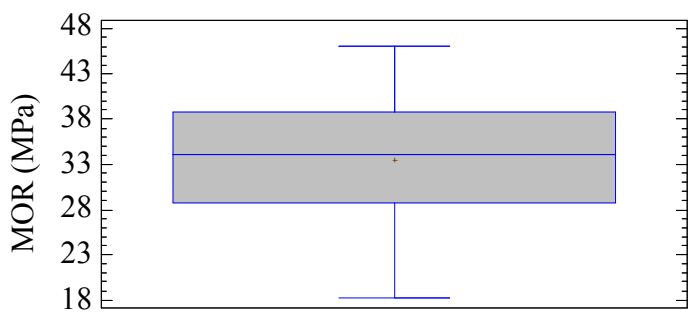

Figura 177. Gráfico de Caja y Bigotes: MOR Chopo (Argentina).

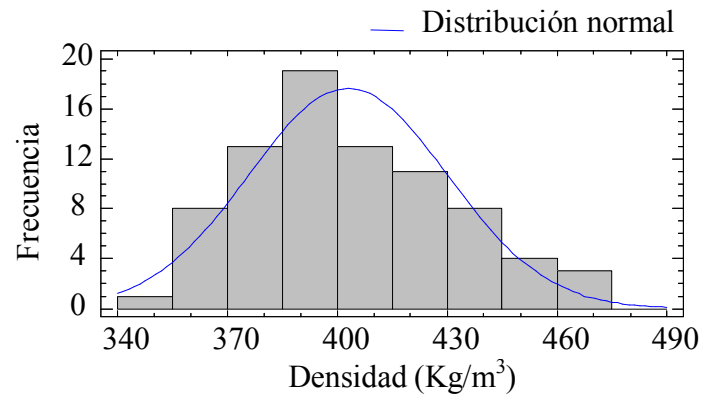

Figura 174. Histograma de Frecuencia: Densidad Chopo (Argentina).

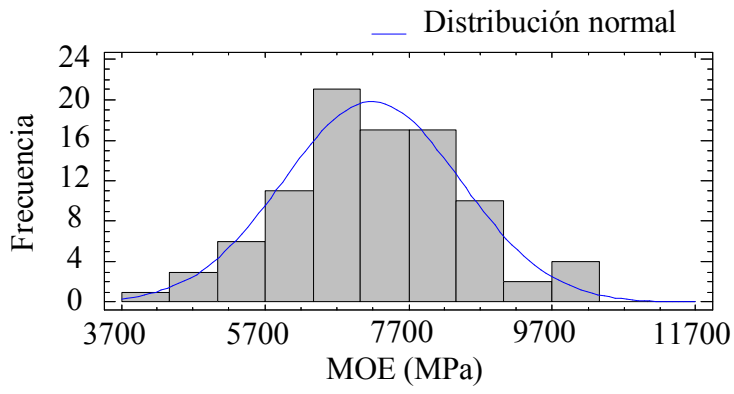

Figura 176. Histograma de Frecuencia: MOE Chopo (Argentina).

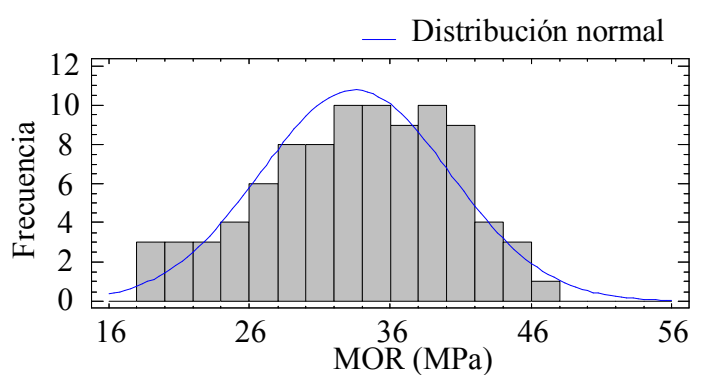

Figura 178. Histograma de Frecuencia: MOR Chopo (Argentina).

Del análisis descriptivo se desprende que las variables densidad, MOE y MOR determinadas en ambos lotes (procedencias) presentan una distribución normal; en concordancia con los coeficientes de variación $(\mathrm{CV} \%)$ hallados, y dado que se trata de un material biológico heterogéneo y anisótropo, su variabilidad puede considerarse baja y/o aceptable.

\section{Análisis comparativo entre procedencias.}

En la Tabla 50 (Figura 179 a Figura 181) se muestra el resumen del análisis comparativo realizado con las variables densidad y elasto-mecánicas, contrastando entre lotes (procedencias); dado el incumplimiento del supuesto de homocedasticidad, Anejo 6.2.2, se empleó el test no paramétrico de Kruskal-Wallis para el análisis. 
Tabla 50. MOE, MOR y Densidad - procedencias: análisis comparativo (Kruskal-Wallis).

\begin{tabular}{cccccc}
\hline & $\begin{array}{c}\text { MOE } \\
(\mathrm{MPa})\end{array}$ & \multicolumn{2}{c}{$\begin{array}{c}\text { MOR } \\
(\mathrm{MPa})\end{array}$} & & $\begin{array}{c}\text { Densidad } \\
\left(\mathrm{Kg} / \mathrm{m}^{3}\right)\end{array}$ \\
\hline Estadístico & P-Valor & Estadístico & P-valor & Estadístico & P-valor \\
\hline 11,07 & 0,00 & 67,44 & 0,00 & 0,60 & 0,44 \\
\hline
\end{tabular}

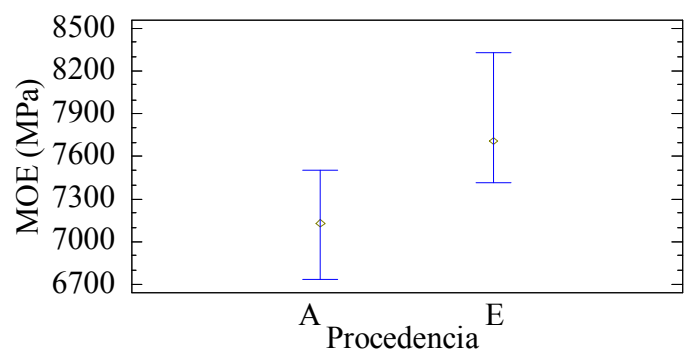

Figura 179. Gráfico de medianas e IC 95\%: MOE - procedencias.

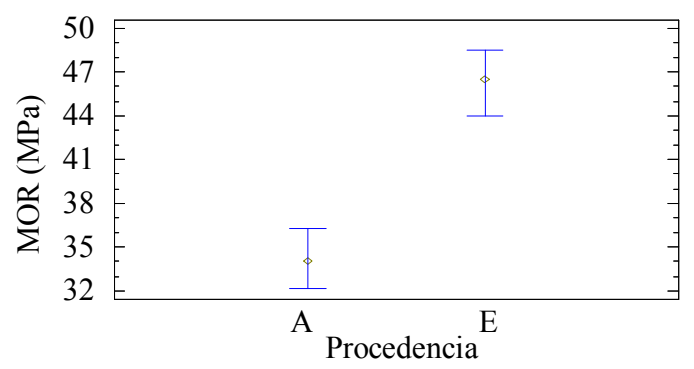

Figura 180. Gráfico de medianas e IC 95\%: MOR - procedencias.

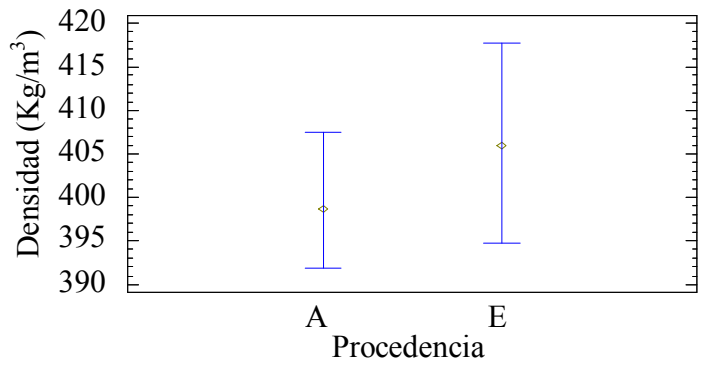

Figura 181. Gráfico de medianas e IC 95\%: Densidad - procedencias.

Si bien no se hallaron diferencias significativas entre los valores de densidad, los valores elasto-resistentes fueron significativamente superiores en la madera de procedencia española; en este sentido y en concordancia con los resultados no destructivos hallados en el material de procedencia Argentina, menores valores de "paso de onda" y "deficiente" rendimiento clasificatorio con altos porcentajes de rechazos, se puede inferir que los daños causados por insectos representan las principales causas de dicho comportamiento. En este sentido y con la finalidad de contrastar esta 
hipótesis, a continuación se presenta una evaluación de influencia de dichas singularidades en el material de estudio.

\subsubsection{Influencia de defectos naturales en el Módulo de elasticidad (MOE)}

\section{Material de procedencia argentina}

En primer término, y a fin de evaluar la existencia de correlación entre las singularidades naturales cuantitativas, diámetro relativo de nudo de cara y de canto, y la variable MOE obtenida en material de procedencia Argentina, se realizó el análisis de correlación ordinal de Spearman que se resume en la Tabla 51.

Tabla 51. MOE - Defectos naturales: Correlación Ordinal de Spearman.

\begin{tabular}{cccc}
\hline & \multicolumn{2}{c}{ Correlación Ordinal de Spearman* } \\
\hline Variables & MOE & Diámetro nudos de cara & Diámetro nudos de canto \\
\cline { 2 - 3 } MOE & & $-0,15$ & 0,24 \\
\cline { 2 - 3 } & & $(31)$ & $(22)$ \\
\cline { 2 - 3 } & & 0,40 & 0,28 \\
\cline { 2 - 3 } Diámetro nudos de cara & $(31)$ & 0,55 \\
\cline { 2 - 3 } & 0,40 & 0,15 & 0,01 \\
\hline \multirow{3}{*}{ Diámetro nudos de canto } & 0,24 & $(21)$ & \\
\cline { 2 - 4 } & $(22)$ & 0,55 & \\
\cline { 2 - 4 } & 0,28 & 0,01 & \\
\hline
\end{tabular}

*Los valores indicados en cada columna expresan: correlación; (tamaño de Muestra); P-valor $(<0,05$ indica correlación estadísticamente significativa), en ese orden.

De acuerdo a los P-valores hallados (superiores a 0,05) no existen correlaciones estadísticamente significativa entre el MOE y las singularidades -nudos de cara y canto- analizadas.

En base a estos resultados y con la finalidad de evaluar si la causa del comportamiento diferencial entre ambas procedencias está representada por los daños (galerías) causados por insectos en el material de Argentina, a continuación se realiza un análisis sobre la influencia de dichas alteraciones biológicas en los valores elásticos.

\subsection{Alteraciones biológicas: influencia en el MOE}

Para ello, se realizó una agrupación según: 1: material rechazado por causas no biológicas (en este caso, nudos de cara, nudos de canto y ambos); 2: material rechazado por causas biológicas (alteraciones-galerías de insectos), a fin de evaluar el comportamiento de la variable elástica en ambos casos; en la Tabla 52 (Figura 182) se muestra el análisis de comparación de medias realizado para entre la variable MOE considerando los dos grupos planteados; la constatación de los supuestos estadísticos es indicada en Anejos 6.2.2.1.1. 
Tabla 52. MOE-Rechazos por causas biológicas-no biológicas: análisis comparativo.

\begin{tabular}{|c|c|c|c|c|c|}
\hline ANOVA* & Razón-F & P-valor & \multirow{3}{*}{$\begin{array}{c}\text { Test de Tukey } \\
\text { HSD }\end{array}$} & Rechazos B/NB & $\begin{array}{c}\text { Grupos } \\
\text { homogéneos } * *\end{array}$ \\
\hline \multirow{2}{*}{ MOE - Rechazos B/NB } & \multirow{2}{*}{0,37} & \multirow{2}{*}{0,54} & & $\mathrm{~B}$ & A \\
\hline & & & & NB & A \\
\hline
\end{tabular}

*MOE: Módulo de elasticidad; B: rechazos por causas biológicas; NB: rechazos por causas no biológicas; **letras diferentes denotan diferencias significativas, Tukey HSD $(\mathrm{P}<0,05)$.

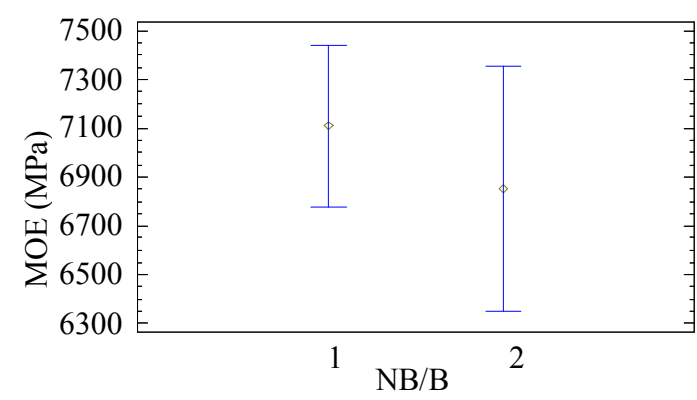

Figura 182. Gráfico de medias e IC 95\% HSD de Tukey: MOE - Rechazos B/NB.

De acuerdo con el análisis comparativo planteado, puede indicarse que no existen diferencias significativas en la variable elástica considerando las causas de rechazo analizadas.

Teniendo en cuenta que las perforaciones y ramificaciones a modo de galerías, causadas por Megaplatypus mutatus, repercuten presumiblemente de forma más negativa en los valores resistentes, a continuación se evalúa el comportamiento del MOR ante la presencia de estos daños.

\subsubsection{Influencia de defectos naturales en el Módulo de rotura (MOR)}

\section{Material de procedencia argentina}

Del mismo modo que lo planteado para el MOE, en primera instancia se realizó un análisis de correlación ordinal de Spearman a fin de evaluar la existencia de correlación entre las singularidades naturales cuantitativas, diámetro relativo de nudos de cara y de canto, y la variable MOR obtenida en material de procedencia Argentina. 
Tabla 53. Correlación Ordinal de Spearman MOR - Defectos naturales

\begin{tabular}{|c|c|c|c|}
\hline \multicolumn{4}{|c|}{ Correlación Ordinal de Spearman } \\
\hline Variables & MOR & Diámetro nudos de cara & Diámetro nudos de canto \\
\hline \multirow{3}{*}{ MOR } & & $-0,18$ & 0,10 \\
\hline & & $(31)$ & $(22)$ \\
\hline & & 0,34 & 0,65 \\
\hline \multirow{3}{*}{ Diámetro nudos de cara } & $-0,18$ & & 0,55 \\
\hline & $(31)$ & & $(21)$ \\
\hline & 0,34 & & 0,01 \\
\hline \multirow{3}{*}{ Diámetro nudos de canto } & 0,10 & 0,55 & \\
\hline & $(22)$ & $(21)$ & \\
\hline & 0,65 & 0,01 & \\
\hline
\end{tabular}

*Los valores indicados en cada columna expresan: correlación; (tamaño de Muestra); P-valor $(<0,05$ indica correlación estadísticamente significativa), en ese orden.

Coincidentemente con lo obtenido para el MOE y de acuerdo al P-valor $>0,05$, no existen correlaciones estadísticamente significativa entre el MOR y los nudos de cara y canto.

En base a ello, a continuación se evalúa la influencia de las alteraciones biológicas en dicho parámetro.

\subsection{Alteraciones biológicas: influencia en el MOR}

En la Tabla 54 se resume el análisis comparativo llevado a cabo entre el MOR considerando las dos categorías de rechazo: causas biológicas y causas no biológicas; la constatación de los supuestos estadísticos se muestra en Anejo 6.2.2.2.1.

Tabla 54. MOR-Rechazos por causas biológicas-no biológicas (Chopo - Argentina): análisis comparativo.

\begin{tabular}{|c|c|c|c|c|c|}
\hline ANOVA & Razón-F & P-valor & & Rechazos B/NB & $\begin{array}{c}\text { Grupos } \\
\text { homogéneos } * *\end{array}$ \\
\hline \multirow{2}{*}{$\begin{array}{c}\text { MOR - Rechazos } \\
\text { B/NB }\end{array}$} & \multirow{2}{*}{0,68} & \multirow{2}{*}{0,42} & HSD & $\mathrm{B}$ & A \\
\hline & & & & NB & A \\
\hline
\end{tabular}

*MOR: Módulo de rotura; B: rechazos por causas biológicas; NB: rechazos por causas no biológicas; **letras diferentes denotan diferencias significativas, Tukey HSD $(\mathrm{P}<0,05)$.

De acuerdo con el P-valor obtenido, puede observarse que no existen diferencias significativas entre el material rechazado por causas no biológicas (nudos) y por causas biológicas (alteraciones causadas por insectos). En base a esto, se realizó una nueva re-categorización para el análisis. En este caso, se incorporó la variable "lugar de rotura" estableciéndose tres clases: 0: rotura normal; 1: rotura por alteraciones (galerías) de insectos; 2: rotura por nudos. Para ello, empleando el ANOVA como método comparativo y el test de Tukey HSD como análisis de múltiples rangos, se obtuvieron los 
resultados presentados en la Tabla 55; en Anejos 6.2.2.2.1, se detalla la constatación de la homogeneidad de varianza.

Tabla 55. MOR-Rechazos por "Lugar de rotura": análisis comparativo.

\begin{tabular}{|c|c|c|c|c|c|}
\hline ANOVA & Razón-F & P-valor & \multirow{4}{*}{$\begin{array}{c}\text { Test de Tukey } \\
\text { HSD }\end{array}$} & Rechazos "Lugar de rotura" & $\mathrm{MOR}^{* *}$ \\
\hline \multirow{3}{*}{$\begin{array}{l}\text { MOR - Rechazos } \\
\text { "Lugar de rotura" }\end{array}$} & \multirow{3}{*}{4,16} & \multirow{3}{*}{0,02} & & 2 & $30,36 \mathrm{~A}$ \\
\hline & & & & 1 & $31,63 \mathrm{AB}$ \\
\hline & & & & 0 & 34,96 \\
\hline
\end{tabular}

*MOR: módulo de rotura; 0: rotura normal; 1: rotura por alteraciones (galerías) de insectos; 2: rotura por nudos; **letras diferentes denotan diferencias significativas, Tukey HSD $(\mathrm{P}<0,05)$.

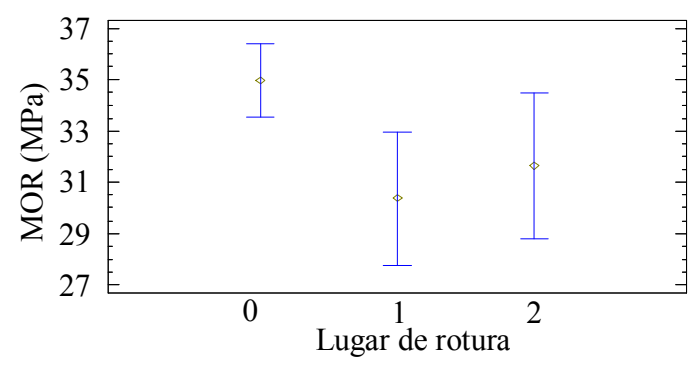

Figura 183. Gráfico de medias e IC 95\% HSD de Tukey: MOR - "Lugar de rotura".

Estos resultados demuestran, que la existencia de perforaciones y galerías ocasionadas por $M$. mutatus, ocasionan la rotura del material disminuyendo significativamente, su resistencia ante la aplicación de una carga. Asimismo, las piezas cuyas roturas fueron ocasionadas por la presencia de nudo, no se diferenciaron estadísticamente de las piezas rotas por la presencia de galerías, lo cual podría indicar un comportamiento resistente similar.

\subsubsection{Predicción de variables elasto-resistentes a partir de NDT}

A lo largo de este apartado, se evaluará el grado de predicción de las variables elastoresistentes a partir de las variables no destructivas, determinadas mediante vibraciones inducidas y ultrasonidos, como así también su comportamiento frente a las singularidades planteadas.

\section{Material de procedencia española}

En la Tabla 56 se presentan los resultados del análisis de regresión realizado entre las variables no destructivas, predictoras, así como las variables predichas, MOE y MOR, para el material de procedencia española. 
Tabla 56. Capacidad predictiva de NDT en las variables caracterizadoras

\begin{tabular}{|c|c|c|c|c|}
\hline \multirow{4}{*}{ Variables predictoras } & \multicolumn{4}{|c|}{ Variables caracterizadoras } \\
\hline & \multicolumn{2}{|c|}{ MOE } & \multicolumn{2}{|c|}{ MOR } \\
\hline & $\mathrm{R}^{2}$ ajust. (\%) & P-valor & $\mathrm{R}^{2}$ ajust. (\%) & P-valor \\
\hline & \multicolumn{4}{|c|}{ Vibraciones inducidas } \\
\hline Frecuencia & 63,77 & 0,00 & 50,68 & 0,00 \\
\hline \multirow[t]{2}{*}{ Frecuencia*Densidad } & 72,28 & 0,00 & 53,81 & 0,00 \\
\hline & \multicolumn{4}{|c|}{ Ultrasonidos } \\
\hline Velocidad & 30,26 & 0,00 & 19,35 & 0,00 \\
\hline Velocidad*Densidad & 46,52 & 0,00 & 24,73 & 0,00 \\
\hline
\end{tabular}

*MOE: módulo de elasticidad; MOR: módulo de rotura.

La representación gráfica de las relaciones halladas se muestra en las siguientes figuras (Figura 184 a Figura 191).

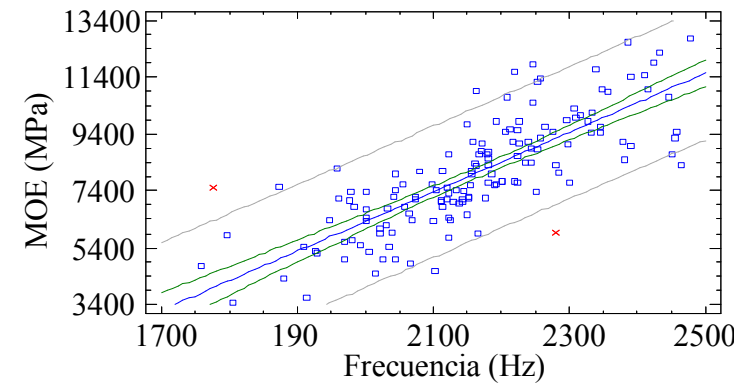

Figura 184. Regresión Simple: MOE - Frecuencia VI.

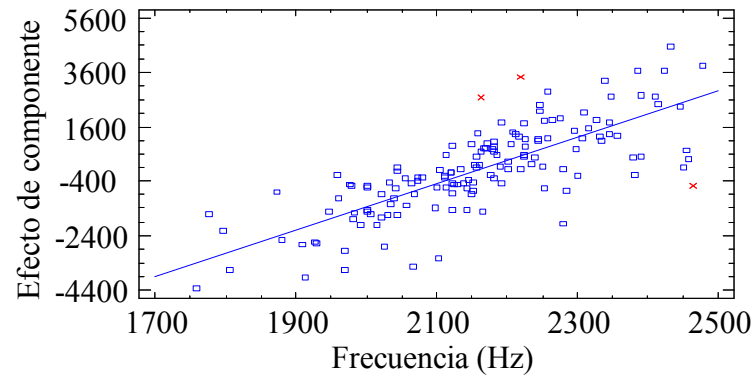

Figura 186. Regresión Múltiple MOE - Fr (VI)Densidad.

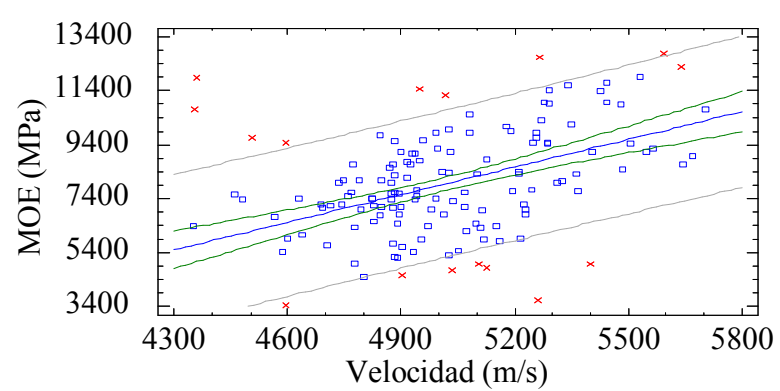

Figura 188. Regresión Simple: MOE - Vel (Ult).

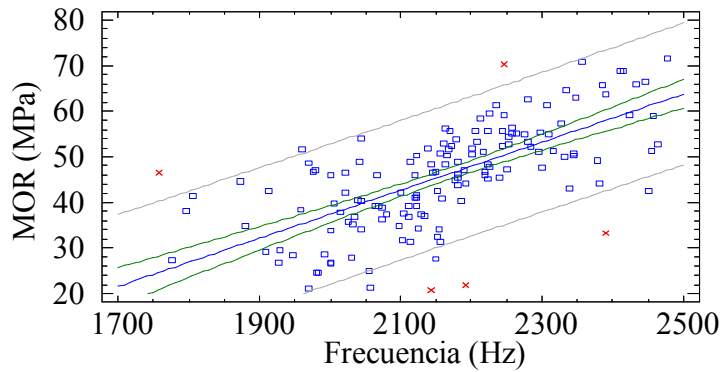

Figura 185. Regresión Simple: MOR - Frecuencia VI.

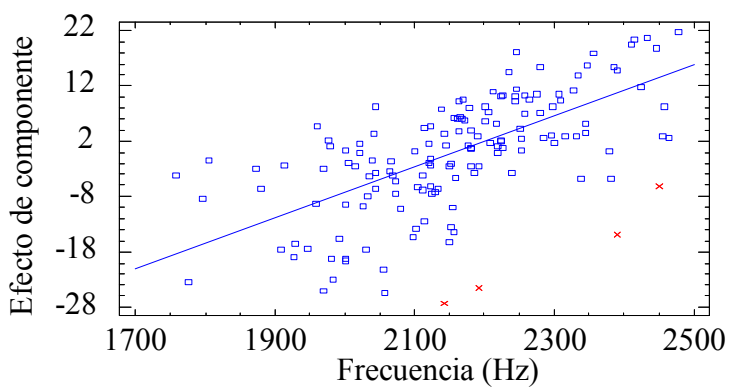

Figura 187. Regresión Múltiple MOR - Fr (VI)Densidad.

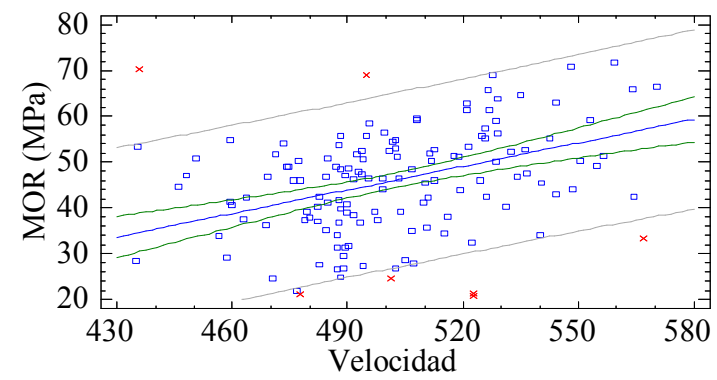

Figura 189. Regresión Simple: MOR - Vel (Ult). 


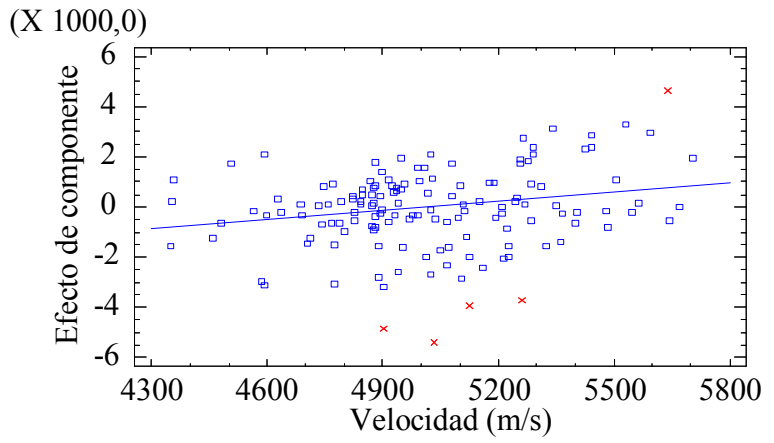

Figura 190. Regresión Múltiple MOE - Vel (Ult). Densidad.

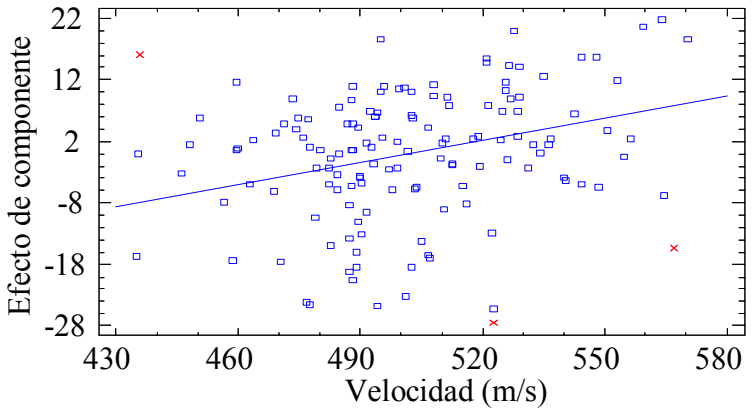

Figura 191. Regresión Múltiple: MOR - Vel (Ult). Densidad.

De acuerdo con estos resultados, puede observarse que la técnica de vibraciones longitudinales presenta los mejores ajustes y, consecuentemente, la mejor predicción de los valores elasto-resistentes.

\section{$\underline{\text { Material de procedencia argentina }}$}

El análisis predictivo de las variables caracterizadoras a partir de las variables influyentes no destructivas se muestra en la Tabla 57, Figura 192 a Figura 199.

Tabla 57. Capacidad predictiva de NDT en las variables caracterizadoras.

\begin{tabular}{|c|c|c|c|c|}
\hline \multirow{4}{*}{ Variables predictoras } & \multicolumn{4}{|c|}{ Variables caracterizadoras } \\
\hline & \multicolumn{2}{|c|}{ MOE* } & \multicolumn{2}{|c|}{ MOR* } \\
\hline & $\mathrm{R}^{2}$ ajust. (\%) & P-valor & $\mathrm{R}^{2}$ ajust. (\%) & P-valor \\
\hline & \multicolumn{4}{|c|}{ Vibraciones inducidas-VI- } \\
\hline Frecuencia & 45,65 & 0,00 & 26,45 & 0,00 \\
\hline \multirow[t]{2}{*}{ Frecuencia*Densidad } & 66,20 & 0,00 & 15,24 & 0,00 \\
\hline & \multicolumn{4}{|c|}{ Ultrasonidos-Ult- } \\
\hline Velocidad & 42,60 & 0,00 & 19,79 & 0,00 \\
\hline Velocidad*Densidad & 56,50 & 0,00 & 19,25 & $0,00 * *$ \\
\hline
\end{tabular}

*MOE: módulo de elasticidad; MOR: módulo de rotura; **la densidad no influyó significativamente en el modelo.

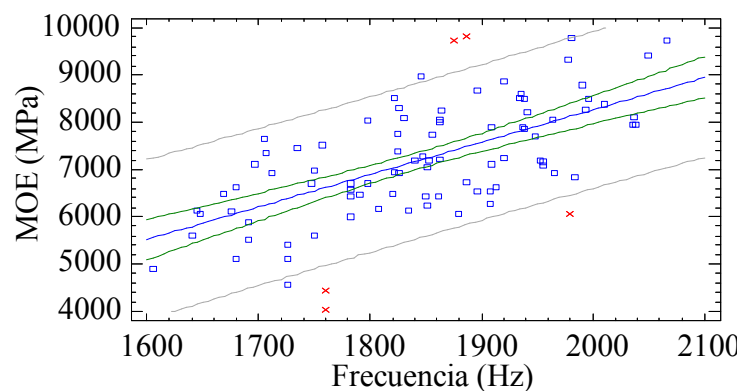

Figura 192. Regresión Simple: MOE - Fr (VI).

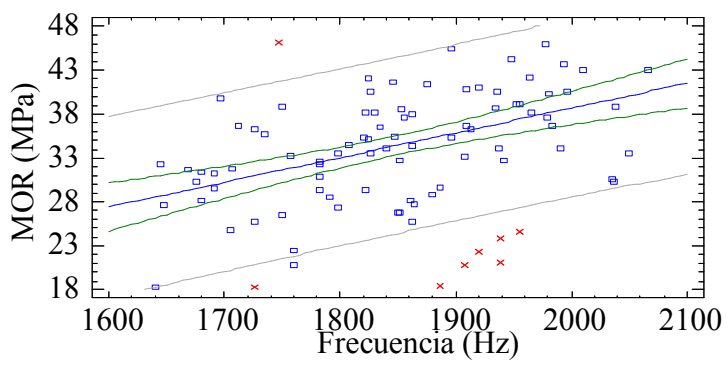

Figura 193. Regresión Simple: MOR - Fr (VI). 


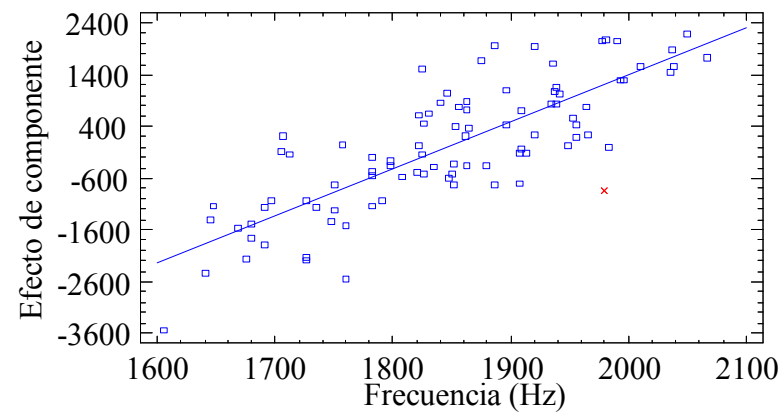

Figura 194. Regresión Múltiple MOE - Fr (VI)Densidad.

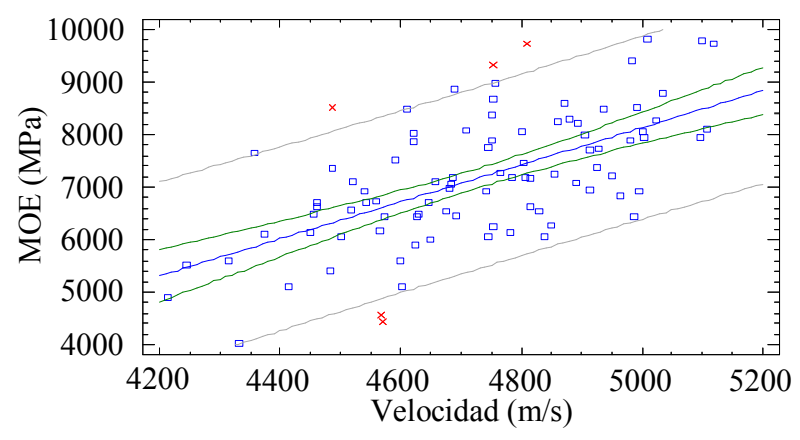

Figura 196. Regresión Simple: MOE - Vel (Ult).

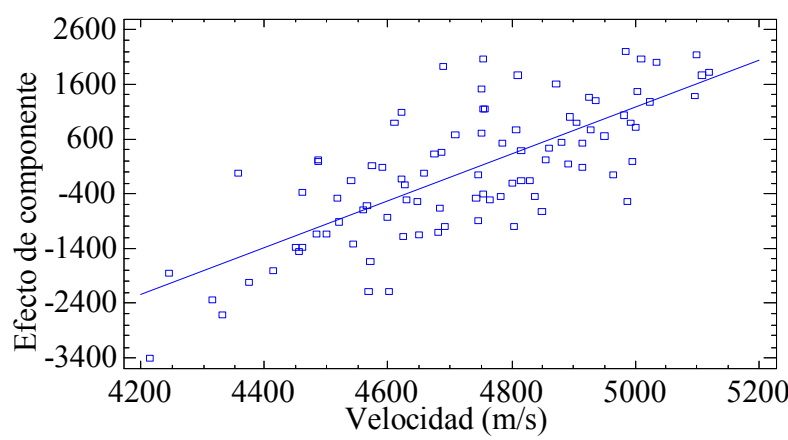

Figura 198. Regresión Múltiple MOE - Vel (Ult) Densidad.

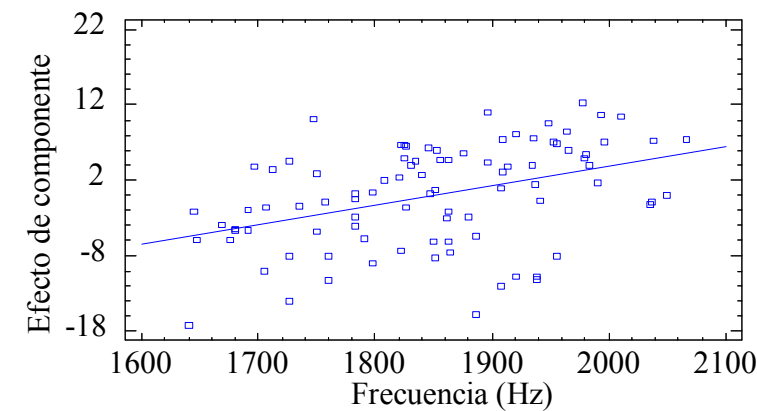

Figura 195. Regresión Múltiple: MOR - Fr (VI)Densidad.

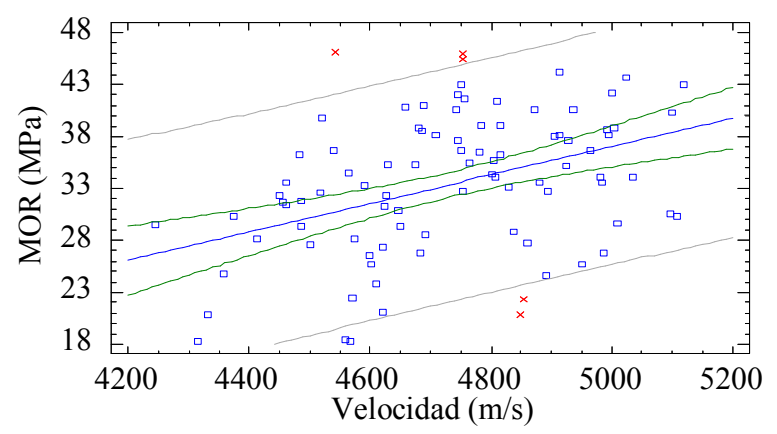

Figura 197. Regresión Simple: MOR - Vel (Ult).

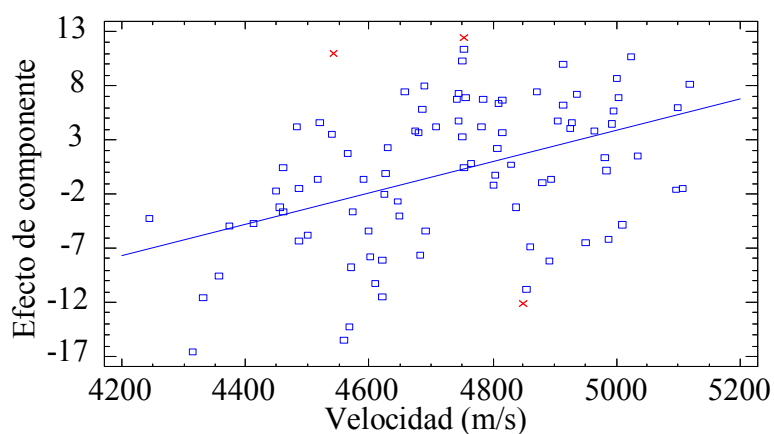

Figura 199. Regresión Múltiple: MOR - Vel (Ult) Densidad.

Del análisis de ambas procedencias, puede observarse que los mejores ajustes/predicciones se obtienen con la técnica de vibración longitudinal, siendo más favorable la predicción para el MOE. De todos modos, el material procedente de España presentó un comportamiento predictivo más aceptable en todos los casos. Siguiendo con la lógica de la influencia de las singularidades, concretamente en cuanto a los daños ocasionados por insectos en el material de procedencia Argentina, se realizó el análisis de predicción en dicho material, considerando las dos categorías antes planteadas: "No biológicas" y "Biológicas"; Tabla 58. 
Tabla 58. Capacidad predictiva de NDT en las variables caracterizadoras.

\begin{tabular}{|c|c|c|c|c|}
\hline \multirow{4}{*}{ Variables predictoras } & \multicolumn{4}{|c|}{ Variables caracterizadoras } \\
\hline & \multicolumn{2}{|c|}{ MOE* $^{*}$} & \multicolumn{2}{|c|}{ MOR* } \\
\hline & $\mathrm{R}^{2}$ ajust. (\%) & P-valor & $\mathrm{R}^{2}$ ajust. (\%) & P-valor \\
\hline & \multicolumn{4}{|c|}{ Vibraciones inducidas- } \\
\hline \multirow{2}{*}{ Frecuencia } & \multicolumn{4}{|c|}{ "No Biológicas" } \\
\hline & 60,88 & 0,00 & 41,13 & 0,00 \\
\hline \multirow{3}{*}{ Frecuencia } & \multicolumn{4}{|c|}{ "Biológicas" } \\
\hline & 25,69 & 0,03 & 17,87 & 0,07 \\
\hline & \multicolumn{4}{|c|}{ Ultrasonidos- } \\
\hline \multirow{2}{*}{ Velocidad } & \multicolumn{4}{|c|}{ "No Biológicas" } \\
\hline & 64,88 & 0,00 & 21,28 & 0,00 \\
\hline \multirow{2}{*}{ Velocidad } & \multicolumn{4}{|c|}{ "Biológicas" } \\
\hline & 19,94 & 0,05 & 9,95 & 0,16 \\
\hline
\end{tabular}

*MOE: módulo de elasticidad; MOR: módulo de rotura.

Los gráficos del modelo ajustado para cada categoría analizada se muestran a continuación (Figura 200 a Figura 207).

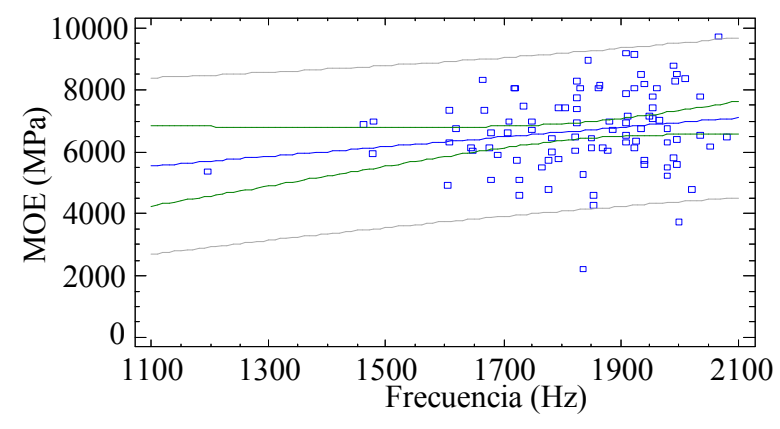

Figura 200. Regresión Simple MOE - Fr (VI)-No Biológicas.

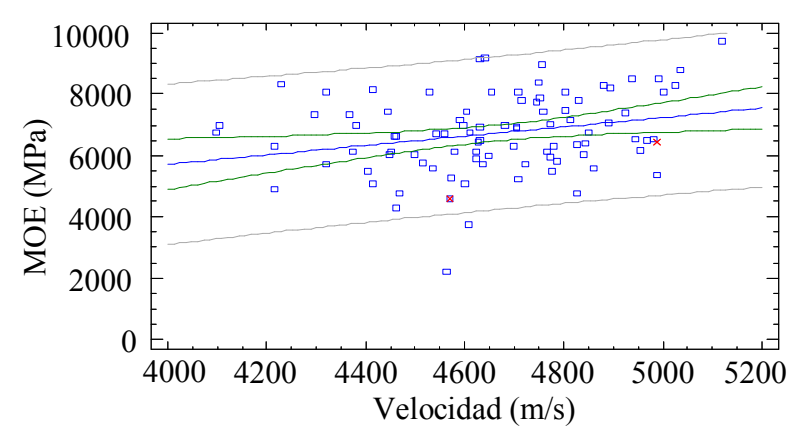

Figura 202. Regresión Simple MOE - Vel (Ult). - No Biológicas. Chopo Argentina.

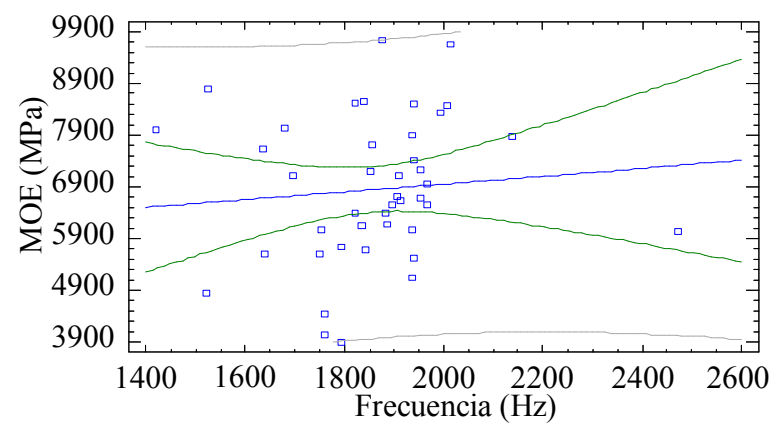

Figura 201. Chopo Argentina. Regresión Simple MOE - Fr (VI)-Biológicas.

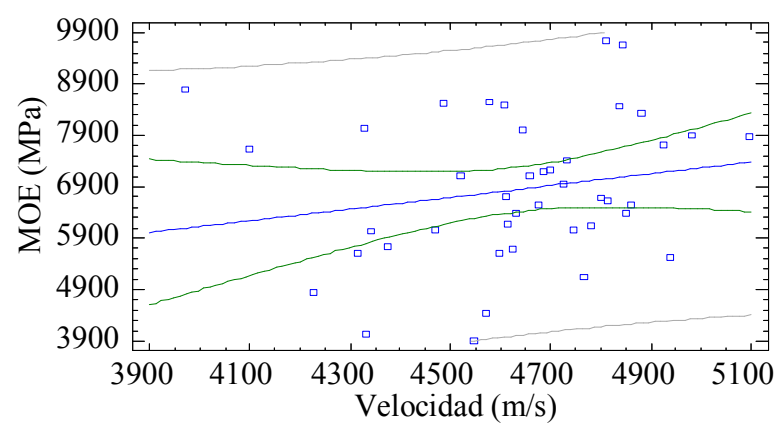

Figura 203. Regresión Simple MOE - Vel (Ult). Biológicas. Chopo Argentina. 


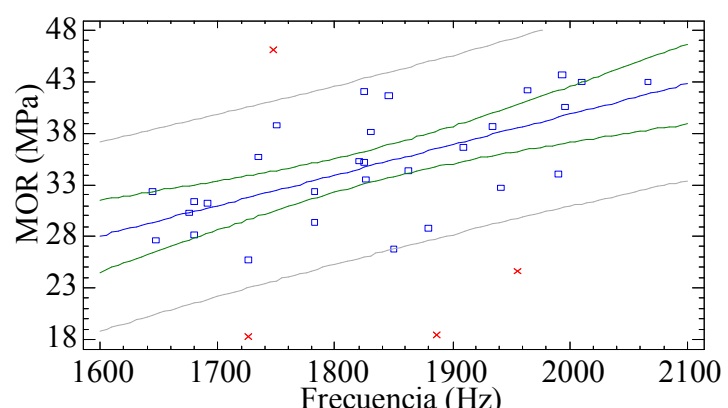

Figura 204. Regresión Simple MOR - Fr (VI)-No Biológicas. Chopo Argentina.

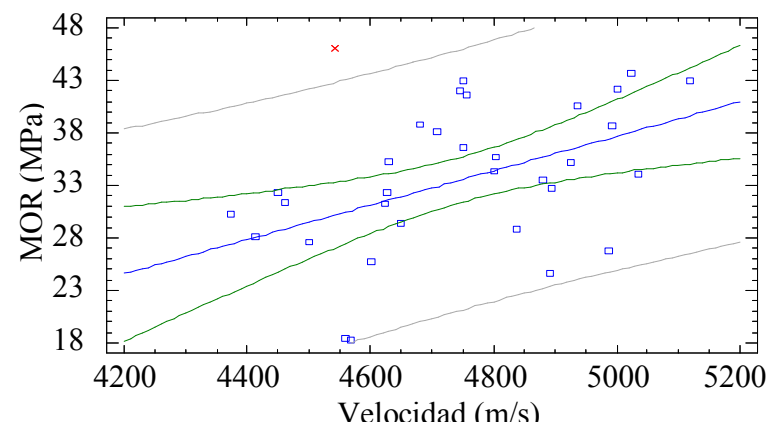

Figura 206. Regresión Simple MOR - Vel (Ult). - No Biológicas. Chopo Argentina.

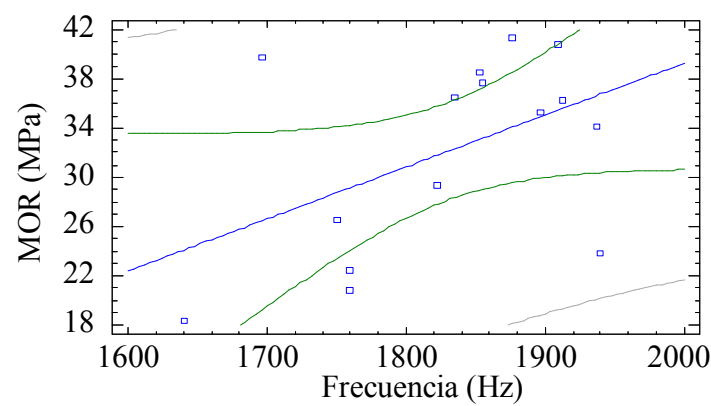

Figura 205. Regresión Simple MOR - Fr (VI)Biológicas. Chopo Argentina.

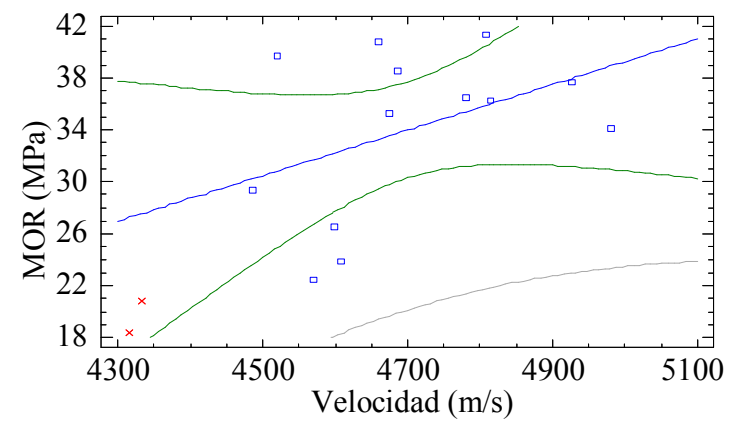

Figura 207. Regresión Simple MOR - Vel (Ult). Biológicas. Chopo Argentina.

De acuerdo con lo observado, cabe destacar que en términos generales, la presencia de daños causados por insectos no permiten establecer una relación estadísticamente significativa entre las variables predictivas, frecuencia de vibración y velocidad de ultrasonidos, y las variables predichas, MOE y MOR, reduciendo incluso, en los casos en que se establecen diferencias significativas (como es el caso de la frecuencia de vibración para predecir el MOE, Tabla 58), el grado de predicción $\left(\mathrm{R}^{2}\right.$ ajustado) entre ellas.

\subsection{Piezas macizas semi-estructurales (escala 1:5): consideraciones generales}

De acuerdo con el análisis realizado en las piezas de tamaño semi-estructural se observa que la madera de Populus $x$ euramericana I-214 de ambas procedencias, si bien presenta valores de densidad estadísticamente similares, difiere en los valores elasto-resistentes hallados, siendo superior el comportamiento mecánico del material procedente de España, resultado directamente influenciado por la presencia de defectos, principalmente, aquellos ocasionados por insectos en el material de procedencia Argentina.

De acuerdo con estos resultados, es digno destacar la importancia que tiene caracterizar el material en piezas que se asemejen a las situaciones reales de trabajo; en concordancia con esto, a continuación se realiza la caracterización del material en tamaño estructural. 


\subsection{Piezas macizas estructurales}

\subsubsection{Presentación de los lotes estudiados.}

\section{Análisis de centralidad y dispersión}

En la Tabla 59 se describen los lotes de madera maciza de tamaño estructural procedente de España; a los fines de análisis nos referiremos a un único lote constituido por la totalidad de las piezas.

Tabla 59. Dimensiones nominales y contenido de humedad de los lotes.

\begin{tabular}{|c|c|c|c|c|c|c|c|c|c|}
\hline \multirow[b]{2}{*}{ Lotes } & \multirow[b]{2}{*}{$\mathrm{n}^{*}$} & \multicolumn{2}{|c|}{$\begin{array}{l}\text { Longitud } \\
(\mathrm{cm})\end{array}$} & \multicolumn{2}{|c|}{$\begin{array}{l}\text { Anchura } \\
(\mathrm{cm})\end{array}$} & \multicolumn{2}{|c|}{$\begin{array}{l}\text { Espesor } \\
(\mathrm{cm})\end{array}$} & \multicolumn{2}{|c|}{$\begin{array}{c}\text { Humedad } \\
(\%)\end{array}$} \\
\hline & & $\begin{array}{c}\text { Media } \\
(\mathrm{CV} \%)^{*}\end{array}$ & $\begin{array}{l}\text { Mín.- } \\
\text { Máx. } \\
(\text { IQR)* }\end{array}$ & $\begin{array}{c}\text { Media } \\
(\mathrm{CV} \%)^{*}\end{array}$ & $\begin{array}{c}\text { Mín.- } \\
\text { Máx. } \\
(\mathrm{IQR})^{*}\end{array}$ & $\begin{array}{c}\text { Media } \\
\left(\mathrm{CV}^{\circ} \%\right)^{*}\end{array}$ & $\begin{array}{c}\text { Mín.- } \\
\text { Máx. } \\
(\mathrm{IQR})^{*}\end{array}$ & $\begin{array}{c}\text { Media } \\
(\mathrm{CV} \%)^{*}\end{array}$ & $\begin{array}{l}\text { Mín.- } \\
\text { Máx. } \\
(\mathrm{IQR})^{*}\end{array}$ \\
\hline Lote 1 & 430 & $\begin{array}{c}303,96 \\
(3,40)\end{array}$ & $\begin{array}{c}228,0- \\
340,8 \\
(7,1)\end{array}$ & $\begin{array}{l}14,93 \\
(3,54)\end{array}$ & $\begin{array}{c}12,33- \\
16,63 \\
(0,77)\end{array}$ & $\begin{array}{c}4,99 \\
(3,59)\end{array}$ & $\begin{array}{c}4,15-5,77 \\
(0,2)\end{array}$ & $\begin{array}{c}8,65 \\
(14,31)\end{array}$ & $\begin{array}{c}6,5-12,2 \\
(2,1)\end{array}$ \\
\hline Lote 2 & 122 & $\begin{array}{c}259,75 \\
(2,39)\end{array}$ & $\begin{array}{l}248,0- \\
276,0 \\
(10,5)\end{array}$ & $\begin{array}{l}13,31 \\
(1,22)\end{array}$ & $\begin{array}{l}12,8-13,6 \\
(0,2)\end{array}$ & $\begin{array}{c}5,22 \\
(2,73)\end{array}$ & $\begin{array}{c}4,8-5,5 \\
(0,2)\end{array}$ & $\begin{array}{c}9,43 \\
(9,29)\end{array}$ & $\begin{array}{c}8,4-11,8 \\
\quad(1,4)\end{array}$ \\
\hline Lote 3 & 40 & $\begin{array}{c}306,62 \\
(1,34)\end{array}$ & $\begin{array}{l}299,8- \\
311,9 \\
(7,55) \\
\end{array}$ & $\begin{array}{l}11,67 \\
(0,95)\end{array}$ & $\begin{array}{c}11,47- \\
12,0 \\
(0,14) \\
\end{array}$ & $\begin{array}{c}7,68 \\
(1,27)\end{array}$ & $\begin{array}{c}7,43-7,87 \\
(0,16)\end{array}$ & $\begin{array}{l}10,75 \\
(6,19)\end{array}$ & $\begin{array}{c}9,5-12,2 \\
(1,05)\end{array}$ \\
\hline Lote 4 & 277 & $\begin{array}{c}308,99 \\
(0,99)\end{array}$ & $\begin{array}{c}300,7- \\
317,0 \\
(4,5) \\
\end{array}$ & $\begin{array}{l}14,69 \\
(1,73)\end{array}$ & $\begin{array}{c}13,07- \\
15,3 \\
(0,3) \\
\end{array}$ & $\begin{array}{c}7,90 \\
(1,52)\end{array}$ & $\begin{array}{c}7,55-8,18 \\
(0,13)\end{array}$ & $\begin{array}{c}10,82 \\
(14,62)\end{array}$ & $\begin{array}{c}8,7-15,6 \\
(2,0)\end{array}$ \\
\hline Lote 5 & 80 & $\begin{array}{c}408,12 \\
(0,68)\end{array}$ & $\begin{array}{c}402,2- \\
413,2 \\
(3,7)\end{array}$ & $\begin{array}{l}19,79 \\
(0,92)\end{array}$ & $\begin{array}{l}19,33- \\
20,17 \\
(0,22) \\
\end{array}$ & $\begin{array}{c}9,85 \\
(0,78)\end{array}$ & $\begin{array}{l}9,7-10,05 \\
(0,12)\end{array}$ & $\begin{array}{c}11,42 \\
(18,05)\end{array}$ & $\begin{array}{c}9,1-15,8 \\
(3,15)\end{array}$ \\
\hline
\end{tabular}

*n: número de individuos; CV: coeficiente de variación, en \%; IQR: recorrido intercuartílico.

Las dimensiones nominales mostradas en la Tabla 59 son aquellas correspondientes al $20 \%$ de contenido de humedad para lo cual se tuvo en cuenta lo especificado en la norma EN 336:2014 donde se menciona que por debajo del $20 \%$ del contenido de humedad las dimensiones se ven reducidas en un $25 \%$ por cada $1 \%$ de reducción del contenido de humedad en la madera. De todos modos, las dimensiones reales se ajustan a las tolerancias permitidas dicha norma.

\subsubsection{Evaluación no destructiva:}

\subsubsection{Inspección-medición de singularidades y clasificación visual}

En cuanto a las singularidades halladas en el material de estudio, puede indicarse que las mismas estuvieron representadas por nudos, grano inclinado, anchura de anillos, entrecasco, gemas, presencia de médula y deformaciones en general (curvatura de cara, canto y alabeos)

La totalidad de los lotes, considerados en su conjunto, fueron clasificados de acuerdo con las normas indicadas en la Tabla 60, en dos clases estructurales y una clase de rechazo; a fin de 
homogeneizar términos se utilizó CS y CI para indicar a la "Clase estructural superior" y a la "Clase estructural inferior" respectivamente, $y$ " $R$ " para la clase de rechazo; para el mejor entendimiento de la homogeneización de clases y su correspondencia con la normativa de clases resistentes, en la Tabla 60 se resumen las homologaciones.

Tabla 60. Homologaciones clases resistentes vs clases asignadas por clasificación visual

\begin{tabular}{|c|c|c|c|}
\hline Normas & Clase Superior (CS) & Clase Inferior (CI) & $\operatorname{Rechazo}(\mathbf{R})$ \\
\hline $\begin{array}{l}\text { UNE 56544: } 1997 \\
\text { EN 338:2010 }\end{array}$ & $\begin{array}{l}\text { ME-I } \\
(\mathrm{C} 18)\end{array}$ & $\begin{array}{l}\text { ME-II } \\
(\mathrm{C} 14)\end{array}$ & $\mathrm{R}$ \\
\hline $\begin{array}{l}\text { UNE 56544: } 2011 \\
\text { EN 338:2010 }\end{array}$ & $\begin{array}{l}\text { ME-I } \\
\text { (C18) }\end{array}$ & $\begin{array}{l}\text { ME-II } \\
(\mathrm{C} 14)\end{array}$ & $\mathrm{R}$ \\
\hline $\begin{array}{c}\text { NF B52-001: } 2007 \\
\text { EN 338:2010 }\end{array}$ & $\begin{array}{l}\text { ST-II } \\
\text { (C24) }\end{array}$ & $\begin{array}{l}\text { ST-III } \\
(\mathrm{C} 18)\end{array}$ & $\mathrm{R}$ \\
\hline $\begin{array}{c}\text { DIN 4074-5: } 2008 \\
\text { EN 338:2010 }\end{array}$ & $\begin{array}{l}\mathrm{LS} 10 \\
(\mathrm{C} 24)\end{array}$ & $\begin{array}{c}\text { LS } 7 \\
(\mathrm{C} 16)\end{array}$ & $\mathrm{R}$ \\
\hline $\begin{array}{c}\text { NCh 1970/1: } 1988 \\
\text { EN 338:2010 }\end{array}$ & $\begin{array}{l}\text { G.E. N } 2 \\
\text { (C24) }\end{array}$ & $\begin{array}{l}\text { G.E. N }{ }^{\circ} 4 \\
(\mathrm{C} 18)\end{array}$ & $\mathrm{R}$ \\
\hline
\end{tabular}

*ME, ST, LS y G.E: = grados visuales estructurales, según cada normativa España, Francia, Alemania y Chile, respectivamente.

Cabe aclarar que si bien, en la norma DIN 4074-5, se establecen tres clases estructurales (más una clase rechazo), en este análisis se consideró la clase inferior y la clase mediana, dado que la clase superior es muy exigente para este material. Asimismo, la norma NCh 1970/1 establece 4 grados resistente, por lo que en este estudio se unificaron considerando el grado $\mathrm{N}^{\circ} 2$ como el más exigente (por ser el grado $\mathrm{N}^{\circ} 1$ muy restrictivo para la calidad de la madera trabajada) y el grado $\mathrm{N}^{\mathrm{o}} 4$ como la categoría menos exigente.

\subsubsection{Comportamiento clasificatorio por norma de clasificación visual}

En la Tabla 61 se indica el comportamiento clasificatorio de cada norma de clasificación visual, indicando el número de individuos $\mathrm{y}$, entre paréntesis, el porcentaje respecto al total, representado en cada clase

Tabla 61. Comportamiento clasificatorio de las normas de clasificación visual.

\begin{tabular}{|c|c|c|c|c|c|}
\hline \multirow[b]{2}{*}{ Clases } & \multicolumn{5}{|c|}{ NORMAS* } \\
\hline & $\begin{array}{c}\text { UNE-56544 } \\
(1997)\end{array}$ & $\begin{array}{c}\text { UNE-56544 } \\
(2011)\end{array}$ & $\begin{array}{c}\text { NF B52-001 } \\
(2007)\end{array}$ & $\begin{array}{c}\text { DIN 4074-5 } \\
(2008)\end{array}$ & $\begin{array}{c}\text { NCh 1970/1 } \\
(1988)\end{array}$ \\
\hline $\mathrm{CS}$ & $\begin{array}{l}30 \\
(3)\end{array}$ & $\begin{array}{l}56 \\
(6)\end{array}$ & $\begin{array}{l}57 \\
(6)\end{array}$ & $\begin{array}{l}24 \\
(2)\end{array}$ & $\begin{array}{l}47 \\
(5)\end{array}$ \\
\hline $\mathrm{CI}$ & $\begin{array}{l}115 \\
(12)\end{array}$ & $\begin{array}{l}173 \\
(18)\end{array}$ & $\begin{array}{l}74 \\
(8)\end{array}$ & $\begin{array}{l}45 \\
(5)\end{array}$ & $\begin{array}{l}60 \\
(6)\end{array}$ \\
\hline RECHAZO & $\begin{array}{l}799 \\
(85) \\
\end{array}$ & $\begin{array}{l}715 \\
(76) \\
\end{array}$ & $\begin{array}{l}813 \\
(86) \\
\end{array}$ & $\begin{array}{l}875 \\
(93) \\
\end{array}$ & $\begin{array}{l}837 \\
(89)\end{array}$ \\
\hline Total (vigas) & 944 & 944 & 944 & 944 & 944 \\
\hline
\end{tabular}

*En cada columna se indica el número de individuos y el porcentaje de los mismos sobre el total. 
A continuación se representan gráficamente los porcentajes correspondientes a las clases estructurales, CS y CI, agrupadas como estructurales (no indicado en Tabla 61) y a la clase no estructural, Rechazo; del mismo modo, se representa la asignación de piezas por clases visuales tal como se indica en la Tabla 61.

\section{Clasificación visual Norma UNE 56544: 1997}

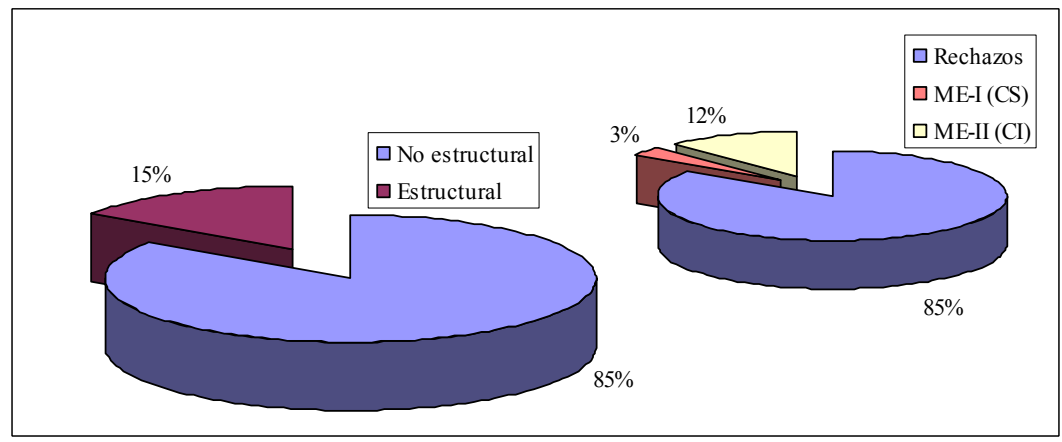

Figura 208. Representación porcentual según clases UNE-56544: 1997.

\section{Clasificación visual Norma UNE 56544: 2011}

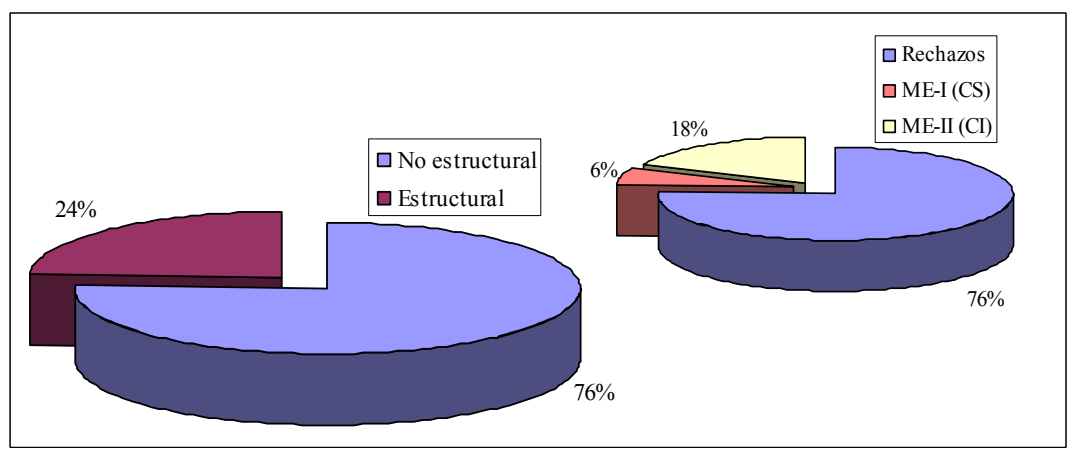

Figura 209. Representación porcentual según clases UNE-56544: 2011.

\section{Clasificación visual Norma NF B52-001: 2007}

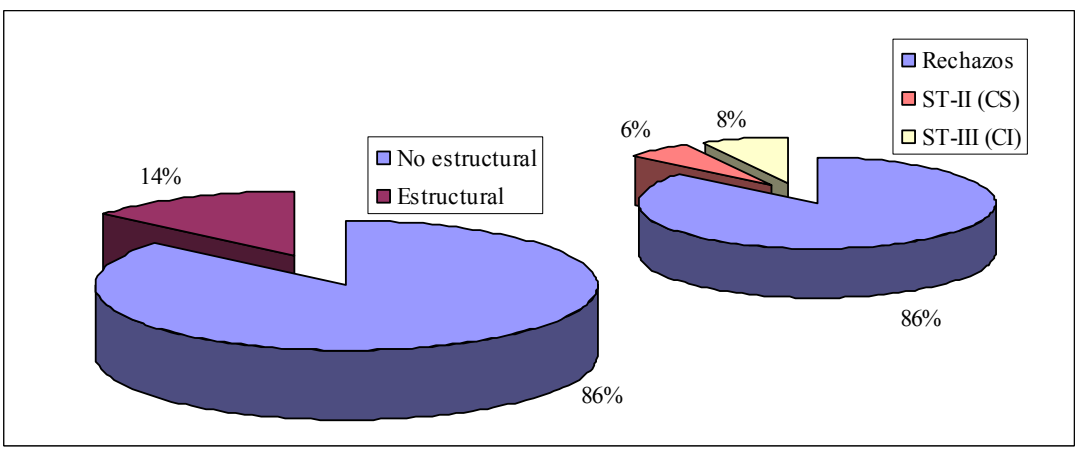

Figura 210. Representación porcentual según clases NF B52-001: 2007. 


\section{Clasificación visual Norma DIN 4074-5: 2003}

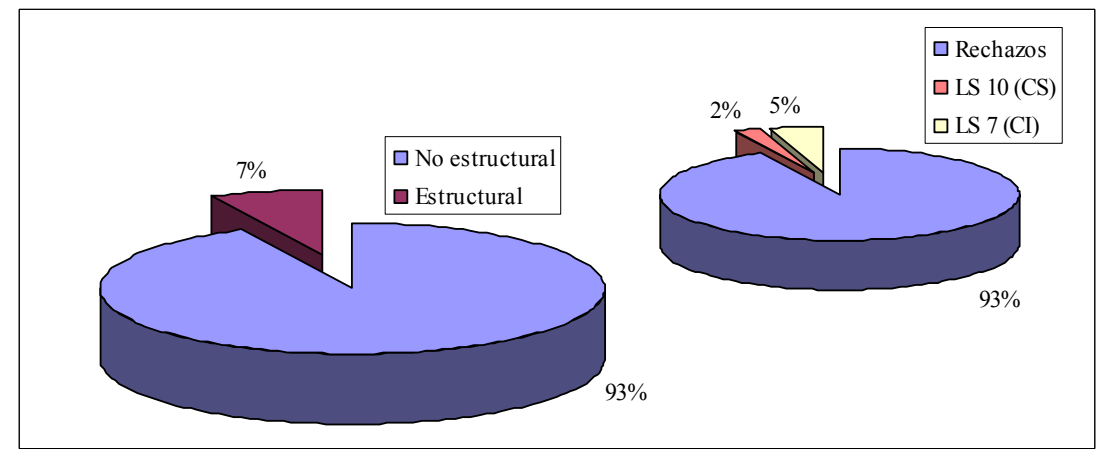

Figura 211. Representación porcentual según clases DIN 4074-5: 2008.

\section{Clasificación visual Norma NCh 1970/1: 1988}

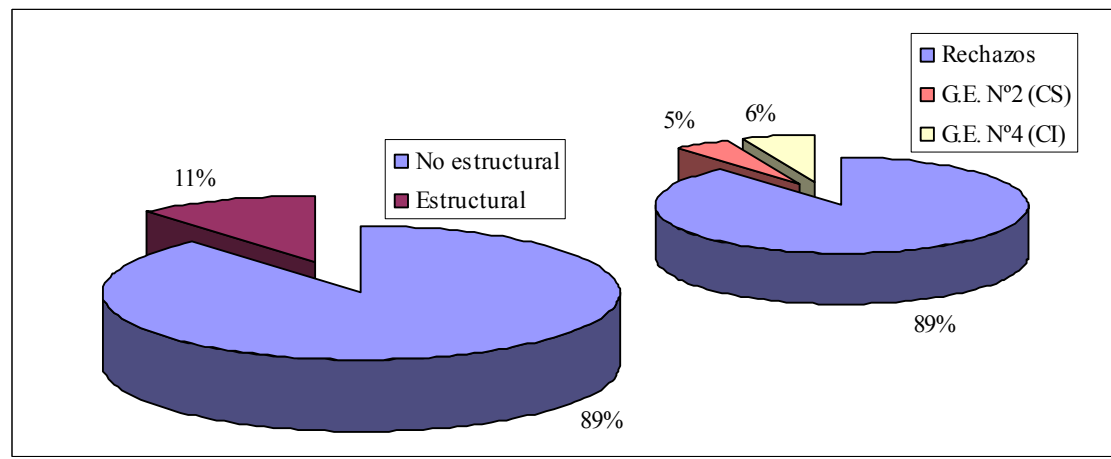

Figura 212. Representación porcentual según clases NCh 1970/1:1988.

Desde el punto de vista clasificatorio visual puede inferirse que el lote de madera estudiado tiene una calidad estructural muy baja. Asimismo, como primer análisis de todas las normas empleadas puede observarse que existe una limitada eficacia en su comportamiento clasificatorio ya que, en términos generales, el porcentaje de rechazo, "Clase No Estructural", ha superado ampliamente al número de piezas con destino estructural.

En este sentido, puede indicarse que, desde el punto de vista estructural, la clasificación visual más exigente es la llevada a cabo mediante la norma alemana DIN 4074-5: 2008, dado que con ella un 93\% de las piezas son clasificadas como "No estructurales". Por el contrario, la clasificación visual menos exigente es llevada a cabo con la norma española UNE-56544: 2011 con un 76\% de las piezas clasificadas como "No estructurales".

Dado que este comportamiento poco satisfactorio está directamente relacionado a la cantidad y tamaño de singularidades presentes en el material de estudio, en la Tabla 62 se muestran las causas de rechazo por norma, donde pueden vislumbrarse cuales de ellas fueron las más influyentes en el proceso clasificatorio. 
Tabla 62. Causa de rechazos por norma.

\begin{tabular}{|c|c|c|c|c|c|}
\hline \multirow{2}{*}{ RECHAZOS } & \multicolumn{5}{|c|}{ NORMA* } \\
\hline & $\begin{array}{c}\text { UNE-56544 } \\
(1997)\end{array}$ & $\begin{array}{c}\text { UNE-56544 } \\
(2011)\end{array}$ & $\begin{array}{c}\text { NF B52-001 } \\
(2007)\end{array}$ & $\begin{array}{l}\text { DIN 4074-5 } \\
(2008)\end{array}$ & $\begin{array}{c}\text { NCh 1970/1 } \\
(1988)\end{array}$ \\
\hline Nudos & $\begin{array}{c}275 \\
(29,13)\end{array}$ & $\begin{array}{c}276 \\
(29,24)\end{array}$ & $\begin{array}{c}320 \\
(33,90)\end{array}$ & $\begin{array}{c}357 \\
(37,82)\end{array}$ & $\begin{array}{c}383 \\
(40,57)\end{array}$ \\
\hline Grano inclinado & - & $\begin{array}{c}10 \\
(1,06) \\
\end{array}$ & $\begin{array}{c}10 \\
(1, .06) \\
\end{array}$ & $\begin{array}{c}10 \\
(1,06) \\
\end{array}$ & $\begin{array}{c}10 \\
(1, .06)\end{array}$ \\
\hline Anchura de anillos & - & - & $\begin{array}{c}34 \\
(3,60) \\
\end{array}$ & - & - \\
\hline Entrecasco & $\begin{array}{c}217 \\
(22,99) \\
\end{array}$ & - & - & - & - \\
\hline Anchura de gemas & $\begin{array}{c}339 \\
(35,91) \\
\end{array}$ & $\begin{array}{c}339 \\
(35,91) \\
\end{array}$ & $\begin{array}{c}339 \\
(35,91) \\
\end{array}$ & $\begin{array}{c}340 \\
(36,02) \\
\end{array}$ & $\begin{array}{c}339 \\
(35,91) \\
\end{array}$ \\
\hline Longitud de gemas & $\begin{array}{c}266 \\
(28,18) \\
\end{array}$ & $\begin{array}{c}246 \\
(26,06) \\
\end{array}$ & $\begin{array}{c}268 \\
(28,39) \\
\end{array}$ & $\begin{array}{c}247 \\
(26,17) \\
\end{array}$ & - \\
\hline Médula & - & - & - & $\begin{array}{c}379 \\
(40.15) \\
\end{array}$ & - \\
\hline Curvatura de cara & $\begin{array}{c}93 \\
(9,85) \\
\end{array}$ & $\begin{array}{c}6 \\
(0,64) \\
\end{array}$ & $\begin{array}{c}6 \\
(0,64) \\
\end{array}$ & $\begin{array}{c}248 \\
(26,27) \\
\end{array}$ & $\begin{array}{c}23 \\
(2,44) \\
\end{array}$ \\
\hline Curvatura de canto & $\begin{array}{c}143 \\
(15,15)\end{array}$ & $\begin{array}{c}52 \\
(5,51) \\
\end{array}$ & $\begin{array}{c}52 \\
(5,51) \\
\end{array}$ & $\begin{array}{c}171 \\
(18,11)\end{array}$ & $\begin{array}{c}241 \\
(25,53)\end{array}$ \\
\hline Alabeo & $\begin{array}{c}179 \\
(18,96)\end{array}$ & $\begin{array}{c}40 \\
(4,24)\end{array}$ & $\begin{array}{c}46 \\
(4,87)\end{array}$ & $\begin{array}{c}46 \\
(4,87)\end{array}$ & $\begin{array}{c}5 \\
(0,53)\end{array}$ \\
\hline
\end{tabular}

*En cada columna se indica el número de individuos y el porcentaje de los mismos sobre el total en paréntesis.

En términos generales puede indicarse que los nudos y las gemas son las causas más recurrentes de rechazo en todas normas; asimismo los datos presentados en la Tabla 62 otorgan una aproximación del estado visual de cada viga, dado que a su vez cada una de ellas puede ser rechazada por más de un defecto.

Con la finalidad de hacer una evaluación más exhaustiva sobre el comportamiento de las normas de clasificación visual, a continuación se presenta un análisis considerando además la incorporación de las variables elasto-resistentes (MOE y MOR) y de la densidad.

\subsection{Valores característicos}

A fin de relacionar el comportamiento de las normas visuales con los valores resistentes del lote estudiado, en primer término se presenta el resumen descriptivo de las variables caracterizadoras, densidad, MOR y MOE, obtenidas mediante ensayo destructivo de flexión estática, EN 408:2011+A1:2012, Tabla 63; Figura 213. Dado el incumplimiento de los supuestos estadísticos de las variables MOE y densidad, las mismas fueron transformadas tal como se indica en la Tabla 63. 
Tabla 63. Resumen descriptivo del material estructural en estudio.

\begin{tabular}{ccccc}
\hline Variable & Repeticiones & $\begin{array}{c}\text { Media }-\mathbf{5}^{\circ} \text { Percentil } \\
(\mathbf{C V} \%)\end{array}$ & $\begin{array}{c}\text { Mín-Máx } \\
(\mathbf{I Q R \%})\end{array}$ & $\begin{array}{c}\text { Normalidad; } \\
\text { Variable } \\
\text { transformada }\end{array}$ \\
\hline $\begin{array}{c}\mathrm{MOE} \\
(\mathrm{MPa})\end{array}$ & 943 & $\begin{array}{c}7653,16^{*}-5613,31 \\
(21,14)\end{array}$ & $\begin{array}{c}3766,97-15198,9 \\
(1896,51)\end{array}$ & No; Log(MOE) \\
\hline $\begin{array}{c}\mathrm{MOR} \\
(\mathrm{MPa})\end{array}$ & 944 & $\begin{array}{c}39,46-20,44^{*} \\
(29,22)\end{array}$ & $\begin{array}{c}10,73-71,16 \\
(16,04)\end{array}$ & Sí \\
\hline $\begin{array}{c}\text { Densidad } \\
\left(\mathrm{Kg} / \mathrm{m}^{3}\right)\end{array}$ & 949 & $\begin{array}{c}361,98-309,26^{*} \\
(11,69)\end{array}$ & $\begin{array}{c}273,41-563,37 \\
(63,43)\end{array}$ & No; $1 /$ Densidad \\
\hline
\end{tabular}

*Valores característicos: media para el MOE y $5^{\circ}$ percentil para la densidad y el MOR (EN 384:2010).

De acuerdo con la falta de normalidad determinada en las variables MOE y densidad, Anejos 6.3.1, se trabajó con sus transformadas 1/Densidad y $\log (\mathrm{MOE})$, respectivamente, cuya distribución de frecuencias se indica en la Figura 213, junto con la variable MOR sin transformar.
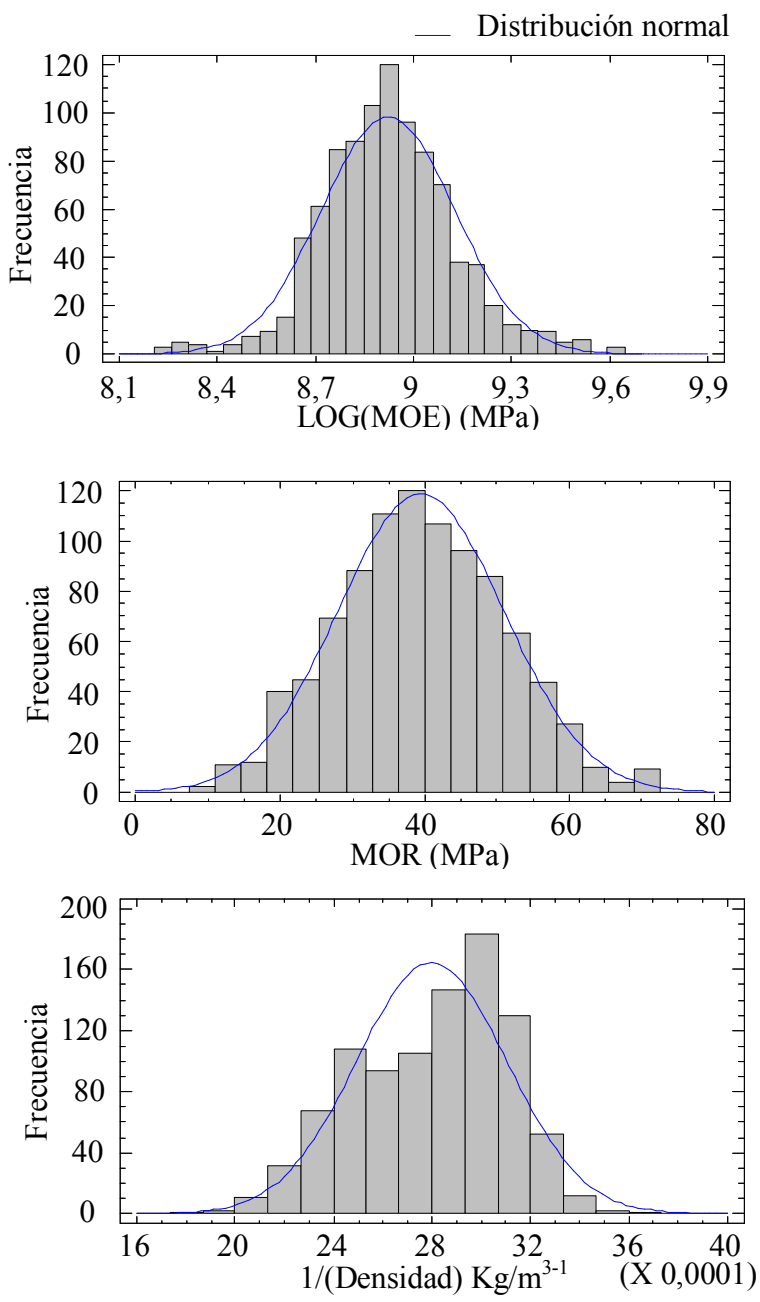

Figura 213. Histograma de frecuencia: LOG(MOE), MOR y 1/Densidad. 


\subsection{Comportamiento clasificatorio resistente}

De este modo, presentados el valor de densidad y los valores elasto-resistentes (MOE y MOR) del lote, a continuación se expone el comportamiento clasificatorio obtenido según la norma de Clases Resistentes EN 338:2010. Como primera instancia en la Tabla 64 se detallan, para cada clase resistente considerada (EN 338:2010) y su equivalencia con la categoría asignada mediante clasificación visual (calidad), los rangos de valores característicos (ensayos destructivos) estipulados; a partir de ello se inició el proceso clasificatorio resistente.

Tabla 64. Rangos de valores característicos: correspondencia calidad - clases resistentes.

\begin{tabular}{|c|c|c|c|c|c|}
\hline \multirow{3}{*}{ Norma* } & \multirow{3}{*}{ Calidad* } & \multirow{3}{*}{ Clases resistentes } & \multicolumn{3}{|c|}{ Ensayos destructivos } \\
\hline & & & \multirow[b]{2}{*}{$\begin{array}{c}\text { Densidad } \\
\left(\mathrm{Kg} / \mathbf{m}^{3}\right)\end{array}$} & \multicolumn{2}{|c|}{ Máquina Universa } \\
\hline & & & & $\begin{array}{l}\text { MOE } \\
\text { (MPa) }\end{array}$ & $\begin{array}{l}\text { MOR } \\
\text { (MPa) }\end{array}$ \\
\hline \multirow{3}{*}{ UNE-56544: 1997-2011 } & CS (ME-I) & C18 & $\geq 320$ & $\geq 9000$ & $\geq 18$ \\
\hline & CI (ME-II) & $\mathrm{C14}$ & $\geq 290$ & $\geq 7000$ & $\geq 14$ \\
\hline & \multicolumn{2}{|c|}{ Rechazo } & $<290$ & $<7000$ & $<14$ \\
\hline \multirow{3}{*}{$\frac{\text { NF B52-001: 2007; }}{\underline{\text { NCh1970/1:1988 }}}$} & CS (ST-II; G.E. No2) & $\mathrm{C24}$ & $\geq 350$ & $\geq 11000$ & $\geq 24$ \\
\hline & CI (ST-III; G.E. No4) & C18 & $\geq 320$ & $\geq 9000$ & $\geq 18$ \\
\hline & \multicolumn{2}{|c|}{ Rechazo } & $<320$ & $<9000$ & $<18$ \\
\hline \multirow{3}{*}{$\underline{\text { DIN-4074-5: } 2003}$} & CS (LS 10) & $\mathrm{C24}$ & $\geq 350$ & $\geq 11000$ & $\geq 24$ \\
\hline & CI (LS 7) & C16 & $\geq 310$ & $\geq 8000$ & $\geq 16$ \\
\hline & \multicolumn{2}{|c|}{ Rechazo } & $<310$ & $<8000$ & $<16$ \\
\hline
\end{tabular}

*CS: clase estructural superior (visual): ME, ST, G.E y LS: = clase estructural (visual), según normativa: España, Francia, Chile y Alemania, respectivamente.

\section{Valores característicos por clase visual (UNE 56544:1997)}

En la Tabla 65, se detallan los valores característicos obtenidos según las categorías de clasificación visual, Clase por calidad; los gráficos de caja y bigotes de cada variable se presentan en la Figura 214, representando la dispersión de los datos.

Tabla 65. Análisis descriptivo: Densidad, MOE y MOR por clases.

\begin{tabular}{ccccc}
\hline \multirow{2}{*}{ Clase por calidad } & $\mathrm{n}^{*}$ & \multicolumn{3}{c}{$\begin{array}{c}\text { Media-5 } \\
\text { (CV\%) }\end{array}$} \\
\cline { 3 - 5 } & $(\%)$ & $\begin{array}{c}\text { Densidad } \\
\left(\mathrm{Kg} / \mathrm{m}^{3}\right)\end{array}$ & $\begin{array}{c}\text { MOE* } \\
(\mathrm{MPa})\end{array}$ & $\begin{array}{c}\text { MOR* } \\
(\mathrm{MPa})\end{array}$ \\
\hline \multirow{2}{*}{ Clase Superior $(\mathbf{C S})$} & 30 & $\begin{array}{c}346,90-309,77^{* *} \\
(6,85)\end{array}$ & $\begin{array}{c}7565,33^{* *}-5529,63 \\
(19,43)\end{array}$ & $\begin{array}{c}41,80-24,90^{* *} \\
(25,88)\end{array}$ \\
\hline \multirow{2}{*}{ Clase Inferior (CI) } & $(3,21)$ & $351,36-304,63^{* *}$ & $7530,86^{* *}-5120,42$ & $39,27-22,49^{* *}$ \\
& $(12,33)$ & $(10,28)$ & $(20,14)$ & $(26,77)$ \\
\hline \multirow{2}{*}{ Rechazo (R) } & 788 & $360,14-309,84^{* *}$ & $7619,94^{* *}-5632,75$ & $39,34-21,39^{* *}$ \\
& $(84,46)$ & $(10,66)$ & $(19,98)$ & $(27,09)$ \\
\hline
\end{tabular}

*n: número de individuos; (\%) porcentaje de individuos en cada clase con referencia al total; valores característicos: media para el MOE; $5^{\circ}$ percentil para el MOR y la densidad (EN 384: 2010). 

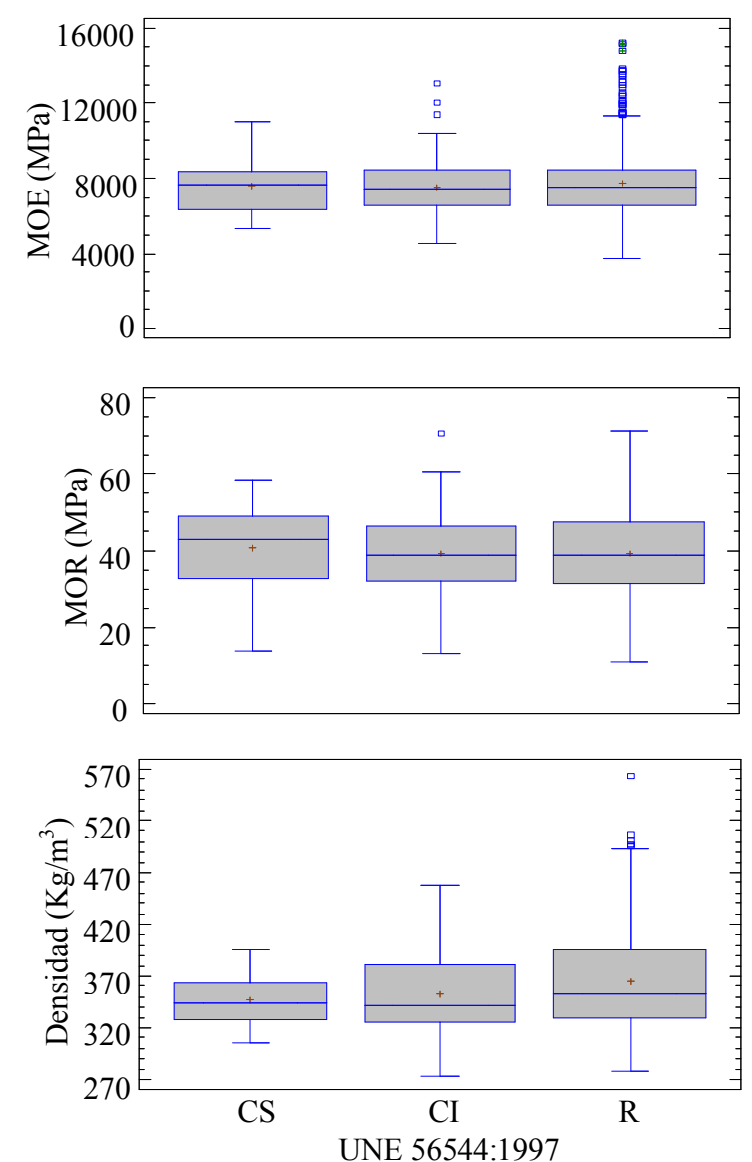

Figura 214. Gráfico de Caja y Bigotes: variables caracterizadoras clases UNE 56544: 1997.

\section{$\underline{\text { Valores característicos por clase visual (UNE 56544:2011) }}$}

En la Tabla 66 y Figura 215, se muestran los valores característicos obtenidos según las categorías de clasificación visual UNE 56544:2011; en la Figura 216 se representan las clases para las dos versiones de la norma UNE 56544.

Tabla 66. Análisis descriptivo: Densidad, MOE y MOR por clases.

\begin{tabular}{|c|c|c|c|c|}
\hline \multirow{2}{*}{ Clase por calidad } & \multirow{2}{*}{$\begin{array}{l}\mathrm{n}^{*} \\
(\%)\end{array}$} & \multicolumn{3}{|c|}{$\begin{array}{c}\text { Media-5Percentil } \\
(\mathrm{CV} \%)\end{array}$} \\
\hline & & $\begin{array}{c}\text { Densidad } \\
\left(\mathrm{Kg} / \mathrm{m}^{3}\right)\end{array}$ & $\begin{array}{c}\mathrm{MOE}^{*} \\
(\mathrm{MPa}) \\
\end{array}$ & $\begin{array}{l}\mathrm{MOR}^{*} \\
(\mathrm{MPa}) \\
\end{array}$ \\
\hline Clase Superior (CS) & $\begin{array}{c}56 \\
(5,99)\end{array}$ & $\begin{array}{c}342,77-304,62 * \\
(7,21)\end{array}$ & $\begin{array}{c}7693,48 *-5529,63 \\
(17,55)\end{array}$ & $\begin{array}{c}43,27-28,16^{*} \\
(21,09)\end{array}$ \\
\hline Clase Inferior (CI) & $\begin{array}{c}172 \\
(18,42)\end{array}$ & $\begin{array}{c}351,05-308,33 * \\
(9,89)\end{array}$ & $\begin{array}{c}7426,71 *-4961,55 \\
(22,28)\end{array}$ & $\begin{array}{c}39,45-23,48^{*} \\
(26,32)\end{array}$ \\
\hline Rechazo (R) & $\begin{array}{c}706 \\
75,59\end{array}$ & $\begin{array}{c}360,61-310,02 * \\
(10,51)\end{array}$ & $\begin{array}{c}7644,46 *-5697,99 \\
(19,56)\end{array}$ & $\begin{array}{c}40,43-23,60 * \\
(25,90)\end{array}$ \\
\hline
\end{tabular}

*n: número de individuos; (\%) porcentaje de individuos en cada clase con referencia al total; valores característicos: media para el MOE; $5^{\circ}$ percentil para el MOR (EN 384: 2010) y la densidad. 

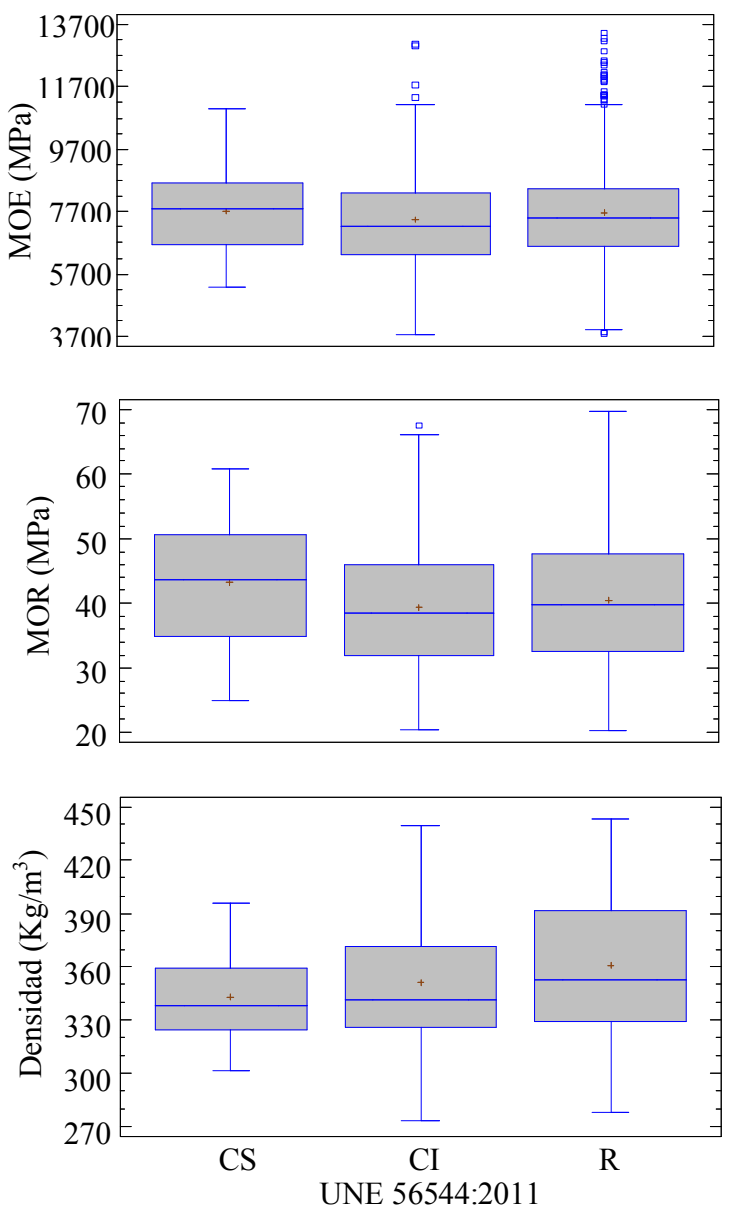

Figura 215. Gráfico de Caja y Bigotes: variables caracterizadoras clases UNE 56544: 2011

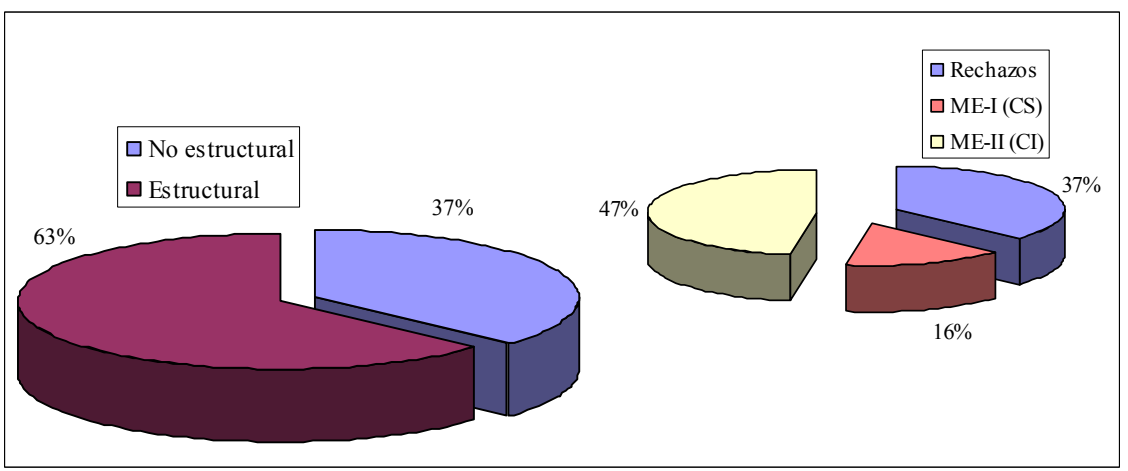

Figura 216. Clasificación resistente: EN-338: 2010 - UNE 56544: 1997-2011

\section{Valores característicos por clase visual (NF B52-001:2007)}

Los valores característicos obtenidos según las categorías de clasificación visual UNE 56544:2011 se detallan en la Tabla 67 y en la Figura 215; la Figura 218 representa porcentualmente las clases. 
Tabla 67. Análisis descriptivo: Densidad, MOE y MOR por clases

\begin{tabular}{|c|c|c|c|c|}
\hline \multirow{2}{*}{ Clase por calidad } & \multirow{2}{*}{$\begin{array}{c}\mathrm{n} \\
(\%)\end{array}$} & \multicolumn{3}{|c|}{$\begin{array}{c}\text { Media-5Percentil } \\
(\mathrm{CV} \%)\end{array}$} \\
\hline & & $\begin{array}{l}\text { Densidad } \\
\left(\mathrm{Kg} / \mathrm{m}^{3}\right)\end{array}$ & $\begin{array}{l}\mathrm{MOE}^{*} \\
(\mathrm{MPa})\end{array}$ & $\begin{array}{l}\text { MOR* } \\
(\mathrm{MPa})\end{array}$ \\
\hline Clase Superior (CS) & $\begin{array}{c}56 \\
(6,03) \\
\end{array}$ & $\begin{array}{c}346,51-308,12^{*} \\
(8,62)\end{array}$ & $\begin{array}{c}7464,31 *-5502,74 \\
(16,98)\end{array}$ & $\begin{array}{c}43,84-29,84^{*} \\
(22,38)\end{array}$ \\
\hline Clase Inferior (CI) & $\begin{array}{c}73 \\
(7,87)\end{array}$ & $\begin{array}{c}348,19-302,81^{*} \\
(10,85)\end{array}$ & $\begin{array}{c}7565,14 *-5756,55 \\
(16,51)\end{array}$ & $\begin{array}{c}41,29-27,41 * \\
(21,13)\end{array}$ \\
\hline Rechazo (R) & $\begin{array}{c}799 \\
(86,10)\end{array}$ & $\begin{array}{c}360,44-310,42 * \\
(10,57)\end{array}$ & $\begin{array}{c}7586,22 *-5525,07 \\
(19,75)\end{array}$ & $\begin{array}{c}40,08-23,55^{*} \\
(26,31)\end{array}$ \\
\hline
\end{tabular}

*n: número de individuos; (\%) porcentaje de individuos en cada clase con referencia al total; valores característicos: media para el MOE; $5^{\circ}$ percentil para el MOR y la densidad y (EN 384: 2010).
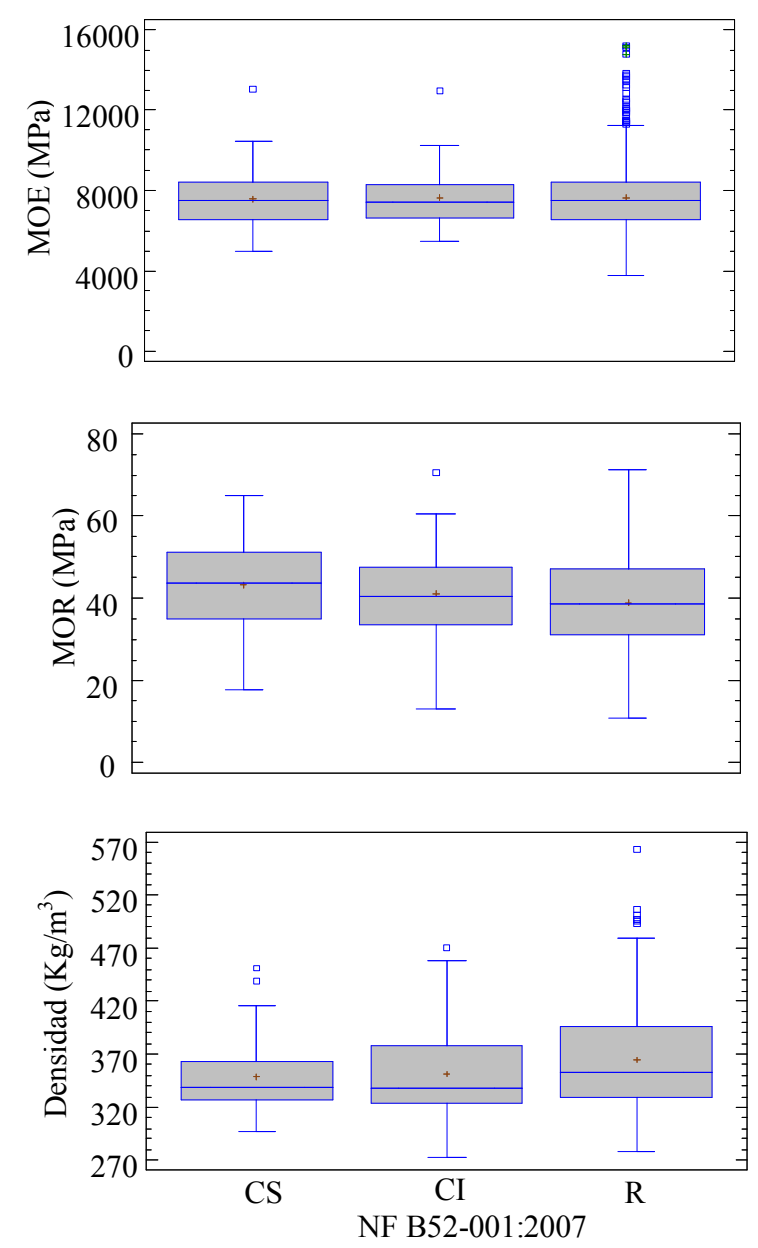

Figura 217. Gráfico de Caja y Bigotes: variables caracterizadoras clases NF B52-001: 2007. 


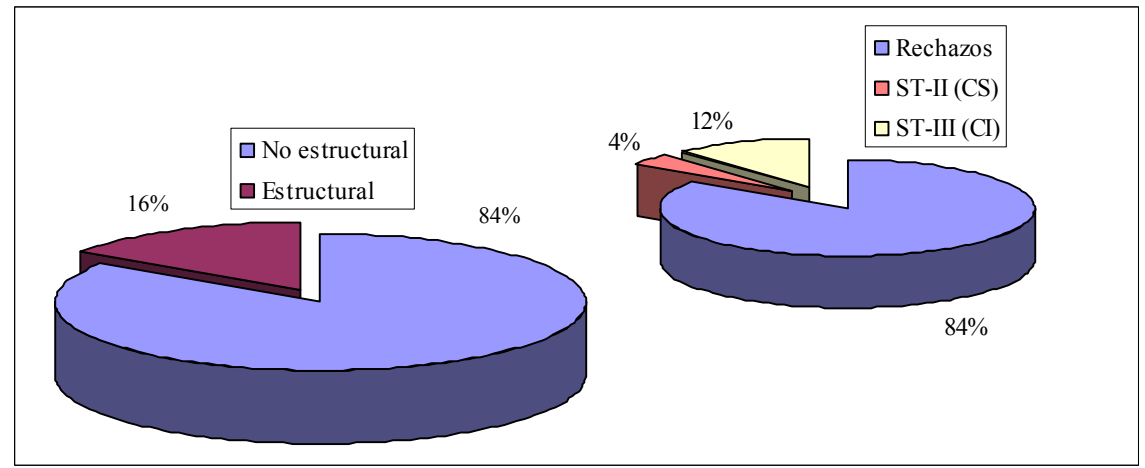

Figura 218. Clasificación resistente: EN-338: 2010 - NF B52-001:2007

\section{$\underline{\text { Valores característicos por clase visual (DIN 4074-5:2003) }}$}

Los valores característicos representados por clases visuales DIN 4074-5 se detallan en la Tabla 68, Figura 219 y Figura 220.

Tabla 68. Análisis descriptivo: Densidad, MOE y MOR por clases

\begin{tabular}{|c|c|c|c|c|}
\hline \multirow{2}{*}{ Clase por calidad } & \multirow{2}{*}{$\begin{array}{c}\mathrm{n} \\
(\%)\end{array}$} & \multicolumn{3}{|c|}{$\begin{array}{c}\text { Media-5Percentil } \\
(\mathrm{CV} \%)\end{array}$} \\
\hline & & $\begin{array}{l}\text { Densidad } \\
\left(\mathrm{Kg} / \mathrm{m}^{3}\right)\end{array}$ & $\begin{array}{c}\mathrm{MOE} \\
(\mathrm{MPa})\end{array}$ & $\begin{array}{l}\text { MOR } \\
(\mathrm{MPa})\end{array}$ \\
\hline Clase Superior (CS) & $\begin{array}{c}24 \\
(2,58)\end{array}$ & $\begin{array}{c}343,40-309,77^{*} \\
(6,47)\end{array}$ & $\begin{array}{c}7582,07 *-5988,51 \\
(16,60)\end{array}$ & $\begin{array}{c}45,91-30,48^{*} \\
(20,54)\end{array}$ \\
\hline Clase Inferior (CI) & $\begin{array}{c}45 \\
(4,83)\end{array}$ & $\begin{array}{c}351,80-308,12^{*} \\
(10,27)\end{array}$ & $\begin{array}{c}7636,54 *-5907,36 \\
(15,06)\end{array}$ & $\begin{array}{c}42,49-29,91^{*} \\
(18,96)\end{array}$ \\
\hline Rechazo (R) & $\begin{array}{c}863 \\
(92,59)\end{array}$ & $\begin{array}{c}361,36-309,26^{*} \\
(11,13)\end{array}$ & $\begin{array}{c}7574,04 *-5525,07 \\
(19,63)\end{array}$ & $\begin{array}{c}39,32-21,80^{*} \\
(26,77)\end{array}$ \\
\hline
\end{tabular}

${ }^{*}$ n: número de individuos; $(\%)$ porcentaje de individuos en cada clase con referencia al total; valores característicos: media para el MOE; $5^{\circ}$ percentil para el MOR y la densidad (EN 384: 2010). 

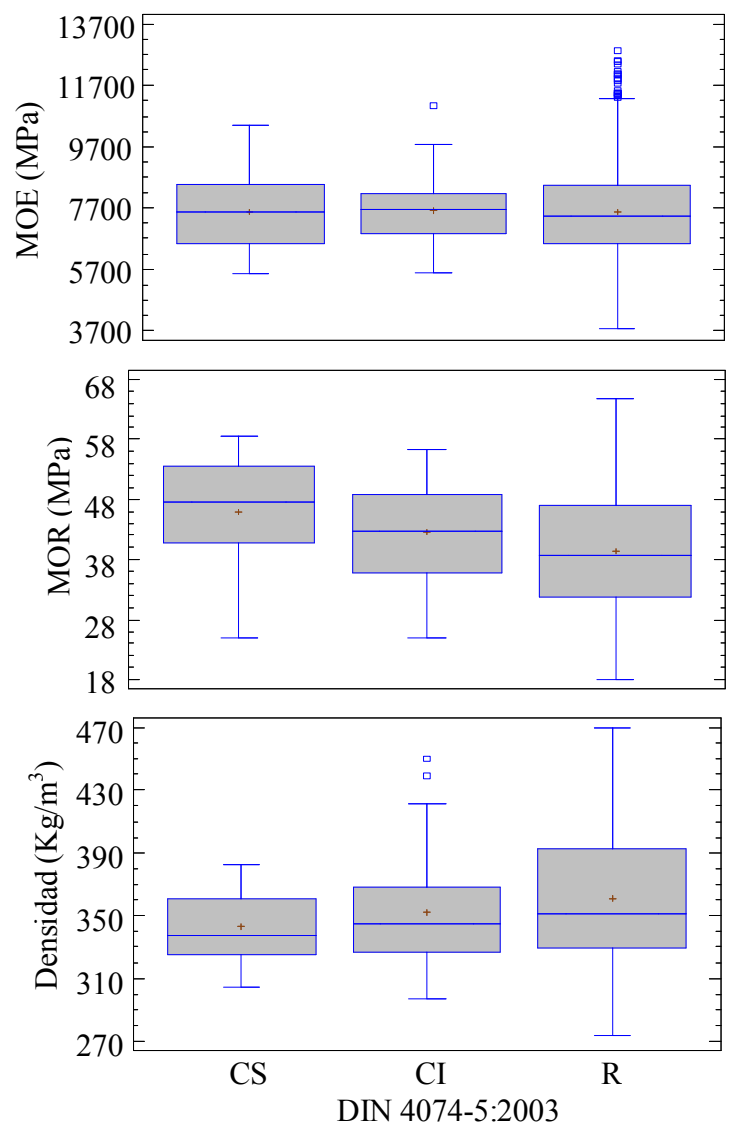

Figura 219. Gráfico de Caja y Bigotes: variables caracterizadoras clases DIN 4074-5:2003.

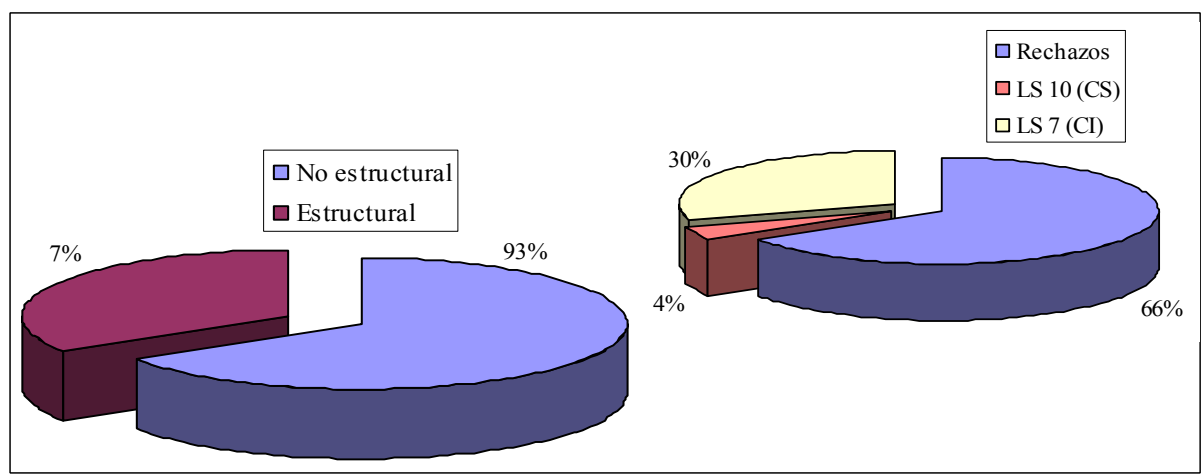

Figura 220. Clasificación resistente: EN-338: 2010 - DIN 4074-5:2003

\section{$\underline{\text { Valores característicos por clase visual (NCh1970-1:1988) }}$}

Los valores característicos representados por clases visuales DIN 4074-5 se detallan en la Tabla 69, Figura 221 y Figura 222. 
Tabla 69. Análisis descriptivo: Densidad, MOE y MOR por clases

\begin{tabular}{|c|c|c|c|c|}
\hline \multirow{2}{*}{ Clase por calidad } & \multirow{2}{*}{$\begin{array}{l}\mathrm{n}^{*} \\
(\%)\end{array}$} & \multicolumn{3}{|c|}{$\begin{array}{l}\text { Media-5Percentil } \\
(\mathrm{CV} \%)^{*}\end{array}$} \\
\hline & & $\begin{array}{l}\text { Densidad } \\
\left(\mathrm{Kg} / \mathrm{m}^{3}\right)\end{array}$ & $\begin{array}{l}\mathrm{MOE}^{*} \\
(\mathrm{MPa})\end{array}$ & $\begin{array}{l}\text { MOR* } \\
(\mathrm{MPa})\end{array}$ \\
\hline Clase Superior (CS) & $\begin{array}{c}47 \\
(5,04)\end{array}$ & $\begin{array}{c}343,55-304,62 * \\
(7,20)\end{array}$ & $\begin{array}{c}8005,55 *-5807,83 \\
(16,90)\end{array}$ & $\begin{array}{c}44,93-27,27^{*} \\
(21,24)\end{array}$ \\
\hline Clase Inferior (CI) & $\begin{array}{c}60 \\
(6,44)\end{array}$ & $\begin{array}{c}348,63-306,38 * \\
(35,91)\end{array}$ & $\begin{array}{c}6939,46 *-4824,26 \\
(21,29)\end{array}$ & $\begin{array}{c}39,58-24,59 * \\
(25,72)\end{array}$ \\
\hline Rechazo (R) & $\begin{array}{c}825 \\
(88,52)\end{array}$ & $\begin{array}{c}362,25-309,84 * \\
(11,16)\end{array}$ & $\begin{array}{c}7553,36 *-5653,89 \\
(18,39)\end{array}$ & $\begin{array}{c}40,22-23,56^{*} \\
(25,89)\end{array}$ \\
\hline
\end{tabular}

*n: número de individuos; $(\%)$ porcentaje de individuos en cada clase con referencia al total; valores característicos: media para el MOE; $5^{\circ}$ percentil para el MOR y la densidad (EN 384: 2010).
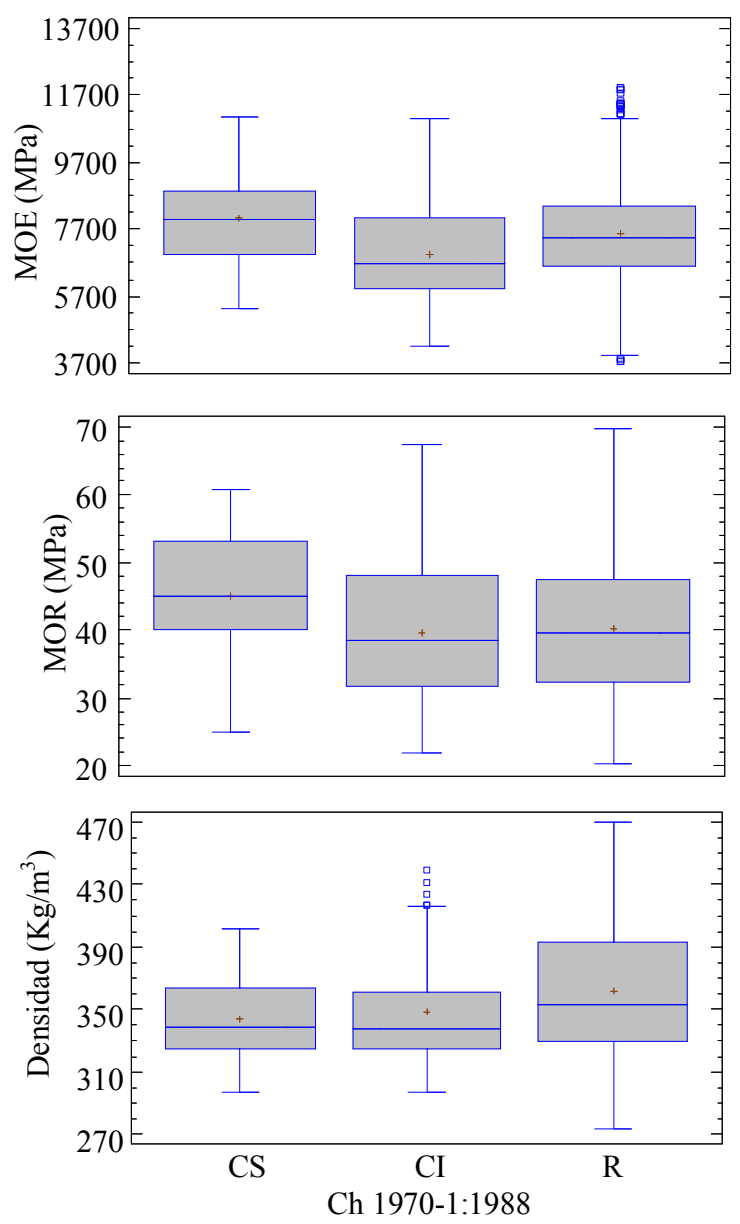

Figura 221. Gráfico de Caja y Bigotes: variables caracterizadoras clases Ch 1970-1:1988. 


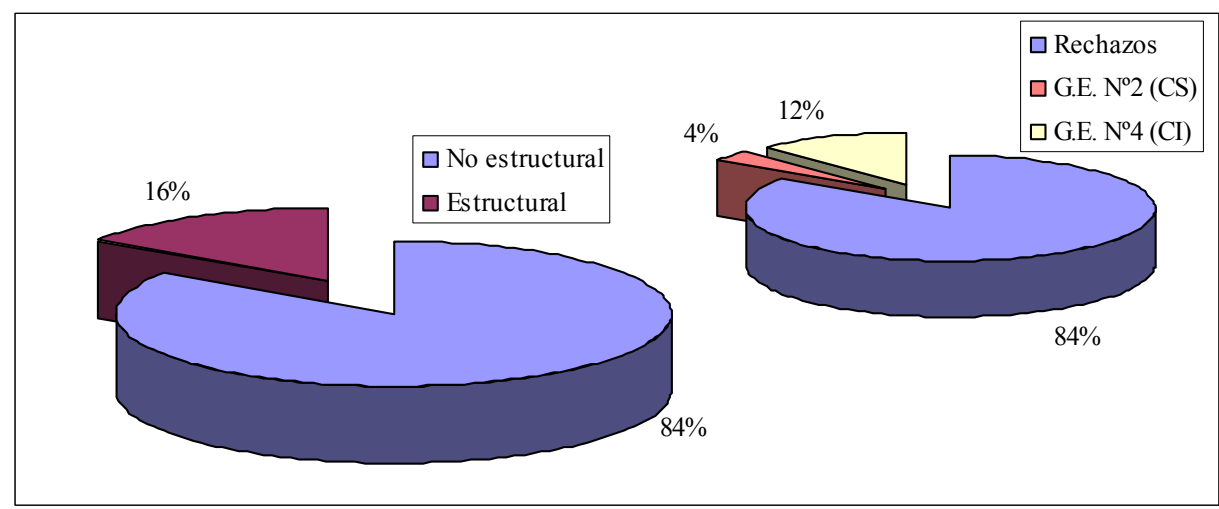

Figura 222. Clasificación resistente: EN-338: 2010 - Norma Ch1970/1:1988

Del análisis clasificatorio puede indicarse que el valor restrictivo en todos los casos, está representado por los bajos valores de MOE hallados, generando una gran proporción de piezas rechazadas.

\subsection{Comportamiento comparativo entre clases visuales y clases resistentes:}

\section{Aciertos, Subestimas y Sobreestimas}

A fin de evaluar la eficiencia comparativa de ambas normativas (visual-resistente), se comparó el comportamiento diferencial entre las mismas, determinando el porcentaje de aciertos, subestimas y sobrestimas entre ellas, Tabla 70. Para ello, tal como se detalló en materiales y métodos, se trabajó con el análisis de los factores categóricos, utilizando el método de tabulación cruzada.

Tabla 70. Comportamiento de las normas de clasificación visual con respecto a la norma EN-338: 2010.

\begin{tabular}{cccccc}
\hline \multirow{2}{*}{ Clases } & \multicolumn{5}{c}{ NORMAS } \\
\cline { 2 - 6 } & $\begin{array}{c}\text { UNE-56544 } \\
\mathbf{( 1 9 9 7 )}\end{array}$ & $\begin{array}{c}\text { UNE-56544 } \\
\mathbf{( 2 0 1 1 )}\end{array}$ & $\begin{array}{c}\text { NF B52-001 } \\
\mathbf{( 2 0 0 7 )}\end{array}$ & $\begin{array}{c}\text { DIN 4074-5 } \\
\mathbf{( 2 0 0 8 )}\end{array}$ & $\begin{array}{c}\text { NCh 1970/1 } \\
\mathbf{( 1 9 8 8 )}\end{array}$ \\
\hline ACIERTOS & 36,96 & 34,43 & 74,16 & 62,92 & 75,74 \\
\hline \% Rechazos & 83,66 & 76,92 & 98,14 & 97,64 & 98,88 \\
\hline \% CS & 1,15 & 2,46 & 1,71 & 0 & 0,14 \\
\hline \% CI & 15,19 & 20,62 & 0,14 & 2,36 & 0,98 \\
\hline SUBESTIMAS & 55,62 & 52,33 & 13,45 & 31,46 & 13,77 \\
\hline \% Rechazos $\rightarrow$ CI & 72,76 & 71,86 & 73,23 & 88,22 & 73,85 \\
\hline \% Rechazos $\rightarrow$ CS & 23,81 & 22,27 & 25,98 & 11,11 & 26,15 \\
\hline \% CI $\rightarrow$ CS & 3,43 & 5,87 & 0,78 & 0,67 & 0,00 \\
\hline SOBREESTIMAS & 7,42 & 13,24 & 12,39 & 5,61 & 10,49 \\
\hline \% CI $\rightarrow$ Rechazos & 62,86 & 61,60 & 52,14 & 54,72 & 53,54 \\
\hline \% CS $\rightarrow$ Rechazos & 18,57 & 17,60 & 41,88 & 30,19 & 37,37 \\
\hline \% CS $\rightarrow$ CI & 18,57 & 20,80 & 5,98 & 15,09 & 9,09 \\
\hline
\end{tabular}

En la Figura 223 se observa el comportamiento porcentual de las normas de clasificación visual (aciertos, subestimas y sobreestimas). 


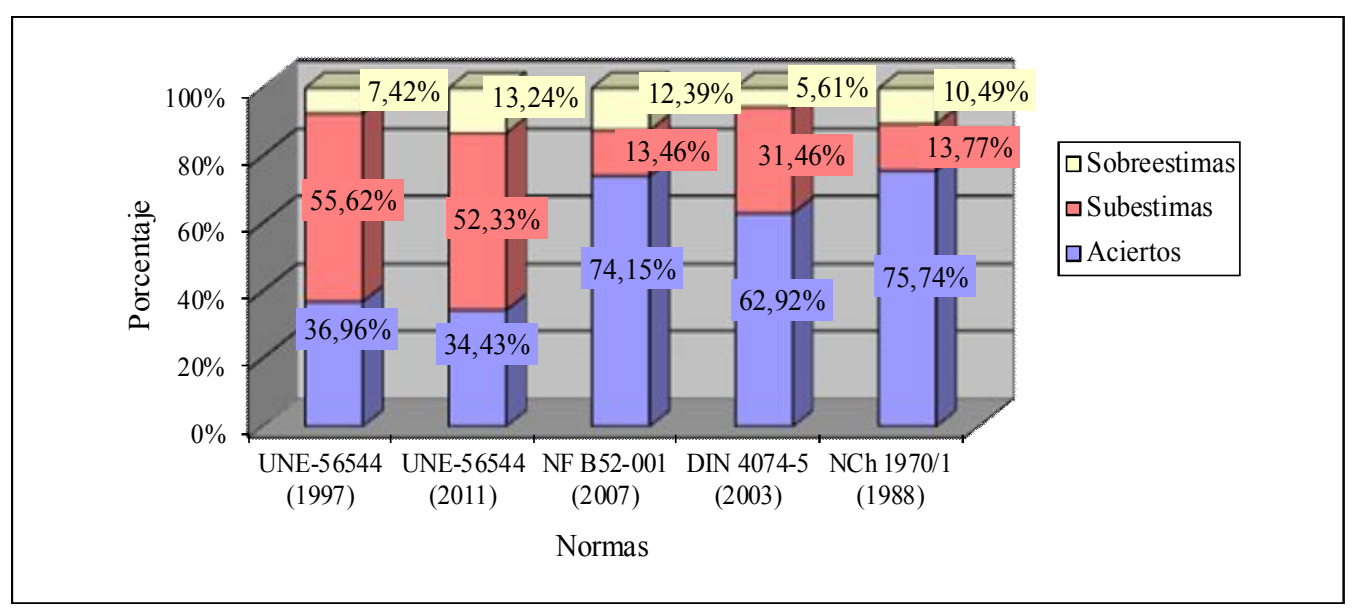

Figura 223. Comportamiento clasificatorio: normas de clasificación visual - norma clase resistente

A continuación se presenta el comportamiento clasificatorio (Acierto, Subestimas y Sobrestimas) detallado por cada norma; para la correcta lectura de los valores correspondientes a dicha evaluación se plantea la referencia coloreada en la Tabla 71.

Tabla 71. Tabla referencial para lectura de comportamiento clasificatorio de Tabla 70.

\begin{tabular}{|c|c|c|c|c|c|c|}
\hline \multirow{2}{*}{ NORMA X* } & \multirow{2}{*}{ Calidad* } & \multicolumn{3}{|c|}{ Clase resistente EN 338: 2010* } & \multirow{2}{*}{$\begin{array}{c}\text { Clasificación } \\
\text { visual }\end{array}$} & \multirow{2}{*}{$\begin{array}{l}\text { Comportamiento } \\
\text { Clasificatorio* }\end{array}$} \\
\hline & & CS & CI & Rechazo & & \\
\hline \multirow{4}{*}{$\begin{array}{c}\text { Clasificación } \\
\text { visual }\end{array}$} & $\mathrm{CS}$ & & & 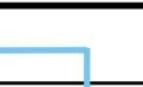 & Total CS & $\begin{array}{c}\text { ACIERTO } \\
\mathrm{N}(\%) \\
\end{array}$ \\
\hline & $\mathrm{CI}$ & & & & Total CI & $\frac{\text { SUBESTIMA }}{\mathrm{N}(\%)}$ \\
\hline & Rechazo & & & 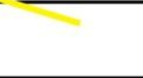 & $\begin{array}{c}\text { Total } \\
\text { Rechazo }\end{array}$ & $\frac{\text { SOBREESTIMA }}{\mathrm{N}(\%)}$ \\
\hline & $\begin{array}{c}\text { Clase resistente } \\
\text { EN 338: } 2010\end{array}$ & Total CS & Total CI & $\begin{array}{c}\text { Total } \\
\text { Rechazo }\end{array}$ & & OTAL \\
\hline
\end{tabular}

*NORMA X: diferentes normas empleadas; CS: Clase superior; CI: Clase Inferior. N: comportamiento expresado en n: número de individuos y en porcentaje $(\%)$.

Tabla 72. Comportamiento clasificatorio: Norma EN 338: 2010 - Norma UNE-56544: 1997

\begin{tabular}{|c|c|c|c|c|c|c|}
\hline \multirow{2}{*}{\multicolumn{2}{|c|}{ NORMA UNE-56544 (1997) }} & \multicolumn{3}{|c|}{ Clase resistente EN 338: 2010} & \multirow{3}{*}{$\begin{array}{c}\begin{array}{c}\text { Clasificación } \\
\text { visual }\end{array} \\
30\end{array}$} & \multirow{3}{*}{$\begin{array}{c}\begin{array}{c}\text { Comportamiento } \\
\text { clasificatorio }\end{array} \\
349 \\
(36,96) \\
\end{array}$} \\
\hline & & $\geq \mathrm{C} 18$ & $\geq \mathrm{C} 14$ & Rechazo & & \\
\hline \multirow{3}{*}{ 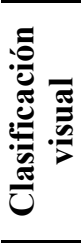 } & ME-1 & 4 & 13 & 13 & & \\
\hline & ME-2 & 18 & 53 & 44 & 115 & $\begin{array}{c}525 \\
(\mathbf{5 5 , 6 2}) \\
\end{array}$ \\
\hline & RECHAZO & 125 & 382 & 292 & 799 & $\begin{array}{c}70 \\
(7,42) \\
\end{array}$ \\
\hline & $\begin{array}{c}\text { Clase resistente EN 338: } \\
2010\end{array}$ & 147 & 448 & 349 & \multicolumn{2}{|c|}{ TOTAL $=944$} \\
\hline
\end{tabular}


En primer término pueden indicarse que la clasificación visual realizada mediante la norma UNE-56544: 1997, clasifica a 145 piezas como "Estructurales" (30 piezas clase ME-1 y 115 piezas Clase ME-2) y a 799 piezas como "No Estructurales" (Rechazo).

Con la finalidad de lograr un mejor entendimiento de los valores presentados tabularmente, a continuación se discute, a modo de ejemplo y para facilitar la lectura de los resultados presentados en todas las tablas, el comportamiento comparativo de esta norma de clasificación visual con respecto a la asignación resistente, Tabla 72:

Aciertos: de la totalidad de aciertos (349 piezas), 4 piezas fueron clasificadas como CS tanto de manera visual como resistente, 53 piezas fueron clasificadas estructuralmente como CI por ambas normativas y 292 piezas fueron rechazadas coincidentemente con ambas metodologías de clasificación.

Subestimas: de la totalidad de subestimas (525 piezas), 18 piezas fueron clasificadas como CIME-2- mediante clasificación visual, mientras que la asignación resistente las catalogaba como CS-> C18-; 125 piezas fueron rechazadas visualmente mientras que la asignación resistente las catalogaba como CS-> C18- y 382 piezas fueron rechazadas visualmente mientras que la asignación resistente las catalogaba como CI-> C14-.

Sobreestimas: de la totalidad de piezas sobreestimadas (70 piezas), 13 piezas fueron clasificadas como CS-ME-1- mediante clasificación visual, mientras que la asignación resistente las cataloga como CI-ME-2-; 13 piezas fueron clasificadas como CS-ME-1- mediante clasificación visual, mientras que la asignación resistente las catalogó como rechazos y 44 piezas fueron clasificadas visualmente como CI-ME-2-, mientras que los valores elasto-resistentes la ubican en la clase de rechazo.

Tabla 73. Comportamiento clasificatorio: Norma EN 338: 2010 - Norma UNE-56544: 2011

\begin{tabular}{|c|c|c|c|c|c|c|}
\hline \multirow{2}{*}{\multicolumn{2}{|c|}{ NORMA UNE-56544 (2011) }} & \multicolumn{3}{|c|}{ Clase resistente EN 338: 2010} & \multirow{3}{*}{$\begin{array}{c}\begin{array}{c}\text { Clasificación } \\
\text { visual }\end{array} \\
56\end{array}$} & \multirow{3}{*}{$\begin{array}{c}\begin{array}{c}\text { Comportamiento } \\
\text { clasificatorio }\end{array} \\
325 \\
(34,43)\end{array}$} \\
\hline & & $\geq \mathrm{C} 18$ & $\geq \mathrm{C} 14$ & Rechazo & & \\
\hline \multirow{3}{*}{ 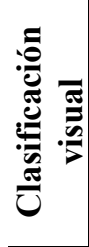 } & ME-1 & 8 & 26 & 22 & & \\
\hline & ME-2 & 29 & 67 & 77 & 173 & $\begin{array}{c}494 \\
(52,33) \\
\end{array}$ \\
\hline & RECHAZO & 110 & 355 & 250 & 715 & $\begin{array}{c}125 \\
(13,24) \\
\end{array}$ \\
\hline & $\begin{array}{c}\text { Clase resistente EN 338: } \\
2010\end{array}$ & 147 & 448 & 349 & \multicolumn{2}{|c|}{ TOTAL $=944$} \\
\hline
\end{tabular}


Tabla 74. Comportamiento clasificatorio: Norma EN 338: 2010 - Norma NF B52-001: 2007

\begin{tabular}{|c|c|c|c|c|c|c|}
\hline \multirow{2}{*}{\multicolumn{2}{|c|}{ NORMA NF B52-001 (2007) }} & \multicolumn{3}{|c|}{ Clase resistente EN 338: 2010} & \multirow{3}{*}{$\begin{array}{c}\begin{array}{c}\text { Clasificación } \\
\text { visual }\end{array} \\
57\end{array}$} & \multirow{3}{*}{$\begin{array}{c}\begin{array}{c}\text { Comportamiento } \\
\text { clasificatorio }\end{array} \\
700 \\
(74,15) \\
\end{array}$} \\
\hline & & $\geq \mathrm{C} 18$ & $\geq \mathrm{C} 14$ & Rechazo & & \\
\hline \multirow{3}{*}{ 昜 } & ST- II & 1 & 7 & 49 & & \\
\hline & ST- III & 1 & 12 & 61 & 74 & $\begin{array}{c}127 \\
(13,46) \\
\end{array}$ \\
\hline & RECHAZO & 33 & 93 & 687 & 813 & $\begin{array}{c}117 \\
(12,39)\end{array}$ \\
\hline & $\begin{array}{c}\text { Clase resistente EN 338: } \\
2010 \\
\end{array}$ & 35 & 112 & 797 & \multicolumn{2}{|c|}{ TOTAL $=944$} \\
\hline
\end{tabular}

Tabla 75. Comportamiento clasificatorio: Norma EN 338: 2010 - Norma DIN 4074-5: 2003

\begin{tabular}{|c|c|c|c|c|c|c|}
\hline \multirow{2}{*}{\multicolumn{2}{|c|}{ NORMA DIN 4074-5 (2003) }} & \multicolumn{3}{|c|}{ Clase resistente EN 338: 2010} & \multirow{3}{*}{$\begin{array}{c}\begin{array}{c}\text { Clasificación } \\
\text { visual }\end{array} \\
24\end{array}$} & \multirow{3}{*}{$\begin{array}{c}\begin{array}{c}\text { Comportamiento } \\
\text { clasificatorio }\end{array} \\
594 \\
(62,92)\end{array}$} \\
\hline & & $>\mathrm{C} 18$ & $>\mathrm{C} 14$ & Rechazo & & \\
\hline \multirow{3}{*}{ 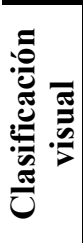 } & LS- 10 & 0 & 8 & 16 & & \\
\hline & LS- 7 & 2 & 14 & 29 & 45 & $\begin{array}{c}297 \\
(31,46) \\
\end{array}$ \\
\hline & RECHAZO & 33 & 262 & 580 & 875 & $\begin{array}{c}53 \\
(5,61)\end{array}$ \\
\hline & $\begin{array}{c}\text { Clase resistente EN 338: } \\
2010\end{array}$ & 35 & 284 & 625 & \multicolumn{2}{|c|}{ TOTAL $=944$} \\
\hline
\end{tabular}

Tabla 76. Comportamiento clasificatorio: Norma EN 338: 2010 - Norma NCh 1970/1: 1988

\begin{tabular}{|c|c|c|c|c|c|c|}
\hline \multirow{2}{*}{\multicolumn{2}{|c|}{ NORMA NCh 1970/1 (1988) }} & \multicolumn{3}{|c|}{ Clase resistente EN 338: 2010} & \multirow{2}{*}{$\begin{array}{c}\text { Clasificación } \\
\text { visual }\end{array}$} & \multirow{2}{*}{$\begin{array}{l}\text { Comportamiento } \\
\text { clasificatorio }\end{array}$} \\
\hline & & $\geq \mathrm{C} 18$ & $\geq \mathrm{C} 14$ & Rechazo & & \\
\hline \multirow{3}{*}{ 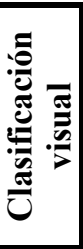 } & GRADO No 1 & 1 & 9 & 37 & 47 & $\begin{array}{c}715 \\
(75,74) \\
\end{array}$ \\
\hline & GRADO No2 & 0 & 7 & 53 & 60 & $\begin{array}{c}130 \\
(13,77)\end{array}$ \\
\hline & RECHAZO & 34 & 96 & 707 & 837 & $\begin{array}{c}99 \\
(10,49)\end{array}$ \\
\hline & $\begin{array}{c}\text { Clase resistente EN 338: } \\
2010\end{array}$ & 35 & 112 & 797 & \multicolumn{2}{|c|}{ TOTAL $=944$} \\
\hline
\end{tabular}

De acuerdo con lo planteado, la norma NCh 1970/1 (1988), la norma NF B52-001 (2007) y en menor medida, la norma DIN 4074-5 (2003), son las que presentan un comportamiento más satisfactorio para predecir las clases resistentes, avalado por los altos porcentajes de aciertos obtenidos; la norma española UNE-56544 en sus dos versiones $(1997$ - 2011) se ha destacado principalmente por la gran proporción de subestimas.

De todas maneras, la conducta común a todas las normas es la alta proporción de rechazos obtenidos. En este sentido, tomando como ejemplo el análisis de los aciertos de la norma chilena, que 
es la que presenta el mayor número de aciertos, puede observarse quede los 715 individuos $(75,74 \%)$, 707 de ellos han sido rechazos por ambas normas.

En cuanto a las subestimas, si bien interesa tener un cierto grado de seguridad al momento de clasificar la madera estructuralmente, los altos porcentajes de subestimas en muchos casos impiden utilizar madera con fines estructurales, cuando realmente sus valores elasto-resistentes lo permitirían.

Por otro lado, otro aspecto a destacar es el porcentaje de sobreestimas que nos brinda cada norma y que representa lo realmente "peligroso" al momento de emplear la madera para fines estructurales; esto es, se corre el riesgo de emplear un material como estructural cuando sus valores elasto-resistentes reales lo limitan.

De acuerdo con esto, se destacada la pobre eficacia clasificatoria de las normas para este material y a fin de evaluar alternativas que permitan una mejor predicción de los valores elastoresistentes, a continuación se incorporan al análisis, las técnicas de ensayo no destructivas.

\subsubsection{Comportamiento clasificatorio mediante metodología de ensayo no destructiva}

En base al "deficiente" comportamiento de las normas de clasificación visual para la estimación de los valores elasto-resistentes, en este apartado se evalúa la efectividad de las variables no destructivas en dicha estimación. Para ello, se trabajó con las dos técnicas de ensayos no destructivos descriptas en Materiales y Métodos: Vibraciones inducidas (mediante software FFT Analyzer) y Ultrasonidos (mediante equipo Sylvatest ${ }^{\circledR}$ ).

\subsection{Determinación de parámetros dinámicos mediante NDT.}

\section{Análisis descriptivo - NDT}

En primera instancia se realiza la presentación del lote a través delas variables dinámicas obtenidas con ambas metodologías de ensayo no destructivo, Tabla 77 y Figura 224 a Figura 231.

Tabla 77. Variables dinámicas NDT - Material estructural: Análisis descriptivo.

\begin{tabular}{|c|c|c|c|c|c|}
\hline \multirow[b]{2}{*}{ Parámetro } & \multirow{2}{*}{$\begin{array}{l}\text { Densidad } \\
\left(\mathrm{Kg} / \mathrm{m}^{3}\right)\end{array}$} & \multicolumn{2}{|c|}{ Vibraciones inducidas } & \multicolumn{2}{|c|}{ Ultrasonidos } \\
\hline & & $\begin{array}{l}\text { Frecuencia } \\
(\mathrm{Hz})\end{array}$ & $\begin{array}{c}E_{\mathrm{d}}{ }^{*} \\
(\mathrm{MPa})\end{array}$ & $\begin{array}{c}\text { Velocidad } \\
(\mathrm{m} / \mathrm{s})\end{array}$ & $\begin{array}{c}E_{\mathrm{d}}^{*} \\
(\mathrm{MPa}) \\
\end{array}$ \\
\hline $\mathrm{n}^{*}$ & 949 & 603 & 603 & 949 & 949 \\
\hline $\begin{array}{l}\text { Media } \\
(\mathrm{CV} \%)\end{array}$ & $\begin{array}{l}361,98 \\
(11,69)\end{array}$ & $\begin{array}{l}784,30 \\
(7,08)\end{array}$ & $\begin{array}{l}8483,25 \\
(17,92)\end{array}$ & $\begin{array}{l}5273,39 \\
(4,33)\end{array}$ & $\begin{array}{l}10097,1 \\
(15,31)\end{array}$ \\
\hline $\begin{array}{l}\text { Min.-Máx. } \\
\text { (IQR) }\end{array}$ & $\begin{array}{c}273,41-563,37 \\
(63,43)\end{array}$ & $\begin{array}{c}596,0-944,0 \\
(67,0\end{array}$ & $\begin{array}{c}4879,13-13881,7 \\
(1741,7)\end{array}$ & $\begin{array}{c}4506,34- \\
6066,19 \\
(285,52) \\
\end{array}$ & $\begin{array}{c}5611,1- \\
16695,7 \\
(1947,72) \\
\end{array}$ \\
\hline $\begin{array}{l}\text { Normalidad, } \\
\text { Variable } \\
\text { transformada }\end{array}$ & Sí & Sí & $\operatorname{No}, \operatorname{LOG}\left(E_{\mathrm{d}}\right)$ & Sí & $\operatorname{No}, \operatorname{LOG}\left(E_{\mathrm{d}}\right)$ \\
\hline
\end{tabular}


El análisis descriptivo de las variables transformadas se desarrolla en Anejos 6.3.3.1.

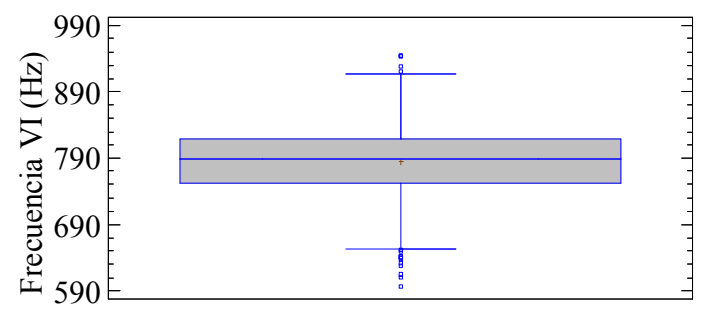

Figura 224. Gráfico de Caja y Bigotes: Fr (VI).

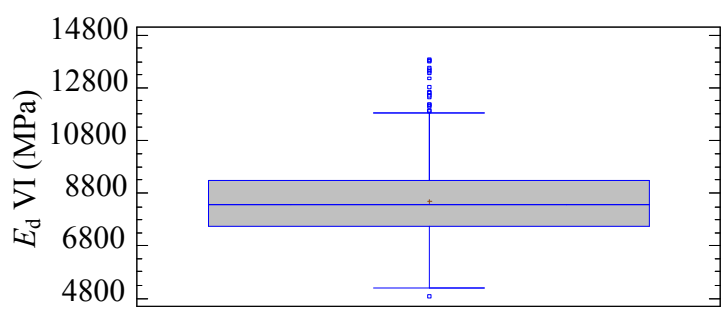

Figura 226. Gráfico de Caja y Bigotes: $E_{\mathrm{d}}(\mathrm{VI})$.

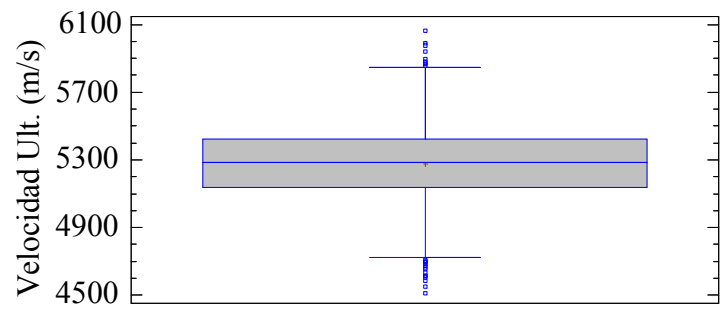

Figura 228. Gráfico de Caja y Bigotes: Vel. (Ult). (X 1000,0)

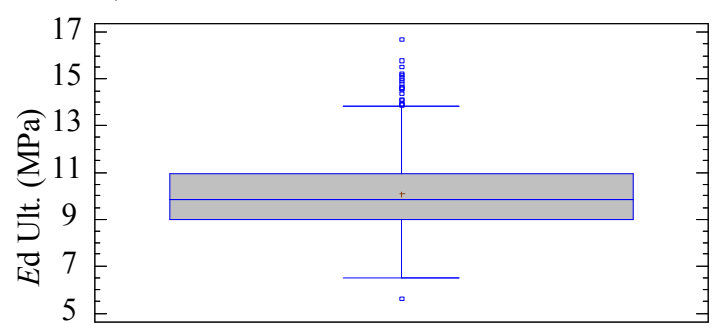

Figura 230. Gráfico de Caja y Bigotes: $E_{\mathrm{d}}$ - (Ult).

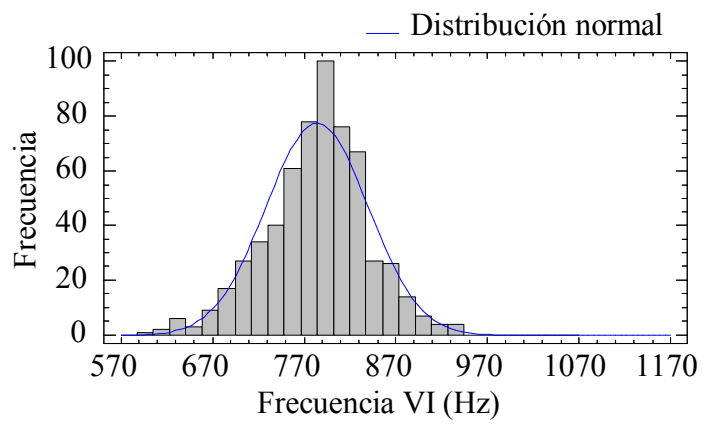

Figura 225. Histograma de frecuencias: Fr (VI).

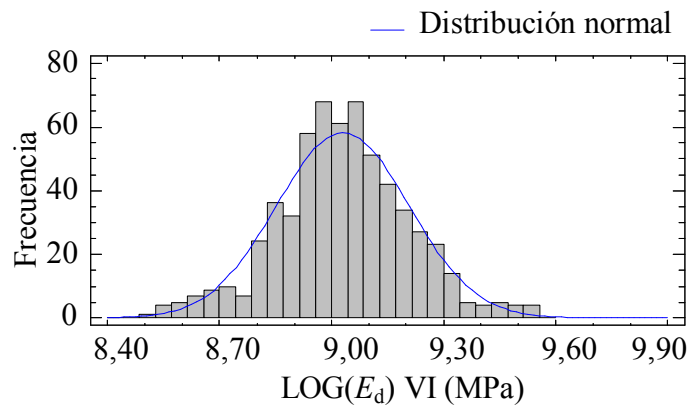

Figura 227. Histograma de frecuencias: $\operatorname{LOG}\left(E_{\mathrm{d}}\right)$ (VI).

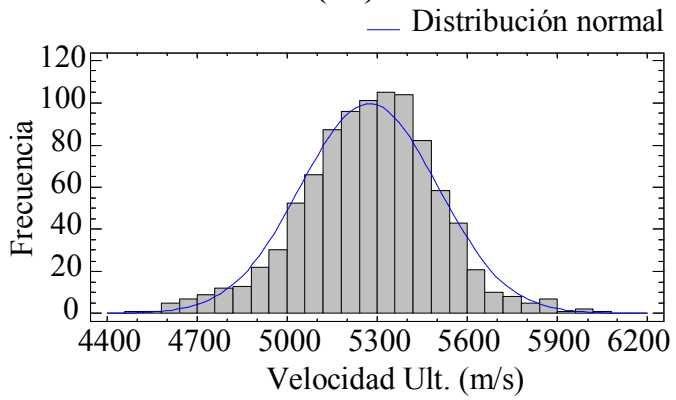

Figura 229. Histograma de frecuencias: Vel. (Ult).

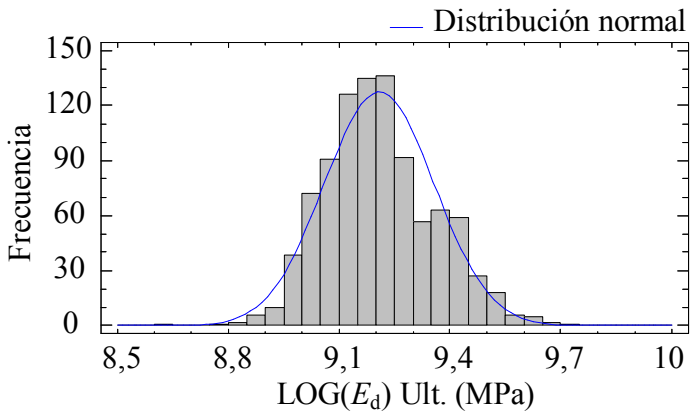

Figura 231. Histograma de frecuencias: $\operatorname{LOG}\left(E_{\mathrm{d}}\right)$ (UIt). 


\section{Análisis comparativo - NDT.}

Dado el incumplimiento del supuesto de homocedasticidad (Anejos 6.3.3.1), se trabajó con la prueba de Kruskal-Wallis comparar las medianas del LOG $\left(E_{\mathrm{d}}\right)$ entre NDT.

Tabla 78. LOG $\left(E_{\mathrm{d}}\right)$ - NDT: análisis comparativo.

\begin{tabular}{ccccc}
\hline KW* & Estadístico & P-Valor & NDT & Grupos homogéneos** \\
\hline MOE $_{\mathrm{d}}$ - NDT & 358,95 & 0,00 & VI & A \\
\cline { 3 - 4 } & & & Ult & B \\
\hline
\end{tabular}

*KW: test de Kruskal-Wallis; $\mathrm{E}_{\mathrm{d}}$ : módulo de elasticidad dinámico; NDT: non destructive testing; VI: vibraciones inducidas; Ult: ultrasonidos; **letras diferentes denotan diferencias significativas entre medianas.

De acuerdo con el P-valor obtenido, existe una diferencia estadísticamente significativa, entre las medianas del $\operatorname{LOG}\left(E_{\mathrm{d}}\right)$ de ambos metodologías no destructivas, con un nivel del 95\% de confianza, siendo superior la mediana de $\operatorname{LOG}\left(E_{\mathrm{d}}\right)$ obtenida mediante la técnica de ultrasonidos (Figura 232).

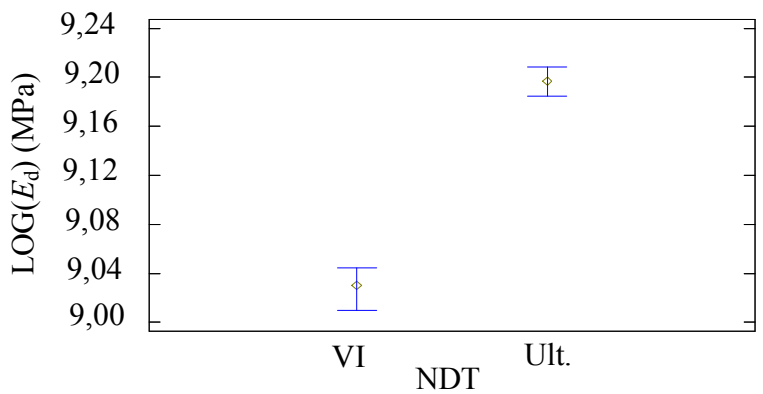

Figura 232. Gráfico de medianas e IC 95\%: $\operatorname{LOG}\left(E_{\mathrm{d}}\right)$ - NDT.

\section{Análisis de regresión: parámetros destructivos - NDT}

Previo al análisis sobre la capacidad predictiva de las variables NDT para estimar las clases resistentes, se evaluó la relación existente entre ellas, empleando el análisis de regresión.

Tabla 79. Capacidad predictiva de NDT en las variables caracterizadoras.

\begin{tabular}{ccccccc}
\hline & \multicolumn{4}{c}{ Variables caracterizadoras } \\
\cline { 2 - 7 } Variables predictoras* & \multicolumn{2}{c}{ LOG(MOE)* } & \multicolumn{2}{c}{ MOR } & \multicolumn{2}{c}{$1 /($ Densidad $)$} \\
\cline { 2 - 7 } & $\begin{array}{c}\mathrm{R}^{2} \text { ajust. } \\
(\%)\end{array}$ & P-valor & $\begin{array}{c}\mathrm{R}^{2} \text { ajust. } \\
(\%)\end{array}$ & P-valor & $\begin{array}{c}\mathrm{R}^{2} \text { ajust. } \\
(\%)\end{array}$ & P-valor \\
\hline Frecuencia - VI- & 34,32 & 0,00 & 24,06 & 0,00 & 0,42 & 0,06 \\
\hline Velocidad - Ult- & 28,93 & 0,00 & 3,89 & 0,00 & 0,31 & 0,05 \\
\hline LOG $\left(E_{\mathrm{d}}\right)$ - VI- & 38,86 & 0,00 & 34,06 & 0,00 & - & - \\
\hline LOG $\left(E_{\mathrm{d}}\right)$ - Ult- & 39,22 & 0,00 & 10,04 & 0,00 & - & - \\
\hline
\end{tabular}

*LOG( $\left.E_{\mathrm{d}}\right)$ : logaritmo del módulo de elasticidad dinámico; VI: vibraciones inducidas; Ult: ultrasonidos; LOG(MOE): logaritmo del módulo de elasticidad estático. 
Las relaciones que mejores ajustes exhibieron se representan gráficamente a continuación; las gráficas pertenecientes a las regresiones menos eficientes se presentan en Anejos 6.3.3.1.

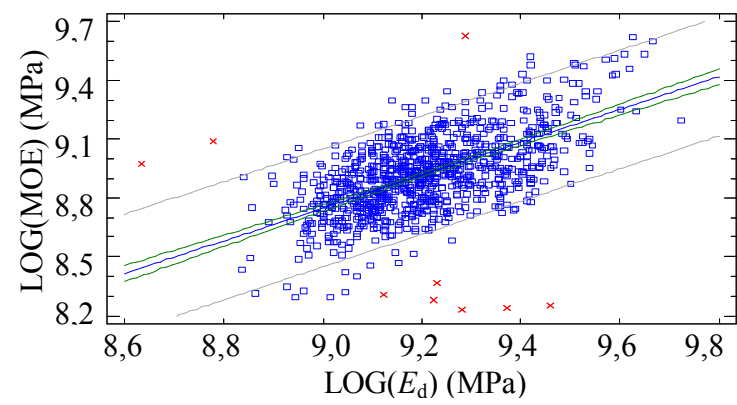

Figura 233.Regresión Simple: LOG(MOE) $\operatorname{LOG}\left(E_{\mathrm{d}}\right)$-Ult-

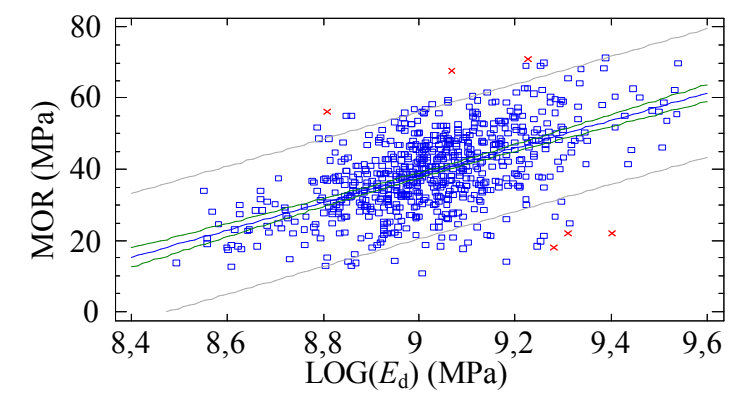

Figura 234. Regresión Simple: MOR - LOG $\left(E_{\mathrm{d}}\right)$-VI

De acuerdo con el análisis de regresión presentado, puede indicarse que la predicción del MOE mediante el $E_{\mathrm{d}}$ obtenido por ultrasonidos y por vibraciones inducidas presentó un ajuste similar al igual que la predicción del MOR mediante $E_{\mathrm{d}}$ por vibraciones; las demás predicciones, si bien fueron significativas, presentaron ajustes menos explicativos. La relación entre la variable densidad y los parámetros no destructivos obtenidos con ambas metodologías no fue significativa.

\subsection{Efectividad de los NDT en la estimación de las clases resistentes}

Los "valores de corte" empleados para las clases no destructivas fueron: $5261 \mathrm{~m} / \mathrm{s}$ de velocidad, para la metodología de ultrasonidos y $776 \mathrm{~Hz}$ de frecuencia, para la metodología de vibraciones inducidas; en la Tabla 80 se presenta la correspondencia de valores y clases.

Tabla 80. Correspondencia Clases NDT-Clases resistentes.

\begin{tabular}{ccc}
\hline & \multicolumn{2}{c}{ Ensayos no destructivos } \\
\cline { 2 - 3 } Clase resistente & Ultrasonidos & Vibraciones inducidas \\
\cline { 2 - 3 } EN 338: 2010 & $\begin{array}{c}\text { Velocidad } \\
(\mathbf{m} / \mathbf{s})\end{array}$ & $\begin{array}{c}\text { Frecuencia } \\
(\mathbf{H z})\end{array}$ \\
\hline Estructural & $\geq 5261$ & $\geq 776$ \\
\hline No Estructural & $\leq 5261$ & $\leq 776$ \\
\hline
\end{tabular}

En base a estas correspondencias, a continuación se presentan los resultados comparativos entre clases resistentes obtenidas con la norma EN 338: 2010 y las clases estimadas por NDT.

El comportamiento comparativo considerando las clases resistentes reales obtenida mediante máquina de ensayo, y las clases asignadas según la metodología no destructiva de ultrasonidos, Ult., se muestra en la Tabla 81 y en la Figura 235. 
Tabla 81. Contraste Clase Resistente (EN 338: 2010)-Clase NDT (Ultrasonido)

\begin{tabular}{|c|c|c|c|c|}
\hline & & \multicolumn{2}{|c|}{ Clase resistente EN 338: 2010} & \multirow{2}{*}{$\begin{array}{c}\text { Clasificación } \\
\text { NDT } \\
\text { (Ultrasonido) }\end{array}$} \\
\hline & & $\underline{\text { Estructural }}$ & No Estructural & \\
\hline \multirow{2}{*}{ 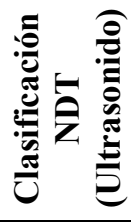 } & Estructural & 403 & 116 & 519 \\
\hline & No Estructural & 192 & 233 & 425 \\
\hline & Clase resistente EN 338: 2010 & 595 & 349 & TOTAL $=944$ \\
\hline
\end{tabular}

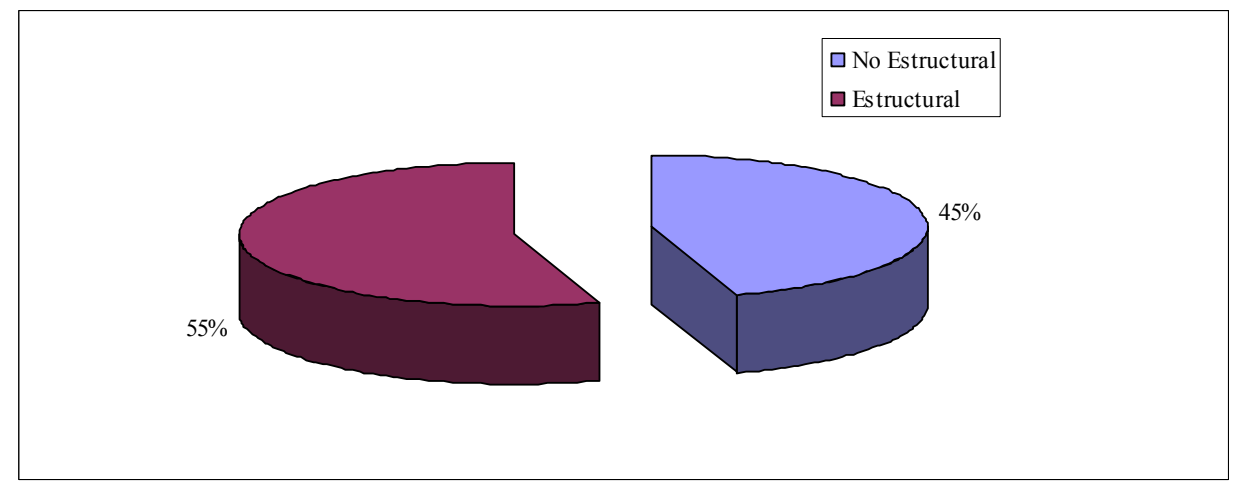

Figura 235. Clasificación según evaluación no destructiva de Ultrasonidos.

Tal como puede observarse, la clasificación mediante la metodología no destructiva de ultrasonidos presentó un comportamiento ampliamente favorable con respecto a la clasificación visual (Tabla 61), catalogando a 519 piezas como "Estructurales" y a 425 piezas como "No Estructurales", acorde al siguiente comportamiento:

Clasificación NDT-Piezas Estructurales: de la totalidad de piezas estructurales (519), 403 piezas son clasificadas como estructurales coincidentemente con la norma de clase resistente, mientras que las 116 piezas restantes, forman parte de las sobreestimas de la clasificación no destructiva, dado que para la clase real resistente dichas piezas son consideradas como material no estructural.

Clasificación NDT-Piezas No Estructurales: de la totalidad de piezas clasificadas como "No Estructurales" por la clasificación no destructiva (425), 233 de ellas son clasificadas como no estructurales coincidentemente con la clasificación resistente, mientas que las 192 piezas restantes forman parte de las subestimas de la clasificación no destructiva, dado que según la clase resistente formarían parte del lote estructural.

En la Tabla 82 y Figura 236 se muestra el comportamiento comparativo considerando las clases resistentes reales, obtenida mediante máquina de ensayo, y las clases asignadas empleando el método de vibraciones inducidas, VI. 
Tabla 82. Contraste Clase Resistente (EN 338: 2010)-Clase NDT (V. inducidas)

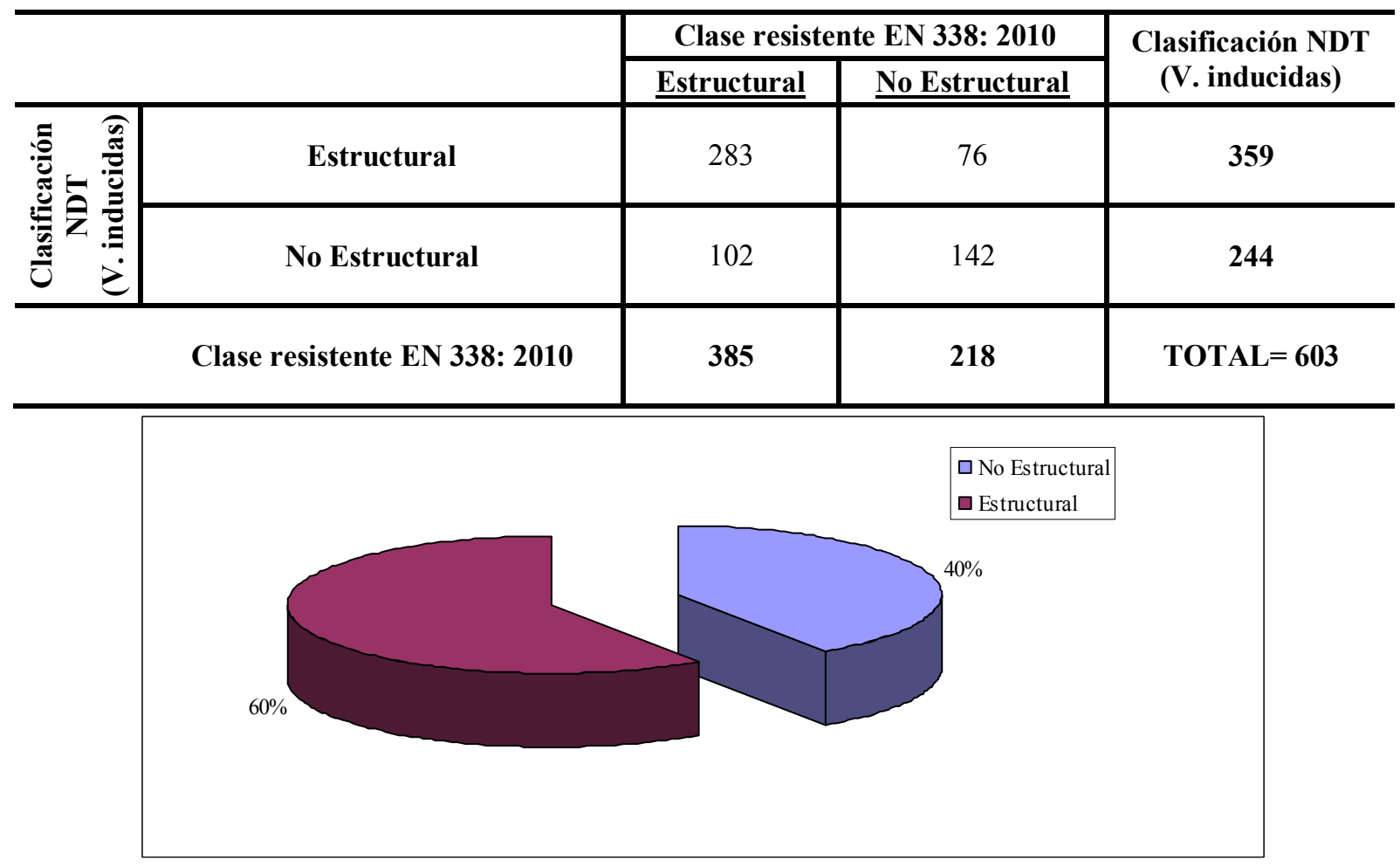

Figura 236. Clasificación según evaluación no destructiva de vibraciones inducidas.

La técnica de vibraciones inducidas superó en un 5\% a la técnica de ultrasonidos en la clasificación estructural de las piezas, resultado coincidente con lo obtenido por Casado et al., 2012; Hermoso, 2001). En este sentido, y atendiendo a lo observado en la Tabla 82, de la totalidad de 603 piezas, 359 fueron catalogadas como "Estructurales" y 244 como "No Estructurales", según el siguiente comportamiento:

Clasificación NDT-Piezas Estructurales: de la totalidad de piezas estructurales (359), 283 fueron clasificadas como estructurales coincidentemente con la norma de clase resistente, mientras que las 76 piezas restantes, forman parte de las sobreestimas de la clasificación no destructiva, dado que para la clase real resistente dichas piezas son consideradas como material no estructural.

Clasificación NDT-Piezas No Estructurales: de la totalidad de piezas clasificadas como "No Estructurales" por la clasificación no destructiva (244), 142 de ellas fueron clasificadas como no estructurales coincidentemente con la clasificación resistente, mientas que las 102 piezas restantes forman parte de las subestimas de la clasificación no destructiva, dado que según la clase resistente formarían parte del lote estructural.

Los porcentajes de aciertos, subestimas y sobreestimas entre las clases reales resistentes y las clases sugeridas mediante metodología no destructiva (ultrasonidos y vibraciones inducidas), se 
representan en la Figura 237. Asimismo, en la Tabla 83 se muestran los aciertos, subestimas y sobreestimas de la clasificación visual, NDT y resistente.

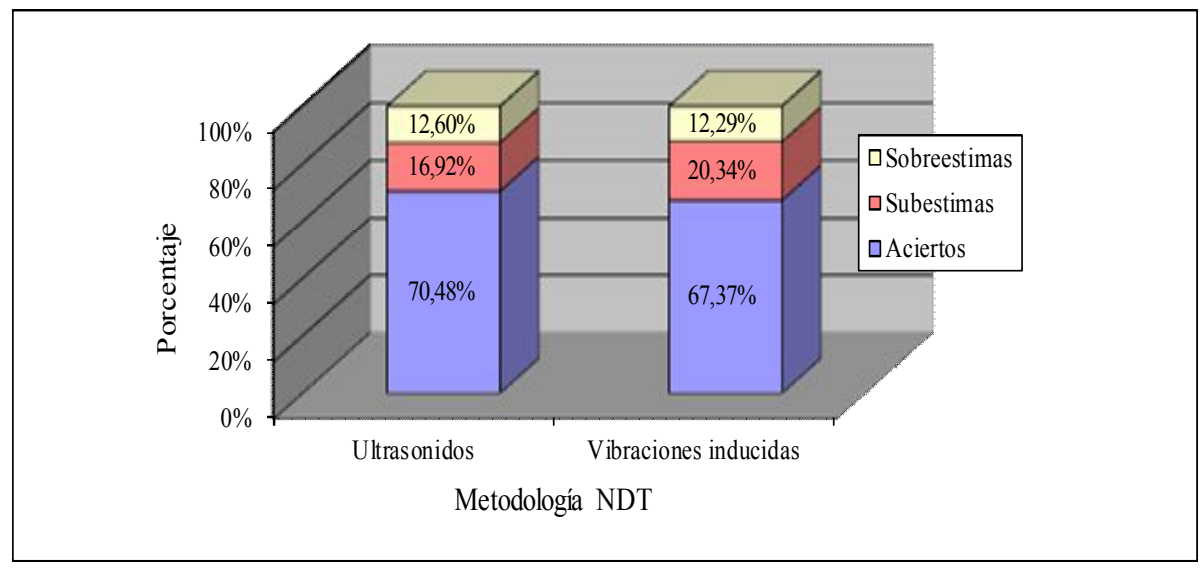

Figura 237. Comportamiento clasificatorio: Clases Resistentes (EN 338:2010) Clases NDT.

Tabla 83. Aciertos, subestimas y sobreestimas: Clasificación: visual - NDT vs resistente.

\begin{tabular}{|c|c|c|c|c|c|c|c|}
\hline \multirow{2}{*}{$\begin{array}{c}\begin{array}{c}\text { Método } \\
\text { Clasificatorio }\end{array} \\
\text { Valoración* }\end{array}$} & \multicolumn{7}{|c|}{ EN 338:2010** } \\
\hline & $\begin{array}{c}\text { UNE } \\
56544 \\
(1997) \\
\end{array}$ & $\begin{array}{c}\text { UNE } \\
56544 \\
(2011)\end{array}$ & NF & DIN & $\mathrm{NCh}$ & $\begin{array}{l}\text { NDT } \\
\text { (Ult.) }\end{array}$ & $\begin{array}{l}\text { NDT } \\
(\mathrm{VI})\end{array}$ \\
\hline $\begin{array}{c}\text { Aciertos } \\
\mathrm{n} ;(\%)\end{array}$ & $\begin{array}{c}380 \\
(40,25)\end{array}$ & $\begin{array}{c}380 \\
(40,25)\end{array}$ & $\begin{array}{c}708 \\
(75,00)\end{array}$ & $\begin{array}{c}604 \\
(63,98)\end{array}$ & $\begin{array}{c}724 \\
(76,69)\end{array}$ & $\begin{array}{c}636 \\
(67,37)\end{array}$ & $\begin{array}{c}425 \\
(70,48)\end{array}$ \\
\hline $\begin{array}{c}\text { Subestimas } \\
\mathrm{n} ;(\%)\end{array}$ & $\begin{array}{c}507 \\
(53,71) \\
\end{array}$ & $\begin{array}{c}465 \\
(49,26)\end{array}$ & $\begin{array}{c}126 \\
(13,35)\end{array}$ & $\begin{array}{c}295 \\
(31,25)\end{array}$ & $\begin{array}{c}130 \\
(13,77)\end{array}$ & $\begin{array}{c}192 \\
(20,34)\end{array}$ & $\begin{array}{c}102 \\
(16,92)\end{array}$ \\
\hline $\begin{array}{c}\text { Sobreestimas } \\
\mathrm{n} ;(\%)\end{array}$ & $\begin{array}{c}57 \\
(6,04)\end{array}$ & $\begin{array}{c}99 \\
(10,49)\end{array}$ & $\begin{array}{c}110 \\
(11,65)\end{array}$ & $\begin{array}{c}45 \\
(4,77)\end{array}$ & $\begin{array}{c}90 \\
(9,53)\end{array}$ & $\begin{array}{c}116 \\
(12,29)\end{array}$ & $\begin{array}{c}76 \\
(12,60) \\
\end{array}$ \\
\hline
\end{tabular}

*En cada columna se expresa: 'número de individuos (n)' y porcentaje de representación entre paréntesis, en ese orden; **944 piezas fueron clasificadas visualmente y mediante ultrasonidos (Ult.); 603 fueron clasificadas mediante vibraciones inducidas (VI).

De acuerdo con los resultados hallados, puede indicarse que la clasificación mediante la metodología no destructiva, considerando ambos métodos, ha logrado mejorar considerablemente el comportamiento clasificatorio de la norma española en las dos versiones (1997 - 2011), mientras que con las otras normas la mejora no tan evidente y generalizada.

\subsubsection{Influencia de las singularidades en las variables estudiadas}

En base a los resultados hallados, y a fin de analizar más profundamente el "pobre" comportamiento clasificatorio de las normas de clasificación visual, en el siguiente apartado se analizan las influencias de los defectos en las variables caracterizadoras: densidad, MOE y MOR. Para ello se establecieron tres categorías de defectos/singularidades como se ha detallado en 
Materiales y Métodos: defectos naturales, defectos de aserrado y defectos de secado, los cuales se relacionaron con el comportamiento de cada variable.

\subsection{Influencia de defectos en el Módulo de elasticidad (MOE)}

\subsection{Defectos naturales: influencia en el MOE}

En la Tabla 84 se muestra el resumen del análisis de la correlación ordinal de Spearman realizado entre la variable $\mathrm{LOG}(\mathrm{MOE})$ y los defectos naturales cuantitativos considerados.

Tabla 84. LOG(MOE) - Defectos naturales: correlación Ordinal de Spearman.

\begin{tabular}{|c|c|c|c|c|c|}
\hline \multicolumn{6}{|c|}{ Correlación Ordinal de Spearman* } \\
\hline Variables* & LOG(MOE) & $\begin{array}{c}\text { Diámetro nudos } \\
\text { de cara }\end{array}$ & $\begin{array}{l}\text { Diámetro nudos de } \\
\text { canto }\end{array}$ & Anchura anillos & $\begin{array}{l}\text { Desviación } \\
\text { fibra }\end{array}$ \\
\hline \multirow{3}{*}{ LOG(MOE) } & & $-0,14$ & $-0,08$ & $-0,22$ & $-0,04$ \\
\hline & & $(863)$ & $(863)$ & $(863)$ & $(863)$ \\
\hline & & $0,00^{*}$ & $0,02 *$ & $0,00 *$ & 0,20 \\
\hline \multirow{3}{*}{ Diámetro nudos de cara } & $-0,14$ & & 0,53 & $-0,07$ & $-0,20$ \\
\hline & $(863)$ & & $(863)$ & $(863)$ & $(863)$ \\
\hline & $0,00^{*}$ & & $0,00^{*}$ & $0,03 *$ & $0,00^{*}$ \\
\hline \multirow{3}{*}{$\begin{array}{l}\text { Diámetro nudos de } \\
\text { canto }\end{array}$} & $-0,08$ & 0,53 & & $-0,07$ & $-0,08$ \\
\hline & & $(863)$ & & $(863)$ & $(863)$ \\
\hline & $0,02 *$ & $0,00^{*}$ & & $0,03 *$ & $0,01 *$ \\
\hline \multirow{3}{*}{ Anchura anillos } & $-0,22$ & $-0,07$ & $-0,07$ & & 0,12 \\
\hline & $(863)$ & $(863)$ & $(863)$ & & $(863)$ \\
\hline & $0,00 *$ & $0,04^{*}$ & $0,03 *$ & & $0,00^{*}$ \\
\hline \multirow{3}{*}{ Desviación fibra } & $-0,04$ & $-0,20$ & $-0,08$ & 0,12 & \\
\hline & $(863)$ & $(863)$ & $(863)$ & $(863)$ & \\
\hline & 0,20 & $0,00^{*}$ & $0,01 *$ & $0,00^{*}$ & \\
\hline
\end{tabular}

*Los valores indicados en cada columna expresan: correlación; (tamaño de muestra); P-Valor (< a 0,05 indica correlación estadísticamente significativa), en ese orden.

En la Tabla 84 se observa una correlación significativa negativa entre el LOG(MOE) y los factores naturales diámetro nudos de cara, de canto y la anchura de anillos, que indica que a medida que el tamaño de estos defectos se incrementa, el módulo de elasticidad disminuye. Asimismo, la desviación de las fibras presentó una correlación negativa no significativa con el LOG(MOE).

\section{Nudos: consideraciones cualitativas}

\section{Por existencia}

\section{a. Presencia nudos de cara}

El comportamiento del LOG(MOE) bajo la influencia de los nudos de cara se presenta en la Tabla 85; la verificación de los supuestos estadísticos es resumido en Anejos 6.3.5.1.1. 
Tabla 85. LOG(MOE) - Presencia de nudos de cara: análisis comparativo.

\begin{tabular}{|c|c|c|c|c|}
\hline $\mathbf{K W} *$ & Estadístico & P-Valor & $\begin{array}{c}\text { Presencia nudos } \\
\text { cara }\end{array}$ & $\begin{array}{c}\text { Grupos } \\
\text { homogéneos } * *\end{array}$ \\
\hline \multirow{2}{*}{$\begin{array}{c}\text { LOG(MOE) - Presencia de } \\
\text { nudos de cara }\end{array}$} & \multirow{2}{*}{12,57} & \multirow{2}{*}{0,00} & 0 & $\mathrm{~A}$ \\
\hline & & & 1 & $\mathrm{~B}$ \\
\hline
\end{tabular}

*KW: Test de Kruskal-Wallis; LOG(MOE): logaritmo del módulo de elasticidad; 0: ausencia nudos de cara; 1: presencia nudos de cara. ${ }^{* *}$ letras diferentes denotan diferencias significativas entre medianas.

Dado el P-valor obtenido, inferior a 0,05 , se puede indicar que la mediana de LOG(MOE) correspondiente a la categoría ausencia de nudos de cara $(0)$ es significativamente superior con respecto a la mediana en presencia de nudos (1); la Figura 238 muestra gráficamente dicho comportamiento.

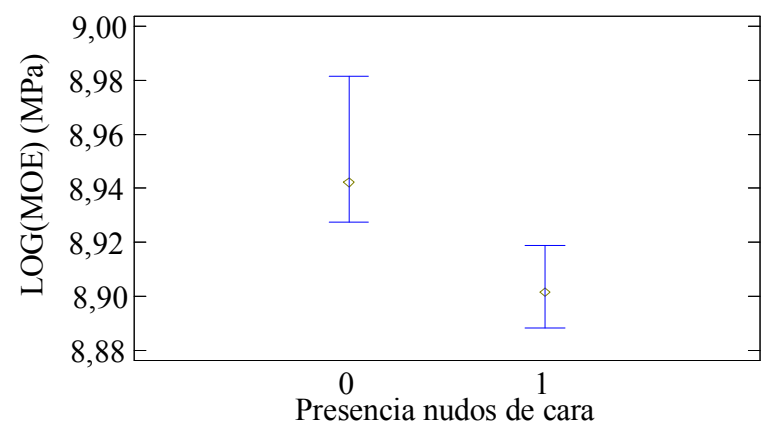

Figura 238. Gráfico de medianas e IC 95\%:

LOG(MOE) - Presencia nudos de cara.

\section{b. Presencia nudos de canto}

Los resultados del test no paramétrico de Kruskal-Wallis para el LOG(MOE) considerando la influencia de los nudos de canto, se muestra en la Tabla 86 (Anejos 6.3.5.1.1).

Tabla 86. LOG(MOE) - Presencia de nudos de canto: análisis comparativo.

\begin{tabular}{|c|c|c|c|c|}
\hline $\mathbf{K W} *$ & Estadístico & P-Valor & $\begin{array}{l}\text { Presencia nudos } \\
\text { canto }\end{array}$ & $\begin{array}{c}\text { Grupos } \\
\text { homogéneos }\end{array}$ \\
\hline \multirow{2}{*}{$\begin{array}{l}\text { LOG(MOE) - Presencia de } \\
\text { nudos de canto }\end{array}$} & \multirow{2}{*}{7,83} & \multirow{2}{*}{0,01} & 0 & $\mathrm{~A}$ \\
\hline & & & 1 & $\mathrm{~B}$ \\
\hline
\end{tabular}

*KW: Test de Kruskal-Wallis; LOG(MOE): logaritmo del módulo de elasticidad; 0: ausencia nudos de canto; 1: presencia nudos de canto. ${ }^{* *}$ letras diferentes denotan diferencias significativas entre medianas.

De acuerdo con el P-valor obtenido, existe una diferencia estadísticamente significativa, entre las medianas del LOG(MOE) considerando presencia de nudos de canto, con un nivel del 95\% de confianza, siendo significativamente superior la mediana de LOG(MOE) obtenida en ausencia de nudos de canto, Figura 239. 


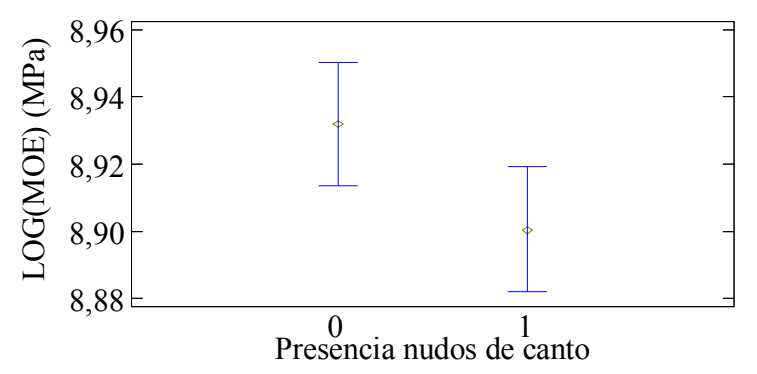

\section{Figura 239. Gráfico de medianas e IC 95\%: LOG(MOE) - Presencia nudos de canto.}

\section{Por existencia y ubicación}

\section{a. Nudos}

$\mathrm{Al}$ análisis sobre la influencia de la presencia de nudos se anexa la ubicación de los mismos y fue agrupada/identificada como variable "Nudos". Para ello, las categorías planteadas son 0: ausencia de nudos, 1: presencia solo de nudos de cara, 2: presencia sólo de nudos de canto y 3: presencia de nudos de cara y canto; la Tabla 87 recoge los resultados de dicho análisis. Dado el bajo número de datos representados en la categoría 2, presencia nudos de canto, no se tuvo en cuenta para el análisis.

Tabla 87. LOG(MOE) - "Nudos": análisis comparativo.

\begin{tabular}{|c|c|c|c|c|}
\hline $\mathbf{K W} *$ & Estadístico & P-Valor & "Nudos" & $\begin{array}{c}\text { Grupos } \\
\text { homogéneos** }\end{array}$ \\
\hline \multirow{3}{*}{ LOG(MOE) - "Nudos" } & \multirow{3}{*}{8,00} & \multirow{3}{*}{0,02} & 0 & $\mathrm{AB}$ \\
\hline & & & 1 & $\mathrm{~B}$ \\
\hline & & & 3 & $\mathrm{BC}$ \\
\hline
\end{tabular}

*KW: test de Kruskal-Wallis; LOG(MOE): logaritmo del módulo de elasticidad; 0: ausencia nudos; 1: presencia nudos de cara; 3: presencia nudos de cara/canto. ${ }^{* *}$ letras diferentes denotan diferencias significativas entre medianas.

Considerando el P-valor obtenido, $<0,05$, existe una diferencia estadísticamente significativa entre las medianas consideradas con un nivel del 95\% de confianza, diferencia establecida entre la mediana de LOG(MOE) considerando la categoría 0: ausencia de nudos y la categoría 3: presencia de ambos tipos de nudos; la mediana de LOG(MOE) considerando la categoría 1: presencia de nudos de cara, no se diferenció significativamente de las medianas obtenidas en la categoría 0 y 3 ; en Anejos 6.3.5.1.1 se detalla la comparación entre pares de medianas que constatan dicho comportamiento.

De este modo podría indicarse que las piezas de madera sin nudos, o bien aquellas sólo con nudos de cara, presentarán un comportamiento similar. 


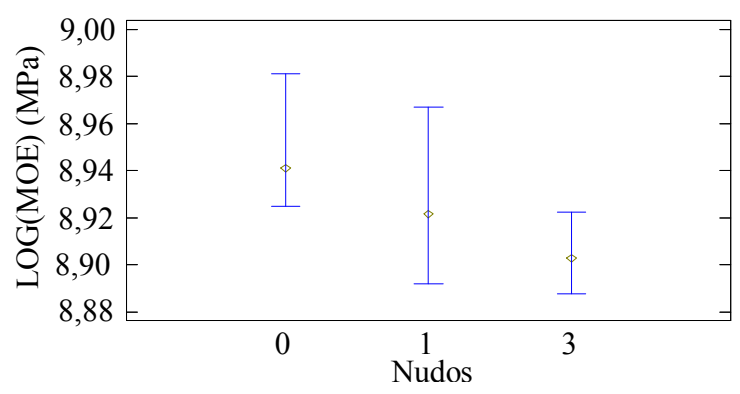

Figura 240. Gráfico de medianas e IC 95\% LOG(MOE) - "Nudos".

\section{Nudos: consideraciones cuantitativas}

\section{$\underline{\text { Por tamaño }}$}

\section{a. Tamaño nudo de cara}

El análisis del comportamiento del LOG(MOE) considerando el "Tamaño de los nudos de cara" según categorías especificadas en el apartado Materiales y Métodos: 1: nudos de tamaño inferior al 33\% de la cara, 2: nudos de tamaño comprendido entre $33 \%$ y $66 \%$ de la cara y 3 : nudos de tamaño superior al 66\% del tamaño de la cara, se muestra en Tabla 88 (ver Anejos 6.3.5.1.1).

Tabla 88. LOG(MOE) - Tamaño nudos de cara: análisis comparativo.

\begin{tabular}{cccccc}
\hline \multirow{2}{*}{ ANOVA } & Razón-F & P-valor & $\begin{array}{c}\text { Tamaño nudo } \\
\text { cara }\end{array}$ & \multicolumn{2}{c}{ Grupos Homogéneos** } \\
\cline { 4 - 6 } & & & 3 & Unequal N HSD & Tukey HSD \\
\hline $\begin{array}{c}\text { LOG(MOE) - Tamaño } \\
\text { nudos de cara }\end{array}$ & 6,54 & 0,00 & 2 & $\mathrm{~A}$ & $\mathrm{~A}$ \\
\cline { 3 - 5 } & & & 1 & $\mathrm{~B}$ & $\mathrm{~B}$ \\
\hline
\end{tabular}

*LOG(MOE): logaritmo del módulo de elasticidad; 1: nudos inferiores al 33\% de la cara; 2: nudos comprendidos entre el 33 y el $66 \%$ de la cara; 3 : nudos superiores al $66 \%$ de la cara. **letras diferentes denotan diferencias significativas entre medias, Tukey HSD, Unequal N HSD $(\mathrm{P}<0,05)$.

Al ser un análisis desbalanceado, el test Unequal N HSD es más adecuado que el test de Tukey HSD para definir la diferencia entre medias, de todos modos, en este caso, ambos test conducen al mismo resultado, indicando que existe una diferencia significativa entre las medias del LOGMOE obtenida en presencia de la categoría 1, con un nivel de confianza del 95\%. Esta tendencia nos permite inferir que a medida que el tamaño de nudos aumenta, superando el 33\% del tamaño de la cara, el LOG(MOE) disminuye. En la Figura 241 se puede observar de manera gráfica dicho comportamiento. 


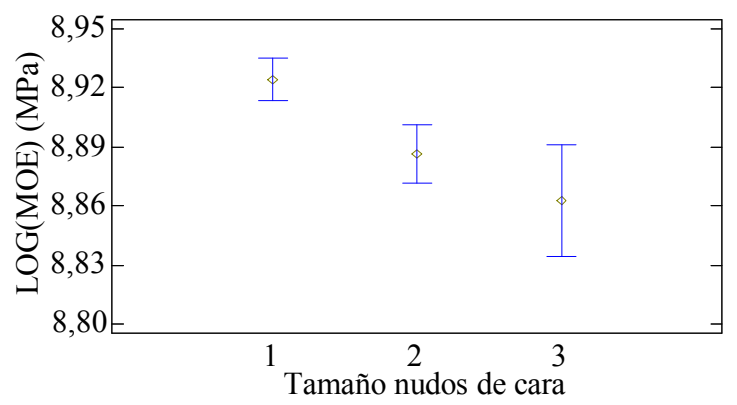

Figura 241. Gráfico de medias e IC 95\%: LOG(MOE)

- Tamaño nudos de cara (Unequal N HSD).

\section{b. Tamaño nudo de canto}

En la Tabla 89 se muestra el análisis comparativo (Test ANOVA) del comportamiento del LOG(MOE) considerando el "Tamaño de los nudos de canto" según categorías especificadas en el apartado Materiales y Métodos: 1: nudos de tamaño inferior al 33\% del canto, 2: nudos de tamaño comprendido entre $33 \%$ y $66 \%$ del canto y 3 : nudos de tamaño superior al $66 \%$ del tamaño del canto. En Anejos 6.3.5.1.1, se presenta el análisis sobre verificación de los supuestos estadísticos.

Tabla 89. LOG(MOE) - "Tamaño nudo de canto": análisis comparativo.

\begin{tabular}{|c|c|c|c|c|}
\hline ANOVA & Razón-F & P-valor & Tamaño nudo canto & $\frac{\text { Grupos Homogéneos }}{\text { Unequal N HSD }}$ \\
\hline \multirow{3}{*}{$\begin{array}{l}\text { LOG(MOE) - Tamaño nudos } \\
\text { de canto }\end{array}$} & \multirow{3}{*}{2,61} & \multirow{3}{*}{0,07} & 1 & $\mathrm{~A}$ \\
\hline & & & 2 & $\mathrm{~A}$ \\
\hline & & & 3 & $\mathrm{~B}$ \\
\hline
\end{tabular}

*LOG(MOE): logaritmo del módulo de elasticidad; 1: nudos inferiores al 33\% del canto; 2: nudos comprendidos entre el 33 y el $66 \%$ del canto; 3 : nudos superiores al $66 \%$ del canto. **letras diferentes denotan diferencias significativas, Unequal $\mathrm{N}$ $\operatorname{HSD}(\mathrm{P}<0,05)$.

Puesto que el P-valor es superior a 0,05 , se puede admitir que no existe diferencia estadísticamente significativa entre la media de LOG(MOE) para las diferentes categorías de tamaño de nudo de canto, lo cual puede visualizarse en la Figura 242; asimismo, dado el desbalance de datos, a modo de constatación se presenta el resultado del Test Unequal N HSD .

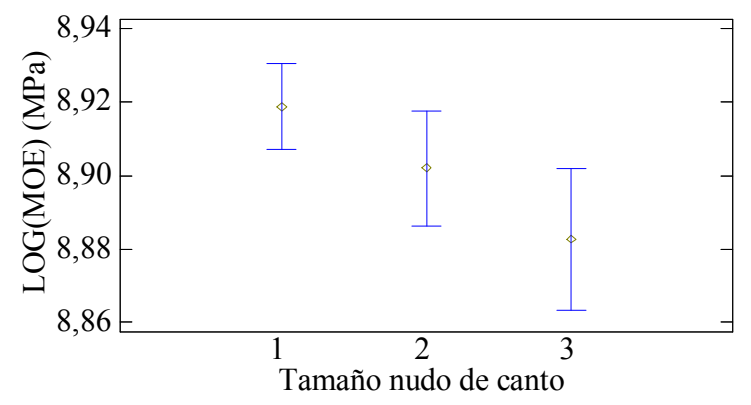

Figura 242. Gráfico de medias e IC 95\%:

LOG(MOE) - Tamaño de nudo de canto. 


\section{Desviación de las fibras}

El resumen del análisis comparativo de $\mathrm{LOG}(\mathrm{MOE})$ considerando la variable categórica “Grupo desviación”, según los rangos detallados en Materiales y Métodos: 0: ausencia de desviación; 1: desviación inferior a 7\%, 2: desviación entre 7\% y $15 \%$ y 3 : desviación superior a $15 \%$, se indica en la Tabla 90. La verificación de los supuestos estadísticos y demás consideraciones ampliatorias del análisis comparativo se muestra en Anejos 6.3.5.1.1. Dado la baja representatividad de los valores en la categoría 3, la misma no fue considerada para este análisis.

Tabla 90. LOG(MOE) - “Grupo desviación”: análisis comparativo.

\begin{tabular}{|c|c|c|c|c|}
\hline \multirow{2}{*}{ ANOVA } & \multirow{2}{*}{ Razón-F } & \multirow{2}{*}{ P-valor } & \multirow{2}{*}{ Grupo desviación } & Grupos Homogéneos** \\
\hline & & & & Unequal N HSD \\
\hline \multirow{3}{*}{$\begin{array}{l}\text { LOG(MOE) - “Grupo } \\
\text { desviación" }\end{array}$} & \multirow{3}{*}{2,93} & \multirow{3}{*}{0,05} & 0 & $\mathrm{~A}$ \\
\hline & & & 1 & $\mathrm{~A}$ \\
\hline & & & 2 & $\mathrm{~A}$ \\
\hline
\end{tabular}

*LOG(MOE): logaritmo del módulo de elasticidad; 0: ausencia de desviación; 1: desviación inferior a 33\%; 2: desviación entre 7 y $15 \%$. ${ }^{* *}$ letras diferentes denotan diferencias significativas, Unequal N $\operatorname{HSD}(\mathrm{P}<0,05)$.

De acuerdo con lo observado en la Tabla 90, y del resultado obtenido mediante el análisis de correlación, se puede afirmar que no existen diferencias significativas entre los valores de LOG(MOE) considerando las diversas categorías de desviación; dicho comportamiento puede observarse gráficamente en la Figura 243.

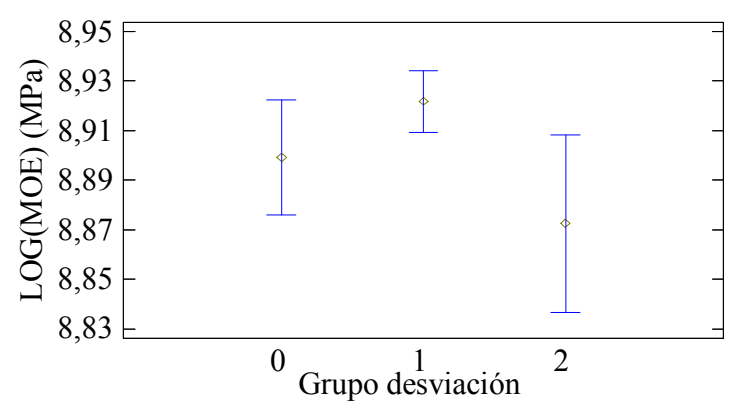

Figura 243. Gráfico de medias LOG(MOE) Grupo desviación (Unequal N HSD).

\section{$\underline{\text { Entrecasco }}$}

Los resultados del Test de Kruskal - Wallis para determinar la existencia de diferencias significativas entre las medianas de LOG(MOE) considerando ausencia-presencia de entrecasco, se indica en la Tabla 91. 
Tabla 91. LOG(MOE) - Entrecasco: análisis comparativo.

\begin{tabular}{|c|c|c|c|c|}
\hline $\mathbf{K W} *$ & Estadístico & P-Valor & "Nudos" & Grupos homogéneos** \\
\hline \multirow{2}{*}{ LOG(MOE) - Entrecasco } & \multirow{2}{*}{29,97} & \multirow{2}{*}{0,00} & 0 & A \\
\hline & & & 1 & B \\
\hline
\end{tabular}

*KW: test de Kruskal-Wallis; LOG(MOE): logaritmo del módulo de elasticidad; 0: ausencia de entrecasco; 1: presencia de entrecasco. **letras diferentes denotan diferencias significativas entre medianas.

De acuerdo con el P-valor obtenido en el análisis comparativo, $<0,05$, puede afirmarse que existen diferencias significativas entre las medianas del LOG(MOE) siendo significativamente superior el comportamiento elástico del material en ausencia de entrecasco (Figura 244).

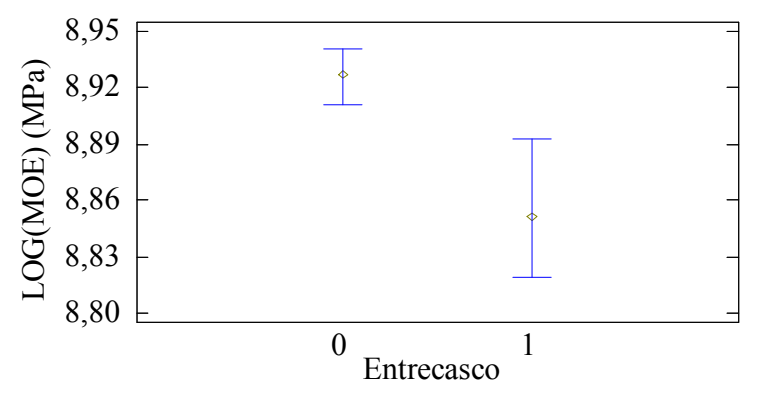

Figura 244. Gráfico de medianas e IC 95\%: LOG(MOE) - Entrecasco.

\subsection{Defectos de aserrado: influencia en el MOE}

En primera instancia se realizó el análisis de correlación ordinal de Spearman existente entre la variable LOG(MOE) y los defectos naturales cuantitativos considerados (anchura y largo de gemas).

Tabla 92. LOG(MOE) - Defectos de aserrado: correlación Ordinal de Spearman.

\begin{tabular}{|c|c|c|c|}
\hline \multirow[b]{2}{*}{ Variables } & \multicolumn{3}{|c|}{ Correlación Ordinal de Spearman* } \\
\hline & LOG(MOE) & Anchura de gema & Longitud de gema \\
\hline \multirow{3}{*}{ LOG(MOE) } & & 0,18 & 0,22 \\
\hline & & $(943)$ & $(943)$ \\
\hline & & $0,00^{*}$ & $0,00^{*}$ \\
\hline \multirow{3}{*}{ Anchura de gema } & 0,18 & & 0,75 \\
\hline & $(943)$ & & $(943)$ \\
\hline & $0,00 *$ & & $0,00 *$ \\
\hline \multirow{3}{*}{ Longitud gema } & 0,22 & 0,75 & \\
\hline & $(943)$ & $(943)$ & \\
\hline & $0,00^{*}$ & $0,00^{*}$ & \\
\hline
\end{tabular}

*Los valores indicados en cada columna expresan: correlación; (tamaño de Muestra); P-Valor (< a 0,05 indica correlación estadísticamente significativa), en ese orden.

De la Tabla 92 se desprende que existe una correlación positiva significativa entre ambos factores (defectos de aserrado) y la variable LOG(MOE), mediante lo cual podría indicarse que el comportamiento elástico de dicho material es más favorable en presencia de gemas de mayor anchura 
y/o longitud. A fin de evaluar más exhaustivamente dicho comportamiento, a continuación se analiza la influencia de dichos factores en la determinación del MOE, para lo cual, dado que no pudo aceptarse la normalidad de los factores anchura y largo de gema (Anejo 6.3.5.1.2), los mismos fueron agrupados según las categorías indicadas en la sección Materiales y Métodos.

\section{$\underline{\text { Gemas }}$}

\section{a. Grupo anchura de gemas}

Dado el incumplimiento de los supuestos estadísticos para los residuos del LOG(MOE) "Grupo anchura de anillos" (Anejos 6.3.5.1.2), en la Tabla 93, se muestra la prueba de Kruskal-Wallis comparando las medianas de dicho modelo.

Tabla 93. LOG(MOE) - Grupo anchura de gema: análisis comparativo.

\begin{tabular}{ccccc}
\hline & Estadístico & P-Valor & Grupo anchura de gema & Grupos homogéneos** \\
\hline $\begin{array}{c}\text { LOG(MOE) - Grupo anchura } \\
\text { de gema }\end{array}$ & 32,31 & 0,00 & 0 & $\mathrm{~A}$ \\
\cline { 3 - 4 } \begin{tabular}{c} 
L \\
\cline { 3 - 4 }
\end{tabular} & & 1 & $\mathrm{~B}$ \\
\hline
\end{tabular}

*KW: Test de Kruskal-Wallis; LOG(MOE): logaritmo del módulo de elasticidad; 0: ausencia de gemas; 1: anchura de gemas inferior a 33\%; 2: anchura de gemas entre 33\% a 66\%. ** letras diferentes denotan diferencias significativas entre medianas.

Puesto que el P-valor es inferior que 0,05, existe una diferencia estadísticamente significativa entre las medianas de LOG(MOE) - "Grupo anchura de gemas", con un nivel de 95\% de confianza. Para determinar entre que medianas se produjeron las diferencias, se realizó la prueba de Kruskal Wallis de a pares de medianas (Anejos 6.3.5.1.2), mediante el cual pudo observarse que la mediana de LOG(MOE) es significativamente inferior en la categoría 0: ausencia de gemas, no hallándose diferencias significativas entre la categoría 1: anchura de gemas inferior a $33 \%$ y la categoría 2 : anchura de gemas entre $33 \%$ y $66 \%$, Figura 245.

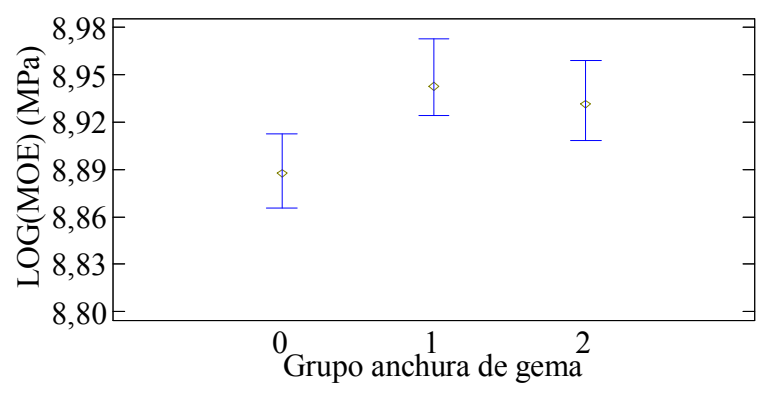

Figura 245. Gráfico de medianas e IC 95\%: LOG(MOE) - "Grupo anchura de gema".

\section{b. Grupo longitud de gemas}

Para analizar el comportamiento del material ante el "Grupo longitud de gemas" se recurrió al análisis de la varianza, previa constatación de la normalidad de los residuos (Anejos 6.3.5.1.2); en 
consecuencia con la significación estadística hallada, se utilizó la prueba Unequal N HSD (Tabla 94) y el Gráfico de medias e intervalos de confianza, Figura 246, para observar entre que pares de medias existía diferencias significativas.

Tabla 94. LOG(MOE) - Grupo longitud de gema: análisis comparativo.

\begin{tabular}{|c|c|c|c|c|}
\hline ANOVA* & Razón-F & P-valor & Grupo longitud de gema & $\begin{array}{c}\text { Grupos Homogéneos** } \\
\text { Unequal N HSD }\end{array}$ \\
\hline \multirow{3}{*}{$\begin{array}{l}\text { LOG(MOE) - Grupo } \\
\text { longitud de gema }\end{array}$} & \multirow{3}{*}{30,72} & \multirow{3}{*}{0,00} & 0 & $\mathrm{~A}$ \\
\hline & & & 1 & $\mathrm{~B}$ \\
\hline & & & 2 & $\mathrm{~B}$ \\
\hline
\end{tabular}

*LOG(MOE): logaritmo del módulo de elasticidad; 0: ausencia de gemas; 1: longitud de gemas inferior a 33\%; 2: longitud de gemas entre $33 \%$ a $66 \%$; **letras diferentes denotan diferencias significativas, Unequal N HSD $(\mathrm{P}<0,05)$.

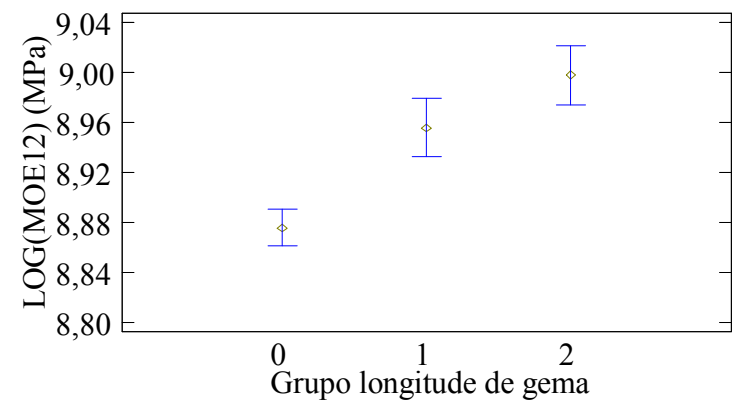

Figura 246. Gráfico de medias e IC 95\%: LOG(MOE) - "Grupo longitud de gema" (Unequal N HSD).

De acuerdo con lo observado en la Tabla 94 y en la Figura 246, la media del LOG(MOE) es significativamente inferior en ausencia de gemas, considerando la longitud, - categoría 0 - con respecto a las otras dos categorías, las cuales no difieren entre sí.

En base a estos resultados, considerando la influencia de la anchura y longitud de gemas, puede inferirse que a medida que el tamaño de las gemas aumenta, el logaritmo del módulo de elasticidad también se incrementa.

\section{Médula}

En la Tabla 95 se muestra la prueba de Kruskal-Wallis para determinar el comportamiento de las medianas del LOG(MOE) en ausencia (0) y presencia (1) de médula; la constatación de los supuestos estadísticos se detalla en Anejos 6.3.5.1.2.

Tabla 95. LOG(MOE) - Médula: análisis comparativo.

\begin{tabular}{ccccc}
\hline KW $^{*}$ & Estadístico & P-Valor & Grupo anchura de gema & Grupos homogéneos** \\
\hline \multirow{2}{*}{ LOG(MOE) - Médula } & \multirow{2}{*}{21,55} & \multirow{2}{*}{0,00} & 0 & $\mathrm{~A}$ \\
\cline { 4 - 5 } & & & 1 & $\mathrm{~B}$ \\
\hline
\end{tabular}

*KW: Test de Kruskal-Wallis; LOG(MOE): logaritmo del módulo de elasticidad; 0: ausencia de médula; 1: presencia de médula; **letras diferentes denotan diferencias significativas entre medianas. 


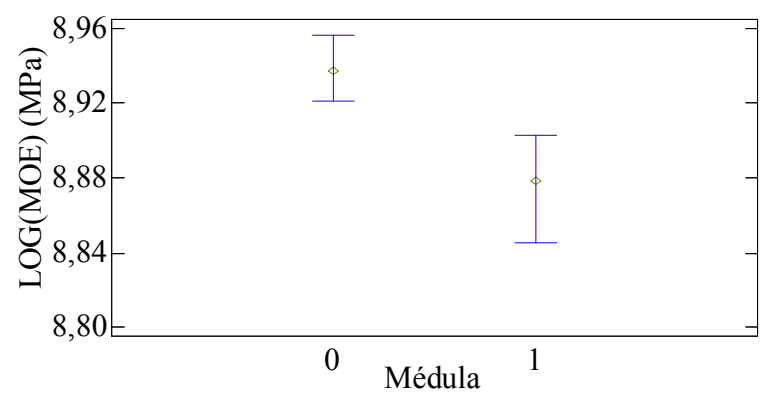

Figura 247. Gráfico de medianas e IC 95\%:

LOG(MOE) - Médula.

La mediana del LOG(MOE) es significativamente superior en ausencia de médula, Figura 247, con un nivel de confianza del 95\%. Estos resultados se corresponden con que la médula es un tejido parenquimatoso y blando que presenta características tecnológicas menos favorables y deseables para la mayoría de los usos.

\subsection{Defectos de secado: influencia en el MOE}

En primera instancia se presenta el análisis de la correlación Ordinal de Spearman realizada a fin de determinar la relación existente entre la variable módulo de elasticidad y defectos de secado cuantitativos, Tabla 96.

Tabla 96. LOG(MOE) - Defectos de secado: correlación ordinal de Spearman.

Correlación ordinal de Spearman*

\begin{tabular}{|c|c|c|c|c|}
\hline Variables & LOG(MOE) & Curvatura cara & Curvatura canto & Alabeo \\
\hline \multirow{3}{*}{ LOG(MOE) } & & 0,05 & 0,11 & $-0,11$ \\
\hline & & $(942)$ & $(942)$ & $(942)$ \\
\hline & & 0,13 & $0,00^{*}$ & $0,00^{*}$ \\
\hline \multirow{3}{*}{ Curvatura cara } & 0,05 & & 0,27 & 0,02 \\
\hline & $(942)$ & & $(942)$ & (942) \\
\hline & 0,13 & & $0,00^{*}$ & 0,56 \\
\hline \multirow{3}{*}{ Curvatura canto } & 0,11 & 0,27 & & $-0,05$ \\
\hline & $(942)$ & $(942)$ & & $(942)$ \\
\hline & $0,00^{*}$ & $0,00^{*}$ & & 0,16 \\
\hline \multirow{3}{*}{ Alabeo } & $-0,11$ & 0,02 & $-0,05$ & \\
\hline & (942) & $(942)$ & (942) & \\
\hline & $0,00^{*}$ & 0,56 & 0,16 & \\
\hline
\end{tabular}

*Los valores indicados en cada columna expresan: correlación; (tamaño de Muestra); P-Valor (< a 0,05 indica correlación estadísticamente significativa), en ese orden.

Del análisis de correlaciones puede indicarse que existe una correlación positiva entre el LOG(MOE) y la curvatura de canto, mientras que la curvatura de cara no presenta influencia en dicha variable; el factor alabeo se correlaciona negativamente con la variable predicha. De este modo, podría esperarse que el LOG(MOE), presente un comportamiento superior en concordancia con valores 
superiores e inferiores de curvaturas de canto y alabeos, respectivamente. A fin de profundizar esta inferencia, a continuación se desarrollan los resultados sobre el análisis de influencia de los defectos de secado, agrupados en sus correspondientes categorías, en la determinación de los valores elásticos.

\section{Curvatura de cara}

El análisis comparativo realizado entre LOG(MOE) por "Grupo curvatura de cara", se muestra en la Tabla 97. Debido a la poca representatividad de la categoría 3, la misma no fue considerada en el análisis; la constatación de los supuestos estadísticos se presenta en Anejo 6.3.5.1.3.

Tabla 97. LOG(MOE) - Grupo Curvatura de cara: análisis comparativo.

\begin{tabular}{cccccc}
\hline \multirow{2}{*}{ ANOVA* } & Razón-F & P-valor & $\begin{array}{c}\text { Grupo curvatura de } \\
\text { cara }\end{array}$ & \multicolumn{2}{c}{ Grupos Homogéneos** } \\
\cline { 3 - 5 } & & & 0 & Unequal N HSD & Tukey HSD \\
\hline $\begin{array}{c}\text { LOG(MOE) - Grupo } \\
\text { curvatura de cara }\end{array}$ & 3,21 & 0,04 & 1 & $\mathrm{~A}$ & $\mathrm{~A}$ \\
\cline { 3 - 5 } & & & 2 & $\mathrm{~A}$ & $\mathrm{AB}$ \\
\hline
\end{tabular}

*LOG(MOE): logaritmo del módulo de elasticidad; 0: ausencia de curvatura de cara; 1: curvatura de cara $<10 \mathrm{~mm} ; 2$ : curvatura de cara entre 10-20 mm. **letras diferentes denotan diferencias significativas, Unequal N HSD, Tukey HSD $(\mathrm{P}<0,05)$.

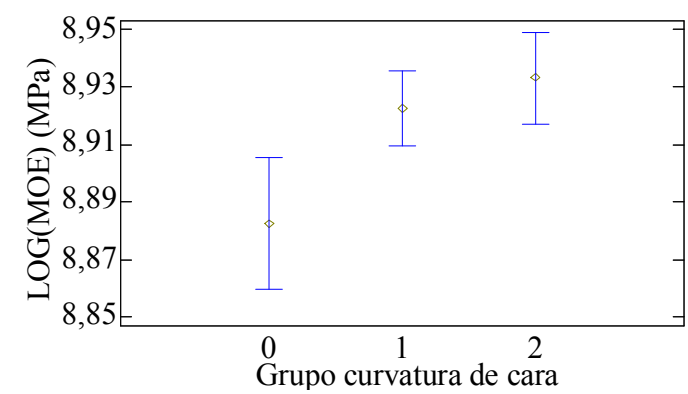

Figura 248. Gráfico de medias e IC 95\% Unequal N HSD: LOG(MOE) - Grupo curvatura de cara.

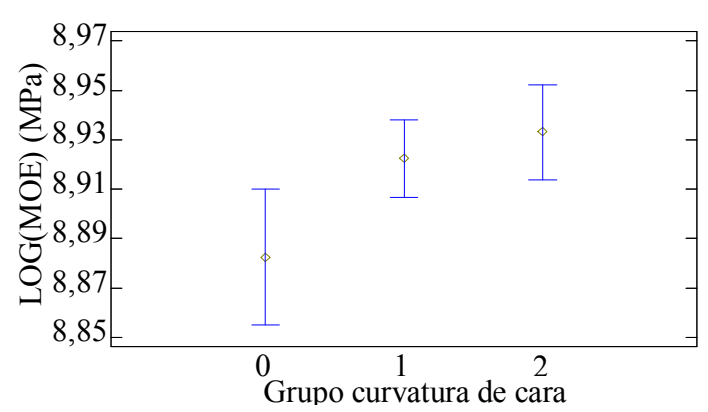

Figura 249. Gráfico de medias e IC 95\% Tukey HSD: LOG(MOE) - Grupo curvatura de cara.

Si bien a causa del desbalance de observaciones el análisis debería basarse en la prueba Unequal N HSD, el cual es coincidente con la ausencia de significación estadística presentada en el análisis de correlaciones de Spearman, Tabla 96, ante la incertidumbre de los resultados se incorporó al análisis el resultado obtenido a partir del Test de Tukey HSD e IC 95\%, mediante el cual se obtuvieron diferencias significativas para las medias del LOG(MOE) entre la categoría 0: ausencia de curvatura de cara y la categoría 2: curvatura de cara comprendida entre 10 y $20 \mathrm{~mm}$; la categoría 1 : curvatura de cara $<10 \mathrm{~mm}$ no fue significativamente diferente con respecto a las anteriores categorías mencionadas. 


\section{Curvatura de canto}

En la Tabla 98 se presenta el análisis de la varianza realizado para determinar la existencia de diferencias significativas entre medias y los test de comparación de medias; en Anejo 6.3.5.1.3 se presentan los análisis de constatación de supuestos.

Tabla 98. LOG(MOE) - Grupo Curvatura de canto: análisis comparativo.

\begin{tabular}{cccccc}
\hline ANOVA* & Razón-F & P-valor & $\begin{array}{c}\text { Grupo Curvatura de } \\
\text { canto }\end{array}$ & \multicolumn{2}{c}{ Grupos Homogéneos** } \\
\cline { 3 - 5 } $\begin{array}{c}\text { LOG(MOE) - Grupo } \\
\text { curvatura de canto }\end{array}$ & 11,26 & 0,00 & 0 & $\mathrm{~A}$ & $\mathrm{~A}$ \\
\cline { 3 - 5 } & & & 2 & $\mathrm{~B}$ & $\mathrm{~B}$ \\
\cline { 3 - 5 }
\end{tabular}

*LOG(MOE): logaritmo del módulo de elasticidad; 0: ausencia de curvatura de canto; 1: curvatura de canto $<10 \mathrm{~mm} ; 2$ : curvatura de canto entre 10-20 mm. **letras diferentes denotan diferencias significativas, Unequal N HSD, Tukey HSD $(\mathrm{P}<0,05)$.

Si bien, dado el desbalance de datos, el Test Unequal N HSD es el más adecuado para comprender estos resultados, con el Test de Tukey HSD se arribó al mismo resultado: las medias de LOG(MOE) son significativamente inferiores en la categoría 0: ausencia de curvatura de canto con respecto a la categoría 1 y 2 , mientras que entre ellas no se presentaron diferencias significativas (Figura 250).

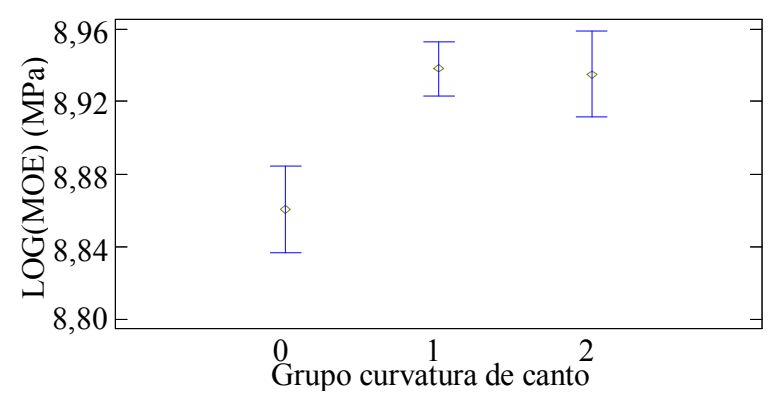

Figura 250. Gráfico de medias e IC 95\%: LOG(MOE)

- Grupo Curvatura de canto (Unequal N HSD).

De acuerdo con este comportamiento, puede esperarse que el LOG(MOE) tenga un comportamiento diferencial superior en presencia de mayores curvaturas de canto, lo cual podría estar estrechamente vinculado con un mal posicionamiento de la pieza en los apoyos de ensayo.

\section{Alabeos}

El análisis comparativo para el LOG(MOE) entre "Grupo alabeo" se presenta en la Tabla 99; en Anejos 6.3.5.1.2 se amplía el análisis para constatación de supuestos estadísticos. 
Tabla 99. LOG(MOE) - Grupo Alabeo: análisis comparativo.

\begin{tabular}{|c|c|c|c|c|c|}
\hline \multirow{2}{*}{ ANOVA* } & \multirow{2}{*}{ Razón-F } & \multirow{2}{*}{ P-valor } & \multirow{2}{*}{ Grupo alabeo } & \multicolumn{2}{|c|}{ Grupos Homogéneos** } \\
\hline & & & & Unequal N HSD & Tukey HSD \\
\hline \multirow{3}{*}{$\begin{array}{l}\text { LOG(MOE) - Grupo } \\
\text { alabeo }\end{array}$} & \multirow{3}{*}{4,28} & \multirow{3}{*}{0,01} & 2 & $\mathrm{~A}$ & $\mathrm{~A}$ \\
\hline & & & 0 & $\mathrm{AB}$ & $\mathrm{B}$ \\
\hline & & & 1 & $\mathrm{BC}$ & $\mathrm{B}$ \\
\hline
\end{tabular}

*LOG(MOE): logaritmo del módulo de elasticidad; 0: ausencia de alabeo; 1: alabeo <6 mm; 2: alabeo entre 6-12 mm.

$* *$ letras diferentes denotan diferencias significativas, Unequal N HSD, Tukey HSD $(\mathrm{P}<0,05)$.

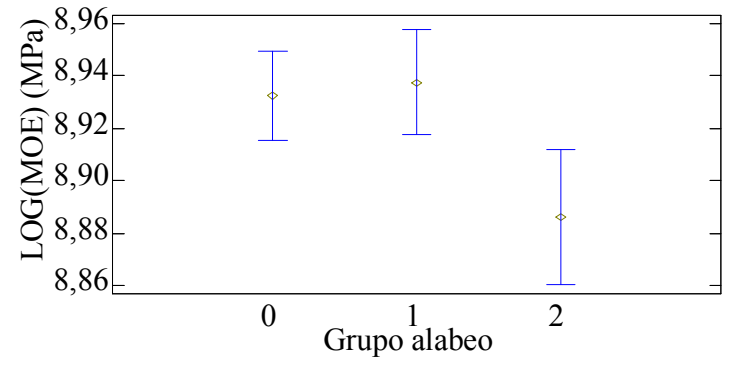

Figura 251. Gráfico de medias e IC 95\% (Unequal N HSD): LOG(MOE) - Grupo alabeo.

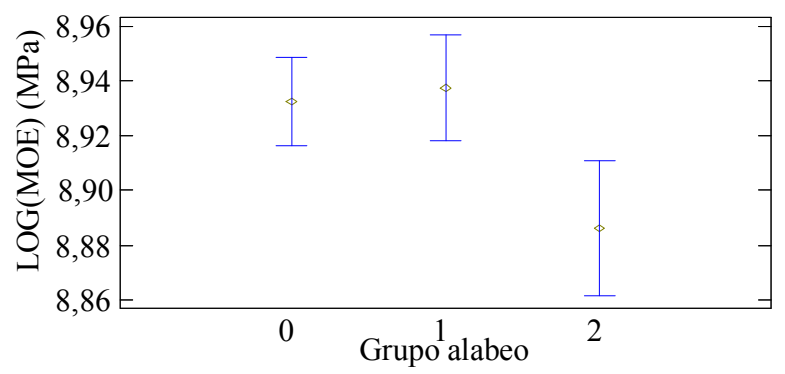

Figura 252. Gráfico de medias e IC 95\% Tukey HSD: LOG(MOE) -Grupo alabeo.

De acuerdo con lo observado en la Tabla 99 y en la Figura 251 y Figura 252, el LOG(MOE) según la prueba Unequal N HSD presenta valores significativamente inferiores entre los valores de alabeo de la categoría 1: alabeos $<6 \mathrm{~mm}$ y categoría 2: alabeos entre $6-12 \mathrm{~mm}$, mientras que la categoría 0: ausencia de alabeo se comporta indistintamente con respecto a las otras categorías.

\subsection{Influencia de defectos en el Módulo de Rotura (MOR)}

A continuación se presenta el análisis sobre la influencia de las singularidades en la variable resistente MOR.

\subsection{Defectos naturales: influencia en el MOR}

En la Tabla 100 se muestra el resumen de la correlación ordinal de Spearman realizado entre la variable MOR y los defectos naturales cuantitativos considerados. 
Tabla 100. MOR - Defectos naturales: Correlación ordinal de Spearman.

\begin{tabular}{|c|c|c|c|c|c|}
\hline & \multicolumn{5}{|c|}{ Correlación Ordinal de Spearman } \\
\hline & MOR & $\begin{array}{l}\text { Diámetro nudo de } \\
\text { cara }\end{array}$ & $\begin{array}{l}\text { Diámetro nudo de } \\
\text { canto }\end{array}$ & Desviación fibra & Anchura anillos \\
\hline \multirow{3}{*}{ MOR } & & $-0,18$ & $-0,20$ & $-0,10$ & $-0,20$ \\
\hline & & $(863)$ & $(863)$ & $(863)$ & $(863)$ \\
\hline & & $0,00^{*}$ & $0,00^{*}$ & $0,00^{*}$ & $0,00^{*}$ \\
\hline \multirow{3}{*}{$\begin{array}{l}\text { Diámetro nudo de } \\
\text { cara }\end{array}$} & $-0,18$ & & 0,53 & $-0,20$ & $-0,07$ \\
\hline & $(863)$ & & $(863)$ & $(863)$ & $(863)$ \\
\hline & $0,00^{*}$ & & $0,00^{*}$ & $0,00^{*}$ & $0,04^{*}$ \\
\hline \multirow{3}{*}{$\begin{array}{l}\text { Diámetro nudo de } \\
\text { canto }\end{array}$} & $-0,20$ & 0,53 & & $-0,08$ & $-0,07$ \\
\hline & $(863)$ & $(863)$ & & $(863)$ & $(863)$ \\
\hline & $0,00^{*}$ & $0,00^{*}$ & & $0,01^{*}$ & $0,03 *$ \\
\hline \multirow{3}{*}{ Desviación fibra } & $-0,10$ & $-0,20$ & $-0,08$ & & 0,12 \\
\hline & $(863)$ & $(863)$ & $(863)$ & & $(863)$ \\
\hline & $0,00^{*}$ & $0,00^{*}$ & $0,01 *$ & & $0,00^{*}$ \\
\hline \multirow{3}{*}{ Anchura anillos } & $-0,20$ & $-0,07$ & $-0,07$ & 0,12 & \\
\hline & $(863)$ & $(863)$ & $(863)$ & $(863)$ & \\
\hline & $0,00^{*}$ & $0,04 *$ & $0,03^{*}$ & $0,00^{*}$ & \\
\hline
\end{tabular}

*Los valores indicados en cada columna expresan: correlación; (tamaño de Muestra); P-Valor (< a 0,05 indica correlación estadísticamente significativa), en ese orden.

De acuerdo a lo indicado en la Tabla 100, existe una correlación negativa y estadísticamente significativa entre el MOR y los defectos naturales, factores, considerados en el análisis. De ello se desprende que cuando dichos defectos sean de mayor tamaño, el MOR disminuirá y viceversa.

El análisis detallado sobre la influencia de cada defecto natural, agrupado por categorías, en la determinación del MOR se muestra a continuación.

\section{Nudos: consideraciones cualitativas}

\section{Por existencia}

\section{a. Presencia nudos de cara}

El análisis comparativo para la evaluación de la influencia de los nudos de cara en el MOR se muestra en la Tabla 101; el análisis de constatación de supuestos estadísticos se detalla en Anejos

\subsubsection{1.}

Tabla 101. MOR - Presencia nudos de cara: análisis comparativo.

\begin{tabular}{|c|c|c|c|c|}
\hline ANOVA* & Razón-F & P-valor & Presencia nudos de cara & $\begin{array}{c}\text { Grupos Homogéneos** } \\
\text { Unequal N HSD }\end{array}$ \\
\hline \multirow{2}{*}{$\begin{array}{c}\text { MOR - Presencia nudos } \\
\text { de cara }\end{array}$} & \multirow{2}{*}{12,32} & \multirow{2}{*}{0,00} & 1 & $\mathrm{~A}$ \\
\hline & & & 0 & $\mathrm{~B}$ \\
\hline
\end{tabular}

*MOR: módulo de rotura; 0: ausencia de nudos de cara; 1: presencia nudos de cara. ${ }^{* *}$ letras diferentes denotan diferencias significativas, Unequal N HSD. 
De acuerdo al P-valor hallado, el MOR obtenido en material sin presencia de nudos de cara es significativamente superior que aquel obtenido en presencia de nudos de cara, Tabla 101; Figura 253.

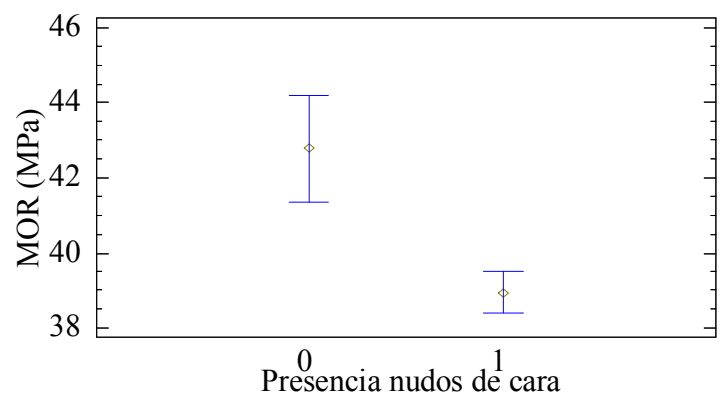

Figura 253. Gráfico de medias e IC 95\% Tukey

HSD: MOR - Presencia nudos de cara.

\section{b. Presencia nudos de canto}

La influencia de los nudos de canto en la determinación del módulo de rotura se resume en la Tabla 102.

Tabla 102. MOR - Presencia nudos de canto: análisis comparativo.

\begin{tabular}{|c|c|c|c|c|}
\hline ANOVA* & Razón-F & P-valor & Presencia nudos de canto & $\begin{array}{c}\text { Grupos Homogéneos** } \\
\text { Unequal N HSD } \\
\end{array}$ \\
\hline \multirow{2}{*}{$\begin{array}{l}\text { MOR - Presencia nudos } \\
\text { de canto }\end{array}$} & \multirow[b]{2}{*}{34,79} & \multirow[b]{2}{*}{0,00} & 1 & A \\
\hline & & & 0 & B \\
\hline
\end{tabular}

*MOR: módulo de rotura; 0: ausencia de nudos de canto; 1: presencia nudos de canto. **letras diferentes denotan diferencias, Unequal N HSD $(\mathrm{P}<0,05)$.

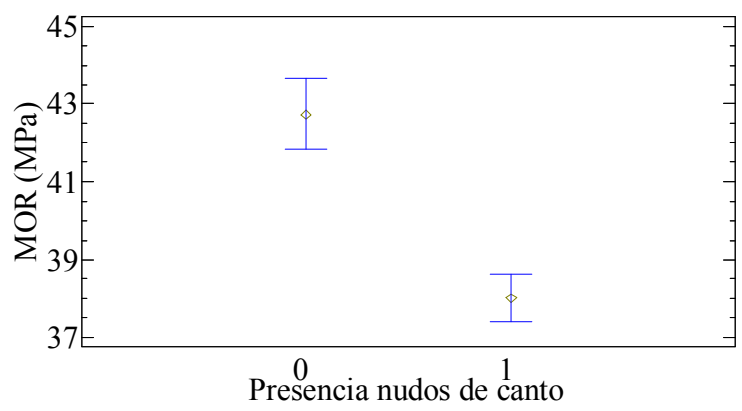

Figura 254. Gráfico de medias e IC 95\% (Unequal N HSD): (MOR) - "Presencia nudos de canto".

De acuerdo con los resultados hallados, el MOR obtenido en material libre de nudos de canto es significativamente superior que el obtenido en material en presencia de nudos de canto. 


\section{Por existencia v ubicación}

\section{a. Nudos}

En este caso se presenta el análisis comparativo entre el MOR y la influencia de los nudos considerando su presencia y ubicación ( 0 : ausencia, 1: presencia solo de nudos de cara, 2: presencia sólo de nudos de canto y 3: presencia de nudos de cara y canto), mediante la variable denominada "Nudos"; como consecuencia de la baja representatividad de valores en la categoría 2, la misma no fue considerada en el análisis.

Tabla 103. MOR - "Nudos".

\begin{tabular}{ccccc}
\hline ANOVA* & Razón-F & P-valor & Nudos & Grupos Homogéneos** \\
\hline \multirow{2}{*}{ MOR - Nudos } & \multirow{2}{*}{18,63} & 0,00 & 3 & Unequal N HSD \\
\cline { 3 - 4 } & & & 1 & $\mathrm{~A}$ \\
\hline
\end{tabular}

*MOR: módulo de rotura; 0: ausencia de nudos; 1: presencia nudos de canto; 3: presencia nudos de cara/canto; **letras diferentes denotan diferencias significativas, Unequal N $\operatorname{HSD}(\mathrm{P}<0,05)$.

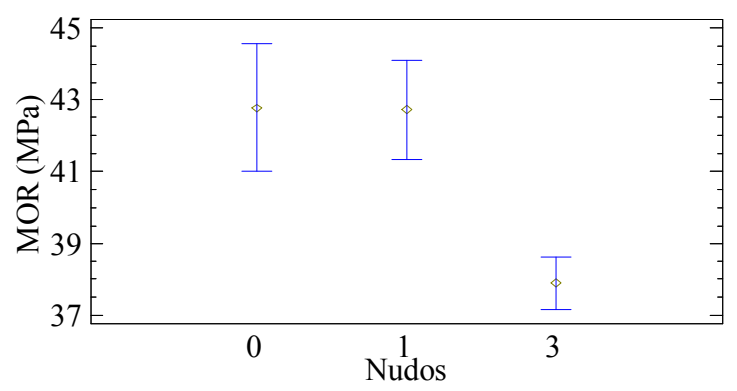

Figura 255. Gráfico de medias e IC 95\% Tukey HSD: MOR - "Nudos".

La media del MOR considerando la categoría 3: presencia de nudos de cara y de canto, es significativamente inferior respecto a la media del MOR en la categoría 0: ausencia de nudos y en la categoría 1: presencia de nudos de cara únicamente, sin observarse diferencias entre estas dos categorías.

\section{Nudos: consideraciones cuantitativas}

\section{Por tamaño}

\section{a. Tamaño nudo de cara}

La Tabla 104 muestra el análisis comparativo considerando el "Tamaño nudos de cara" en el comportamiento del MOR. 
Tabla 104. MOR - "Tamaño nudo de cara": análisis comparativo.

\begin{tabular}{|c|c|c|c|c|}
\hline ANOVA* & Razón-F & P-valor & Tamaño nudo de cara & $\begin{array}{c}\text { Grupos Homogéneos** } \\
\text { Unequal N HSD }\end{array}$ \\
\hline \multirow{3}{*}{$\begin{array}{c}\text { MOR - Tamaño nudo de } \\
\text { cara }\end{array}$} & \multirow{3}{*}{6,82} & \multirow{3}{*}{0,00} & 1 & $\mathrm{~A}$ \\
\hline & & & 2 & $\mathrm{~B}$ \\
\hline & & & 3 & $\mathrm{AB}$ \\
\hline
\end{tabular}

*MOR: módulo de rotura; 1 : nudos inferiores al 33\% de la cara; 2 : nudos comprendidos entre el 33 y el $66 \%$ de la cara; 3 : nudos superiores al $66 \%$ de la cara; **letras diferentes denotan diferencias significativas, Unequal $\mathrm{N} \operatorname{HSD}(\mathrm{P}<0,05)$.

Del análisis se desprende que la media de MOR fue estadísticamente significativa entre la categoría 1: nudos inferiores a 33\% del tamaño de la cara y la categoría 2: nudos entre el 33\% y el $66 \%$ del tamaño de la cara, no hallándose diferencias entre las medias de MOR en estas categorías y la categoría 3: nudos de tamaño superior al 66\% del tamaño de la cara.

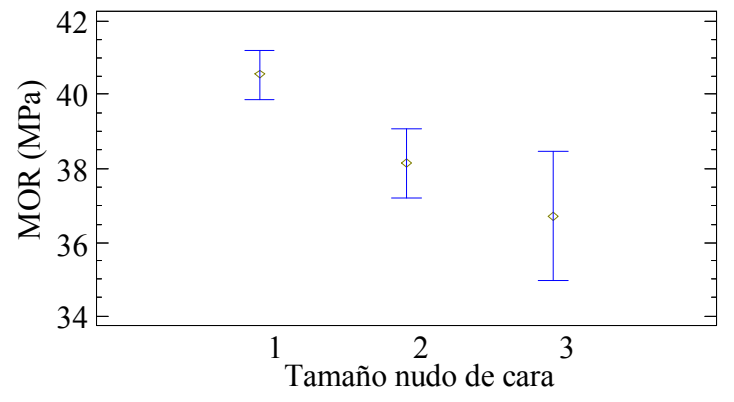

Figura 256. Gráfico de medias e IC 95\%: MOR "Tamaño nudo de cara".

\section{b. Tamaño nudo de canto}

El análisis comparativo considerando el "Tamaño nudos de canto" en el comportamiento del MOR se muestra en la Tabla 105.

Tabla 105. MOR - "Tamaño nudo de canto": análisis comparativo.

\begin{tabular}{|c|c|c|c|c|}
\hline ANOVA* & Razón-F & P-valor & Tamaño nudo de canto & $\begin{array}{c}\text { Grupos Homogéneos** } \\
\text { Unequal N HSD }\end{array}$ \\
\hline \multirow{3}{*}{$\begin{array}{l}\text { MOR - Tamaño nudo de } \\
\text { canto }\end{array}$} & \multirow{3}{*}{8,84} & \multirow{3}{*}{0,00} & 2 & $\mathrm{~A}$ \\
\hline & & & 3 & $\mathrm{~A}$ \\
\hline & & & 1 & $\mathrm{~B}$ \\
\hline
\end{tabular}

*MOR: módulo de rotura; 1 : nudos inferiores al 33\% del canto; 2: nudos comprendidos entre el 33 y el $66 \%$ del canto; 3 : nudos superiores al $66 \%$ del canto; ${ }^{* *}$ Letras diferentes denotan diferencias significativas; $* *$ letras diferentes denotan diferencias significativas, Unequal N HSD $(\mathrm{P}<0,05)$. 


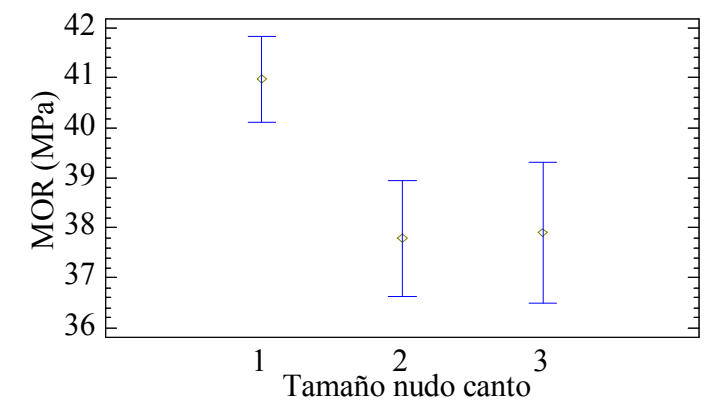

Figura 257. Gráfico de medias e IC 95\%: MOR -

"Tamaño nudo de canto".

El menor tamaño de nudos de canto, categoría 1, determina una media de MOR significativamente superior con respecto a los tamaños de nudos superiores al $33 \%$ del canto, categorías 2 y 3 .

\section{Desviación de las fibras}

La influencia de la desviación de las fibras determinada mediante la variable "Grupo desviación" en la variable MOR, se muestra en Tabla 106 y en la Figura 258.

Tabla 106. MOR - “Grupo desviación”.

\begin{tabular}{|c|c|c|c|c|}
\hline \multirow{2}{*}{ ANOVA* } & \multirow{2}{*}{ Razón-F } & \multirow{2}{*}{ P-valor } & \multirow{2}{*}{ Grupo desviación } & Grupos Homogéneos** \\
\hline & & & & Unequal N HSD \\
\hline \multirow{3}{*}{ MOR - Grupo desviación } & \multirow{3}{*}{11,83} & \multirow{3}{*}{0,00} & 2 & $\mathrm{~A}$ \\
\hline & & & 1 & A \\
\hline & & & 0 & $\mathrm{~B}$ \\
\hline
\end{tabular}

*MOR: módulo de rotura; 0: ausencia de desviación; 1: desviación inferior a 33\%; 2: desviación entre 7 y $15 \%$; **letras diferentes denotan diferencias significativas, Unequal N HSD $(\mathrm{P}<0,05)$.

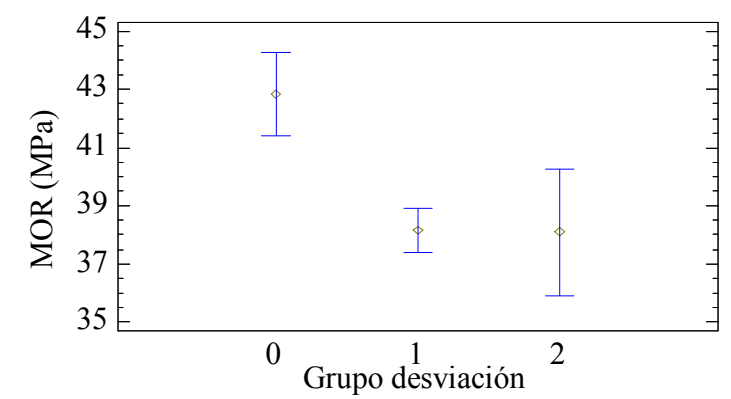

Figura 258. Gráfico de medias e IC 95\% Tukey HSD: MOR - “Grupo desviación”.

De acuerdo con lo observado, las diferencias estadísticamente significativas entre las medias del MOR considerando la desviación de las fibras se ponen de manifiesto entre la categoría 0: ausencia de desviación y la categoría 1 y 2 , mientras que la media del MOR en estas dos categorías no presentan significancia estadística. 


\section{$\underline{\text { Entrecasco }}$}

En la Tabla 107 se presenta el análisis comparativo realizado entre la media del MOR considerando ausencia (0) y presencia de entrecasco (1); los tests de constatación de los supuestos estadísticos se presentan en Anejos 6.3.5.2.1.

Tabla 107. MOR - "Entrecasco".

\begin{tabular}{ccccc}
\hline ANOVA* & Razón-F & P-valor & Entrecasco & Grupos Homogéneos** \\
\hline MOR - Entrecasco & 3,81 & 0,05 & 0 & Unequal N HSD \\
\cline { 3 - 4 } & & & 1 & $\mathrm{~A}$ \\
\hline
\end{tabular}

*MOR: módulo de rotura; 0: ausencia de entrecasco; 1: presencia de entrecasco; **letras diferentes denotan diferencias significativas, Unequal N HSD $(\mathrm{P}<0,05)$.

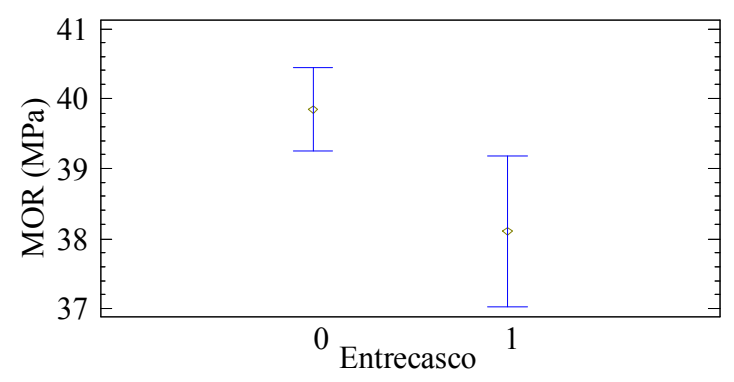

Figura 259. Gráfico de medias e IC 95\% Tukey HSD: MOR - "Entrecasco".

Según lo observado del análisis, la media del MOR se comporta estadísticamente igual ante la ausencia/presencia de entrecasco.

\subsection{Defectos de aserrado: influencia en el MOR}

En primera instancia se realizó el análisis de correlación ordinal de Spearman a fin de determinar la relación entre el MOR y los defectos de aserrado cuantitativos, Tabla 108.

Tabla 108. MOR - Defectos de aserrado: Correlación Ordinal de Spearman.

\begin{tabular}{|c|c|c|c|}
\hline & MOR & Anchura de gema & Longitud de gema \\
\hline \multirow{3}{*}{ MOR } & & 0,07 & 0,10 \\
\hline & & $(944)$ & $(944)$ \\
\hline & & $0,03 *$ & $0,00 *$ \\
\hline \multirow{3}{*}{ Anchura de gema } & 0,07 & & 0,75 \\
\hline & $(944)$ & & $(944)$ \\
\hline & $0,03 *$ & & $0,00 *$ \\
\hline \multirow{3}{*}{ Longitud de gema } & 0,10 & 0,75 & \\
\hline & $(944)$ & $(944)$ & \\
\hline & $0,00^{*}$ & $0,00^{*}$ & \\
\hline
\end{tabular}

*Los valores indicados en cada columna expresan: correlación; (tamaño de Muestra); P-Valor (< a 0,05 indica correlación estadísticamente significativa), en ese orden. 
Mediante el análisis de correlaciones se determinó que existe una correlación estadísticamente significativa y positiva entre el MOR y la presencia de gemas, determinadas mediante la anchura y longitud máxima en relación con la anchura y longitud de la pieza, respectivamente; el análisis de cada situación se presenta a continuación.

\section{$\underline{\text { Gemas }}$}

\section{a. Grupo anchura de gemas}

En la Tabla 109 y en la Figura 260 se muestra el análisis comparativo llevado a cabo a fin de evaluar la influencia de gemas en la determinación del MOR.

Tabla 109. MOR - "Grupo anchura de gema".

\begin{tabular}{|c|c|c|c|c|}
\hline \multirow{2}{*}{ ANOVA* } & \multirow{2}{*}{ Razón-F } & \multirow{2}{*}{ P-valor } & \multirow{2}{*}{ Grupo anchura de gema } & Grupos Homogéneos** \\
\hline & & & & Unequal N HSD \\
\hline \multirow{3}{*}{$\begin{array}{l}\text { MOR - Grupo anchura de } \\
\text { gema }\end{array}$} & \multirow{3}{*}{5,20} & \multirow{3}{*}{0,01} & 0 & $\mathrm{~A}$ \\
\hline & & & 2 & $\mathrm{AB}$ \\
\hline & & & 1 & $\mathrm{~B}$ \\
\hline
\end{tabular}

*MOR: módulo de rotura; 0: ausencia de gemas; 1: anchura de gemas inferior a 33\%; 2: anchura de gemas entre 33\% a $66 \%$; $* *$ letras diferentes denotan diferencias significativas, Unequal N HSD $(\mathrm{P}<0,05)$.

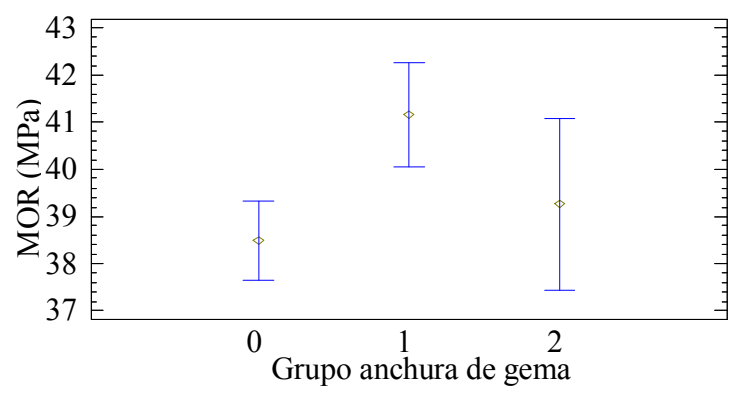

Figura 260. Gráfico de medias e IC 95\% Tukey HSD: MOR - "Grupo anchura de gema".

La media del MOR se comportó significativamente superior con la categoría 0: ausencia de gemas y la categoría 1: anchura de gemas inferior a 33\%, mientras que la categoría 2: anchura de gemas entre $33 \%$ y $66 \%$ no se diferenció de las anteriores.

\section{b. Grupo longitud de gemas}

Posteriormente se analizó la influencia de la longitud de gemas en la variable MOR, tal como se indica en la Tabla 110 y Figura 261. 
Tabla 110. MOR - Grupo longitud de gema: análisis comparativo.

\begin{tabular}{cccccc}
\hline \multirow{2}{*}{ ANOVA* } & \multirow{2}{*}{ Razón-F } & P-valor & $\begin{array}{c}\text { Grupo longitud } \\
\text { gema }\end{array}$ & \multicolumn{2}{c}{ Grupos Homogéneos** } \\
\cline { 4 - 6 } & & & 0 & Unequal N HSD & Tukey HSD \\
\cline { 3 - 5 } $\begin{array}{c}\text { MOR - Grupo } \\
\text { longitud de gema }\end{array}$ & 3,56 & 0,03 & $\mathrm{~A}$ & $\mathrm{~A}$ & $\mathrm{AB}$ \\
\cline { 3 - 5 } & & & 2 & $\mathrm{~A}$ & $\mathrm{~B}$ \\
\hline
\end{tabular}

*MOR: módulo de rotura; 0 : ausencia de gemas; 1 : longitud de gemas inferior a 33\%; 2: longitud de gemas entre 33\% a 66\%;

**letras diferentes denotan diferencias significativas, Unequal N HSD, Tukey HSD $(\mathrm{P}<0,05)$.

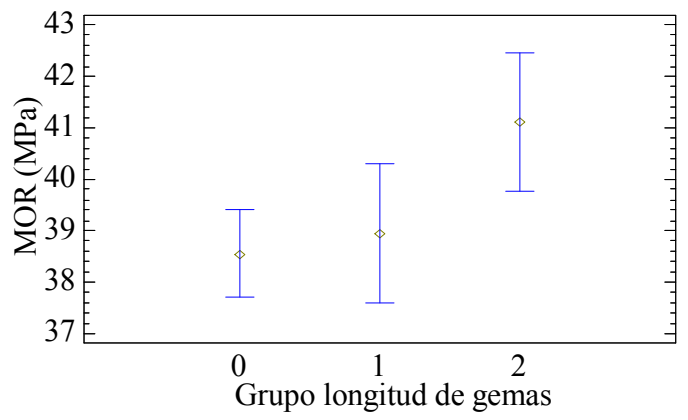

Figura 261. Gráfico de medias e IC 95\% Tukey HSD: MOR - Grupo longitud de gema.

Dada la falta de diferenciación entre las medias del MOR esbozadas por el Test Unequal $\mathrm{N}$ HSD, apropiado para la evaluación de observaciones desbalanceadas, se procedió a constatar el comportamiento mediante el test ANOVA (significación estadística: $\mathrm{p}<0,05$ ) y el test de múltiples rangos de Tukey HSD, con el que pudo observarse que existe una diferencia entre las medias del MOR correspondiente a la categoría 0 : ausencia de gemas y la categoría 2: longitud de gemas entre 33\% y $66 \%$, siendo superior el MOR en esta última categoría; la categoría 1 no mostró diferencias significativas con respecto a las otras categorías.

\section{Médula}

La Tabla 111 y la Figura 262 muestran el análisis comparativo entre las medias del MOR para la ausencia (0) y presencia de médula (1) en el material de estudio.

Tabla 111. MOR - Médula.

\begin{tabular}{ccccc}
\hline ANOVA* & Razón-F & P-valor & Grupo anchura de gema & Grupos Homogéneos** \\
\hline MOR - Médula & 29,05 & 0,00 & 0 & Unequal N HSD \\
\cline { 3 - 4 } & & & 1 & $\mathrm{~B}$ \\
\hline
\end{tabular}

*MOR: módulo de rotura; 0: ausencia de médula; 1: presencia de médula; **letras diferentes denotan diferencias significativas, Unequal N HSD $(\mathrm{P}<0,05)$. 


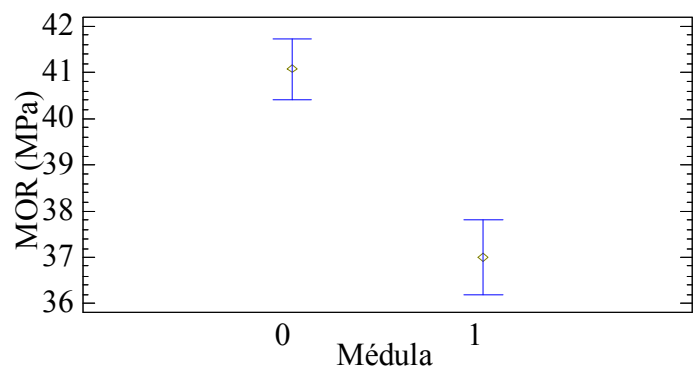

Figura 262. Gráfico de medias e IC 95\%: MOR - Médula.

De acuerdo con los resultados, puede indicarse que el MOR es significativamente inferior en ausencia de médula.

\subsection{Defectos de secado: influencia en el MOR}

La influencia de los defectos de secado en la variable MOR, determinada mediante análisis de correlación, se muestra en la Tabla 112.

Tabla 112. MOR - Defectos de secado: Correlación Ordinal de Spearman.

\begin{tabular}{|c|c|c|c|c|}
\hline & MOR & Curvatura cara & Curvatura canto & Alabeo \\
\hline \multirow{3}{*}{ MOR } & & $-0,02$ & $-0,04$ & $-0,12$ \\
\hline & & (943) & (943) & $(943)$ \\
\hline & & 0,65 & 0,23 & $0,00 *$ \\
\hline \multirow{3}{*}{ Curvatura cara } & $-0,02$ & & 0,27 & 0,02 \\
\hline & $(943)$ & & (943) & $(943)$ \\
\hline & 0,65 & & $0,00 *$ & 0,53 \\
\hline \multirow{3}{*}{ Curvatura canto } & $-0,04$ & 0,27 & & $-0,04$ \\
\hline & $(943)$ & $(943)$ & & $(943)$ \\
\hline & 0,23 & $0,00^{*}$ & & 0,17 \\
\hline \multirow{3}{*}{ Alabeo } & $-0,12$ & 0,02 & $-0,04$ & \\
\hline & (943) & (943) & (943) & \\
\hline & $0,00^{*}$ & 0,53 & 0,17 & \\
\hline
\end{tabular}

*Los valores indicados en cada columna expresan: correlación; (tamaño de Muestra); P-Valor (< a 0,05 indica correlación estadísticamente significativa), en ese orden.

De acuerdo con el análisis de correlaciones puede indicarse que el MOR presenta una correlación significativa y negativa en presencia del factor alabeo, mientras que la curvatura de cara y de canto no mostraron correlaciones significativas. De todos modos, a fin de constatar este comportamiento, a continuación se analiza la evolución del MOR en presencia de estos factores de aserrado, pero considerados como factores categóricos (ver Materiales y Métodos).

\section{Curvatura de cara}

Para este análisis, se procedió a analizar la significación de las categorías "Curvatura de cara" planteadas (ver Materiales y Métodos) en las medianas del MOR -Prueba de Kruskal-Wallis, Tabla 113; Figura 263; los resultados de los test de corroboración de los supuestos estadísticos se muestran 
en Anejos 6.3.5.2.3). Dado que la categoría 3 presentó muy pocas observaciones, se procedió a realizar el análisis sin su consideración.

Tabla 113. MOR - Grupo curvatura de cara: análisis comparativo.

\begin{tabular}{|c|c|c|c|c|}
\hline $\mathbf{K W} *$ & Estadístico & P-Valor & Curvatura de cara & Grupos homogéneos** \\
\hline \multirow{3}{*}{$\begin{array}{l}\text { MOR - Grupo curvatura de } \\
\text { cara }\end{array}$} & \multirow{3}{*}{11,90} & \multirow{3}{*}{0,00} & 0 & $\mathrm{~A}$ \\
\hline & & & 1 & $\mathrm{~B}$ \\
\hline & & & 2 & $\mathrm{AB}$ \\
\hline
\end{tabular}

*KW: Test de Kruskal-Wallis; MOR: módulo de rotura; 0: ausencia de curvatura de cara; 1: curvatura de cara $<10 \mathrm{~mm}$; 2 : curvatura de cara entre $10-20 \mathrm{~mm}$; **letras diferentes denotan diferencias significativas entre medianas.

Dado el P-valor hallado (inferior a 0,05) y consecuentemente con el posterior análisis entre pares de medianas realizado (Anejos 6.3.5.2.3), se determinó que existen diferencias significativas entre las medianas del MOR considerando la categoría 0: ausencia de curvatura de cara y la categoría 1: curvatura de cara menor que $10 \mathrm{~mm}$, siendo superior el MOR obtenido en ausencia de curvatura de cara; las medias del MOR entre la categoría 1 y la categoría 2: curvatura de cara entre $10 \mathrm{~mm}$ y $20 \mathrm{~mm}$, no se diferenciaron entre ellas como así tampoco con la categoría 0, Figura 263.

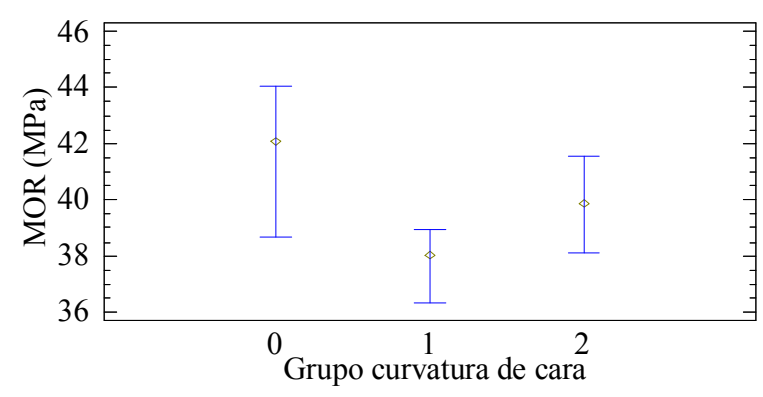

Figura 263. Gráfico de medianas: MOR - Grupo curvatura de cara.

\section{Curvatura de canto}

De acuerdo con el incumplimiento de los supuestos estadísticos (Anejos 6.3.5.2.3), se recurrió a la Prueba de Kruskal-Wallis, Tabla 114, para determinar la significación del MOR en presencia de las categorías planteadas para la curvatura de canto.

Tabla 114. MOR - Grupo curvatura de canto: análisis comparativo.

\begin{tabular}{|c|c|c|c|c|}
\hline $\mathbf{K W} *$ & Estadístico & P-Valor & Curvatura de canto & $\begin{array}{c}\text { Grupos } \\
\text { homogéneos } * *\end{array}$ \\
\hline \multirow{3}{*}{$\begin{array}{l}\text { MOR - Grupo curvatura de } \\
\text { canto }\end{array}$} & \multirow{3}{*}{2,78} & \multirow{3}{*}{0,25} & 0 & $\mathrm{~A}$ \\
\hline & & & 1 & A \\
\hline & & & 2 & $\mathrm{~A}$ \\
\hline
\end{tabular}

*KW: Test de Kruskal-Wallis; MOR: módulo de rotura; 0: ausencia de curvatura de canto; 1: curvatura de canto $<10 \mathrm{~mm}$; 2 : curvatura de canto entre $10-20 \mathrm{~mm}$; **letras diferentes denotan diferencias significativas entre medianas. 


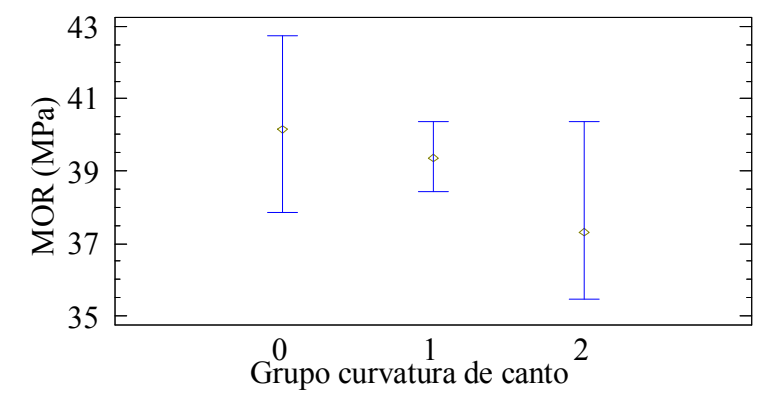

Figura 264. Gráfico de medianas: MOR - Grupo curvatura de canto.

Atendiendo al P-valor obtenido se puede afirmar que no existen diferencias significativas entre las medianas del MOR considerando las diversas categorías de "Grupo curvatura de canto" planteadas.

\section{$\underline{\text { Alabeos }}$}

El análisis comparativo realizado para evaluar el comportamiento del MOR en las diferentes categorías de alabeos planteadas, se muestra en Tabla 115; dado el bajo número de observaciones en la categoría 3 no fue considerada para el análisis. Los supuestos estadísticos son evaluados en Anejos 6.3.5.2.3.

Tabla 115. MOR - Grupo alabeo: análisis comparativo.

\begin{tabular}{|c|c|c|c|c|}
\hline $\mathbf{K W}^{*}$ & Estadístico & P-Valor & Alabeo & Grupos homogéneos** \\
\hline \multirow{3}{*}{ MOR - Grupo alabeo } & \multirow{3}{*}{13,28} & \multirow{3}{*}{0,00} & 0 & $\mathrm{~A}$ \\
\hline & & & 1 & A \\
\hline & & & 2 & $\mathrm{~B}$ \\
\hline
\end{tabular}

*KW: Test de Kruskal-Wallis; MOR: módulo de rotura; 0: ausencia de alabeo; 1: alabeo $<6 \mathrm{~mm}$; 2: alabeo entre 6-12 mm; **letras diferentes denotan diferencias significativas entre medianas.

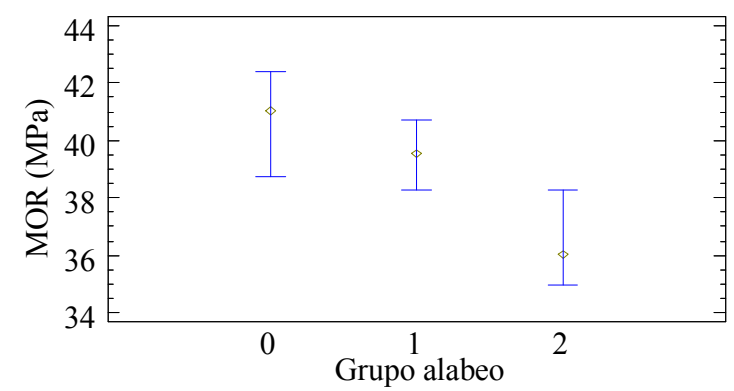

Figura 265. Gráfico de medianas: MOR - Grupo alabeo.

El valor de la mediana del MOR de la categoría 2: alabeos entre 6 y $12 \mathrm{~mm}$, es significativamente inferior respecto a los valores de las medianas del MOR de las categorías 0 : ausencia de alabeos y 1: alabeos inferiores a $6 \mathrm{~mm}$, mientras que las medianas de estas últimas no se diferenciaron entre sí, Figura 265. 


\subsection{Influencia de los defectos en la densidad}

En el siguiente apartado se analizaran las influencias de los defectos en la variable densidad, considerando su transformada $1 /$ (Densidad).

\subsection{Defectos naturales: influencia en la densidad}

El análisis realizado mediante la correlación Ordinal de Spearman se recoge en la Tabla 116.

Tabla 116. 1/(Densidad) - Defectos naturales: Correlación Ordinal de Spearman.

\begin{tabular}{|c|c|c|c|c|c|}
\hline & $1 /(\text { Densidad })^{*}$ & $\begin{array}{l}\text { Anchura } \\
\text { anillos * }\end{array}$ & $\begin{array}{c}\text { Diámetro relativo } \\
\text { de cara* }\end{array}$ & $\begin{array}{c}\text { Diámetro relativo } \\
\text { de canto* }\end{array}$ & $\begin{array}{l}\text { Desviación } \\
\text { fibra } *\end{array}$ \\
\hline \multirow{3}{*}{ 1/(Densidad) } & & 0,21 & $-0,09$ & $-0,09$ & 0,18 \\
\hline & & $(868)$ & $(868)$ & $(868)$ & $(868)$ \\
\hline & & $0,00^{* *}$ & $0,01 * *$ & $0,01 * *$ & $0,00^{* *}$ \\
\hline \multirow{2}{*}{ Anchura anillos } & 0,21 & & $-0,07$ & $-0,07$ & 0,12 \\
\hline & $0,00^{*}$ & & $0,04^{*}$ & $0,03^{*}$ & $0,00^{*}$ \\
\hline \multirow{2}{*}{$\begin{array}{c}\text { Diámetro relativo de } \\
\text { cara }\end{array}$} & $-0,09$ & $-0,07$ & & 0,53 & $-0,20$ \\
\hline & $0,01 *$ & $0,04 *$ & & $0,00 *$ & $0,00 *$ \\
\hline \multirow{2}{*}{$\begin{array}{l}\text { Diámetro relativo de } \\
\text { canto }(\%)\end{array}$} & $-0,09$ & $-0,07$ & 0,53 & & $-0,09$ \\
\hline & $0,01 *$ & $0,03 *$ & $0,00^{*}$ & & $0,01 *$ \\
\hline \multirow{2}{*}{ Desviación fibra (\%) } & 0,18 & 0,12 & $-0,20$ & $-0,09$ & \\
\hline & $0,00^{*}$ & $0,00^{*}$ & $0,00^{*}$ & $0,01 *$ & \\
\hline
\end{tabular}

*Los valores indicados en cada columna expresan: correlación; (tamaño de Muestra); P-Valor (< a 0,05 indica correlación estadísticamente significativa), en ese orden.

De acuerdo con el análisis de correlaciones puede indicarse que la variable densidad se relaciona significativa y negativamente con el factor anchura de anillos y desviación de las fibras (positivamente con la variable transformada), mientras que el diámetro relativo de cara y canto se relaciona significativa y positivamente con la variable densidad (negativamente con la variable transformada). De acuerdo con esto, puede inferirse que a medida que la anchura de anillos y/o la desviación de las fibras aumenten, el valor de la densidad tenderá a disminuir mientras que el comportamiento contrario ocurrirá a medida que el diámetro relativo de cara y canto aumenten.

Los resultados de las evaluaciones realizadas considerando la densidad en relación con los defectos naturales categorizados según se indicó en Materiales y Métodos, se detallan a continuación.

\section{Nudos: consideraciones cualitativas}

\section{a. Presencia nudos de cara}

La influencia de los nudos de cara, considerando únicamente ausencia: 0 y presencia: 1, en la determinación de 1/(Densidad), se muestra en la Tabla 117 y en la Figura 266. La constatación de los requisitos estadísticos se detalla en Anejos 6.3.5.3.1. 
Tabla 117. 1/(Densidad) - Presencia de nudos de cara: análisis comparativo.

\begin{tabular}{|c|c|c|c|c|}
\hline $\mathbf{K W} *$ & Estadístico & P-Valor & Presencia nudos cara & Grupos homogéneos** \\
\hline \multirow{2}{*}{$\begin{array}{c}\text { 1/Densidad - Presencia de } \\
\text { nudos de cara }\end{array}$} & \multirow{2}{*}{6,82} & \multirow{2}{*}{0,01} & 0 & A \\
\hline & & & 1 & B \\
\hline
\end{tabular}

*KW: test de Kruskal-Wallis; 0: ausencia nudos de cara; 1: presencia nudos de cara. **letras diferentes denotan diferencias significativas entre medianas.

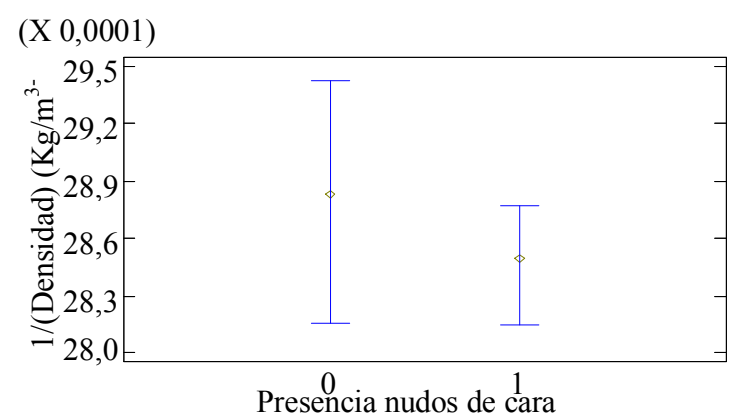

Figura 266. Gráfico de medianas: 1/Densidad -

Presencia nudos de cara.

La mediana de 1/(Densidad) es significativamente superior en ausencia de nudos de cara, con un $95 \%$ de confianza.

\section{b. Presencia nudos de canto}

La influencia de los nudos de canto, considerando únicamente ausencia: 0 y presencia: 1 , en la determinación de 1/(Densidad), se muestra a continuación; los supuestos estadísticos son evaluados en Anejos 6.3.5.3.1.

Tabla 118. 1/(Densidad) - Presencia de nudos de canto: análisis comparativo.

\begin{tabular}{|c|c|c|c|c|}
\hline $\mathbf{K W} *$ & Estadístico & P-Valor & $\begin{array}{l}\text { Presencia nudos } \\
\text { canto }\end{array}$ & $\begin{array}{c}\text { Grupos } \\
\text { homogéneos } * *\end{array}$ \\
\hline \multirow{2}{*}{$\begin{array}{c}\text { 1/Densidad - Presencia de } \\
\text { nudos de canto }\end{array}$} & \multirow{2}{*}{16,21} & \multirow{2}{*}{0,00} & 0 & $\mathrm{~A}$ \\
\hline & & & 1 & $\mathrm{~B}$ \\
\hline
\end{tabular}

*KW: Test de Kruskal-Wallis; 0: ausencia nudos de canto; 1: presencia nudos de canto; **letras diferentes denotan diferencias significativas entre medianas.

$(\mathrm{X} 0,0001)$

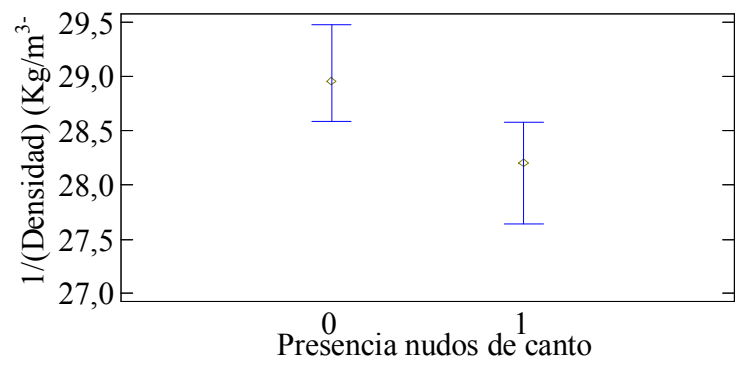

Figura 267. Gráfico de medianas: 1/Densidad Presencia nudos de canto. 
De acuerdo a lo observado, la variable 1/(Densidad) es significativamente superior en ausencia de nudos de cara: categoría 0 .

De acuerdo con estos análisis, puede inferirse que la variable densidad sin transformar en presencia de nudos de cara y de canto, presentará un comportamiento diferencial y significativamente superior con respecto a la densidad considerada en ausencia de dichos defectos.

\section{c. Nudos}

Con la finalidad de incorporar al también el tipo de nudo, de cara, de canto o ambos, se realizó una categorización denominada "Nudos", tal como fue detallado en Materiales y Métodos, cuyo comportamiento en relación con la variable 1/Densidad es detallado a continuación; la categoría 2: presencia de nudos de canto, no fue considerada en el análisis dado el número reducido de observaciones. De acuerdo con el incumplimiento del supuesto de normalidad de residuos (Anejos, 4.5.2.4.3.1), se procedió al análisis comparativo mediante el test no paramétrico de Kruskal-Wallis, Tabla 119.

Tabla 119. 1/(Densidad) - "Nudos": análisis comparativo.

\begin{tabular}{|c|c|c|c|c|}
\hline $\mathbf{K W} *$ & Estadístico & P-Valor & Nudos & Grupos homogéneos** \\
\hline \multirow{3}{*}{ 1/Densidad - Nudos } & \multirow{3}{*}{16,80} & \multirow{3}{*}{0,00} & 0 & $\mathrm{~A}$ \\
\hline & & & 1 & $\mathrm{~A}$ \\
\hline & & & 3 & $\mathrm{~B}$ \\
\hline
\end{tabular}

*KW: Test de Kruskal-Wallis; 0: ausencia nudos; 1: presencia nudos de cara; 3: presencia nudos de cara/canto; **letras diferentes denotan diferencias significativas entre medianas.

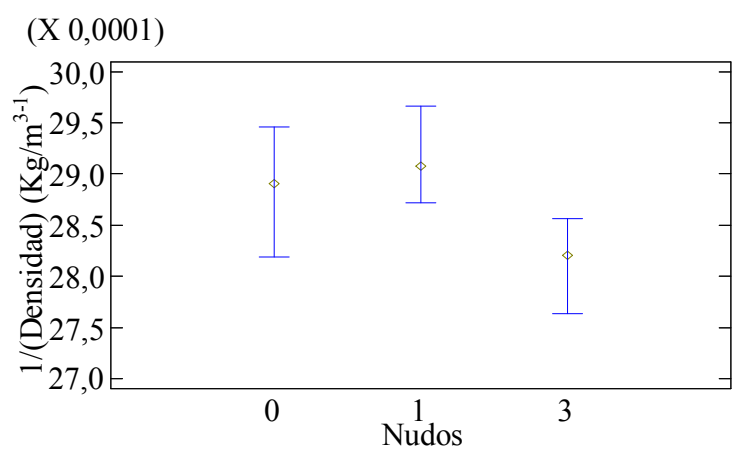

Figura 268. Gráfico de medianas: 1/Densidad "Nudos".

De acuerdo con el análisis presentado, puede concluirse que la mediana de 1/(Densidad), considerando la categoría 3: presencia de nudos de cara y de canto, es significativamente inferior respecto a las medianas de la categoría 0 : ausencia de nudos y la categoría 1: presencia de nudos de cara, las cuales no presentan diferencias entre sí.

Para finalizar con la evaluación sobre la influencia de los nudos en la densidad, se procedió a incluir la influencia del tamaño de los nudos en el análisis, tal como se desarrolla a continuación. 


\section{Nudos: consideraciones cuantitativas}

\section{a. Tamaño nudo de cara}

En la Tabla 120 se muestran los resultados del análisis de Kruskal-Wallis realizado para evaluar el comportamiento de la variable 1/(Densidad) considerando las diversas categorías del "Tamaño nudo de cara" que fueron planteadas.

Tabla 120. 1/(Densidad) - "Tamaño nudos de cara": análisis comparativo.

\begin{tabular}{|c|c|c|c|c|}
\hline $\mathbf{K W} *$ & Estadístico & P-Valor & Tamaño nudo cara & Grupos homogéneos** \\
\hline \multirow{3}{*}{$\begin{array}{c}\text { 1/Densidad - Tamaño nudo } \\
\text { de cara }\end{array}$} & \multirow{3}{*}{14,14} & \multirow{3}{*}{0,00} & 1 & $\mathrm{~A}$ \\
\hline & & & 2 & A \\
\hline & & & 3 & $\mathrm{~B}$ \\
\hline
\end{tabular}

*KW: Test de Kruskal-Wallis; 1: nudos inferiores al 33\% de la cara; 2 : nudos comprendidos entre el 33 y el $66 \%$ de la cara; 3: nudos superiores al $66 \%$ de la cara; **letras diferentes denotan diferencias significativas entre medianas.

Los resultados obtenidos indican que la variable 1/(Densidad) es significativamente superior en presencia de nudos inferiores al 33\% de la sección de la cara, categoría 1, no diferenciándose estadísticamente en presencia de nudos superiores al 33\% de la cara: categoría 2 y 3 , con un $95 \%$ de confianza, Figura 269.

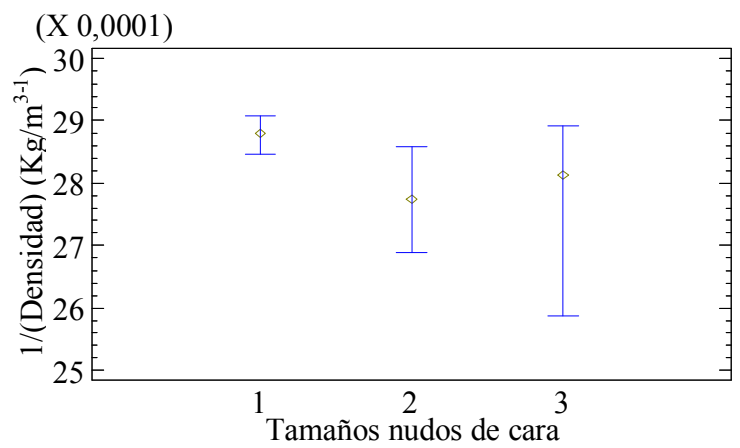

Figura 269. Gráfico de medianas: 1/Densidad Tamaño nudo de cara.

\section{b. Tamaño nudos de canto}

Los resultados obtenidos considerando la influencia del tamaño de los nudos de canto en la variable 1/(Densidad), son planteados en la Tabla 121.

Tabla 121. 1/(Densidad) - Tamaño nudo de canto: análisis comparativo.

\begin{tabular}{|c|c|c|c|c|}
\hline $\mathbf{K W} *$ & Estadístico & P-Valor & Tamaño nudo canto & Grupos homogéneos** \\
\hline \multirow{3}{*}{$\begin{array}{l}\text { 1/Densidad - Tamaño nudo } \\
\text { de canto }\end{array}$} & \multirow{3}{*}{31,63} & \multirow{3}{*}{0,00} & 1 & $\mathrm{~A}$ \\
\hline & & & 2 & A \\
\hline & & & 3 & $\mathrm{~B}$ \\
\hline
\end{tabular}

*KW: Test de Kruskal-Wallis; 1 : nudos inferiores al 33\% del canto; 2: nudos comprendidos entre el 33 y el $66 \%$ del canto; 3 : nudos superiores al $66 \%$ del canto; $* *$ letras diferentes denotan diferencias significativas entre medianas. 


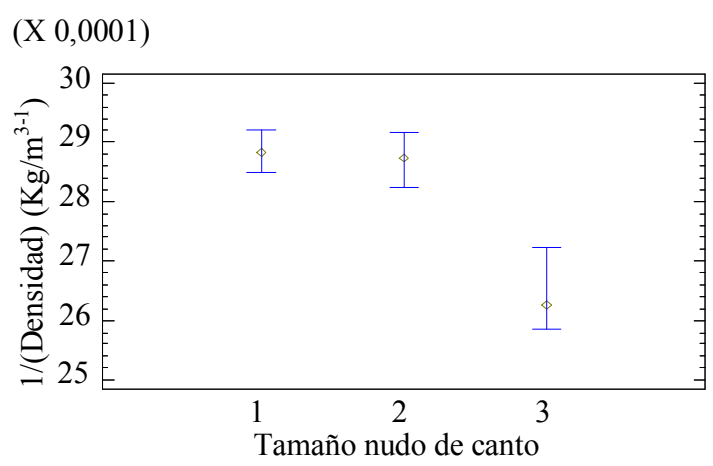

Figura 270. Gráfico de medianas e IC 95\%: 1/(Densidad) - Tamaño nudo de canto.

La mediana de 1/(Densidad) considerando la categoría 3, resultó significativamente inferior respecto a la mediana analizada en presencia de los tamaños de nudos considerados en la categoría 1 y 2, Figura 270, mientras que estas dos categorías no se diferenciaron estadísticamente.

En concordancia con los resultados hallados, considerando los tamaños de nudos de cara y de canto, puede inferirse que la variable densidad, será superior en presencia de nudos de mayor tamaño.

\section{Desviación de las fibras}

Para la determinación de la influencia de la desviación de las fibras se trabajó con la variable "Grupo desviación" tal como se expresó en la sección Materiales y Métodos; dado el incumplimiento del supuesto de normalidad de residuos (Anejos 6.3.5.3.1), se recurrió a la prueba de Kruskal-Wallis para el análisis comparativo que se detalla a continuación.

Tabla 122. 1/(Densidad) - “Grupo desviación”: análisis comparativo.

\begin{tabular}{|c|c|c|c|c|}
\hline $\mathbf{K W} *$ & Estadístico & P-Valor & Grupo desviación & Grupos homogéneos** \\
\hline \multirow{3}{*}{$\begin{array}{c}\text { 1/Densidad - "Grupo } \\
\text { desviación" }\end{array}$} & \multirow{3}{*}{22,61} & \multirow{3}{*}{0,00} & 0 & $\mathrm{~A}$ \\
\hline & & & 1 & $\mathrm{~B}$ \\
\hline & & & 2 & $\mathrm{C}$ \\
\hline
\end{tabular}

*KW: Test de Kruskal-Wallis; 0: ausencia de desviación; 1: desviación inferior a 33\%; 2: desviación entre 7 y $15 \%$; **letras diferentes denotan diferencias significativas entre medianas.

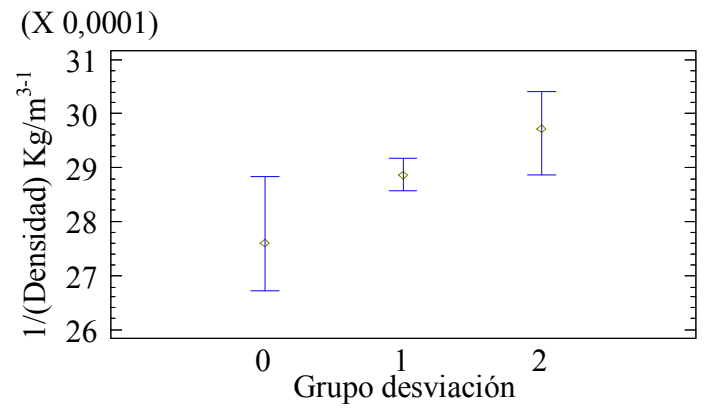

Figura 271. Gráfico de medianas e IC 95\%: 1/(Densidad) - "Grupo desviación". 
La mediana de 1/(Densidad) resultó significativamente diferente en las tres categorías, siendo la superior la categoría 2: desviación entre 7\%-15\%, Figura 271. En base a estos resultados puede indicarse que la mediana de la variable densidad, será superior en ausencia de desviaciones o en presencia de desviaciones inferiores.

\section{$\underline{\text { Entrecasco }}$}

El análisis comparativo de Kruskal-Wallis se muestra en la Tabla 123.

Tabla 123. 1/(Densidad) - Entrecasco: análisis comparativo.

\begin{tabular}{|c|c|c|c|c|}
\hline $\mathbf{K} \mathbf{W}^{*}$ & Estadístico & P-Valor & Entrecasco & Grupos homogéneos** \\
\hline \multirow{2}{*}{ 1/Densidad - Entrecasco } & \multirow{2}{*}{5,03} & \multirow{2}{*}{0,03} & 0 & A \\
\hline & & & 1 & $\mathrm{~B}$ \\
\hline
\end{tabular}

*KW: Test de Kruskal-Wallis; 0: ausencia de entrecasco; 1: presencia de entrecasco; **letras diferentes denotan diferencias significativas entre medianas.

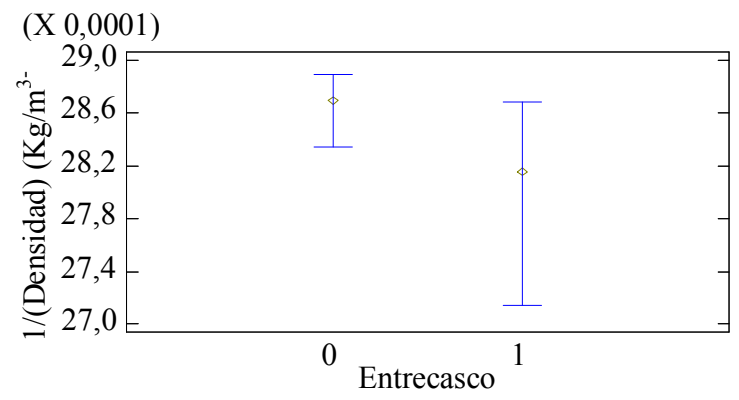

Figura 272. Gráfico de medianas: 1/(Densidad) Entrecasco.

De acuerdo con el resultado obtenido, puede concluirse que la mediana de la variable $1 /($ Densidad) es significativamente superior en ausencia de entrecasco, lo cual indicaría el comportamiento inverso (superior en presencia de entrecasco) en la variable densidad; resultado esperado teniendo en cuenta que el entrecasco es la presencia de corteza inclusa dentro del material, siendo un material menos denso.

\subsection{Defectos de aserrado: influencia en la densidad}

El análisis de correlación para evaluar la relación existente entre la densidad (1/(Densidad) y las variables cuantitativas (defectos de aserrado), se muestra en la Tabla 124. 
Tabla 124. 1/(Densidad) - Defectos de aserrado: correlación Ordinal de Spearman.

\begin{tabular}{|c|c|c|c|}
\hline & Densidad* & Anchura de gema* & Longitud de gema* \\
\hline \multirow{3}{*}{ Densidad } & & $-0,03$ & $-0,11$ \\
\hline & & $(949)$ & $(949)$ \\
\hline & & 0,33 & $0,00 * *$ \\
\hline \multirow{3}{*}{ Anchura de gema } & $-0,03$ & & 0,7532 \\
\hline & (949) & & $(949)$ \\
\hline & 0,33 & & $0,00 * *$ \\
\hline \multirow{3}{*}{ Longitud de gema } & $-0,11$ & 0,75 & \\
\hline & (949) & (949) & \\
\hline & $0,00 * *$ & $0,00 * *$ & \\
\hline
\end{tabular}

*Los valores indicados en cada columna expresan: correlación; (tamaño de Muestra); P-Valor $(<$ a 0,05 indica correlación estadísticamente significativa), en ese orden.

En base al análisis de correlaciones puede indicarse que la anchura de gemas no se correlaciona con la variable 1/(Densidad) mientras que la longitud de gemas se correlaciona negativa y significativamente con dicha variable, o lo que es lo mismo, positivamente con la variable densidad sin transformar; en base a esto puede inferirse que la densidad presentará valores superiores en zonas del material con presencia de gemas. Este comportamiento podría estar relacionado con una mayor proporción de madera madura existente en el borde de la troza, donde precisamente es posible encontrar las gemas.

A fin de profundizar este análisis, a continuación se presentan los resultados de los análisis realizados considerando la influencia de gemas, según las categorías establecidas en Materiales y Métodos, en la variable 1/Densidad.

\section{$\underline{\text { Gemas }}$}

\section{a. Grupo anchura de gemas}

El análisis comparativo de Kruskal-Wallis realizado entre la variable 1/(Densidad) y las diferentes categorías de anchura de gemas establecidas, se indica en la Tabla 125 y Figura 273; el incumplimiento de supuestos estadísticos se muestra en Anejos 6.3.5.3.2.

Tabla 125. 1/(Densidad) - "Grupo anchura de gema": análisis comparativo.

\begin{tabular}{|c|c|c|c|c|}
\hline $\mathbf{K W} *$ & Estadístico & P-Valor & Anchura de gema & Grupos homogéneos** \\
\hline \multirow{3}{*}{$\begin{array}{c}\text { 1/Densidad - Grupo anchura } \\
\text { de gema }\end{array}$} & \multirow{3}{*}{4,62} & \multirow{3}{*}{0,01} & 0 & A \\
\hline & & & 1 & $\mathrm{~B}$ \\
\hline & & & 2 & $\mathrm{C}$ \\
\hline
\end{tabular}

*KW: test de Kruskal-Wallis; 0: ausencia de gemas; 1: anchura de gemas inferior a 33\%; 2: anchura de gemas entre 33\% a $66 \% ; * *$ letras diferentes denotan diferencias significativas entre medianas. 


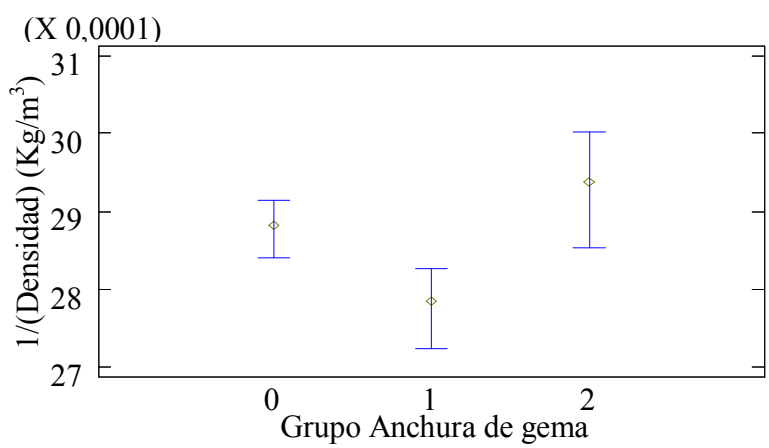

Figura 273. Gráfico de medianas e IC 95\%: 1/Densidad - "Grupo Anchura de gemas".

De acuerdo con el análisis comparativo entre las categorías de anchura de gema planteadas y la variable 1/(Densidad), pudo observarse que la mediana de 1/(Densidad) es significativamente diferente entre categorías, siendo significativamente superior en la categoría 2 e inferior en la categoría 1, ocupando un estado intermedio la categoría 1, Figura 273.

\section{b. Grupo longitud de gemas}

El comportamiento de la variable 1/(Densidad) considerando las diferentes categorías planteadas para la longitud de gemas, se indica en la Tabla 126.

Tabla 126. 1/(Densidad) - "Grupo longitud de gema": análisis comparativo.

\begin{tabular}{ccccc}
\hline $\mathbf{K W}^{*}$ & Estadístico & P-Valor & Longitud de gema & Grupos homogéneos** \\
\hline \multirow{2}{*}{$\begin{array}{c}\text { 1/Densidad - Grupo longitud } \\
\text { de gema }\end{array}$} & 10,41 & 0,01 & 0 & $\mathrm{~A}$ \\
\cline { 3 - 4 } & & & 1 & $\mathrm{AB}$ \\
\hline
\end{tabular}

*KW: Test de Kruskal-Wallis; 0: ausencia de gemas; 1 : longitud de gemas inferior a 33\%; 2: longitud de gemas entre 33\% a $66 \%$;**letras diferentes denotan diferencias significativas entre medianas.

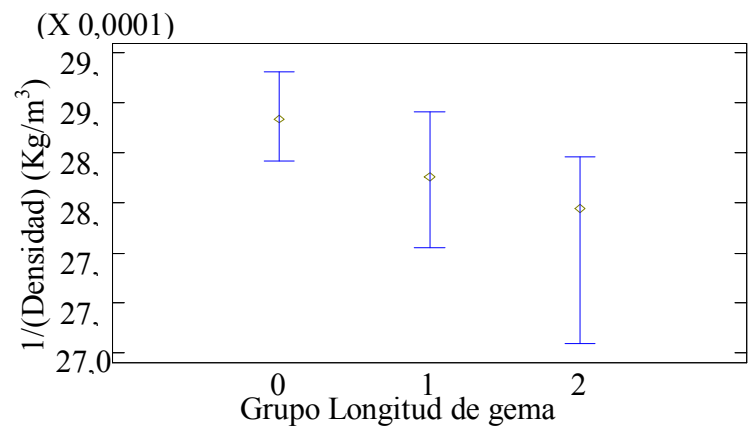

Figura 274. Gráfico de medianas e IC 95\%:

1/(Densidad) - "Grupo Longitud de gemas".

De acuerdo con la significación estadística hallada ( $\mathrm{P}$ valor $<0,05)$ en el test de comparación de medianas y posterior comparación de medianas por pares (Kruskal-Wallis) a fin de evaluar entre cuales se establecían las diferencias, se observó que la mediana de 1/(Densidad) considerando la 
categoría 0 fue significativamente superior a la mediana obtenida en presencia de gemas consideradas en la categoría 2, mientras que la mediana obtenida considerando la categoría 1 , no se diferenció del resto, Tabla 126 y Figura 274. En este sentido, podría indicarse que en presencia de gemas de mayor tamaño (expresadas como anchura relativa o como longitud relativa), obtendremos valores de densidad superiores; este comportamiento podría estar relacionado con que la existencia de gemas o más precisamente, la presencia de gemas de mayor tamaño, está relacionada con el tipo de corte realizado en la troza y su relación con el tipo de madera obtenida (juvenil-madura). Así, las piezas obtenidas de las zonas más cercanas al borde de la troza son más propensas a presentar gemas de mayor tamaño, con mayor proporción de madera madura y, en consecuencia, con mayores valores de densidad. Por el contrario, al alejarnos del borde de la troza, aumenta la posibilidad de obtener mayor proporción de manera juvenil, acercándonos a la zona central de la troza, con menores tamaños de gemas o sin ellas y, por ello, con menores valores de densidad en el material.

\section{Médula}

La prueba de Kruskal-Wallis para evaluar existencias de diferencias significativas entre las medianas de 1/(Densidad) considerando como factor influyente la médula, se indica en la Tabla 127 y en la Figura 275.

Tabla 127. 1/(Densidad) - Médula: análisis comparativo.

\begin{tabular}{ccccc}
\hline KW* & Estadístico & P-Valor & Médula & Grupos homogéneos** \\
\hline 1/Densidad - Médula & 0,04 & 0,83 & 0 & $\mathrm{~A}$ \\
\cline { 3 - 4 } & & & 1 & $\mathrm{~A}$
\end{tabular}

*KW: test de Kruskal-Wallis; 0: ausencia de médula; 1: presencia de médula; **letras diferentes denotan diferencias significativas entre medianas.

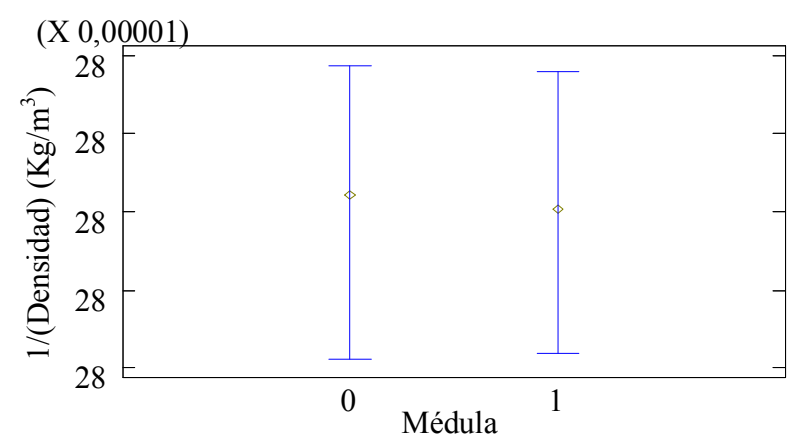

Figura 275. Gráfico de medianas e IC 95\%: 1/(Densidad) - Médula.

De acuerdo con los resultados hallados, y contrariamente a lo esperado, no existen diferencias significativas entre las medianas de 1/(Densidad) en ausencia y presencia de médula. 


\subsection{Defectos de secado: influencia en la densidad}

En primer término se muestra el resultado de la correlación Ordinal de Spearman entre la variable $1 /$ (Densidad) y los defectos de secado (cuantitativos).

Tabla 128. 1/Densidad - Defectos de secado: Correlación Ordinal de Spearman.

\begin{tabular}{|c|c|c|c|c|}
\hline & 1/(Densidad)* & Alabeo* & Curvatura cara* & Curvatura canto* \\
\hline \multirow{3}{*}{ 1/(Densidad) } & & 0,14 & 0,09 & $-0,00$ \\
\hline & & (948) & (948) & (948) \\
\hline & & $0,00^{*}$ & $0,01^{*}$ & 0,93 \\
\hline \multirow{3}{*}{ Alabeo } & 0,14 & & 0,02 & $-0,05$ \\
\hline & (948) & & (948) & (948) \\
\hline & $0,00^{*}$ & & 0,51 & 0,16 \\
\hline \multirow{3}{*}{ Curvatura cara } & 0,09 & 0,02 & & 0,27 \\
\hline & $(948)$ & $(948)$ & & $(948)$ \\
\hline & $0,01^{*}$ & 0,51 & & $0,00^{*}$ \\
\hline \multirow{3}{*}{ Curvatura canto } & $-0,00$ & $-0,05$ & 0,27 & \\
\hline & $(948)$ & $(948)$ & (948) & \\
\hline & 0,93 & 0,16 & $0,00^{*}$ & \\
\hline
\end{tabular}

*Los valores indicados en cada columna expresan: correlación; (tamaño de Muestra); P-Valor (< a 0,05 indica correlación estadísticamente significativa), en ese orden.

De acuerdo a lo observado en el presente análisis, el alabeo y la curvatura de cara presentan una correlación positiva y estadísticamente significativa con la variable 1/(Densidad), correlación negativa con la variable densidad sin transformar, mientras que la curvatura de canto no se correlaciona significativamente con dicha variable.

Un análisis más exhaustivo, considerando las variables categóricas para los defectos de secado establecidas en Materiales y métodos, se detalla a continuación.

\section{Curvatura de cara}

No pudiendo aceptarse la normalidad de los residuos (Anejos 6.3.5.3.3), se recurrió al análisis de Kruskal-Wallis para evaluar la influencia de la curvatura de cara en la variable 1/(densidad); Tabla 129. Dado el bajo número de observaciones en la categoría 3, ésta no fue considerada en el análisis.

Tabla 129. 1/(Densidad) - "Grupo curvatura de cara": análisis comparativo.

\begin{tabular}{|c|c|c|c|c|}
\hline $\mathbf{K W} *$ & Estadístico & P-Valor & Curvatura de cara & Grupos homogéneos** \\
\hline \multirow{3}{*}{$\begin{array}{c}\text { 1/Densidad - Grupo curvatura } \\
\text { de cara }\end{array}$} & \multirow{3}{*}{35,61} & \multirow{3}{*}{0,00} & 0 & $\mathrm{~A}$ \\
\hline & & & 1 & $\mathrm{~B}$ \\
\hline & & & 2 & $\mathrm{BC}$ \\
\hline
\end{tabular}

*KW: test de Kruskal-Wallis; 0: ausencia de curvatura de cara; 1 : curvatura de cara $<10 \mathrm{~mm}$; 2: curvatura de cara entre 10-20 $\mathrm{mm} ; * *$ letras diferentes denotan diferencias significativas entre medianas. 
(X 0,0001$)$

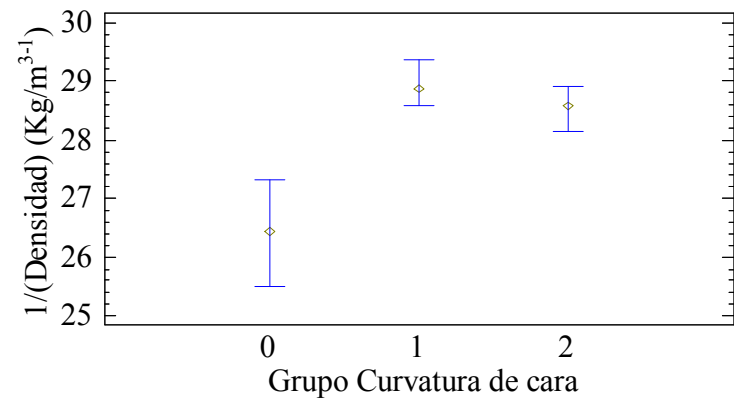

Figura 276. Gráfico de Medianas e IC 95\%: Densidad - "Grupo curvatura de cara".

De acuerdo con la significación del Test de Kruskal-Wallis y posterior análisis entre pares de medianas para evaluar entre cuales existían diferencias significativas, Tabla 129 y Figura 276, se puede concluir que existen diferencias significativas entre la mediana de 1/(Densidad) de la categoría 0 y de las categorías 1 y 2 , no hallándose diferencias significativas entre estas dos categorías.

\section{Curvatura de canto}

La prueba de Kruskal-Wallis para la comparación de medianas de 1/(Densidad) considerando las categorías de "Grupo curvatura de canto" se muestra en la Tabla 130 y Figura 277; debido a la baja representación de datos en la categoría 3, la misma no fue considerada en el análisis. La constatación de los supuestos estadísticos se muestra en Anejos 6.3.5.3.3.

Tabla 130. 1/(Densidad) - "Grupo curvatura de canto": análisis comparativo.

\begin{tabular}{|c|c|c|c|c|}
\hline $\mathbf{K} \mathbf{W}^{*}$ & Estadístico & P-Valor & Curvatura de canto & Grupos homogéneos** \\
\hline \multirow{3}{*}{$\begin{array}{c}\text { 1/Densidad - Grupo curvatura } \\
\text { de canto }\end{array}$} & \multirow{3}{*}{29,58} & \multirow{3}{*}{0,00} & 0 & $\mathrm{~A}$ \\
\hline & & & 1 & $\mathrm{~B}$ \\
\hline & & & 2 & $\mathrm{C}$ \\
\hline
\end{tabular}

*KW: Test de Kruskal-Wallis; 0: ausencia de curvatura de canto; 1: curvatura de canto $<10 \mathrm{~mm}$; 2: curvatura de canto entre 10-20 mm; **letras diferentes denotan diferencias significativas entre medianas.

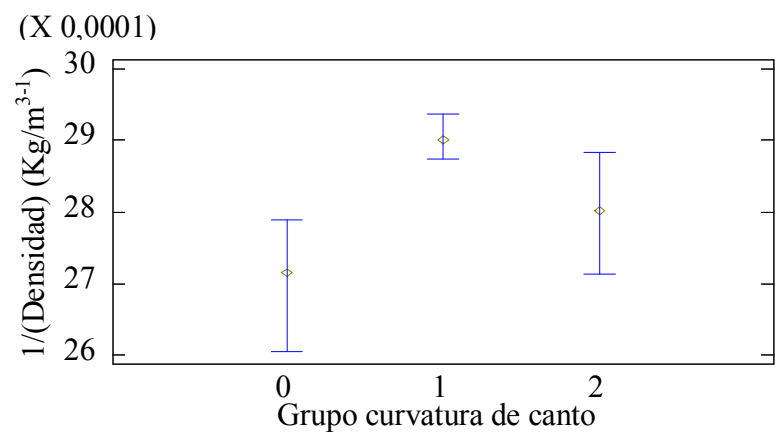

Figura 277. Gráfico de Medianas e IC 95\%: 1/(Densidad) - "Grupo curvatura de canto". 
Constatada la significancia estadística del test comparativo y realizado el análisis entre pares de medianas (Anejos 6.3.5.3.3), puede indicarse que la mediana de la variable 1/(Densidad) para la categoría 1 fue significativamente inferior que las otras dos categorías, que también se diferenciaron significativamente entre sí, Figura 277.

\section{$\underline{\text { Alabeos }}$}

La Tabla 131 muestra el resumen, Kruskal-Wallis, para la evaluación del comportamiento de la mediana de 1/(Densidad) para el "Grupo alabeo"; dada la baja representatividad de la categoría 3, ésta no fue considerada. En Anejos 6.3.5.3.3 se presenta la constatación estadística del análisis.

Tabla 131. 1/(Densidad) - "Grupo alabeo": análisis comparativo.

\begin{tabular}{|c|c|c|c|c|}
\hline $\mathbf{K W} *$ & Estadístico & P-Valor & Alabeo & Grupos homogéneos** \\
\hline \multirow{3}{*}{ 1/Densidad - Grupo alabeo } & \multirow{3}{*}{27,02} & \multirow{3}{*}{0,00} & 0 & $\mathrm{~A}$ \\
\hline & & & 1 & $\mathrm{~B}$ \\
\hline & & & 2 & $\mathrm{~B}$ \\
\hline
\end{tabular}

*KW: test de Kruskal-Wallis; 0: ausencia de alabeo; 1: alabeo $<6 \mathrm{~mm}$; 2: alabeo entre 6-12 mm; **letras diferentes denotan diferencias significativas entre medianas.

Dada la significación estadística, $\mathrm{P}$-valor $<0,05$, observada y la posterior comparación entre pares de medianas, pudo determinarse que en la categoría 0 es significativamente inferior que en las categorías 1 y 2, que no se diferenciaron entre sí, Figura 278.

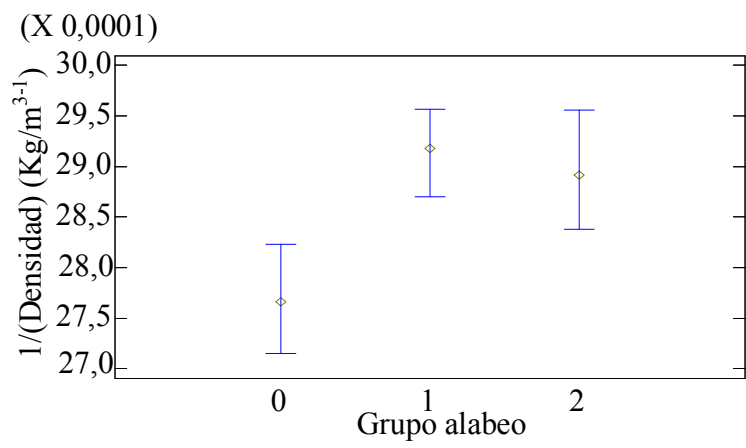

Figura 278. Gráfico de Medianas e IC 95\%: 1/(Densidad) - "Grupo alabeo".

De acuerdo con los resultados generales sobre la influencia de los factores de secado en la densidad, se puede inferir que el comportamiento de la madera puede verse influenciado por la presencia de madera juvenil y con anillos de crecimientos más anchos, con valores inferiores de densidad, siendo éstos considerados una de las causas más habituales de deformaciones de la madera mediante el proceso de secado (UNE 56544: 2011). Con la finalidad de resumir todos estos resultados, se presentan los modelos lineales generalizados de las variables predictoras: defectos naturales, de aserrado y de secado, sobre las variables caracterizadoras: MOE, MOR y densidad. 


\subsection{Influencia de los defectos (agrupados por tipo) en la predicción de las variables caracterizadoras}

En la Influencia de los defectos naturales, de aserrado y de secado en la predicción del MOE, MOR y densidad se muestra en la Tabla 132, Tabla 133 y Tabla 134 (Anejos 6.3.5.4.1; 6.3.5.4.2; 6.3.5.4.3).

\subsection{Defectos naturales}

Tabla 132. Influencia de los defectos naturales en la determinación de las variables caracterizadoras.

\begin{tabular}{|c|c|c|c|c|c|c|}
\hline \multirow{5}{*}{ Variables predictoras } & \multicolumn{6}{|c|}{ Variables caracterizadoras* } \\
\hline & \multicolumn{2}{|c|}{ LOG(MOE) } & \multicolumn{2}{|c|}{ MOR } & \multicolumn{2}{|c|}{ 1/(Densidad) } \\
\hline & $\begin{array}{c}R^{2} \text { ajust. } \\
(\%)\end{array}$ & P-valor & $\begin{array}{c}R^{2} \text { ajust. } \\
(\%)\end{array}$ & P-valor & $\begin{array}{c}R^{2} \text { ajust. } \\
(\%)\end{array}$ & P-valor \\
\hline & 12,15 & 0,00 & 11,69 & 0,00 & 9,36 & 0,00 \\
\hline & \multicolumn{2}{|c|}{ P-valor } & \multicolumn{2}{|c|}{ P-valor } & \multicolumn{2}{|c|}{ P-valor } \\
\hline Entrecasco & \multicolumn{2}{|c|}{0,15} & \multicolumn{2}{|c|}{0,91} & \multicolumn{2}{|c|}{0,11} \\
\hline Tamaño nudo cara & \multicolumn{2}{|c|}{0,52} & \multicolumn{2}{|c|}{0,36} & \multicolumn{2}{|c|}{0,93} \\
\hline Tamaño nudo canto & \multicolumn{2}{|c|}{0,55} & \multicolumn{2}{|c|}{0,49} & \multicolumn{2}{|c|}{0,01} \\
\hline Grupo desviación & \multicolumn{2}{|c|}{0,01} & \multicolumn{2}{|c|}{0,09} & \multicolumn{2}{|c|}{0,02} \\
\hline Anchura anillos & \multicolumn{2}{|c|}{0,42} & \multicolumn{2}{|c|}{0,66} & \multicolumn{2}{|c|}{0,29} \\
\hline Entrecasco*Tamaño nudo cara & \multicolumn{2}{|c|}{0,28} & \multicolumn{2}{|c|}{0,13} & \multicolumn{2}{|c|}{0,02} \\
\hline Entrecasco*Tamaño nudo canto & \multicolumn{2}{|c|}{0,13} & \multicolumn{2}{|c|}{0,03} & \multicolumn{2}{|c|}{0,16} \\
\hline Entrecasco*Grupo desviación & \multicolumn{2}{|c|}{0,09} & \multicolumn{2}{|c|}{0,07} & \multicolumn{2}{|c|}{0,32} \\
\hline Entrecasco*Anchura anillos & \multicolumn{2}{|c|}{0,01} & \multicolumn{2}{|c|}{0,08} & \multicolumn{2}{|c|}{0,09} \\
\hline Tamaño nudo cara*Tamaño nudo canto & \multicolumn{2}{|c|}{0,89} & \multicolumn{2}{|c|}{0,41} & & \\
\hline Tamaño nudo cara*Anchura anillos & 0 , & & & & & \\
\hline Tamaño nudo canto*Anchura anillos & 0 , & & & & & \\
\hline Grupo desviación*Anchura anillos & 0 , & & & & & \\
\hline
\end{tabular}

*LOG(MOE): logaritmo del módulo de elasticidad; MOR: módulo de rotura. 


\subsection{Defectos de aserrado}

Tabla 133. Influencia de los defectos de aserrado en la determinación de las variables caracterizadoras.

\begin{tabular}{|c|c|c|c|c|c|c|}
\hline \multirow[b]{3}{*}{ Variables predictoras } & \multicolumn{6}{|c|}{ Variables caracterizadoras } \\
\hline & \multicolumn{2}{|c|}{ LOG(MOE) } & \multicolumn{2}{|c|}{ MOR } & \multicolumn{2}{|c|}{ 1/Densidad } \\
\hline & $\begin{array}{c}\mathrm{R}^{2} \text { ajust. } \\
(\%)\end{array}$ & $\begin{array}{c}\text { P- } \\
\text { valor }\end{array}$ & $\begin{array}{c}R^{2} \text { ajust. } \\
(\%)\end{array}$ & $\begin{array}{c}\text { P- } \\
\text { valor }\end{array}$ & $\begin{array}{c}R^{2} \text { ajust. } \\
(\%)\end{array}$ & $\begin{array}{c}\text { P- } \\
\text { valor }\end{array}$ \\
\hline & 6,43 & 0,00 & 3,87 & 0,00 & 4,04 & 0,00 \\
\hline & \multicolumn{2}{|c|}{ P-valor } & \multicolumn{2}{|c|}{ P-valor } & \multicolumn{2}{|c|}{ P-valor } \\
\hline Médula & \multicolumn{2}{|c|}{0,02} & \multicolumn{2}{|c|}{0,00} & \multicolumn{2}{|c|}{0,29} \\
\hline Grupo anchura gema & \multicolumn{2}{|c|}{0,81} & \multicolumn{2}{|c|}{0,90} & \multicolumn{2}{|c|}{0,09} \\
\hline Grupo longitud gema & \multicolumn{2}{|c|}{0,93} & \multicolumn{2}{|c|}{0,17} & \multicolumn{2}{|c|}{0,03} \\
\hline Grupo anchura gema*Grupo longitud gema & \multicolumn{2}{|c|}{0,22} & \multicolumn{2}{|c|}{0,26} & \multicolumn{2}{|c|}{0,02} \\
\hline
\end{tabular}

*LOG(MOE): logaritmo del módulo de elasticidad; MOR: módulo de rotura.

\subsection{Defectos de secado}

Tabla 134. Influencia de los defectos de secado en la determinación de las variables caracterizadoras.

\begin{tabular}{|c|c|c|c|c|c|c|}
\hline \multirow{3}{*}{ Variables predictoras } & \multicolumn{6}{|c|}{ Variables caracterizadoras } \\
\hline & \multicolumn{2}{|c|}{ LOG(MOE) } & \multicolumn{2}{|c|}{ MOR } & \multicolumn{2}{|c|}{ 1/Densidad } \\
\hline & $\begin{array}{l}\mathbf{R}^{2} \text { ajust. } \\
(\%)\end{array}$ & $\begin{array}{c}\text { P- } \\
\text { valor }\end{array}$ & $\begin{array}{c}R^{2} \text { ajust. } \\
(\%)\end{array}$ & $\begin{array}{c}\text { P- } \\
\text { valor }\end{array}$ & $\begin{array}{c}R^{2} \text { ajust. } \\
(\%)\end{array}$ & $\begin{array}{c}\text { P- } \\
\text { valor }\end{array}$ \\
\hline & 5,96 & 0,00 & 3,87 & 0,00 & 5,12 & 0,00 \\
\hline & \multicolumn{2}{|c|}{ P-valor } & \multicolumn{2}{|c|}{ P-valor } & \multicolumn{2}{|c|}{ P-valor } \\
\hline Grupo curvatura cara & \multicolumn{2}{|c|}{0,32} & \multicolumn{2}{|c|}{0,94} & \multicolumn{2}{|c|}{0,49} \\
\hline Grupo curvatura canto & \multicolumn{2}{|c|}{0,11} & \multicolumn{2}{|c|}{0,53} & \multicolumn{2}{|c|}{0,65} \\
\hline Grupo alabeo & \multicolumn{2}{|c|}{0,00} & \multicolumn{2}{|c|}{0,02} & \multicolumn{2}{|c|}{0,17} \\
\hline $\begin{array}{c}\text { Grupo curvatura cara* Grupo curvatura } \\
\text { canto }\end{array}$ & \multicolumn{2}{|c|}{0,05} & \multicolumn{2}{|c|}{0,03} & \multicolumn{2}{|c|}{0,55} \\
\hline Grupo curvatura cara*Grupo alabeo & \multicolumn{2}{|c|}{0,30} & \multicolumn{2}{|c|}{0,25} & \multicolumn{2}{|c|}{0,81} \\
\hline Grupo curvatura canto*Grupo alabeo & \multicolumn{2}{|c|}{0,03} & \multicolumn{2}{|c|}{0,21} & \multicolumn{2}{|c|}{0,54} \\
\hline
\end{tabular}

*LOG(MOE): logaritmo del módulo de elasticidad; MOR: módulo de rotura.

En términos generales, se puede destacar la escasa influencia ( $\mathrm{R}^{2}$ ajustado) de los defectos visuales en las variables caracterizadoras. En este sentido, los defectos naturales influyentes sólo logran explicar el 12,15\% de la variabilidad de LOG(MOE), el 11,66\% de la variabilidad del MOR y el 9,36\% de la variabilidad de 1/(Densidad), Tabla 132. En cuanto a los defectos de aserrado, los factores influyentes sólo logran explicar el 6,43\% de la variabilidad del LOG(MOE), el 3,87\% de la variabilidad del MOR y el 4,04\% de la variabilidad de 1/(Densidad), Tabla 133. 
Por último, los defectos de secado sólo logran explicar un 5,96\% de la variabilidad del LOG(MOE), un 3,87\% de la variabilidad del MOR y un 5,12\% de la variabilidad de 1/(Densidad), Tabla 134.

A continuación se plantea la incorporación de las técnicas de ensayo no destructivas a fin de evaluar su capacidad predictiva en las variables caracterizadoras estudiadas.

\subsection{Influencia de los parámetros no destructivos en la predicción de las variables caracterizadoras}

Los resultados del modelo lineal generalizado, considerando las variables no destructivas obtenidas por vibraciones longitudinales inducidas y por ultrasonidos para predecir las variables caracterizadoras, se muestran en la Tabla 135, Tabla 136 y Tabla 137 (Anejos 6.3.5.5).

Tabla 135. Influencia de los parámetros NDT (Vibraciones inducidas) en las variables caracterizadoras.

\begin{tabular}{|c|c|c|c|c|c|c|}
\hline \multirow{4}{*}{ Variables predictoras } & \multicolumn{6}{|c|}{ Variables caracterizadoras } \\
\hline & \multicolumn{2}{|c|}{ LOG(MOE) } & \multicolumn{2}{|c|}{ MOR } & \multicolumn{2}{|c|}{ 1/(Densidad) } \\
\hline & $\begin{array}{c}\mathrm{R}^{2} \text { ajust. } \\
(\%)\end{array}$ & P-valor & $\begin{array}{c}\mathrm{R}^{2} \text { ajust. } \\
(\%)\end{array}$ & P-valor & $\begin{array}{c}\mathrm{R}^{2} \text { ajust. } \\
(\%)\end{array}$ & P-valor \\
\hline & 35,85 & 0,00 & 28,86 & 0,00 & 0,42 & 0,06 \\
\hline Vibraciones inducidas & \multicolumn{2}{|c|}{ P-valor } & \multicolumn{2}{|c|}{ P-valor } & \multicolumn{2}{|c|}{ P-valor } \\
\hline Frecuencia & \multicolumn{2}{|c|}{0,00} & \multicolumn{2}{|c|}{0,00} & \multicolumn{2}{|c|}{$0,06^{*}$} \\
\hline 1/(Densidad) & \multicolumn{2}{|c|}{0,00} & \multicolumn{2}{|c|}{0,16} & \multicolumn{2}{|c|}{-} \\
\hline Frecuencia*1/(Densidad) & \multicolumn{2}{|c|}{$0,00 *$} & \multicolumn{2}{|c|}{$0,05^{*}$} & \multicolumn{2}{|c|}{-} \\
\hline
\end{tabular}

*Combinación de variables predictoras utilizadas en el ajuste del modelo.

Tabla 136. Influencia de los parámetros NDT (Ultrasonidos) en las variables caracterizadoras.

\begin{tabular}{|c|c|c|c|c|c|c|}
\hline \multirow{4}{*}{ Variables predictoras } & \multicolumn{6}{|c|}{ Variables caracterizadoras } \\
\hline & \multicolumn{2}{|c|}{ LOG(MOE) } & \multicolumn{2}{|c|}{ MOR } & \multicolumn{2}{|c|}{ 1/(Densidad) } \\
\hline & $\begin{array}{c}\mathrm{R}^{2} \text { ajust. } \\
(\%)\end{array}$ & P-valor & $\begin{array}{c}\mathrm{R}^{2} \text { ajust. } \\
(\%)\end{array}$ & P-valor & $\begin{array}{c}\mathrm{R}^{2} \text { ajust. } \\
(\%)\end{array}$ & P-valor \\
\hline & 38,79 & 0,00 & 9,49 & 0,00 & 0,31 & 0,05 \\
\hline$\underline{\text { Ultrasonidos }}$ & \multicolumn{2}{|c|}{ P-valor } & \multicolumn{2}{|c|}{ P-valor } & \multicolumn{2}{|c|}{ P-valor } \\
\hline Velocidad & \multicolumn{2}{|c|}{0,00} & \multicolumn{2}{|c|}{0,00} & \multicolumn{2}{|c|}{$0,05^{*}$} \\
\hline 1/(Densidad) & \multicolumn{2}{|c|}{0,00} & \multicolumn{2}{|c|}{0,03} & \multicolumn{2}{|c|}{-} \\
\hline Velocidad*1/(Densidad) & \multicolumn{2}{|c|}{$0,00^{*}$} & \multicolumn{2}{|c|}{$0,01 *$} & \multicolumn{2}{|c|}{-} \\
\hline
\end{tabular}

*Combinación de variables predictoras utilizadas en el ajuste del modelo. 
Tabla 137. Influencia del $E_{\mathrm{d}}$ en las variables caracterizadoras.

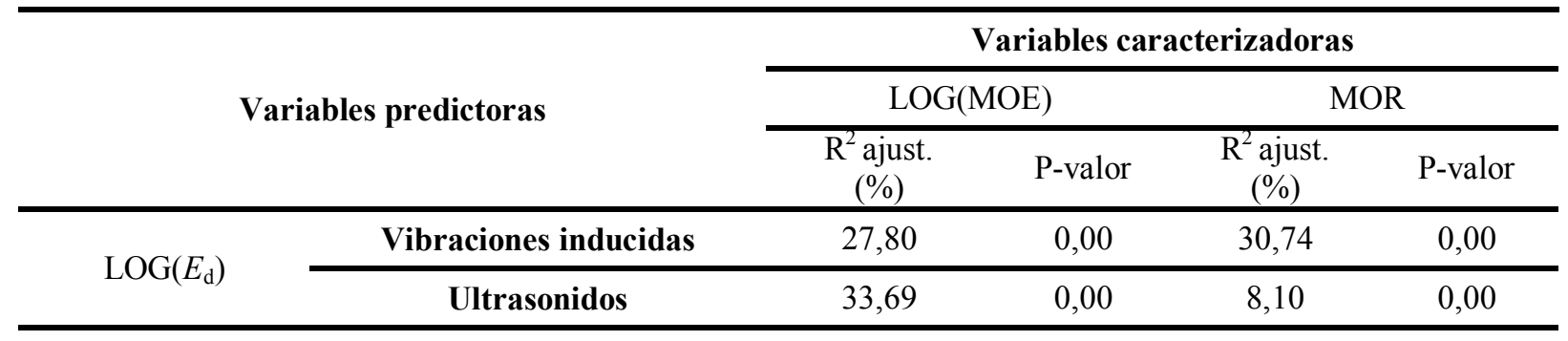

De este análisis se desprende que, en términos generales, mediante las NDT empleadas se ha logrado mejorar la explicación de las variables caracterizadoras, con respecto a la explicación lograda por las singularidades naturales, de aserrado y de secado.

A este respecto, puede indicarse que ambas metodologías presentan comportamientos similares en la estimación de la variable elástica, LOG(MOE), mientras que la técnica de vibraciones inducidas ha logrado explicar más eficientemente el comportamiento del MOR. La explicación de la variable densidad mediante NDT no ha sido significativa en el modelo.

Tomando en consideración estos resultados junto con los resultados obtenidos mediante las singularidades consideradas en las normas de clasificación visual, Tabla 132, Tabla 133 y Tabla 134, puede indicarse que la explicación de la variable caracterizadora LOG(MOE) ha mejorado utilizando las dos metodologías no destructivas. Para el caso del MOR, la explicación ha mejorado con la técnica de vibraciones inducidas, mientras que la técnica de ultrasonidos, si bien ha tenido relación significativa, no ha logrado mejorar la explicación lograda con las variables visuales naturales.

\subsection{Piezas macizas estructurales: consideraciones generales}

Tal como se apreció en los resultados de los ensayos en piezas de tamaño semi-estructural, el análisis en piezas de tamaño estructural sirvió para corroborar esos resultados.

En este sentido, de la evaluación realizada puede concluirse que las normas de clasificación visual empleadas, presentan un rendimiento clasificatorio muy exigente y una relación con las características elasto-resistentes escasa; resultados avalados por la pequeña explicación de las variables MOE, MOR y densidad lograda a partir de las diferentes singularidades evaluadas. Asimismo, un factor no tenido en cuenta en las normas de clasificación visual y que aparenta tener una marcada influencia en estos resultados es el "Tipo de corte" empleado en las piezas aserradas, principalmente relacionado con la presencia de gemas, pero con estrecha relación con otros factores como la mayor proporción de madera madura. Para constatar esta influencia se presenta un resumen gráfico de los análisis realizados; los supuestos estadísticos y el detalle del análisis comparativo de estos resultados, se presentan en Anejos 6.4. 

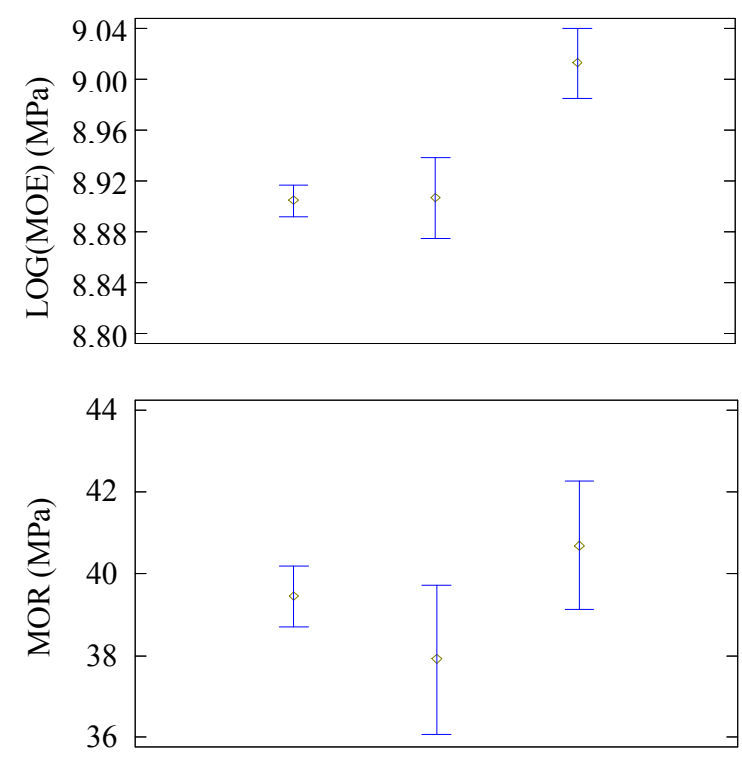

(X 0,0001$)$

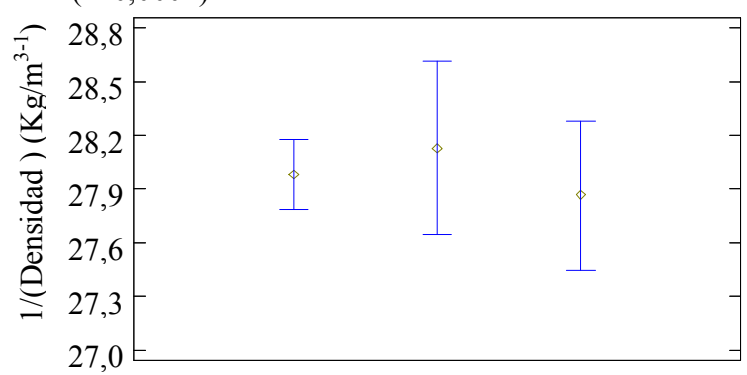

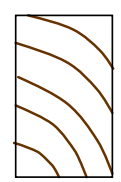

Mezcla

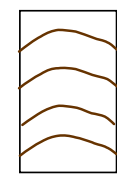

Radial Tangencial

Figura 279. LOG(MOE), MOR y 1/Densidad - Tipo de corte. Chopo (España).

El comportamiento del LOG(MOE) con los distintos "Tipos de corte", Figura 279, indica que dicha variable es significativamente superior cuando se trabaja con madera de corte tangencial, mientras que no existe diferencia de comportamiento cuando se trabaja con madera en corte radial o mixto. Asimismo, si bien los valores de MOR no se diferenciaron estadísticamente, se puede observar que los valores obtenidos de piezas con corte tangencial, presentan una tendencia creciente con respecto a los otros cortes. En cuanto a los valores de densidad, no puede vislumbrarse un claro comportamiento ante los diferentes tipos de cortes analizados.

Tal como se expresó anteriormente, esto podría tener explicación en que el corte tangencial neto es el que presenta mayor proporción de gemas o bien, es donde las gemas se presentan con mayor tamaño (tanto anchura como longitud), coincidentemente con la mayor proporción de madera madura en las piezas consideradas. Asimismo, a medida que nos alejamos de la zona periférica de la troza, la 
proporción de madera con corte radial o mixto aumenta coincidentemente también con una mayor proporción de madera juvenil.

Por último, en cuanto a la predicción de las variables caracterizadoras a partir de las metodologías no destructivas, puede concluirse que estos métodos resultan más promisorios que las singularidades incluidas en las normas de clasificación visual.

\subsection{Caracterización de madera maciza: consideraciones finales.}

En primer término, cabe destacar que la densidad, junto con la resistencia y el módulo de elasticidad longitudinal a flexión estática, forman parte del conjunto de propiedades denominadas "rectoras" y son las de obligado ensayo ya que permiten asignar los resultados a las clases resistentes según la norma EN 338.

En este sentido, y considerando los valores medios de densidad puede indicarse que los mismos fueron estadísticamente similares considerando el material de pequeñas dimensiones y el material obtenido de las piezas de tamaño semi-estructural, mientras que la densidad obtenida según la norma EN 408:2011+A1:2012, en el material de procedencia española, fue significativamente inferior a las otras dos densidades mencionadas. Esto podría corresponderse con que al aumentar el tamaño de la pieza, haya coincidido una mayor proporción de madera juvenil.

En cuanto a la elasticidad, el comportamiento fue significativamente inferior en probetas de pequeñas dimensiones y libre de defectos, mientras que en las piezas semi-estructurales y estructurales el comportamiento puede aceptarse como estadísticamente similar.

Sin embargo, la resistencia a rotura en flexión, expresada a través del MOR, fue estadísticamente diferente en los tres casos, aunque con valores superiores en el material de pequeñas dimensiones y libre de defectos, seguido por el material semi-estructural y por último el estructural. Una posible explicación de ello se encuentra en la relación altura de la probeta/distancia entre apoyos ya que es distinta en ambos ensayos: 1/12 con probetas de pequeñas dimensiones y 1/18 con piezas semi - estructurales y estructurales; cumpliéndose, además, que cuanto más grande es la pieza, existen más puntos donde puede fallar, lo cual implica que en piezas más grandes, la rotura se produzca antes, con valores inferiores.

Un resumen gráfico de estos resultados detallados por tipo de piezas: pequeñas, $\mathrm{P}$, semiestructurales, S-E, y estructurales, E, se muestra en la Figura 280 y en la Figura 281, para el material procedente de España y Argentina, respectivamente. 

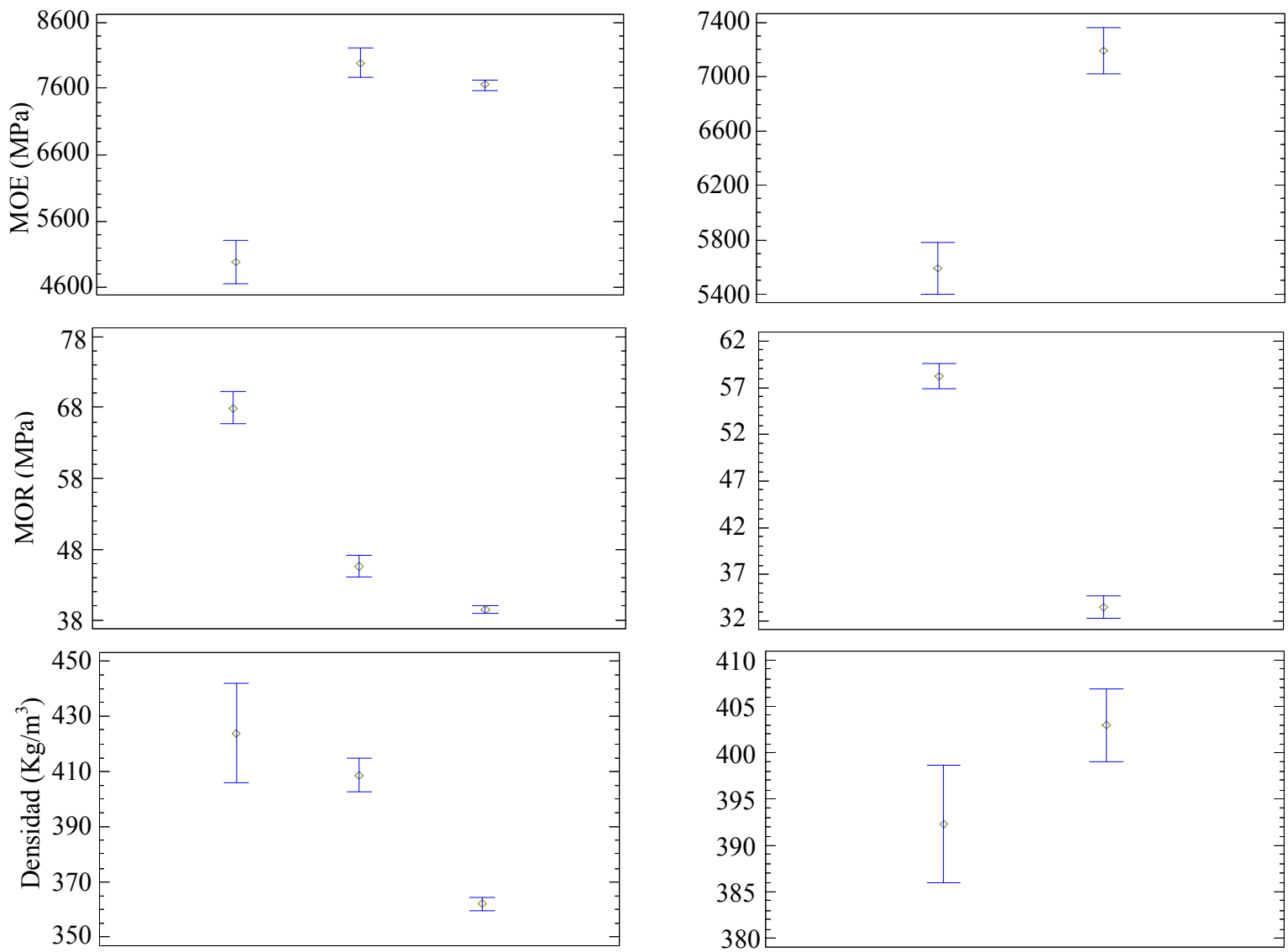

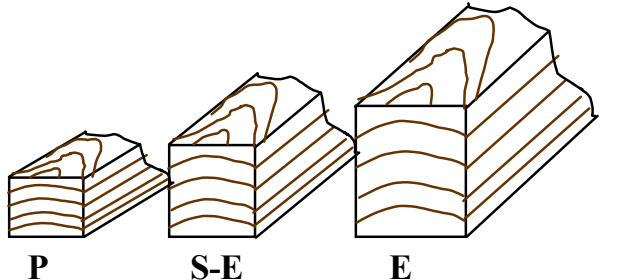

Figura 280. MOE, MOR y Densidad - Tamaño de pieza. Chopo (España).

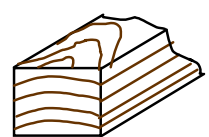

$\mathbf{P}$

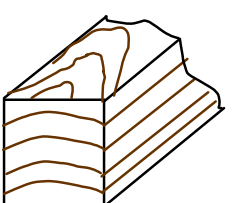

S-E
Figura 281. MOE, MOR y Densidad - Tamaño de pieza. Chopo (Argentina).

Asimismo, la determinación de los cambios dimensionales, permiten establecer la estabilidad de la madera en servicio. En este sentido, acorde con estos valores hallados, era factible intuir la presencia de las deformaciones halladas en las piezas aserradas, ocasionadas posiblemente, por un proceso de secado inadecuado junto con malas prácticas de aserrado.

Los bajos valores de dureza, en estrecha vinculación con los bajos valores de densidad obtenidos, plantean una limitación en las aplicaciones de uso que requieran de esta característica.

La baja resistencia al deterioro biológico, deja clara la necesidad de considerar con precaución su uso en situaciones que resulten de alto riesgo, más aún si se la pretende utilizar sin ningún método profiláctico, dado que su uso ha quedado limitado a usos de clase 1 y 2: uso interior, ambiente seco -o exterior bajo cubierta, al resguardo de la intemperie-, y sin contacto con el suelo. A su vez, si bien su 
clase de durabilidad es la misma que para otros clones y especies del género, su inclusión en la normativa EN 350-2:1995 le otorgaría mayor identidad a este clon coincidentemente con la importancia que acompaña a su amplia distribución.

En cuanto a las normas de clasificación visual empleadas, parece clara la necesidad de establecer grados clasificatorios más acordes al material aserrado hallado en el mercado español, considerando, además, otros factores, como el tipo de corte, dentro de ellos.

Las metodologías de ensayo no destructivo demuestran ser una alternativa viable de mejoras a las técnicas visuales empleadas, presentando valores de predicción aceptables considerando que se trata de un material biológico, heterogéneo y anisótropo.

Si bien por cuestiones de infraestructura, los ensayos estructurales no pudieron replicarse en el material de procedencia argentina, en base a los demás resultados hallados en probetas de pequeñas dimensiones y en piezas de tamaño semi-estructural, puede intuirse que la procedencia no ha sido la máxima responsable de diferencias entre los resultados hallados. Esto nos sirve para concluir que los resultados no replicados en material de Argentina, principalmente todos aquellos relacionados al material estructural, podrían corresponderse con el material procedente de España.

Salvando las influencias de los métodos de ensayo empleados y de las procedencias del material, la comparación de resultados usando probetas de pequeñas dimensiones y piezas de tamaño semi-estructural y estructural, nos permite apreciar la influencia real que los "defectos" procedentes de causas naturales, de aserrado o secado del material, tienen en los valores elasto-resistentes de la madera y nos permite deducir, a su vez, la influencia que la selvicultura aplicada puede tener en los mismos.

A continuación se presentan una líneas de mejoras tecnológicas que hacen al mejor uso del material -Populus euramericana I-214- estudiado. 


\section{SECCIÓN II: Mejoras tecnológicas}

\subsection{Probetas de pequeñas dimensiones y libres de defectos.}

\subsubsection{Termo-modificación}

\subsubsection{Propiedades mecánicas}

\subsection{Dureza superficial}

Tal como se mencionó en Materiales y métodos, estos ensayos se realizaron sobre el material de procedencia española.

\section{Análisis descriptivo: dureza en material termo-modificado}

El detalle descriptivo de cada tratamiento se muestra en la Tabla 138 (ver Anejos 7.1.1.1.1).

Tabla 138. Diseño experimental en bloques: dureza.

\begin{tabular}{|c|c|c|c|}
\hline \multirow[b]{2}{*}{ Tratamiento } & \multirow[b]{2}{*}{$\mathrm{n}^{*}$} & \multicolumn{2}{|c|}{ Dureza } \\
\hline & & $\begin{array}{c}\text { Media (MPa) } \\
\text { (CV\%)* }\end{array}$ & $\begin{array}{l}\text { Mín. - Máx. } \\
\text { (IQR)* }\end{array}$ \\
\hline Testigo $(\mathrm{T})^{*}$ & 320 & $\begin{array}{c}4,45 \\
(18,03)\end{array}$ & $\begin{array}{c}2,49-6,52 \\
(1,14)\end{array}$ \\
\hline TM 80-45 & 20 & $\begin{array}{c}3,72 \\
(31,35)\end{array}$ & $\begin{array}{c}1,52-5,49 \\
(1,39)\end{array}$ \\
\hline TM 80-90 & 20 & $\begin{array}{c}4,00 \\
(20,08)\end{array}$ & $\begin{array}{c}1,86-5,43 \\
(0,78)\end{array}$ \\
\hline TM 80-135 & 20 & $\begin{array}{c}3,60 \\
(30,67)\end{array}$ & $\begin{array}{c}1,69-6,11 \\
(1,44)\end{array}$ \\
\hline TM 80-180 & 20 & $\begin{array}{c}3,58 \\
(29,98)\end{array}$ & $\begin{array}{c}1,48-5,27 \\
(1,30)\end{array}$ \\
\hline TM 120-45 & 20 & $\begin{array}{c}3,78 \\
(37,56)\end{array}$ & $\begin{array}{c}1,42-5,74 \\
(2,54)\end{array}$ \\
\hline TM $120-90$ & 20 & $\begin{array}{c}4,21 \\
(23,98)\end{array}$ & $\begin{array}{c}2,32-6,57 \\
(1,33)\end{array}$ \\
\hline TM 120-135 & 20 & $\begin{array}{c}4,08 \\
(30,47)\end{array}$ & $\begin{array}{c}2,21-6,24 \\
(1,83)\end{array}$ \\
\hline TM $120-180$ & 20 & $\begin{array}{c}4,53 \\
(20,82)\end{array}$ & $\begin{array}{c}2,3-6,07 \\
(1,10)\end{array}$ \\
\hline TM 160-45 & 20 & $\begin{array}{c}4,52 \\
(24,01)\end{array}$ & $\begin{array}{c}1,88-6,33 \\
(0,69)\end{array}$ \\
\hline TM 160-90 & 20 & $\begin{array}{c}4,74 \\
(18,69)\end{array}$ & $\begin{array}{c}3,24-5,86 \\
(1,58)\end{array}$ \\
\hline TM 160-135 & 20 & $\begin{array}{c}5,14 \\
(14,00)\end{array}$ & $\begin{array}{c}3,43-6,95 \\
(0,63)\end{array}$ \\
\hline TM 160-180 & 20 & $\begin{array}{c}4,59 \\
(20,79)\end{array}$ & $\begin{array}{c}2,95-6,45 \\
(1,39)\end{array}$ \\
\hline TM 200-45 & 20 & $\begin{array}{c}4,69 \\
(22,16)\end{array}$ & $\begin{array}{c}3,04-6,6 \\
(1,78)\end{array}$ \\
\hline TM 200-90 & 20 & $\begin{array}{c}4,31 \\
(24,48)\end{array}$ & $\begin{array}{c}2,8-6,0 \\
(2,06)\end{array}$ \\
\hline TM 200-135 & 20 & $\begin{array}{c}4,56 \\
(18,85)\end{array}$ & $\begin{array}{c}2,68-5,77 \\
(1,24)\end{array}$ \\
\hline TM 200-180 & 20 & $\begin{array}{c}4,02 \\
(19,52)\end{array}$ & $\begin{array}{c}2,75-5,23 \\
(1,31)\end{array}$ \\
\hline
\end{tabular}

*T: material sin termo-modificar: testigo; TM: material termo-modificado (los números indican combinación temperaturatiempo, respectivamente); n: número de individuos; CV: coeficiente de variación, en \%; IQR: recorrido intercuartílico. 


\section{Análisis comparativo: dureza material testigo y termo-modificado}

Mediante análisis multifactorial se evaluó la influencia de los factores tiempo y temperatura en la determinación de la dureza, Tabla 139.

Tabla 139. Dureza por $\mathrm{T}^{\circ}$ y Tiempo: análisis multifactorial.

\begin{tabular}{ccc}
\hline Efectos principales & Razón-F & P-valor \\
\hline $\mathrm{T}^{\circ}$ & 13,88 & 0,00 \\
\hline Tiempo & 0,59 & 0,63 \\
\hline
\end{tabular}

*Gl: grados de libertad; $\mathrm{T}^{\circ}$ : temperatura; P-valor $<0,05$ indica efecto estadísticamente significativo en el valor de la dureza.

Según lo indicado en la Tabla 139, la temperatura es el único factor que influye estadísticamente en los valores de dureza. De acuerdo con esto, se realizó el test HSD de Tukey a fin de evaluar entre qué temperaturas se evidenciaron dichas diferencias, Tabla 140; Figura 282.

Tabla 140. Dureza - temperaturas: análisis comparativo.

\begin{tabular}{|c|c|c|c|c|c|}
\hline Madera & $\mathrm{n}^{*}$ & Temperatura & Dureza & $\mathrm{MPa})$ & \\
\hline \multirow{5}{*}{ P. euramericana I-214 } & 320 & $\mathrm{~T}^{*}$ & 4,45 & A & \\
\hline & 80 & 80 & 3,72 & $\mathrm{~B}$ & \\
\hline & 80 & 120 & 4,15 & $\mathrm{C}$ & $\mathrm{F}$ \\
\hline & 80 & 160 & 4,75 & \multicolumn{2}{|c|}{$\mathrm{D}$} \\
\hline & 80 & 200 & 4,40 & $\mathrm{~A}$ & $\mathrm{~F}$ \\
\hline
\end{tabular}

*n: número de individuos; T: testigo sin termotratamiento; letras diferentes denotan diferencias significativas, Tukey HSD $(\mathrm{P}<0,05)$.

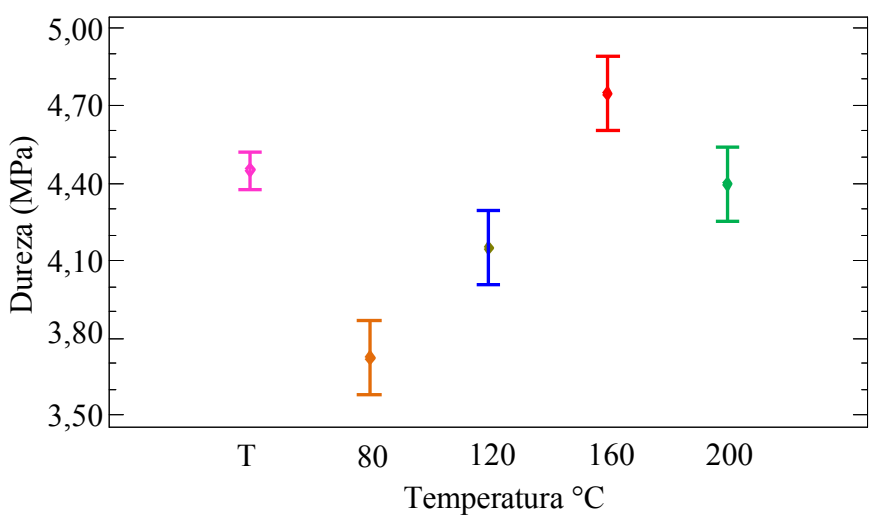

Figura 282. Variación dureza por tiempo a diferentes temperaturas.

Tal como se indica en la Tabla 140 y en la Figura 282, en términos generales existen diferencias significativas entre las medias obtenidas en cada temperatura, evidenciándose un aumento significativo de la dureza a $160^{\circ} \mathrm{C}$. En base a ello, interesa saber si en cada temperatura, el tiempo tiene influencia, lo cual puede verse reflejado en la Figura 283. 


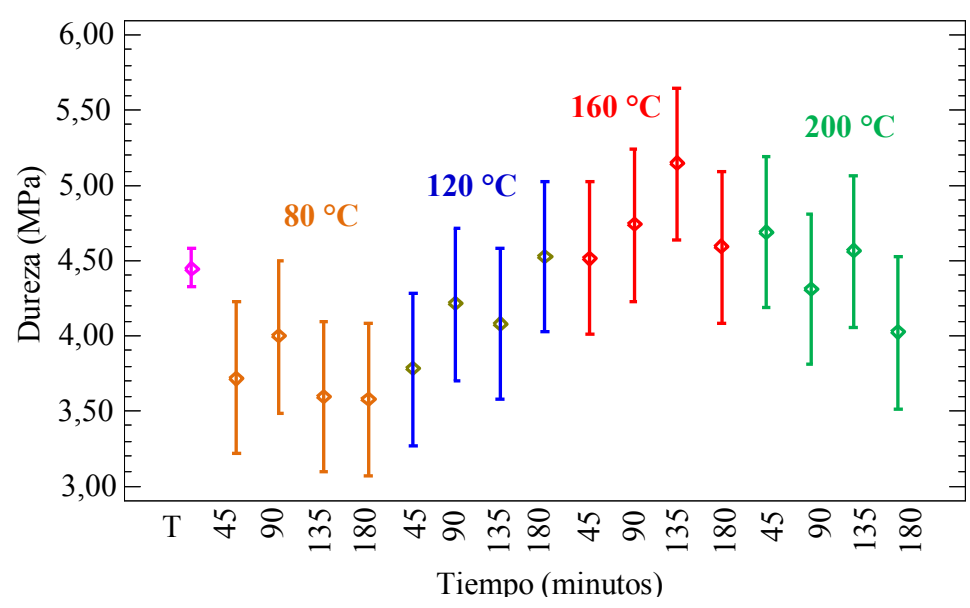

Figura 283. Dureza por tratamiento.

De acuerdo al análisis comparativo, considerando la temperatura de $160^{\circ} \mathrm{C}$, puede observarse que el tiempo óptimo de exposición se corresponde con 135 minutos, a partir del cual la dureza va en detrimento, lo que podría corresponderse con la transición del estado vítreo al elástico de la lignina, el cual se encuentra entre $130-140{ }^{\circ} \mathrm{C}$ cuando la madera se encuentra exenta de humedad. Con temperaturas superiores a los $160^{\circ} \mathrm{C}$ comienzan a producirse cambios en la estructura amorfa de la celulosa, lo cual va en detrimento de los valores de dureza, en correspondencia con lo hallado en esta investigación (Kocaefe, et al., 2008)

\subsection{Durabilidad natural}

De acuerdo con los resultados hallados en torno a la baja resistencia a la degradación causada por hongos xilófagos y termitas en la madera de P. euramericana I-214, en esta sección se desarrolla la alternativa de termo-modificación para evaluar la mejora dicha degradación.

Dada la homogeneidad de los resultados obtenidos mediante los ensayos de durabilidad en el material de ambas procedencias (apartado 4.1.2.4), esta evaluación se realizó únicamente en material de procedencia española.

\subsection{Determinación de la durabilidad frente a hongos basidiomicetos xilófagos}

\section{Análisis descriptivo: material termo-modificado expuesto a pudrición blanca}

A continuación se expone el análisis sobre las pérdidas de peso, Pp (\%), ocasionadas en el material termo-modificado expuesto a Trametes versicolor. 
Tabla 141. Deterioro causado por $T$. versicolor: diseño experimental en bloques.

\begin{tabular}{|c|c|c|c|}
\hline \multirow[b]{2}{*}{ Tratamiento* } & \multirow[b]{2}{*}{$n^{*}$} & \multicolumn{2}{|c|}{ Pérdida de peso } \\
\hline & & $\begin{array}{c}\text { Media (\%) } \\
(\mathrm{CV} \%)^{*}\end{array}$ & $\begin{array}{l}\text { Mín. - Máx. } \\
\text { (IQR)* }\end{array}$ \\
\hline Testigo (T) & 64 & $\begin{array}{c}52,83 \\
(25,14)\end{array}$ & $\begin{array}{c}25,11-80,86 \\
(20,63)\end{array}$ \\
\hline TM 80-45 & 4 & $\begin{array}{c}8,15 \\
(28,06)\end{array}$ & $\begin{array}{c}5,19-10,17 \\
(3,59)\end{array}$ \\
\hline TM 80-90 & 3 & $\begin{array}{c}21,92 \\
(32,83)\end{array}$ & $\begin{array}{c}14,08-28,23 \\
(14,15)\end{array}$ \\
\hline TM 80-135 & 4 & $\begin{array}{c}6,59 \\
(66,50)\end{array}$ & $\begin{array}{c}2,70-11,19 \\
(7,49)\end{array}$ \\
\hline TM 80-180 & 4 & $\begin{array}{c}4,59 \\
(13,10)\end{array}$ & $\begin{array}{c}4,07-5,17 \\
(1,04)\end{array}$ \\
\hline TM 120-45 & 4 & $\begin{array}{c}5,11 \\
(58,08)\end{array}$ & $\begin{array}{c}2,96-9,46 \\
(3,66)\end{array}$ \\
\hline TM 120-90 & 4 & $\begin{array}{c}2,02 \\
(27,15)\end{array}$ & $\begin{array}{c}1,57-2,82 \\
(0,64)\end{array}$ \\
\hline TM 120-135 & 3 & $\begin{array}{c}1,04 \\
(33,81)\end{array}$ & $\begin{array}{c}0,80-1,44 \\
(0,64)\end{array}$ \\
\hline TM 120-180 & 4 & $\begin{array}{c}15,77 \\
(23,98)\end{array}$ & $\begin{array}{c}10,89-19,84 \\
(5,53)\end{array}$ \\
\hline TM 160-45 & 4 & $\begin{array}{l}88,40 \\
(7,55)\end{array}$ & $\begin{array}{c}80,14-95,50 \\
(10,34)\end{array}$ \\
\hline TM 160-90 & 4 & $\begin{array}{l}83,24 \\
(3,27)\end{array}$ & $\begin{array}{c}79,54-86,04 \\
(3,66)\end{array}$ \\
\hline TM 160-135 & 4 & $\begin{array}{l}83,59 \\
(7,93)\end{array}$ & $\begin{array}{c}73,90-87,94 \\
(8,54)\end{array}$ \\
\hline TM 160-180 & 4 & $\begin{array}{c}75,37 \\
(10,90)\end{array}$ & $\begin{array}{c}67,82-84,47 \\
(13,86)\end{array}$ \\
\hline TM 200-45 & 4 & $\begin{array}{c}67,38 \\
(29,25)\end{array}$ & $\begin{array}{c}50,19-84,91 \\
(34,13)\end{array}$ \\
\hline TM 200-90 & 4 & $\begin{array}{c}66,58 \\
(33,36)\end{array}$ & $\begin{array}{c}44,24-92,92 \\
(36,15)\end{array}$ \\
\hline TM 200-135 & 4 & $\begin{array}{c}47,96 \\
(37,28)\end{array}$ & $\begin{array}{c}28,98-69,61 \\
(28,28)\end{array}$ \\
\hline TM 200-180 & 3 & $\begin{array}{l}59,50 \\
(2,47)\end{array}$ & $\begin{array}{c}58,13-61,06 \\
(2,93)\end{array}$ \\
\hline
\end{tabular}

*T: material sin termo-modificar: testigo; TM: material termo-modificado (los números indican combinación temperaturatiempo, respectivamente); n: número de individuos; CV: coeficiente de variación, en \%; IQR: recorrido intercuartílico.

La dispersión y simetría de los datos de cada tratamiento se muestra en la Figura 284; en Anejos 7.1.1.1.2.1 se amplía el análisis descriptivo. 


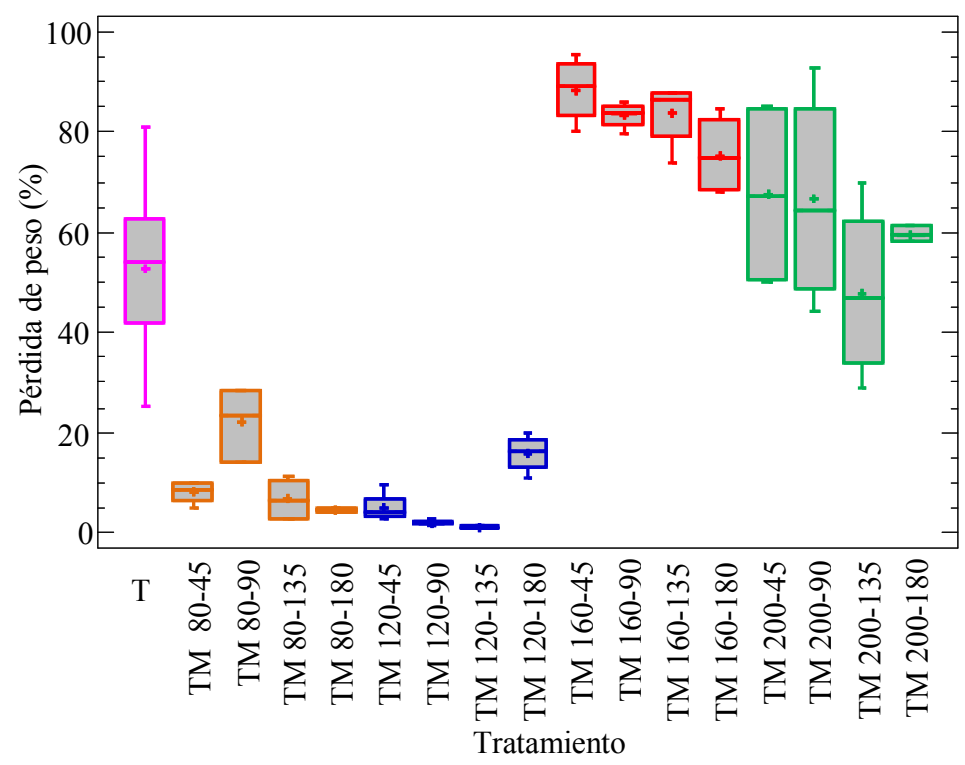

Figura 284. Gráfico de caja y bigotes: Pp (\%) - tratamientos.

En la Figura 284 se aprecian dos grupos definidos: un grupo correspondiente a las temperaturas de $80^{\circ}$ y $120^{\circ} \mathrm{C}$ y otro grupo representado por las temperaturas de $160^{\circ}$ y $200^{\circ} \mathrm{C}$, todas con sus respectivos tiempos.

\section{Análisis comparativo: material testigo y termo-modificado expuesto a pudrición blanca}

Atendiendo a la Figura 284 en la que se aprecian dos grupos bien diferenciados, se realizó un análisis multifactorial a fin de evaluar dicho comportamiento, Tabla 142.

Tabla 142. Pp (\%) por temperatura - tiempo: análisis multifactorial.

\begin{tabular}{ccc}
\hline & Pérdida de peso (\%) por tratamiento \\
\hline Efectos principales & Razón-F & P-valor \\
\hline Temperatura & 193,58 & 0,00 \\
\hline Tiempo & 1,83 & 0,15 \\
\hline
\end{tabular}

Según este análisis, la temperatura es el único factor influyente en la resistencia a la degradación por agentes de pudrición blanca. Por ello, se realizó el test de rangos múltiples de Tukey para evaluar entre qué temperaturas se establecían esas diferencias, Tabla 143 y Figura 285. 
Tabla 143. Pp (\%) por temperatura - tiempo: test de Tukey HSD.

\begin{tabular}{cccc}
\hline $\mathrm{n}^{*}$ & Temperatura & Pp (\%) & Grupos homogéneos** \\
\hline 15 & $80^{\circ}$ & 9,54 & $\mathrm{~A}$ \\
\hline 15 & $120^{\circ}$ & 6,31 & $\mathrm{~A}$ \\
\hline 16 & $160^{\circ}$ & 82,65 & $\mathrm{~B}$ \\
\hline 15 & $200^{\circ}$ & 60,41 & $\mathrm{C}$ \\
\hline
\end{tabular}

$\mathrm{n}^{*}$ : número de individuos; Pp (\%): pérdida de peso, en \%; **letras diferentes denotan diferencias significativas, Tukey HSD $(\mathrm{P}<0,05)$.

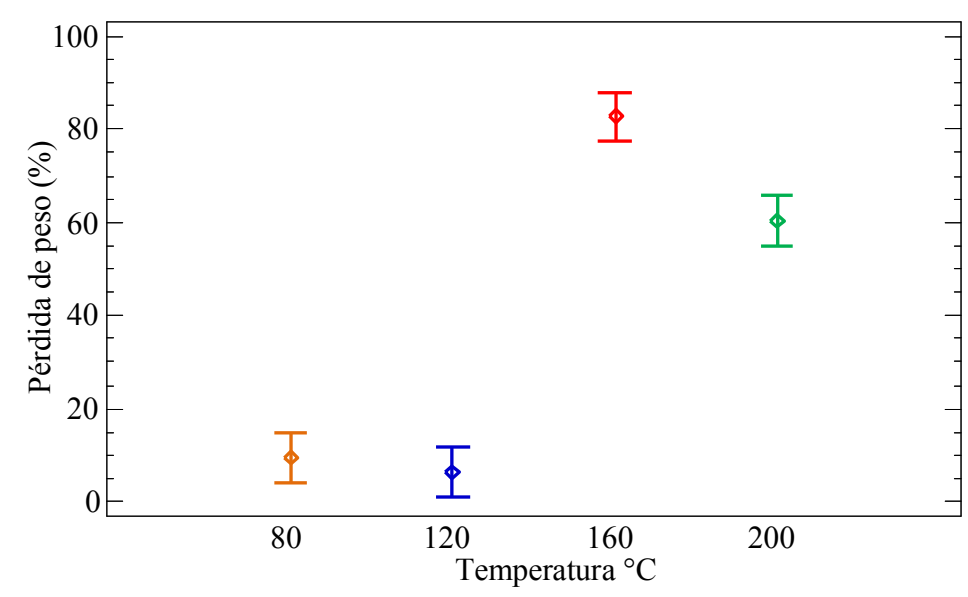

Figura 285. Gráfico de medias e IC 95\% Tukey HSD: Pp (\%) - To .

De acuerdo con los resultados, no existen diferencias significativas entre las medias de $\mathrm{Pp}(\%)$ para el TM 80 y TM 120, mientras que aparecieron diferencias entre estas medias y las de TM 160 y TM 200, las que, a su vez, difirieron entre sí, siendo superiores las Pp (\%) de TM 160, Figura 285.

En concordancia con esto, no pudo evidenciarse un comportamiento homogéneo en la evolución de las $\mathrm{Pp}(\%)$ con los rangos de temperaturas empleados, dado que, a diferencia de todo lo expresado en la bibliografía de referencia (Hillis, 1984; Militz, 2002; Mazela et al., 2003; Esteves et al., 2007 a, b; Shi et al., 2007; Boonstra, 2008; Esteves and Pereira, 2009), las menores pérdidas de peso se han hallado a temperaturas más bajas. Quizás esto tenga relación con que a temperaturas más elevadas la lignina empieza a degradarse y se suma a la acción fúngica.

\section{Análisis descriptivo: material termo-modificado expuesto a pudrición parda}

En la Tabla 144 y Figura 286 se resume el análisis descriptivo para las Pp (\%) ocasionadas por Coniophora puteana en la madera testigo y termo-modificada; el detalle del análisis descriptivo se amplía en Anejos 7.1.1.1.2.1. 
Tabla 144. Deterioro causado por $C$. puteana: diseño experimental en bloques.

\begin{tabular}{|c|c|c|c|}
\hline \multirow{2}{*}{ Tratamiento* } & \multirow{2}{*}{$\mathrm{n}^{*}$} & \multicolumn{2}{|c|}{ Pérdida de peso } \\
\hline & & $\begin{array}{c}\text { Media (\%) } \\
(\mathrm{CV} \%)^{*}\end{array}$ & $\begin{array}{l}\text { Mín.-Máx. } \\
\text { (IQR)* }\end{array}$ \\
\hline Testigo (T) & 30 & $\begin{array}{c}30,56 \\
(28,09)\end{array}$ & $\begin{array}{c}20,95-51,84 \\
(10,85)\end{array}$ \\
\hline TM 80-45 & 4 & $\begin{array}{c}46,88 \\
(11,94)\end{array}$ & $\begin{array}{c}40,05-52,18 \\
(9,07)\end{array}$ \\
\hline TM 80-90 & 3 & $\begin{array}{c}15,22 \\
(16,19)\end{array}$ & $\begin{array}{c}12,37-16,70 \\
(4,32)\end{array}$ \\
\hline TM 80-135 & 3 & $\begin{array}{c}38,21 \\
(44,53)\end{array}$ & $\begin{array}{c}18,66-49,67 \\
(31,01)\end{array}$ \\
\hline TM 80-180 & 4 & $\begin{array}{c}38,89 \\
(15,96)\end{array}$ & $\begin{array}{c}30,06-44,35 \\
(8,19)\end{array}$ \\
\hline TM 120-45 & 4 & $\begin{array}{l}39,99 \\
(2,21)\end{array}$ & $\begin{array}{c}39,17-40,97 \\
(1,49)\end{array}$ \\
\hline TM 120-90 & 4 & $\begin{array}{c}38,65 \\
(22,69)\end{array}$ & $\begin{array}{c}28,97-46,65 \\
(14,83)\end{array}$ \\
\hline TM 120-135 & 3 & $\begin{array}{c}1,01 \\
(17,25)\end{array}$ & $\begin{array}{c}0,82-1,16 \\
(0,34)\end{array}$ \\
\hline TM 120-180 & 4 & $\begin{array}{c}42,72 \\
(22,72)\end{array}$ & $\begin{array}{c}32,53-53,03 \\
(16,27)\end{array}$ \\
\hline TM 160-45 & 3 & $\begin{array}{c}0,50 \\
(71,89)\end{array}$ & $\begin{array}{c}0,12-0,84 \\
(0,72)\end{array}$ \\
\hline TM 160-90 & 4 & $\begin{array}{c}44,16 \\
(13,10)\end{array}$ & $\begin{array}{c}37,72-50,88 \\
(9,20)\end{array}$ \\
\hline TM 160-135 & 4 & $\begin{array}{c}7,01 \\
(17,47)\end{array}$ & $\begin{array}{c}5,34-8,03 \\
(1,82)\end{array}$ \\
\hline TM 160-180 & 4 & $\begin{array}{c}38,20 \\
(27,43)\end{array}$ & $\begin{array}{c}24,02-49,28 \\
(13,29)\end{array}$ \\
\hline TM 200-45 & 4 & $\begin{array}{c}39,22 \\
(11,36) \\
\end{array}$ & $\begin{array}{c}33,68-43,35 \\
(7,15)\end{array}$ \\
\hline TM 200-90 & 4 & $\begin{array}{c}18,80 \\
(27,34) \\
\end{array}$ & $\begin{array}{c}11,34-23,08 \\
(6,17)\end{array}$ \\
\hline TM 200-135 & 4 & $\begin{array}{c}4,26 \\
(79,37) \\
\end{array}$ & $\begin{array}{c}1,60-8,66 \\
(5,33)\end{array}$ \\
\hline TM 200-180 & 4 & $\begin{array}{c}5,39 \\
(11,01)\end{array}$ & $\begin{array}{c}4,75-5,92 \\
(1,17)\end{array}$ \\
\hline
\end{tabular}

*T: material sin termo-modificar: testigo; TM: material termo-modificado (los números indican combinación temperaturatiempo, respectivamente); n: número de individuos; CV: coeficiente de variación, en \%; IQR: recorrido intercuartílico. 


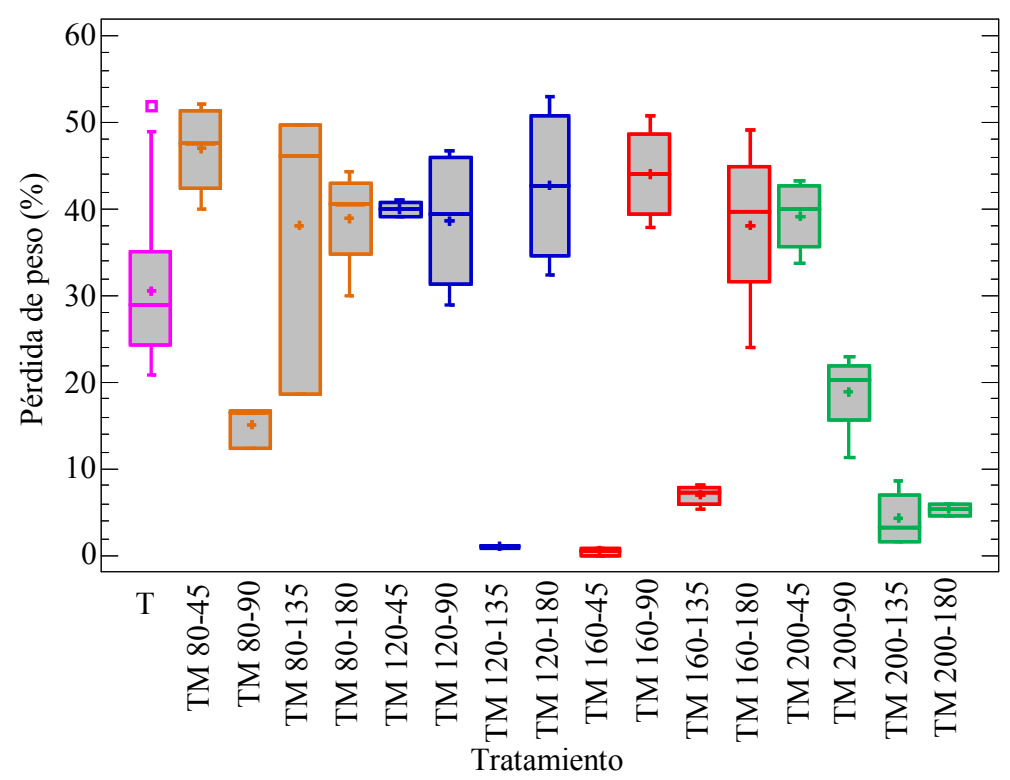

Figura 286. Gráfico de caja y bigotes: Pp (\%) - TM.

\section{Análisis comparativo: material testigo y termo-modificado expuesto pudrición parda}

Dada la variabilidad de los tratamientos, Figura 286, se realizó un análisis multifactorial, Tabla 145 a fin de determinar qué variables influyen en ese comportamiento; la comprobación de los supuestos estadísticos se detalla en Anejos 7.1.1.1.2.1.

Tabla 145. Pp (\%) por temperatura - tiempo: análisis multifactorial.

\begin{tabular}{ccc}
\hline & \multicolumn{3}{c}{ Pérdida de peso (\%) por tratamiento } \\
\hline Efectos principales & Razón-F & P-valor \\
\hline Temperatura & 3,78 & 0,02 \\
\hline Tiempo & 6,25 & 0,00 \\
\hline
\end{tabular}

Ambos factores presentaron una influencia significativa sobre las Pp (\%) ocasionadas por el agente de pudrición parda; el test de rangos múltiples de Tukey para determinar las medias que ocasionaban dicha significancia se muestra en Tabla 145 y en la Figura 287 y Figura 288.

Tabla 146. Pp (\%) por temperatura - tiempo: test de Tukey HSD.

\begin{tabular}{ccccccc}
\hline $\mathrm{n}^{*}$ & Temperatura & $\mathrm{Pp}(\%)$ & $\begin{array}{c}\text { Grupos } \\
\text { homogéneos }\end{array}$ & Tiempo & Pp (\%) & $\begin{array}{c}\text { Grupos } \\
\text { homogéneos** }\end{array}$ \\
\hline 14 & $80^{\circ}$ & 35,14 & $\mathrm{~A}$ & 45 & 33,53 & $\mathrm{~A}$ \\
\hline 15 & $120^{\circ}$ & 31,58 & $\mathrm{AB}$ & 90 & 30,66 & $\mathrm{~A}$ \\
\hline 15 & $160^{\circ}$ & 24,35 & $\mathrm{AB}$ & 135 & 12,50 & $\mathrm{~B}$ \\
\hline 15 & $200^{\circ}$ & 18,03 & $\mathrm{BC}$ & 180 & 32,41 & $\mathrm{~A}$ \\
\hline $\begin{array}{l}\text { n*: número de individuos; Pp (\%): pérdida de peso, en \%; **letras diferentes denotan diferencias significativas, Tukey HSD } \\
(\mathrm{P}<0,05) .\end{array}$
\end{tabular}




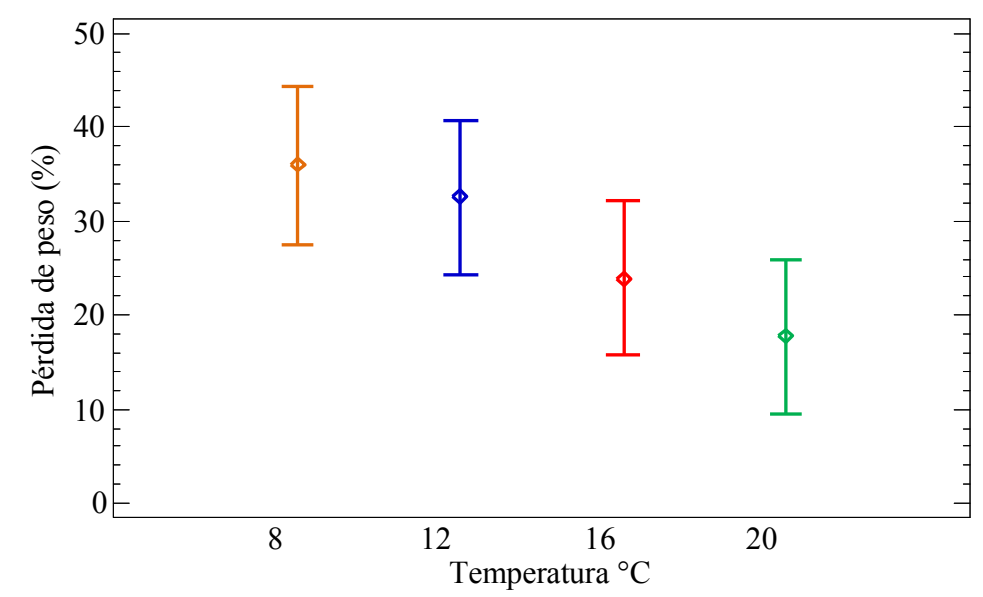

Figura 287. Gráfico de medias e IC 95\% Tukey HSD: Pp (\%) - Tº

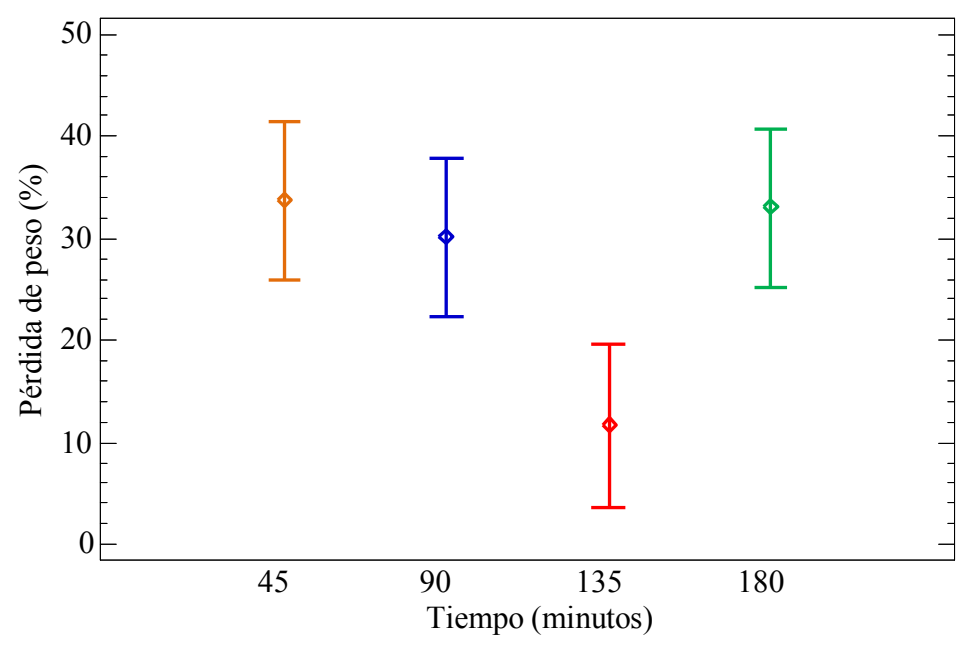

Figura 288. Gráfico de medias e IC 95\% Tukey HSD: Pp (\%) Tiempos.

De acuerdo con la comparación por temperaturas, se establecieron diferencias significativas a $80^{\circ}$ y a $200^{\circ} \mathrm{C}$, obteniéndose una $\mathrm{Pp}(\%)$ alrededor del $50 \%$ inferior en la temperatura más agresiva, $200^{\circ} \mathrm{C}$. Asimismo, independientemente de la significación estadística, en la Figura 287 puede observarse una tendencia descendente de la $\mathrm{Pp}(\%)$ con el aumento de la temperatura. Este resultado coincide con lo mencionado en diferentes bibliografías relacionadas a este temática, en las que se menciona que la mejora de la resistencia a la degradación fúngica causada por el tratamiento con temperaturas elevadas, muy probablemente esté vinculada a la menor concentración de grupos hidroxilos con capacidad de absorber agua, lo que proporciona un ambiente menos propicio para el ataque de hongos (Boonstra, 2008; Esteves and Pereira, 2009).

En cuanto a duración de la exposición, sólo tuvo efectos estadísticamente diferentes en la Pp (\%) el tiempo de 135 minutos, aunque no pudo establecerse una clara razón para este comportamiento, 
dado que con exposiciones inferiores, 45-90 minutos, y superiores, 180 minutos, se establecieron pérdidas de peso estadísticamente similares.

\subsection{Determinación de la durabilidad frente a termitas}

\section{Análisis descriptivo: material termo-modificado expuesto al ataque de termitas}

La tasa de supervivencia, TS, presentada por los "obreros" de Reticulitermis grassei en cada termo-tratamiento, junto con sus parámetros descriptivos, se indica en la Tabla 147 más detalles de dicho análisis son presentados en Anejos 7.1.1.1.2.2.

Tabla 147. Deterioro causado por $\boldsymbol{R}$. grassei: diseño experimental en bloques.

\begin{tabular}{|c|c|c|c|c|}
\hline \multirow[b]{2}{*}{ Tratamiento* } & \multirow[b]{2}{*}{$\mathrm{n}^{*}$} & \multirow[b]{2}{*}{ Grado de ataque } & \multicolumn{2}{|c|}{ Tasa de supervivencia } \\
\hline & & & $\begin{array}{c}\text { Media (\%) } \\
(\mathrm{CV} \%)^{*}\end{array}$ & $\begin{array}{l}\text { Mín.-Máx. } \\
\text { (IQR)* }\end{array}$ \\
\hline Testigo (T) & 17 & 4 & $\begin{array}{c}75,58 \\
(14,56)\end{array}$ & $\begin{array}{c}54,0-96,0 \\
(12,6)\end{array}$ \\
\hline TM 80-45 & 4 & 4 & $\begin{array}{c}66,0 \\
(18,22)\end{array}$ & $\begin{array}{c}49,0-75,0 \\
(17,0)\end{array}$ \\
\hline TM 80-90 & 3 & 4 & $\begin{array}{l}67,33 \\
(8,45)\end{array}$ & $\begin{array}{c}61,0-72,0 \\
(11,0)\end{array}$ \\
\hline TM 80-135 & 3 & 4 & $\begin{array}{c}42,67 \\
(50,29)\end{array}$ & $\begin{array}{c}18,0-57,0 \\
(39,0)\end{array}$ \\
\hline TM 80-180 & 2 & 4 & - & - \\
\hline TM 120-45 & 4 & 4 & $\begin{array}{c}36,05 \\
(68,47)\end{array}$ & $\begin{array}{c}21,6-73,0 \\
(26,1)\end{array}$ \\
\hline TM 120-90 & 4 & 4 & $\begin{array}{c}18,1 \\
(14,02)\end{array}$ & $\begin{array}{c}15,2-21,2 \\
(3,8)\end{array}$ \\
\hline TM 120-135 & 4 & 4 & $\begin{array}{c}30,8 \\
(44,33)\end{array}$ & $\begin{array}{c}20,4-50,8 \\
(16,8)\end{array}$ \\
\hline TM 120-180 & 4 & 4 & $\begin{array}{c}45,6 \\
(45,86)\end{array}$ & $\begin{array}{c}22,8-67,6 \\
(34,8)\end{array}$ \\
\hline TM 160-45 & 3 & 4 & $\begin{array}{c}26,13 \\
(20,78)\end{array}$ & $\begin{array}{c}20,4-31,2 \\
(10,8)\end{array}$ \\
\hline TM 160-90 & 3 & 4 & $\begin{array}{c}30,13 \\
(22,70)\end{array}$ & $\begin{array}{c}25,6-38,0 \\
(12,4)\end{array}$ \\
\hline TM 160-135 & 4 & 4 & $\begin{array}{c}53,6 \\
(33,54)\end{array}$ & $\begin{array}{c}32,8-74,8 \\
(27,6)\end{array}$ \\
\hline TM 160-180 & 4 & 4 & $\begin{array}{c}25,5 \\
(37,41)\end{array}$ & $\begin{array}{c}14,0-37,2 \\
(13,0)\end{array}$ \\
\hline TM 200-45 & 2 & 4 & $\begin{array}{c}31,60 \\
(25,06)\end{array}$ & $\begin{array}{c}26,0-37,2 \\
(11,2)\end{array}$ \\
\hline TM 200-90 & 4 & 4 & $\begin{array}{c}37,2 \\
(39,04)\end{array}$ & $\begin{array}{c}22,4-57,2 \\
(17,6)\end{array}$ \\
\hline TM 200-135 & 3 & 4 & $\begin{array}{c}21,6 \\
(29,40)\end{array}$ & $\begin{array}{c}16,8-28,8 \\
(12,0)\end{array}$ \\
\hline TM 200-180 & 4 & 4 & $\begin{array}{c}30,4 \\
(40,18)\end{array}$ & $\begin{array}{c}21,6-48,4 \\
(14,8)\end{array}$ \\
\hline
\end{tabular}

*T: material sin termo-modificar: testigo; TM: material termo-modificado (los números indican combinación temperaturatiempo, respectivamente); n: número de individuos; CV: coeficiente de variación, en \%; IQR: recorrido intercuartílico. 
El gráfico de caja y bigotes mostrando la dispersión y simetría de TS en cada tratamiento, se indica en la Figura 289.

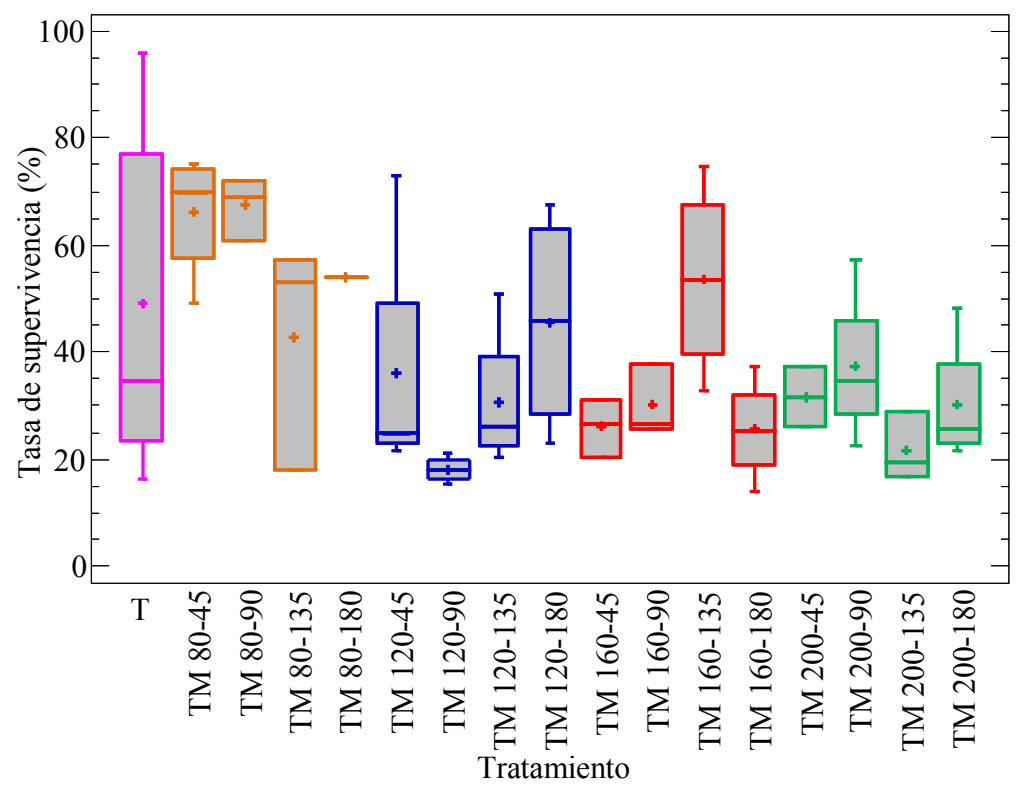

Figura 289. Gráfico de caja y bigotes: TS - tratamiento. Chopo (España).

\section{Análisis comparativo: material sin modificar - termo-modificado expuesto a termitas}

Para comprobar el comportamiento del material termo-modificado, se realizó un análisis factorial, Tabla 148, y posterior test de rangos múltiples, Tabla 149 y Figura 290.

Tabla 148. TS (\%) por temperatura - tiempo: análisis multifactorial.

\begin{tabular}{ccc}
\hline & \multicolumn{2}{c}{ Pérdida de peso (\%) por tratamiento } \\
\hline Efectos principales & Razón-F & P-valor \\
\hline Temperatura & 7,56 & 0,00 \\
\hline Tiempo & 0,08 & 0,97 \\
\hline
\end{tabular}

La temperatura es el único factor influyente en las diferencias de TS (\%) ocasionadas por termitas; de acuerdo con esto, se realizó el test de rangos múltiples de Tukey para determinar qué temperaturas ocasionaban dichas significancias. 
Tabla 149. TS (\%) por temperatura - tiempo: test de Tukey HSD.

\begin{tabular}{cccc}
\hline $\mathrm{n}^{*}$ & Temperatura & TS (\%) & Grupos homogéneos* \\
\hline 12 & $80^{\circ}$ & 58,40 & $\mathrm{~A}$ \\
\hline 16 & $120^{\circ}$ & 32,64 & $\mathrm{~B}$ \\
\hline 14 & $160^{\circ}$ & 34,67 & $\mathrm{~B}$ \\
\hline 13 & $200^{\circ}$ & 30,85 & $\mathrm{~B}$ \\
\hline
\end{tabular}

$\mathrm{n}^{*}$ : número de individuos; TS: tasa de supervivencia, en $\% ; * *$ letras diferentes denotan diferencias significativas, Tukey HSD $(\mathrm{P}<0,05)$.

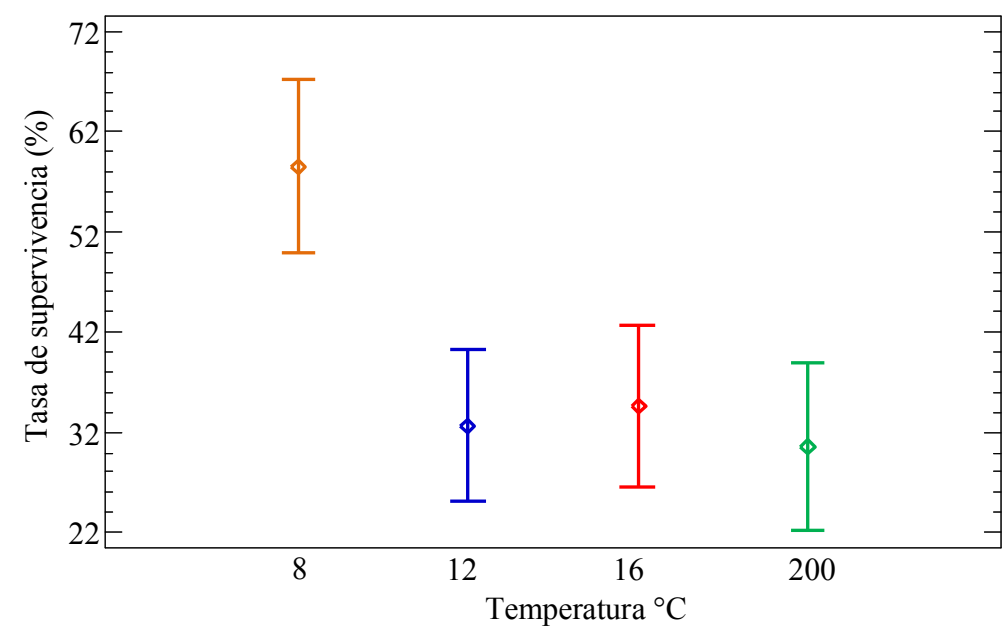

Figura 290. Gráfico de medias e IC 95\% Tukey HSD: TS (\%) - T TM. $^{\circ}$

La temperatura es el único factor influyente en el comportamiento de la TS, pudiendo determinarse que la madera termo-modificada a $80^{\circ} \mathrm{C}$ presenta una TS estadísticamente superior con respecto a las temperaturas superiores, que no se diferencian entre sí, Figura 290.

De acuerdo con estos resultados, se podría pensar que los mismos estén relacionados con la humedad disponible en la madera para su supervivencia, pero existen estudios contradictorios en cuando a la facilidad de esta terme, de comportamiento subterráneo, para obtener agua directamente de la madera (Ramírez and Lanfranco, 2001; Randall, 2000).

\subsection{Piezas macizas semi-estructurales (escala 1:5).}

\subsubsection{Ensayos no destructivos.}

\subsubsection{Determinación del MOE a través de la frecuencia propia de vibración en} piezas en voladizo

Tal como se indicó en Materiales y métodos, este ensayo fue realizado únicamente con material de procedencia española. 


\section{Análisis descriptivo: frecuencia de vibración según longitud libre}

En la Tabla 150 se muestran los parámetros descriptivos correspondientes a la frecuencia de vibración obtenida en las diferentes longitudes libres, y para cada orientación de ensayo.

Tabla 150. Frecuencia - longitudes libres: orientación vertical.

\begin{tabular}{|c|c|c|c|c|c|c|}
\hline \multirow[b]{2}{*}{$\mathrm{n}^{*}$} & \multirow[b]{2}{*}{ Repeticiones } & \multirow{2}{*}{$\begin{array}{l}\text { Longitud } \\
\text { libre }\end{array}$} & \multicolumn{2}{|c|}{ Vertical (V) } & \multicolumn{2}{|c|}{ Horizontal (H) } \\
\hline & & & $\begin{array}{l}\text { Media }(\mathrm{Hz}) \\
(\mathrm{CV} \%)^{*}\end{array}$ & $\begin{array}{l}\text { Mín.-Máx. } \\
\text { (IQR)* }\end{array}$ & $\begin{array}{l}\text { Media }(\mathrm{Hz}) \\
(\mathrm{CV} \%)^{*}\end{array}$ & $\begin{array}{l}\text { Mín.-Máx. } \\
\text { (IQR)* }\end{array}$ \\
\hline 12 & 48 & 0,500 & $\begin{array}{c}1183,15 \\
(8,38) \\
\end{array}$ & $\begin{array}{c}931,4-1394,2 \\
(116,55)\end{array}$ & $\begin{array}{l}791,68 \\
(13,79) \\
\end{array}$ & $\begin{array}{c}534,5-1018,1 \\
(165,4)\end{array}$ \\
\hline 12 & 48 & 0,525 & $\begin{array}{c}1063,17 \\
(5,92)\end{array}$ & $\begin{array}{c}891,7-1195,9 \\
(74,4)\end{array}$ & $\begin{array}{l}714,38 \\
(7,72)\end{array}$ & $\begin{array}{c}606,2-827,7 \\
(84,1)\end{array}$ \\
\hline 12 & 48 & 0,550 & $\begin{array}{c}984,72 \\
(5,19) \\
\end{array}$ & $\begin{array}{c}880,2-1100,7 \\
(66,0) \\
\end{array}$ & $\begin{array}{l}648,65 \\
(8,90) \\
\end{array}$ & $\begin{array}{c}534,1-784,5 \\
(85,5)\end{array}$ \\
\hline 12 & 48 & 0,575 & $\begin{array}{l}895,23 \\
(5,29) \\
\end{array}$ & $\begin{array}{c}777,1-992,1 \\
(70,35) \\
\end{array}$ & $\begin{array}{l}604,70 \\
(6,88) \\
\end{array}$ & $\begin{array}{c}514,7-676,4 \\
(63,45) \\
\end{array}$ \\
\hline 12 & 48 & 0,600 & $\begin{array}{l}823,95 \\
(5,31)\end{array}$ & $\begin{array}{c}710,5-920,2 \\
(54,6)\end{array}$ & $\begin{array}{c}553,36 \\
(6,67)\end{array}$ & $\begin{array}{c}482,8-626,1 \\
(51,4)\end{array}$ \\
\hline 12 & 48 & 0,625 & $\begin{array}{l}760,22 \\
(4,86)\end{array}$ & $\begin{array}{c}683,4-855,1 \\
(47,8)\end{array}$ & $\begin{array}{l}509,01 \\
(7,20)\end{array}$ & $\begin{array}{c}438,3-585,2 \\
(54,1)\end{array}$ \\
\hline 12 & 48 & 0,650 & $\begin{array}{l}706,03 \\
(5,18)\end{array}$ & $\begin{array}{c}617,5-779,8 \\
(39,9) \\
\end{array}$ & $\begin{array}{c}469,69 \\
(7,33)\end{array}$ & $\begin{array}{c}404,3-527,9 \\
(51,0)\end{array}$ \\
\hline 12 & 48 & 0,675 & $\begin{array}{l}657,97 \\
(4,85)\end{array}$ & $\begin{array}{c}592,0-726,2 \\
(46,0)\end{array}$ & $\begin{array}{c}437,62 \\
(7,51) \\
\end{array}$ & $\begin{array}{c}361,5-529,4 \\
\quad(48,0)\end{array}$ \\
\hline 12 & 48 & 0,700 & $\begin{array}{l}613,31 \\
(5,22) \\
\end{array}$ & $\begin{array}{c}531,6-679,0 \\
(28,7) \\
\end{array}$ & $\begin{array}{l}408,09 \\
(8,19) \\
\end{array}$ & $\begin{array}{c}338,0-472,1 \\
(47,5)\end{array}$ \\
\hline 12 & 48 & 0,725 & $\begin{array}{c}569,58 \\
(4,85) \\
\end{array}$ & $\begin{array}{c}497,0-621,7 \\
(34,1)\end{array}$ & $\begin{array}{c}383,36 \\
(8,66)\end{array}$ & $\begin{array}{c}311,6-448,9 \\
(54,85)\end{array}$ \\
\hline 12 & 48 & 0,750 & $\begin{array}{l}544,69 \\
(16,08)\end{array}$ & $\begin{array}{c}396,0-700,2 \\
(155,35)\end{array}$ & $\begin{array}{c}353,08 \\
(7,34)\end{array}$ & $\begin{array}{c}294,8-400,3 \\
(45,3)\end{array}$ \\
\hline 12 & 48 & 0,775 & $\begin{array}{l}495,95 \\
(10,08) \\
\end{array}$ & $\begin{array}{c}386,1-590,7 \\
(71,4)\end{array}$ & $\begin{array}{l}327,74 \\
(7,96) \\
\end{array}$ & $\begin{array}{c}275,7-378,4 \\
\quad(37,8) \\
\end{array}$ \\
\hline 12 & 48 & 0,80 & $\begin{array}{l}469,73 \\
(6,88) \\
\end{array}$ & $\begin{array}{c}402,6-545,0 \\
(50,5)\end{array}$ & $\begin{array}{l}311,89 \\
(7,19) \\
\end{array}$ & $\begin{array}{c}270,1-375,0 \\
(30,9)\end{array}$ \\
\hline 12 & 48 & 0,825 & $\begin{array}{c}438,49 \\
(6,75)\end{array}$ & $\begin{array}{c}371,6-500,0 \\
(44,75)\end{array}$ & $\begin{array}{c}290,93 \\
(8,43)\end{array}$ & $\begin{array}{c}248,7-349,4 \\
(33,75)\end{array}$ \\
\hline 12 & 48 & 0,850 & $\begin{array}{c}420,84 \\
(6,59)\end{array}$ & $\begin{array}{c}369,4-476,0 \\
(41,0)\end{array}$ & $\begin{array}{r}273,22 \\
(7,48) \\
\end{array}$ & $\begin{array}{c}227,8-306,8 \\
\quad(29,7)\end{array}$ \\
\hline 12 & 48 & 0,875 & $\begin{array}{l}393,83 \\
(5,62) \\
\end{array}$ & $\begin{array}{c}338,6-435,2 \\
(31,9) \\
\end{array}$ & $\begin{array}{l}261,28 \\
(7,33) \\
\end{array}$ & $\begin{array}{c}221,8-298,0 \\
(27,4)\end{array}$ \\
\hline 12 & 48 & 0,900 & $\begin{array}{c}373,14 \\
(5,83) \\
\end{array}$ & $\begin{array}{c}326,0-412,9 \\
(39,1)\end{array}$ & $\begin{array}{c}250,68 \\
(6,86) \\
\end{array}$ & $\begin{array}{c}215,8-295,1 \\
(25,6)\end{array}$ \\
\hline 12 & 48 & 0,925 & $\begin{array}{l}351,25 \\
(6,48)\end{array}$ & $\begin{array}{c}296,3-395,8 \\
(32,8)\end{array}$ & $\begin{array}{c}238,82 \\
(8,15)\end{array}$ & $\begin{array}{c}196,1-283,6 \\
(24,6)\end{array}$ \\
\hline 12 & 48 & 0,950 & $\begin{array}{c}339,32 \\
(6,01)\end{array}$ & $\begin{array}{c}284,7-373,9 \\
(29,4) \\
\end{array}$ & $\begin{array}{c}227,38 \\
(8,31) \\
\end{array}$ & $\begin{array}{c}184,3-262,3 \\
(28,6)\end{array}$ \\
\hline 12 & 48 & 0,975 & $\begin{array}{l}323,17 \\
(5,76) \\
\end{array}$ & $\begin{array}{c}278,4-360,3 \\
(26,55) \\
\end{array}$ & $\begin{array}{l}213,31 \\
(7,61) \\
\end{array}$ & $\begin{array}{c}180,7-256,6 \\
(22,6)\end{array}$ \\
\hline 12 & 48 & 1,000 & $\begin{array}{l}312,85 \\
(10,70)\end{array}$ & $\begin{array}{c}251,6-375,8 \\
(49,2)\end{array}$ & $\begin{array}{l}198,36 \\
(6,75)\end{array}$ & $\begin{array}{c}169,4-223,7 \\
(20,75)\end{array}$ \\
\hline
\end{tabular}

*n: número de individuos; CV: coeficiente de variación, en \%; IQR: recorrido intercuartílico. 
En la Figura 291 se representa el gráfico de caja y bigotes para las frecuencias en vibración libre, $f$, considerando todas las piezas y las dos orientaciones ensayadas.

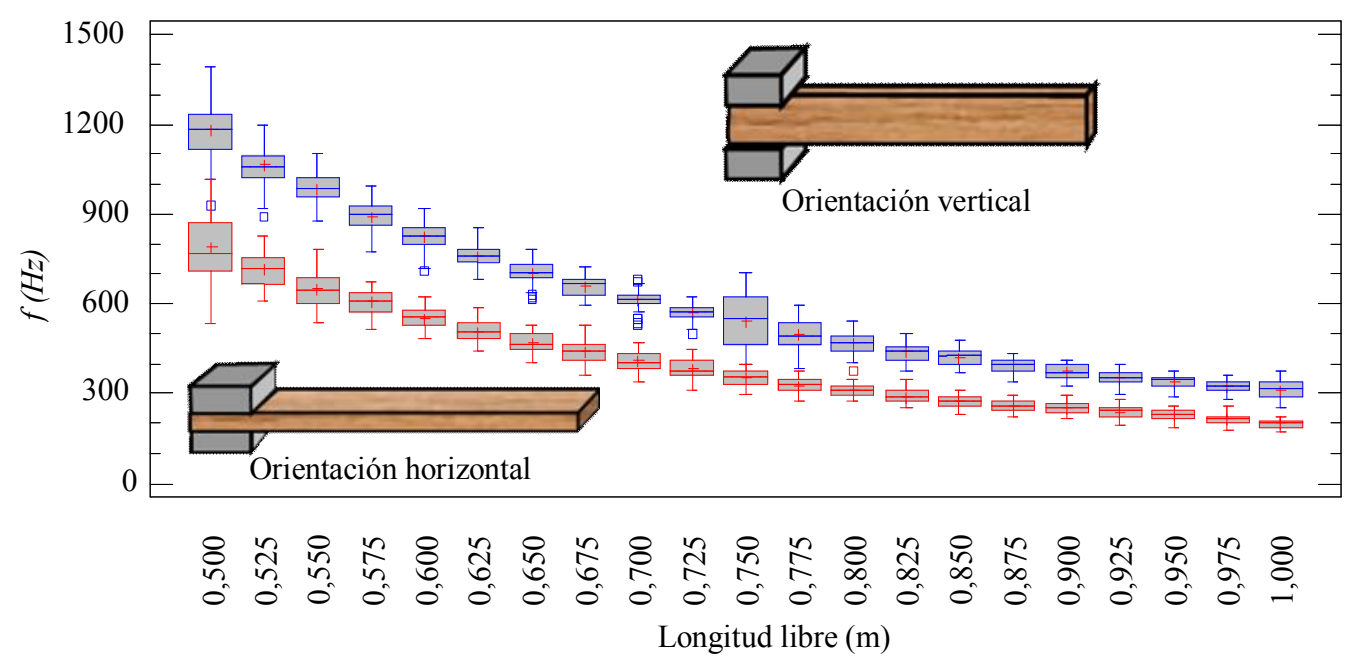

Figura 291. Gráfico de caja y bigotes: frecuencia de vibración - longitud libre.

De acuerdo a lo observado en la Figura 291, la frecuencia se comporta inversamente proporcional a la frecuencia, por lo que la frecuencia vibratoria disminuye a medida que la longitud libre, L, de la pieza en voladizo, se incrementa.

\section{Análisis predictivo: frecuencia de vibración según longitud libre}

Dado el inconveniente práctico para determinar el modo de la frecuencia obtenida durante el ensayo, se procedió tal como fue explicado en Materiales y Métodos. Por lo tanto, para cada pieza se seleccionó un módulo de elasticidad, determinado a partir del coeficiente $\mathrm{a}_{1}$, el cual se obtuvo por regresión a partir de la relación $f^{2}$ y $1 / \mathrm{L}^{4}$. Con el MOE calculado se determinó la frecuencia teórica en cada modo $\left(C_{1}=0,56 ; C_{2}=3,51 ; C_{3}=9,82 \ldots\right)$, la cual fue posteriormente comparada con la frecuencia "real", obtenida mediante el ensayo de vibración, a fin de determinar, cuál era el valor semejante a ella.

De dicho análisis se obtuvo que la frecuencia real determinada mediante el ensayo de vibraciones en las piezas en voladizo, se correspondió con el primer armónico, coeficiente $C_{n}=3,51$.

En base a ello, para obtener el $E$ correspondiente a ese armónico, en cada pieza se representó la relación entre $f^{2}$ y $1 / \mathrm{L}^{4}$ (Figura 292), obteniendo la recta de regresión correspondiente (Anejos 7.2.1.1) a partir de la cual se obtuvo el coeficiente $\mathrm{a}_{1}$ con el que se determinó, junto con la densidad, sección y momento de inercia, el módulo de elasticidad real dinámico de cada pieza. 

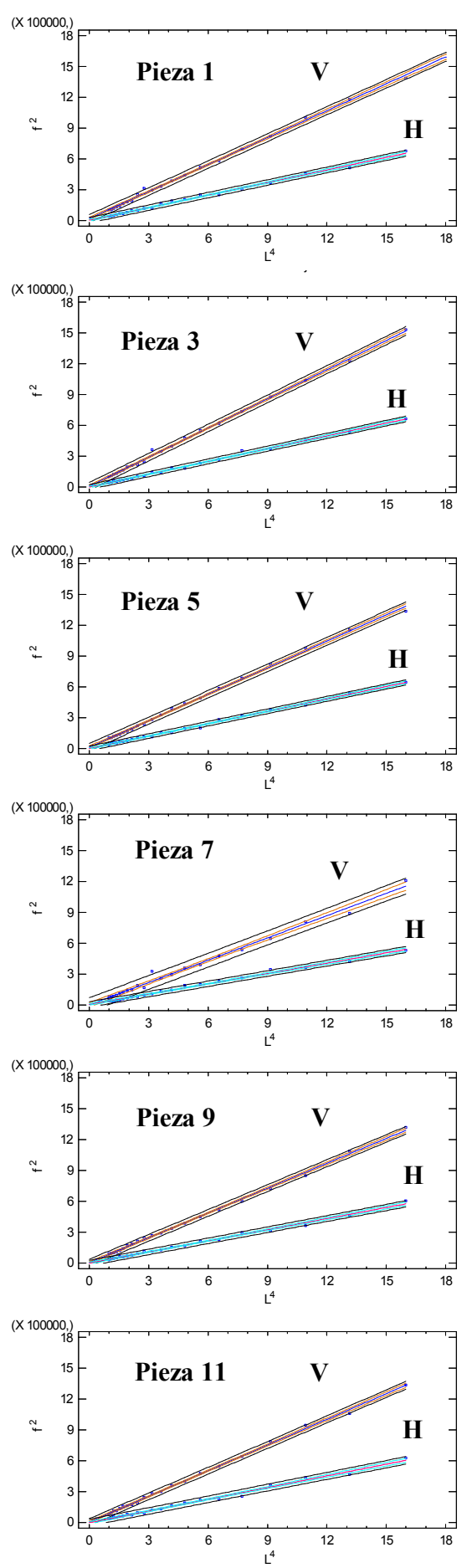
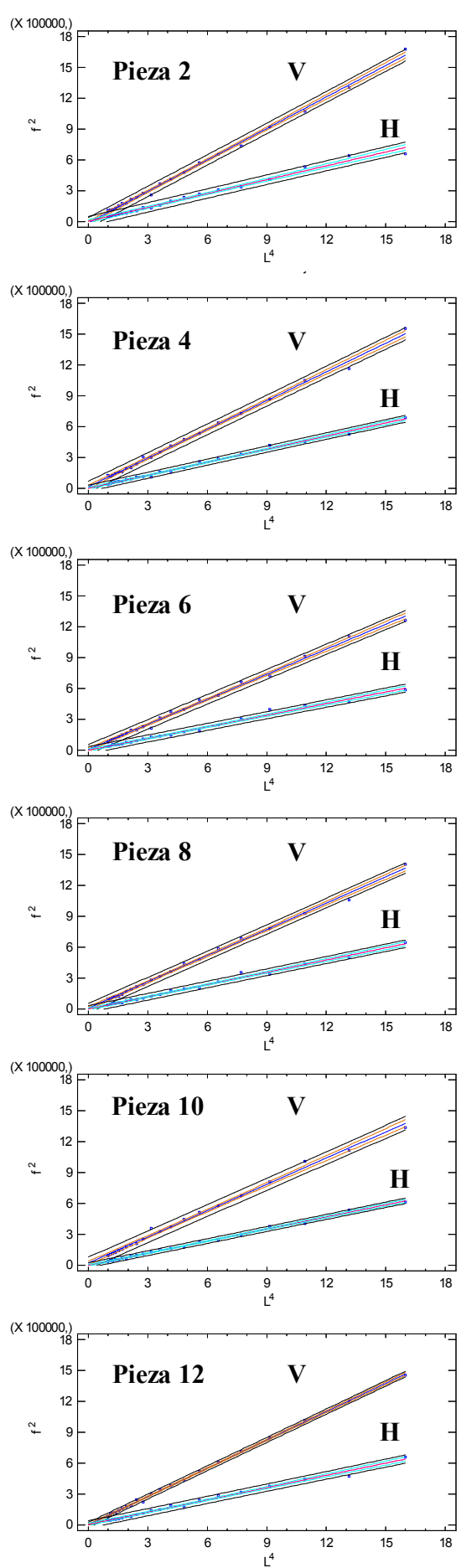

Figura 292. Regresión $\mathrm{f}^{2}$ y $1 / \mathrm{L}^{4}$.

Posteriormente, se determinó el módulo de elasticidad de las piezas a través del ensayo de flexión estática en máquina Universal, el cual fue realizado hasta el límite elástico a fin de relacionarlo con los valores de $E$ obtenidos por vibración libre; los resultados de ambos módulos de elasticidad se presentan en la Tabla 151. 
Tabla 151. $E$ en vibración libre y MOE en máquina Universal: resumen descriptivo.

\begin{tabular}{|c|c|c|c|}
\hline \multirow[t]{2}{*}{ Pieza } & $\begin{array}{c}E^{*} \\
(\mathrm{MPa}) \\
(\mathrm{CV} \%) \\
\end{array}$ & $\begin{array}{c}E(\mathrm{MPa}) \\
(\mathrm{CV} \%)\end{array}$ & \multirow[t]{2}{*}{$\begin{array}{c}\mathrm{MOE}^{*}(\mathrm{MPa}) \\
(\mathrm{CV} \%)\end{array}$} \\
\hline & V & $\mathrm{H}$ & \\
\hline 1 & 9867,85 & 11519 & 10356,74 \\
\hline 2 & 10784,03 & 9741,5 & 10706,43 \\
\hline 3 & 11860,52 & 11778 & 11691,17 \\
\hline 4 & 9986,66 & 10140 & 9763,23 \\
\hline 5 & 9348,80 & 8856,3 & 9903,93 \\
\hline 6 & 7314,65 & 8136 & 7174,96 \\
\hline 7 & 6096,22 & 6696,7 & 6114,77 \\
\hline 8 & 8931,87 & 9613,3 & 9143,66 \\
\hline 9 & 7328,89 & 7021,6 & 7379,53 \\
\hline 10 & 9924,84 & 9398 & 10287,87 \\
\hline 11 & 8309,98 & 7769,1 & 8510,63 \\
\hline 12 & 10599,91 & 9418 & 10607,06 \\
\hline $\begin{array}{c}\text { Media } E(\mathrm{MPa}) \\
(\mathrm{CV} \%)\end{array}$ & $\begin{array}{c}9196,18 \\
(18,17)\end{array}$ & $\begin{array}{c}9303,33 \\
(18,07)\end{array}$ & $\begin{array}{c}9173,96 \\
(17,32)\end{array}$ \\
\hline $\begin{array}{l}\text { Mín. - Máx. } \\
\text { (IQR) }\end{array}$ & $\begin{array}{c}6096,22-11860,5 \\
(2473,85)\end{array}$ & $\begin{array}{c}6114,77-11691,2 \\
(2536,82)\end{array}$ & $\begin{array}{c}6696,7-11778,0 \\
(1988,2)\end{array}$ \\
\hline
\end{tabular}

La relación significativa entre los módulos de elasticidad horizontal y vertical se muestra en la Figura 293.

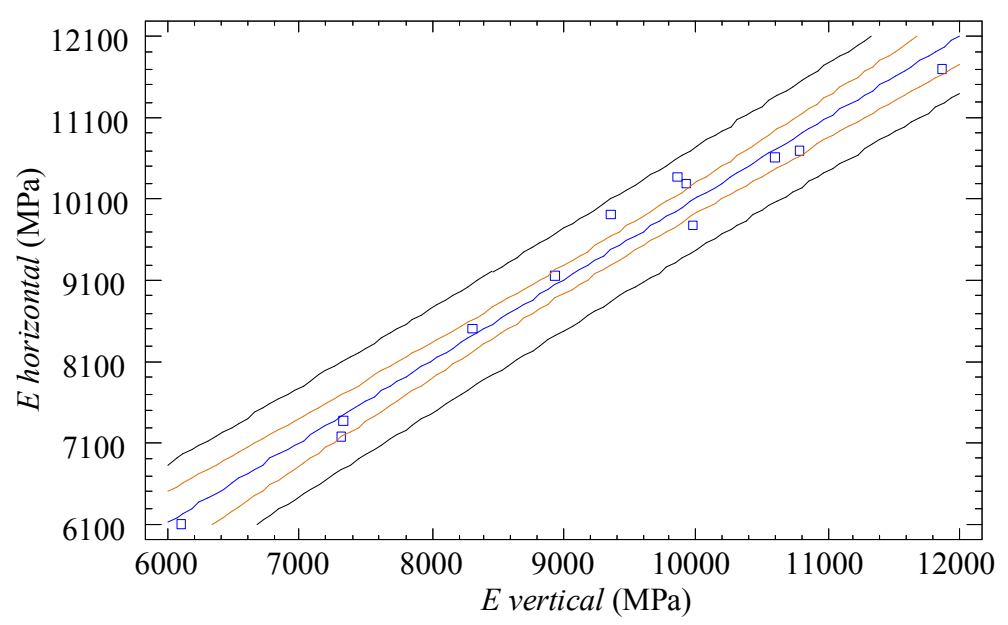

Figura 293. Regresión $E$ horizontal $-E$ vertical.

La ecuación del modelo ajustado expresada como: $E$ horizontal $=162,976+0,993929 * E$ vertical, explicó el 97,40\% de la variabilidad del $E$ horizontal, comprobando la validez del método con independencia de la orientación utilizada en la realización del ensayo. 


\subsubsection{Predicción del MOE a partir del ensayo de vibración libre en voladizo}

Mediante el análisis de regresión simple se buscó evaluar la capacidad predictiva del módulo de elasticidad de vibración libre, $E$, en el módulo de elasticidad, MOE, obtenido de máquina, Tabla 152.

Tabla 152. MOE: análisis predictivo a partir del ensayo de vibración en piezas en voladizo.

\begin{tabular}{ccccc}
\hline & \multicolumn{4}{c}{ Variable predicha* } \\
\cline { 2 - 5 } Variables predictoras* & \multicolumn{4}{c}{ MOE } \\
\cline { 2 - 5 } & \multicolumn{4}{c}{$\mathbf{V}$} \\
\cline { 2 - 5 } & $\mathbf{R}^{2}$ ajust. (\%) & P-valor & $\mathbf{R}^{2}$ ajust. (\%) & P-valor \\
\hline$E$ & 73,34 & 0,00 & 73,37 & 0,00 \\
\hline Modelo ajustado & MOE: $1563,84+0,82753 * E$ vertical & MOE: $1518,53+0,822869 *$ Horizontal \\
\hline
\end{tabular}

*MOE: módulo de elasticidad; $E$ : módulo de elasticidad por vibración libre.
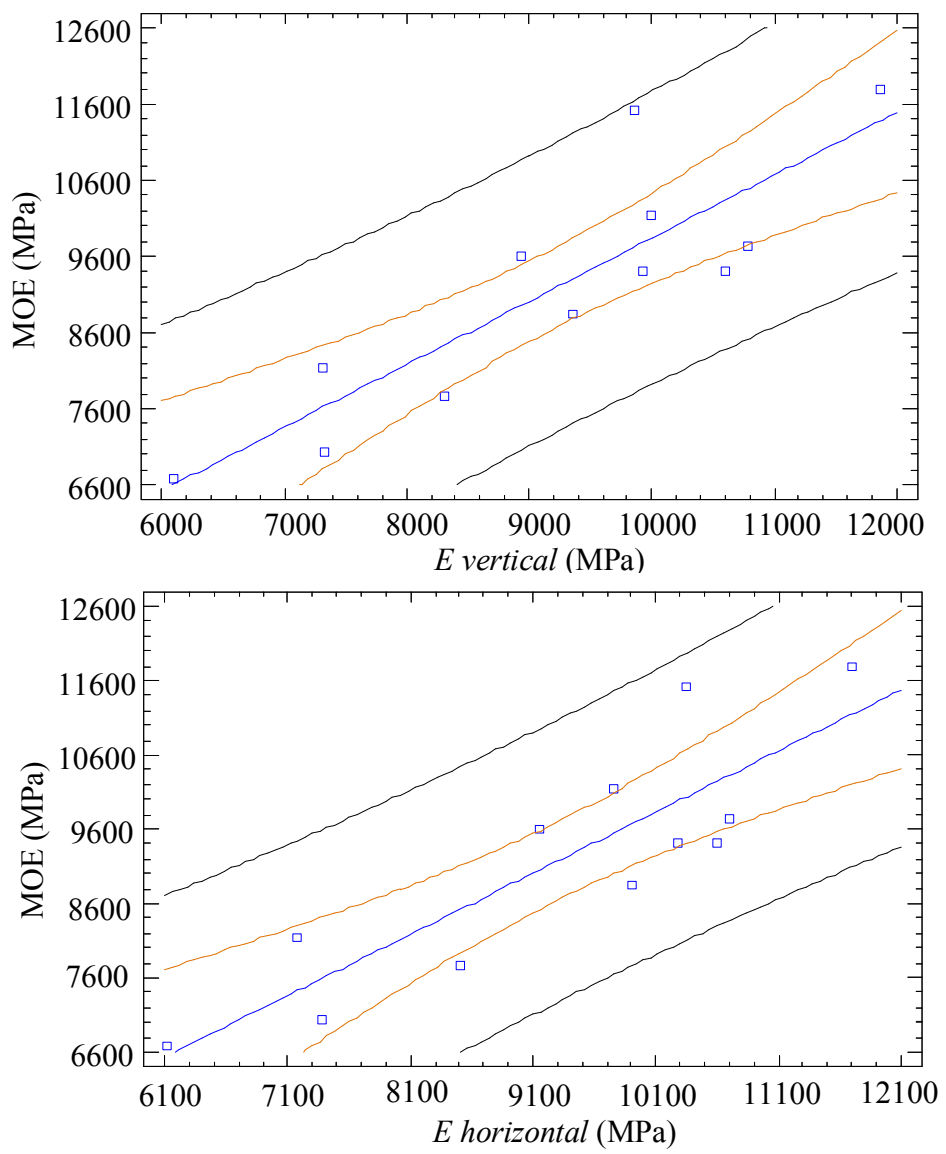

Figura 294. Regresión MOE - E vertical-horizontal

Puesto que el P-valor de ambos modelos es inferior a 0,05 , existe una relación estadísticamente significativa entre la variable predicha, MOE, y las variables predictoras, con un nivel de confianza del $95,0 \%$. 
En concordancia con el $\mathrm{R}^{2}$ ajustado, los modelos ajustados considerando el $E$ en posición vertical y el $E$ en posición horizontal, presentan ajustes similares y aceptables, explicando un 73,34 \% y un 73,37\% de la variabilidad del MOE, cuyas ecuaciones son indicadas en la Tabla 152.

De acuerdo con esto puede indicarse que los modelos ajustados, considerando el módulo de elasticidad en voladizo, son más precisos para explicar el comportamiento del MOE que los ensayos realizados sobre piezas bi-apoyadas mediante vibraciones longitudinales, a partir de los cuales se obtuvo un valor de $\mathrm{R}^{2} 63,77 \%$, apartado 4.3.3.3; valores de $\mathrm{R}^{2}$ del orden de $70 \%$ fueron hallados por Casado et al., 2012 en Populus x euramericana I-214, teniendo en cuenta la frecuencia de vibración longitudinal y las variables densidad, diámetro relativo de nudos en cara, canto y anchura promedio de anillos. Considerando la naturaleza orgánica, heterogénea y anisótropa de la madera, este método resulta una alternativa muy valiosa y precisa en el campo de calidad de la madera.

\subsubsection{Ensayos destructivos: piezas dúo y trío.}

\section{Análisis de centralidad y dispersión: material de ambas procedencias}

En la Tabla 153 se describen las dimensiones y contenido de humedad de las piezas dúos y tríos; en Anejos 7.2.2 se describen las características de las piezas "parte".

Tabla 153. Dimensiones nominales y contenido de humedad de ambos lotes.

\begin{tabular}{|c|c|c|c|c|c|c|c|c|c|c|}
\hline \multirow[b]{2}{*}{ Lotes } & \multirow[b]{2}{*}{ Pieza } & \multirow[b]{2}{*}{$\mathrm{n}^{*}$} & \multicolumn{2}{|c|}{$\begin{array}{l}\text { Longitud } \\
(\mathrm{cm})\end{array}$} & \multicolumn{2}{|c|}{$\begin{array}{l}\text { Anchura } \\
(\mathrm{cm})\end{array}$} & \multicolumn{2}{|c|}{$\begin{array}{l}\text { Espesor } \\
(\mathrm{cm})\end{array}$} & \multicolumn{2}{|c|}{$\begin{array}{c}\text { Humedad } \\
(\%) \\
\end{array}$} \\
\hline & & & $\begin{array}{l}\text { Media } \\
\text { (CV\%) }\end{array}$ & $\begin{array}{l}\text { Mín.- } \\
\text { Máx. } \\
\text { (IQR) }\end{array}$ & $\begin{array}{l}\text { Media } \\
(\mathrm{CV} \%)\end{array}$ & $\begin{array}{l}\text { Mín.- } \\
\text { Máx. } \\
\text { (IQR) }\end{array}$ & $\begin{array}{l}\text { Media } \\
\text { (CV\%) }\end{array}$ & $\begin{array}{l}\text { Mín.- } \\
\text { Máx. } \\
\text { (IQR) }\end{array}$ & $\begin{array}{l}\text { Media } \\
(\mathrm{CV} \%)\end{array}$ & $\begin{array}{l}\text { Mín.- } \\
\text { Máx. } \\
\text { (IQR) }\end{array}$ \\
\hline \multirow{2}{*}{ España } & Dúo & 80 & $\begin{array}{c}1198,68 \\
(0,12)\end{array}$ & $\begin{array}{c}1190,0- \\
1200,5 \\
(1,75)\end{array}$ & $\begin{array}{l}59,60 \\
(3,15)\end{array}$ & $\begin{array}{l}55,4- \\
63,85 \\
(3,06) \\
\end{array}$ & $\begin{array}{l}40,54 \\
(3,49)\end{array}$ & $\begin{array}{c}36,1- \\
43,5 \\
(2,05) \\
\end{array}$ & $\begin{array}{c}7,93 \\
(6,48)\end{array}$ & $\begin{array}{c}6,66- \\
8,80 \\
(0,81) \\
\end{array}$ \\
\hline & Trío & 45 & $\begin{array}{c}1198,49 \\
(0,21)\end{array}$ & $\begin{array}{c}1186,0- \\
1201,0 \\
(2,0)\end{array}$ & $\begin{array}{l}59,76 \\
(1,78)\end{array}$ & $\begin{array}{c}56,0- \\
61,3 \\
(0,85)\end{array}$ & $\begin{array}{l}39,09 \\
(0,83)\end{array}$ & $\begin{array}{c}38,2- \\
39,8 \\
(0,4)\end{array}$ & $\begin{array}{c}8,09 \\
(4,15)\end{array}$ & $\begin{array}{c}7,41- \\
8,77 \\
(0,51) \\
\end{array}$ \\
\hline \multirow{2}{*}{ Argentina } & Dúo & 80 & $\begin{array}{c}1202,83 \\
(0,16)\end{array}$ & $\begin{array}{c}1199,5- \\
1207,0 \\
(3,0)\end{array}$ & $\begin{array}{l}63,40 \\
(1,24)\end{array}$ & $\begin{array}{c}61,63- \\
65,38 \\
(1,13) \\
\end{array}$ & $\begin{array}{l}37,30 \\
(3,84)\end{array}$ & $\begin{array}{c}34,44- \\
40,95 \\
(1,88)\end{array}$ & $\begin{array}{c}11,58 \\
(10,86)\end{array}$ & $\begin{array}{l}10,49- \\
22,14 \\
(0,63) \\
\end{array}$ \\
\hline & Trío & 80 & $\begin{array}{c}1198,96 \\
(0,30)\end{array}$ & $\begin{array}{c}1188,0- \\
1207,67 \\
(3,67)\end{array}$ & $\begin{array}{l}62,90 \\
(2,20)\end{array}$ & $\begin{array}{c}60,67- \\
66,7 \\
(1,97)\end{array}$ & $\begin{array}{l}35,41 \\
(3,94)\end{array}$ & $\begin{array}{c}31,69- \\
38,31 \\
(1,56)\end{array}$ & $\begin{array}{l}13,02 \\
(5,71)\end{array}$ & $\begin{array}{c}10,12- \\
14,33 \\
(0,79)\end{array}$ \\
\hline
\end{tabular}

*n: número de individuos; CV: coeficiente de variación en \%; IQR: recorrido intercuartílico.

\section{Análisis descriptivo: material de procedencia española}

Las propiedades estructurales y la densidad del lote de madera encolada, dúo y trío, procedente de España se muestran en la Tabla 154 (Anejos 7.2.2.1); los gráficos de caja y bigotes e histogramas de frecuencia de cada una de ellas se indica a continuación del resumen tabular. 
Tabla 154. Propiedades estructurales de los diferentes tipos de piezas.

\begin{tabular}{ccccc}
\hline Variable* & Tipo pieza & $\mathrm{n}^{*}$ & $\begin{array}{c}\text { Media }-5^{\circ} \text { percentil } \\
(\mathrm{CV} \%)\end{array}$ & $\begin{array}{c}\text { Mín. }- \text { Máx. } \\
(\mathrm{IQR})\end{array}$ \\
\hline & Dúo & 80 & $\begin{array}{c}7198,71-5425,36 \\
(16,85)\end{array}$ & $\begin{array}{c}5150,36-9716,59 \\
(1568,69)\end{array}$ \\
\cline { 2 - 5 } MOE $(\mathrm{MPa})$ & Trío & 45 & $\begin{array}{c}8286,54-6863,95 \\
(10,83)\end{array}$ & $\begin{array}{c}6767,4-10000,4 \\
(1355,6)\end{array}$ \\
\hline MOR $(\mathrm{MPa})$ & Dúo & 80 & $\begin{array}{c}43,80-27,04 \\
(21,50)\end{array}$ & $\begin{array}{c}20,77-66,22 \\
(12,24)\end{array}$ \\
\cline { 2 - 5 } & Trío & 45 & $\begin{array}{c}50,92-40,92 \\
(13,00)\end{array}$ & $\begin{array}{c}40,16-63,04 \\
(10,52)\end{array}$ \\
\hline Densidad $\left(\mathrm{kg} / \mathrm{m}^{3}\right)$ & Dúo & 80 & $\begin{array}{c}373,80-327,79 \\
(9,31)\end{array}$ & $\begin{array}{c}319,06-447,87 \\
(57,16)\end{array}$ \\
\cline { 2 - 4 } & Trío & 80 & $\begin{array}{c}384,54-345,03 \\
(8,01)\end{array}$ \\
\hline
\end{tabular}

*MOE: módulo de elasticidad; MOR: módulo de rotura; n: número de individuos; CV: coeficiente de variación en \%; IQR: recorrido intercuartílico; valores característicos: media para el MOE y $5^{\circ}$ percentil para la densidad y el MOR (EN 384: 2010).
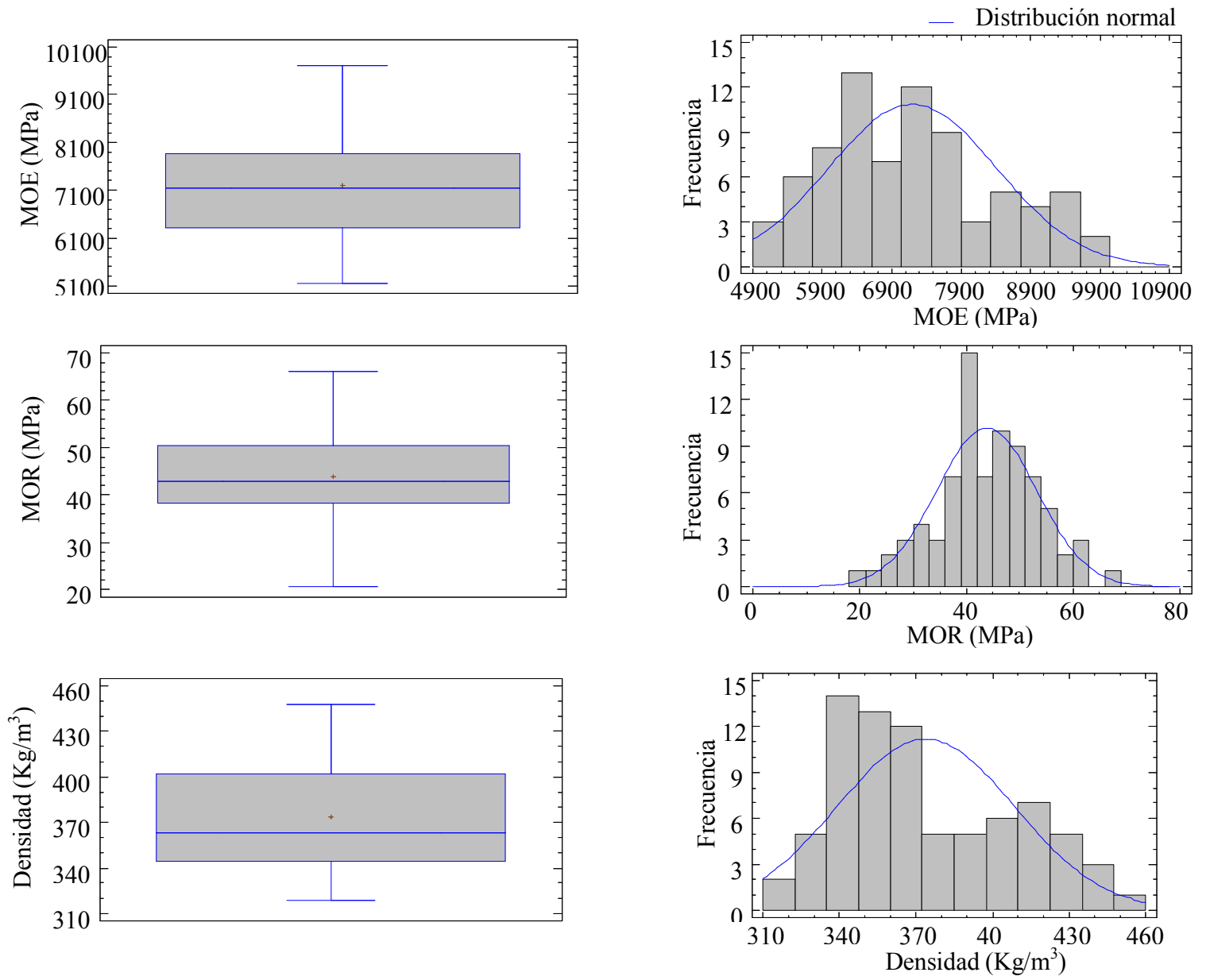

Figura 295. Gráfico de Caja y Bigotes MOE, MOR y densidad. Piezas Dúos (España).

Figura 296. Histograma de Frecuencias MOE, MOR y densidad. Piezas Dúos (España). 

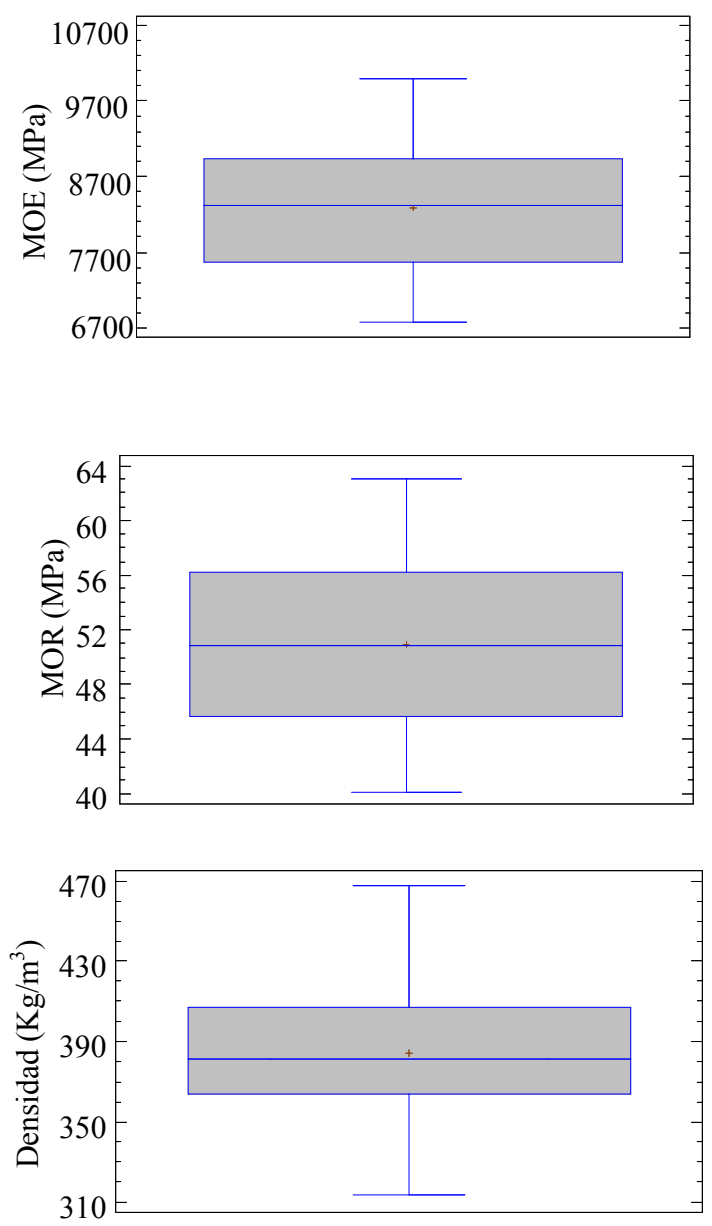

Figura 297. Gráfico de Caja y Bigotes MOE, MOR y densidad. Piezas Tríos (España).
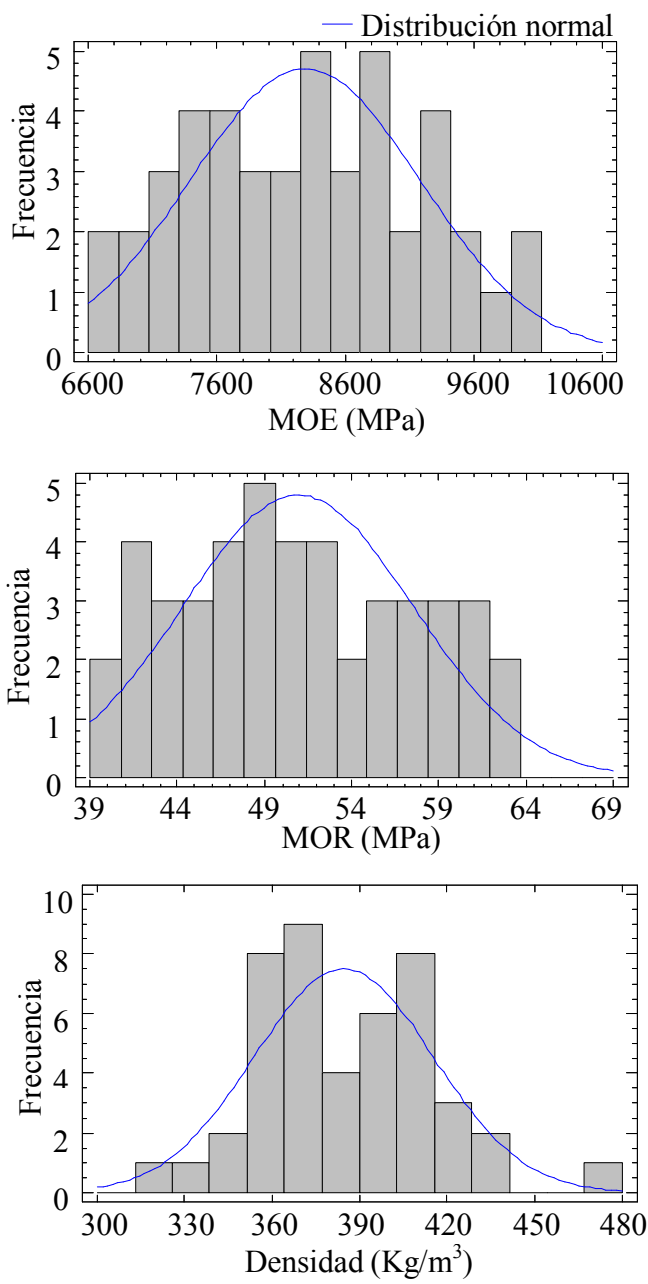

Figura 298. Histograma de Frecuencias MOE, MOR y densidad. Piezas Tríos (España).

\section{Análisis descriptivo: material de procedencia argentina.}

Las propiedades estructurales y la densidad del lote de madera encolada, dúo y trío, procedente de España se muestran en la Tabla 155 (Anejos 7.2.2.1) 
Tabla 155. Propiedades estructurales de los diferentes tipos de piezas.

\begin{tabular}{|c|c|c|c|c|}
\hline Variable* & Tipo pieza & $\mathrm{n}^{* \mathrm{o}}$ & $\begin{array}{c}\text { Media }-5^{\circ} \text { percentil } \\
(\mathrm{CV} \%)\end{array}$ & $\begin{array}{l}\text { Mín. - Máx. } \\
\text { (IQR) }\end{array}$ \\
\hline \multirow{2}{*}{ MOE (MPa) } & Dúo & 80 & $\begin{array}{c}7008,22-5356,02 \\
(13,27)\end{array}$ & $\begin{array}{c}5150,2-8883,45 \\
(1380,73)\end{array}$ \\
\hline & Trío & 80 & $\begin{array}{c}6975,27-4300,86 \\
(19,18) \\
\end{array}$ & $\begin{array}{c}3738,4-9656,48 \\
(1982,21) \\
\end{array}$ \\
\hline \multirow{2}{*}{ MOR (MPa) } & Dúo & 80 & $\begin{array}{c}35,78-21,98 \\
(20,80)\end{array}$ & $\begin{array}{c}20,29-49,42 \\
(11,39)\end{array}$ \\
\hline & Trío & 80 & $\begin{array}{c}35,16-22,53 \\
(20,29)\end{array}$ & $\begin{array}{c}20,02-47,57 \\
(11,73)\end{array}$ \\
\hline \multirow{2}{*}{ Densidad (kg/m3) } & Dúo & 80 & $\begin{array}{c}413,77-375,05 \\
(6,38) \\
\end{array}$ & $\begin{array}{c}365,13-475,59 \\
(34,49) \\
\end{array}$ \\
\hline & Trío & 80 & $\begin{array}{c}397,86-357,73 \\
(5,24)\end{array}$ & $\begin{array}{c}352,18-437,24 \\
(29,99)\end{array}$ \\
\hline
\end{tabular}

*MOE: módulo de elasticidad; MOR: módulo de rotura; n: número de individuos; CV: coeficiente de variación, en \%; IQR: recorrido intercuartílico; valores característicos: media para el MOE y $5^{\circ}$ percentil para el MOR y la densidad (EN 384: 2010).
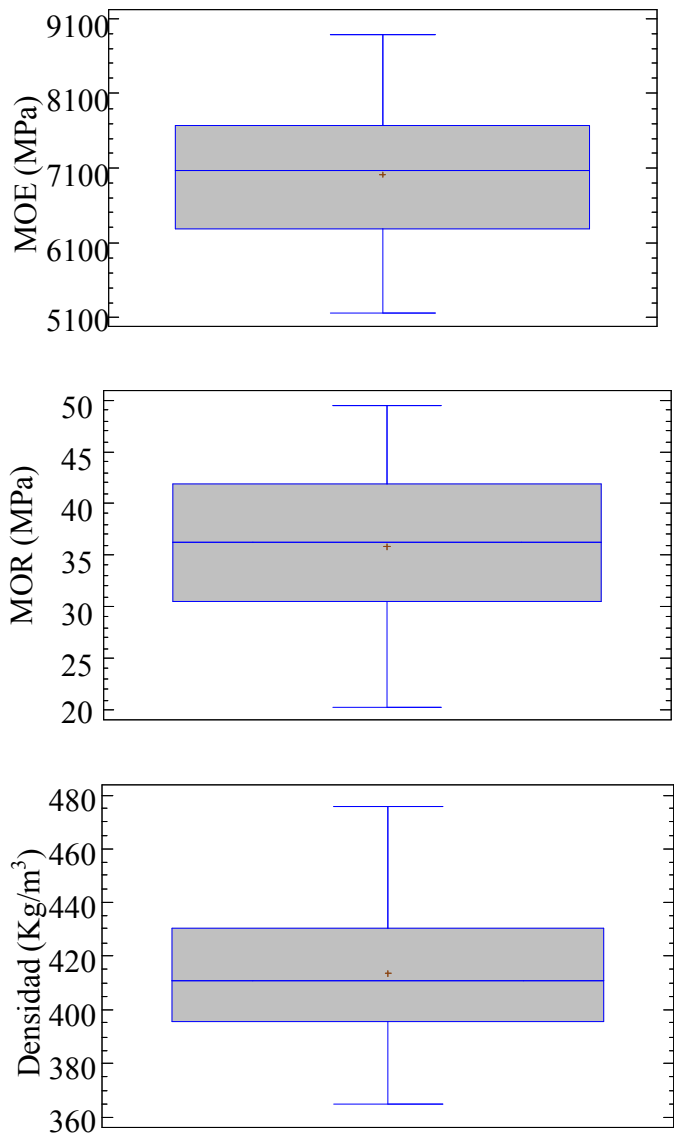

Figura 299. Gráfico de Caja y Bigotes MOE, MOR y densidad. Piezas dúos (Argentina).
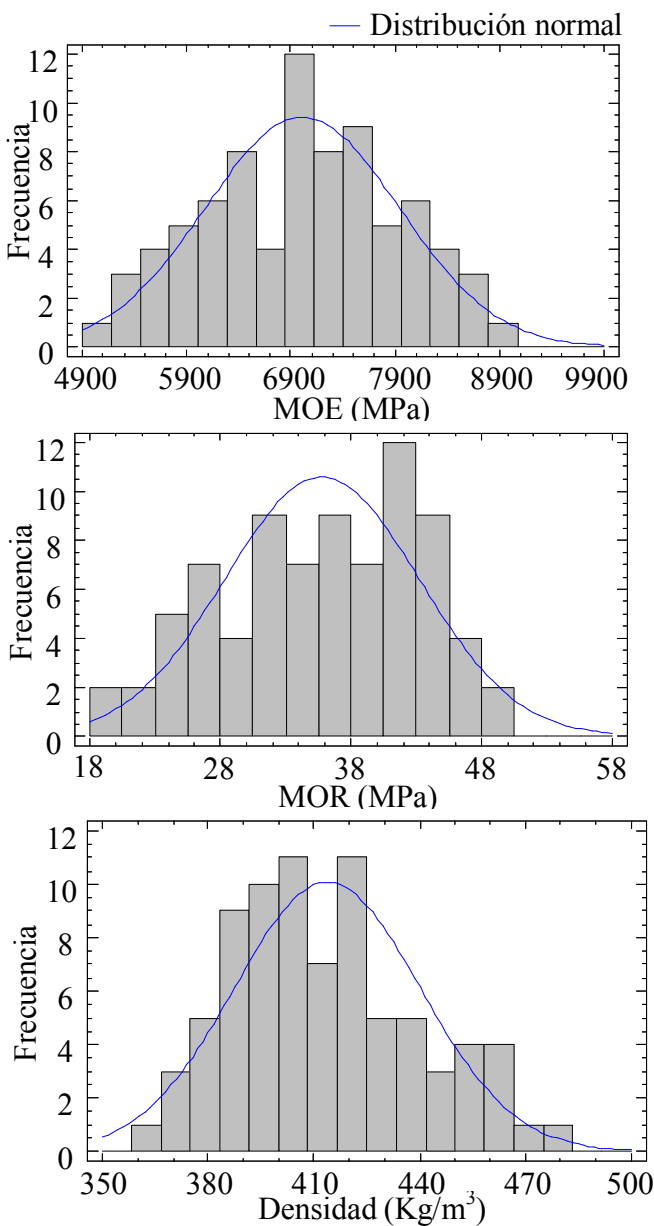

Figura 300. Histograma de Frecuencias MOE, MOR y densidad. Piezas dúos (Argentina). 

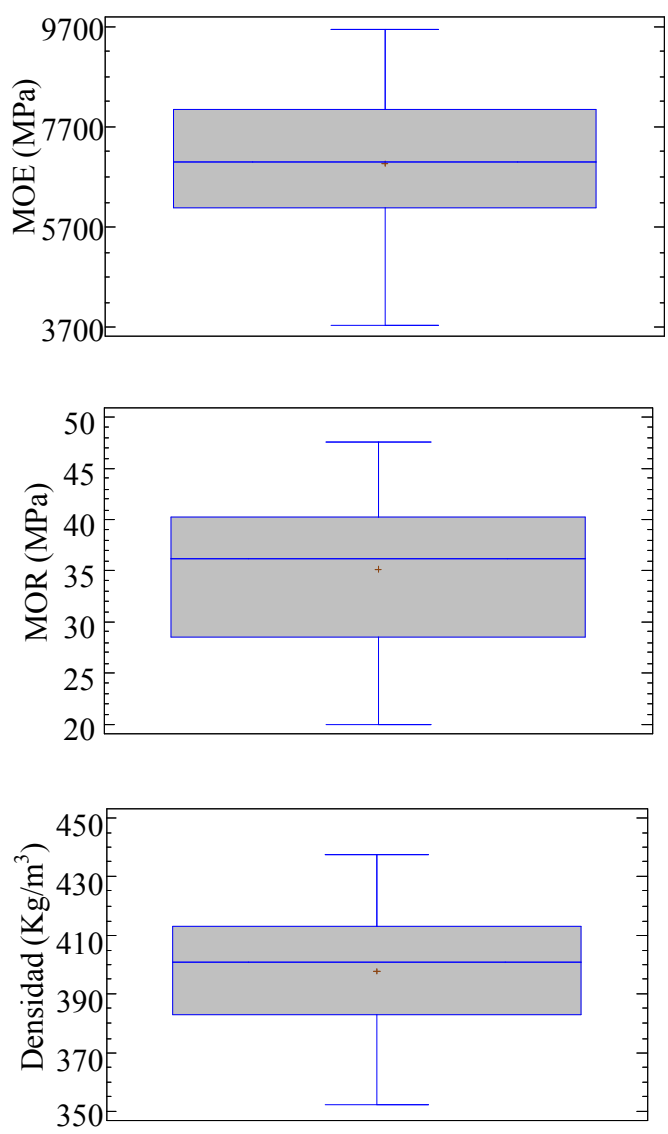

Figura 301. Gráfico de Caja y Bigotes MOE, MOR y densidad. Piezas tríos (Argentina).
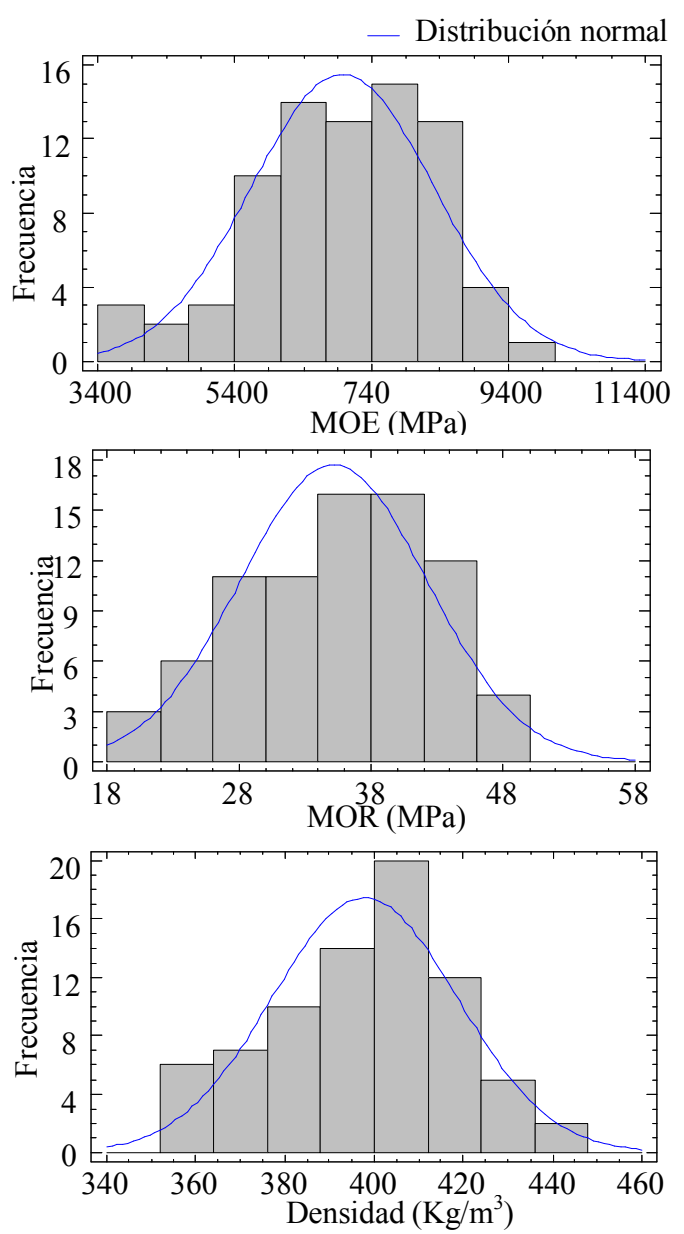

Figura 302. Histograma de Frecuencias MOE, MOR y densidad. Piezas tríos (Argentina).

A fin de evaluar el comportamiento entre los tratamientos realizados (dúo y trío) a continuación se presentan los análisis comparativos realizados entre ambas propuestas, tomando como material testigo el material macizo descrito en 4.3.3; los valores característicos poblacionales, Media para el MOE y $5^{\circ}$ percentil para el MOR y la densidad, se muestran la Figura 303, Figura 304 y Figura 305 , respectivamente. 

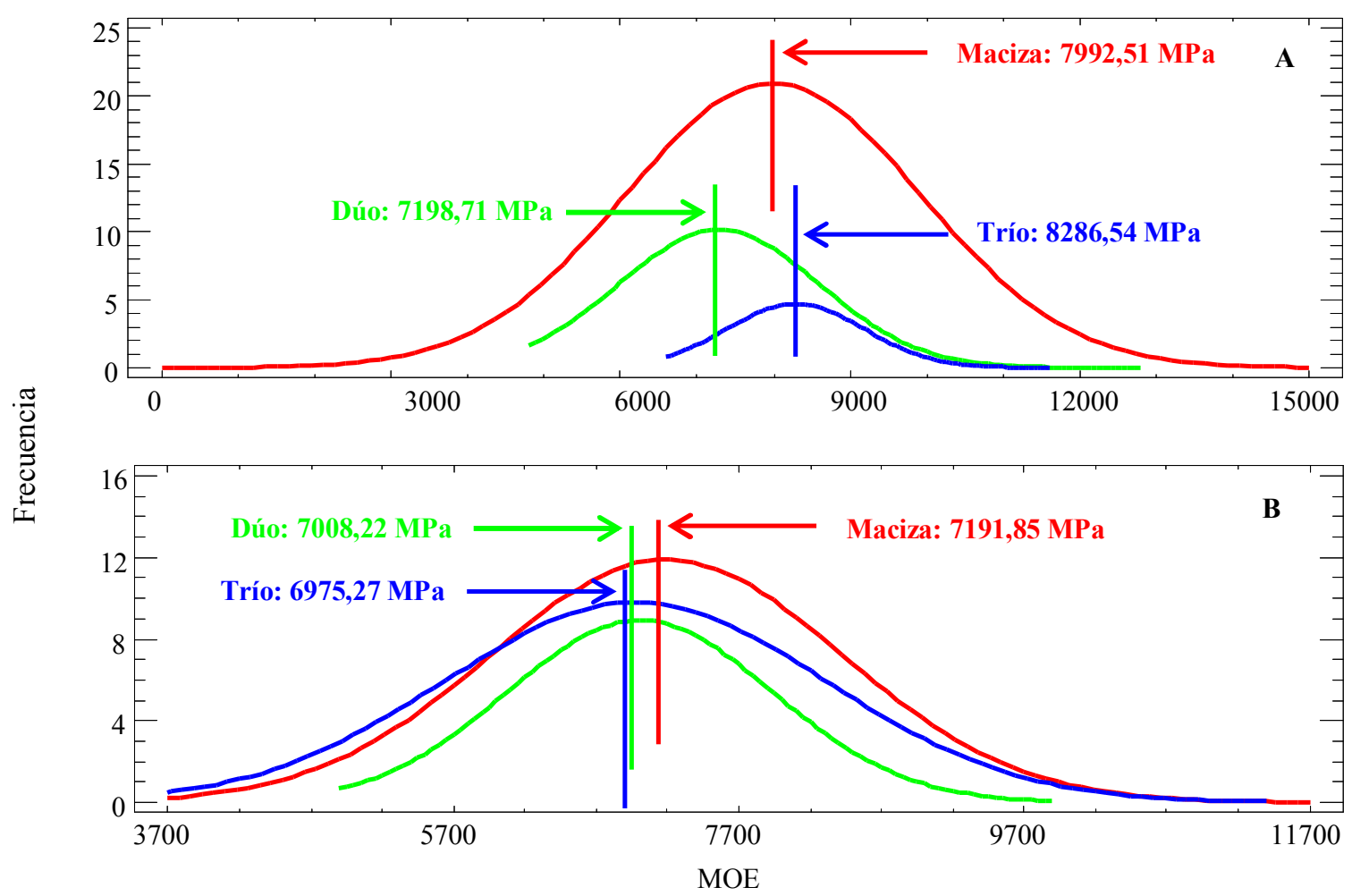

Figura 303. Valores característicos poblacionales del MOE:

A: material de España; B: material de Argentina.

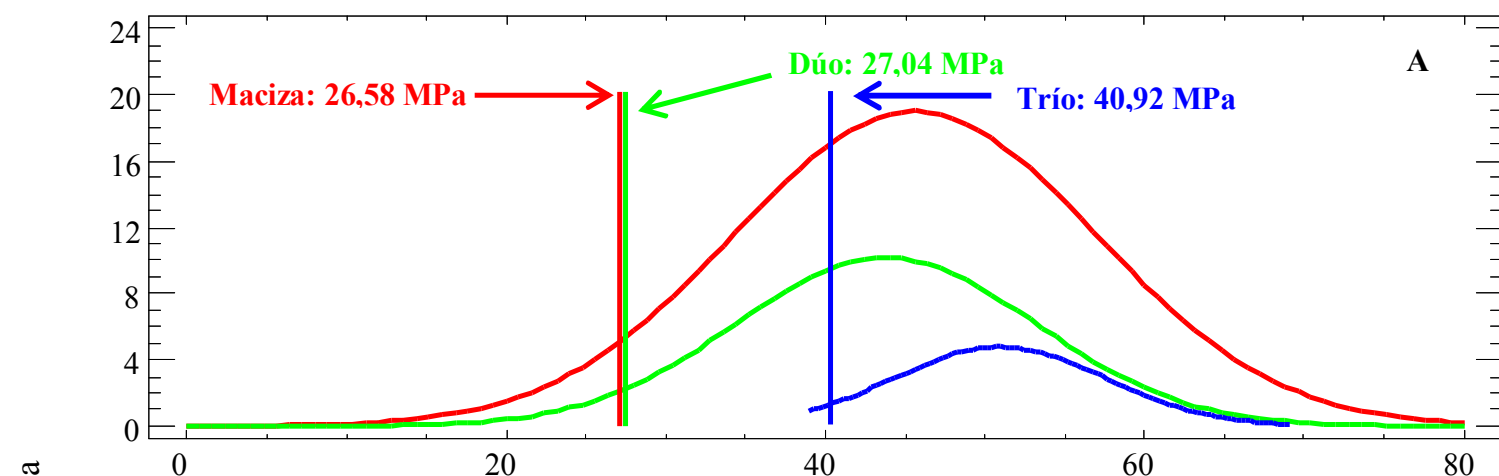

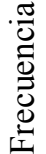

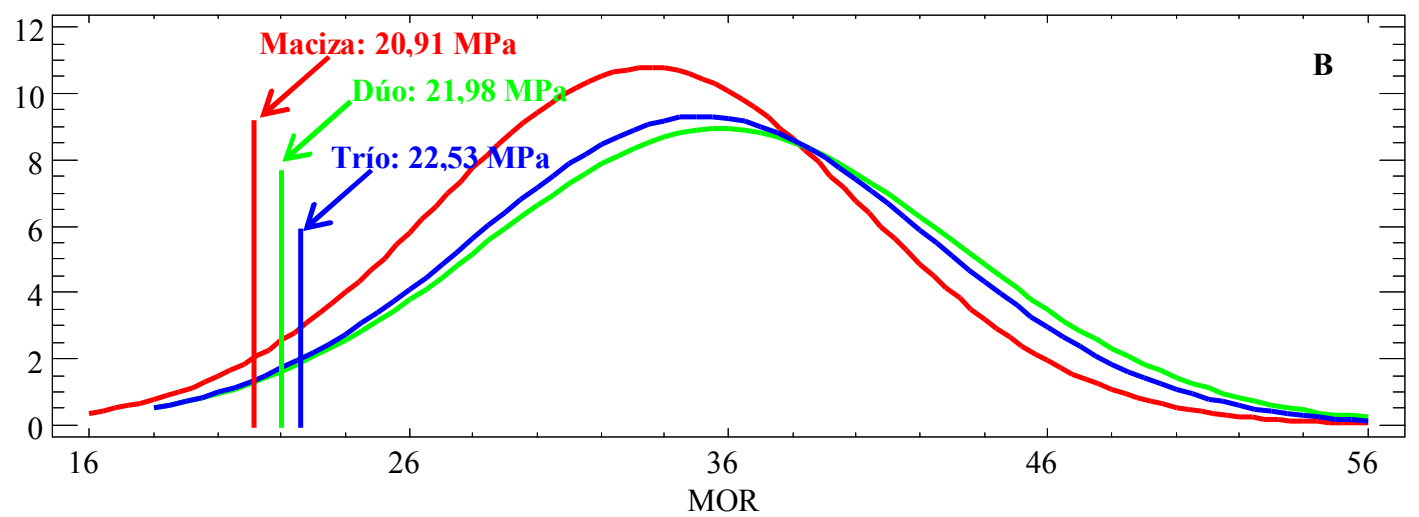

Figura 304. Valores característicos poblacionales del MOR:

A: material de España; B: material de Argentina. 


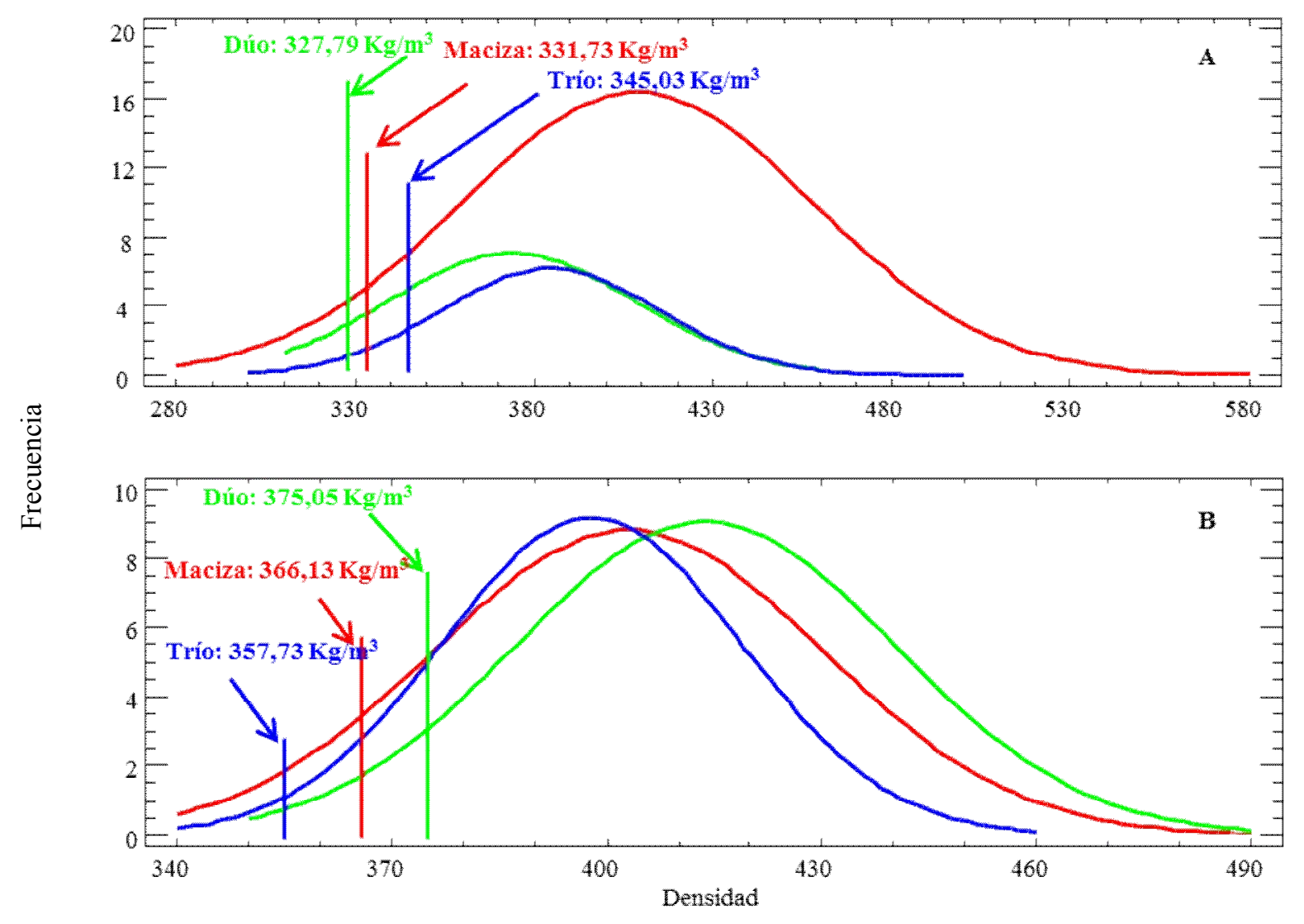

Figura 305. Valores característicos poblacionales de la densidad: A: material de España; B: material de Argentina.

\section{Análisis comparativo: material de procedencia española}

En la Tabla 156 y Tabla 157 se muestra el análisis comparativo para la variable MOE y MOR, respectivamente. Dado el incumplimiento del supuesto de homocedasticidad (Anejos 7.2.2), se trabajó con el test de Kruskal-Wallis para la evaluación de diferencias significativas del modelo y para la evaluación de diferencias entre pares de medianas.

Teniendo en cuenta que el adhesivo empleado puede influir en los valores de densidad, se considerarán únicamente los valores de densidad de piezas macizas, siendo estadísticamente similares entre procedencias, según lo indicado en el apartado 4.3.3.

Tabla 156. Análisis comparativo: MOE - Tipo de pieza (España).

\begin{tabular}{cccc}
\hline \multirow{2}{*}{ Estadístico } & P-valor & Tipo de pieza & \multicolumn{1}{c}{$\begin{array}{l}\text { MOE* } \\
(\mathrm{MPa})\end{array}$} \\
\hline \multirow{2}{*}{19,34} & \multirow{2}{*}{0,00} & Maciza & $7992,51 \mathrm{~A}$ \\
\cline { 3 - 4 } & & Dúo & $7198,71 \quad \mathrm{~B}$ \\
\cline { 3 - 4 } & & Trío & $8286,54 \mathrm{~A}$ \\
\hline
\end{tabular}

*Letras diferentes denotan diferencias significativas entre medianas; MOE: módulo de elasticidad. 
De acuerdo con este análisis puede indicarse que, si bien no se hallaron diferencias significativas entre el MOE en piezas macizas y piezas tríos, a simple vista, los valores elásticos tienden a mejorar en estas últimas piezas. Por su parte, las piezas dúos resultaron con valores de MOE significativamente inferiores respecto a los otros dos tipos de piezas.

Tabla 157. Análisis comparativo: MOR - Tipo de pieza (España).

\begin{tabular}{|c|c|c|c|}
\hline Estadístico & P-valor & Tipo de pieza & $\begin{array}{c}\text { MOR* } \\
(\mathrm{MPa})\end{array}$ \\
\hline \multirow{3}{*}{15,85} & \multirow{3}{*}{0,00} & Maciza & $45,62 \mathrm{~A}$ \\
\hline & & Dúo & $43,80 \mathrm{~A}$ \\
\hline & & Trío & $50,92 \quad$ B \\
\hline
\end{tabular}

*Letras diferentes denotan diferencias significativas entre medianas; MOR: módulo de rotura.

De acuerdo este análisis puede observarse que la mejora resistente se logra con las piezas trío, no hallándose diferencias significativas entre los otros dos tipos de piezas.

\section{Análisis comparativo: material de procedencia argentina.}

El análisis comparativo para MOE, empleando el test de Kruskal-Wallis, y para MOR, empleando el test de ANOVA, se muestra en la Tabla 158 y Tabla 159, respectivamente; en Anejos 7.2.2, se amplían estos resultados.

Tabla 158. MOE - tipo de pieza: análisis comparativo (Argentina).

\begin{tabular}{ccccc}
\hline Kruskal-Wallis & Estadístico & P-valor & Tipo de pieza & $\begin{array}{c}\text { MOE* } \\
(\mathrm{MPa})\end{array}$ \\
\hline \multirow{2}{*}{ MOE-Tipo pieza } & 1,12 & 0,57 & Maciza & $7191,85 \mathrm{~A}$ \\
\cline { 3 - 4 } & & & Dúo & $7008,22 \mathrm{~A}$ \\
\hline
\end{tabular}

*Letras diferentes denotan diferencias significativas entre medianas; MOE: módulo de elasticidad.

Tabla 159. MOR - tipo de pieza: análisis comparativo (Argentina).

\begin{tabular}{ccccc}
\hline ANOVA & Razón - F & P-valor & Tipo de pieza & $\begin{array}{c}\text { MOR* } \\
(\mathrm{MPa})\end{array}$ \\
\hline \multirow{2}{*}{ MOR-Tipo pieza } & 2,38 & 0,10 & Maciza & $33,50 \mathrm{~A}$ \\
\cline { 3 - 4 } & & & Dúo & $35,78 \mathrm{~A}$ \\
\hline
\end{tabular}

*Letras diferentes denotan diferencias significativas, Tukey HSD $(\mathrm{P}<0,05)$; MOR: módulo de rotura. 
El encolado de la madera en el material de procedencia argentina no ha generado diferencias significativas en los valores elasto-resistentes con respecto a la madera maciza.

\section{$\underline{\text { Análisis comparativo entre procedencias }}$}

A continuación se presenta el análisis comparativo realizado a fin de evaluar el comportamiento de las piezas dúos y tríos entre procedencias.

En el caso de incumplimiento estadístico en la distribución de los datos, se trabajó con el Test de Kruskal-Wallis; caso contrario se trabajó con el test paramétrico ANOVA (Anejos 7.2.2).

Tabla 160. MOE: piezas dúos - procedencia: análisis comparativo.

\begin{tabular}{cccc}
\hline Estadístico & P-valor & Procedencia & $\begin{array}{c}\text { MOE* } \\
(\mathrm{MPa})\end{array}$ \\
\hline 0,41 & 0,52 & España & $7198,71 \mathrm{~A}$ \\
\cline { 2 - 4 } & & Argentina & $7008,22 \mathrm{~A}$ \\
\hline
\end{tabular}

*MOE: módulo de elasticidad; letras diferentes denotan diferencias significativas mediante contraste de medianas, KruskalWallis.

Tabla 161. MOR: piezas dúos - procedencia: análisis comparativo.

\begin{tabular}{cccc}
\hline Razón - F & P-valor & Procedencia & $\begin{array}{c}\text { MOR* }^{*} \\
(\mathrm{MPa})\end{array}$ \\
\hline 35,49 & 0,00 & España & $43,80 \mathrm{~A}$ \\
\cline { 2 - 4 } & & Argentina & 35,78 \\
\hline
\end{tabular}

*MOR: módulo de rotura; letras diferentes denotan diferencias, Tukey $\operatorname{HSD}(\mathrm{P}<0,05)$.

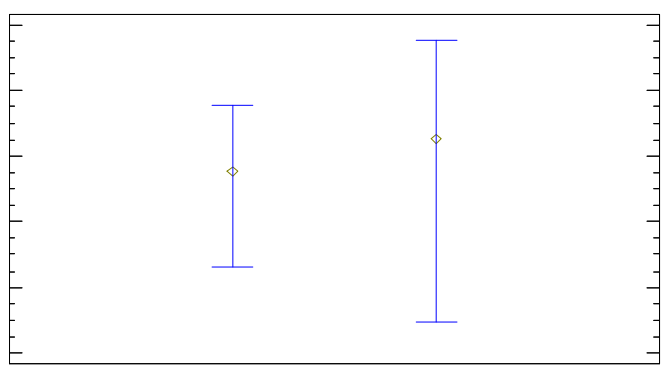

Figura 306. Gráfico de medianas e IC 95\%: MOE. Piezas dúos - Procedencias.

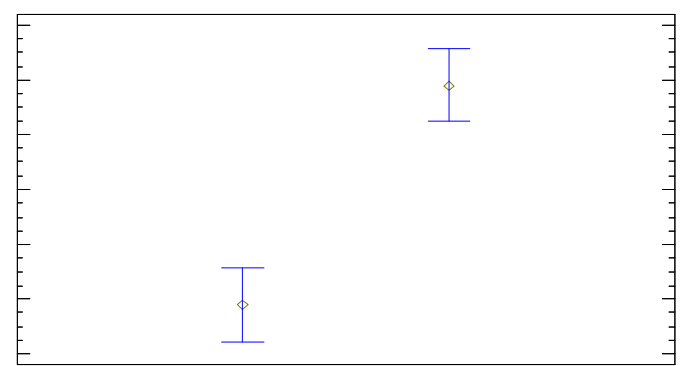

Figura 307. Gráfico de medias e IC 95\%: MOR. Piezas dúos - Procedencias.

Del análisis comparativo se destaca la ausencia de diferencias en el MOE de las piezas dúos para ambas procedencias, mientras que el MOR fue significativamente inferior en el material procedente de Argentina. 
Tabla 162. MOE: Piezas tríos - procedencia: análisis comparativo.

\begin{tabular}{cccc}
\hline Estadístico & P-valor & Procedencia & $\begin{array}{c}\text { MOE* } \\
(\mathrm{MPa})\end{array}$ \\
\hline \multirow{2}{*}{27,74} & 0,00 & España & $8286,54 \mathrm{~A}$ \\
\cline { 2 - 4 } & & Argentina & $6975,27 \quad \mathrm{~B}$ \\
\hline
\end{tabular}

*MOE: módulo de elasticidad; letras diferentes denotan diferencias significativas mediante contraste de medianas, KruskalWallis.

Tabla 163. MOR: Piezas tríos - procedencia: análisis comparativo.

\begin{tabular}{cccc}
\hline Razón - F & P-valor & Procedencia & $\begin{array}{c}\text { MOR } \\
(\mathrm{MPa})\end{array}$ \\
\hline \multirow{2}{*}{147,24} & 0,00 & España & $50,92 \mathrm{~A}$ \\
\cline { 2 - 4 } & & Argentina & $35,16 \quad \mathrm{~B}$ \\
\hline
\end{tabular}

*MOR: módulo de rotura; letras diferentes denotan diferencias, Tukey HSD $(\mathrm{P}<0,05)$.

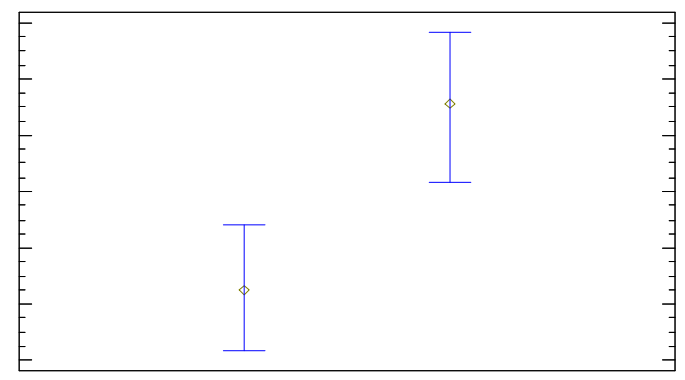

Figura 308. Gráfico de medianas e IC 95\%: MOE. Piezas Tríos - Procedencias.

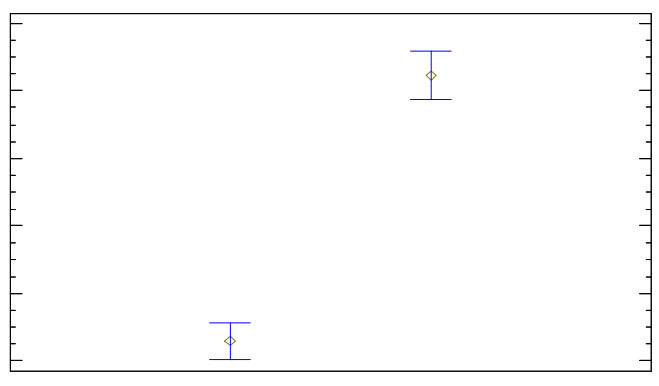

Figura 309. Gráfico de medias e IC 95\%: MOR. Piezas tríos - Procedencias.

El MOE y MOR obtenido en las piezas tríos fueron estadísticamente superiores en el material procedente de España. Teniendo en cuenta la influencia de los daños de insectos en el material macizo de Argentina, a continuación se plantea un análisis sobre dicha influencia en las piezas "parte" constituyentes del material dúo y trío, a fin de determinar si son los responsables de la falta de mejora en dicho material.

Visto los resultados obtenidos en el material encolado y partiendo de la premisa de la ausencia de selección de las piezas parte que constituyeron las piezas encoladas, se procedió a evaluar la influencia de las singularidades presentes en el material de partida y constituyente de las piezas encoladas. En la Tabla 164 se presentan los resultados sobre la clasificación visual realizada en todas las piezas según el procedimiento establecido en la norma UNE 56544: 2011. 
Tabla 164. Piezas dúos-tríos: respuesta clasificatoria y causa de rechazos, norma UNE-56544:2011.

\begin{tabular}{|c|c|c|c|c|c|c|c|c|c|c|c|c|}
\hline \multirow{4}{*}{$\begin{array}{c}\begin{array}{c}\text { Respuesta } \\
\text { clasificatoria }\end{array} \\
\text { Causa: }\end{array}$} & \multicolumn{12}{|c|}{ UNE-56544:2011* } \\
\hline & \multicolumn{6}{|c|}{ Partes constitutivas de piezas dúos } & \multicolumn{6}{|c|}{ Partes constitutivas de piezas tríos } \\
\hline & \multicolumn{3}{|c|}{ España } & \multicolumn{3}{|c|}{ Argentina } & \multicolumn{3}{|c|}{ España } & \multicolumn{3}{|c|}{ Argentina } \\
\hline & ME-1 & ME-2 & $\mathrm{R}$ & ME-1 & ME-2 & $\mathrm{R}$ & ME-1 & ME-2 & $\mathrm{R}$ & ME-1 & ME-2 & $\mathrm{R}$ \\
\hline & 132 & 8 & 20 & 106 & 11 & 43 & 120 & 3 & 12 & 110 & 13 & 114 \\
\hline Nudos cara & & 8 & 7 & & 11 & 6 & & 3 & 4 & & 13 & 35 \\
\hline Nudos canto & & & 2 & & & 6 & & & 5 & & & 20 \\
\hline $\begin{array}{c}\text { Nudos } \\
\text { cara/canto }\end{array}$ & & & 11 & & & 12 & & & 3 & & & 19 \\
\hline Entrecasco & & & - & & & - & & & - & & & 12 \\
\hline $\begin{array}{c}\text { Galería de } \\
\text { insecto }\end{array}$ & & & - & & & 19 & & & - & & & 28 \\
\hline $\mathrm{n}^{*}$ & & 160 & & & 160 & & & 135 & & & 237 & \\
\hline
\end{tabular}

*n: número de individuos (piezas partes) totales; en cada columna se expresa el número de individuos clasificados en la clase correspondiente.

En el material procedente de España, piezas dúos y tríos, las principales causas de rechazos estuvieron representadas por la presencia de nudos, principalmente ante la presencia de nudos de cara y de canto juntos. Sin embargo, en las piezas dúos y tríos obtenidas del material procedente de Argentina, las principales causas de rechazos estuvieron representadas por la presencia de galerías ocasionados por insectos, aunque también se presentó una proporción importante de rechazos por la presencia de nudos.

De acuerdo con esto, y remitiéndonos en primer término a los resultados hallados en las piezas dúos (Tabla 160), puede inferirse que los valores significativamente inferiores en las piezas procedentes de Argentina, guardan estrecha relación con la presencia de los daños ocasionados por los insectos, no afectando los valores elásticos.

Asimismo, en lo referente a los resultados hallados en las piezas tríos, tanto los valores de MOE y MOR se vieron disminuidos significativamente en el material de Argentina, Tabla 162 y Tabla 163. En este sentido, es esperable que dichos valores guarden estrecha relación con la gran proporción de piezas rechazadas por la presencia de nudos y galerías empleadas en la constitución del material encolado.

\subsubsection{Valores elasto-resistentes del material encolado reagrupado por clases visuales}

Con la finalidad de evidenciar los valores elasto-resistentes en cada clase, se realizó un reclasificación de las piezas encoladas, realizando las siguientes consideraciones: si las piezas dúos o tríos estaban constituida por al menos una pieza de rechazo, el material encolado era considerado como rechazo; del mismo modo, si el material encolado estaba constituido por al menos una pieza 
ME-2, la pieza encolada fue considerada como calidad inferior (CI). Las piezas constituidas por elementos ME-1 fueron consideradas clase superior (CS). En base a dicha re-clasificación se procedió a evaluar los valores elasto- resistentes establecido en cada clase, Tabla 165 (Figura 310, Figura 311).

Tabla 165. Análisis descriptivo: MOE y MOR por clases.

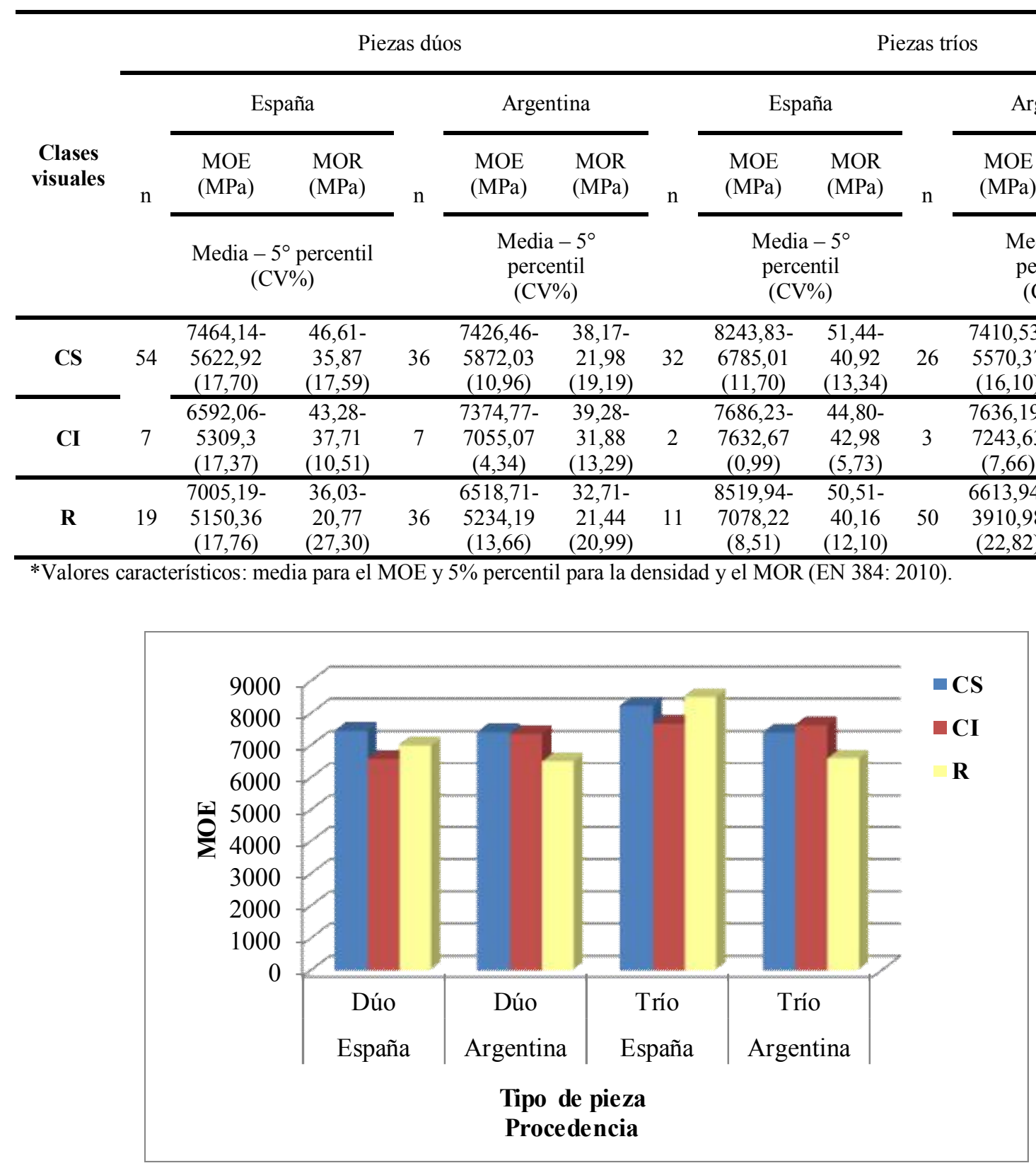

Figura 310. MOE por tipo de especie-procedencia. 


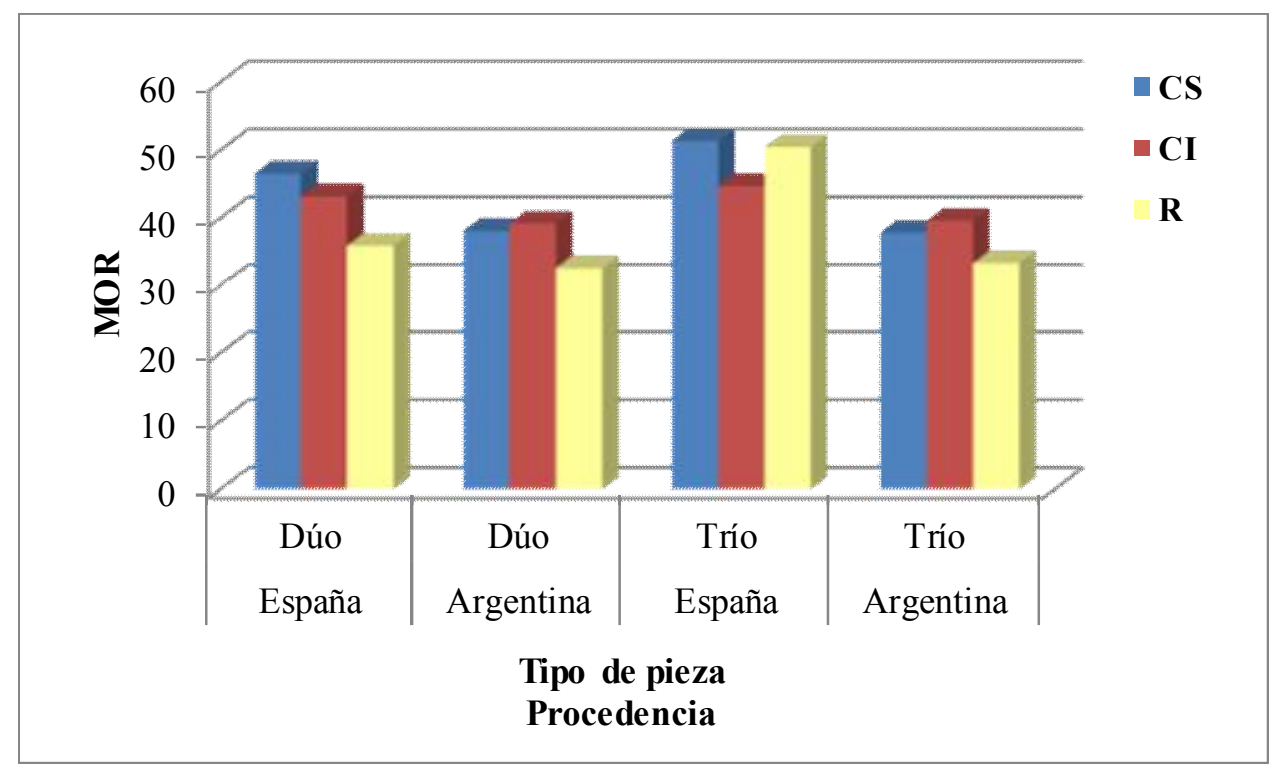

Figura 311. MOR por tipo de especie-procedencia.

De acuerdo a lo observado, puede indicarse que según el agrupamiento visual, los valores resistentes son los más afectados por el efecto de las singularidades y existe una influencia creciente a medida que nos desplazamos de la clase estructural superior hacía la clase de rechazo. Sin embargo, para el caso del MOE, no existe un comportamiento homogéneo en cuanto a los valores resistentes hallados en cada clase visual establecida, esto es, en algunos casos pueden verse valores de elasticidad superiores en la clase estructural inferior o inclusive, en la clase no estructural (rechazo).

\subsection{Piezas macizas estructurales.}

\subsubsection{Evaluación no destructiva}

\subsubsection{Propuesta de mejora de norma de clasificación visual}

En base a los resultados obtenidos en cuanto a la influencia de las singularidades en la determinación de los valores elasto-resistentes y de la densidad, las cuales en mayor o menor proporción afectan dichos valores, es importante dejar plasmado en una norma los aspectos más importantes a considerar para una correcta utilización de la madera de Populus x euramericana I-214 actualmente comercializable en el mercado español. Para ello, se han propuesto una serie de criterios, tomando como base los criterios clasificatorios considerados en la actual norma de clasificación vigente en España (UNE 56544: 2011), que entre otras consideraciones no incorpora a dicha especie dentro de su alcance. 
Tabla 166. Criterios de clasificación propuestos en la norma de clasificación visual.

\begin{tabular}{|c|c|c|c|}
\hline $\begin{array}{c}\text { Criterios de } \\
\text { calidad }\end{array}$ & & Clase I & Clase II \\
\hline $\begin{array}{c}\text { Diámetros nudo } \\
\text { de cara }\end{array}$ & & $\leq 1 / 3$ & $\leq 2 / 3$ \\
\hline $\begin{array}{l}\text { Diámetro nudos } \\
\text { de canto }\end{array}$ & & & $2 / 3$ \\
\hline $\begin{array}{c}\text { Anchura de } \\
\text { anillos }\end{array}$ & & $\leq 12 \mathrm{~mm}$ & $\leq 10 \mathrm{~mm}$ \\
\hline Entrecasco & & \multicolumn{2}{|c|}{ Se admiten si su longitud es $\leq$ a $1,5 \mathrm{~h}$} \\
\hline $\begin{array}{l}\text { Desviación de } \\
\text { las fibras }\end{array}$ & & \multicolumn{2}{|c|}{ Admitida } \\
\hline \multirow{2}{*}{ Gemas } & Longitud & \multicolumn{2}{|c|}{$1 / 31 / \mathrm{L}$} \\
\hline & Anchura & \multicolumn{2}{|c|}{$\leq 1 / 3 \mathrm{~h} / \mathrm{H}$} \\
\hline Médula & & No admitida & Admitida \\
\hline $\begin{array}{c}\text { Curvatura de } \\
\text { cara }\end{array}$ & & $\begin{array}{l}10 \mathrm{~mm} \text { para una longitud de } 2 \\
\text { metros }\end{array}$ & $15 \mathrm{~mm}$ para una longitud de 2 metros \\
\hline $\begin{array}{l}\text { Curvatura de } \\
\text { canto }\end{array}$ & & $\begin{array}{l}8 \mathrm{~mm} \text { para una longitud de } 2 \\
\text { metros }\end{array}$ & $12 \mathrm{~mm}$ para una longitud de 2 metros \\
\hline Alabeo & & $1 \mathrm{~mm}$ por cada $25 \mathrm{~mm}$ de $\mathrm{h}$ & $2 \mathrm{~mm}$ por cada $25 \mathrm{~mm}$ de $\mathrm{h}$ \\
\hline Abarquillado & & $1 \mathrm{~mm}$ por cada $25 \mathrm{~mm}$ de $\mathrm{h}$ & $2 \mathrm{~mm}$ por cada $25 \mathrm{~mm}$ de $\mathrm{h}$ \\
\hline Alteraciones & & \multicolumn{2}{|c|}{ No admitidas } \\
\hline Corte & & Tangencial & Admitidos todos \\
\hline
\end{tabular}

De acuerdo con las modificaciones e incorporaciones plasmadas en la propuesta de norma, se evaluó su comportamiento clasificatorio, Tabla 167. En base a ello, se realizó un análisis sobre los valores resistentes perteneciente a la clasificación lograda, Tabla 168.

Tabla 167. Comportamiento de la norma de clasificación propuesta.

\begin{tabular}{|c|c|}
\hline RESPUESTA CLASIFICATORIA & Criterios de clasificación propuestos \\
\hline ACIERTO n; $(\%)^{*}$ & $365(38,67)$ \\
\hline Rechazos (\%) & $261(27,65)$ \\
\hline Clase I (\%) & $0(0)$ \\
\hline Clase II (\%) & $104(11,02)$ \\
\hline SUBESTIMA n; $(\%)^{*}$ & $491(52,01)$ \\
\hline Rechazos $(\%) ;($ Clase II)** & $344(36,44)$ \\
\hline Rechazos $(\%) ;($ Clase I)** & $114(12,08)$ \\
\hline Clase II $(\%) ;(\text { Clase I })^{* *}$ & $33(3,50)$ \\
\hline SOBRESTIMA n; (\%)* & $88(9,32)$ \\
\hline Clase II $(\%) ;(\text { Rechazos })^{* *}$ & $88(9,32)$ \\
\hline Clase I (\%); (Rechazos)** & $0(0)$ \\
\hline Clase I $(\%) ;(\text { Clase II })^{* *}$ & $0(0)$ \\
\hline
\end{tabular}

*n: número de piezas clasificadas dentro de la clase; (\%): porcentaje de piezas analizadas respecto al total (944 piezas); ${ }^{* *}$ Clase resistente real. 
Tabla 168. Análisis descriptivo de la norma de clasificación visual propuesta.

\begin{tabular}{|c|c|c|c|c|}
\hline & $\mathbf{n}$ & $\begin{array}{c}\text { Media } \\
(\mathrm{CV} \%)\end{array}$ & $\begin{array}{c}\text { Mín. -Máx. } \\
\text { (IQR) }\end{array}$ & $5 \%$ Percentil \\
\hline Clase I & - & - & - & - \\
\hline \multicolumn{5}{|l|}{ Clase II } \\
\hline $\operatorname{MOE}(\mathrm{MPa})^{*}$ & 221 & $\begin{array}{l}7464,05 \\
(18,51) \\
\end{array}$ & $\begin{array}{c}4100,0-11363,2 \\
(1915,12)\end{array}$ & 5494,49 \\
\hline $\operatorname{MOR}(\mathrm{MPa})^{*}$ & 225 & $\begin{array}{c}40,50 \\
(27,38)\end{array}$ & $\begin{array}{c}10,88-70,77 \\
(13,87)\end{array}$ & 21,89 \\
\hline Densidad $\left(\mathrm{Kg} / \mathrm{m}^{3}\right)^{*}$ & 225 & $\begin{array}{l}358,99 \\
(11,30) \\
\end{array}$ & $\begin{array}{c}273,41-497,57 \\
(63,24)\end{array}$ & 308,36 \\
\hline \multicolumn{5}{|l|}{ Rechazo } \\
\hline $\operatorname{MOE}(\mathrm{MPa})^{*}$ & 694 & $\begin{array}{l}7528,15 \\
(18,19)\end{array}$ & $\begin{array}{c}3766,97-11450,9 \\
(1778,88)\end{array}$ & 5615,83 \\
\hline $\operatorname{MOR}(\mathrm{MPa})^{*}$ & 716 & $\begin{array}{c}39,14 \\
(29,84)\end{array}$ & $\begin{array}{c}10,73-71,16 \\
(16,85)\end{array}$ & 19,67 \\
\hline Densidad $\left(\mathrm{Kg} / \mathrm{m}^{3}\right)^{*}$ & 719 & $\begin{array}{l}363,11 \\
(11,81)\end{array}$ & $\begin{array}{c}277,93-563,37 \\
(63,58)\end{array}$ & 309,52 \\
\hline
\end{tabular}

Los criterios clasificatorios propuestos lograron mejorar levemente el porcentaje de aciertos con respecto a ambas versiones de la norma UNE 56544. Del mismo modo, el resultado más favorable y alentador está relacionado con la menor proporción de sobreestimas obtenidas, aunque a expensas de un porcentaje más elevado de subestimas con respecto a las normas antes mencionado. De todos modos, a los fines de uso estructural del material siempre es preferible un resultado más conservador.

Asimismo y como conclusión general, ya antes predicha, debe recalcarse la deficiente calidad del material actualmente comercializado, ya que independientemente de las mejoras logradas con esta propuesta, la clase estructural superior no logró ser representada en esta clasificación.

\subsubsection{Procedimiento para control triboluminiscente de sobrecarga en madera estructural}

Dado que las mejoras propuestas en la normativa no han sido del todo satisfactorias para el material en estudio, se ha planteado un procedimiento para controlar la sobrecarga de madera estructural cuando la misma está puesta en servicio. Dado que este procedimiento fue planteado bajo un Título de Propiedad Intelectual, solicitud de patente P201400866, a continuación se anexa el desarrollo del mismo con su formato original. La solicitud de dicha patente se adjunta en Anejos 7.3.1.1.

Estado de la técnica:

El campo de industrialización, comercialización y utilización de la madera con fines estructurales es muy amplio y entre las diversas consideraciones a tener en cuenta para su aplicación en estos fines, se 
encuentra la determinación de la resistencia máxima que la misma pueda soportar durante su vida útil en servicio. En este sentido, diversas técnicas de ensayos no destructivos (clasificación visual, ultrasonidos, vibraciones inducidas, entre otras) y destructivos (técnica en máquina universal de ensayo) son realizados para establecer grados de calidad resistente; dicha resistencia estructural variará de acuerdo con las diferentes especies madereras como así también dependerá de la solicitación a la que esté expuesta (flexión, compresión paralela, entre otros).

Asimismo, uno de los factores limitantes en el uso de la madera cuando es utilizada como material estructural principal o secundario, es la determinación o el conocimiento de valores de sobrecarga a los que la misma pueda estar expuesta durante dicha vida útil en servicio. Esto es, se necesitan conocer estos valores de sobrecarga a fin de constituir una medida de seguridad para poder actuar en consecuencia, ante algún tipo de eventualidad.

Desde el siglo XVII es conocido que la radiación luminosa se desvía al atravesar un medio de densidad distinta, por lo que al salir del medio que atraviesan, los componentes de la radiación salen separados por distintos ángulos y se pueden identificar visualmente por los diferentes colores que muestran. La principal emisión de radiación de los cuerpos es la radiación electromagnética en forma de luz visible. Asimismo, cuando un elemento irradia energía no lo hace en todas las longitudes de onda sino solamente en aquellas de las que está "provisto". Esas longitudes de onda sirven para caracterizar, por tanto, a cada elemento. También ocurre que cuando un elemento recibe energía no absorbe todas las longitudes de onda, sino solo aquellas de las que es capaz de "proveerse". Coinciden por tanto, las bandas del espectro en las que emite radiación con los huecos o líneas negras del espectro de absorción de la radiación, como si un espectro fuera el negativo del otro. Todos los cuerpos emiten y absorben energía a ciertas temperaturas. El espectro de la radiación energética emitida/absorbida es su espectro de emisión/absorción. Cada uno de los elementos químicos tiene su propio espectro de emisión y de absorción, lo cual sirve para identificarlos.

De este modo, existen aparatos capaces de obtener el espectro de una radiación, es decir, de separar la radiación en sus componentes: espectroscopio; de fotografiarla: espectrógrafo y de medirla: espectrómetro. Cuando es capaz de medir la intensidad de la radiación, se llama espectrofotómetro.

Dependiendo de la energía que origina esa radiación o emisión de luz, se puede hablar de diferentes clases de luminiscencia. En esta invención sólo consideraremos la Triboluminiscencia, TL (también referible como fractoluminiscencia o mecanoluminiscencia), que consiste en la emisión de luz que acompaña a la deformación y/o rotura mecánica de ciertos compuestos cristalinos (Xu et al., 1999). 
En este sentido, existen un gran número de sales inorgánicas y compuestos sólidos orgánicos que muestran esta característica y por lo tanto producen luminiscencia debido a la creación de nuevas superficies cargadas durante su fractura (Takada et al., 1997).

La primera referencia a la utilización del fenómeno de la triboluminiscencia procede de los indios ute, pobladores de la región de Colorado Central, quienes desde una remota antigüedad han utilizado sonajas de cristales de cuarzo para generar luz. Tales sonajas, de uso ceremonial, se elaboraban con piel de búfalo (traslúcida), que se rellenaba con cristales de cuarzo. Cuando, durante las ceremonias nocturnas, las sacudían los chamanes, la fricción y la tensión mecánica de los cristales de cuarzo producían destellos de luz triboluminiscente.

En tiempos modernos, Nicolas Monardes (1508-1588) refirió la triboluminiscencia haciéndose eco de observaciones de porteadores sevillanos de sacos de azúcar en noches sin luna. En 1663 el científico Robert Boyle también informó acerca de algunos de sus trabajos sobre la triboluminiscencia.

Otra teoría, también reciente, sobre la triboluminiscencia es que la emisión de luz procede de una ruptura de conexiones intermoleculares dentro de cristales asimétricos. Las fracturas inducen una separación de cargas dentro de la malla cristalina y sus recombinaciones producen emisión de luz (Walton, 1977; Sweeting et al., 1997).

Actualmente, algunos científicos de la Universidad de Illinois en Urbana-Champaign han empleado el método de ultrasonido de alta intensidad en soluciones acuosas de azúcar y otros cristales orgánicos para crear una triboluminiscencia mil veces más intensa que en la pulverización (Eddingsaas and Suslick, 2006).

Asimismo, dentro de las Tierras raras -nombre común otorgado a 17 elementos químicos: escandio, itrio, y 15 elementos del grupo de lantánidos (lantano, cerio, preseodimio, neodimio, prometio, samario, europio, gadolinio, terbio, disprosio, holmio, erbio, tulio, iterbio y lutecio)- los complejos de europio (III), erbio (III), iterbio (III) y algunos materiales dopados con ellos, también presentan este fenómeno (Akiyama et al., 2002; Hurt et al., 1966). El europio se encuentra en la naturaleza en sus dos formas más estables: Eu 153 y Eu 151 esencialmente en minerales como la monacita, xenotima y bastnasita. Otras formas isotópicas (Eu 150, 152, 154 y 155) se obtienen a partir de procesos de fisión nuclear de uranio o plutonio. Estos isótopos se desexcitan con emisiones peligrosas de radiaciones $\beta$ y $\gamma$ con una vida media de entre 5 y 34 años. Aunque no es una de las tierras raras más utilizadas, se pueden encontrar ejemplos de compuestos de europio en distintas aplicaciones como por ejemplo: 
detección de cromo en el medio ambiente, absorbente de neutrones procedentes de fisiones en reactores nucleares y detección de sustancias tóxicas (Briz et al., 2006).

En los últimos años se ha incrementado el interés de estas sustancias debido a sus excepcionales propiedades de luminiscentes (foto-, electro- y triboluminiscencia). En efecto, las emisiones de luz de este compuesto en los estados de oxidación II y III son uno de los más puras en la obtención de colores como el azul $\left(\mathrm{Eu}^{2+}\right)$ y el rojo $\left(\mathrm{Eu}^{3+}\right)$, haciendo de ellos compuestos excepcionales para aplicaciones innovadoras e interesantes como usos en fibra óptica, fotoalmacenamiento, en diodos inorgánicos y láser, como marcadores en medicina y en diodos orgánicos electroluminiscentes -OLED- (Briz et al., 2006).

El europio en su estado de oxidación III es la forma más utilizada de este elemento y comercialmente se encuentra en forma de sales como por ejemplo el $\mathrm{Eu}_{2} \mathrm{O}_{3}, \mathrm{EuCl}_{3} ; \mathrm{Eu}\left(\mathrm{NO}_{3}\right)_{3}$. Este tipo de sales se emplean para la preparación de compuestos inorgánicos que, de forma similar al Eu(II), incorporan al catión como agente dopante. Algunos ejemplos de estos compuestos lo constituyen: $\mathrm{ZrSiO}_{4}: \mathrm{Eu}$; $\mathrm{GaN}: \mathrm{Eu} ; \mathrm{CaS}: \mathrm{Eu} ; \mathrm{Y}_{2} \mathrm{O}_{3}: \mathrm{Eu}$. Los compuestos anteriores, así como las nanopartículas de $\mathrm{Eu}_{2} \mathrm{O}_{3}$, se suelen utilizar para la preparación de semiconductores de tipo-p mediante técnicas de sol-gel, epitaxia y síntesis en fase sólida (Briz et al., 2006).

Otra manera de potenciar las propiedades de $\mathrm{Eu}^{3+}$ es empleándolo en complejos órgano-metálicos que permiten la adición de propiedades físicas y/o un incremento de su emisión intrínseca, para lo cual la estructura del complejo no debe ser centro-simétrica si se pretende llegar a su emisión máxima. Una parte de los complejos de europio(III) y algunos compuestos inorgánicos dopados con $\mathrm{Eu}^{2+} \mathrm{o} \mathrm{Eu}^{3+}$ presentan este fenómeno. En el caso de los complejos $\mathrm{Eu}^{3+}$, una de las condiciones necesarias parece ser la funcionalización de los ligandos con grupos moleculares que induzcan un desorden en estado sólido, lo que favorece la no simetría y por lo tanto, la separación de cargas durante la fractura (Cheng et al., 2002). Por ejemplo, en el complejo que se representa en la Figura 1, la triboluminiscencia se atribuye a la presencia de la cadena perfluorada (Yu et al., 2004).

La emisión de luz por triboluminiscencia es generalmente la misma que se observa por fotoluminiscencia y en el caso de los complejos de europio (como así también en los de erbio) es más intensa que la de otros materiales triboluminiscentes (Hurt et al., 1966).

Al respecto, Takada et al., 1997, en una investigación realizada sobre las propiedades mecanoluminiscentes de complejos de europio utilizando ligandos derivados de la fenantrolina observaron que de los cuatros compuestos analizados (Figura 2), sólo el $\operatorname{Eu}(\mathrm{TTA})_{3}$ (phen) y 
$\mathrm{Eu}(\mathrm{TTA})_{3}(5$-methyl-phen) -en forma de polvo- fueron los que mostraron el fenómeno, el cual fue lo suficientemente fuerte para ser visible a la luz del día.

Asimismo, algunos óxidos mixtos dopados con Europio $\mathrm{Sr}_{3} \mathrm{Al}_{2} \mathrm{O}_{6}: \mathrm{Eu}^{2+} ; \operatorname{SrMgAl}_{6} \mathrm{O}_{11}: \mathrm{Eu}^{2+} ; \mathrm{Sr}_{1-}$ ${ }_{x} \mathrm{BaxAl}_{2} \mathrm{O}_{4}: \mathrm{Eu}^{3+}$ presentan igualmente propiedades triboluminiscentes con alta emisión, pero en este caso los mecanismos de excitación son muy poco conocidos. Si bien queda mucho por estudiar sobre las propiedades triboluminiscentes de estos compuestos, sus características radiantes han llevado a la creación de sensores de deformación o ruptura en fibras ópticas y plásticos de alta deformación (Briz et al., 2006).

Del mismo modo, existen otras sustancias dopadas con otros elementos, como es el caso del sulfuro de Zinc dopado de manganeso, que también presentan estas propiedades. Al respecto, Xu et al., 1999, han realizado estudios sobre la elaboración de un film de sulfuro de $\mathrm{Zn}$ dopado con Mn mediante el cual han obtenido resultados promisorios desde el punto de vista de TL.

Asimismo, a continuación se citan algunas patentes y referencias que revelan el uso de la triboluminiscencia o de material triboluminiscentes en algún contexto específico: Zhang et al., 2004; Mastro et al. U.S. Pat. No. 6,710,328 B1 issued Mar. 23, 2004; Qiu et al. U.S. Pat. No. 6,281,617 B1 issued Aug. 18, 2001; Storey U.S. Pat. No. 6,270,117 B1 issued Aug. 7, 2001; Akiyama et al. U.S. Pat. No. 6,159,394 issued Dec. 12, 2000; Hall-Goulle U.S. Pat. No. 6,071,632 issued Jun. 6, 2000; Watanabe et al. U.S. Pat. No. 6,117,574 issued Sep. 12, 2000; Sage et al, U.S. Pat. No. 5,905,260, issued May 18, 1999; Xu et al., 1999; Takada et al., 1997; Hansma et al. U.S. Pat. No. 5,581,082 issued Dec. 3, 1996; Pappalardo et al. U.S. Pat. No. 4,772,417 issued Sep. 20, 1988; Dante U.S. Pat. No. 4,372,211 issued Feb. 8, 1983; Glass, deceased et al. U.S. Pat. No. 4,020,765 issued May 3, 1977.

En este contexto, y dada la estructura anatómica de la madera, constituida por diversos elementos que le otorgan porosidad y permeabilidad, en la presente invención se plantea el uso de sustancias químicas triboluminiscentes, de fácil cristalización y capaces de penetrar en su interior. Para esto, se requiere de un método de impregnación por vacío presión, por ser el apropiado para permitir la penetración de las sustancias químicas a una profundidad de al menos, 1/4 de la sección de referencia. La función de esta sustancia triboluminiscente es la de "sensor - detector" de sobrecargas estructurales en madera en uso, emitiendo luminiscencia cuando esto ocurra.

En base a esto, la presente invención podría enmarcarse como una técnica de carácter no destructivo, al igual que muchas de las técnicas ampliamente utilizadas en la actualidad, cuya finalidad es estimar los valores elasto-resistente de las maderas puestas en servicio; cuestiones inherentes a diferentes 
metodologías de ensayos no destructivos pueden encontrarse en diversos trabajos de investigación y patentes (Casado et al., 2012; Casado et al., 2011; Wu et al., 2011; Divos \& Sismandy Kiss, 2010; Casado et al., 2009; Carballo Collar et al., 2009; Acuña, et al., 2007; Basterra et al., 2006; Bicho et al., 2006; Álvarez, et al., 2005; Casado et al., 2005; Schafer et al., 2008; Fry et al., 1993, entre otros).

Referencias bibliográficas

Acuña, L.; I. Barranco; M. Casado; C. Martínez; A. González. 2007. Análisis y validación de la técnica resistográfica aplicada a la madera estructural. $11^{\circ}$ Congreso de Ensayos no Destructivos. Sociedad Española de Ensayos no Destructivos AEND. Gijón. 343 - 354.

Álvarez, J.; L. Acuña; I. Barranco; M. Casado. 2005. Aplicación del resistógrafo al diagnóstico de elementos singulares en estructuras de madera. Jornadas de Investigación en la Construcción Instituto Torroja. Madrid. $12 \mathrm{Pp}$.

Akiyama M.; C.N. Xu; K. Nonaka. 2002. Intense Deformation Luminescence from Sintered Sr 3Al 2O 6: Eu. Journal of the Ceramic Society of Japan. Ceramic Soc of Japan, 110(1287), 10291031.

Akiyama M.; C. Xu; K. Nonaka; T. Watanabe. 2000. Stress emission material and its manufacturing method. Patent US6159394A, 4 Pp.

Basterra, L.A.; M. Casado; L. Acuña; O. Pinazo. 2006. Techniques of pseudo-nondestructive testing on structural wood, by extraction of screws. Revista: ReCo PaR. № 2, 37-59.

Bicho, P.; S. Huntley; D. Leclerc; T. Trung; P. Watson. 2006. Method for determining native wood constituents using visible-light raman spectrometry. Patent WO2006086873A1.

Briz, A.; M. de la Fuente; L. Bautista; L. Aubouy; A. Paz; O. García; M. Dela Varga; M. Tzvetkova; J. Parra. 2006. Europio: naturaleza, luminiscencia y aplicaciones. An. Química, 102(4), 40-45.

Carballo Collar, J.; E. Hermoso Prieto y R. Díez Barra. 2009. Ensayos no destructivos sobre madera estructural. Una revisión de 30 años en España. Nota Técnica. Kurú: Revista Forestal (Costa Rica) 6 (17), 2009. $16 \mathrm{Pp}$.

Casado, M.; L. Acuña; L.A. Basterra; G. Ramón-Cueto; D. Vecilla. 2012. Grading of structural timber of Populus $\times$ euramericana clone I-214. Holzforschung 66 (5): 633-638. 
Casado, M.; L. Acuña; D. Vecilla; L.A. Basterra; E. Relea; G. López. 2011. Ultrasonidos y parámetros de clasificación visual para la caracterización de madera estructural de Populus x Euramericana I-214. $1^{\circ}$ Congresso Ibero-LatinoAmericano da Madeira na Construção. Coimbra, Portugal. 9 Pp.

Casado, M.; L. Acuña; D. Vecilla; A. Basterra; E. Relea; G. López; G. Ramón. 2009. “Técnicas vibratorias aplicadas a madera estructural de Populus x euramericana". V Congreso Forestal Español. Ávila. $14 \mathrm{Pp}$.

Casado, M.; A. Basterra; L. Acuña; O. Pinazo.; C. Martínez; E. Relea; I. Barranco; G. Ramón. 2005. Determinación de la capacidad resistente mediante métodos no destructivos. Aplicación en viguetas de forjado de un edificio singular. IV Congreso Forestal Español. Zaragoza, $10 \mathrm{Pp}$.

Cheng, X.F.; X.H. Zhu; Y.H. Xu; S.S.S. Raj; J. Wu; X.Z. You. 2002. Crystal structure and Triboluminescense spectrum of a $\mu_{2}-\left(\mathrm{ONC}_{5} \mathrm{H}_{5}\right)$ bridging dinuclear europium(III) complex. Journal of Coordination Chemistry. 55, 421-428.

Dante, J. 1983. Thermoelectric power supply for warheads. Patent US4372211, 5 Pp.

Divos, F. \& F. Sismandy Kiss. 2010. "Strength Grading of Structural Lumber by Portable Lumber Grading - effect of knots". The Future of Quality Control for Wood \& Wood Products, Edinburgh The Final Conference of COST Action E53. 7 pp.

Eddingsaas, N.C.; K.S, Suslick. 2006. Mechanoluminescence: Light from sonication of crystal slurries. Nature, $444,163$.

EN 408:2011+A1:2012. Estructuras de madera. Madera aserrada y madera laminada encolada para uso estructural. Determinación de algunas propiedades físicas y mecánicas.

Fontenot, R.S.; Hollerman, W.A.; Bhat, K.N.; Aggarwal, M.D. 2012. Comparison of the triboluminescent properties for europium tetrakis and $\mathrm{ZnS}: \mathrm{Mn}$ powders. Journal of Theoretical and Applied Physics, 6, 15 (9 pp)

Fry, R.; F. Bechtel; J. Logan. 1993. Stress wave method and apparatus for estimating the structural quality of finger joints. Patent US5237870A, $20 \mathrm{Pp}$.

Glass, C.; J. Dante. 1977. Light activated fuze. Patent US4020765, 5 Pp.

Hall-Goulle, V. 2000. Triboluminescent lanthanide ${ }^{\mathrm{III}}$ complexes. Patent US6071632A, 4 Pp. 
Hansma, P.; D. Walters; P. Hillner. 1996. Combined scanning probe and scanning energy microscope. Patent US5581082A, 15 Pp.

Hurt, C.R.; N. Macvoy; S. Bjorklum; N. Filipesc. 1966. High Intensity Triboluminescence in Europium Tetrakis (Dibenzoylmethide)-triethylammonium. Nature. 212, 179-180.

Mastro, S.; V. Mathur; A. Jarret. 2004. Fiber optic composite damage sensor. Patent US6710328B1, $19 \mathrm{Pp}$.

Pappalardo, R; T. Peters. 1988. Process for preparing high-brightness yellow-emitting triboluminescent phosphors. Patent US4772417, 6 Pp.

Qiu, H.; K. Sumi; T. Nishiwaki. 2001. Piezoelectric luminous element display device and method for manufacturing same. Patent US6281617B1, 8 Pp.

Sage, I.; N. Geddes. 1999. Triboluminescent damage sensors. Patent US5905260A, 9 Pp.

Schafer, M.; R. Ross; J. Erickson; R. Degroot. 2008. System and method of assessing the structural properties of wooden members using ultrasound. Patent CA2386173A1.

Storey, E. 2001. Deceleration sensor for vehicle air bag. Patent US6270117B1. 4 Pp.

Sweeting, L.M.; A.L. Rheingold; J.M. Gingerich; A.W. Rutter; R.A. Spence; C.D. Cox; T.J. Kim. 1997. Crystal structure and triboluminescence .2. 9-anthracenecarboxylic acid and its esters. Chem. Mater. 9 (5), 1103-1115.

Takada, N.; J-I Sugiyama; R. Katoh; N. Minami; S. Hieda. 1997. Mechanoluminescent properties of europium complexes. Synthetic Metals 91, 351-354.

Walton, A. J. 1977. Triboluminescence. Advances in Physics. 26, 887-948.

Watanabe, T.; C. Xu; M. Akiyama. 2000. Triboluminescent inorganic material and a method for preparation thereof. Patent US6117574A, 8 Pp.

Wu, S.J.; J.M. Xu; G.Y. Lin; V. Risto; Z.H. Lu; B.Q. Lin; W. Wang. 2011. Estimation of basic density and modulus of elasticity of Eucalypt clones in southern China using Non-destructive methods. Journal of Tropical Forest Science 23(1): 51-56. 
Xu, C.N.; T. Watanabe; M. Akiyama; X.G. Zheng. 1999. Preparation and characteristics of highly triboluminescent ZnS Film. Materials Research Bulletin, 34(10/11), 1491-1500.

Yu, J.B.; H.J. Zhang; R.P. Deng; L. Zhou; Z.P. Peng; L.S. Fu. 2004. J. Of Rares earths, 22, 126-128.

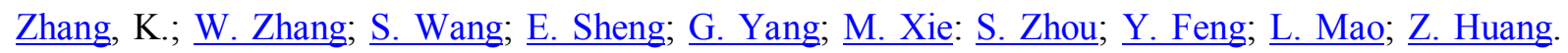
2004. Homolysis of the $\mathrm{Ln}-\mathrm{N}(\mathrm{Ln}=\mathrm{Yb}, \mathrm{Eu})$ bond. Synthesis, structural characterization and catalytic activity of ytterbium(II) and europium(II) complexes with methoxyethyl functionalized indenyl ligands. Dalton Trans., 1029-1037.

Breve descripción de la invención

La presente invención tiene como objeto proporcionar un indicador de sobrecarga en madera estructural mediante la emisión de luminiscencia a medida que la estructura esté soportando un exceso de carga en servicio, brindando una garantía de seguridad estructural. Para ello, se requiere el empleo de una sustancia de fácil cristalización y de tamaño molecular acorde a la estructura anatómica de la madera.

Mediante la solución propuesta, una viga de madera impregnada con una sustancia triboluminiscente y sometida a esfuerzos de flexión o compresión, puede emitir luminescencia durante la sobrecarga en el rango de longitud de onda de la que esté provista (Ver Figura 3, Figura 4, Figura 5, Figura 6 y Figura 7).

La invención podrá ser aplicada sobre diversas especies madereras de interés en el ámbito de la construcción y se aplicará el método de impregnación por vacío-presión para asegurar la penetración del producto químico dentro de la madera en una concentración suficiente para asegurar la presencia de microcristales de aquel tras la evaporación del disolvente.

El valor de resistencia a considerar será, dependiendo de la especie de madera, geometría y la tipología estructural, el correspondiente a la carga máxima en la zona elástica del material por unidad de área tensión en el límite de proporcionalidad, TLP-, dado que valores superiores a los contemplados en la misma indicaran zonas de comprometimiento estructural de la madera por encontrarse en el rango plástico e irreversible de dicho material (Figura 8).

Mediante equipos de detección, como el constituido por fotodiodos, amplificador y osciloscopio, se determinará la intensidad de la radiación, la cual dependerá de la sustancia de impregnación utilizada. 
Con los datos de elasticidad obtenidos y de intensidad de la luminiscencia emitida en ese punto, se determinaran las relaciones estadísticas existentes entre valores de sobrecarga e intensidad de luminiscencia.

Breve descripción de las figuras

Figura 1: "Ejemplo de complejo de $\mathrm{Eu}^{3+}$ triboluminiscente". En este complejo la triboluminiscencia se atribuye a la presencia de la cadena perfluorada (Yu et al., 2004).

Figura 2: “Complejos $\mathrm{Eu}^{3+}$-fenantrolina": $\mathrm{E}(1)$ : $\mathrm{Eu}(\mathrm{TTA})_{3}\left(\right.$ phen); $\mathrm{E}(2): \mathrm{Eu}(\mathrm{TTA})_{3}($ bath); $\mathrm{E}(3)$ : $\operatorname{Eu}(T T A)_{3}(5-m e t h y l-p h e n) ; E(4): \operatorname{Eu}(T T A)_{3}(5-$ phenyl-phen).

Figura 3: "Espectros de emisión triboluminiscente" para ZnS:Mn, donde: I: intensidad lumínica; W: longitud de onda (nm); Z(30): $30 \mu \mathrm{m}$ ZnS:Mn; Z(24.1): 24,1 $\mu \mathrm{m}$ ZnS:Mn; Z(8.5): 8,5 $\mu \mathrm{m}$ ZnS:Mn.

Figura 4. "Espectros de emisión triboluminiscente" para $\beta$-dicetonatos de europio(III), donde: I: intensidad lumínica; W: longitud de onda (nm); TL: triboluminiscencia; FL: fotoluminiscencia.

Figura 5. "Respuesta típica para un fotodetector de silicio" donde se aprecia como la responsividad (R) aumenta con la longitud de onda (W) hasta alcanzar un máximo en $900 \mathrm{~nm}$, punto a partir del cual decae.

Figura 6: "Ensayo de flexión en viga de madera (sin tratamiento)-Esfuerzos implicados": se quiere reflejar un ensayo de flexión estática en una viga de madera sin ningún tratamiento, indicando los esfuerzos implicados. El ensayo de flexión estática se corresponde a la metodología tradicional destructiva para realizar una caracterización mecánico-resistente de la misma.

Donde: $\mathrm{A}=$ Zona-Esfuerzo de compresión; $\mathrm{B}=$ Zona-Esfuerzo de tracción; $\mathrm{C}=$ Zona-Esfuerzo cortante; $\mathrm{P}=$ Carga aplicada $(\mathrm{Kg})$.

Figura 7: "Ensayo de flexión en viga de madera impregnada con sustancia triboluminiscente-Esquema del comportamiento de la invención": se trata de reflejar el objetivo de la invención mediante el ensayo de flexión estática de madera impregnada con una sustancia luminiscente. En el mismo se indican la zona-esfuerzo de compresión-A- (superior: líneas punteadas en diagonales), la capa neutra (franja central con línea de punto) y la zona-esfuerzo de tracción-B- (inferior: dobles líneas punteadas) y la zona-esfuerzo cortante-C- (línea continua-sinuosa transversal indicada en la zona central). De este modo quedaría representada la triboluminiscencia mediante la acción de una sobrecarga. Los 
diferentes patrones son esquemáticos y tratan de indicar las diferentes zonas de esfuerzos obtenidas mediante la aplicación de una carga constante; las intensidades de luminiscencia variarán acorde a la longitud de onda de la sustancia luminiscente utilizada, aunque cabe indicar que la longitud de onda será constante para cada sustancia utilizada, lo que variará con el nivel de carga será la intensidad de la luminiscencia emitida.

Figura 8: "Curva ideal Tensión (carga/unidad de área: $\mathrm{Kg} / \mathrm{mm}^{2}$ ) vs Deformación (mm)" se pretende explicar el comportamiento teórico de la madera ante la acción de una carga. En el mismo se indica la TLP, siendo éste el último punto de comportamiento lineal de la deformación (elástico) según la Ley de Hooke (deformaciones proporcionales a la carga aplicada).

Donde: $\mathrm{T}=$ Tensión $\left(\mathrm{Kg} / \mathrm{mm}^{2}\right) ; \mathrm{D}=$ Deformación $(\mathrm{mm}) ; 1=$ Tensión de rotura $(\mathrm{TR}) ; 2$ = Tensión en el límite de proporcionalidad (TLP).

Descripción detallada de la invención

De una manera más detallada las etapas fundamentales del procedimiento planteando son:

1 - Selección de especies de madera de interés.

2 - Impregnación de la madera mediante un método de vacío - presión (por ser el método que mayor profundidad de impregnación permite), con una sustancia triboluminiscente de fácil cristalización como las que se detallan en los ejemplos de realización.

3 - Realización de un ensayo de flexión estática en máquina universal, a fin de evaluar la eficacia de la técnica triboluminiscente planteada y simulando el comportamiento de la madera en servicio ante la solicitación a esfuerzos combinados de flexión, compresión y tracción, se realiza. Se comienza el ensayo normalmente y tras la deformación mecánica tiene lugar la emisión de luz de longitud de onda variable según sustancia triboluminiscente que se utilice (ver ejemplos de realización).

4 - Monitorización de la TL mediante un sistema constituido por un fotomultiplicador, un filtro, un osciloscopio y dos fotodiodos; sistema portátil, versátil y confiable. A la salida del fotomultiplicador, para capturar adecuadamente la luz, se debe ubicar un osciloscopio en secuencia sencilla. La ganancia del fotomultiplicador se ajusta hasta alcanzar la mitad de su intervalo máximo. La luz emitida es, finalmente, medida con dos fotodiodos de silicio con orientaciones diferentes respecto la fuente. 
5 - Posteriormente, evaluación de la rigidez y rotura de la pieza de madera. La rigidez del material es evaluado mediante el módulo de elasticidad a flexión (MOE), mientras que la rotura del material o resistencia máxima será evaluada mediante la determinación del módulo de rotura (MOR).

6 - Determinación de las relaciones existentes entre la sobrecarga establecida y la intensidad de emisión lumínica, la cual estará directamente relacionada con la energía mecánica ejercida en los cristales de la sustancia utilizada.

7 - En términos generales, mediante este procedimiento se intenta simular la situación real de una viga trabajando en una estructura. Cabe aclarar que la mera detección de luminiscencia mediante el ensayo ya nos permitirá inferir que algo está sucediendo, independientemente de su valor de rigidez y/o rotura.

Ejemplos de realización de la invención

En primer término se expresan las condiciones que son comunes a todos los ejemplos:

1 - Como representación de los dos grandes grupos taxonómicos, el material de ensayo puede estar constituido por vigas de tamaño estructural de $50 \mathrm{~mm}$ x $150 \mathrm{~mm}$ x $3000 \mathrm{~mm}$ de madera de Populus sp y de Pinus sp.

2 - En ambos casos (Populus sp y Pinus sp) se podrá lograr una impregnación aceptable utilizando una presión de entre $8-10 \mathrm{Kg} / \mathrm{cm}^{2}$ de presión durante $40 \mathrm{~min}$.

3 - La concentración estará comprendida entre el 10 y el 30\% P/V (expresadas en peso de sustancia activa (emisor) por unidad de volumen de disolvente o dispersante a utilizar, como aproximación a la relación peso emisor/volumen de madera), suficiente para asegurar la presencia de microcristales de producto tras la evaporación del disolvente.

3 - Para evaluar la eficacia de la técnica planteada y simulando el comportamiento de la madera en servicio ante la solicitación a esfuerzos combinados de flexión, compresión y tracción, se realiza un ensayo de flexión estática en máquina universal con carga constante a una velocidad de $0,003 \mathrm{~h} \mathrm{~mm} / \mathrm{s}$ (siendo h la altura de la sección de ensayo en los ensayos de flexión), según lo establecido en la Norma EN 408:2011+A1: 2012. Para conseguir la máxima eficacia, las observaciones se realizarán con la luz del laboratorio de ensayo, apagada. Se comienza el ensayo normalmente y tras la deformación mecánica tiene lugar la emisión de luz, dependiendo de la sustancia que se utilice (ver ejemplos de realización), será la longitud de onda en la que emita. 
A continuación se mencionan los ejemplos de realización haciendo hincapié en las diferentes sustancias factibles de utilizar.

Ejemplo 1. Sulfuro de Zinc dopado con manganeso (ZnS:Mn): El impregnado de la madera se realiza con una dispersión de ZnS:Mn en un disolvente orgánico de alta volatilidad como etanol, acetona, acetato de etilo, benceno, tolueno o xilol. Evaporado el disolvente e incorporado el polvo microcristalino de ZnS:Mn a la madera, ésta es susceptible de ser sometida a esfuerzos de flexión, compresión y subsiguiente emisión TL. Tras deformación mecánica tiene lugar la emisión de luz, en este caso amarilla-anaranjada con un pico ancho centrado a $585 \mathrm{~nm}$ y un FWHM (Full Width at Half Maximum) de alrededor $125 \mathrm{~nm}$ (Figura 3). Para monitorizar la TL se puede utilizar un sistema constituido por un fotomultiplicador (puede ser de tipo Hamamatsu H5783), un filtro, un osciloscopio y dos fotodiodos. El filtro debe ser de $589 \mathrm{~nm}$ y ha de ser colocado enfrente del fotomultiplicador. A la salida del fotomultiplicador, para capturar adecuadamente la luz, se debe ubicar un osciloscopio (puede ser Tektronix TDS $3052 \mathrm{u}$ otro similar) en secuencia sencilla. La ganancia del fotomultiplicador se ajusta hasta alcanzar la mitad de su intervalo máximo. La luz emitida es, finalmente, medida con dos fotodiodos de silicio con orientaciones diferentes respecto la fuente. El tiempo de decaimiento de la TL es de alrededor $300 \mu$ s. Una vez que la señal (luz) es adquirida se procede a su análisis utilizando el programa LABVIEW que integra el área bajo la curva y calcula el tiempo de decaimiento para cada emisión particular.

Para lograr la eficacia apropiada es preciso realizar las observaciones con la luz de la habitación apagada.

Aunque los reactivos de partida son abundantes y baratos, el proceso de dopado precisa altas temperaturas $\left(>1100^{\circ} \mathrm{C}\right)$ y esto encarece el producto resultante, sin que sea posible establecer precios determinados en el mercado.

Ejemplo 2. Europio tetraquis(dibenzoilmetanato) trietilamonio, [Eu(DBM) 4 (TEA)]: el impregnado de la madera puede hacerse con una solución altamente concentrada de este complejo, solo o mezclado con morfina, utilizando como disolventes preferentemente etanol o acetona. Evaporado el disolvente y sometida la madera a esfuerzos de flexión, compresión, la emisión TL (en el rango 610-620 nm; Figura 4) puede ser analizada utilizando como equipo un detector como el mencionado en el ejemplo anterior. Alternativamente, aprovechando que el Eu(III) tiene bandas de emisión "tipo línea" muy estrechas (monocromaticidad de la emisión mucho mayor, o FWHM mucho menor), se podría utilizar un sistema portátil de doble monocromador UV-Vis (como el G\&H OL 756 de OPTE-E-MA) o un monocromador manual (como la serie Manual Mini-Chrom de EdmundOptics) junto con fotodiodo de 
silicio. Otra alternativa pasaría por recurrir a técnicas de espectroscopía de fluorescencia (o fluorometría) resuelta en el tiempo (con equipos compactos como el FluoTime 100 de PicoQuant o el Quantaurus-Tau C11367-11 de Hamamatsu), aprovechando el carácter fosforescente de la emisión del $\mathrm{Eu}(\mathrm{III})$ (tiempos de vida de los estados excitados $>500 \mu$ s, frente a tiempos de vida $<50$ ns para emisiones fluorescentes).

La principal ventaja de esta opción es que su rendimiento de emisión triboluminiscente duplica al del $\mathrm{ZnS}: \mathrm{Mn}$, siendo visible en condiciones de luz diurna normales. A esto se suma que las características de monocromaticidad y tiempo de vida de la emisión del Eu(III) facilitan su identificación y su separación de otras bandas de fluorescencia que pudieran aparecer. Adicionalmente, se ha demostrado que es más aconsejable que el ZnS:Mn por su mayor capacidad de detección cuando los esfuerzos son de pequeña magnitud (Fontenot et al., 2012).

Ejemplo 3: Complejo betadicetonato de europio (III): complejo $\left[\mathrm{Eu}_{2}(\mathrm{TTA})_{6}(\mathrm{PyO})_{2}\right](\mathrm{HTTA}=2$ tenoiltrifluoroacetona y $\mathrm{PyO}=\mathrm{N}$-óxido de piridina) cuyo máximo triboluminiscente es similar al de la fotoluminiscencia siendo el desorden de los anillos tienilo y grupos $\mathrm{CF}_{3}$ el responsable de la actividad triboluminiscente. El procedimiento es el mismo que el indicado en el Ejemplo 2. Al originarse la emisión en el ión $\mathrm{Eu}(\mathrm{III})$ y ser independiente del entorno de coordinación, la longitud de onda es la misma $(\sim 615 \mathrm{~nm})$ que en el Ejemplo 2 y la cromaticidad es similar. La eficiencia triboluminiscente no está establecida, pero se considera similar a la del $\left[\mathrm{Eu}(\mathrm{DBM})_{4}(\mathrm{TEA})\right]$.

También se plantea la posibilidad de combinar el material emisor del Ejemplo 1 con un $\beta$-dicetonato de europio como los referidos en los Ejemplos 2 y 3, toda vez que, si se dopan en distintas zonas de la muestra, es posible distinguir -con un mismo sistema de detección- la región sometida a esfuerzo en base a la diferencia de tiempos de vida para cada material.

Si bien las opciones recogidas en los tres ejemplos anteriores son opciones preferidas, los autores no excluimos la utilización de especies emisoras en otras regiones del rango visible. En concreto, se puede plantear también el uso de $\beta$-dicetonatos de $\mathrm{Sm}(\mathrm{III}), \mathrm{Tb}(\mathrm{III})$ y $\mathrm{Nd}(\mathrm{III})$, óxidos de trifenilfosfina con bromuro y cloruro de manganeso, o de azúcares como glucosa, maltosa, ramnosa o sacarosa, como emisores en la región del verde (525-555 nm); y del cloruro de anilinio como material triboluminiscente en la región del azul-violeta (450-460 nm). Estos compuestos tienen el inconveniente de presentar rendimientos de emisión triboluminiscente notablemente inferiores a los de los tres materiales de opción preferente. Adicionalmente, al emitir en longitudes de onda más cortas, la respuesta del detector de silicio es menor que para los productos seleccionados en los Ejemplos 1 a 3. 
Reivindicaciones:

1. Procedimiento para control triboluminiscente de sobrecarga en madera estructural el cual es caracterizado porque comprende las siguientes etapas:

a. Selección de especies de madera de interés.

b. Impregnación de la madera mediante un método vacío - presión, con una sustancia de fácil cristalización que genera luminiscencia mediante la acción de una sobrecarga (Triboluminiscencia).

c. Realización de ensayo de flexión estática en máquina universal corroborando la luminescencia de la madera ante la aplicación de la carga (Triboluminiscencia), a fin de simular la situación en servicio de la madera.

d. Determinación de la intensidad de luminescencia emitida mediante un equipo para determinación de la radiación correspondiente.

e. Determinación de la deformación por unidad de longitud en flexión a la que se expone el material sin que se produzcan deformaciones permanentes y del esfuerzo máximo por unidad de superficie, módulo de elasticidad (MOE) y módulo de rotura (MOR), constituyendo un valor indicativo de la rigidez y la resistencia del material, respectivamente. El primero de ellos se determinará entre el $10-40 \%$ de la carga máxima, continuando luego el ensayo hasta la rotura del material para la determinación de su resistencia máxima.

f. Determinación de la relación existente entre la sobrecarga y la intensidad de la luminiscencia. La intensidad de emisión está directamente relacionada con la energía mecánica ejercida en los cristales de la sustancia utilizada.

2. Procedimiento para control triboluminiscente, según reivindicación 1, caracterizado porque el complejo triboluminiscente es sulfuro de zinc dopado con manganeso ( $\mathrm{ZnS}: \mathrm{Mn}$ ).

3. Procedimiento de control triboluminiscente, según reivindicación 1, caracterizado porque el complejo triboluminiscente betadicetonatos de europio(III).

4. Procedimiento de control triboluminiscente, según reivindicación 1, caracterizado porque el complejo triboluminiscente Europio tetraquis(dibenzoilmetanato) trietilamonio, $\left[E u(D B M)_{4}(T E A)\right]$

5. Procedimiento de control triboluminiscente, según reivindicación 1, caracterizado porque se puede usar una o una combinación de sustancias triboluminiscentes.

6. Procedimiento de control triboluminiscente, según reivindicación 1, caracterizado porque la impregnación debe ser profunda y suficiente para asegurar la presencia de microcristales de producto tras la evaporación del disolvente mediante una presión entre $8-10 \mathrm{Kg} / \mathrm{cm}^{2}$ durante un período comprendido entre 40 -60 min y con una concentración entre el 10 y el 30\% P/V 
7. Procedimiento de control triboluminiscente, según reivindicación 1, caracterizado porque es útil para la detección de sobrecargas en estructuras de madera.

8. Procedimiento de control triboluminiscente, según reivindicación 1, caracterizado porque el equipo de determinación de la radiación comprende un fotomultiplicador, un filtro, un osciloscopio y dos fotodiodos de silicio.

9. Procedimiento de control triboluminiscente, según reivindicación 1, caracterizado porque el equipo de determinación de la radiación comprende un equipo monocromador portátil.

10. Procedimiento de control triboluminiscente, según reivindicación 1, caracterizado porque el equipo de determinación de la radiación comprende un equipo compacto de espectroscopía.

Figuras

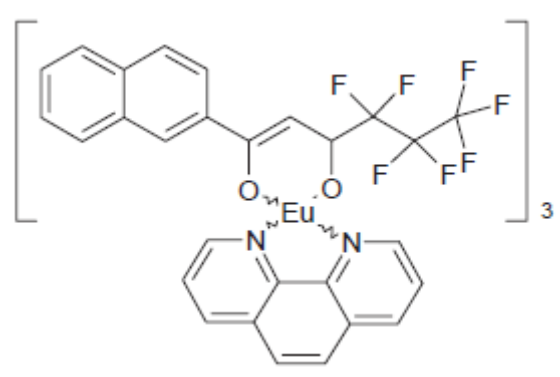

Figura 1

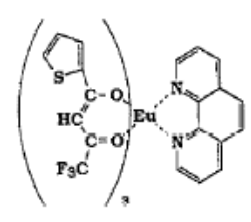

$\mathrm{E}(1)$

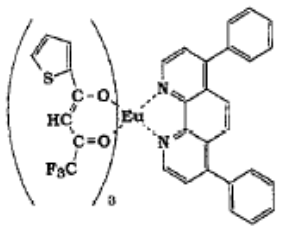

$\mathrm{E}(2)$

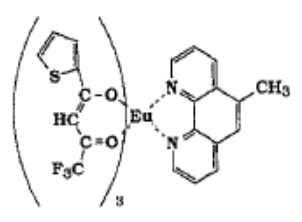

$\mathrm{E}(3)$

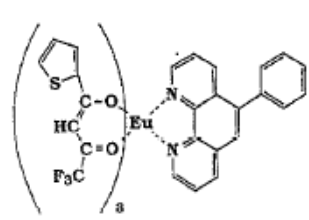

$\mathrm{E}(4)$

Figura 2 


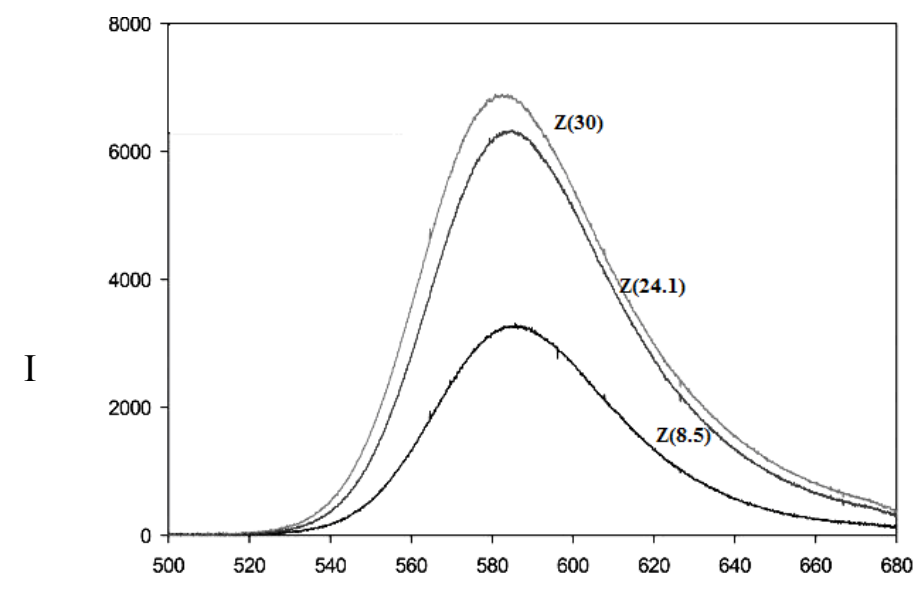

W

Figura 3

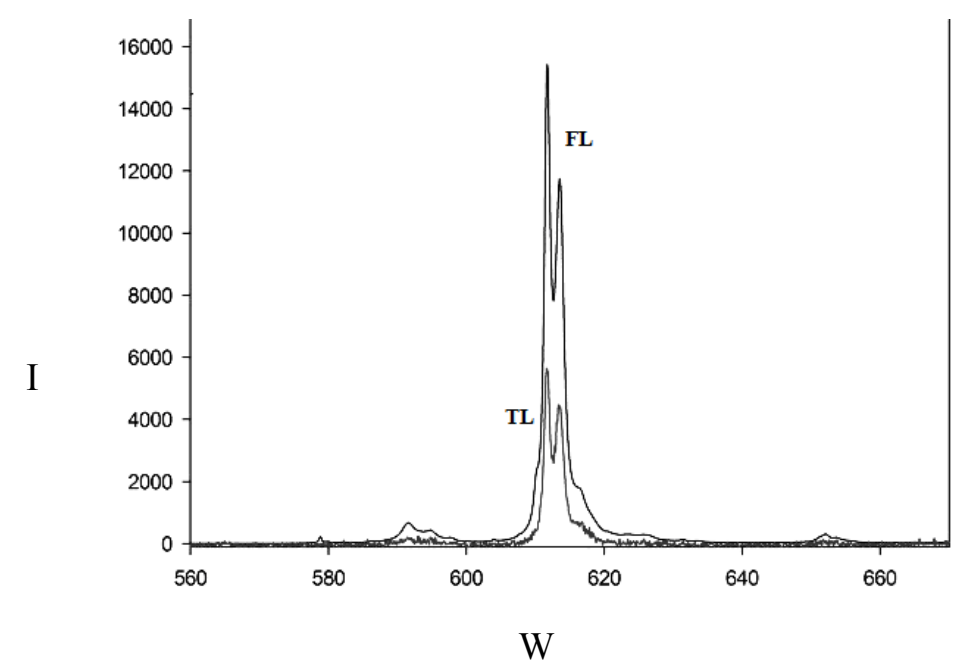

Figura 4

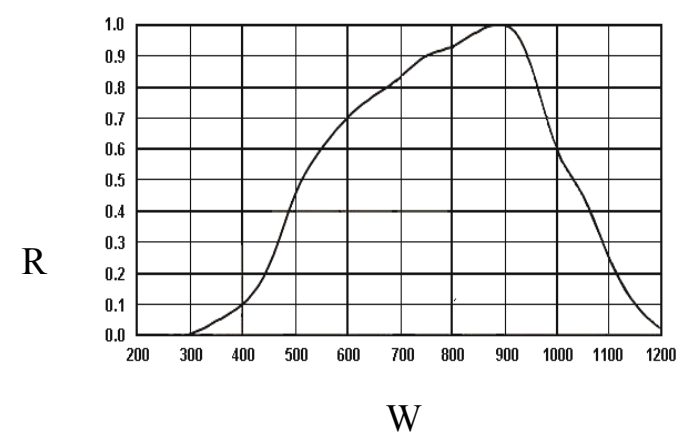

Figura 5 


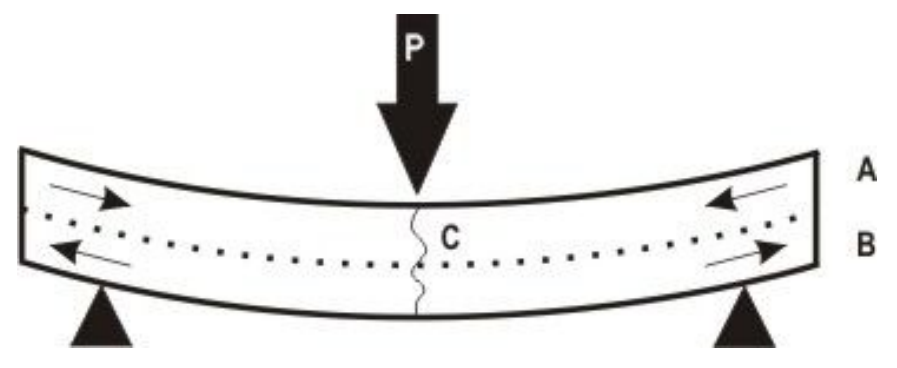

Figura 6

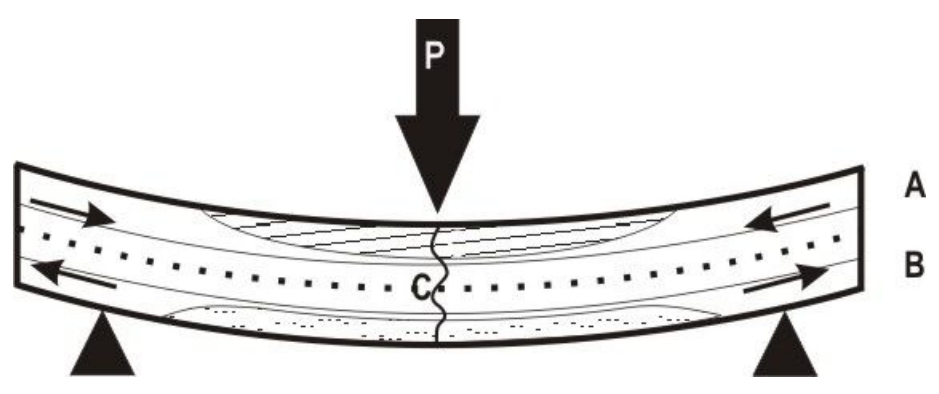

Figura 7

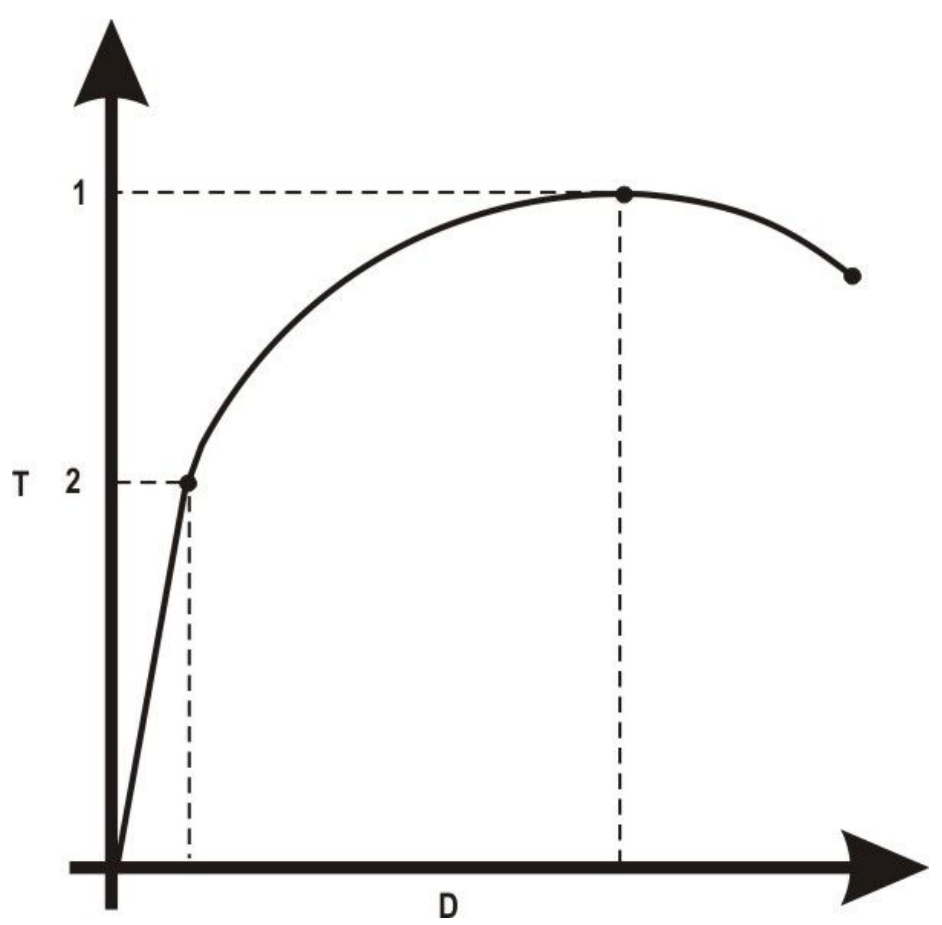

Figura 8 


\section{Resumen}

Procedimiento para control triboluminiscente de sobrecarga en madera estructural mediante el cual se impregna la madera con una solución triboluminiscente mediante un método de vacío presión, hasta impregnación profunda y con concentraciones entre $10-30 \% \mathrm{P} / \mathrm{V}$, para asegurar la presencia de microcristales del producto tras la evaporación del disolvente. Esta madera sometida a un esfuerzo mecánico emite luminiscencia (tras la deformación) con longitudes de onda en regiones variables según la sustancia empleada. Para monitorizar la triboluminiscencia (TL) se utiliza preferentemente un sistema fotomultiplicador - filtro - osciloscopio - dos fotodiodos de silicio. Para capturar la luz a la salida del fotomultiplicador, se ubican los osciloscopios en secuencia sencilla. La luz emitida es medida con los dos fotodiodos en orientaciones diferentes respecto la fuente. Posteriormente, se evalúa la relación sobrecarga - intensidad de emisión lumínica, la cual está directamente relacionada con la energía mecánica ejercida en los cristales de la sustancia utilizada. 


\section{CAPITULO V. CONCLUSIONES}

A continuación se exponen las conclusiones de este trabajo:

\section{Caracterización de madera maciza}

En cuanto a la caracterización general realizada sobre material macizo, de pequeñas dimensiones libre de defectos, semi-estructural y estructural, de Populus x euramericana I-214 presente en el mercado español y argentino, se concluye que la misma presenta características similares expresadas mediante valores físicos, mecánicos y de durabilidad natural.

Las determinaciones en piezas de tamaño semi-estructural han permitido obtener resultados más acordes, que los obtenidos en piezas de pequeñas dimensiones, con los hallados en piezas de tamaño estructural.

En términos generales el material presenta una calidad visual baja, dado que en ambas procedencias, existe un gran número de singularidades que dejan en evidencia la necesidad de adaptación de una norma que permita el reconocimiento de esta especie dentro de su alcance, con grados clasificatorios más acordes a esta realidad.

En cuanto a su calidad resistente se concluye que la misma se encuentra limitada principalmente por el valor característico del módulo de elasticidad, mientras que los valores característicos del módulo de rotura y de la densidad, no parecen afectar tan marcadamente dicha calidad. Esto, a excepción del material proveniente de Argentina, el cuál presenta limitada su capacidad resistente a causa de los daños causados por insectos.

Las técnicas de ensayo no destructivos presentaron mayor eficacia para estimar los valores elasto-resistentes que la metodología de clasificación visual.

\section{Mejoras tecnológicas}

\section{Probetas de pequeñas dimensiones y libre de defectos}

En cuanto a la termo-modificación planteada, presentó resultados favorables en los valores de dureza, hallándose el óptimo a temperaturas de $160{ }^{\circ} \mathrm{C}$ con tiempos de exposición de 135 minutos. La mejora lograda en la durabilidad no fue tan clara ni homogénea para todos los organismos xilófagos empleados.

\section{Piezas macizas semi-estructurales (escala 1:5)}

La estimación del módulo de elasticidad a partir de la vibración libre en voladizo, resulta una alternativa útil y más eficiente que la obtenida a partir de vibraciones longitudinales y de ultrasonidos, pudiendo considerarse una alternativa viable como método de clasificación. 
Las piezas encolados tríos lograron mejorar los valores elasto-resistentes en la madera de procedencia española, mientras que en el material argentino, la presencia de daños ocasionados por insectos no permitió evidenciar ninguna mejora. Las piezas dúos, en ambos casos no evidenciaron mejora.

\section{Piezas macizas estructurales}

Las modificaciones propuestas en la norma han logrado una mejora, principalmente, al reducir el porcentaje de sobreestimas en la clasificación, lo que contribuiría a conseguir un menor riesgo en la utilización del material. De todos modos, mediante este análisis ha quedado constancia de la baja calidad del material comercializado en España. Si bien, este análisis no ha sido llevado a cabo en material de Argentina, de acuerdo con los resultados obtenidos a lo largo del trabajo, puede concluirse que el comportamiento podría ser similar o incluso peor, dada la gran proporción de material afectado por galerías de insectos, que dejaría directamente a esta madera fuera de norma.

La patente planteada, si bien es aplicable a cualquier tipo de especie, en el caso particular del clon estudiado podría ser una alternativa viable a fin de tener un control de sobrecarga de la madera puesta en servicio.

Como consideración general del trabajo, se plantea que mediante los resultados obtenidos se ha logrado obtener una base de datos consistente sobre la madera de Populus $x$ euramericana I-214 procedente de España y de Argentina.

En España en particular, podría plantearse en el seno del Comité AEN/CTN 56, la inclusión de esta especie y procedencia en las normativas españolas correspondientes a clasificación visual, readaptando los límites establecidos en cada singularidad y teniendo en cuenta las consideraciones planteadas en este trabajo. Del mismo modo, esta consideración sería válida para los datos de durabilidad natural obtenidos del presente estudio.

En Argentina, el aporte de la información brindada por este trabajo puede ser el comienzo de futuras investigaciones en material de tamaño estructural tendientes al planteamiento de una norma de clasificación visual que lo considere dentro de su alcance. 


\section{CAPITULO VI. REFERENCIAS BIBLIOGRÁFICAS}

\section{Libros y revistas}

Acuña, L.; I. Barranco; M. Casado; C. Martínez; A. González. 2007. Análisis y validación de la técnica resistográfica aplicada a la madera estructural. $11^{\circ}$ Congreso de Ensayos no Destructivos. Sociedad Española de Ensayos no Destructivos AEND. Gijón. 343 - 354 pp.

Ahvenainen, J.; García Barbero. M. 2007. Uso estructural de vigas DÚO y TRÍO. Vigas de madera compuestas por dos o tres piezas: una alternativa ideal para estructuras ligeras de alta exigencia estética. Informes de construcción 59 (506): 117-121.

Alfaro, R. 2003. El Taladrillo grande de los forestales Platypus mutatus (=sulcatus): importante plaga de la populicultura argentina. Plan de acción. SAGPyA Forestal (28), 11-18.

Alfaro, R.; H. Leland; P. González; R. Villaverde; G. Allegro. 2007. The Threat of the ambrosia beetle Megaplatypus mutatus (Chapuis) (=Platypus mutatus Chapuis) to world poplar resources. Forestry, 80(4); 471-479.

Álvarez, J.; L. Acuña; I. Barranco; M. Casado. 2005. Aplicación del resistógrafo al diagnóstico de elementos singulares en estructuras de madera. Jornadas de Investigación en la Construcción Instituto Torroja. Madrid. 12 p.

Álvarez, H.; J.I. Fernández-Golfín. 1993. Aptitud de diferentes maderas de coníferas y frondosas al secado con vapor sobrecalentado. Determinación del punto final del secado. Revista de Investigación Agraria 2(2). 245-252.

Álvarez-Moreno, C. 2004. Las choperas: plantaciones para la conservación activa del medio ambiente. Revista: Páginas de información ambiental (La Rioja), 18, 5 pp.

Arcidiácono, R.; C. Lucero; M. J. Martín; C. Murcia; F. Naldini; N. Oberti; G. Paiva; F. Pediccone; N. Pierini; G. Poggi; F. Genovese; H. Reviglio; W. Guarino; R. Bassotti. 2011. Caracterización físico mecánica de la madera de álamo del sur de la provincia de Mendoza, para la fabricación de elementos estructurales multilaminados encolados. Tercer Congreso Internacional de Salicáceas en Argentina.

Balatinecz, D.; E. Kretschmann; A. Leclercq. 2001. Achievements in the utilization of poplarwood-guideposts for the future. The Forestry Chronicle 77 (2). 5 pp.

Bamber, R.K.; K. Fukazawa. 1985. Sapwood and heartwood: A review. Forestry Abstracts 46:567-580.

Baonza Merino, M.V.; A Gutiérrez Oliva. 1997. Variación de algunas características dendrométricas y físicas, según su posición en el tronco. Caso de Populus $x$ euramericana (Dode) Guinier cv. Luisa Avanzo. 6 pp. 
Baradit, E.; Niemz, P. and Fernández-Pérez, A. 2013. "Physical and mechanical properties of some chilean softwoods and hardwoods using ultrasound". Maderas. Ciencia y tecnología 15 (2): 235-244.

Basterra, L. A.; Acuña, L.; Casado, M.; Ramón-Cueto, G. and López, G. 2009. "Diagnóstico y análisis de estructuras de madera mediante técnicas no destructivas: aplicación a la Plaza Mayor de Chinchón (Madrid)”. Informes de la Construcción 61 (516): 21-36.

Basterra, L.A.; M. Casado; L. Acuña; O. Pinazo. 2006. Techniques of pseudonondestructive testing on structural wood, by extraction of screws. Revista: ReCo PaR. No 2 , $37-59$.

Beale, I.; Ortíz, E. 2013. El sector forestal argentino bosques implantados. Revista de Divulgación Técnica Agrícola y Agroindustrial. Revista de Divulgación Técnica Agrícola y Agroindustrial (ISSN: $1852-7086), 43,6$ pp.

Blanchette, R. A. 1995. Degradation of the lignocellulose complex in wood. Canad. J. Bot. 73 (Suppl. 1): 999-1010.

Blaß H.J. \& Görlacher R. (1996) Visuelle und maschinelle Festigkeitssortierung von Vollholz. Mikado 5:64-71.

Boonstra, M. 2008. “A Two-stage Thermal Modification of Wood. Ph.D. 299 pp.

Boom, B.K. 1957. Populus canadensis Moench vs. Populus euramericana Guinier. Acta Botánica Neerlandica 6: 54-59.

Burdzik, W. M. G.and Nkwera, P. D. 2002. "Transverse vibration tests for prediction of stiffness and strength properties of full size Eucalyptus grandis". Forest Prod. J. 52: 63-67.

Burmester, A. 1973. Effect of Heat-Press Ure Treatments of Semi-Dry Wood on its Dimensional Stability.Holz Roh-u. Werkstoff. 31 (6):237-243.

Calderón, A. 2006. Forestación con álamos para la obtención de madera de calidad. Facultad de Ciencias Agrarias, Universidad Nacional de Cuyo. 24 pp.

Calderón, A.D.; F.A. Roig; R.P. Zanetti; E.G. Aguado; A.M. Furlani; F.G. Martinez. 2011. Características físico-mecánicas de maderas de clones de álamo Ensayadas en la provincia de Mendoza - República Argentina - Parte I. Tercer Congreso Internacional de Salicáceas en Argentina. 9p.

Cancio, H.; E. Thomas. 2011. Utilización de una barreta hidráulica para la plantación de guías de álamos en los valles irrigados de Patagonia Norte. Tercer Congreso Internacional de Salicáceas en Argentina. 4 Pp.

Carballo-Collar, J.; E. Hermoso Prieto y R. Díez Barra. 2009. Ensayos no destructivos sobre madera estructural. Una revisión de 30 años en España. Nota Técnica. Kurú: Revista Forestal (Costa Rica) 6 (17), 2009. 16p. 
Casado, M.; L. Acuña; L.A. Basterra; G. Ramón-Cueto; D. Vecilla. 2012. Grading of structural timber of Populus $\times$ euramericana clone I-214. Holzforschung 66 (5): 633-638.

Casado, M.; L. Acuña; D. Vecilla; L.A. Basterra; E. Relea; G. López. 2011. Ultrasonidos y parámetros de clasificación visual para la caracterización de madera estructural de Populus x Euramericana I-214. $1^{\circ}$ Congresso Ibero-LatinoAmericano da Madeira na Construção. Coimbra, Portugal. 9 Pp.

Casado, M.; L. Acuña; D. Vecilla; A. Basterra; E. Relea; G. López; G. Ramón. 2009. "Técnicas vibratorias aplicadas a madera estructural de Populus x euramericana". V Congreso Forestal Español. Ávila. 14 Pp.

Casado, M.; A. Basterra; L. Acuña; O. Pinazo.; C. Martínez; E. Relea; I. Barranco; G. Ramón. 2005. Determinación de la capacidad resistente mediante métodos no destructivos. Aplicación en viguetas de forjado de un edificio singular. IV Congreso Forestal Español. Zaragoza, $10 \mathrm{Pp}$.

Castro, G. 2006. Usos actuales y posibilidades futuras de la madera de álamo. Jornadas de Salicáceas 2006. 9 pp.

Castro, G.; G. Fragnelli. 2006. New technologic and alternative uses for poplar wood. Boletin CIDEU. 2: 27-36.

Castro, G.; R. Zanuttini. 2004. Multinaminar wood: Manufacturing process and main physical-mechanical properties. Forest Prod. J. 54(2): 61-67.

Confemadera (Confederación española de empresarios de la madera), 2010. El cultivo y utilización del chopo en España. 50 Pp.

Coronel E. O. 1995. Fundamentos de las propiedades físicas y mecánicas de las maderas, $2^{\circ}$ parte, fundamentos de las propiedades mecánicas de las maderas. Instituto de Tecnología de la Madera, Facultad de Ciencias Forestales, Universidad Nacional de Santiago del Estero.

Cortizo, S. 2011. Mejoramiento genético del álamo, una ciencia en apoyo a la producción forestal sostenible. Tercer Congreso Internacional de Salicáceas en Argentina. 14 Pp.

Cottrell, J.E., V. Krystufek, H.E. tabbener, A.D. milner, T. Connolly, L. Sing, S. Fluch, K. Burg, F. Lefèvre, P. Achard, S. Bordács, K. Gebhardt, B. Vornam, M.J.M. Smulders, A.H. Vanden broeck, J. Van slycken, V. Storme, W. Boerjan, S. Castiglione, T. Fossati, N. Alba, D. Agúndez, C. Maestro, E. Notivol, J. Bovenschen, B.C. van dam. 2005. Postglacial migration of Populus nigra L.: lessons learnt from chloroplast DNA. Forest Ecology and Management 219: 293-312. 
Díaz, B.; Murace, M.; Peri, P.; Keil, G.; Luna, L.; Otaño M. 2003. Natural and preservative-treated durability of Populus nigra cv Italica timber grown in Santa Cruz Province, Argentina. International Biodeterioration \& Biodegradation 52 (1): 43-47.

Dickmann, D.I. 2006. Silviculture and biology of short-rotation woody crops in temperate regions: Then and now. Biomass \& Bioenergy 30: 696-705.

Divos, F. \& F. Sismandy Kiss. 2010. "Strength Grading of Structural Lumber by Portable Lumber Grading - effect of knots". The Future of Quality Control for Wood \& Wood Products, Edinburgh The Final Conference of COST Action E53. 7 pp.

Divos, F. and T. Tanaka. 2005. "Relation between static and dynamic modulus of elasticity of wood". Acta Silv. Lign. Hung 1: 105-110

D’Jakonov, K.; T. Konepleva. 1967. Moisture absorption by ScotsPine wood after heat treatment. Lesn. Z., Arhangel'sk 10(1):112-114.

Esteves, B., Domingos, I., and Pereira, H. 2007. a. "Improvement of technological quality of eucalypt wood by heat treatment in air at $170-200^{\circ} \mathrm{C}$," For. Prod. J.57 (1/2): 47-52.

Esteves, B., Velez Marques, A., Domingos, I., and Pereira, H. 2007. b. "Influence of steam heating on the properties of pine (Pinus pinaster) and eucalypt (Eucalyptus globulus) wood," Wood Sci. and Technol. 41:193-207.

Esteves, B., Pereira, H. 2009. Wood modification by Heat treatment: a review. BioResources 4(1): 370-404.

ESYRCE. 2014. Encuesta sobre Superficies y Rendimientos de Cultivos. Ministerio de Medio Ambiente y medio Rural y Marino.

Fengel, D. 1966. On the Changes of the Wood and its Components within the Temperature Range up to 200 oC-Part I, Holz Roh Werkstoff; 24:9-14.

Fengel, D. 1966. On the Changes of the Wood and its Components within the Temperature Range up to 200 oC-Part II, Holz Roh Werkstoff; 24:98-109.

Fengel, D. 1966. On the Changes of the Wood and its Components within the Temperature Range up to 200 oC-Part III: Thermally and Mechanically Caused Structural Changes in Sprucewood, Holz Roh Werkstoff; 24 (11):529-536.

Fernández-Golfín, J.I.; M.R. Díez; E. Hermoso. 2001. Análisis y estado del arte de la técnica de clasificación mecánica por máquina de la madera aserrada estructural (Revisión). Revista de Investigación Agraria 10(1): 5-19.

Funes, H.M.; P. González Audino; E. N. Zerba. 2013. Megaplatypus mutatus: descripción de su biología y optimización del uso de su principal componente feromonal. Sns, Publicación Periódica Científico-Tecnológica, 1 (1); 23-36. 
García-Caballero J.L. 2011. Plantación de chopos a raíz profunda. Tercer Congreso Internacional de Salicáceas en Argentina. 25 pp.

García-Pérez, A. 2005. Métodos Avanzados de Estadística Aplicada. Técnicas Avanzadas. Editorial UNED. Colección Educación Permanente.

Giebeler, E. 1983. Dimensional Stabilization of Wood by Moisture-Heat-Pressure Treatment, Holz Roh. Werkstoff; 41:87-94.

Glass, S.; S. Zelinka. Moisture relations and physical properties of Wood. Wood Handbook. Wood as an engineering material. Chapter 4. 19 pp.

Glos, P. 1995b. Strength grading. In Timber Engineering STEP 1, pp. A6/1-A6/8. Centrum Hout, The Netherlands.

Glos, P.; R. Diebold. 1994. Verfahrensentwicklung und Erprobung zur maschinellen Schnittholzsortierung. Abschlußbericht 89505, Institut für Holzforschung der Universität München.

Glos, P.; B. Lederer. 2000. Sortierung von Buchen- und Eichenschnittholz nach der Tragfähigkeit und Bestimmung der zugehörigen Festigkeits- und Steifigkeitskennwerte. Bericht Nr. 98508, Institut für Holzforschung, München.

Guerrero, R. T. 1966. Una nueva especie de hongo imperfecto asociado con el coleóptero Platypus sulcatus Chapuis. Revista de Investigaciones Agropecuarias, III (8) 5; 97 103.

Guy-Quint, C. 2009. Frente al cambio climático: Utiliza madera. Boletín informativo. $84 \mathrm{Pp}$.

Haines, D. W.; J. M. Leban; C. Herbe. 1996. "Determination of Young's modulus for spruce, fir and isotropic materials by the resonance flexure method with comparisons to static flexure and other dynamic methods". Wood Science and Technology 30 (z996) 253-263.

Halabe, U. B.; Bidigalu, G. M.; Gangarao, H. V. S. and Ross, R. J. 1995. Nondestructive evaluation of green wood using stress wave and transverse vibration techniques. Materials Evaluation: 1013-1018.

Hearmon, R. 1958. The influence of shear and rotary inertia on the free flexural vibration of wooden beams. Brit J Appl Phys 9: 381-388.

Hearmon, R. 1966. Theory of the Vibration Testing of Wood. For Prod J 16: 29-40

Highley, T.L.; Clausen, C.A.; Croan, S.C; Green, F.; Illman, B.L; Micales, J.A. 1994. Research on biodeterioration of wood, 1987-1992. I. Decay mechanisms and biocontrol. USDA Forest Service, Research Paper FPL-RP-529: 1-22.

Hillis W. 1984. High temperature and chemical effects on wood stability. Wood Sci Technol 18:281-293. 
Hunt, J.; Zhang, H.; Guo, Z. and Fu, F. 2013. Cantilever beam static and dinamic response comparison with Mid-point bending for thin MDF composite panels. BioResources 8(1): 115-129.

Ilic, J. 2003. Dynamic MOE of 55 species using small wood beams. HolzRoh-Werkstoff 61(3): 167-172.

Íñiguez-González, G.; F. Arriaga Martitegui; M. Esteban Herrero y R. Argüelles Álvarez. 2007. Los métodos de vibración como herramienta no destructiva para la estimación de las propiedades resistentes de la madera aserrada estructural. Informes de la Construcción. Vol. 59, 506, 97-105. ISSN: 0020-0883. 9 Pp.

Jalas, J. \& J. Suominen. 1976. Atlas Florae Europaeae. Distribution of Vascular Plants in Europe. 3. Salicaceae to Balanophoraceae. Societas Biologica Fennica Vanamo. Helsinki.

Jozsa, L.A.; G.R. Middleton. 1994. A Discussion of Wood Quality Attributes and Their Practical Implications. Special Publication No. SP-34. 51 pp.

Keil, G.; L. Acuña; E. Spavento; M. Casado; M. Refort. 2014. Metodología de ensayo no destructivo y destructivo aplicado a madera de Populus canadensis I-214 de procedencia Argentina. Jornadas de Salicáceas 2014- IV Congreso Internacional de Salicáceas en Argentina. TT N ${ }^{\circ} 63$, Área temática: Tecnología, 8p.

Keil, G.; Murace, M.; Luna, L.; Acciaresi, G. 2006. Durabilidad de la madera de Populus deltoides cv Stoneville 66 impregnada con metacrilato de metilo. Jornadas de Salicáceas, Buenos Aires, Argentina: 339-345.

Kocaefe, D.; J. L. Shi; Y. Dian-Qing; M. Bouazara. 2008. Mechanical properties, dimensional stability, and mold resistance of heat-treated jack pine and aspen. Forest Products Journal 58 (6). 6 pp.

Kollmann F. 1936. Tecnologies des Holzes un der Holzwerkstoffe, Springer Verlag, Berlín.

Kollmann F, Schneider A. 1963. On the sorption behaviour of heat stabilized wood. Holz Roh -Werkst 21 (3): 77-85

Kollmann F, Fengel D. 1965. Changes in the chemical composition of wood by thermal treatment. Holz Roh-Werkst 12: 461-468.

Koubaa, A.; N. Isabel; S. Yin Zhang; J. Beaulieu; J. Bousquet. 2005. Transition from juvenile to mature wood in black spruce (Picea mariana (mill.) B.s.p.). Wood and Fiber Science, 37 (3): 445-455.

Landi, L.; C. Braccini; O. Bruzzone. 2011. Análisis del patrón de ataque de Megaplatypus mutatus (Taladrillo Grande de los Forestales) mediante el modelado de 
características individuales de los árboles en forestaciones de álamos del Bajo Delta del Paraná. Tercer Congreso Internacional de Salicáceas en Argentina. Trabajo técnico. 6 Pp.

Levene, H. 1960. Robust tests for equality of variance. Contributions to Probability and Statistics, editor I. Olkin. Stanford University Press.

López, F. 2002. Selvicultura y mecanización de los aprovechamientos del chopo en la Vega de Granada. E.T.S. de Ingenieros Agrónomos y de Montes. Universidad de Córdoba. 137 pp.

Marquina, J.; R. Marlats; M. Núñez Cresto. 2006. Susceptibilidad clonal del álamo (Populus sp) al ataque de Platypus mutatus en Buenos Aires, Argentina. Bosque, 27(2): 92-97.

Martinuzzi, F. 2013. Fichas Técnicas de Madera. INTI Maderas y Muebles. Revista CEMA (114): 64.

Matyás C, Pezslen I (1994). Effect of age on selected wood quality traits of poplar clones. Silvae Genetica 46(2-3): 64-72.

Mazela, B.; R. Zakrzewski; W. Grzeskowiak; G. Cofta; M. Bartkowiak. 2003. "Preliminary research on the biological resistance of thermally modified wood," In: Abstracts of the First European Conference on Wood Modification, Ghent, Belgium.

Militz H. 2002. Thermal treatment of wood: European Processes and their background. In:International Research Group Wood Pre, Section 4-Processes, Nº IRG/WP 02-40241.

Mora, N.; Encinas, O.; Molina, Y.; Vielma, J. 2006. Durabilidad de Maderas Tratadas con CCA y CCB en Suelos de Judibana y San Juan de Lagunillas, Estado Mérida, Venezuela. Revista Forestal Latinoamericana 39: 17-37.

Moslemi, A. 1967. Dynamic viscoelasticity of hardboard. Forest Prod. J. 17(1): 25-33.

Murace, M.; E. Spavento; G.D. Keil y M. Saparrat. 2010. Pudrición castaña: efectos sobre las propiedades de resistencia mecánica de la madera. Quebracho - Revista de Ciencias Forestales 18(1, 2): 37-46.

Murace, M; E. Spavento; P. Rivas; M. Saparrat ; G. Keil. 2014. Comportamiento de Pinus ponderosa Dougl. ex. Laws. expuesto al hongo de pudrición castaña Gloeophyllum sepiarium (Wulf.: Fr.) P. Karst.". Quebracho Revista de Ciencias Forestales. Facultad de Ciencias Forestales. Universidad Nacional de Santiago del Estero 22 (1,2): 114-124.

Nikolov S, Encev E. 1967. Effect of heat treatment on the sorption dynamics of Beech wood, Nauc. Trud. Lesoteh. Inst., Sofija (Ser. meh. Tehn. Darv.). 14 (3): 71-77.

Padró, A. 1992. Clones de chopo para el valle medio del Ebro. Diputación General de Aragón. Zaragoza. 203 pág. 
Pincemin, J.M., S.J.; Monlezun; H. Zunino; P.S. Cornaglia; E. Borodowski, E. 2007. Sistemas Silvopastoriles en el Delta del Río Paraná: Producción de materia seca y estructura de gramíneas templadas bajo álamos. APPA ALPA-Cusco, Perú.

Ramirez, J.C.; D. Lanfranco. 2001. Descripción de la biología, daño y control de las termitas: especies existentes en Chile. BOSQUE 22(2): 77-84.

Randall, C. 2000. Management of termites and other Word destroying pest. Michigan State University, 114 pp.

Reglamento Argentino de Estructuras de Madera. 2013. Manual de aplicación de los criterios de diseño adoptados por el reglamento CIRSOC 601. 125 pp.

Ripoll-Morales, M.; F.B., Navarro-Reyes; M. N. Jiménez-Morales; J. M. MontosaSalas; E. Gallego-Teruel; L. Terrón-López; E. De Simón-Navarrete. 2009. Cultivos forestales para la producción de madera de calidad en la Vega de Granada: crecimiento inicial y comportamiento forestal de Juglans regia L., Celtis australis L., Platanus hispanica Münchh. y Prunus avium L. $5^{\circ}$ Congreso Forestal Español (ISBN: 978-84-936854-6-1). 13 Pp.

Rodrigo, B.G.; L. G. Esteban; P. de Palacios; F. García-Fernández; A. Guindeo. 2013. Caracterización físico-mecánica de la madera de Abies alba Miller procedente del pirineo español mediante probetas libres de defectos. Informes de la Construcción, Vol. 65(530): 213218.

Ross, R. J.; Geske, E.A.; Larson, G.L. and Murphy, J.F. 1991. "Transverse vibration nondestructive testing using a personal computer”. Res. Pap. FPL-RP-502.Madison, WI, USA.

Ross, R.J.; Zerbe, J.I.; Wang, X.; Green, D.W. and Pellerin, R.F. 2005. Stress Wave Nondestructive Evaluation of Douglas - Fir Peeler Cores, Forest Products Journal 55 (3): 90-94.

Rubio-Meléndez, M.E.; F. Zamudio; C. Ramírez. 2011. Susceptibilidad de híbridos de Populus spp. al ataque de afidos y roya en tres localidades de Chile. Bosque 32(2): 127-134.

Ruiz-Maya Pérez, L. 1986. Métodos estadísticos de investigación: (introducción al análisis de la varianza). Editorial Instituto Nacional de Estadística. ISBN 84-260-0880-1.

Rusche, H. 1973. Thermal Degradation of Wood at Temperatures up to 200 oC-Part I: Strength Properties of Dried Wood after Heat Treatment. Holz Roh Werkstoff. 31:273-281.

Rusche, H. 1973. Thermal Degradation of Wood at Temperatures up to 200 oC-Part II: Strength Properties of Dried Wood after Heat Treatment. Holz Roh Werkstoff. 31:307-312.

Sanchez-Beitia, S.; J. Barrallo. 2000. Learning heritage restoration, learning mathematics. En Proceedings of the International Conference on Mathematics Education into the 21st Century: Mathematics for Living, editado por Alan Rogerson. Amman, Jordania. http://math.unipa.it/ grim/Jsanchezbarrallo.pdf. 5 pp. 
Schad, K.C.; D.E. Kretschmann; K.A. McDonald; R.J. Ross; D.A. Green. 1995. "Stress Wave Techniques for Determining Quality of Dimensional Lumber from Switch Ties", Forest products Laboratory, FPL-RN-0265.

Scheffer, T. \& Morrell, J. 1998. Natural Durability of Wood: A Worldwide Checklist of Species. Forest Research Laboratory. Oregon State University. 62 Pp.

Seborg RM, Millet MA, Stamm AJ. 1945. Heat -stabilized compressed wood (Staypak). Mech Eng 67: 25-31

Seborg RM, Tarkow H, Stamm AJ. 1953. Effect of heat upon dimensional stabilisation of wood. Journal of Forest Products Research Society 3: 59-67.

Serventi, N; J. García. 2004. Revista SAGPyA Forestal No 32: 24-27.

Shi, J.L., Kocaefe, D., and Zhang, J. 2007. Mechanical behaviour of Quebec wood species heat-treated using Thermo Wood process. Holz Roh Werkst. 65(4):255-259.

Stamm A.J.; H.K. Burr; A.A. Kline. 1946. Heat stabilized wood (staybwood). Rep. Nr. R. 1621. Madison: Forest Prod. Lab

Soriano, C. 1993. Populus L. En S. Castroviejo \& al. (eds.) Flora iberica 3: 471-477. CSIC. Madrid.

Schwarse, F. 2007. Review: Wood decay under the microscope. Fungal biology reviews; 2 (1); 133 - 170.

Schwarze, F.; J. Engels; C. Mattheck. 2000. Fungal strategies of wood decay in trees. Springer Verlag, Berlin. 184 pp.

Spavento, E. 2011. Informe de consultoría sobre situación foresto-industrial Argentina. Ministerio de Agricultura, Ganaderia y Pesca. 271 pp.

Thomas, E.; A. Garcés. 2011. Crecimiento inicial de 13 clones de álamo en el Valle Medio del río Negro. Tercer Congreso Internacional de Salicáceas en Argentina. Comunicación. $5 \mathrm{pp}$.

Tiemann, H.D. 1920. Effect of Different Methods of Drying on the Strength and Hygroscopicity of Wood, 3rd ed., The Kiln Drying of Lumber; Chap. 11, J.P. Lippincott Co., Philadelphia PA.

Troya M.T.; E. Navarrete; E. Sanchéz; J.E. García de los Ríos; E. Rodriguez-Trobajo. 1995. Evaluation of the permeability of fast grown wood species, Int. Res. Gr. on Wood Preserv, 95, 40.042, pp. 1 - 13.

Tukey, J.W. 1977. Exploratory Data Analysis. Editorial Addison-Wesley.

Vanden Broeck, A. 2003. EUFORGEN Technical Guidelines for genetic conservation and use for European black poplar (Populus nigra). International Plant Genetic Resources Institute. Rome. 
Wan, X. 2010. An Overview of Populus Genetic Resource in Southwest China. Consultado 08-2015.

Wang, SY.; J.H. Chen; M.J.Tsai; C.J. Lin; T.H. Yang. 2008. Grading of softwood lumber using non-destructive techniques. Journal Of Material Processing Technology 208 (1): 149-158.

Wang, Z.; Li, L.; Gong, M. 2012. Measurement of dynamic modulus of elasticity and damping ratio of wood-based composites using the cantilever beam vibration technique. Construction and Building Materials 28: 831-834.

Wilcox, W. 1978. Review of literature on the effects of early stages of decay on wood strength. Wood and Fiber, 9 (4): $252-257$.

Winer, B.J; D. R. Brown; K. M. Michels. 1991. Statistical Principles in Experimental Design Ed. McGraw-Hill, New York. 3rd edition

Winandy, J.; J. Morrell. 1993. Relationship between incipient decay, strength, and chemical composition of Douglas - Fir heartwood. Wood and Fiber Science, 25 (3): 278 - 288.

\section{Tesis doctorales y proyectos}

Basterra, A. Fabricación y caracterización de vigas de madera reforzadas con fibras. Memoria proyecto de investigación. $36 \mathrm{pp}$.

De la Cruz-Calleja, A.C. 2005. Dinámica de nutrientes en parcelas de Populus $\mathrm{x}$ euramericana (Dode) Guinier I-214. Tesis doctoral. Escuela Técnica Superior de Ingenieros de Montes. Universidad Politécnica de Madrid. 265 pp.

Esteban Herrero, M. 2003. Determinación de la capacidad resistente de la madera estructural de gran escuadría y su aplicación en estructuras existentes de madera de conífera. Tesis doctoral. Escuela Técnica Superior de Ingenieros de Montes. Universidad Politécnica de Madrid. 365 pp.

Hermoso, E. 2001. Caracterización mecánica de la madera estructural de Pinus sylvestris L. Tesis doctoral. Madrid, ES, Universidad Politécnica. 253 pp.

Íñiguez-González, G. 2007. Clasificación mediante técnicas no destructivas y evaluación de las propiedades mecánicas de la madera aserrada de coníferas de gran escuadría para uso estructural. Tesis doctoral. Departamento de Construcción y vías rurales. Escuela Técnica Superior de Ingenieros de Montes. Universidad Politécnica de Madrid. 236 pp.

Piter, J.C. 2003. Clasificación por resistencia de la madera aserrada como material estructural. Desarrollo de un método para el Eucalyptus grandis de Argentina. Tesis Doctoral. Universidad Nacional de la Plata. 206 pp. 


\section{Normativas}

CEN/TS 15083-1. 2005. Durability of wood and wood-based products. Determination of the natural durability of solid wood against wood-destroying fungi, test methods-Part 1 : Basidiomycetes. 19 pp.

CEN/TS 15083-2. 2005. Durability of wood and wood-based products. Determination of the natural durability of solid wood against wood-destroying fungi, test methods-Part 2: Softrotting micro-fungi. $19 \mathrm{pp}$.

DIN 4074: 2003. Parte 1 "Clasificación de la Madera Aserrada para su uso estructural". Alemania.

EN 350-1. 1995. Durabilidad de la madera y de los materiales derivados de la madera. Durabilidad natural de la madera maciza. Parte 1: guía para los principios de ensayo y clasificación de la durabilidad natural de la madera. 20 pp.

EN 350-2. 1995. Durabilidad de la madera y de los materiales derivados de la madera. Durabilidad natural de la madera maciza. Parte 2: guía de la durabilidad natural y de la impregnabilidad de especies de madera seleccionadas por su importancia en Europa. 46 pp.

EN 844-7. 1997. Madera aserrada y madera en rollo. Terminología. Parte 7: Términos relativos a la estructura anatómica de la madera. $7 \mathrm{pp}$

EN 1310. 1997. Madera aserrada y madera en rollo. Método de medida de las singularidades. $26 \mathrm{pp}$.

ENV 1995-1-1. 1997. Eurocódigo 5: Proyecto de estructuras de madera. Parte 1-1: Reglas generales y reglas para edificación.

EN 13183-1. 2002. Contenido de humedad de una pieza de madera aserrada. Parte 1: Determinación por el método de secado en estufa. 8 pp.

EN 14081-1:2006+A1:2011. Estructuras de madera. Madera estructural con sección transversal rectangular clasificada por su resistencia. Parte 1: requisitos generales. $32 \mathrm{pp}$.

EN 14081-2. 2010. Estructuras de madera. Madera estructural con sección transversal rectangular clasificada por su resistencia. Parte 2: clasificación mecánica. Requisitos complementarios para el ensayo inicial de tipo. $22 \mathrm{pp}$.

EN 338. 2010. Madera estructural. Clases resistentes. $12 \mathrm{pp.}$

EN 384. 2010. Madera estructural. Determinación de los valores característicos de las propiedades mecánicas y la densidad. $20 \mathrm{pp}$.

EN 408:2011+A1:2012. Estructuras de madera. Madera aserrada y madera laminada encolada para uso estructural. Determinación de algunas propiedades físicas y mecánicas. 38 pp.

EN 117. 2012. Protectores de la madera. Determinación del umbral de eficacia contra las especies de reticulitermes (termitas europeas): método de laboratorio. $24 \mathrm{pp}$. 
EN 14081-3. 2010. Estructuras de madera. Madera estructural con sección transversal rectangular clasificada por su resistencia. Parte 3: clasificación mecánica. Requisitos complementarios para el control de producción en fábrica. 18 pp.

EN 335. 2013. Durabilidad de la madera y de los productos derivados de la madera. Clases de uso: definiciones, aplicación a la madera maciza y a los productos derivados de la madera. $16 \mathrm{pp}$.

EN 336. 2014. Madera estructural. Medidas y tolerancias. $10 \mathrm{pp}$.

IRAM 9570. 1971. "Método de ensayo de la dureza janka". Instituto Argentino de Racionalización de Materiales. 6 pp.

IRAM 9542. 1977. "Método de ensayo de flexión estática de maderas con densidad aparente mayor de $0,5 \mathrm{~g} / \mathrm{cm}^{3}$ ". Instituto Argentino de Racionalización de materiales $10 \mathrm{pp}$.

IRAM 9551. 1985. Maderas: método de determinación de la compresión axil o paralela al grano. Instituto Argentino de Racionalización de Materiales. 6 pp

NCh1970. 1988. Maderas-Parte 1: Especies latifoliadas- Clasificación visual para uso estructural- Especificaciones de los grados de calidad. Chile.

NF B 52-001: 2007. Clasificación visual de la madera aserrada de coníferas y frondosas para uso estructural. Francia

UNE 56529. 1977. Características físico-mecánicas de la madera: preparación de probetas de ensayos. $3 \mathrm{pp}$.

UNE 56529. 1977. Características físico-mecánicas de la madera: determinación del contenido de humedad por desecación hasta el estado anhidro. 2 pp.

UNE 56531. 1977. Características físico-mecánicas de la madera: determinación del peso específico. $2 \mathrm{pp}$.

UNE 56532. 1977. Características físico-mecánicas de la madera: determinación de la higroscopicidad. $1 \mathrm{pp}$.

UNE 56533. 1977. Características físico-mecánicas de la madera: determinación de las contracciones lineales y volumétricas. $2 \mathrm{pp}$.

UNE 56534. 1977. Características físico-mecánicas de la madera: determinación de la dureza. $1 \mathrm{pp}$.

UNE 56535. 1977. Características físico-mecánicas de la madera: determinación de la resistencia a la compresión axial. 2 pp.

UNE 56540. 1978. Características físico-mecánicas de la madera: interpretación de los resultados de los ensayos. $6 \mathrm{pp}$.

UNE 56537. 1979. Características físico-mecánicas de la madera: determinación de la resistencia a la flexión estática. 1 pp. 
UNE 56544. 1997. Clasificación visual de la madera aserrada para uso estructural. Madera de coníferas. $16 \mathrm{pp}$.

UNE 56544. 2011. Clasificación visual de la madera aserrada para uso estructural. Madera de coníferas. $22 \mathrm{pp}$.

\section{Páginas web consultadas}

Comisión Nacional del Chopo: http://www.magrama.gob.es/es/desarrollorural/temas/politica-forestal/comision-nacional-del-chopo/default.aspx

Comisión Internacional del Álamo. http://www.fao.org/forestry/ipc/69637@125653/en/ MAGyP.http://www.minagri.gob.ar/new/0-0/forestacion/

Vilar Fernández, 2006. http://www.udc.es/dep/mate/estadistica2/sec9_3.html 


\section{CAPITULO VII. ANEJOS}

\section{SECCIÓN I: Caracterización de madera maciza}

6.1. Probetas de pequeñas dimensiones y libres de defectos.

\subsubsection{Propiedades físicas}

\subsubsection{Contenido de humedad $(\mathrm{CH})$}

\section{Análisis descriptivo por procedencias}

En la Tabla 169 se detalla el resumen estadístico y los resultados de las pruebas de normalidad para el $\mathrm{CH}$ discriminado por procedencias; la Figura 312 y Figura 313 muestran las gráficas de dispersión y de probabilidad normal en cada caso.

Tabla 169. CH por procedencias: resumen estadístico y pruebas de normalidad.

\begin{tabular}{|c|c|c|c|c|c|c|c|c|c|c|c|}
\hline \multirow{2}{*}{ Variable } & \multirow{2}{*}{$\mathrm{DE}^{*}$} & \multirow{2}{*}{$\mathrm{SE}^{*}$} & \multirow{2}{*}{$\mathrm{CE}^{*}$} & \multicolumn{2}{|c|}{ Chi-Cuadrado } & \multicolumn{2}{|c|}{$\begin{array}{l}\text { W de Shapiro- } \\
\text { Wilk } \\
\end{array}$} & \multicolumn{2}{|c|}{$\begin{array}{c}\text { Valor-Z para } \\
\text { asimetría } \\
\end{array}$} & \multicolumn{2}{|c|}{$\begin{array}{l}\text { Valor-Z para } \\
\text { curtosis }\end{array}$} \\
\hline & & & & Estad. & $\begin{array}{c}\mathrm{P}- \\
\text { valor }\end{array}$ & Estad. & $\begin{array}{c}\text { P- } \\
\text { valor }\end{array}$ & Estad. & $\begin{array}{c}\text { P- } \\
\text { valor }\end{array}$ & Estad. & $\begin{array}{c}\text { P- } \\
\text { valor }\end{array}$ \\
\hline \multirow{4}{*}{$\mathrm{CH}(\%)$} & \multicolumn{11}{|c|}{ España } \\
\hline & 0,23 & $-1,15$ & $-0,50$ & 8,0 & 0,53 & 0,92 & 0,15 & 0,90 & 0,37 & - & - \\
\hline & \multicolumn{11}{|c|}{ Argentina } \\
\hline & 0,28 & 0,84 & $-1,04$ & 18,0 & 0,12 & 0,94 & 0,12 & 0,65 & 0,51 & $-1,45$ & 0,15 \\
\hline
\end{tabular}

*DE: desvío estándar; SE: sesgo estandarizado; CE: curtosis estandarizada.

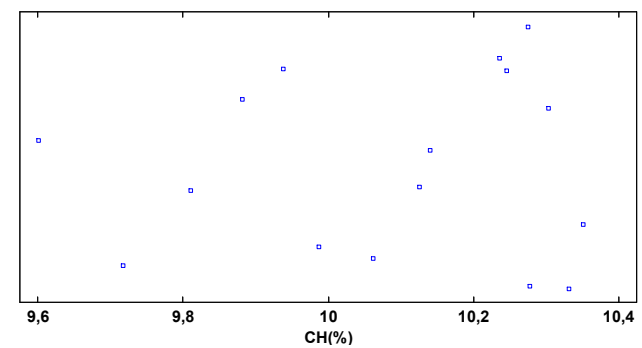

Figura 312. Gráfico de dispersión CH España

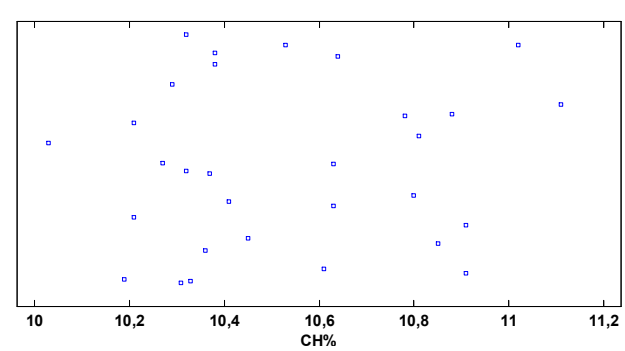

Figura 314. Gráfico de dispersión CH Argentina

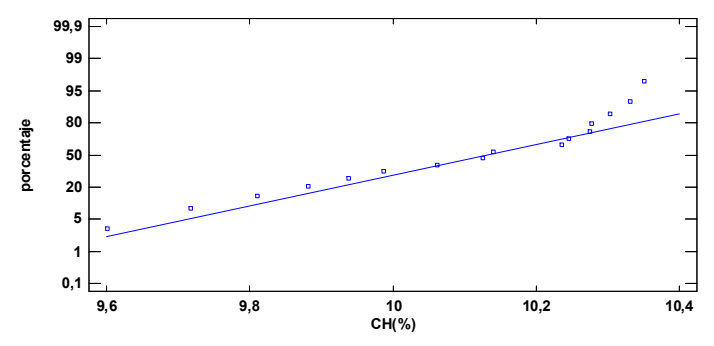

Figura 313. Gráfico probabilidad normal CH España

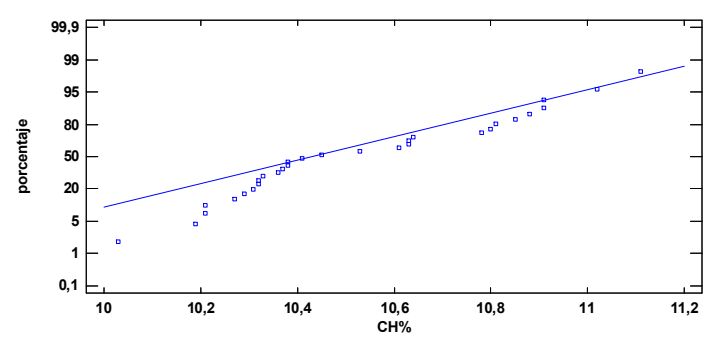

Figura 315. Gráfico probabilidad normal CH Argentina 


\subsubsection{Densidades aparentes}

\section{Análisis descriptivo por procedencias}

El resumen estadístico y los resultados de las pruebas de normalidad para las densidades aparentes discriminadas por procedencias se detallan en la Tabla 170; las gráficas de dispersión y de probabilidad normal se muestran en a continuación del resumen tabular.

Tabla 170. Densidades aparentes por procedencias: resumen estadístico y pruebas de normalidad.

\begin{tabular}{|c|c|c|c|c|c|c|c|c|c|c|c|}
\hline \multirow{2}{*}{ Variable } & \multirow{2}{*}{ DE* } & \multirow{2}{*}{ SE* } & \multirow{2}{*}{$\mathrm{CE}^{*}$} & \multicolumn{2}{|c|}{ Chi-Cuadrado } & \multicolumn{2}{|c|}{$\begin{array}{l}\text { W de Shapiro- } \\
\text { Wilk }\end{array}$} & \multicolumn{2}{|c|}{$\begin{array}{c}\text { Valor-Z para } \\
\text { asimetría }\end{array}$} & \multicolumn{2}{|c|}{$\begin{array}{c}\text { Valor-Z para } \\
\text { curtosis }\end{array}$} \\
\hline & & & & Estad. & $\begin{array}{c}\mathrm{P}- \\
\text { valor }\end{array}$ & Estad. & $\begin{array}{c}\text { P- } \\
\text { valor }\end{array}$ & Estad. & P-valor & Estad. & $\begin{array}{c}\mathrm{P}- \\
\text { valor }\end{array}$ \\
\hline \multicolumn{12}{|c|}{ España } \\
\hline Do $\left(\mathrm{Kg} / \mathrm{m}^{3}\right)$ & 33,51 & 0,59 & $-\overline{40}$ & 6,5 & 0,69 & 0,97 & 0,79 & 0,48 & 0,63 & - & - \\
\hline $\begin{array}{c}\text { Dn }-12 \% \mathrm{CH}- \\
\left(\mathrm{Kg} / \mathrm{m}^{3}\right)\end{array}$ & 27,58 & 0,34 & $\begin{array}{c}- \\
0,15 \\
\end{array}$ & 5,0 & 0,83 & 0,98 & 0,96 & 0,28 & 0,78 & - & - \\
\hline $\mathrm{Db}\left(\mathrm{Kg} / \mathrm{m}^{3}\right)$ & 12,12 & $\overline{-}$ & $\overline{0}-\overline{07}$ & 14,76 & 0,19 & 0,98 & 0,94 & 0,17 & 0,87 & 0,14 & 0,89 \\
\hline \multicolumn{12}{|c|}{ Argentina } \\
\hline Do $\left(\mathrm{Kg} / \mathrm{m}^{3}\right)$ & 16,13 & 0,08 & $\overline{-}$ & 21,0 & 0,05 & 0,93 & 0,04 & 0,06 & 0,95 & $-2,40$ & 0,02 \\
\hline $\begin{array}{c}\text { Dn }-12 \% \text { CH- } \\
\left(\mathrm{Kg} / \mathrm{m}^{3}\right)\end{array}$ & 17,18 & 0,68 & - & 19,0 & 0,09 & 0,92 & 0,02 & 0,53 & 0,60 & $-2,14$ & 0,03 \\
\hline $\mathrm{Db}(\mathrm{Kg} / \mathrm{m} 3)$ & 23,01 & 1,71 & $\overline{-}, 40$ & 21,0 & 0,05 & 0,91 & 0,01 & 1,26 & 0,21 & $-0,29$ & 0,77 \\
\hline
\end{tabular}

*DE: desvío estándar; SE: sesgo estandarizado; CE: curtosis estandarizada.

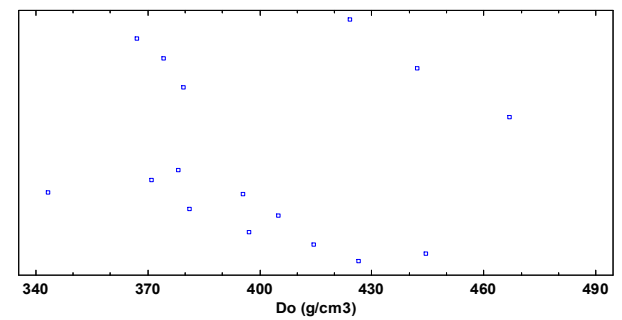

Figura 316. Gráfico de dispersión Do - España

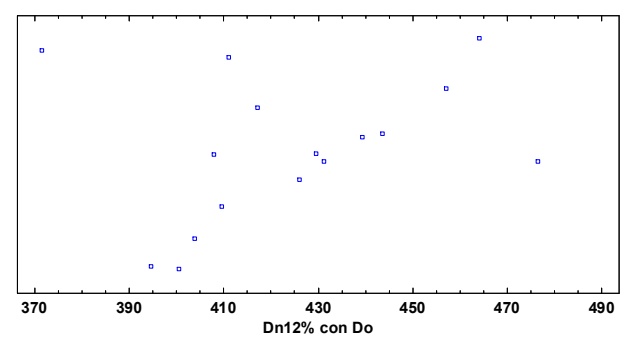

Figura 318. Gráfico de dispersión Dn - España

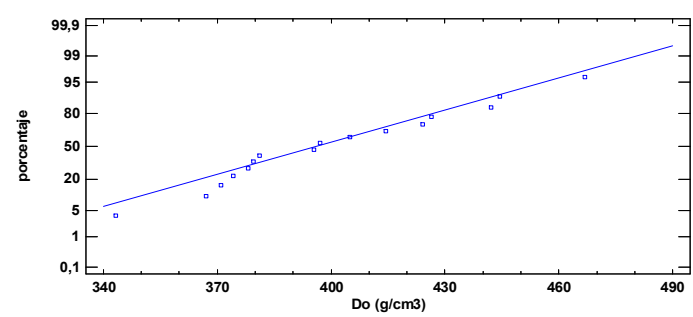

Figura 317. Gráfico probabilidad normal Do España

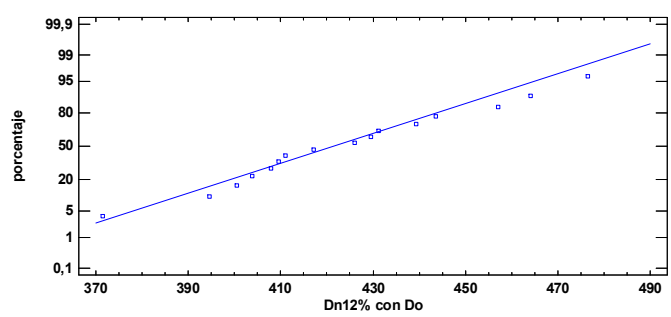

Figura 319. Gráfico probabilidad normal Dn España 


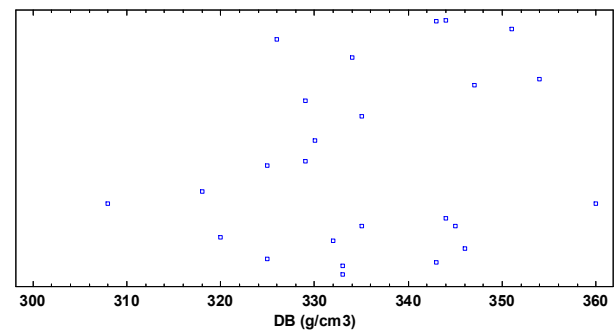

Figura 320. Gráfico de dispersión Db - España

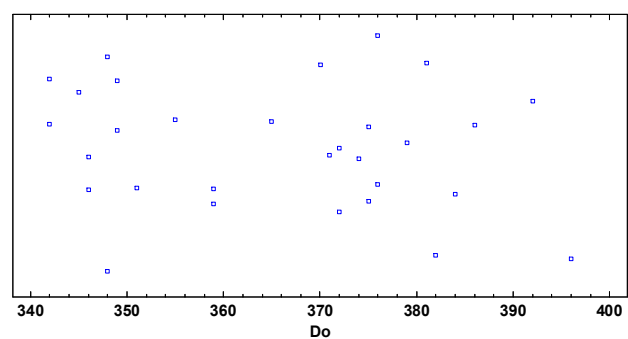

Figura 322. Gráfico de dispersión Do Argentina

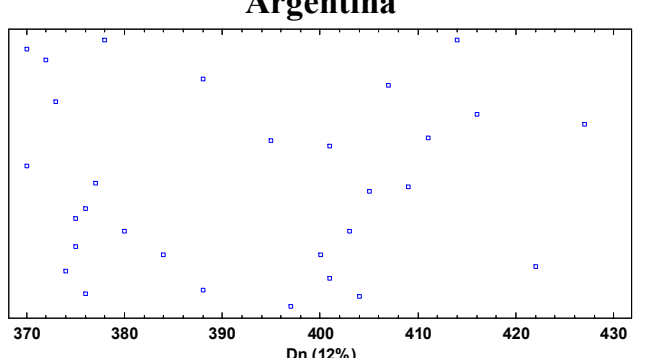

Figura 324. Gráfico de dispersión Dn Argentina

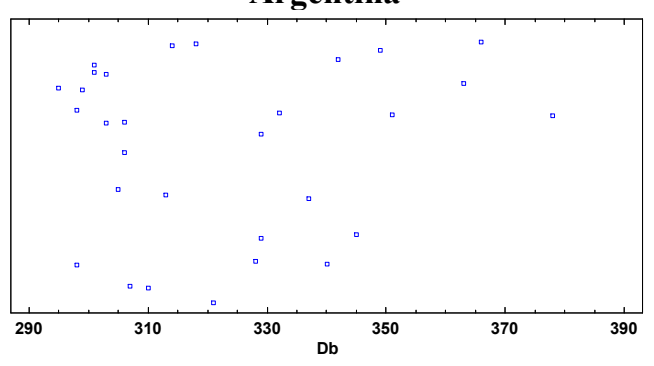

Figura 326. Gráfico de dispersión Db Argentina

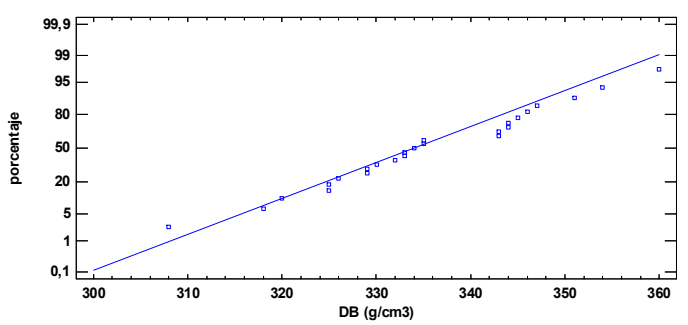

Figura 321. Gráfico probabilidad normal Db España

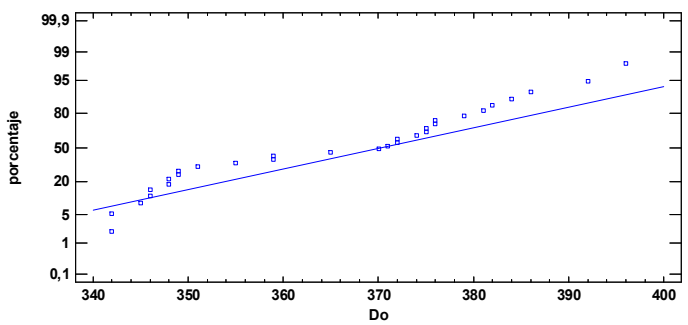

Figura 323. Gráfico probabilidad normal Do Argentina

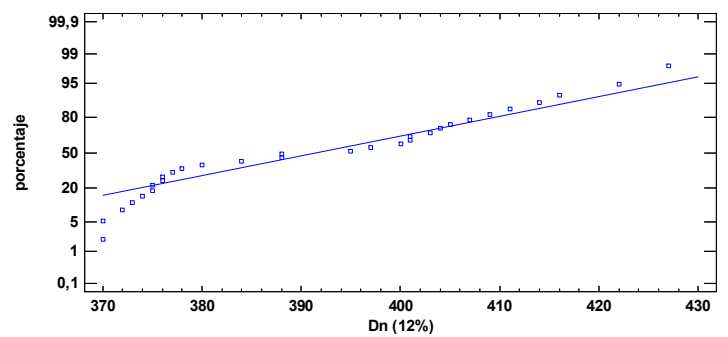

Figura 325. Gráfico probabilidad normal Dn Argentina

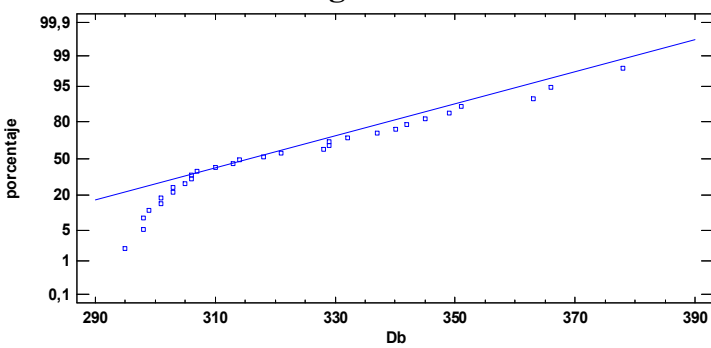

Figura 327. Gráfico probabilidad normal Db Argentina

\section{Análisis comparativo entre procedencias}

En la Tabla 171 se muestran los resultados del test de Levene para Do, Dn y Db.

Tabla 171. Densidades aparentes: Test de Levene.

\begin{tabular}{|c|c|c|c|}
\hline \multirow{4}{*}{ Test de Levene } & Parámetro dimensional & Prueba & P-valor \\
\hline & Do & 9,67 & 0,00 \\
\hline & Dn & 3,90 & 0,05 \\
\hline & $\mathrm{Db}$ & 8,76 & 0,00 \\
\hline
\end{tabular}

Puesto que el P-valor obtenido para Do y $\mathrm{Db}$ fue inferior a 0,05, existe una diferencia significativa entre las desviaciones estándar analizadas, con un nivel de confianza del 95\%. De 
acuerdo con esto, se incumple el supuesto de homogeneidad de la varianza, razón por la cual se procedió a trabajar con la prueba de Kruskal-Wallis para comparación de medianas. El P-valor igual a 0,05 para Dn deja de manifiesto que no existen diferencias significativas entre las desviaciones estándar analizadas con un nivel de confianza del 95\%, en cuyo caso, para el análisis comparativo se trabajó con el test paramétrico ANOVA.

\subsubsection{Cambios dimensionales}

\subsection{Parámetros dimensionales lineales}

\section{Análisis descriptivo: material de procedencia española}

La Tabla 172 presenta otros parámetros descriptivos junto con los resultados de las pruebas de normalidad para las variables dimensionales estudiadas; los gráficos de dispersión y de probabilidad normal para cada variable son presentados a continuación del resumen tabular (Figura 328 a Figura 335).

Tabla 172. Parámetros dimensionales lineales: resumen estadístico y pruebas de normalidad

\begin{tabular}{|c|c|c|c|c|c|c|c|c|c|c|c|}
\hline \multirow{2}{*}{ Variable } & \multirow{2}{*}{$\mathrm{DE}^{*}$} & \multirow{2}{*}{ SE* } & \multirow{2}{*}{$\mathrm{CE}^{*}$} & \multicolumn{2}{|c|}{ Chi-Cuadrado } & \multicolumn{2}{|c|}{$\begin{array}{c}\text { W de Shapiro- } \\
\text { Wilk }\end{array}$} & \multicolumn{2}{|c|}{$\begin{array}{c}\text { Valor-Z para } \\
\text { asimetría }\end{array}$} & \multicolumn{2}{|c|}{$\begin{array}{c}\text { Valor-Z para } \\
\text { curtosis }\end{array}$} \\
\hline & & & & Estad. & P-valor & Estad. & P-valor & Estad. & P-valor & Estad. & P-valor \\
\hline$\underset{(\%)}{\text { CnmáxL }}$ & 0,16 & 1,86 & $-0,10$ & 93,8 & 0,00 & 0,95 & 0,02 & 1,33 & 0,18 & 0,08 & 0,93 \\
\hline$\underset{(\%)}{\text { CnmáxRd }}$ & 0,65 & 0,34 & $-0,44$ & 29,13 & 0,06 & 0,98 & 0,50 & 0,25 & 0,80 & $-0,34$ & 0,74 \\
\hline$\underset{(\%)}{C n \operatorname{máxTg}}$ & 1,08 & $-0,87$ & $-0,65$ & 13,29 & 0,82 & 0,97 & 0,34 & 0,65 & 0,52 & $-0,64$ & 0,52 \\
\hline $\mathrm{T} / \mathrm{R}$ & 0,40 & $-0,47$ & $-0,57$ & 20,33 & 0,37 & 0,97 & 0,27 & 0,35 & 0,72 & $-0,52$ & 0,60 \\
\hline
\end{tabular}

*DE: desvío estándar; SE: sesgo estandarizado; CE: curtosis estandarizada; Cnmáx: Contracción normal máxima; L, Rd y Tg: Longitudinal, Radial y Tangencial, respectivamente; T/R: coeficiente de anisotropía.

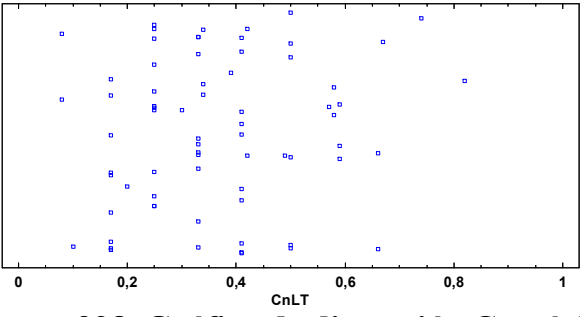

Figura 328. Gráfico de dispersión CnmáxL España

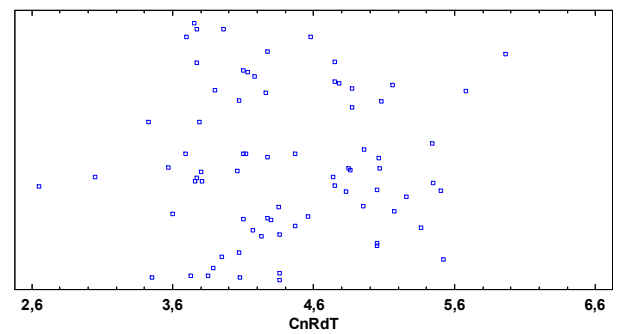

Figura 330. Gráfico de dispersión CnmáxRd España

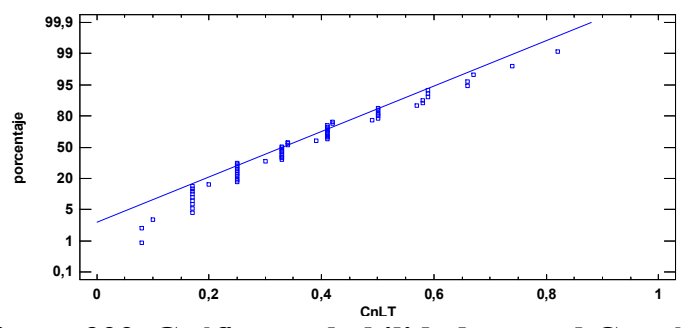

Figura 329. Gráfico probabilidad normal CnmáxL - España

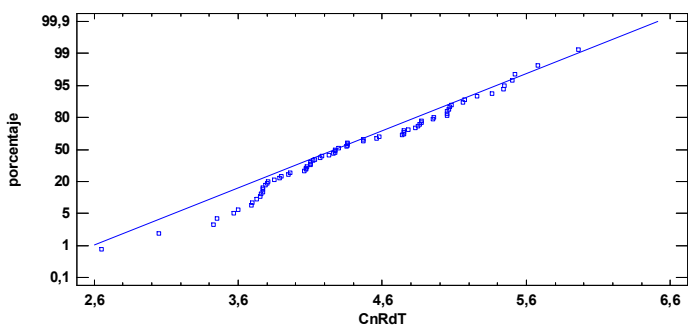

Figura 331. Gráfico probabilidad normal CnmáxRd - España 


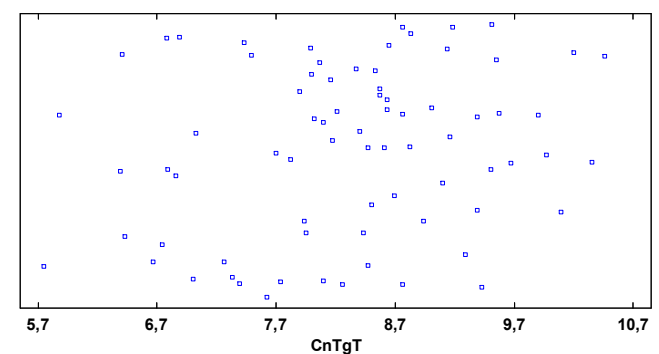

Figura 332. Gráfico de dispersión CnmáxTg España

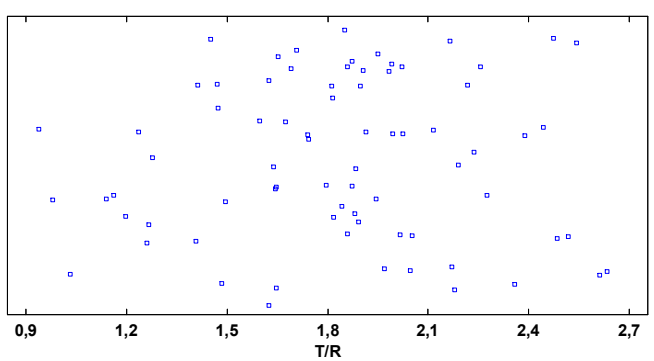

Figura 334. Gráfico de dispersión T/R España

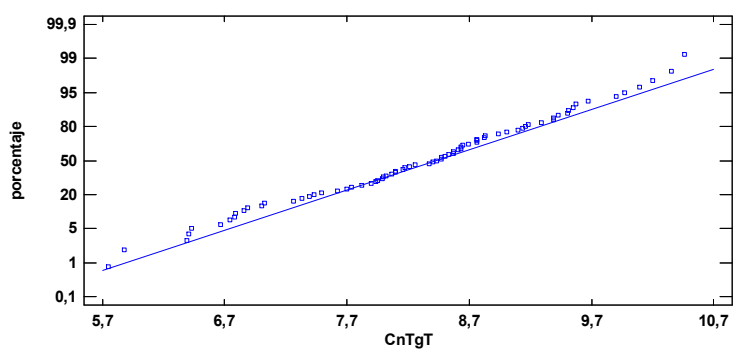

Figura 333. Gráfico probabilidad normal CnmáxTg - España

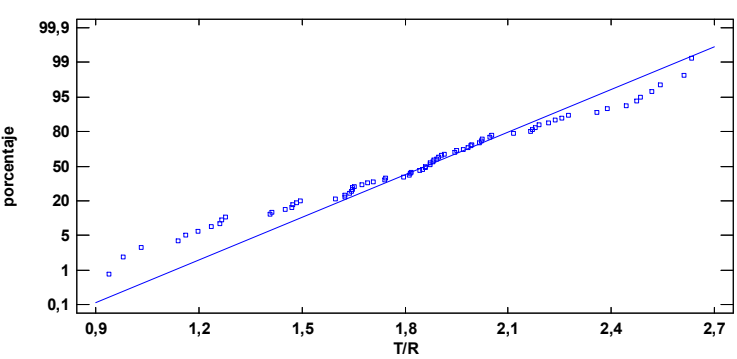

Figura 335. Gráfico probabilidad normal T/R España

Las ecuaciones de regresión para la obtención del punto de saturación de la pared celular (PSPC), en las tres direcciones de estudio, son indicadas en la Tabla 173.

Tabla 173. Ecuaciones de regresión para obtención del PSPC

\begin{tabular}{ccc}
\hline Parámetro & Ecuación de regresión & $\mathrm{R}^{2}$ \\
\hline $\mathrm{CnL}$ & $\mathrm{y}=-0,012 \mathrm{x}+0,3292$ & 0,2554 \\
\hline $\mathrm{CnRd}$ & $\mathrm{y}=-0,1839 \mathrm{x}+4,2807$ & 0,6435 \\
\hline $\mathrm{CnTg}$ & $\mathrm{y}=-0,2959 \mathrm{x}+8,0539$ & 0,7553 \\
\hline
\end{tabular}

\section{Análisis descriptivo: material de procedencia argentina}

En la Tabla 174 (Figura 336 a Figura 343) se detalla el resumen estadístico y las pruebas de normalidad para las variables dimensionales lineales.

Tabla 174. Parámetros dimensionales lineales: resumen estadístico y pruebas de normalidad

\begin{tabular}{|c|c|c|c|c|c|c|c|c|c|c|c|}
\hline \multirow{2}{*}{ Variable } & \multirow{2}{*}{$\mathrm{DE}^{*}$} & \multirow{2}{*}{$\mathrm{SE}^{*}$} & \multirow{2}{*}{$\mathrm{CE}^{*}$} & \multicolumn{2}{|c|}{ Chi-Cuadrado } & \multicolumn{2}{|c|}{$\begin{array}{c}\text { W de Shapiro- } \\
\text { Wilk }\end{array}$} & \multicolumn{2}{|c|}{$\begin{array}{l}\text { Valor-Z para } \\
\text { asimetría }\end{array}$} & \multicolumn{2}{|c|}{$\begin{array}{l}\text { Valor-Z para } \\
\text { curtosis }\end{array}$} \\
\hline & & & & Estad. & $\begin{array}{c}\mathrm{P}- \\
\text { valor }\end{array}$ & Estad. & $\begin{array}{c}\mathrm{P}- \\
\text { valor }\end{array}$ & Estad. & P-valor & Estad. & P-valor \\
\hline $\begin{array}{c}\text { CnmáxL } \\
(\%)\end{array}$ & 0,37 & 0,92 & $0, \overline{98}$ & 62,56 & 0,00 & 0,93 & 0,03 & 0,70 & 0,48 & $-1,28$ & 0,20 \\
\hline $\begin{array}{c}\text { CnmáxRd } \\
(\%)\end{array}$ & 0,38 & 1,86 & 1,54 & 10,0 & 0,62 & 0,96 & 0,28 & 1,36 & 0,17 & 1,53 & 0,13 \\
\hline $\begin{array}{c}\text { CnmáxTg } \\
(\%)\end{array}$ & 0,51 & $\overline{1,38}$ & $0, \overline{25}$ & 19,0 & 0,09 & 0,93 & 0,07 & 1,04 & 0,30 & $-0,09$ & 0,93 \\
\hline $\mathrm{T} / \mathrm{R}$ & 0,24 & 0,83 & 0,79 & 11,0 & 0,53 & 0,95 & 0,24 & 0,64 & 0,52 & $-0,94$ & 0,35 \\
\hline
\end{tabular}

*DE: desvío estándar; SE: sesgo estandarizado; CE: curtosis estandarizada; Cnmáx: Contracción normal máxima; L, Rd y Tg: Longitudinal, Radial y Tangencial, respectivamente; T/R: coeficiente de anisotropía. 


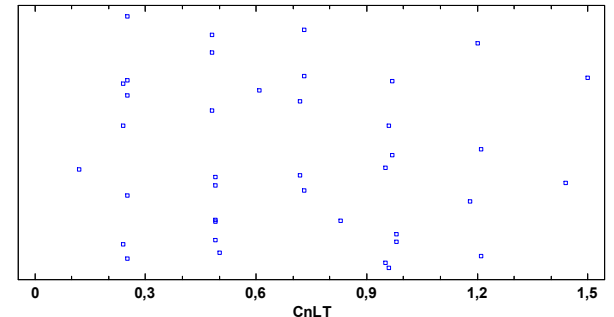

Figura 336. Gráfico de dispersión CnmáxL Argentina

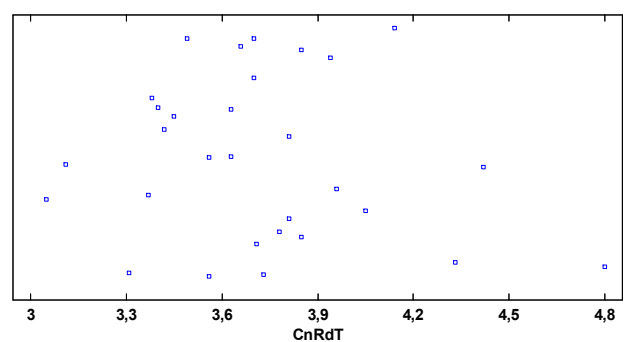

Figura 338. Gráfico de dispersión CnmáxRd Argentina

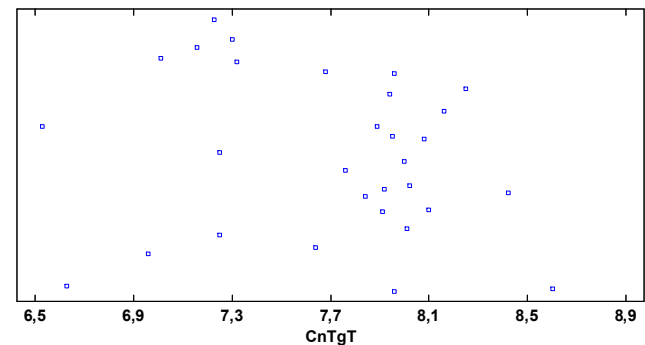

Figura 340. Gráfico de dispersión CnmáxTg Argentina

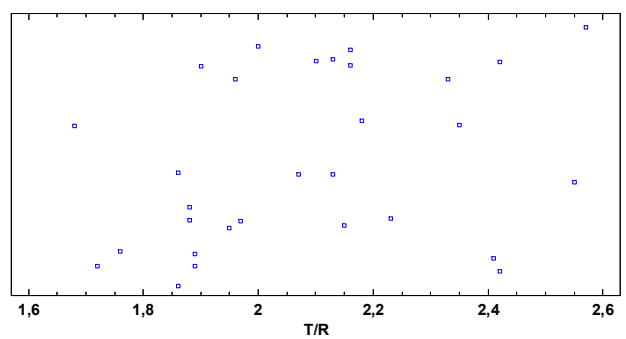

Figura 342. Gráfico de dispersión T/R Argentina

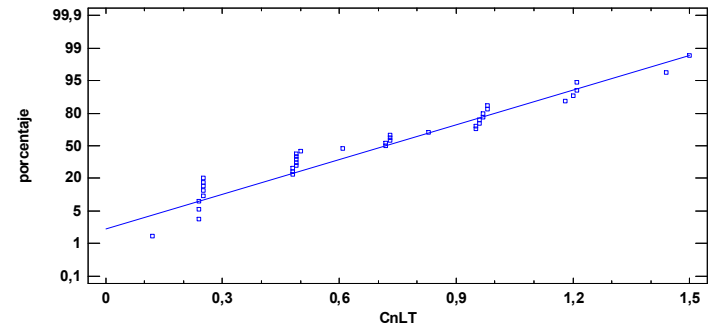

Figura 337. Gráfico probabilidad normal CnmáxL - Argentina

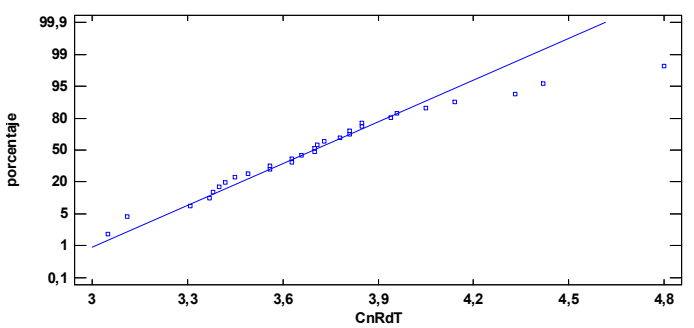

Figura 339. Gráfico probabilidad normal CnmáxRd - Argentina

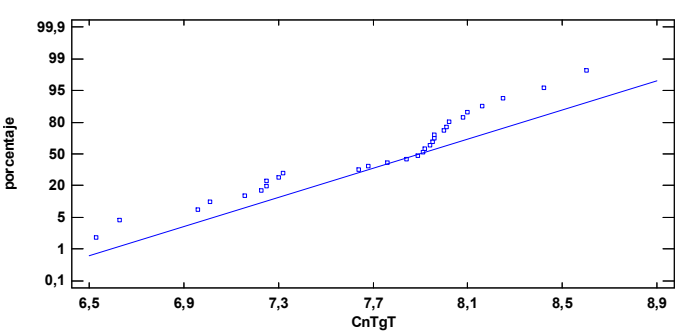

Figura 341. Gráfico probabilidad normal CnmáxTg - Argentina

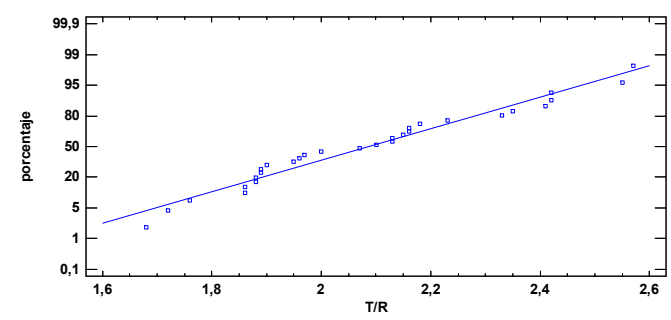

Figura 343. Gráfico probabilidad normal T/R Argentina

Tabla 175. Ecuaciones de regresión para obtención del PSPC.

\begin{tabular}{ccc}
\hline Parámetro & Ecuación de regresión & $\mathrm{R}^{2}$ \\
\hline CnmáxL & $\mathrm{y}=-0,0167 \mathrm{x}+0,7101$ & 0,0929 \\
\hline CnmáxRd & $\mathrm{y}=-0,0981 \mathrm{x}+3,712$ & 0,7636 \\
\hline CnmáxTg & $\mathrm{y}=-0,2372 \mathrm{x}+7,6853$ & 0,893 \\
\hline
\end{tabular}

Cabe destacar que el coeficiente de regresión obtenido para la ecuación del CnmáxL, es muy bajo, lo cual advierte que el PSPC obtenido a partir de dicha ecuación debe ser tomado en cuenta con precaución. 


\subsection{Parámetros volumétricos}

\section{Análisis descriptivo: material de procedencia española}

En la Tabla 176 se amplía el análisis descriptivo y se detallan las pruebas de normalidad de los parámetros volumétricos; a continuación se muestran los gráficos de dispersión y de probabilidad normal (Figura 344 a Figura 347).

Tabla 176. Parámetros volumétricos: resumen estadístico y pruebas de normalidad

\begin{tabular}{|c|c|c|c|c|c|c|c|c|c|c|c|}
\hline \multirow{2}{*}{ Variable } & \multirow{2}{*}{$\mathrm{DE}^{*}$} & \multirow{2}{*}{$\mathrm{SE}^{*}$} & \multirow{2}{*}{ CE* } & \multicolumn{2}{|c|}{ Chi-Cuadrado } & \multicolumn{2}{|c|}{$\begin{array}{c}\text { W de Shapiro- } \\
\text { Wilk } \\
\end{array}$} & \multicolumn{2}{|c|}{$\begin{array}{c}\text { Valor-Z para } \\
\text { asimetría } \\
\end{array}$} & \multicolumn{2}{|c|}{$\begin{array}{l}\text { Valor-Z para } \\
\text { curtosis } \\
\end{array}$} \\
\hline & & & & Estad. & $\begin{array}{c}\text { P- } \\
\text { valor }\end{array}$ & Estad. & P-valor & Estad. & P-valor & Estad. & P-valor \\
\hline $\mathrm{CnV}$ & 1,05 & 0,92 & $\begin{array}{c}- \\
1,22 \\
\end{array}$ & 18,12 & 0,08 & 0,90 & 0,02 & 0,72 & 0,47 & $-1,94$ & 0,05 \\
\hline $\mathrm{V}$ & 0,08 & 1,36 & $\overline{-}$ & 15,88 & 0,15 & 0,95 & 0,22 & 1,04 & 0,30 & 0,14 & 0,89 \\
\hline
\end{tabular}

*DE: desvío estándar; SE: sesgo estandarizado; CE: curtosis estandarizada; CnV: contracción volumétrica; V: coeficiente de contracción volumétrica.

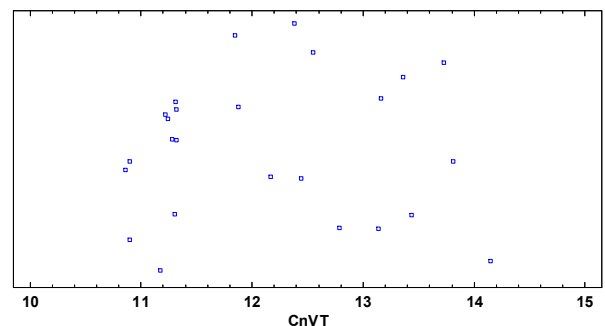

Figura 344. Gráfico de dispersión CnV - España

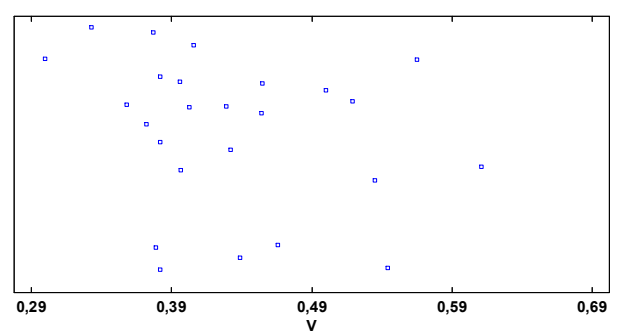

Figura 346. Gráfico de dispersión V - España

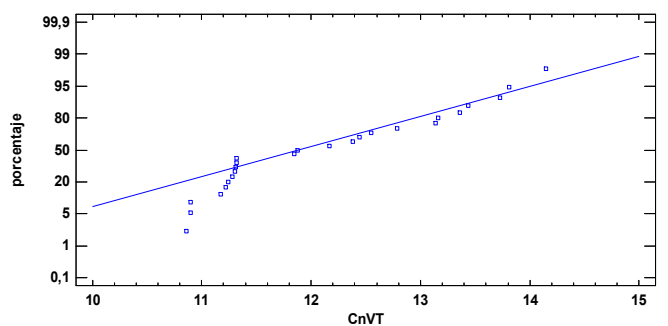

Figura 345. Gráfico probabilidad normal CnV España

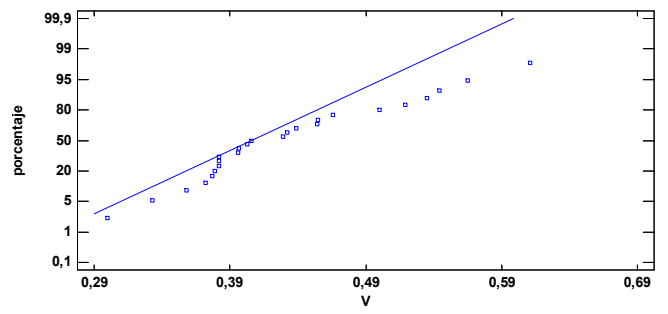

Figura 347. Gráfico probabilidad normal V España

En base a estos análisis, se ha aceptado la normalidad de las variables dimensionales (lineales y volumétricas) para el material procedente de España.

\section{Análisis descriptivo: material de procedencia española}

En la Tabla 177 se detalla el análisis descriptivo y las pruebas de normalidad para los parámetros volumétricos.

Tabla 177. Parámetros volumétricos: resumen estadístico. 


\begin{tabular}{|c|c|c|c|c|c|c|c|c|c|c|c|}
\hline \multirow{2}{*}{ Variable } & \multirow{2}{*}{$\mathrm{DE}^{*}$} & \multirow{2}{*}{ SE* } & \multirow{2}{*}{ CE* } & \multicolumn{2}{|c|}{ Chi-Cuadrado } & \multicolumn{2}{|c|}{$\begin{array}{c}\text { W de Shapiro- } \\
\text { Wilk }\end{array}$} & \multicolumn{2}{|c|}{$\begin{array}{l}\text { Valor-Z para } \\
\text { asimetría }\end{array}$} & \multicolumn{2}{|c|}{$\begin{array}{l}\text { Valor-Z para } \\
\text { curtosis }\end{array}$} \\
\hline & & & & Estad. & $\begin{array}{c}\text { P- } \\
\text { valor }\end{array}$ & Estad. & P-valor & Estad. & P-valor & Estad. & P-valor \\
\hline $\mathrm{CnV}$ & 1,23 & $\overline{-}, \overline{38}$ & 1,64 & 18,08 & 0,64 & 0,97 & 0,27 & 0,28 & 0,78 & 1,54 & 0,12 \\
\hline $\mathrm{V}$ & 0,09 & 0,88 & 0,18 & 24,94 & 0,25 & 0,99 & 0,79 & 0,64 & 0,52 & 0,37 & 0,71 \\
\hline
\end{tabular}

*DE: desvío estándar; SE: sesgo estandarizado; CE: curtosis estandarizada; CnV: contracción volumétrica; V: coeficiente de contracción volumétrica.

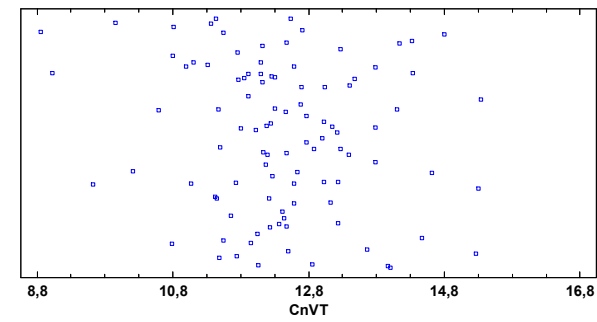

Figura 348. Gráfico de dispersión $\mathrm{CnV}$ Argentina

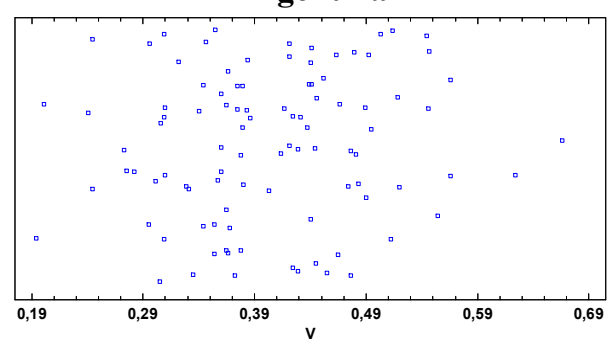

Figura 350. Gráfico de dispersión V - Argentina

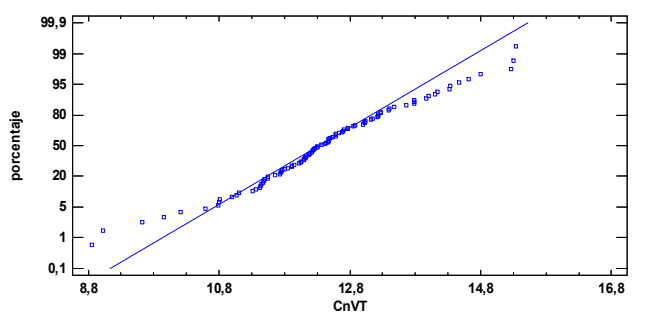

Figura 349. Gráfico probabilidad normal CnV Argentina

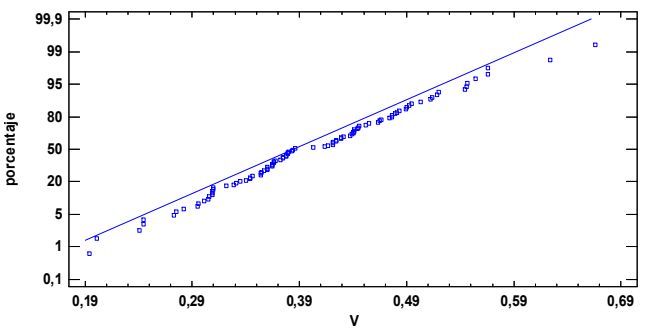

Figura 351. Gráfico probabilidad normal V -

Argentina

\section{Análisis comparativo entre procedencias}

En la Tabla 178 se muestran los resultados del test de Levene para los parámetros dimensionales lineales y volumétricos analizados.

Tabla 178. Parámetros dimensionales lineales y volumétricos: Test de Levene.

\begin{tabular}{cccc}
\hline & Parámetros* & Prueba & P-valor \\
\cline { 2 - 4 } & $\mathrm{CnL}$ & 40,54 & 0,00 \\
\cline { 2 - 4 } Test de Levene & $\mathrm{CnRd}$ & 11,00 & 0,00 \\
\cline { 2 - 4 } & $\mathrm{CnTg}$ & 12,58 & 0,00 \\
\cline { 2 - 4 } & $\mathrm{T} / \mathrm{R}$ & 5,11 & 0,03 \\
\cline { 2 - 4 } & $\mathrm{CnV}$ & 0,00 & 0,99 \\
\cline { 2 - 4 } & $\mathrm{V}$ & 1,16 & 0,28 \\
\hline
\end{tabular}

Cnmáx: Contracción normal máxima; L, Rd y Tg: Longitudinal, Radial y Tangencial, respectivamente; T/R: coeficiente de anisotropía; $\mathrm{CnV}$ : contracción volumétrica; V: coeficiente de contracción volumétrica.

Puesto que el P-valor obtenido en todos los parámetros lineales fue inferior a 0,05 , existe una diferencia significativa entre las desviaciones estándar analizadas, con un nivel de confianza del 95\%. De acuerdo con esto, se incumple el supuesto de homogeneidad de la varianza, razón por la cual se procedió a trabajar con la prueba de Kruskal-Wallis para 
comparación de medianas. Del mismo modo, en concordancia con el P-valor superior a 0,05 obtenido para los dos parámetros volumétricos, no existe diferencia estadísticamente significativa entre las desviaciones estándar, con un nivel del 95,0\% de confianza, por lo que se utilizó el ANOVA como prueba comparativa.

\subsubsection{Higroscopicidad}

\section{Análisis descriptivo por procedencias}

En la Tabla 179 (Figura 352 a Figura 355) se completa el análisis descriptivo y de constatación de normalidad.

Tabla 179. Higroscopicidad de la madera por procedencias: resumen estadístico y pruebas de normalidad.

\begin{tabular}{|c|c|c|c|c|c|c|c|c|c|c|c|}
\hline \multirow{2}{*}{ Variable } & \multirow{2}{*}{$\mathrm{DE}^{*}$} & \multirow{2}{*}{$\mathrm{SE}^{*}$} & \multirow{2}{*}{$\mathrm{CE}^{*}$} & \multicolumn{2}{|c|}{ Chi-Cuadrado } & \multicolumn{2}{|c|}{$\begin{array}{c}\text { W de Shapiro- } \\
\text { Wilk }\end{array}$} & \multicolumn{2}{|c|}{$\begin{array}{c}\text { Valor-Z para } \\
\text { asimetría }\end{array}$} & \multicolumn{2}{|c|}{$\begin{array}{l}\text { Valor-Z para } \\
\text { curtosis }\end{array}$} \\
\hline & & & & Estad. & $\begin{array}{c}\mathrm{P}- \\
\text { valor }\end{array}$ & Estad. & P-valor & Estad. & P-valor & Estad. & P-valor \\
\hline \multicolumn{12}{|c|}{ España } \\
\hline hi & 0,00033 & $\begin{array}{c}- \\
1,36\end{array}$ & $\begin{array}{c}- \\
0,08\end{array}$ & 11,4 & 0,41 & 0,95 & 0,23 & 1,04 & 0,30 & 0,13 & 0,89 \\
\hline \multicolumn{12}{|c|}{ Argentina } \\
\hline hi & 0,00036 & 0,44 & 0,61 & 30,82 & 0,08 & 0,99 & 0,97 & 0,33 & 0,74 & 0,78 & 0,44 \\
\hline
\end{tabular}

* hi: higroscopicidad; DE: desvío estándar; SE: sesgo estandarizado; CE: curtosis estandarizada; Estad.: estadístico.

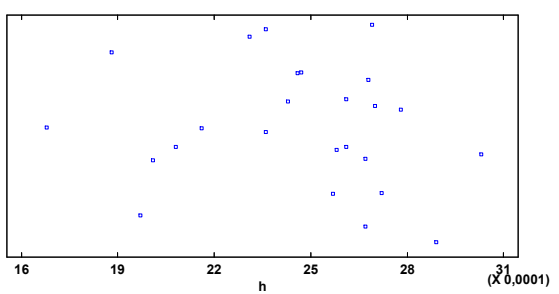

Figura 352. Gráfico de dispersión h - España

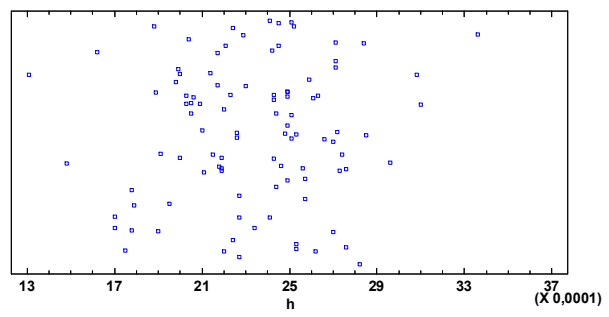

Figura 354. Gráfico de dispersión h - Argentina

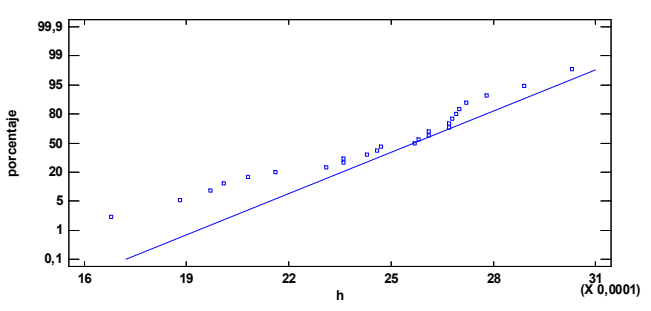

Figura 353. Gráfico probabilidad normal h España

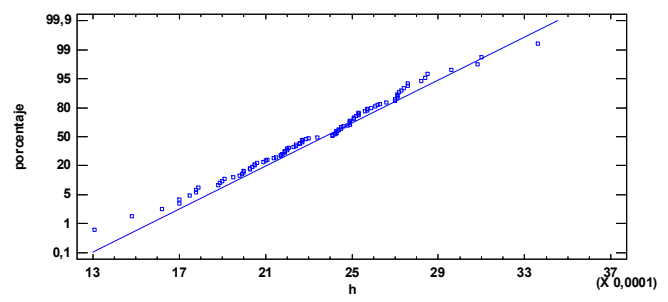

Figura 355. Gráfico probabilidad normal h Argentina

\section{Análisis comparativo entre procedencias}

En la Tabla 180 se resume el test de Levene para los valores de hi para ambas procedencias. 
Tabla 180. hi - procedencias: test de Levene.

\begin{tabular}{ccc}
\hline \multirow{2}{*}{ Levene's } & Prueba & P-valor \\
\cline { 2 - 3 } & 0,31 & 0,58 \\
\hline
\end{tabular}

De acuerdo con el P-valor > 0,05 hallado en el test de Levene, se empleó el análisis comparativo paramétrico (ANOVA) para evaluar el comportamiento de hi entre el material de ambas procedencias.

\subsubsection{Propiedades mecánicas}

\subsubsection{Flexión estática}

\section{Análisis descriptivo por procedencias}

En la Tabla 181 se detalla el resumen estadístico y los resultados de las pruebas de normalidad para las variables estudiadas considerando ambas procedencias; las Figura 356 a Figura 363 muestran las gráficas de dispersión y de probabilidad normal en cada caso.

Tabla 181. Flexión estática: MOE y MOR por procedencias: resumen estadístico y pruebas de normalidad.

\begin{tabular}{|c|c|c|c|c|c|c|c|c|c|c|c|}
\hline \multirow{2}{*}{ Variable } & \multirow{2}{*}{$\mathrm{DE}^{*}$} & \multirow{2}{*}{$\mathrm{SE}^{*}$} & \multirow{2}{*}{$\mathrm{CE}^{*}$} & \multicolumn{2}{|c|}{ Chi-Cuadrado } & \multicolumn{2}{|c|}{$\begin{array}{c}\text { W de Shapiro- } \\
\text { Wilk }\end{array}$} & \multicolumn{2}{|c|}{$\begin{array}{c}\text { Valor-Z para } \\
\text { asimetría }\end{array}$} & \multicolumn{2}{|c|}{$\begin{array}{l}\text { Valor-Z para } \\
\text { curtosis }\end{array}$} \\
\hline & & & & Estad. & P-valor & Estad. & $\begin{array}{c}\mathrm{P}- \\
\text { valor }\end{array}$ & Estad. & P-valor & Estad. & P-valor \\
\hline \multicolumn{12}{|c|}{ España } \\
\hline $\mathrm{MOE}$ & 743,22 & 0,53 & $-0,92$ & 15,66 & 0,62 & 0,97 & 0,40 & 0,40 & 0,69 & $-1,06$ & 0,29 \\
\hline MOR & 10,73 & 0,07 & $-1,21$ & 9,15 & 0,96 & 0,97 & 0,17 & 0,05 & 0,96 & $-1,63$ & 0,10 \\
\hline \multicolumn{12}{|c|}{ Argentina } \\
\hline MOE & 1095,98 & $-0,65$ & $-1,13$ & 16,23 & 0,64 & 0,97 & 0,27 & 0,49 & 0,63 & $-1,45$ & 0,15 \\
\hline MOR & 9,29 & $-0,42$ & $-1,10$ & 12,71 & 0,85 & 0,97 & 0,22 & 0,31 & 0,75 & $-1,40$ & 0,16 \\
\hline
\end{tabular}

*MOE: módulo de elasticidade; MOR: módulo de rotura; DE: desvio estándar; SE: sesgo estandarizado; CE: curtosis estandarizada.

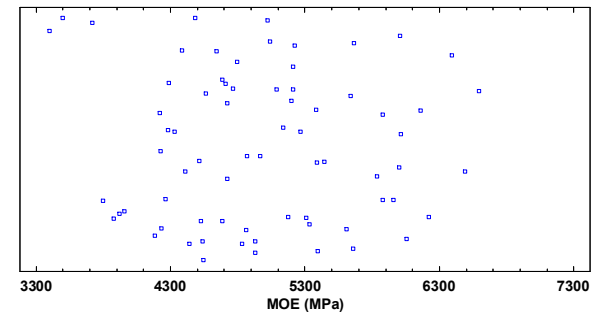

Figura 356. Gráfico de dispersión MOE -

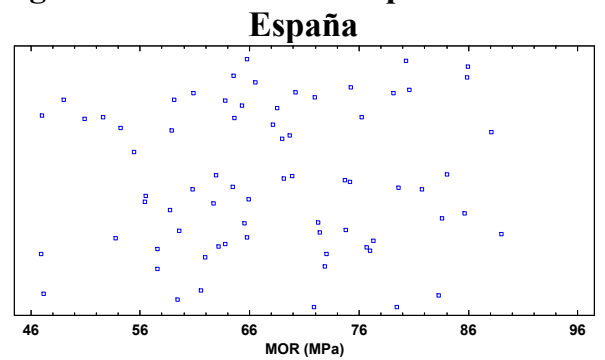

Figura 358. Gráfico de dispersión MOR España

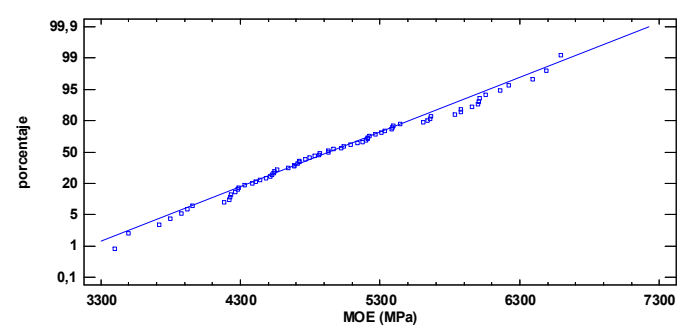

Figura 357. Gráfico probabilidad normal MOE España

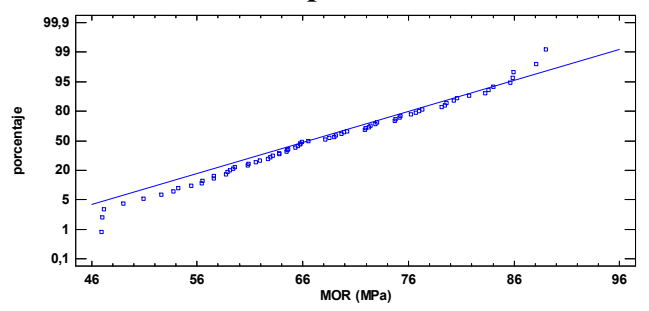

Figura 359. Gráfico probabilidad normal MOR España 


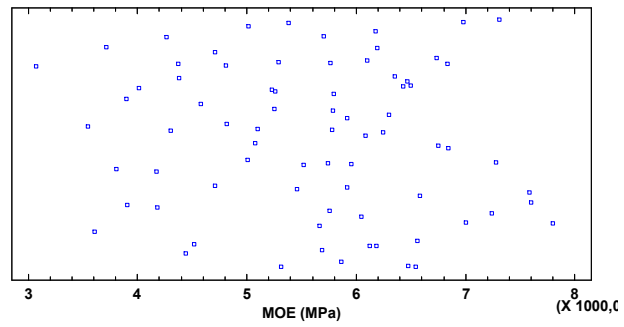

Figura 360. Gráfico de dispersión MOE Argentina

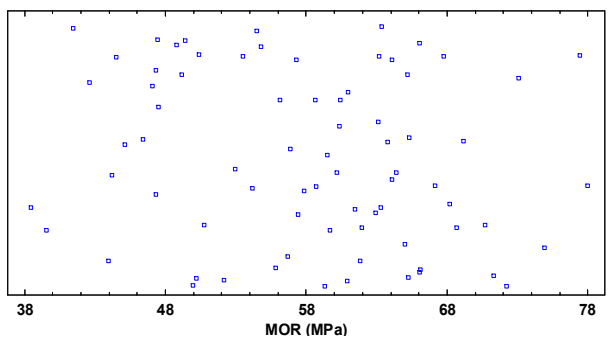

Figura 362. Gráfico de dispersión MOR Argentina

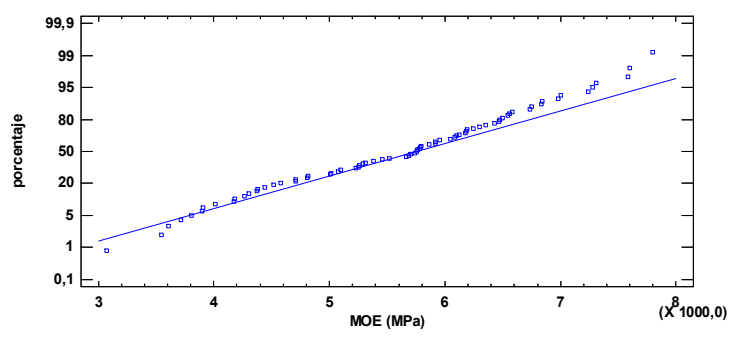

Figura 361. Gráfico probabilidad normal MOE Argentina

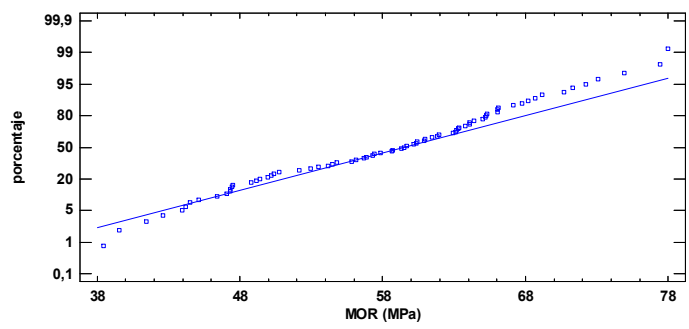

Figura 363. Gráfico probabilidad normal MOR Argentina

\section{Análisis comparativo entre procedencias}

En la Tabla 182 se muestra el resultado del test de Levene el MOE contrastando entre procedencias.

Tabla 182. MOE-MOR por procedencias: test de Levene y Tukey HSD.

\begin{tabular}{|c|c|c|c|c|c|c|c|c|c|}
\hline \multirow{4}{*}{ Levene } & \multicolumn{2}{|c|}{ MOE } & \multicolumn{2}{|c|}{ MOR } & \multirow{4}{*}{ Tukey HSD } & & & MOR & \\
\hline & Prueba & P-valor & Prueba & P-valor & & Procedencia & Casos & Media & Grupos Homogéneos* \\
\hline & \multirow{2}{*}{9,41} & \multirow{2}{*}{0,00} & \multirow{2}{*}{1,73} & \multirow{2}{*}{0,19} & & Argentina & 75 & 58,20 & A \\
\hline & & & & & & España & 75 & 67,93 & B \\
\hline
\end{tabular}

*MOE: módulo de elasticidad; MOR: módulo de rotura; letras diferentes indican diferencias significativas entre medias.

Para el MOE, el $\mathrm{P}$-valor< 0,05, demostró que existe una diferencia significativa entre las desviaciones estándar analizadas, con un nivel de confianza del 95\%. De acuerdo con esto, se incumple el supuesto de homogeneidad de la varianza, razón por la cual se procedió a trabajar con la prueba de Kruskal-Wallis para la comparación de medianas. En cuanto al MOR, de acuerdo con el P-valor > 0,05, se utilizó el ANOVA como test de comparación de medias; mediante el test de Tukey HSD e IC 95\% se avaluó el comportamiento entre dichas medias, el cual indicó una diferencia significativamente superior para el MOR del material español.

La Figura 364 y la Figura 365 muestran los gráficos de caja y bigotes para MOE y MOR, respectivamente. 


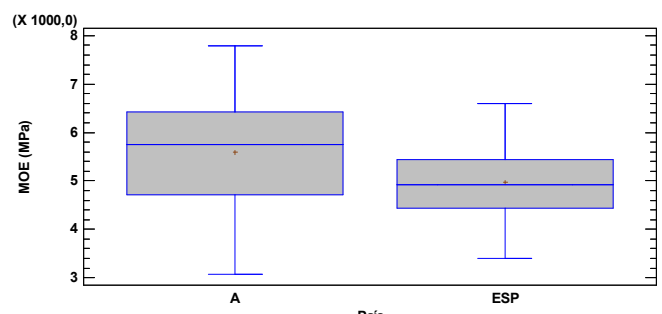

Figura 364. Gráfico de Caja y Bigotes MOE Procedencias

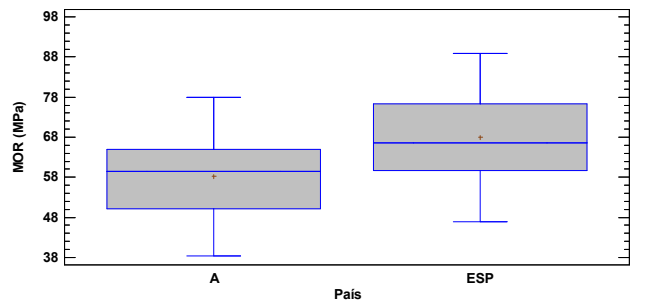

Figura 365. Gráfico de Caja y Bigotes MOR Procedencias

\subsubsection{Dureza}

\section{Análisis descriptivo por procedencias}

La Tabla 183 (Figura 366 a Figura 369) muestra el resumen descriptivo y las pruebas de normalidad para la variable dureza.

Tabla 183. Dureza: análisis descriptivo discriminado por procedencias

\begin{tabular}{|c|c|c|c|c|c|c|c|c|c|c|c|}
\hline \multirow{2}{*}{$\begin{array}{l}\text { Tipo } \\
\text { ensayo }\end{array}$} & \multirow{2}{*}{$\mathrm{DE}^{*}$} & \multirow{2}{*}{$\mathrm{SE}^{*}$} & \multirow{2}{*}{$\mathrm{CE}^{*}$} & \multicolumn{2}{|c|}{ Chi-Cuadrado } & \multicolumn{2}{|c|}{$\begin{array}{c}\text { W de Shapiro- } \\
\text { Wilk }\end{array}$} & \multicolumn{2}{|c|}{$\begin{array}{c}\text { Valor-Z para } \\
\text { asimetría }\end{array}$} & \multicolumn{2}{|c|}{$\begin{array}{l}\text { Valor-Z para } \\
\text { curtosis }\end{array}$} \\
\hline & & & & Estad. & $\begin{array}{l}\mathrm{P}- \\
\text { valor }\end{array}$ & Estad. & P-valor & Estad. & P-valor & Estad. & P-valor \\
\hline \multicolumn{12}{|c|}{ España } \\
\hline UNE & 0,80 & $\begin{array}{c}- \\
0,75\end{array}$ & $\begin{array}{c}- \\
1,86\end{array}$ & 41,0 & 0,22 & 0,97 & 0,02 & 0,54 & 0,59 & $-2,45$ & 0,01 \\
\hline \multicolumn{12}{|c|}{ Argentina } \\
\hline IRAM & 3,50 & 0,92 & $\begin{array}{c}- \\
1,25\end{array}$ & 19,52 & 0,15 & 0,94 & 0,05 & 0,69 & 0,49 & $-1,87$ & 0,06 \\
\hline
\end{tabular}

*DE: desvío estándar; SE: sesgo estandarizado; CE: curtosis estandarizada.

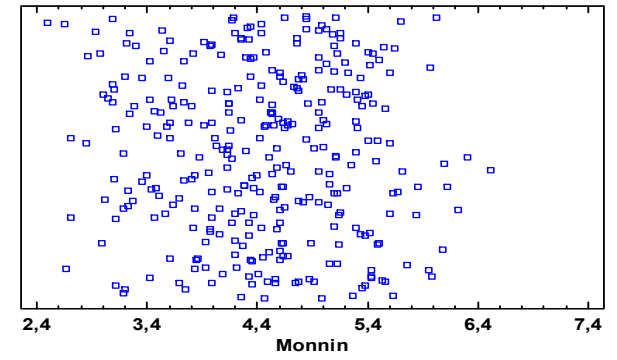

Figura 366. Gráfico de dispersión: Dureza UNE

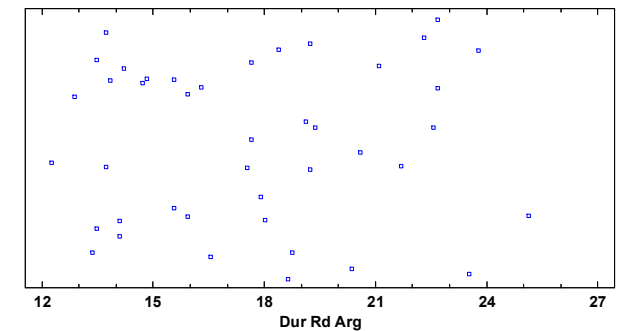

Figura 368. Gráfico de dispersión: Dureza Janka IRAM

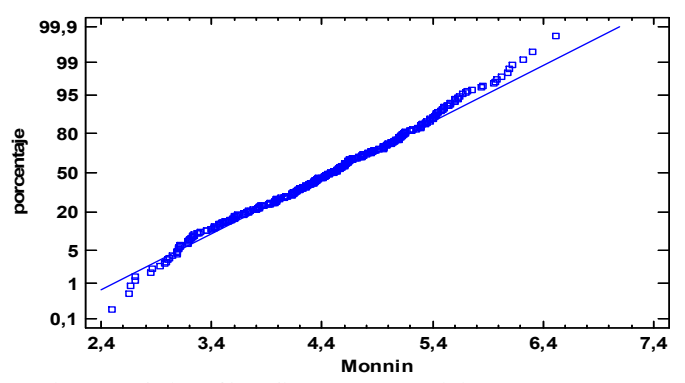

Figura 367. Gráfico probabilidad normal: Dureza UNE

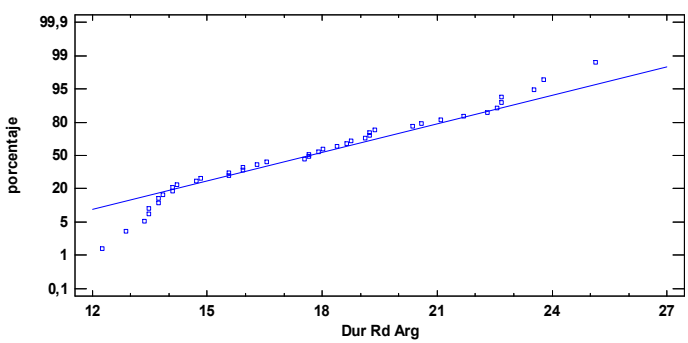

Figura 369. Gráfico probabilidad normal: Dureza IRAM 


\subsubsection{Compresión paralela a las fibras}

\section{Análisis descriptivo por procedencias}

En la Tabla 184 (Figura 370 a Figura 381) se detalla el resumen estadístico y los resultados de las pruebas de normalidad para las variables estudiadas discriminadas por procedencias y tamaño/normativa de ensayos.

Tabla 184. Compresión paralela a las fibras: MOE y MOR por procedencias y tipo de ensayo: resumen estadístico y pruebas de normalidad.

\begin{tabular}{|c|c|c|c|c|c|c|c|c|c|c|c|c|}
\hline \multirow{2}{*}{ Variable } & \multirow{2}{*}{$\begin{array}{l}\text { Tipo } \\
\text { ensayo }\end{array}$} & \multirow{2}{*}{$\mathrm{DE}^{*}$} & \multirow{2}{*}{ SE* } & \multirow{2}{*}{ CE* } & \multicolumn{2}{|c|}{ Chi-Cuadrado } & \multicolumn{2}{|c|}{$\begin{array}{c}\text { W de Shapiro- } \\
\text { Wilk }\end{array}$} & \multicolumn{2}{|c|}{$\begin{array}{c}\text { Valor-Z para } \\
\text { asimetría } \\
\end{array}$} & \multicolumn{2}{|c|}{$\begin{array}{c}\text { Valor-Z para } \\
\text { curtosis }\end{array}$} \\
\hline & & & & & Estad. & $\begin{array}{l}\text { P- } \\
\text { valor }\end{array}$ & Estad. & $\begin{array}{c}\mathrm{P}- \\
\text { valor }\end{array}$ & Estad. & $\begin{array}{c}\mathrm{P}- \\
\text { valor }\end{array}$ & Estad. & $\begin{array}{c}\mathrm{P}- \\
\text { valor }\end{array}$ \\
\hline \multicolumn{13}{|c|}{ España } \\
\hline MOE & \multirow{2}{*}{ UNE } & 427,35 & 0,64 & $0, \overline{29}$ & 19,88 & 0,53 & 0,98 & 0,73 & 0,47 & 0,64 & $-0,14$ & 0,89 \\
\hline MOR & & 4,20 & 0,67 & $\begin{array}{c}- \\
0,66\end{array}$ & 12,35 & 0,93 & 0,98 & 0,61 & 0,50 & 0,62 & $-0,63$ & 0,53 \\
\hline \multicolumn{13}{|c|}{ España } \\
\hline MOE & \multirow{2}{*}{ IRAM } & 183,34 & $\begin{array}{c}- \\
0,67 \\
\end{array}$ & $0, \overline{39}$ & 7,94 & 0,93 & 0,98 & 0,82 & 0,51 & 0,61 & $-0,28$ & 0,78 \\
\hline MOR & & 1,66 & $0, \overline{19}$ & 0,91 & 13,36 & 0,57 & 0,99 & 0,94 & 0,15 & 0,88 & 1,06 & 0,29 \\
\hline \multicolumn{13}{|c|}{ Argentina } \\
\hline $\mathrm{MOE}$ & \multirow[t]{2}{*}{ IRAM } & 1723,07 & 0,82 & $\begin{array}{c}- \\
1,16\end{array}$ & 24,11 & 0,09 & 0,96 & 0,20 & 0,62 & 0,54 & $-1,59$ & 0,11 \\
\hline MOR & & 3,08 & 0,80 & 0,11 & 12,91 & 0,80 & 0,98 & 0,68 & 0,60 & 0,55 & 0,31 & 0,75 \\
\hline
\end{tabular}

*MOE: módulo de elasticidade; MOR: módulo de rotura; DE: desvío estándar; SE: sesgo estandarizado; CE: curtosis estandarizada.

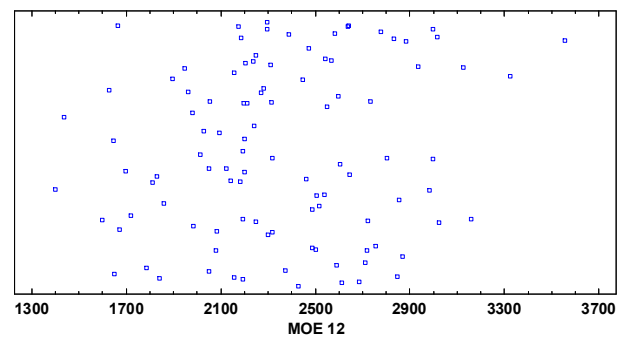

Figura 370. Gráfico de dispersión: MOE UNE España

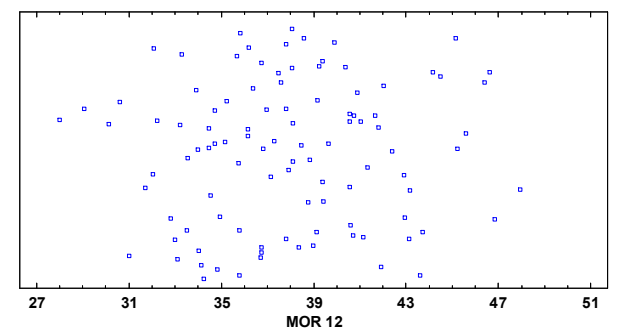

Figura 372. Gráfico de dispersión: MOE UNE. España

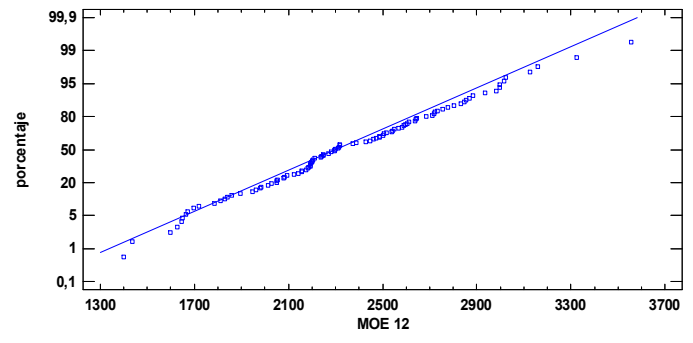

Figura 371. Gráfico probabilidad normal: MOE UNE. España

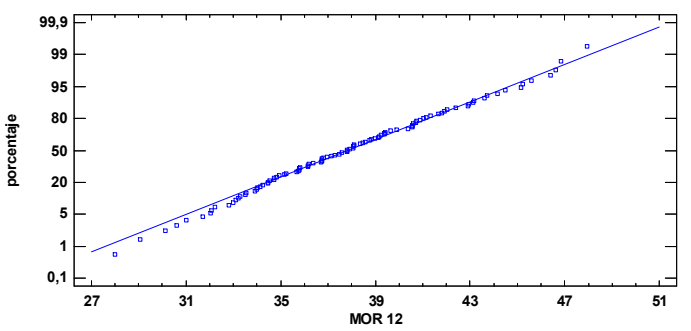

Figura 373. Gráfico probabilidad normal: MOR UNE. España 


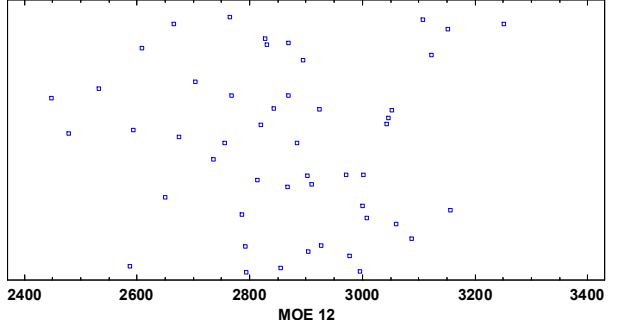

Figura 374. Gráfico de dispersión: MOE IRAM. España

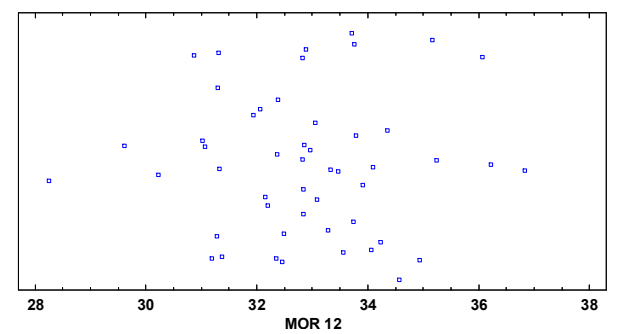

Figura 376. Gráfico de dispersión: MOR IRAM. España

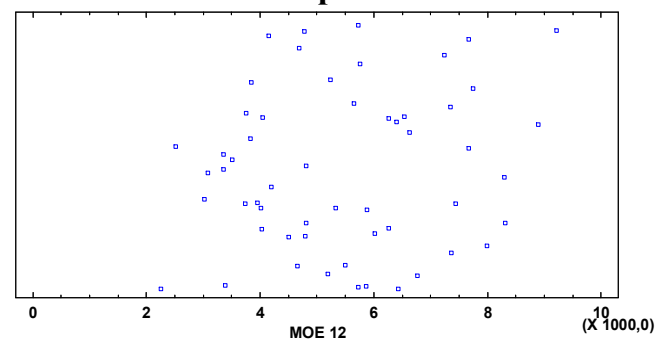

Figura 378. Gráfico de dispersión: MOE IRAM. Argentina

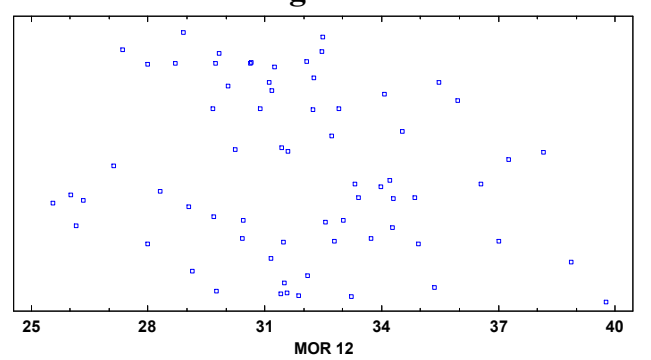

Figura 380. Gráfico de dispersión: MOR IRAM Argentina

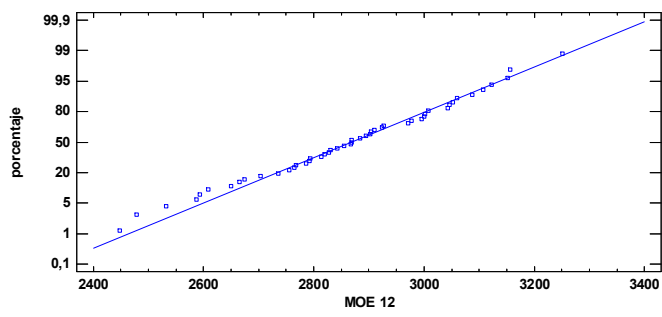

Figura 375. Gráfico probabilidad normal: MOE IRAM. España

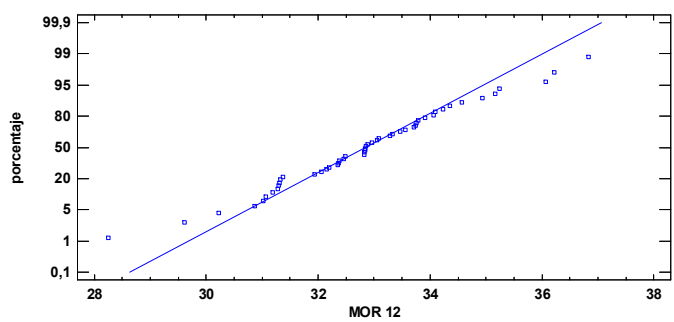

Figura 377. Gráfico probabilidad normal: MOR IRAM. España

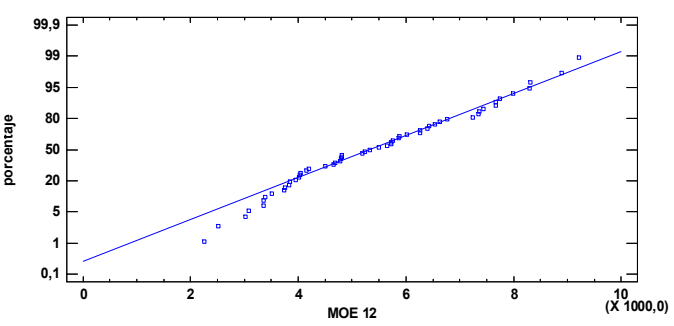

Figura 379. Gráfico probabilidad normal: MOE IRAM. Argentina

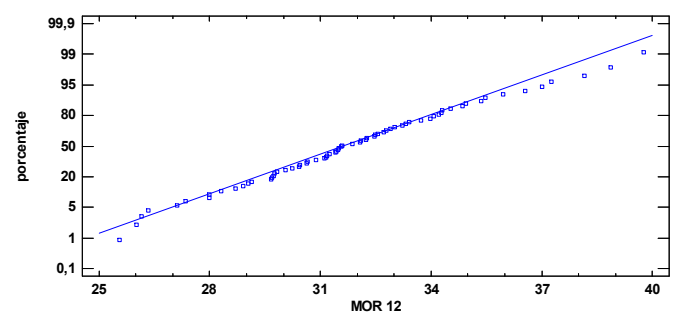

Figura 381. Gráfico probabilidad normal: MOR IRAM. Argentina

\section{Análisis comparativo entre normativas de ensayos: procedencia española}

En la Tabla 185 se muestra el resultado del test de Levene para el MOE y MOR por normativa de ensayo.

Tabla 185. MOE - MOR por normativa de ensayo: test de Levene.

\begin{tabular}{|c|c|c|c|c|c|c|}
\hline & & Prueba & $\begin{array}{l}\text { P-valor } \\
\text { Pal }\end{array}$ & & Prueba & P-valor \\
\hline Test Levene & MOE & 25,70 & 0,00 & MOR & 32,77 & 0.00 \\
\hline
\end{tabular}


Puesto que el P-valor obtenido fue inferior a 0,05, existe una diferencia significativa entre las desviaciones estándar analizadas, con un nivel de confianza del 95\%. De acuerdo con esto, se incumple el supuesto de homogeneidad de la varianza, razón por la cual se procedió a trabajar con la prueba de Kruskal-Wallis para comparación de medianas.

\section{Análisis comparativo por procedencias (norma IRAM)}

El test de constatación de homogeneidad de la varianza se muestra en la Tabla 186.

Tabla 186. MOR (IRAM) por procedencias: test de Levene.

\begin{tabular}{ccc}
\hline & Prueba & P-valor \\
\cline { 2 - 3 } Test Levene & 14,01 & 0,00 \\
\hline
\end{tabular}

El P-valor $<0,05$, demostró la existencia de una diferencia significativa entre las desviaciones estándar analizadas, con un nivel de confianza del 95\%; de acuerdo con esto, el análisis comparativo fue llevado a cabo mediante la prueba de Kruskal-Wallis.

\subsubsection{Durabilidad natural}

A continuación se presentan las pruebas de comprobación de normalidad realizada a la variable pérdida de peso para cada una de las muestras/secciones.

\subsubsection{Determinación de la durabilidad frente a hongos basidiomicetos xilófagos}

\section{Análisis descriptivo: material de procedencia española}

En la Tabla 187 (Figura 382 a Figura 387) se presentan los resultados descriptivos y de comprobación de normalidad para $\mathrm{Pp}(\%)$ por $\mathrm{ME}, \mathrm{MR}$, cepa fúngica y sección de ensayo.

Tabla 187. Pp (\%) - cepa fúngica: resumen estadístico y pruebas de normalidad.

\begin{tabular}{|c|c|c|c|c|c|c|c|c|c|c|c|c|c|}
\hline \multirow{2}{*}{ Madera } & \multirow{2}{*}{$\begin{array}{l}\text { Cepa } \\
\text { fúngica }\end{array}$} & \multirow{2}{*}{ Sección } & \multirow{2}{*}{$\mathrm{DE}^{*}$} & \multirow{2}{*}{$\mathrm{SE}^{*}$} & \multirow{2}{*}{$\mathrm{CE}^{*}$} & \multicolumn{2}{|c|}{$\begin{array}{c}\text { Chi- } \\
\text { Cuadrado }\end{array}$} & \multicolumn{2}{|c|}{$\begin{array}{c}\text { W de } \\
\text { Shapiro-Wilk }\end{array}$} & \multicolumn{2}{|c|}{$\begin{array}{c}\text { Valor-Z para } \\
\text { asimetría }\end{array}$} & \multicolumn{2}{|c|}{$\begin{array}{c}\text { Valor-Z para } \\
\text { curtosis }\end{array}$} \\
\hline & & & & & & Estad. & $\begin{array}{c}\mathrm{P}- \\
\text { valor }\end{array}$ & Estad. & $\begin{array}{l}\mathrm{P}- \\
\text { valor }\end{array}$ & Estad. & $\begin{array}{c}\mathrm{P}- \\
\text { valor }\end{array}$ & Estad. & $\begin{array}{l}\mathrm{P}- \\
\text { valor }\end{array}$ \\
\hline \multirow{2}{*}{$\mathrm{ME}$} & \multirow{3}{*}{$\begin{array}{c}T . \\
\text { versicolor }\end{array}$} & Int. & 13,49 & $-0,79$ & $-0,23$ & 10,19 & 0,60 & 0,98 & 0,75 & 0,61 & 0,54 & $-0,07$ & 0,95 \\
\hline & & Ext. & 12,61 & $-0,49$ & $-1,23$ & 9,25 & 0,68 & 0,95 & 0,24 & 0,38 & 0,70 & $-1,92$ & 0,06 \\
\hline MR & & & 10,51 & $-0,94$ & $-0,19$ & 9,2 & 0,33 & 0,94 & 0,41 & 0,75 & 0,45 & - & - \\
\hline \multirow{2}{*}{$\mathrm{ME}$} & \multirow{3}{*}{$\begin{array}{c}C . \\
\text { puteana }\end{array}$} & Int. & 5,93 & 1,22 & 0,005 & 6,0 & 0,42 & 0,89 & 0,19 & 0,99 & 0,32 & - & - \\
\hline & & Ext. & 9,24 & 1,51 & $-0,05$ & 11,14 & 0,19 & 0,88 & 0,06 & 1,18 & 0,24 & - & - \\
\hline MR & & & 7,12 & 1,65 & 0,52 & 8,0 & 0,33 & 0,85 & 0,05 & 1,31 & 0,19 & - & - \\
\hline
\end{tabular}

*ME: material de ensayo (Populus x euramericana I-214); MR: material de referencia (Fagus sylvatica); Int: sección interna; Ext: sección externa; DE.: desvío estándar; SE: sesgo estandarizado; CE: curtosis estandarizada. 


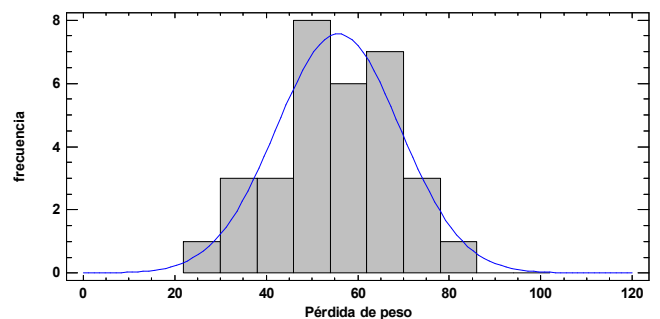

Figura 382. Histograma de frecuencia: Pp (\%) T. versicolor - ME Int.

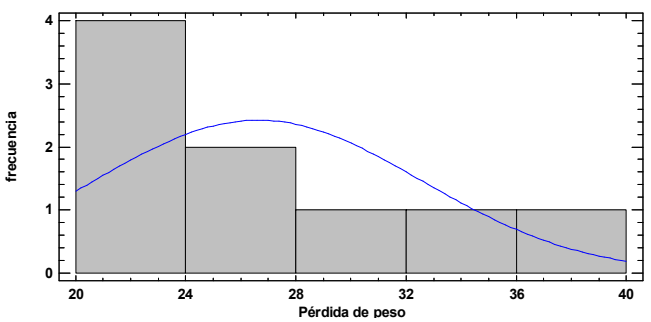

Figura 384. Histograma de frecuencia: Pp (\%) C. puteana - ME Int.

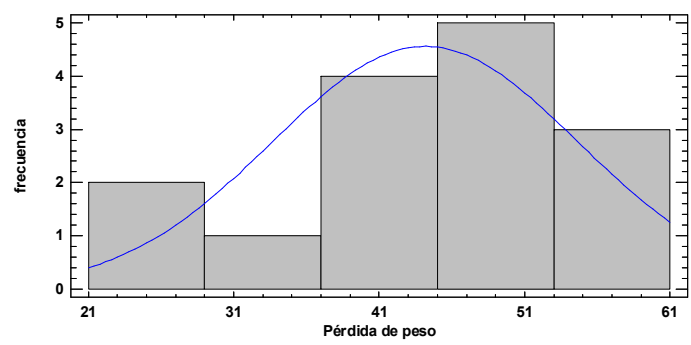

Figura 386. Histograma de frecuencia: Pp (\%) T. versicolor - MR (España)

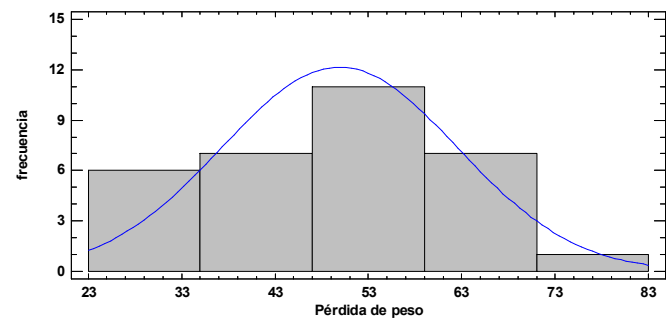

Figura 383. Histograma de frecuencia: Pp (\%) T. versicolor - ME Ext.

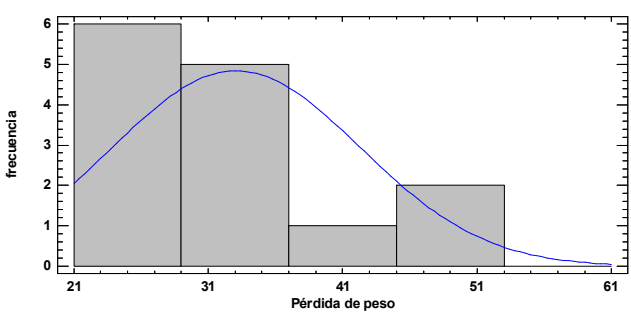

Figura 385. Histograma de frecuencia: Pp (\%) C. puteana - ME Ext.

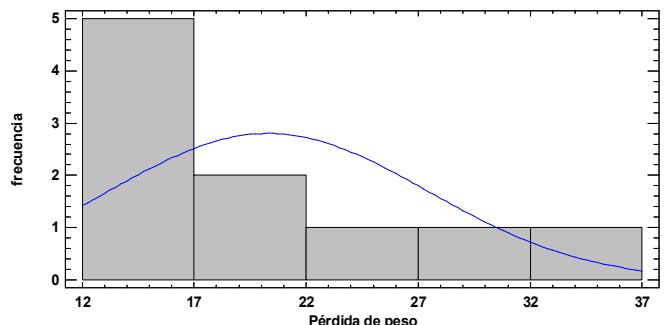

Figura 387. Histograma de frecuencia: Pp (\%) C. puteana - MR (España).

\section{Análisis descriptivo: material de procedencia argentina}

Los resultados descriptivos y de comprobación de normalidad para Pp (\%) por ME, MR y cepa fúngica, son presentados en la Tabla 188 (Figura 388 a Figura 391).

Tabla 188. Pp (\%) - Cepa fúngica: resumen estadístico y pruebas de normalidad

\begin{tabular}{|c|c|c|c|c|c|c|c|c|c|c|c|c|}
\hline \multirow{2}{*}{ Madera } & \multirow{2}{*}{$\begin{array}{l}\text { Cepa } \\
\text { fúngica }\end{array}$} & \multirow{2}{*}{$\mathrm{DE}^{*}$} & \multirow{2}{*}{ SE* } & \multirow{2}{*}{$\mathrm{CE}^{*}$} & \multicolumn{2}{|c|}{ Chi-Cuadrado } & \multicolumn{2}{|c|}{$\begin{array}{l}\text { W de Shapiro- } \\
\text { Wilk }\end{array}$} & \multicolumn{2}{|c|}{$\begin{array}{l}\text { Valor-Z para } \\
\text { asimetría }\end{array}$} & \multicolumn{2}{|c|}{$\begin{array}{l}\text { Valor-Z para } \\
\text { curtosis }\end{array}$} \\
\hline & & & & & Estad. & $\begin{array}{c}\mathrm{P}- \\
\text { valor }\end{array}$ & Estad. & $\begin{array}{l}\text { P- } \\
\text { valor }\end{array}$ & Estad. & $\begin{array}{c}\mathrm{P}- \\
\text { valor }\end{array}$ & Estad. & $\begin{array}{l}\text { P- } \\
\text { valor }\end{array}$ \\
\hline $\mathrm{ME}$ & \multirow{2}{*}{$\begin{array}{c}T . \\
\text { versicolor }\end{array}$} & 10,76 & 1,10 & $0, \overline{42}$ & 8,16 & 0,52 & 0,94 & 0,28 & 0,86 & 0,39 & - & - \\
\hline MR & & 7,57 & 0,92 & $0, \overline{35}$ & 11,89 & 0,37 & 0,96 & 0,32 & 0,71 & 0,48 & $-0,23$ & 0,82 \\
\hline $\mathrm{ME}$ & \multirow{2}{*}{ C.puteana } & 11,94 & 1,50 & 0,35 & 11,33 & 0,13 & 0,89 & 0,10 & 1,18 & 0,24 & - & - \\
\hline MR & & 9,86 & 0,99 & $0, \overline{9}$ & 15,74 & 0,07 & 0,88 & 0,02 & 0,78 & 0,44 & - & - \\
\hline
\end{tabular}

*ME: material de ensayo (Populus x euramericana I-214); MR: material de referencia (Fagus sylvatica); DE: desvío estándar; SE: sesgo estandarizado; CE: curtosis estandarizada. 


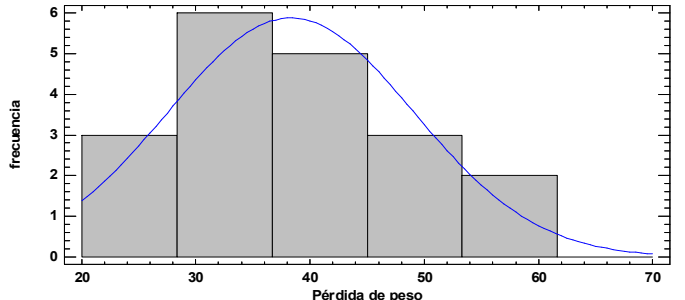

Figura 388. Histograma de frecuencia: Pp (\%) T. versicolor - ME

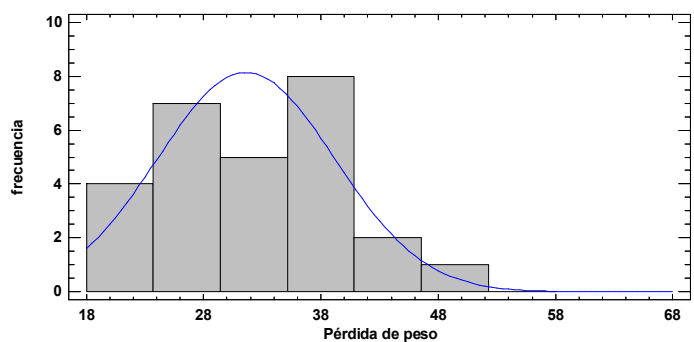

Figura 390. Histograma de frecuencia: Pp (\%) T. versicolor - MR

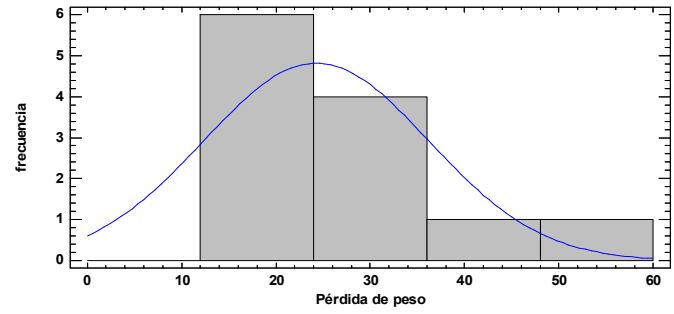

Figura 389. Histograma de frecuencia: Pp (\%) C. puteana-ME

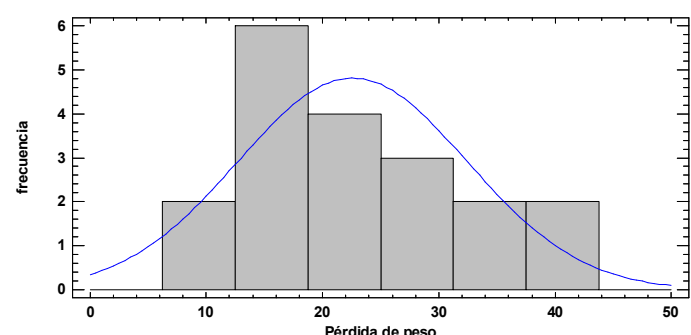

Figura 391. Histograma de frecuencia: Pp (\%) C. puteana-MR

\section{Análisis comparativo: material de procedencia española}

En la Tabla 189 se muestran los resultados del test de verificación de homogeneidad de varianza (Levene), como así también el test de Tukey HSD e IC 95\%, para las comparaciones entre secciones.

Tabla 189. Pp (\%) - Secciones: test de Levene - test de Tukey HSD

\begin{tabular}{|c|c|c|c|c|c|c|c|}
\hline \multirow{3}{*}{ Levene's } & Prueba & P-valor & \multirow{3}{*}{ Tukey HSD } & $\begin{array}{l}\text { Agente de } \\
\text { deterioro }\end{array}$ & \multirow{3}{*}{$\begin{array}{l}\text { Chopo por } \\
\text { secciones }\end{array}$} & Razón-F & P-valor \\
\hline & 0,02 & 0,88 & & T. versicolor & & 3,21 & 0,08 \\
\hline & 1,10 & 0,31 & & C. puteana & & 3,46 & 0,08 \\
\hline
\end{tabular}

$*$ P-valor $<0,05$ denota diferencias significativas.

En concordancia con el P-valor $>0,05$ obtenido del test de Levene, se realizó el ANOVA para evaluar el comportamiento de las medias de Pp (\%) en cada sección de estudio, mediante el cual pudo constatarse la ausencia de significancia estadística en las comparaciones realizadas, $\mathrm{P}$-valor $>0,05$.

\section{Análisis comparativo: material de procedencia argentina}

En la Tabla 190 se presentan los resultados para la comparación entre cepas del material de sección interna.

Tabla 190. Pp (\%) - Cepas: test de Levene - test de Tukey HSD

\begin{tabular}{|c|c|c|c|c|c|c|c|}
\hline \multirow{3}{*}{ Levene's } & Prueba & P-valor & & Agente de deterioro & \multirow{3}{*}{ Chopo sección interna } & Razón-F & P-valor* \\
\hline & \multirow{2}{*}{0,18} & \multirow{2}{*}{0,67} & \multirow[t]{2}{*}{ Tukey HSD } & T. versicolor & & \multirow{2}{*}{11,53} & \multirow{2}{*}{0,00} \\
\hline & & & & C. puteana & & & \\
\hline
\end{tabular}

*P-valor $<0,05$ denota diferencias significativas entre medias: test de Tukey HSD. 
De acuerdo con los -valores $>0,05$ obtenidos en el test de Levene, se realizó el análisis de la varianza para comparación de medias. Mediante dicho test se corroboró que las medias de Pp (\%) fueron significativamente diferentes entre cepas, tal como se ha discutido en la sección de Resultados y discusión.

\section{Análisis comparativo entre procedencias (sección interna)}

En la Tabla 191 se presentan los resultados del test de Levene y el test de Tukey HSD, para las Pp (\%) del material de sección interna, para ambas procedencias.

Tabla 191. Pp (\%) Chopo - Procedencias: test de Levene - test de Tukey HSD

\begin{tabular}{|c|c|c|c|c|c|c|c|}
\hline \multirow{3}{*}{ Levene's } & Prueba & P-valor & \multirow{3}{*}{ Tukey HSD } & $\begin{array}{c}\text { Agente de } \\
\text { deterioro }\end{array}$ & \multirow{3}{*}{$\begin{array}{c}\text { Chopo por } \\
\text { procedencias }\end{array}$} & Razón-F & P-valor* \\
\hline & 3,29 & 0,08 & & T. versicolor & & 7,81 & 0,00 \\
\hline & 1,04 & 0,33 & & C. puteana & & 3,11 & 0,10 \\
\hline
\end{tabular}

*P-valor $<0,05$ denota diferencias significativas entre medias: test de Tukey $(\mathrm{p}<0,05)$.

De acuerdo con el P-valor $>0,05$ del test de Levene (Tabla 191), se realizó el análisis de la varianza para comparación de medias. Mediante dicho test se corroboró que las medias de Pp (\%) para la cepa de pudrición blanca se diferenciaron significativamente entre procedencias, asimismo, mediante el test HSD de Tukey, se corroboró que la media del material de procedencia española fue significativamente superior al de procedencia Argentina (Resultados y discusión). Para la cepa de pudrición castaña no se hallaron diferencias entre procedencias.

\subsubsection{Determinación de la durabilidad frente a hongos ascomicetos e imperfectos}

\section{Análisis descriptivo: material de procedencia española}

El resumen estadístico y los parámetros de constatación de normalidad para la variable Pp (\%) del ME y MR, para hongos de pudrición blanda, se muestra en la Tabla 192 y en la Figura 392 a Figura 394, respectivamente.

Tabla 192. Pudrición blanda: resumen descriptivo y pruebas de normalidad.

\begin{tabular}{|c|c|c|c|c|c|c|c|c|c|c|c|c|}
\hline \multirow{2}{*}{ Madera } & \multirow{2}{*}{ Sección } & \multirow{2}{*}{$\mathrm{DE}^{*}$} & \multirow{2}{*}{ SE* } & \multirow{2}{*}{ CE* } & \multicolumn{2}{|c|}{ Chi-Cuadrado } & \multicolumn{2}{|c|}{$\begin{array}{l}\text { W de Shapiro- } \\
\text { Wilk }\end{array}$} & \multicolumn{2}{|c|}{$\begin{array}{c}\text { Valor-Z para } \\
\text { asimetría } \\
\end{array}$} & \multicolumn{2}{|c|}{$\begin{array}{c}\text { Valor-Z para } \\
\text { curtosis } \\
\end{array}$} \\
\hline & & & & & Estad. & $\begin{array}{c}P- \\
\text { valor }\end{array}$ & Estad. & $P$-valor & Estad. & $\begin{array}{c}P- \\
\text { valor }\end{array}$ & Estad. & $P$-valor \\
\hline \multirow{2}{*}{ ME } & Int. & 8,15 & $0,-$ & $0, \overline{48}$ & 12,0 & 0,45 & 0,97 & 0,61 & 0,41 & 0,68 & $-0,42$ & 0,68 \\
\hline & Ext. & 5,85 & 2,19 & $\begin{array}{c}- \\
0,12\end{array}$ & 19,0 & 0,09 & 0,87 & 0,00 & 1,57 & 0,12 & 0,08 & 0,94 \\
\hline MR & & 5,91 & $\overline{-}$ & $\overline{-}$ & 16,0 & 0,19 & 0,95 & 0,21 & 0,62 & 0,53 & $-0,44$ & 0,66 \\
\hline
\end{tabular}

*ME: material de ensayo (Populus x euramericana I-214); MR: material de referencia (Fagus sylvatica); Int: sección interna; Ext: sección externa; DE: desvío estándar; SE: sesgo estandarizado; CE: curtosis estandarizada. 


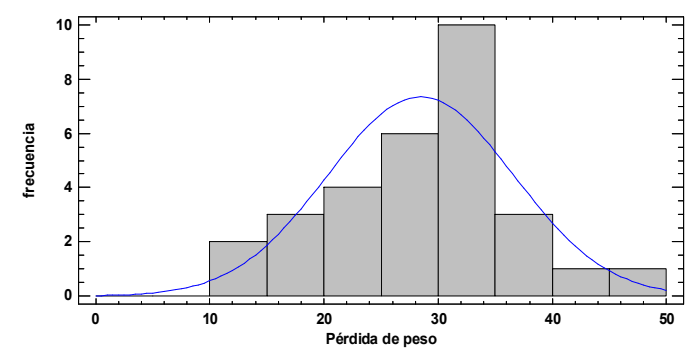

Figura 392. Histograma de frecuencia: Pp (\%) Ascomicetes e imperfectos - ME Int.

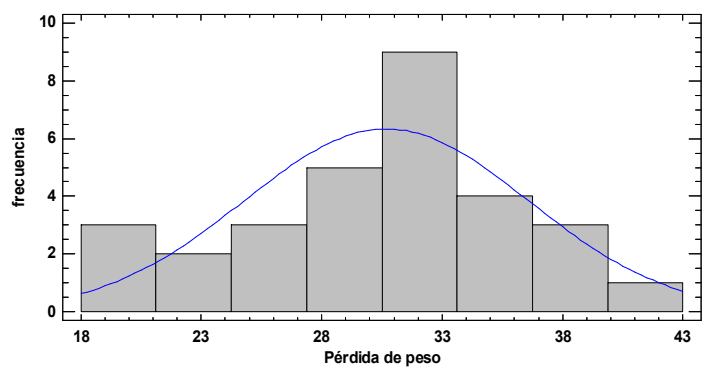

Figura 394. Histograma de frecuencia: Pp (\%)ascomicetes e imperfectos - MR

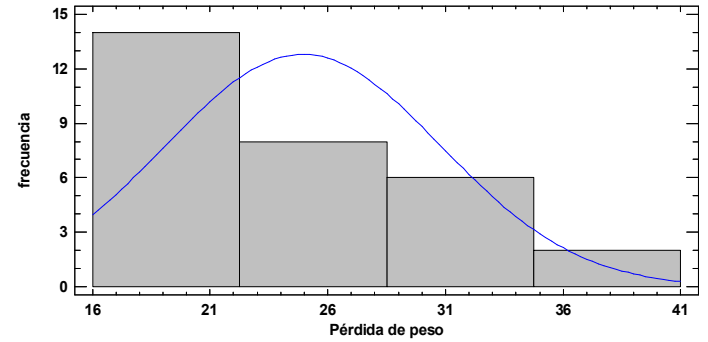

Figura 393. Histograma de frecuencia: Pp (\%) Ascomicetes e imperfectos - ME Ext.

\section{Análisis comparativo entre secciones: material de procedencia española}

En la Tabla 193 se presenta el resultado de la constatación de la homocedasticidad y el test de Tukey HSD e IC 95\% para las Pp (\%) causadas por agentes de pudrición blanda analizado por secciones.

Tabla 193. Pp (\%) ME - Ascomicetes e imperfectos: Test de Levene - Tukey HSD

\begin{tabular}{|c|c|c|c|c|c|c|c|c|}
\hline \multirow{3}{*}{$\begin{array}{l}\text { Test de } \\
\text { Levene }\end{array}$} & Prueba & $\begin{array}{c}\mathrm{P}- \\
\text { valor }\end{array}$ & \multirow{3}{*}{$\begin{array}{l}\text { Tukey } \\
\text { HSD }\end{array}$} & Agente de deterioro & Sección & Casos & Media & $\begin{array}{c}\text { Grupos } \\
\text { Homogéneos* }\end{array}$ \\
\hline & & & & \multirow{2}{*}{$\begin{array}{l}\text { Ascomicetos e } \\
\text { imperfectos }\end{array}$} & Externa & 30 & 24,95 & $\mathrm{~A}$ \\
\hline & 2,87 & 0,10 & & & Interna & 30 & 28,46 & $\mathrm{~A}$ \\
\hline
\end{tabular}

*letras diferentes indican diferencias significativas entre secciones, test de Tukey HSD $(p<0,05)$.

Dada la constatación de homogeneidad de la varianza se trabajó con ANOVA para comparar las medias del Pp (\%) considerando las secciones de estudios, el cual comprobó la ausencia de significancia estadística para dicha comparación; el resultado del Test de Tukey mostrado en la Tabla 193, constata dicho resultado.

\subsubsection{Determinación de la durabilidad frente a Termitas}

\section{Análisis descriptivo por procedencias}

El análisis descriptivo y las pruebas de normalidad se muestran en la Tabla 194 (Figura 395 a Figura 399). 
Tabla 194. Pp (\%) Termitas por procedencias: análisis descriptivo y pruebas de normalidad.

\begin{tabular}{|c|c|c|c|c|c|c|c|c|c|c|c|}
\hline \multirow{3}{*}{ Madera } & \multirow{3}{*}{ Procedencia } & \multirow{3}{*}{ Sección } & \multicolumn{9}{|c|}{ Pérdida de peso (\%) } \\
\hline & & & \multirow{2}{*}{$\mathrm{DE}$} & \multirow{2}{*}{$\mathrm{SE}$} & \multirow{2}{*}{$\mathrm{CE}$} & \multicolumn{2}{|c|}{ Chi-Cuadrado } & \multicolumn{2}{|c|}{$\begin{array}{l}\text { W de Shapiro- } \\
\text { Wilk }\end{array}$} & \multicolumn{2}{|c|}{$\begin{array}{c}\text { Valor-Z para } \\
\text { asimetría }\end{array}$} \\
\hline & & & & & & Estad. & $\begin{array}{c}\mathrm{P}- \\
\text { valor }\end{array}$ & Estad. & P-valor & Estad. & P-valor \\
\hline \multirow{3}{*}{$\mathrm{ME}$} & \multirow{2}{*}{ España } & Int. & 4,76 & 0,37 & $0, \overline{0}$ & 3,25 & 0,78 & 0,98 & 0,95 & 0,30 & 0,76 \\
\hline & & Ext. & 8,81 & $0, \overline{2}$ & $0, \overline{71}$ & 1,0 & 0,97 & 0,97 & 0,87 & - & - \\
\hline & Argentina & Int. & 1,30 & 0,03 & 0,85 & 6,5 & 0,69 & 0,96 & 0,59 & 0,02 & 0,98 \\
\hline \multirow{2}{*}{ MR } & \multicolumn{2}{|c|}{ España } & 0,47 & 0,25 & $\begin{array}{c}- \\
1,31 \\
\end{array}$ & 2,0 & 0,74 & 0,86 & 0,24 & - & - \\
\hline & \multicolumn{2}{|c|}{ Argentina } & 0,91 & 0,02 & $\begin{array}{c}- \\
0,51\end{array}$ & 4,0 & 0,68 & 0,97 & 0,91 & 0,02 & 0,99 \\
\hline
\end{tabular}

*ME: material de ensayo $=$ Populus $x$ euramericana $\mathrm{I}-214 ;$ MR: material de referencia $=$ Pinus sylvestris; Int: sección interna; Ext: sección externa; DE: Desvío estándar; SE: sesgo estandarizado; CE: Curtosis estandarizada.

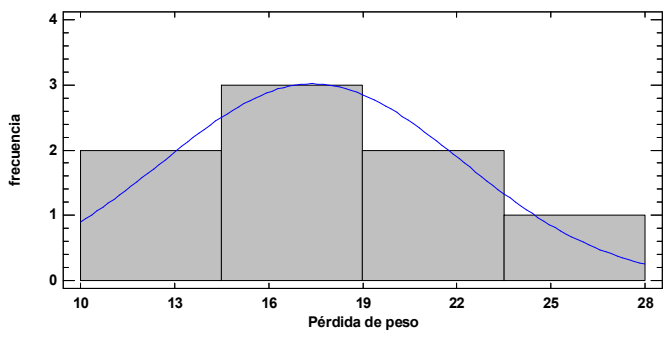

Figura 395. Histograma de frecuencia: Pp (\%) Termitas - ME Int (España)

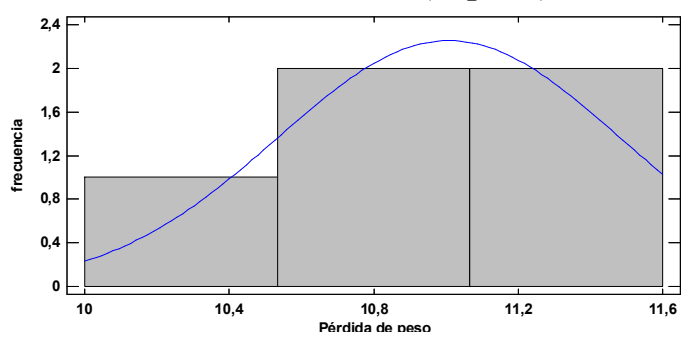

(A)

Figura 397. Histograma de frecuencia: Pp (\%) Termitas - MR (España)

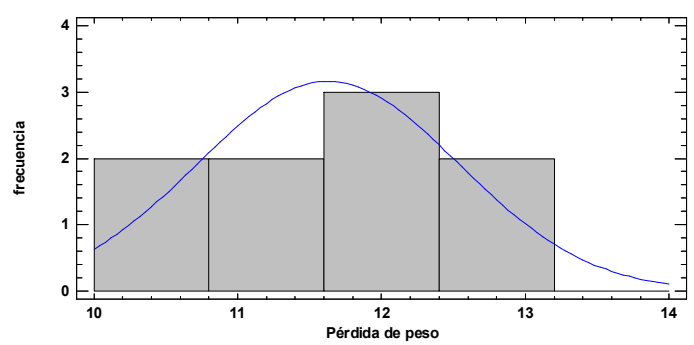

(B)

Figura 399. Histograma de frecuencia: Pp (\%) Termitas - MR (Argentina)

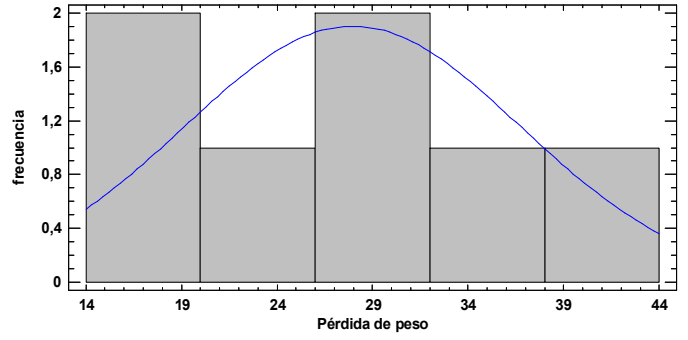

Figura 396. Histograma de frecuencia: Pp (\%) Termitas - ME Ext (España)

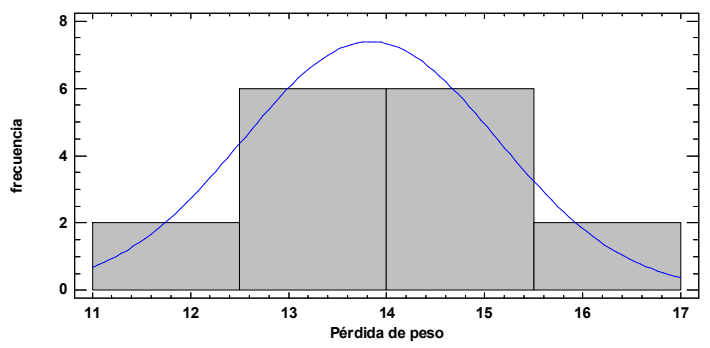

Figura 398. Histograma de frecuencia: Pp (\%) Termitas - ME Int (Argentina) 


\section{Análisis comparativo entre procedencias y secciones}

A continuación se muestra el test de Levene para la verificación del supuesto de homocedasticidad y el test de comparación de medias para Pp (\%) por secciones de estudio del material español.

Tabla 195. Pp (\%) Termitas - Secciones (España). Test de Levene - ANOVA

\begin{tabular}{lllllllll}
\hline \multirow{2}{*}{ Test de Levene } & Prueba & P-valor & & Agente de deterioro & Procedencia & Sección & Razón - F & P - Valor \\
\cline { 2 - 6 } & \multirow{2}{*}{ ANOVA } & 0,10 & Termitas & España & Interna & 8,64 & 0,01 \\
\hline
\end{tabular}

El test de Levene para verificación del supuesto de homocedasticidad comparando Pp (\%) entre procedencias y el test de comparación de medianas (Kruskal-Wallis), se muestra en la Tabla 196.

Tabla 196. Pp (\%) Termitas - Procedencias (Sección interna). Test de Levene - Kruskal Wallis

\begin{tabular}{|c|c|c|c|c|c|c|c|c|}
\hline \multirow{2}{*}{ Levene } & Prueba & P-valor & \multirow{2}{*}{$\begin{array}{l}\text { Kruskal- } \\
\text { Wallis }\end{array}$} & $\begin{array}{l}\text { Agente de } \\
\text { deterioro }\end{array}$ & Sección & Procedencia & Estadístico & P-valor \\
\hline & 9,90 & 0,00 & & Termitas & Interna & $\frac{\text { Argentina }}{\text { España }}$ & 3,60 & 0,06 \\
\hline
\end{tabular}

*P-valor $<0,05$ denota diferencias significativas entre medianas: test de Kruskal-Wallis.

De acuerdo con lo planteado, puede indicarse que no existen diferencias significativas entre las medianas de Pp (\%) de ambas procedencias (sección interna).

\subsection{Piezas macizas semi-estructurales (escala 1:5)}

\subsubsection{Ensayos no destructivos}

\subsubsection{Determinación de parámetros dinámicos mediante ensayos no destructivos (NDT)}

Tal como se mencionó en Materiales ymétodos, para los ensayos mediante ultrasonidos se emplearon dos equipos: Sylvatest ${ }^{\circledR}$ Dúo y Sylvatest ${ }^{\circledR}$ Trío, empleados indistintamente, lo cual se fundamenta por el fuerte ajuste obtenido entre ambas técnicas.

Tabla 197. Relación entre Sylvatest $\circledR^{\text {Dúo y Sylvatest } ® T r i ́ o ~}$

\begin{tabular}{ccc}
\hline P-valor modelo & Ecuación de regresión & $\mathrm{R}^{2}$ ajustado \\
\hline 0,00 & Sylvatets dúo $=9,64779+0,972373 *$ Sylvatest Trío & 99,06 \\
\hline
\end{tabular}




\section{Análisis descriptivo - NDT: material de procedencia española}

El resumen estadístico y las pruebas de normalidad de las distintas variables analizadas se muestra en la Tabla 198 (Figura 400 a Figura 409).

Tabla 198. Variables dinámicas: resumen estadístico y pruebas de normalidad.

\begin{tabular}{|c|c|c|c|c|c|c|c|c|c|c|c|}
\hline \multirow{2}{*}{ Variable* } & \multirow{2}{*}{$\mathrm{DE}^{*}$} & \multirow{2}{*}{$\mathrm{SE}^{*}$} & \multirow{2}{*}{$\mathrm{CE}^{*}$} & \multicolumn{2}{|c|}{ Chi-Cuadrado } & \multicolumn{2}{|c|}{$\begin{array}{c}\text { W de Shapiro- } \\
\text { Wilk }\end{array}$} & \multicolumn{2}{|c|}{$\begin{array}{c}\text { Valor-Z para } \\
\text { asimetría }\end{array}$} & \multicolumn{2}{|c|}{$\begin{array}{c}\text { Valor-Z para } \\
\text { curtosis } \\
\end{array}$} \\
\hline & & & & Estad. & $\begin{array}{c}\mathrm{P}- \\
\text { valor }\end{array}$ & Estad. & P-valor & Estad. & P-valor & Estad. & P-valor \\
\hline Densidad & 34,64 & 1,78 & $\overline{-}$ & 34,60 & 0,10 & 0,97 & 0,10 & 1,27 & 0,20 & $-0,01$ & 0,99 \\
\hline $\begin{array}{c}\text { Frecuencia } \\
\text { VI }\end{array}$ & 151,48 & $\begin{array}{c}- \\
0,62 \\
\end{array}$ & $\begin{array}{c}- \\
0,29 \\
\end{array}$ & 16,18 & 0,91 & 0,98 & 0,19 & 0,45 & 0,65 & $-0,16$ & 0,87 \\
\hline $\begin{array}{l}\text { Velocidad } \\
\text { Ult. }\end{array}$ & 285,25 & 0,70 & $\overline{-}$ & 27,99 & 0,31 & 0,97 & 0,12 & 0,51 & 0,61 & $-0,18$ & 0,86 \\
\hline $\begin{array}{c}E_{d} \\
\text { VI } \\
\end{array}$ & 1497,41 & 0,90 & $\begin{array}{c}- \\
1,14\end{array}$ & 15,68 & 0,90 & 0,97 & 0,03 & 0,65 & 0,51 & $-1,38$ & 0,17 \\
\hline $\begin{array}{l}E_{d} \\
\text { Ult. }\end{array}$ & 2017,39 & $\overline{-}$ & 1,53 & 27,59 & 0,33 & 0,97 & 0,08 & 0,22 & 0,82 & 1,46 & 0,14 \\
\hline
\end{tabular}

*VI: vibraciones inducidas; Ult: ultrasonidos; $\mathrm{E}_{\mathrm{d}}$ : módulo de elasticidad dinámico; DE.: Desvío estándar; SE: sesgo estandarizado; CE: Curtosis estandarizada

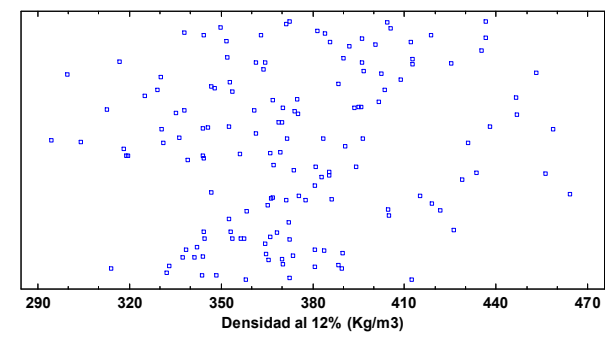

Figura 400. Gráfico dispersión: densidad

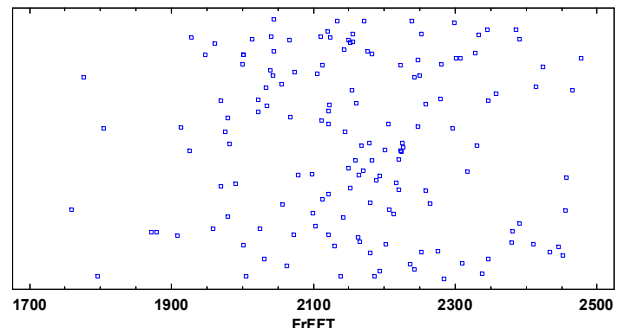

Figura 402. Gráfico dispersión: Frecuencia VI

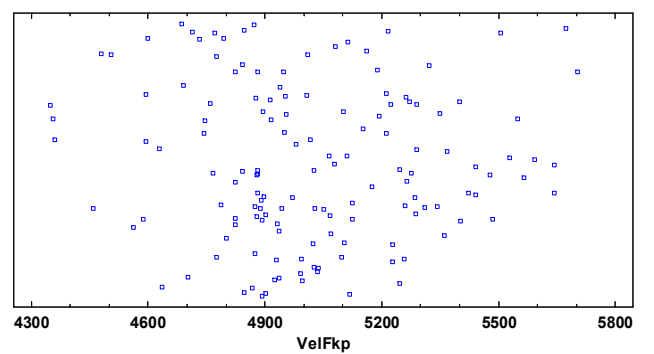

Figura 404. Gráfico dispersión: Velocidad Ult.

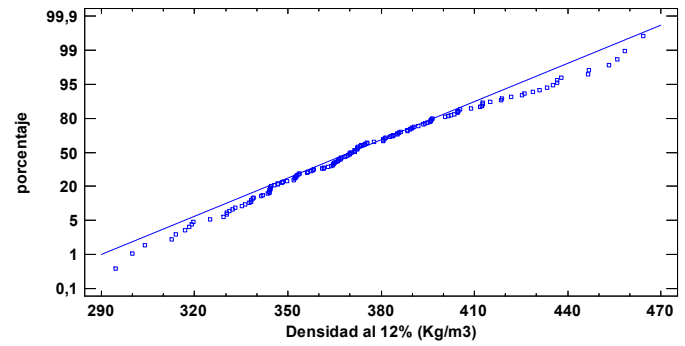

Figura 401. Gráfico probabilidad normal: densidad

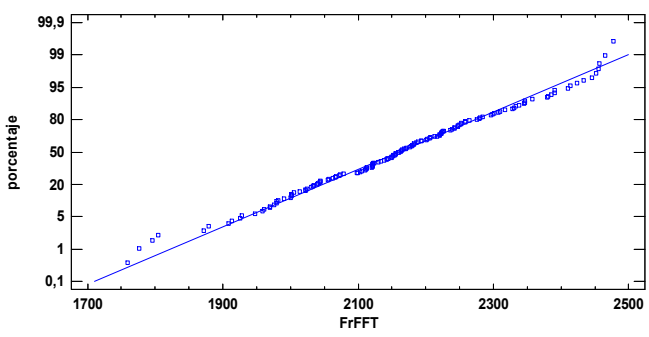

Figura 403. Gráfico probabilidad normal: Frecuencia VI

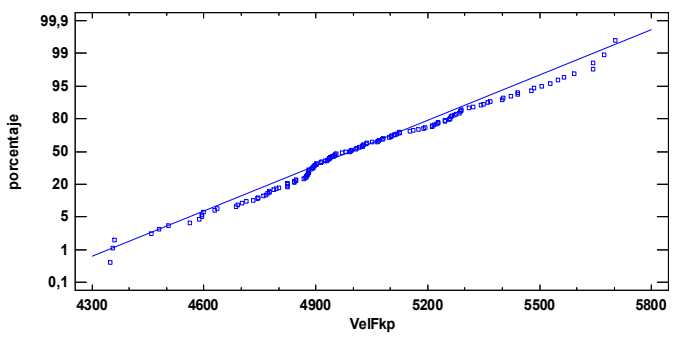

Figura 405. Gráfico probabilidad normal: Velocidad Ult. 


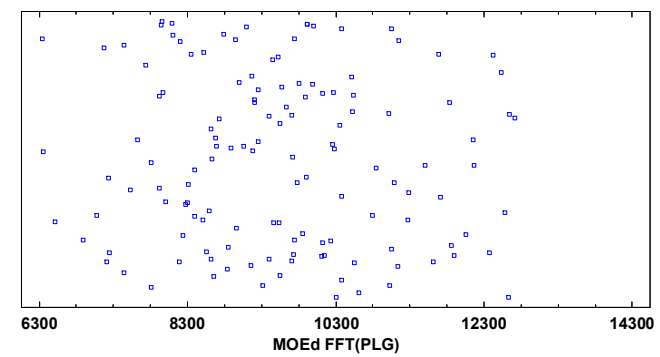

Figura 406. Gráfico dispersión: $E_{\mathrm{d}}$ VI

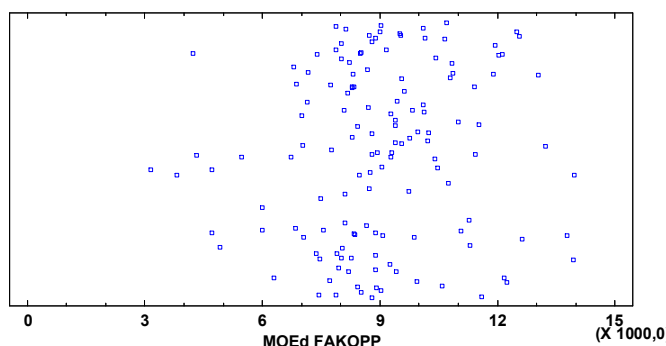

Figura 408. Gráfico dispersión: $E_{\mathrm{d}}$ Ult.

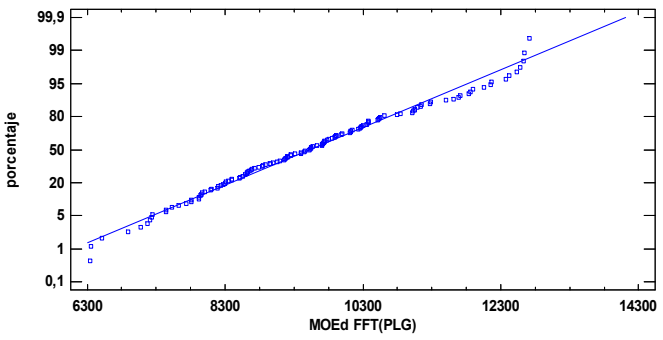

Figura 407. Gráfico probabilidad normal: $E_{\mathrm{d}}$ VI

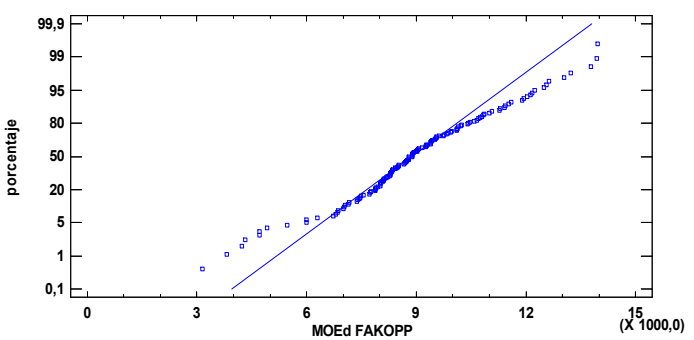

Figura 409. Gráfico probabilidad normal: $E_{\mathrm{d}}$

\section{Análisis comparativo entre NDT: material de procedencia española.}

El resultado del test de Levene se indica en la Tabla 199.

Tabla 199. $E_{\mathrm{d}}$ - NDT: Test de Levene.

\begin{tabular}{ccc}
\hline \multirow{2}{*}{ Levene's } & Prueba & P-valor \\
\cline { 2 - 3 } & 4,37 & 0,04 \\
\hline
\end{tabular}

De acuerdo con el P-valor $<0,05$, se trabajó con el test de Kruskal-Wallis para la evaluación de diferencias significativas entre medianas del $E_{\mathrm{d}}$ por NDT.

\section{Análisis descriptivo - NDT: material de procedencia Argentina}

El resumen estadístico y las pruebas de normalidad para las variables dinámicas NDT y para la densidad se muestran en la Tabla 200 (Figura 410 a Figura 417).

Tabla 200. Variables dinámicas: resumen estadístico y pruebas de normalidad.

\begin{tabular}{|c|c|c|c|c|c|c|c|c|c|c|c|}
\hline \multirow{2}{*}{ Variable* } & \multirow{2}{*}{$\mathrm{DE}^{*}$} & \multirow{2}{*}{ SE* } & \multirow{2}{*}{ CE* } & \multicolumn{2}{|c|}{ Chi-Cuadrado } & \multicolumn{2}{|c|}{$\begin{array}{c}\text { W de Shapiro- } \\
\text { Wilk } \\
\end{array}$} & \multicolumn{2}{|c|}{$\begin{array}{l}\text { Valor-Z para } \\
\text { asimetría } \\
\end{array}$} & \multicolumn{2}{|c|}{$\begin{array}{c}\text { Valor-Z para } \\
\text { curtosis } \\
\end{array}$} \\
\hline & & & & Estad. & $\begin{array}{c}\mathrm{P}- \\
\text { valor }\end{array}$ & Estad. & P-valor & Estad. & P-valor & Estad. & P-valor \\
\hline Densidad & 25,83 & 1,00 & $\begin{array}{c}- \\
1,33\end{array}$ & 10,5 & 0,96 & 0,96 & 0,058 & 0,74 & 0,46 & $-1,80$ & 0,07 \\
\hline $\begin{array}{c}\text { Frecuencia } \\
\text { VI }\end{array}$ & 109,48 & $0,-$ & $\begin{array}{c}- \\
1,45 \\
\end{array}$ & 27,5 & 0,12 & 0,97 & 0,12 & 0,37 & 0,71 & $-2,07$ & 0,04 \\
\hline $\begin{array}{l}\text { Velocidad } \\
\text { Ult. } \\
\end{array}$ & 210,10 & $\overline{-}, 84$ & $\overline{-}$ & 29,0 & 0,09 & 0,97 & 0,17 & 0,62 & 0,54 & $-1,28$ & 0,20 \\
\hline $\begin{array}{c}E_{d} \\
V I \\
\end{array}$ & 937,18 & $\overline{-}$ & $\begin{array}{c}- \\
1,17 \\
\end{array}$ & 14,5 & 0,80 & 0,97 & 0,14 & 0,26 & 0,80 & $-1,48$ & 0,14 \\
\hline $\begin{array}{l}\mathrm{E}_{\mathrm{d}} \\
\text { Ult. }\end{array}$ & 890,51 & 0,21 & $\overline{-}$ & 14,5 & 0,80 & 0,98 & 0,41 & 0,16 & 0,88 & $-0,79$ & 0,43 \\
\hline
\end{tabular}

*VI: vibraciones inducidas; Ult: ultrasonidos; $\mathrm{MOE}_{\mathrm{d}}$ : módulo de elasticidad dinámico; DE.: Desvío estándar; SE: sesgo estandarizado; CE: Curtosis estandarizada 


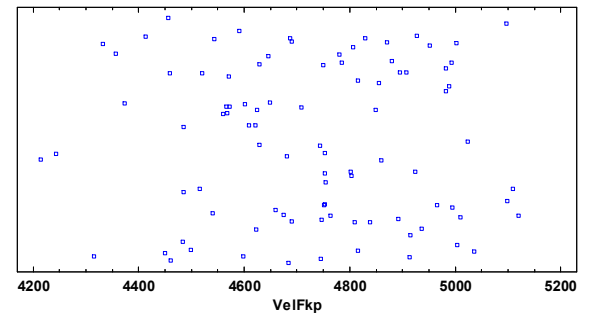

Figura 410. Gráfico dispersión: Velocidad

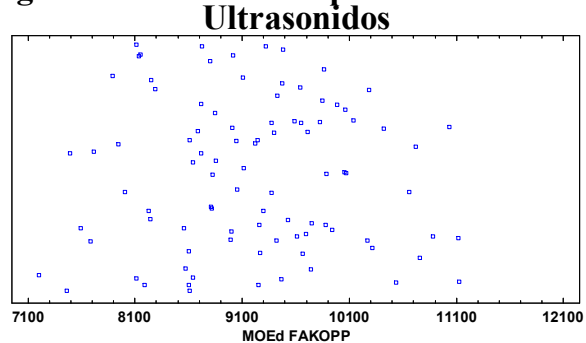

Figura 412. Gráfico dispersión: $E_{d}$ Ult.

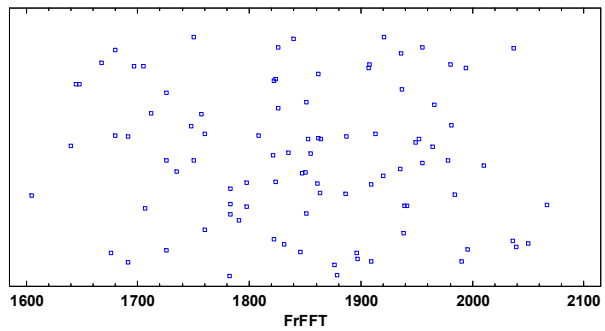

Figura 414. Gráfico dispersión: Frecuencia VI

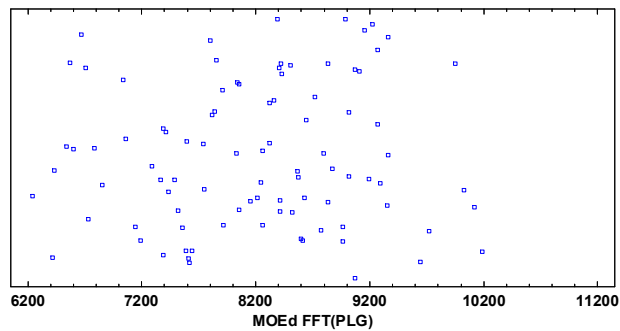

Figura 416. Gráfico dispersión: $\mathbf{E}_{\mathrm{d}}-\mathrm{VI}$

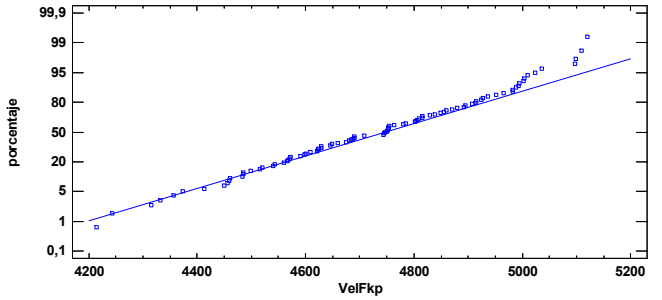

Figura 411. Gráfico probabilidad normal: Velocidad Ultrasonidos

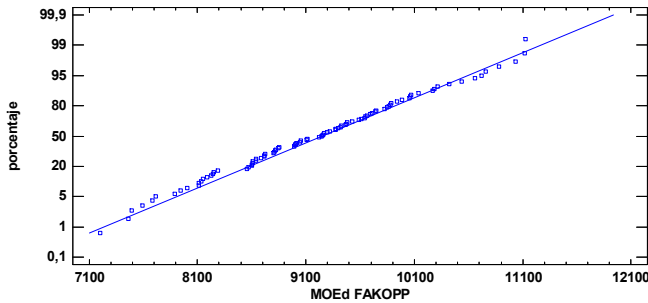

Figura 413. Gráfico probabilidad normal: $E_{d}$ Ult.

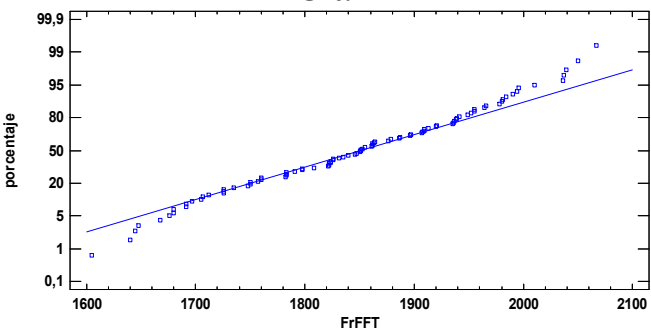

Figura 415. Gráfico probabilidad normal: Frecuencia VI

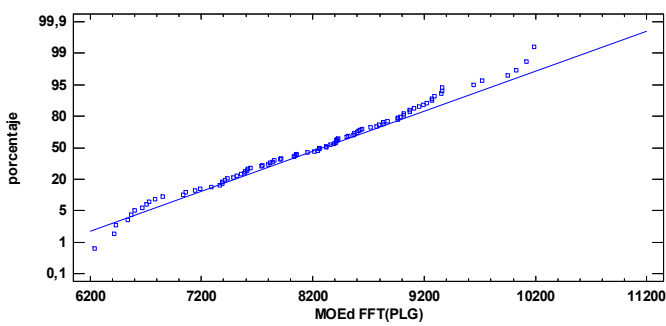

Figura 417. Gráfico probabilidad normal: $\mathbf{E}_{\mathrm{d}}-\mathrm{VI}$

\section{Análisis comparativo entre NDT: material de procedencia argentina.}

El test de Levene y el análisis de comparación de medias para $E_{\mathrm{d}}$ por NDT, se muestra en la Tabla 201.

Tabla 201. $E_{d}$ - NDT: test de Levene - Comparación de medias.

\begin{tabular}{|c|c|c|c|c|c|}
\hline \multirow[b]{2}{*}{ Levene } & Prueba & P-valor & \multirow[b]{2}{*}{ Comparación de medias } & \multicolumn{2}{|c|}{ IC $95 \%$ para la media de $\boldsymbol{E}_{\mathbf{d}}$} \\
\hline & 0,45 & 0,50 & & $\begin{array}{c}\mathbf{V I} \\
8197,03+/-194,085 \\
{[8002,95,8391,12]}\end{array}$ & $\begin{array}{c}\text { Ult. } \\
9197,76+/-184,42 \\
{[9013,34,9382,18]}\end{array}$ \\
\hline
\end{tabular}

*VI: vibraciones inducidas; Ult: ultrasonidos; $\mathrm{MOE}_{\mathrm{d}}$ : módulo de elasticidad dinámico.

De acuerdo con el P-valor de 0,05, no existen diferencias significativas entre los desvíos estándar con lo que se procedió al análisis de comparación de medias. 


\section{Análisis comparativo - NDT vs procedencia.}

En la Tabla 202 se presenta el resultado de constatación del supuesto de homocedasticidad para frecuencia y Ed obtenido mediante VI, comparando entre procedencias.

Tabla 202. Frecuencia y $E_{\mathrm{d}}(\mathrm{VI})$ - procedencias: test de Levene.

\begin{tabular}{|c|c|c|c|c|c|}
\hline \multicolumn{6}{|c|}{ Vibraciones Inducidas } \\
\hline \multirow{3}{*}{ Test Levene } & Frecuen & ración & \multirow{3}{*}{ Test Levene } & \multicolumn{2}{|c|}{$E_{\mathrm{d}} *$} \\
\hline & Prueba & Valor-P & & Prueba & Valor-P \\
\hline & 7,13 & 0,00 & & 18,22 & 0,00 \\
\hline
\end{tabular}

$\mathrm{E}_{\mathrm{d}}$ : módulo de elasticidad dinámico.

La verificación del supuesto de homocedasticidad para la velocidad y el $\mathrm{E}_{\mathrm{d}}$ obtenido por ultrasonidos contrastando procedencias, se muestra en la Tabla 203.

Tabla 203. Velocidad y $E_{\mathrm{d}}$ (Ult.) - procedencias: test de Levene

\begin{tabular}{|c|c|c|c|c|c|}
\hline \multicolumn{6}{|c|}{ Ultrasonidos } \\
\hline \multirow{3}{*}{ Test Levene } & \multicolumn{2}{|c|}{ Velocidad } & \multirow{3}{*}{ Test Levene } & \multicolumn{2}{|c|}{$E_{\mathrm{d}}{ }^{*}$} \\
\hline & Prueba & Valor-P & & Prueba & Valor-P \\
\hline & 6,67 & 0,01 & & 27,92 & $4,60 \mathrm{E}-7$ \\
\hline
\end{tabular}

* $E_{\mathrm{d}}$ : módulo de elasticidad dinámico.

De acuerdo con los P-valores presentados en la Tabla 48 y en la Tabla 203, no pudo corroborarse la igualdad de varianzas en ninguno de los casos, razón por la cual se procedió a trabajar con el Test de Kruskal-Wallis para comparación de medianas.

\subsubsection{Ensayos destructivos:}

\section{Análisis descriptivo: material de procedencia española}

El análisis descriptivo y las pruebas de normalidad se resumen en la Tabla 204 y Tabla 205, respectivamente (Figura 418 a Figura 423).

Tabla 204. Flexión estática: resumen estadístico.

\begin{tabular}{cccc}
\hline Variable* & Desvío estándar & Sesgo estandarizado & Curtosis estandarizada \\
\hline MOE & 1935,51 & 1,01 & $-0,63$ \\
\hline MOR & 11,39 & $-0,25$ & $-0,82$ \\
\hline Densidad & 44,37 & 0,49 & $-0,002$ \\
\hline
\end{tabular}

Tabla 205. Flexión estática. Chopo (España): pruebas de normalidad

\begin{tabular}{ccccccccc}
\hline & \multicolumn{2}{c}{ Chi-Cuadrado } & \multicolumn{2}{c}{ W de Shapiro-Wilk } & \multicolumn{2}{c}{ Valor-Z para asimetría } & \multicolumn{2}{c}{ Valor-Z para curtosis } \\
\cline { 2 - 9 } & Estad. & P-valor & Estad. & P-valor & Estad. & P-valor & Estad. & P-valor \\
\hline MOE & 18,81 & 0,81 & 0,98 & 0,24 & 0,73 & 0,46 & $-0,58$ & 0,56 \\
\hline MOR & 22,95 & 0,58 & 0,97 & 0,08 & 0,18 & 0,85 & $-0,85$ & 0,39 \\
\hline Densidad & 21,44 & 0,66 & 0,98 & 0,44 & 0,36 & 0,72 & 0,16 \\
\hline
\end{tabular}




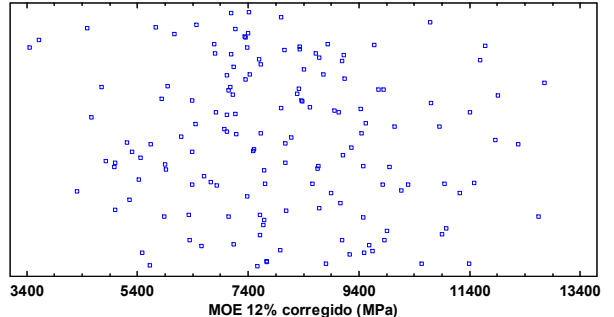

Figura 418. Gráfico dispersión: MOE-España

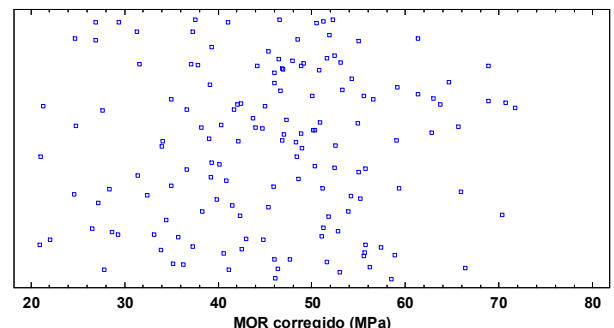

Figura 420. Gráfico dispersión: MOR-España

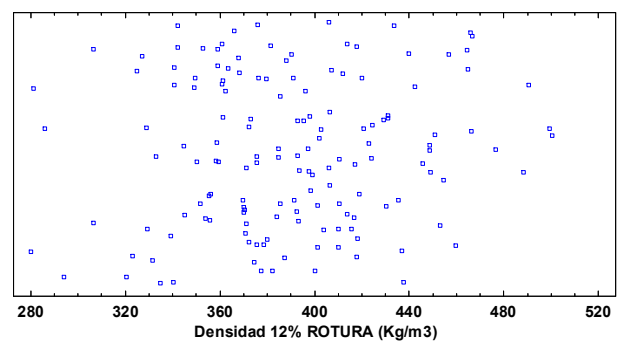

Figura 422. Gráfico dispersión: densidad España

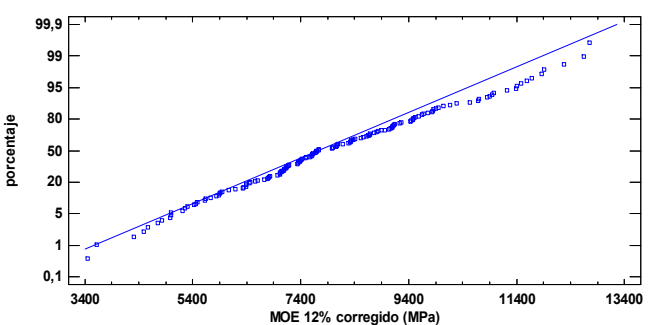

Figura 419. Gráfico probabilidad normal: MOE-España

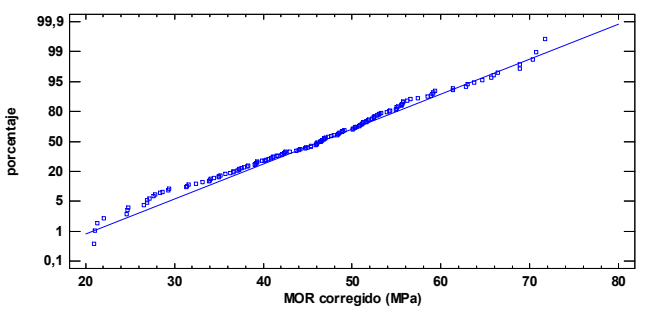

Figura 421. Gráfico probabilidad normal: MOR-España

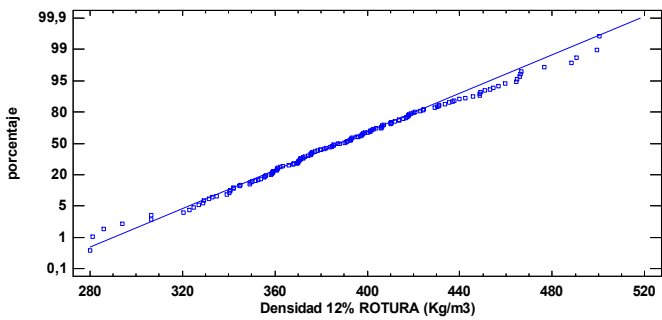

Figura 423. Gráfico probabilidad normal: densidad. España

\section{Análisis descriptivo y pruebas de normalidad: material procedencia argentina.}

El análisis descriptivo y las pruebas de normalidad se resumen en la Tabla 206 y Tabla 207, respectivamente (Figura 424 a Figura 429).

Tabla 206. Flexión estática: resumen estadístico.

\begin{tabular}{cccc}
\hline Variable & Desvío estándar & Sesgo estandarizado & Curtosis estandarizadas \\
\hline MOE & 1234,42 & $-0,18$ & $-0,20$ \\
\hline MOR & 6,74 & $-1,29$ & $-0,88$ \\
\hline Densidad & 27,16 & 1,65 & $-0,75$ \\
\hline
\end{tabular}

Tabla 207. Flexión estática: pruebas de normalidad

\begin{tabular}{ccccccccc}
\hline & \multicolumn{2}{c}{ Chi-Cuadrado } & \multicolumn{2}{c}{ W de Shapiro-Wilk } & \multicolumn{2}{c}{ Valor-Z para asimetría } & \multicolumn{2}{c}{ Valor-Z para curtosis } \\
\cline { 2 - 10 } & Estad. & $P$-valor & Estad. & $P$-valor & Estad. & $P$-valor & Estad. & $P$-valor \\
\hline MOE & 19,5 & 0,49 & 0,98 & 0,50 & 0,13 & 0,89 & $-0,04$ & 0,97 \\
\hline MOR & 10,35 & 0,96 & 0,96 & 0,06 & 0,94 & 0,35 & $-0,99$ & 0,32 \\
\hline Densidad & 16,8 & 0,60 & 0,96 & 0,04 & 1,19 & 0,23 & $-0,79$ & 0,43 \\
\hline
\end{tabular}




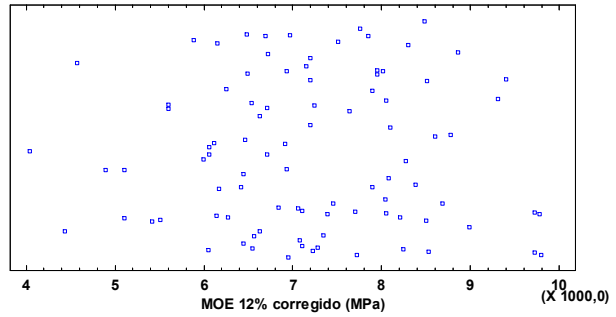

Figura 424. Gráfico dispersión: MOE Argentina

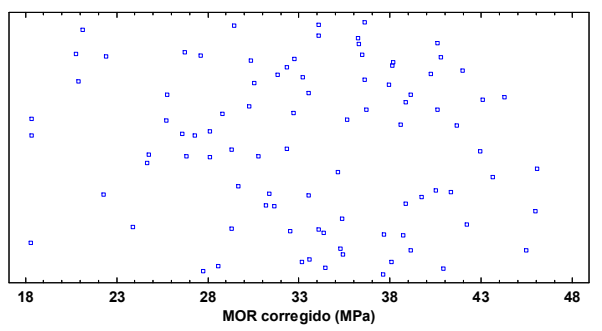

Figura 426. Gráfico dispersión: MOR Argentina

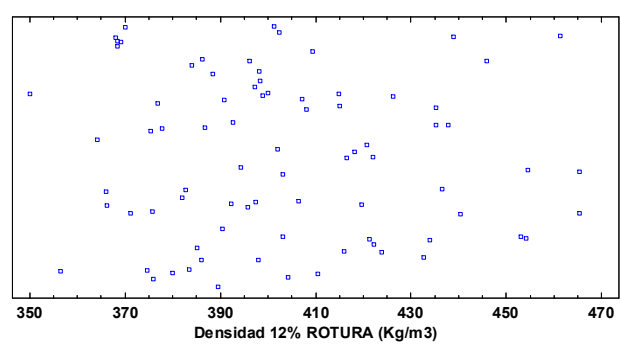

Figura 428. Gráfico dispersión: densidad Argentina

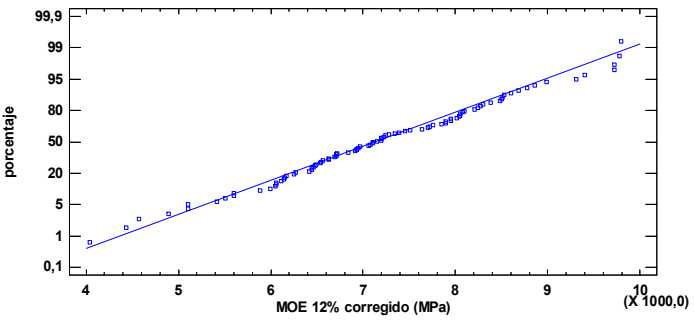

Figura 425. Gráfico probabilidad normal: MOE Argentina

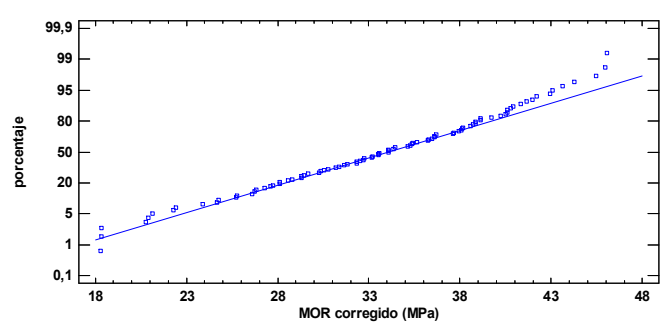

Figura 427. Gráfico probabilidad normal: MOR Argentina

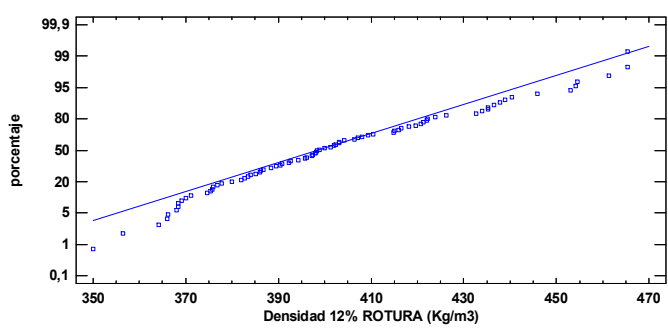

Figura 429. Gráfico probabilidad normal: densidad. Argentina

\section{Análisis comparativo entre procedencias.}

En la Tabla 208 se presenta el test de Levene para MOE, MOR y la densidad entre procedencias.

Tabla 208. MOE, MOR y densidad - procedencias: test de Levene.

\begin{tabular}{ccccccc}
\hline \multirow{3}{*}{ Test de Levene } & \multicolumn{2}{c}{$\begin{array}{c}\text { MOE* } \\
(\mathrm{MPa})\end{array}$} & \multicolumn{2}{c}{$\begin{array}{c}\text { MOR* } \\
(\mathrm{MPa})\end{array}$} & \multicolumn{2}{c}{$\begin{array}{c}\text { Densidad } \\
\left(\mathrm{Kg} / \mathrm{m}^{3}\right)\end{array}$} \\
\cline { 2 - 8 } & Prueba & P-valor & Prueba & P-valor & Prueba & P-valor \\
\cline { 2 - 8 } & 0,00 & 20,66 & 0,00 & 24,66 & 0,00 \\
\hline
\end{tabular}

*MOE: módulo de elasticidad; MOR: módulo de rotura.

Dado que no pudo comprobarse la homogeneidad de las varianzas ( $\mathrm{P}$-valores $<0,05$ ) se trabajó con el test de comparación de medianas (Kruskal-Wallis).

\subsubsection{Influencia de defectos naturales en el Módulo de elasticidad (MOE)}

\section{Material de procedencia argentina}

\subsection{Alteraciones biológicas: influencia en el MOE}

El test de Levene y la comparación de medias se muestran en la Tabla 209. 
Tabla 209. MOE - Influencia de alteraciones biológicas: test de Levene y comparación de medias.

\begin{tabular}{cccccc}
\hline \multirow{2}{*}{ Levene } & Prueba & Valor-P & & \multicolumn{2}{c}{ IC 95\% para la media de MOE* } \\
\cline { 2 - 3 } \cline { 5 - 5 } & \multirow{2}{*}{0,66} & & \multirow{2}{*}{ Comparación de medias } & Rechazo B & Rechazo NB \\
& 0,19 & 0,66 & & $6849,39+/-853,46$ & $7108,4+/-449,32$ \\
& & & {$[5995,93,7702,85]$} & {$[6659,09,7557,72]$} \\
\hline
\end{tabular}

*MOE: Módulo de elasticidad; B: rechazos por causas biológicas; NB: rechazos por causas no biológicas.

\subsubsection{Influencia de defectos naturales en el Módulo de rotura (MOR)}

\section{Material de procedencia argentina}

\subsection{Alteraciones biológicas: influencia en el MOR}

El test de Levene y la comparación de medias se muestran en la Tabla 210 para las alteraciones biológicas y en la Tabla 211 para el "Lugar de rotura".

Tabla 210. MOR - Influencia de alteraciones biológicas: test de Levene y comparación de medias.

\begin{tabular}{ccccc}
\hline \multirow{2}{*}{ Levene } & Prueba & Valor-P & & \multicolumn{2}{c}{ IC 95\% para la media de MOR* } \\
\cline { 2 - 3 } \cline { 4 - 5 } & \multirow{2}{*}{0,30} & \multirow{2}{*}{ Comparación de medias } & Rechazo B & Rechazo NB \\
& \multirow{2}{*}{0,30} & & $33,95+/-2,48$ & $32,09+/-4,34$ \\
& & & {$[31,47,36,43]$} & {$[27,76,36,43]$} \\
\hline
\end{tabular}

*MOR: Módulo de rotura; B: rechazos por causas biológicas; NB: rechazos por causas no biológicas.

Tabla 211. MOR - Rechazos por "Lugar de rotura" (Chopo-Argentina): test de Levene.

\begin{tabular}{ccc}
\hline \multirow{2}{*}{ Levene } & Prueba & Valor-P \\
\cline { 2 - 3 } & 1,88 & 0,16 \\
\hline
\end{tabular}

\subsubsection{Predicción de variables elasto-resistentes a partir de NDT}

\section{Material de procedencia española}

Los análisis de constatación de supuestos estadísticos para los residuos estudentizados del análisis de regresión, ensayo de vibraciones inducidas, se muestran en la Tabla 212 y Tabla 213 (Figura 430 a Figura 437).

Tabla 212. Predicciones MOE-MOR - NDT (VI): pruebas de normalidad de residuos

\begin{tabular}{|c|c|c|c|c|c|c|c|c|c|}
\hline \multirow{2}{*}{$\begin{array}{l}\text { Variable } \\
\text { predicha }\end{array}$} & \multirow{2}{*}{ Variable predictora } & \multicolumn{2}{|c|}{ Chi-Cuadrado } & \multicolumn{2}{|c|}{$\begin{array}{c}\text { W de Shapiro- } \\
\text { Wilk }\end{array}$} & \multicolumn{2}{|c|}{$\begin{array}{c}\text { Valor-Z para } \\
\text { asimetría }\end{array}$} & \multicolumn{2}{|c|}{$\begin{array}{l}\text { Valor-Z para } \\
\text { curtosis }\end{array}$} \\
\hline & & Estad. & $\begin{array}{c}\mathrm{P}- \\
\text { valor }\end{array}$ & Estad. & $\begin{array}{c}\mathrm{P}- \\
\text { valor }\end{array}$ & Estad. & P-valor & Estad. & P-valor \\
\hline \multirow{2}{*}{ MOE } & Frecuencia & 28,21 & 0,30 & 0,98 & 0,70 & 0,74 & 0,46 & 1,21 & 0,23 \\
\hline & Frecuencia*Densidad & 24,62 & 0,48 & 0,97 & 0,02 & 0,02 & 0,98 & 2,37 & 0,02 \\
\hline \multirow{2}{*}{ MOR } & Frecuencia & 35,35 & 0,08 & 0,98 & 0,40 & 1,32 & 0,19 & 1,22 & 0,22 \\
\hline & Frecuencia*Densidad & 31,30 & 0,18 & 0,96 & 0,01 & 1,46 & 0,14 & $-0,78$ & 0,43 \\
\hline
\end{tabular}


Tabla 213. Predicciones MOE-MOR - NDT (VI): prueba de bondad de ajuste (KolmogorovSmirnov)

\begin{tabular}{ccc}
\hline \multirow{2}{*}{ Variable predicha } & Variable predictora & \multicolumn{2}{c}{ Bondad de Ajuste (Kolmogorov-Smirnov) } \\
\cline { 2 - 3 } & Frecuencia & P-valor \\
\cline { 2 - 3 } MOE & Frecuencia*Densidad & 0,82 \\
\cline { 2 - 3 } & Frecuencia & 0,20 \\
\cline { 2 - 3 } MOR & Frecuencia*Densidad & 0,76 \\
\cline { 2 - 3 } & &
\end{tabular}

De acuerdo con los P-valores obtenidos $\geq 0,05$, no se pudo rechazar la hipótesis de que los residuos provenían de una distribución normal, con 95\% de confianza.

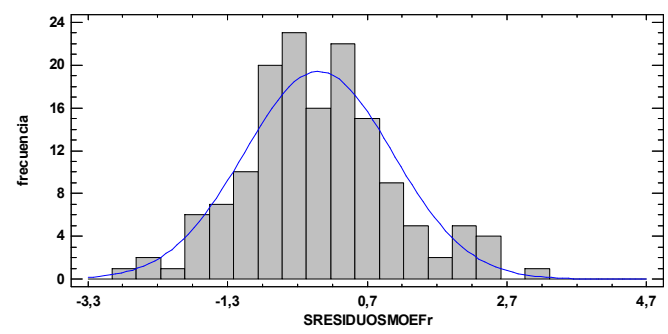

Figura 430. Histograma de Frecuencia: Residuos MOE - Fr (VI). Chopo (España)

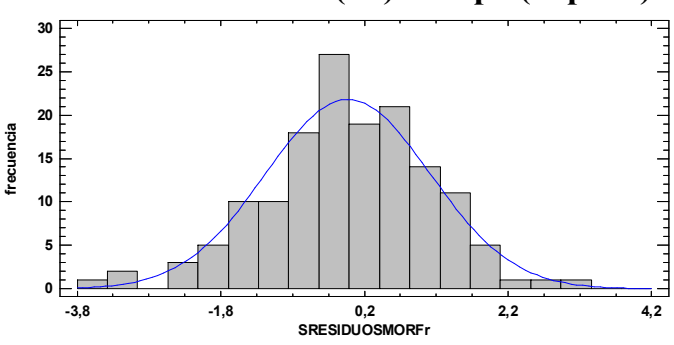

Figura 432. Histograma de Frecuencia: Residuos MOR - Fr (VI). Chopo (España)

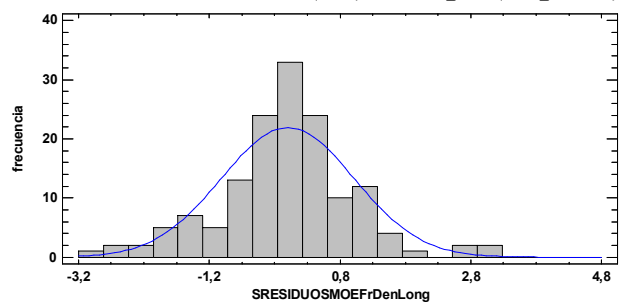

Figura 434. Histograma de Frecuencia: Residuos MOE - Fr (VI)*Densidad. Chopo (España)

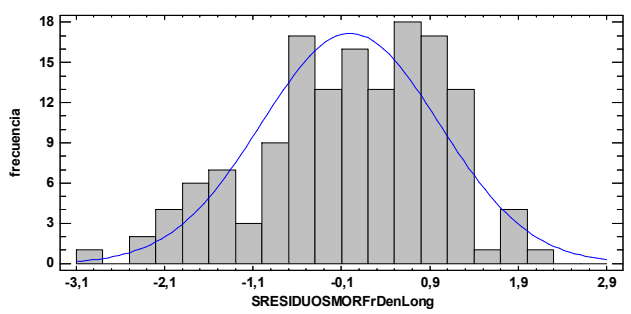

Figura 436. Histograma de Frecuencia: Residuos MOR - Fr (VI)*Densidad. Chopo (España)

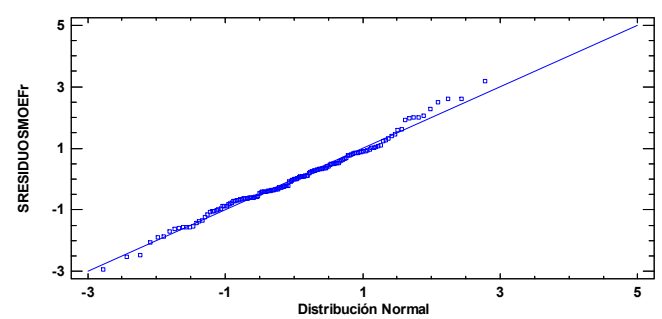

Figura 431. Gráfico probabilidad normal: Residuos MOE - Fr (VI). Chopo (España)

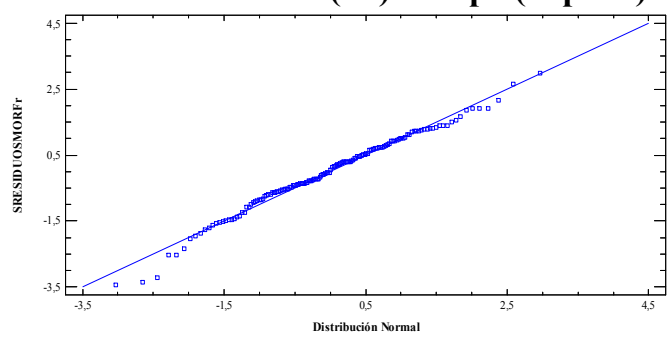

Figura 433. Gráfico probabilidad normal: Residuos MOR - Fr (VI). Chopo (España)

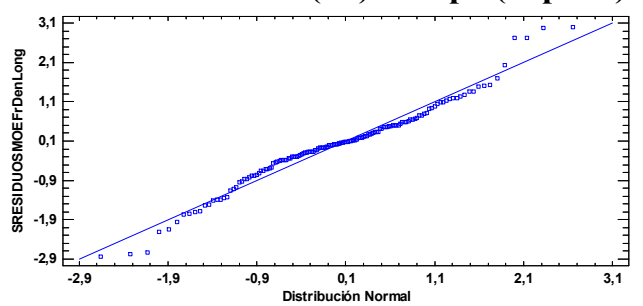

Figura 435. Gráfico probabilidad normal: Residuos MOE - Fr (VI)*Densidad. Chopo (España)

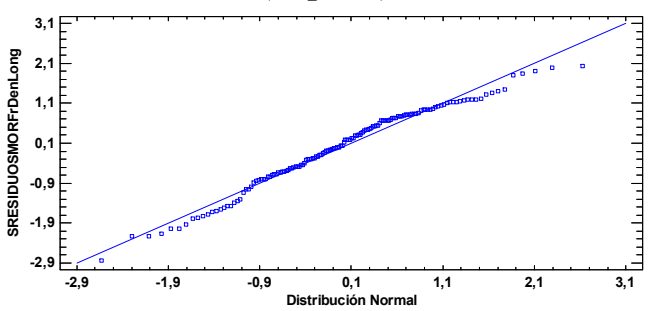

Figura 437. Gráfico probabilidad normal: Residuos MOR - Fr (VI)*Densidad. Chopo (España) 
Los análisis de constatación de supuestos estadísticos para los residuos estudentizados del análisis de regresión, ensayo de ultrasonidos, se muestran en la Tabla 214 y Tabla 215 (Figura 438 a Figura 445).

Tabla 214.Predicciones MOE-MOR - NDT (UIt.): pruebas de normalidad de residuos

\begin{tabular}{cccccccccc}
\hline \multirow{2}{*}{$\begin{array}{c}\text { Variable } \\
\text { predicha }\end{array}$} & \multirow{2}{*}{$\begin{array}{c}\text { Chi-Cuadrado } \\
\text { Variable predictora }\end{array}$} & \multicolumn{2}{c}{$\begin{array}{c}\text { W de Shapiro- } \\
\text { Wilk }\end{array}$} & \multicolumn{2}{c}{$\begin{array}{c}\text { Valor-Z para } \\
\text { asimetría }\end{array}$} & \multicolumn{2}{c}{$\begin{array}{c}\text { Valor-Z para } \\
\text { curtosis }\end{array}$} \\
\cline { 2 - 10 } & & Estad. & P-valor & Estad. & $\begin{array}{c}\text { P- } \\
\text { valor }\end{array}$ & Estad. & P-valor & Estad. & P-valor \\
\hline \multirow{2}{*}{ MOE } & Velocidad & 14,49 & 0,95 & 0,99 & 0,99 & 0,74 & 0,46 & 2,11 & 0,04 \\
\cline { 2 - 10 } & Velocidad*Densidad & 22,82 & 0,53 & 0,96 & 0,02 & 0,77 & 0,44 & $-0,97$ & 0,33 \\
\hline \multirow{2}{*}{ MOR } & Velocidad & 33,16 & 0,13 & 0,99 & 0,74 & 0,28 & 0,78 & 0,99 & 0,32 \\
\cline { 2 - 10 } & Velocidad*Densidad & 43,57 & 0,01 & 0,95 & 0,00 & 1,99 & 0,05 & $-0,11$ & 0,91 \\
\hline
\end{tabular}

Tabla 215. Predicciones MOE-MOR - NDT. Chopo (España): prueba de bondad de ajuste (Kolmogorov-Smirnov)

\begin{tabular}{ccc}
\hline \multirow{2}{*}{ Variable predicha } & Variable predictora & \multicolumn{2}{c}{ Bondad de Ajuste (Kolmogorov-Smirnov) } \\
\cline { 2 - 3 } & Velocidad & P-valor \\
\cline { 2 - 3 } MOE & Velocidad*Densidad & 0,96 \\
\cline { 2 - 3 } & Velocidad & 0,85 \\
\cline { 2 - 3 } MOR & Velocidad*Densidad & 0,70 \\
\hline
\end{tabular}

Dado que al menos uno de los parámetros considerados para evaluar la normalidad de los residuos ha presentado P-valores $>=$ a 0,05 , no se pudo rechazar la hipótesis de que los residuos provenían de una distribución normal, con 95\% de confianza.

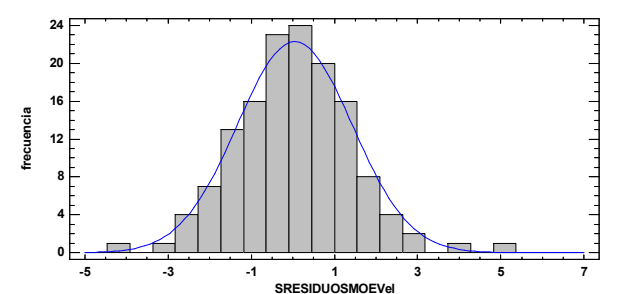

Figura 438. Histograma de Frecuencia: Residuos MOE - Vel (Ult). Chopo (España)

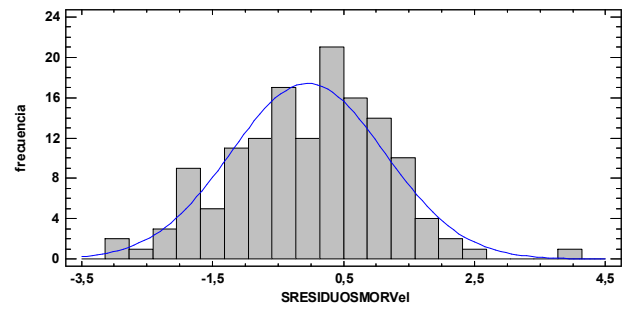

Figura 440. Histograma de Frecuencia: Residuos MOR - Vel (Ult). Chopo (España)

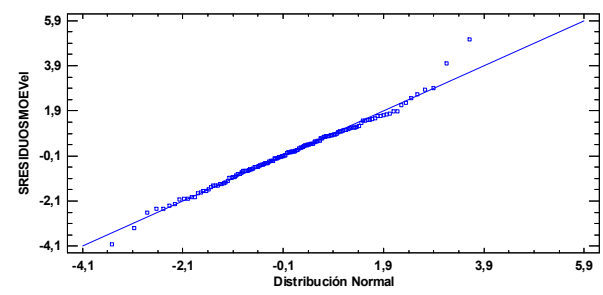

Figura 439. Gráfico probabilidad normal: Residuos MOE - Vel (Ult). Chopo (España)

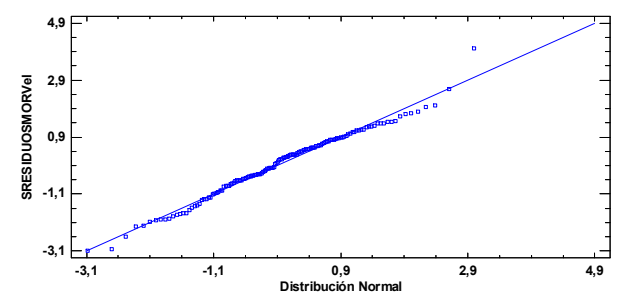

Figura 441. Gráfico probabilidad normal Residuos MOR - Vel (Ult). Chopo (España) 


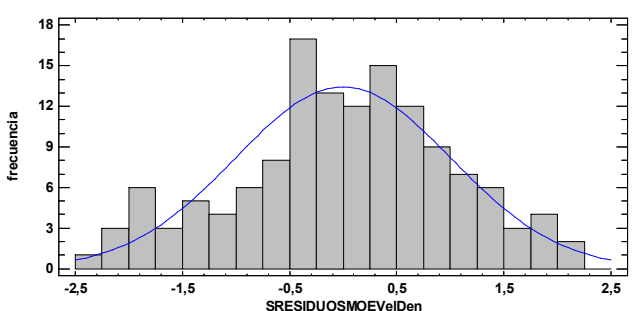

Figura 442. Histograma de Frecuencia: Residuos MOE - Vel (Ult)*Densidad. Chopo (España)

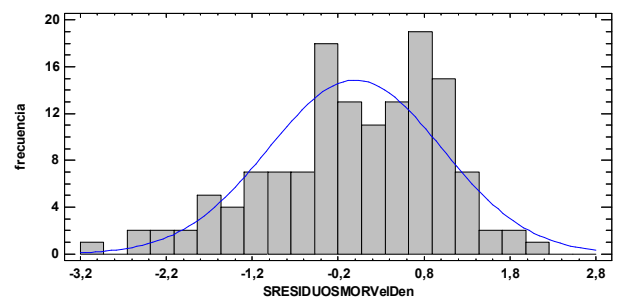

Figura 444. Histograma de Frecuencias Residuos MOR - Vel (Ult)*Densidad. Chopo (España)

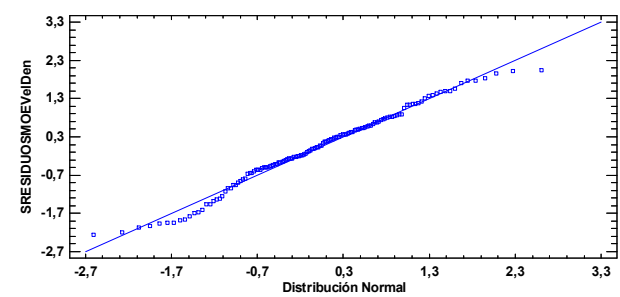

Figura 443. Gráfico probabilidad normal: Residuos MOE - Vel (Ult)*Densidad. Chopo (España)

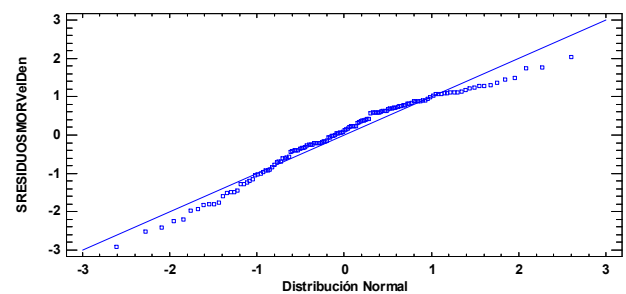

Figura 445. Gráfico probabilidad normal Residuos MOR - Vel (Ult)*Densidad. Chopo (España)

\section{Material de procedencia argentina}

Los análisis de constatación de supuestos estadísticos para los residuos estudentizados del análisis de regresión, ensayo de vibraciones inducidas, se muestran en la Tabla 216 y Tabla 217 (Figura 446 a Figura 453).

Tabla 216. Predicciones MOE-MOR - NDT: pruebas de normalidad de residuos

\begin{tabular}{cccccccccc}
\hline \multirow{2}{*}{$\begin{array}{c}\text { Variable } \\
\text { predicha }\end{array}$} & \multirow{2}{*}{ Variable predictora } & \multicolumn{2}{c}{ Chi-Cuadrado } & \multicolumn{2}{c}{$\begin{array}{c}\text { W de Shapiro- } \\
\text { Wilk }\end{array}$} & \multicolumn{2}{c}{$\begin{array}{c}\text { Valor-Z para } \\
\text { asimetría }\end{array}$} & \multicolumn{2}{c}{$\begin{array}{c}\text { Valor-Z para } \\
\text { curtosis }\end{array}$} \\
\cline { 2 - 10 } & & Estad. & P-valor & Estad. & P-valor & Estad. & P-valor & Estad. & P-valor \\
\hline \multirow{2}{*}{ MOE } & Frecuencia & 17,0 & 0,65 & 0,99 & 0,87 & 0,11 & 0,91 & 0,55 & 0,58 \\
\cline { 2 - 10 } & Frecuencia*Densidad & 19,45 & 0,49 & 0,98 & 0,75 & 0,51 & 0,61 & 0,03 & 0,97 \\
\hline \multirow{2}{*}{ MOR } & Frecuencia & 27,03 & 0,13 & 0,96 & 0,06 & 1,51 & 0,13 & 0,56 & 0,58 \\
\cline { 2 - 10 } & Frecuencia*Densidad & 26,53 & 0,15 & 0,95 & 0,01 & 1,76 & 0,08 & 0,15 & 0,88 \\
\hline
\end{tabular}

Tabla 217. Predicciones MOE-MOR - NDT: prueba de bondad de ajuste (Kolmogorov-Smirnov)

\begin{tabular}{ccc}
\hline \multirow{2}{*}{ Variable predicha } & Variable predictora & \multicolumn{2}{c}{ Bondad de Ajuste (Kolmogorov-Smirnov) } \\
\cline { 2 - 3 } & Frecuencia & P-valor \\
\cline { 2 - 3 } MOE & Frecuencia*Densidad & 0,98 \\
\cline { 2 - 3 } & Frecuencia & 0,88 \\
\cline { 2 - 3 } MOR & Frecuencia*Densidad & 0,13 \\
\hline
\end{tabular}

Debido a que al menos uno de los parámetros considerados para evaluar la normalidad de los residuos ha presentado P-valores $>=0,05$, no se pudo rechazar la hipótesis de que los residuos provenían de una distribución normal, con 95\% de confianza. 


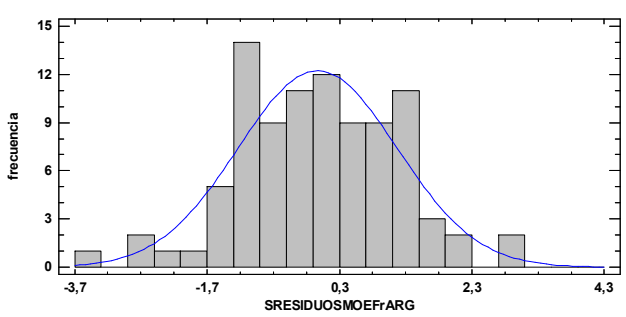

Figura 446. Histograma de Frecuencia: Residuos MOE - Fr (VI). Chopo (Argentina)

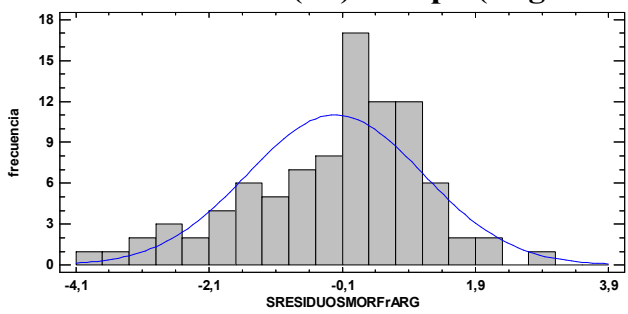

Figura 448. Histograma de Frecuencia: Residuos MOR - Fr (VI). Chopo (Argentina)

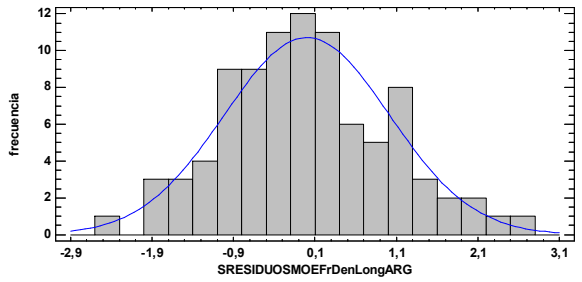

Figura 450. Histograma de Frecuencia: Residuos MOE - Fr (VI)*Densidad. Chopo (Argentina)

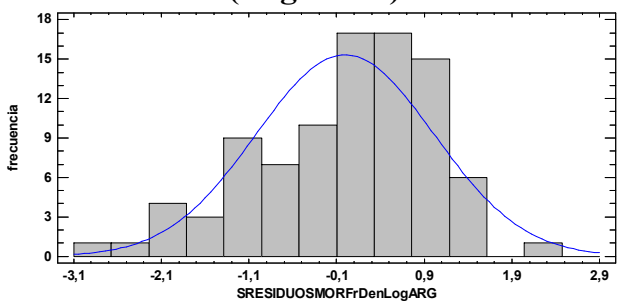

Figura 452. Histograma de Frecuencia: Residuos MOR - Fr (VI)*Densidad. Chopo (Argentina)

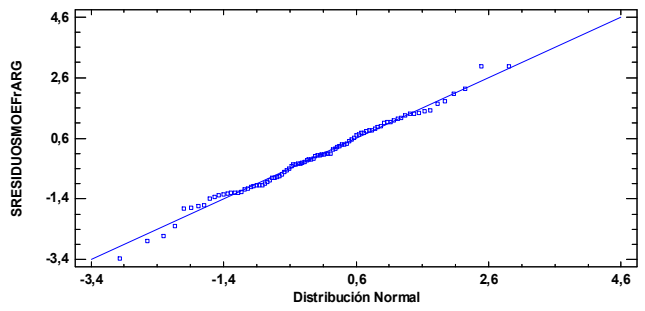

Figura 447. Gráfico probabilidad normal: Residuos MOE - Fr (VI). Chopo (Argentina)

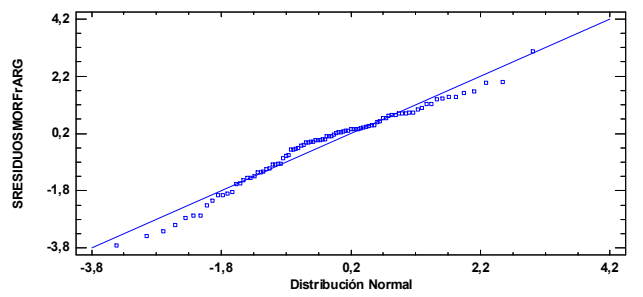

Figura 449. Gráfico probabilidad normal: Residuos MOR - Fr (VI). Chopo (Argentina)

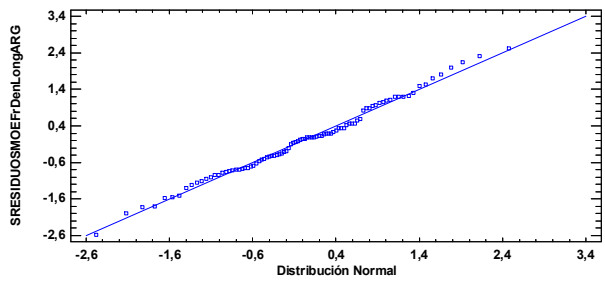

Figura 451. Gráfico probabilidad normal: Residuos MOE - Fr (VI)*Densidad. Chopo (Argentina)

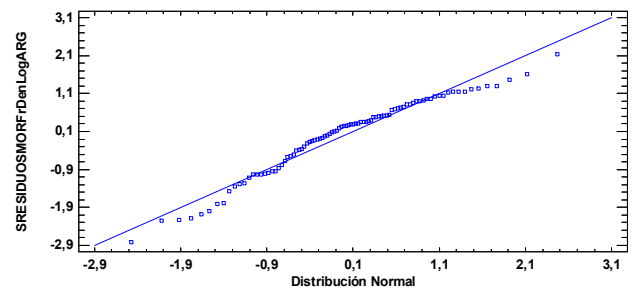

Figura 453. Gráfico probabilidad normal: Residuos MOR - Fr (VI)*Densidad. Chopo (Argentina)

Los análisis de constatación de supuestos estadísticos para los residuos estudentizados del análisis de regresión, ensayo de ultrasonidos, se muestran en la Tabla 218 y Tabla 219 (Figura 454 a Figura 461).

Tabla 218.Predicciones MOE-MOR - NDT: pruebas de normalidad de residuos

\begin{tabular}{|c|c|c|c|c|c|c|c|c|c|}
\hline \multirow{2}{*}{$\begin{array}{l}\text { Variable } \\
\text { predicha }\end{array}$} & \multirow[t]{2}{*}{ Variable predictora } & \multicolumn{2}{|c|}{ Chi-Cuadrado } & \multicolumn{2}{|c|}{$\begin{array}{c}\text { W de Shapiro- } \\
\text { Wilk }\end{array}$} & \multicolumn{2}{|c|}{$\begin{array}{c}\text { Valor-Z para } \\
\text { asimetría }\end{array}$} & \multicolumn{2}{|c|}{$\begin{array}{c}\text { Valor-Z para } \\
\text { curtosis }\end{array}$} \\
\hline & & Estad. & P-valor & Estad. & P-valor & Estad. & P-valor & Estad. & P-valor \\
\hline \multirow{2}{*}{ MOE } & Velocidad & 13,0 & 0,88 & 0,98 & 0,42 & 0,54 & 0,59 & $-0,11$ & 0,91 \\
\hline & Velocidad*Densidad & 14,0 & 0,83 & 0,98 & 0,35 & 0,97 & 0,33 & $-0,03$ & 0,97 \\
\hline \multirow{2}{*}{ MOR } & Velocidad & 30,57 & 0,06 & 0,97 & 0,21 & 0,79 & 0,43 & $-0,33$ & 0,74 \\
\hline & Velocidad*Densidad & 14,45 & 0,81 & 0,96 & 0,02 & 1,22 & 0,22 & $-1,20$ & 0,23 \\
\hline
\end{tabular}


Tabla 219.Predicciones MOE-MOR - NDT: prueba de bondad de ajuste (Kolmogorov-Smirnov)

\begin{tabular}{ccc}
\hline \multirow{2}{*}{ Variable predicha } & Variable predictora & \multicolumn{2}{c}{ Bondad de Ajuste (Kolmogorov-Smirnov) } \\
\cline { 2 - 3 } & Velocidad & P-valor \\
\cline { 2 - 3 } MOE & Velocidad*Densidad & 0,79 \\
\cline { 2 - 3 } & Velocidad & 0,84 \\
\cline { 2 - 3 } MOR & Velocidad*Densidad & 0,24 \\
\hline
\end{tabular}

Dado que al menos uno de los parámetros considerados para evaluar la normalidad de los residuos ha presentado P-valores $\geq 0,05$, no se pudo rechazar la hipótesis de que los residuos provenían de una distribución normal, con 95\% de confianza.

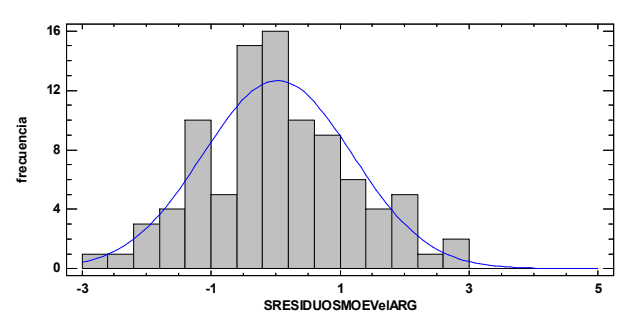

Figura 454. Histograma de Frecuencia: Residuos MOE - Vel (Ult). Chopo (Argentina)

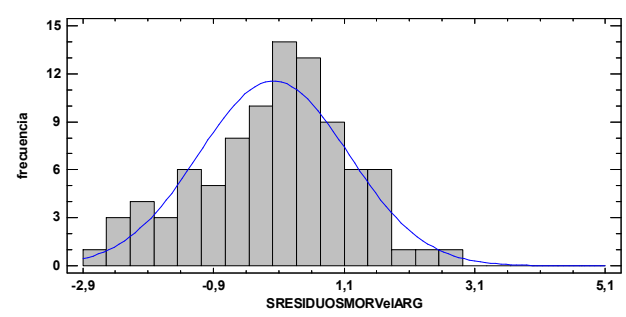

Figura 456. Histograma de Frecuencia: Residuos MOR - Vel (Ult). Chopo (Argentina)

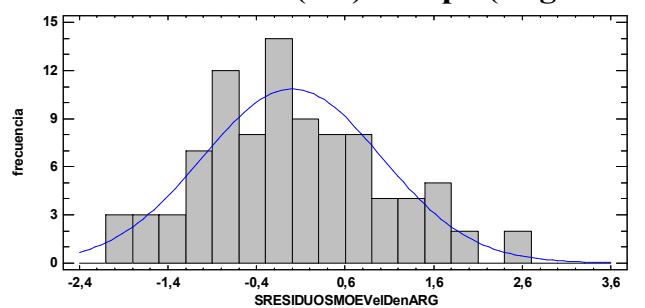

Figura 458. Histograma de Frecuencia: Residuos MOE - Vel (Ult)*Densidad. Chopo (Argentina)

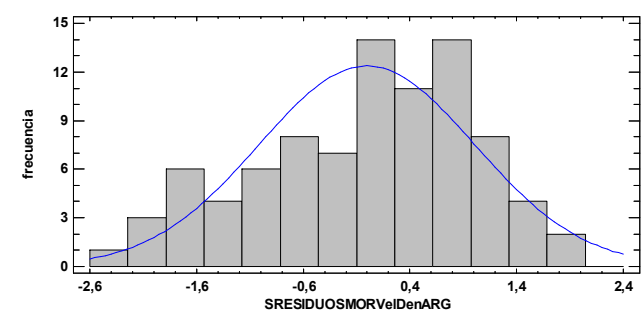

Figura 460. Histograma de Frecuencia: Residuos MOR - Vel (Ult)*Densidad. Chopo (Argentina)

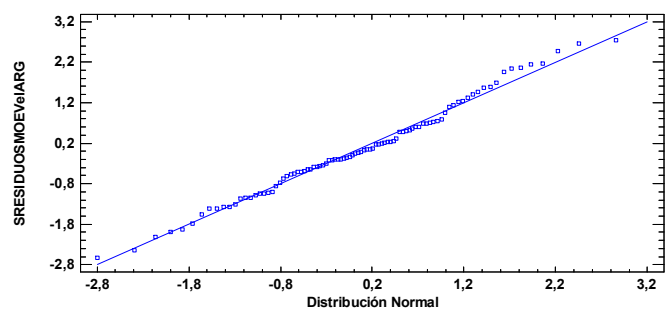

Figura 455. Gráfico probabilidad normal: Residuos MOE - Vel (Ult). Chopo (Argentina)

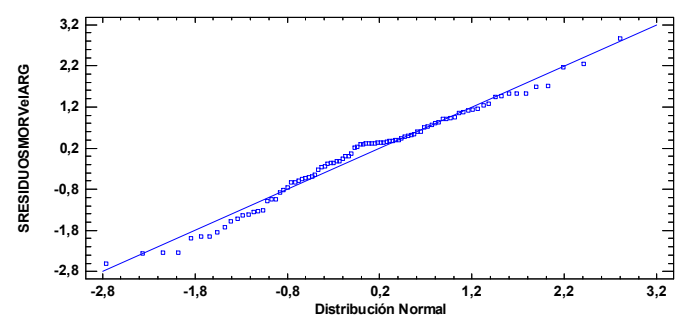

Figura 457. Gráfico probabilidad normal: Residuos MOR - Vel (Ult). Chopo (Argentina)

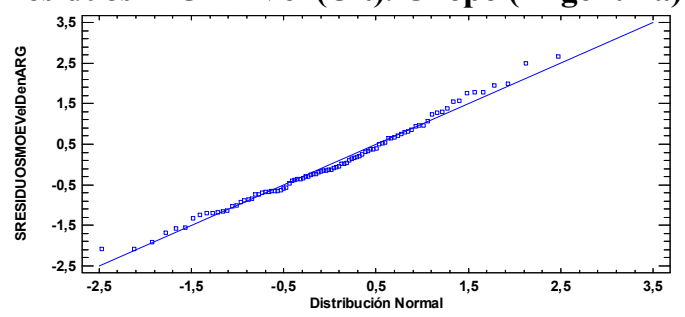

Figura 459. Gráfico probabilidad normal: Residuos MOE - Vel (Ult)*Densidad. Chopo (Argentina)

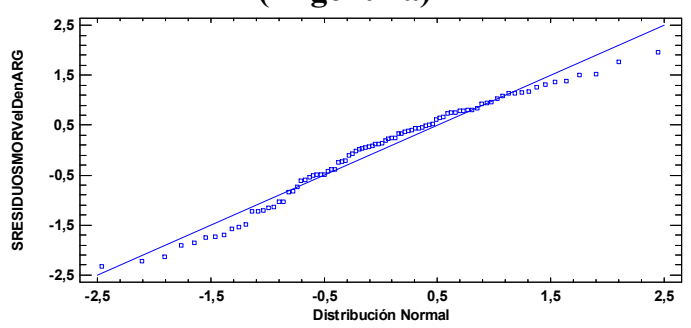

Figura 461. Gráfico probabilidad normal: Residuos MOR - Vel (Ult)*Densidad. Chopo (Argentina) 


\section{Material de ambas procedencia: ecuaciones de regresión}

Las ecuaciones de regresión de los modelos ajustados para el MOE y MOR por cada parámetro de ensayo NDT y cada procedencia del material, se indican en la Tabla 220.

Tabla 220. Ecuaciones de regresión: ensayos destructivos-NDT: material de ambas procedencias

\begin{tabular}{|c|c|c|}
\hline NDT $^{*}$ & Procedencia & Ecuación de regresión* \\
\hline \multirow{8}{*}{ Vibraciones inducidas } & \multirow{2}{*}{ España } & $\mathrm{MOE}=-14545+10,4341 * \mathrm{FrVI}$ \\
\hline & & MOR $=-67,9152+0,0526652 *$ FrVI \\
\hline & \multirow{2}{*}{ Argentina } & $\mathrm{MOE}=-5417,6+6,83832 * \mathrm{FrVI}$ \\
\hline & & $\mathrm{MOR}=-17,5544+0,0281084 * \mathrm{FrVI}$ \\
\hline & \multirow{2}{*}{ España } & MOE $=-17325,2+8,56354 *$ FrVI $+18,2046 *$ Densidad $12 \%$ \\
\hline & & MOR $=-80,491+0,0459245 *$ FrVI $+0,073761 *$ Densidad $12 \%$ \\
\hline & \multirow{2}{*}{ Argentina } & MOE $=-19741,4+9,13138 *$ FrVI $+24,7242 *$ Densidad $12 \%$ \\
\hline & & MOR $=-39,2476+0,0258838 *$ FrVI $+0,0610228 *$ Densidad $12 \%$ \\
\hline \multirow{8}{*}{ Ultrasonidos } & \multirow{2}{*}{ España } & MOE $=-9129,27+3,40399 *$ VelUlt \\
\hline & & MOR $=-39,9331+0,0171108 *$ VelUlt \\
\hline & \multirow{2}{*}{ Argentina } & MOE $=-9465,1+3,51877 *$ VelUlt \\
\hline & & MOR $=-31,5604+0,0137192 *$ VelUlt \\
\hline & \multirow{2}{*}{ España } & MOE $=-10283,2+1,20528 *$ VelUlt $+32,9149 *$ Densidad $12 \%$ \\
\hline & & MOR $=-54,2542+0,0120655 *$ VelUlt $+0,105025 *$ Densidad $12 \%$ \\
\hline & \multirow{2}{*}{ Argentina } & MOE $=-21888,8+4,26653 *$ VelUlt $+21,8514 *$ Densidad $12 \%$ \\
\hline & & MOR $=-52,2368+0,0143665 *$ VelUlt $+0,0432449 *$ Densidad $12 \%$ \\
\hline
\end{tabular}

*Fr: frecuencia de vibración; VI: vibraciones inducidas; Vel: velocidad; Ult: ultrasonidos

\subsection{Piezas macizas estructurales}

\subsubsection{Valores característicos}

El análisis descriptivo y las pruebas de normalidad se resumen en la Tabla 221 (Figura 462 a Figura 469).

Tabla 221. Variables caracterizadoras: resumen estadístico y pruebas de normalidad

\begin{tabular}{|c|c|c|c|c|c|c|c|c|c|c|c|c|}
\hline \multirow{2}{*}{ Variable* } & \multirow{2}{*}{$\mathrm{DE}^{*}$} & \multirow{2}{*}{$\mathrm{SE}^{*}$} & \multirow{2}{*}{$\mathrm{CE}^{*}$} & \multicolumn{2}{|c|}{ Chi-Cuadrado } & \multicolumn{2}{|c|}{$\begin{array}{c}\text { W de } \\
\text { Shapiro-Wilk }\end{array}$} & \multicolumn{2}{|c|}{$\begin{array}{l}\text { Valor-Z para } \\
\text { asimetría }\end{array}$} & \multicolumn{2}{|c|}{$\begin{array}{l}\text { Valor-Z para } \\
\text { curtosis }\end{array}$} & \multirow[t]{2}{*}{$\begin{array}{c}\text { Bondad } \\
\text { de } \\
\text { Ajuste* }\end{array}$} \\
\hline & & & & Estad. & $\begin{array}{c}\text { P- } \\
\text { valor }\end{array}$ & Estad. & $\begin{array}{l}\mathrm{P}- \\
\text { valor }\end{array}$ & Estad. & $\begin{array}{l}\text { P- } \\
\text { valor }\end{array}$ & Estad. & $\begin{array}{c}\mathrm{P}- \\
\text { valor }\end{array}$ & \\
\hline MOE & 1617,79 & 13,04 & 14,85 & 159,11 & 0,00 & 0,94 & 0,0 & 7,76 & 0,00 & 7,23 & 0,00 & 0,00 \\
\hline MOR & 11,53 & 0,99 & $-1,72$ & 44,5 & 0,87 & 0,98 & 0,00 & 0,70 & 0,48 & $-1,96$ & 0,05 & 0,91 \\
\hline Densidad & 42,30 & 10,25 & 2,10 & 260,66 & 0,0 & 0,94 & 0,0 & 6,45 & 0,00 & 1,90 & 0,06 & 0,0 \\
\hline
\end{tabular}

*MOE: módulo de elasticidad; MOR: módulo de rotura; DE: desvío estándar; *SE: sesgo estandarizado; *CE: curtosis estandarizada; *Bondad de ajuste: Kolmogorov-Smirnov. 


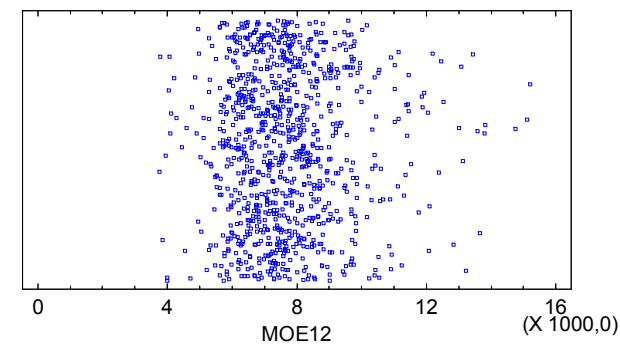

Figura 462. Gráfico de dispersión: MOE

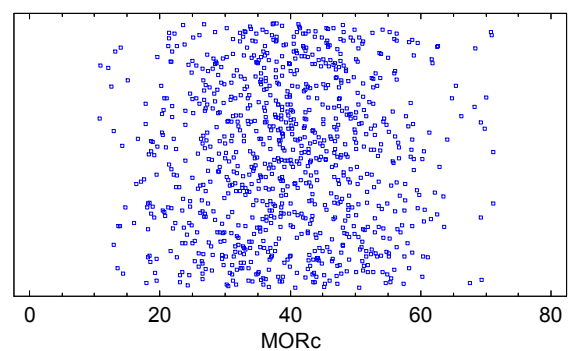

Figura 464. Gráfico de dispersión: MOR

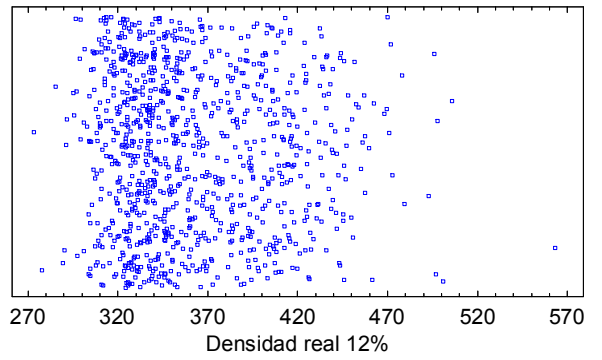

Figura 466. Gráfico de dispersión: Densidad

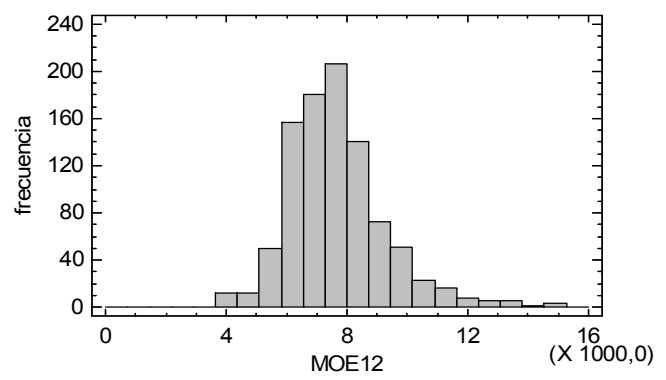

Figura 468. Histograma de frecuencias: MOE

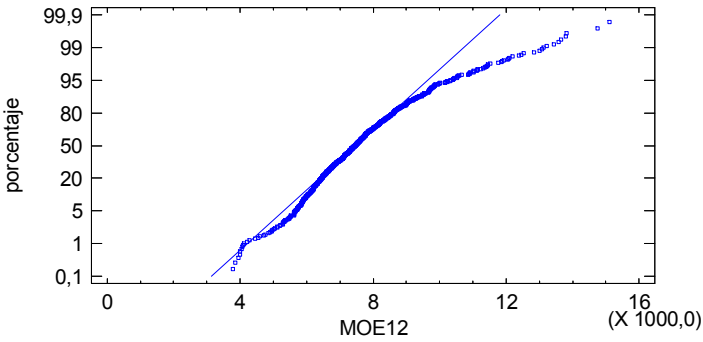

Figura 463. Gráfico probabilidad normal MOE

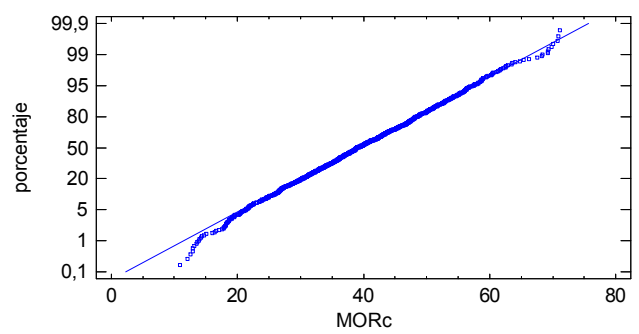

Figura 465. Gráfico probabilidad normal MOR

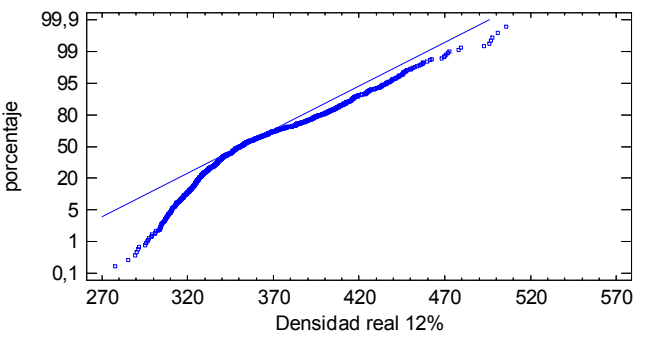

Figura 467. Gráfico probabilidad normal Densidad

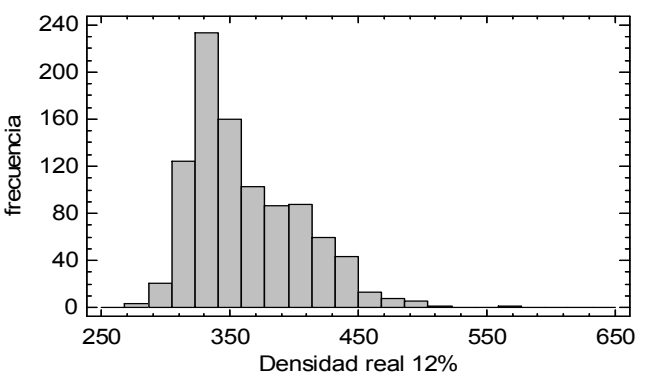

Figura 469. Histograma de frecuencias: Densidad

Dado el incumplimiento del supuesto de normalidad, la variable MOE y densidad fueron transformadas mediante la función LOG y 1/X, respectivamente. El resumen descriptivo, pruebas de normalidad y los gráficos de dispersión y de probabilidad normal con las variables transformadas, se muestran en la Tabla 222 (Figura 470 a Figura 473). 
Tabla 222. Variables caracterizadoras transformadas: resumen estadístico y pruebas de normalidad

\begin{tabular}{|c|c|c|c|c|c|c|c|c|c|c|c|}
\hline \multirow{2}{*}{$\begin{array}{c}\text { Variable } \\
\text { transformada }\end{array}$} & \multirow{2}{*}{ SE } & \multirow{2}{*}{$\mathrm{CE}$} & \multicolumn{2}{|c|}{$\begin{array}{c}\text { Chi- } \\
\text { Cuadrado }\end{array}$} & \multicolumn{2}{|c|}{$\begin{array}{l}\text { W de Shapiro- } \\
\text { Wilk }\end{array}$} & \multicolumn{2}{|c|}{$\begin{array}{c}\text { Valor-Z para } \\
\text { asimetría }\end{array}$} & \multicolumn{2}{|l|}{$\begin{array}{l}\text { Valor-Z para } \\
\text { curtosis }\end{array}$} & $\begin{array}{c}\text { Bondad de } \\
\text { Ajuste* }\end{array}$ \\
\hline & & & Estad. & $\begin{array}{c}\text { P- } \\
\text { valor }\end{array}$ & Estad. & $\begin{array}{c}\text { P- } \\
\text { valor }\end{array}$ & P-valor & $\begin{array}{c}\text { P- } \\
\text { valor }\end{array}$ & Estad. & $\begin{array}{l}\text { P- } \\
\text { valor }\end{array}$ & $\begin{array}{l}\text { P- } \\
\text { valor }\end{array}$ \\
\hline LOG(MOE) & 1,58 & 6,46 & 96,79 & 0,00 & 0,98 & 0,00 & 1,12 & 0,26 & 4,43 & 0,00 & 0,13 \\
\hline 1/(Densidad) & $-4,19$ & $-3,62$ & 161,56 & 0,00 & 0,97 & 0,0 & 2,91 & 0,00 & $-5,35$ & 0,00 & 0,00 \\
\hline
\end{tabular}

*Prueba de Bondad de Ajuste: Kolmogorov-Smirnov.

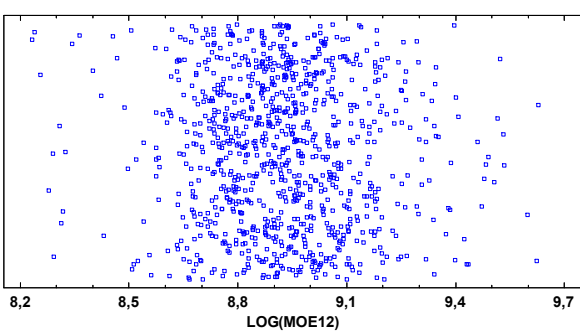

Figura 470. Gráfico de dispersión: LOG(MOE)

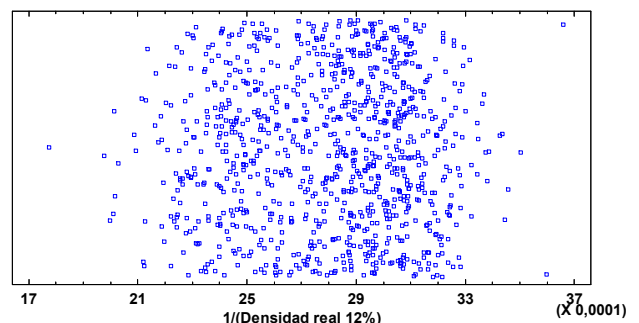

Figura 472. Gráfico de dispersión: 1/(Densidad)

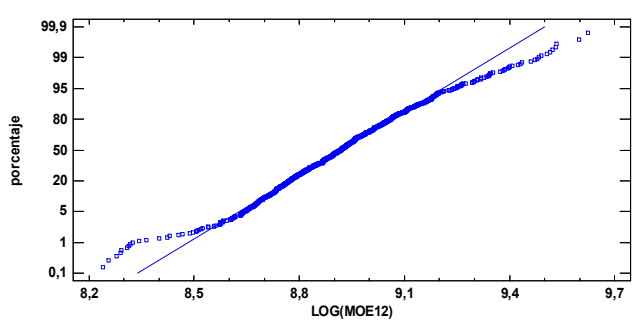

Figura 471. Gráfico probabilidad normal: LOG(MOE)

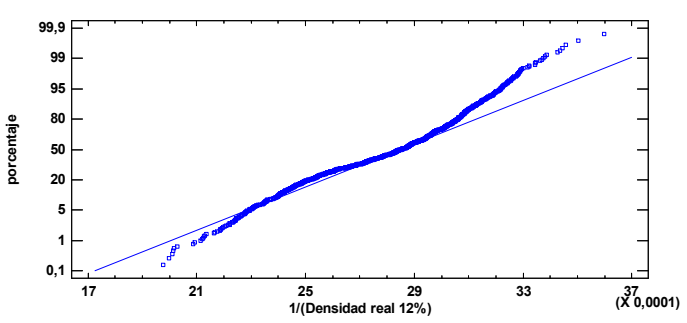

Figura 473. Gráfico probabilidad normal: 1/(Densidad)

\subsubsection{Comportamiento clasificatorio resistente}

A continuación se presenta el resumen descriptivo de las variables características según clases visuales asignadas.

Tabla 223. Análisis descriptivo: MOE, MOR y densidad según clases UNE 56544:1997.

\begin{tabular}{cccc}
\hline Variable & \multicolumn{3}{c}{ Clase Superior (CS) } \\
\cline { 2 - 4 } & Mínimo & Máximo & IQR $^{*}$ \\
\hline MOE $(\mathrm{MPa})$ & 5339,24 & 11013,7 & 2003,04 \\
MOR $(\mathrm{MPa})$ & 17,81 & 58,46 & 16,0 \\
Densidad $\left(\mathrm{Kg} / \mathrm{m}^{3}\right)$ & 304,62 & 395,03 & 35,85 \\
\hline & \multicolumn{4}{c}{ Clase Inferior $(\mathbf{C I})$} & 13075,80 & 1898,38 \\
MOE $(\mathrm{MPa})$ & 4548,09 & 60,67 & 14,15 \\
MOR $(\mathrm{MPa})$ & 18,19 & 445,35 & 48,85 \\
\hline Densidad $\left(\mathrm{Kg} / \mathrm{m}^{3}\right)$ & 273,41 & Rechazo (R) \\
\hline MOE $(\mathrm{MPa})$ & 3766,97 & 13438,1 & 1863,97 \\
MOR $(\mathrm{MPa})$ & 15,05 & 64,83 & 15,75 \\
Densidad $\left(\mathrm{Kg} / \mathrm{m}^{3}\right)$ & 277,93 & 448,09 & 61,28 \\
\hline
\end{tabular}

*IQR: recorrido intercuartílico. 
Tabla 224. Análisis descriptivo: MOE, MOR y densidad según clases UNE 56544:2011.

\begin{tabular}{|c|c|c|c|c|c|c|}
\hline \multirow{3}{*}{ Variable } & \multicolumn{3}{|c|}{ Clase por calidad } & \multicolumn{3}{|c|}{ Clase resistente } \\
\hline & \multicolumn{6}{|c|}{ Clase Superior (CS) } \\
\hline & Mínimo & Máximo & $\mathrm{IQR}^{*}$ & Mínimo & Máximo & $\mathrm{IQR}^{*}$ \\
\hline MOE (MPa) & 5294,14 & 11013,7 & 1990,66 & 9009,22 & 15198,9 & 1606,2 \\
\hline MOR (MPa) & 24,90 & 60,67 & 15,91 & 18,43 & 71,16 & 17,41 \\
\hline \multirow[t]{2}{*}{ Densidad $\left(\mathrm{Kg} / \mathrm{m}^{3}\right)$} & 301,53 & 396,02 & 35,06 & 321,95 & 505,96 & 65,17 \\
\hline & \multicolumn{6}{|c|}{ Clase Inferior (CI) } \\
\hline MOE (MPa) & 3766,97 & 13075,8 & 1957,93 & 7009,42 & 11129,9 & 916,11 \\
\hline MOR (MPa) & 20,44 & 67,58 & 13,87 & 17,15 & 71,12 & 13,65 \\
\hline \multirow[t]{2}{*}{ Densidad $\left(\mathrm{Kg} / \mathrm{m}^{3}\right)$} & 273,41 & 439,37 & 45,88 & 291,09 & 563,37 & 58,25 \\
\hline & \multicolumn{6}{|c|}{ Rechazo (R) } \\
\hline MOE (MPa) & 3789,39 & 13438,10 & 1817,77 & 3766,97 & 11013,7 & 772,9 \\
\hline MOR (MPa) & 20,21 & 69,77 & 15,15 & 10,73 & 59,44 & 13,58 \\
\hline Densidad $\left(\mathrm{Kg} / \mathrm{m}^{3}\right)$ & 277,93 & 443,78 & 62,27 & 273,41 & 479,28 & 47,43 \\
\hline
\end{tabular}

Tabla 225. Análisis descriptivo: MOE, MOR y densidad según clases NF B52-001: 2007.

\begin{tabular}{|c|c|c|c|c|c|c|}
\hline \multirow{3}{*}{ Variable } & \multicolumn{3}{|c|}{ Clase por calidad } & \multicolumn{3}{|c|}{ Clase resistente } \\
\hline & \multicolumn{6}{|c|}{ Clase Superior (CS) } \\
\hline & Mínimo & Máximo & IQR* & Mínimo & Máximo & IQR* \\
\hline MOR (MPa) & 22,49 & 64,83 & 16,0 & 29,91 & 71,16 & 17,23 \\
\hline Densidad $\left(\mathrm{Kg} / \mathrm{m}^{3}\right)$ & 297,55 & 439,37 & 34,03 & 357,94 & 505,96 & 50,82 \\
\hline MOR (MPa) & 25,01 & 60,45 & 11,93 & 18,43 & 70,88 & 17,23 \\
\hline \multirow[t]{2}{*}{ Densidad $\left(\mathrm{Kg} / \mathrm{m}^{3}\right)$} & 273,41 & 445,35 & 48,27 & 321,95 & 497,57 & 56,68 \\
\hline & \multicolumn{6}{|c|}{$\operatorname{Rechazo}(\mathbf{R})$} \\
\hline $\mathrm{MOE}(\mathrm{MPa})$ & 3766,97 & 12830,5 & 1869,56 & 3766,97 & 11129,9 & 1476,68 \\
\hline MOR (MPa) & 20,21 & 69,77 & 15,59 & 10,73 & 71,12 & 15,97 \\
\hline
\end{tabular}

Tabla 226. Análisis descriptivo: MOE, MOR y densidad según clases DIN 4074-5:2003.

\begin{tabular}{|c|c|c|c|c|c|c|}
\hline \multirow{3}{*}{ Variable } & \multicolumn{3}{|c|}{ Clase por calidad } & \multicolumn{3}{|c|}{ Clase resistente } \\
\hline & \multicolumn{6}{|c|}{ Clase Superior (CS) } \\
\hline & Mínimo & Máximo & $\mathrm{IQR}^{*}$ & Mínimo & Máximo & IQR* \\
\hline MOR (MPa) & 24,90 & 58,46 & 12,76 & 29,91 & 71,16 & 17,23 \\
\hline \multirow[t]{2}{*}{ Densidad $\left(\mathrm{Kg} / \mathrm{m}^{3}\right)$} & 304,62 & 382,73 & 36,16 & 357,94 & 505,96 & 50,82 \\
\hline & \multicolumn{6}{|c|}{ Clase Inferior (CI) } \\
\hline MOR (MPa) & 24,99 & 56,30 & 13,01 & 17,15 & 71,12 & 14,78 \\
\hline \multirow[t]{2}{*}{ Densidad $\left(\mathrm{Kg} / \mathrm{m}^{3}\right)$} & 296,79 & 450,49 & 41,32 & 310,02 & 563,37 & 64,10 \\
\hline & \multicolumn{6}{|c|}{ Rechazo (R) } \\
\hline MOE (MPa) & 3766,97 & 12830,5 & 1883,06 & 3766,97 & 11013,7 & 1222,51 \\
\hline MOR (MPa) & 18,05 & 64,83 & 15,42 & 10,73 & 67,58 & 15,72 \\
\hline
\end{tabular}


Tabla 227. Análisis descriptivo: MOE, MOR y densidad según clases NCh1970/1:1988.

\begin{tabular}{|c|c|c|c|c|c|c|}
\hline \multirow{3}{*}{ Variable } & \multicolumn{3}{|c|}{ Clase por calidad } & \multicolumn{3}{|c|}{ Clase resistente } \\
\hline & \multicolumn{6}{|c|}{ Clase Superior (CS) } \\
\hline & Mínimo & Máximo & IQR* & Mínimo & Máximo & $\mathrm{IQR}^{*}$ \\
\hline MOR (MPa) & 24,90 & 60,67 & 13,11 & 29,91 & 71,16 & 17,23 \\
\hline Densidad $\left(\mathrm{Kg} / \mathrm{m}^{3}\right)$ & 296,79 & 401,85 & 38,81 & 357,94 & 505,96 & 50,82 \\
\hline MOR (MPa) & 21,78 & 67,58 & 16,37 & 18,43 & 70,88 & 17,23 \\
\hline \multirow[t]{2}{*}{ Densidad $\left(\mathrm{Kg} / \mathrm{m}^{3}\right)$} & 297,55 & 439,37 & 36,66 & 321,95 & 497,57 & 56,68 \\
\hline & \multicolumn{6}{|c|}{$\operatorname{Rechazo}(\mathbf{R})$} \\
\hline $\operatorname{MOE}(\mathrm{MPa})$ & 3766,97 & 11924,2 & 1798,14 & 3766,97 & 11129,9 & 1476,68 \\
\hline MOR (MPa) & 20,21 & 69,77 & 15,11 & 10,73 & 71,12 & 15,97 \\
\hline
\end{tabular}

\subsubsection{Comportamiento clasificatorio mediante metodología de ensayo no destructiva}

\subsubsection{Determinación de parámetros dinámicos mediante NDT}

\section{Análisis descriptivo - NDT.}

El análisis descriptivo y las pruebas de normalidad se resumen en la Tabla 228 (Figura

474 a Figura 481).

Tabla 228. Parámetros dinámicos: resumen estadístico y pruebas de normalidad.

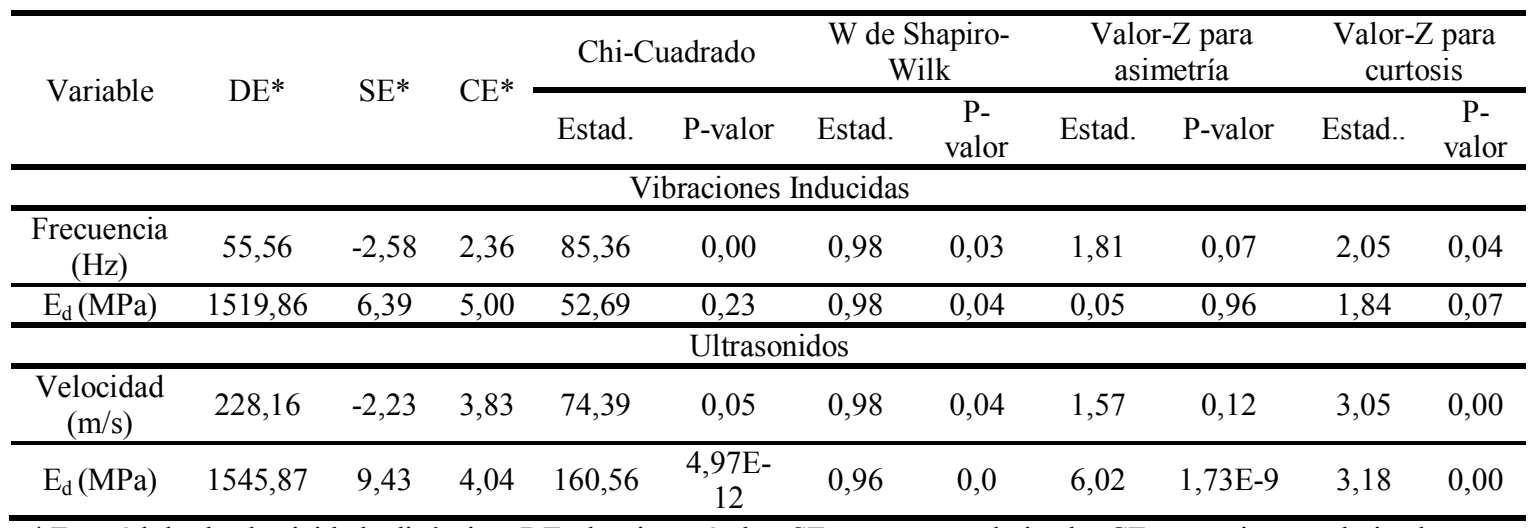

* $E_{\mathrm{d}}$ : módulo de elasticidade dinâmico; DE: desvio estándar; SE: sesgo estandarizado; CE: curtosis estandarizada.

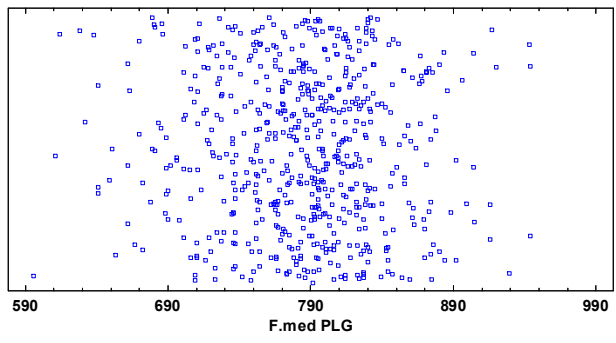

Figura 474. Gráfico dispersión: Fr (VI)

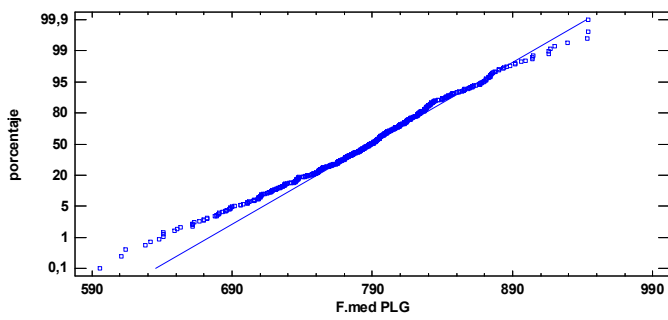

Figura 475. Gráfico probabilidad normal: $\mathrm{Fr}$ (VI) 


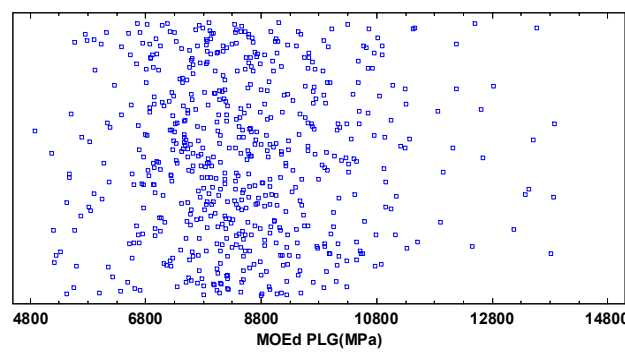

Figura 476. Gráfico dispersión: $E_{\mathrm{d}}(\mathrm{VI})$

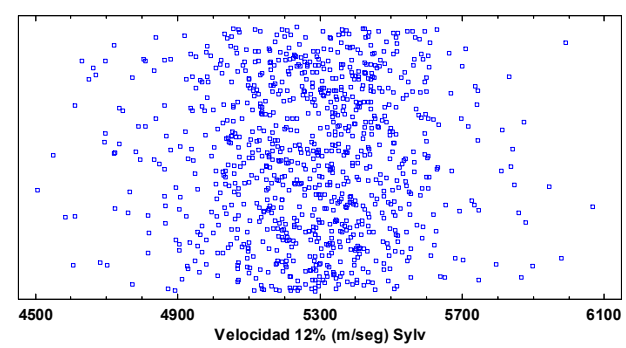

Figura 478. Gráfico dispersión: Vel (Ult)

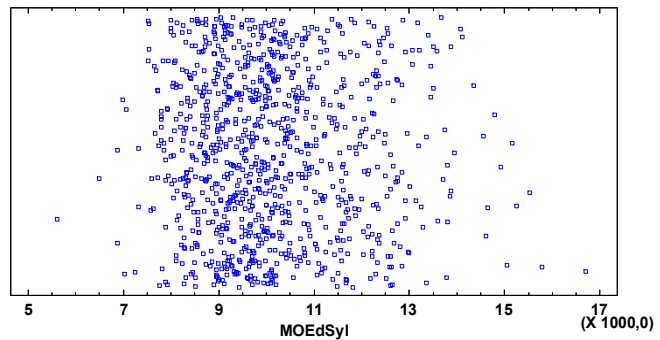

Figura 480. Gráfico dispersión: $E_{\mathrm{d}}$

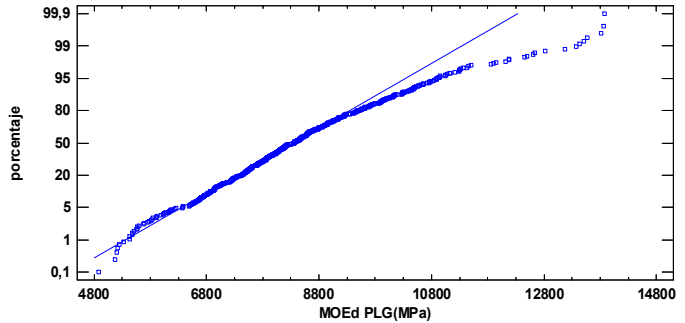

Figura 477. Gráfico probabilidad normal:

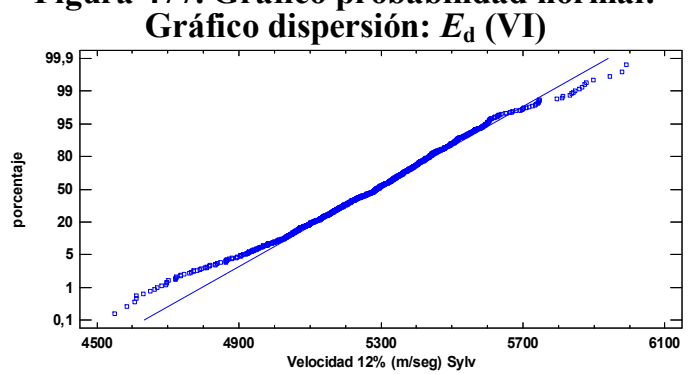

Figura 479. Gráfico probabilidad normal: Vel (Ult)

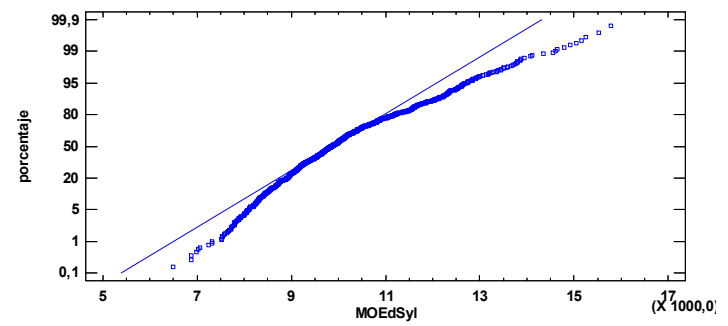

Figura 481. Gráfico probabilidad normal: $E_{\mathrm{d}}$

Dado que los $E_{\mathrm{d}}$ no presentaron una distribución normal, se procedió a realizar la transformación de la variable mediante la función LOG. De acuerdo con esto, a continuación se presenta el resumen estadístico descriptivo (Tabla 229) y las correspondientes gráficas de las variables transformadas y sin transformar en el caso de los histogramas de $E_{\mathrm{d}}$ (Figura 482 a Figura 489).

Tabla 229. Variable $E_{d}$ transformada: resumen estadístico y pruebas de normalidad

\begin{tabular}{|c|c|c|c|c|c|c|c|c|c|c|c|}
\hline \multirow{2}{*}{ Variable } & \multirow{2}{*}{$\begin{array}{c}\mathrm{DE}^{*} \\
(\mathrm{CV} \%)\end{array}$} & \multirow{2}{*}{$\mathrm{SE}^{*}$} & \multirow{2}{*}{$\mathrm{CE}^{*}$} & \multicolumn{2}{|c|}{ Chi-Cuadrado } & \multicolumn{2}{|c|}{$\begin{array}{c}\text { W de } \\
\text { Shapiro-Wilk } \\
\end{array}$} & \multicolumn{2}{|c|}{$\begin{array}{c}\text { Valor-Z para } \\
\text { asimetría } \\
\end{array}$} & \multicolumn{2}{|c|}{$\begin{array}{c}\text { Valor-Z para } \\
\text { curtosis }\end{array}$} \\
\hline & & & & Estad. & P-valor & Estad & $\begin{array}{c}\text { P- } \\
\text { valor }\end{array}$ & Estad. & $\begin{array}{c}\text { P- } \\
\text { valor }\end{array}$ & Estad & $\begin{array}{c}\text { P- } \\
\text { valor }\end{array}$ \\
\hline \multicolumn{12}{|c|}{ Vibraciones Inducidas } \\
\hline $\begin{array}{c}\operatorname{LOG}\left(E_{\mathrm{d}}\right) \\
(\mathrm{MPa})\end{array}$ & $\begin{array}{c}0,18 \\
(1,96)\end{array}$ & $-0,07$ & 2,05 & 52,69 & 0,23 & 0,98 & 0,04 & 0,05 & 0,96 & 1,84 & 0,07 \\
\hline \multicolumn{12}{|c|}{ Ultrasonidos } \\
\hline $\begin{array}{c}\operatorname{LOG}\left(E_{\mathrm{d}}\right) \\
(\mathrm{MPa})\end{array}$ & $\begin{array}{c}0,15 \\
(1,62)\end{array}$ & 3,84 & 0,67 & 88,07 & 0,00 & 0,98 & 0,05 & 2,67 & 0,01 & 0,73 & 0,47 \\
\hline
\end{tabular}

*LOG $\left(E_{\mathrm{d}}\right)$ : logaritmo del módulo de elasticidade dinámico; DE: desvio estándar; CV: coeficiente de variación, en \%; SE: sesgo estandarizado; CE: curtosis estandarizada. 


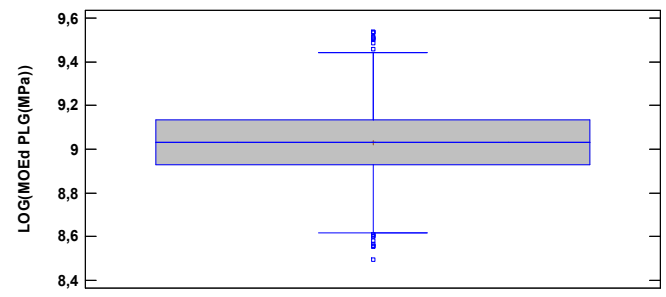

Figura 482. Gráfico de Caja y Bigotes: $\operatorname{LOG}\left(E_{\mathrm{d}}\right)$ - VI

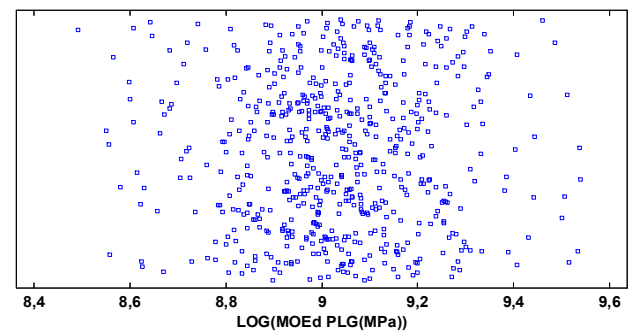

Figura 484. Gráfico dispersión: LOG $\left(E_{\mathrm{d}}\right)$ - VI

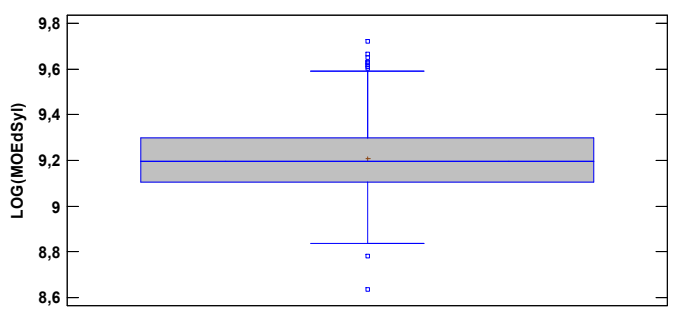

Figura 486. Gráfico de Caja y Bigotes: $\operatorname{LOG}\left(E_{\mathrm{d}}\right)$ - Ult.

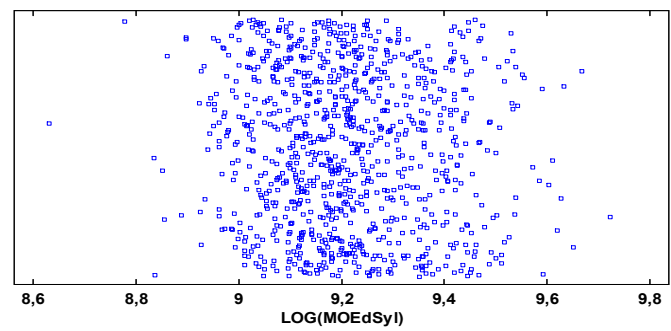

Figura 488. Gráfico dispersión: $\operatorname{LOG}\left(\mathbf{E}_{\mathbf{d}}\right)-$ Ult.

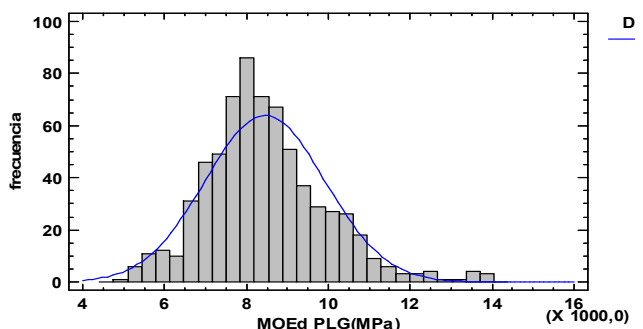

Figura 483. Histograma de frecuencia: $E_{\mathrm{d}}-$ VI

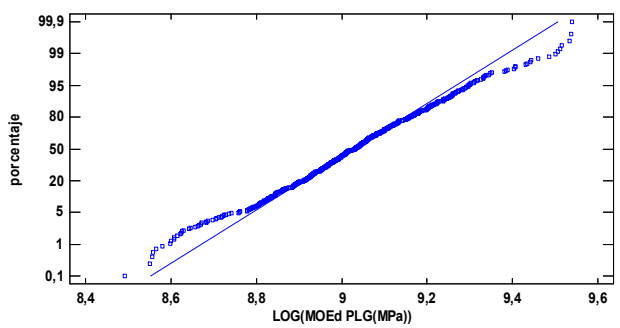

Figura 485. Gráfico probabilidad normal: $\operatorname{LOG}\left(E_{\mathrm{d}}\right)$ - VI

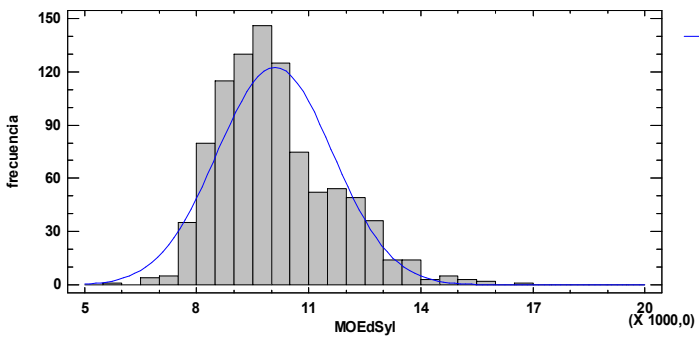

Figura 487. Histograma de frecuencia: $E_{\mathrm{d}}-$ Ult.

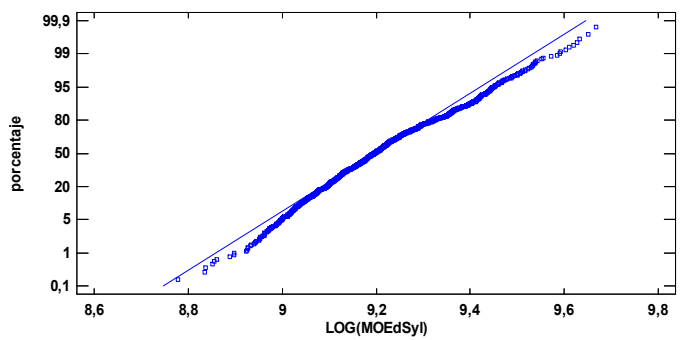

Figura 489. Gráfico probabilidad normal: $\operatorname{LOG}\left(E_{\mathrm{d}}\right)$-Ult.

\section{Análisis comparativo - NDT.}

En la Tabla 230 se presenta el test de verificación de la varianza para el $\operatorname{LOG}\left(E_{\mathrm{d}}\right)$-NDT.

Tabla 230. LOG $\left(E_{\mathrm{d}}\right)-\mathrm{NDT}$ : Test de Levene

\begin{tabular}{ccc}
\hline Test de Levene & Prueba & Valor-P \\
\cline { 2 - 3 } & 13,08 & 0,00 \\
\hline
\end{tabular}

De acuerdo con el P-valor $<0,05$, se empleó el test de Kruskal-Wallis de comparación de medianas. 


\section{Análisis de regresión: parámetros destructivos - NDT}

La constatación del supuesto de normalidad de los residuos estudentizados para el ensayo de vibraciones inducidas se muestra en la Tabla 231 y Tabla 232 (Figura 490 a Figura 499).

Tabla 231. Predicciones MOE-MOR-Densidad - NDT (VI): pruebas de normalidad de residuos

\begin{tabular}{|c|c|c|c|c|c|c|c|c|c|}
\hline \multirow{2}{*}{$\begin{array}{l}\text { Variable } \\
\text { predicha }\end{array}$} & \multirow{2}{*}{$\begin{array}{l}\text { Variable } \\
\text { predictora }\end{array}$} & \multicolumn{2}{|c|}{ Chi-Cuadrado } & \multicolumn{2}{|c|}{ W de Shapiro-Wilk } & \multicolumn{2}{|c|}{$\begin{array}{c}\text { Valor-Z para } \\
\text { asimetría }\end{array}$} & \multicolumn{2}{|c|}{$\begin{array}{c}\text { Valor-Z para } \\
\text { curtosis }\end{array}$} \\
\hline & & Estad. & P-valor & Estad. & P-valor & Estad. & P-valor & Estad. & P-valor \\
\hline \multirow{2}{*}{ LOG(MOE) } & Frecuencia & 152,54 & 0,00 & 0,94 & 0,0 & 5,56 & 0,00 & 6,82 & 0,00 \\
\hline & $\operatorname{LOG}\left(E_{\mathrm{d}}\right)$ & 104,19 & 0,00 & 0,96 & 0,0 & 1,52 & 0,13 & 7,09 & 0,00 \\
\hline \multirow{2}{*}{ MOR } & Frecuencia & 40,34 & 0,71 & 0,98 & 0,41 & 0,55 & 0,58 & 0,41 & 0,68 \\
\hline & $\operatorname{LOG}\left(E_{\mathrm{d}}\right)$ & 67,61 & 0,04 & 0,98 & 0,02 & 2,16 & 0,03 & 2,41 & 0,02 \\
\hline $1 /($ Densidad $)$ & Frecuencia & 132,81 & 0,00 & 0,96 & 0,00 & 2,65 & 0,01 & $-3,63$ & 0,00 \\
\hline
\end{tabular}

Tabla 232. Predicciones MOE-MOR-Densidad - NDT (VI): prueba de bondad de ajuste (Kolmogorov-Smirnov)

\begin{tabular}{ccc}
\hline \multirow{2}{*}{ Variable predicha } & Variable predictora & Bondad de Ajuste (Kolmogorov-Smirnov) \\
\cline { 3 - 3 } & Frecuencia & P-valor \\
\cline { 2 - 3 } MOE & LOG $\left(E_{\mathrm{d}}\right)$ & 0,00 \\
\hline \multirow{2}{*}{ MOR } & Frecuencia & 0,00 \\
\cline { 2 - 3 } & LOG $\left(E_{\mathrm{d}}\right)$ & 1,00 \\
\hline $1 /($ Densidad $)$ & Frecuencia & 0,37 \\
\hline
\end{tabular}

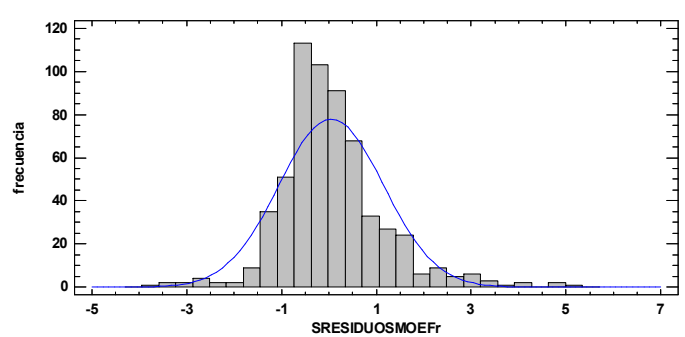

Figura 490. Histograma de Frecuencias LOG(MOE)-Frecuencia VI.

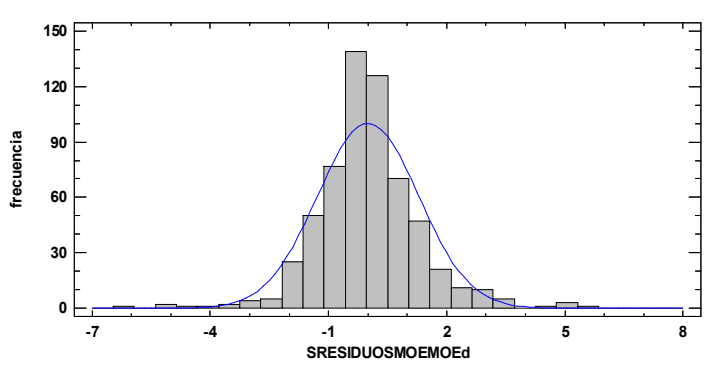

Figura 492. Histograma de Frecuencias LOG(MOE)- LOG(Ed) VI.

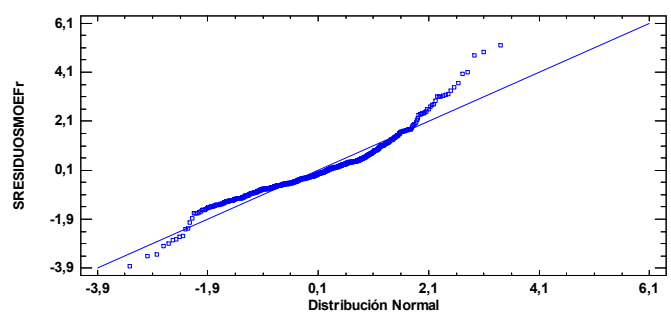

Figura 491. Gráfico probabilidad normal LOG(MOE)-Frecuencia VI.

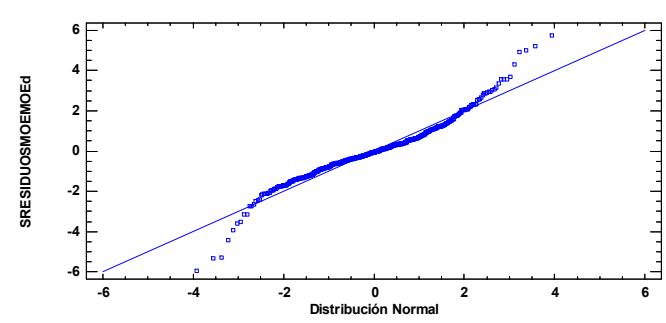

Figura 493. Gráfico probabilidad normal LOG(MOE)- LOG(Ed) VI. 


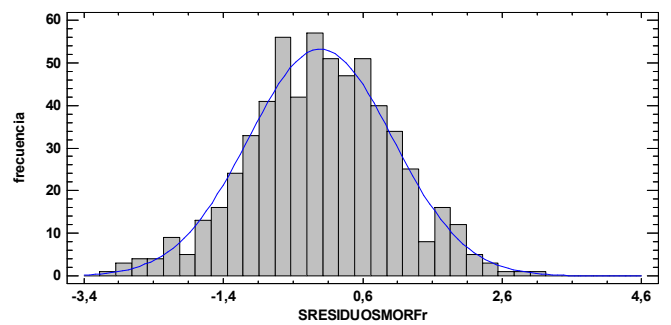

Figura 494. Histograma de Frecuencias MORFrecuencia VI.

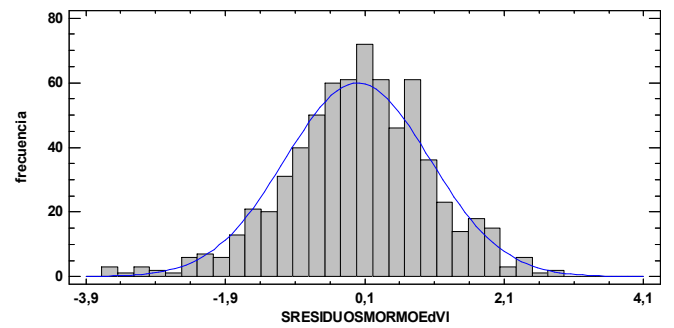

Figura 496. Histograma de Frecuencias MORLOG(Ed) VI.

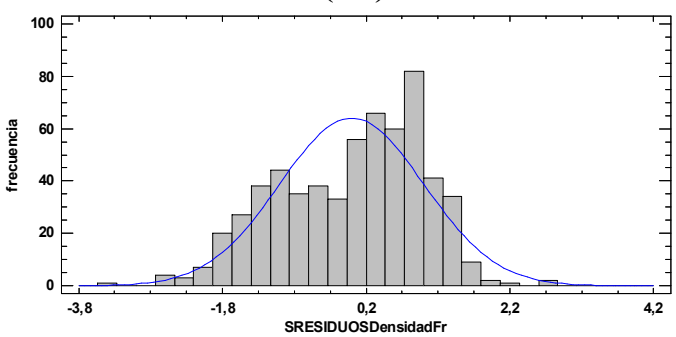

Figura 498. Histograma de Frecuencias 1/(Densidad)-Frecuencia VI.

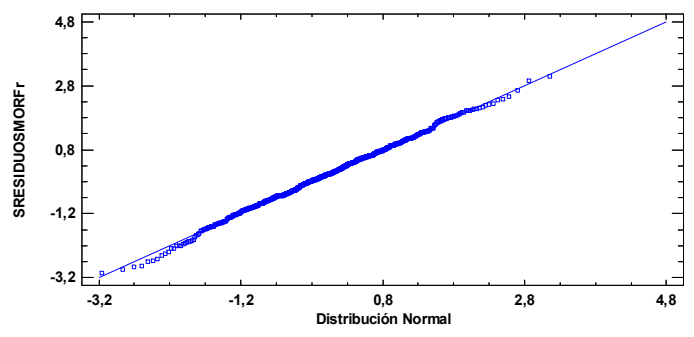

Figura 495. Gráfico probabilidad normal MOR-Frecuencia VI.

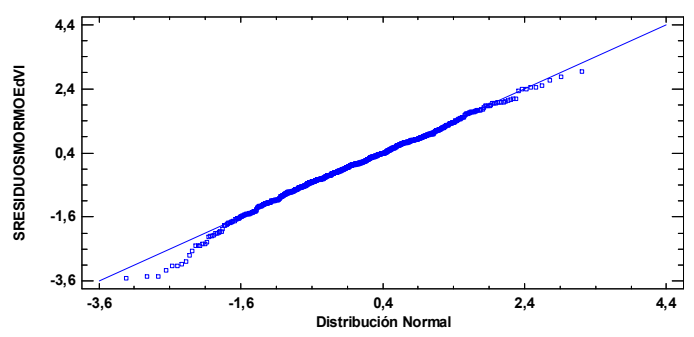

Figura 497. Gráfico probabilidad normal MOR-LOG(Ed) VI.

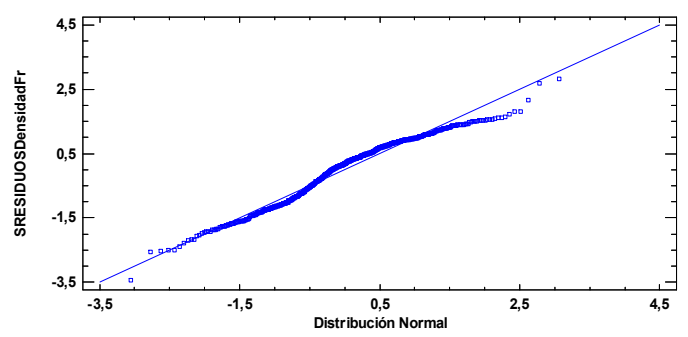

Figura 499. Gráfico probabilidad normal 1/(Densidad)-Frecuencia VI.

La constatación del supuesto de normalidad de los residuos estudentizados para el ensayo de ultrasonidos se muestra en la Tabla 233 y Tabla 234 (Figura 500 a Figura 509).

Tabla 233. Predicciones MOE-MOR-Densidad - NDT (Ult.): pruebas de normalidad de residuos

\begin{tabular}{ccccccccccc}
\hline \multirow{2}{*}{$\begin{array}{c}\text { Variable } \\
\text { predicha }\end{array}$} & $\begin{array}{c}\text { Variable } \\
\text { predictora }\end{array}$ & \multicolumn{2}{c}{ Chi-Cuadrado } & \multicolumn{2}{c}{$\begin{array}{c}\text { W de Shapiro- } \\
\text { Wilk }\end{array}$} & \multicolumn{2}{c}{$\begin{array}{c}\text { Valor-Z para } \\
\text { asimetría }\end{array}$} & \multicolumn{2}{c}{$\begin{array}{c}\text { Valor-Z para } \\
\text { curtosis }\end{array}$} \\
\cline { 3 - 11 } & & Estad. & P-valor & Estad. & $\begin{array}{c}\text { P- } \\
\text { valor }\end{array}$ & Estad. & P-valor & Estad. & P-valor \\
\hline \multirow{2}{*}{ LOG(MOE) } & Velocidad & 90,78 & 0,00 & 0,98 & 0,00 & 2,21 & 0,03 & 4,49 & 0,00 \\
\cline { 2 - 11 } & LOG $\left(\mathrm{E}_{\mathrm{d}}\right)$ & 63,94 & 0,03 & 0,97 & 0,00 & 1,46 & 0,14 & 3,27 & 0,00 \\
\hline \multirow{2}{*}{ MOR } & Velocidad & 43,0 & 0,90 & 0,98 & 0,04 & 0,31 & 0,76 & $-1,36$ & 0,17 \\
\cline { 2 - 11 } & LOG $\left(\mathrm{E}_{\mathrm{d}}\right)$ & 49,63 & 0,71 & 0,98 & 0,23 & 1,05 & 0,29 & $-0,26$ & 0,79 \\
\hline $1 /($ Densidad $)$ & Velocidad & 151,24 & 0,00 & 0,97 & 0,0 & 2,96 & 0,00 & $-4,92$ & $8,68 \mathrm{E}-7$ \\
\hline
\end{tabular}


Tabla 234. Predicciones MOE-MOR-Densidad - NDT (Ult.): prueba de bondad de ajuste (Kolmogorov-Smirnov)

\begin{tabular}{ccc}
\hline \multirow{2}{*}{ Variable predicha } & & $\begin{array}{c}\text { Bondad de Ajuste (Kolmogorov- } \\
\text { Smirnov) }\end{array}$ \\
\cline { 2 - 3 } & Variable predictora & P-valor \\
\cline { 2 - 3 } MOE & Velocidad & 0,14 \\
\hline \multirow{2}{*}{ MOR } & LOG $\left(E_{\mathrm{d}}\right)$ & 0,03 \\
\hline $1 /($ Densidad $)$ & Velocidad & 0,98 \\
\hline
\end{tabular}

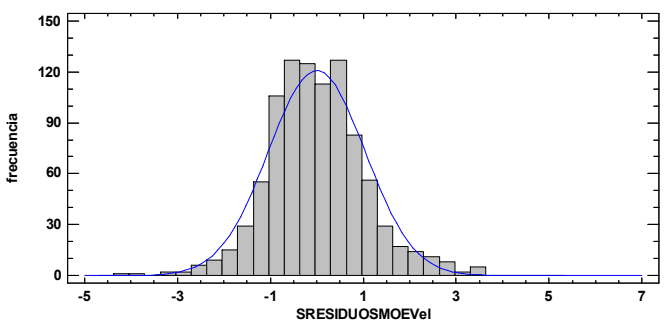

Figura 500. Histograma de Frecuencias LOG(MOE)-Velocidad Ultrasonidos.

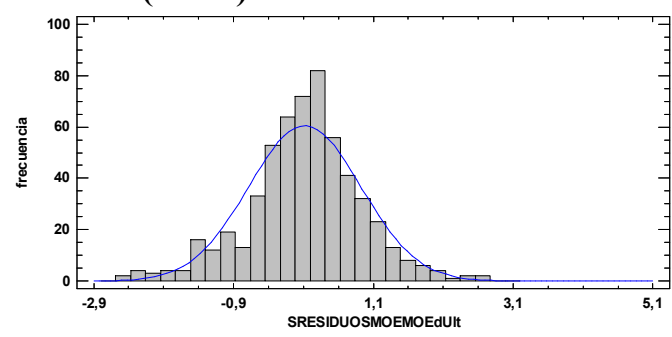

Figura 502. Histograma de Frecuencias LOG(MOE)-LOG(Ed) Ultrasonidos.

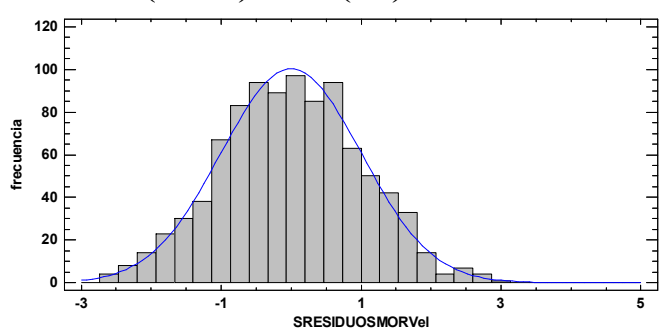

Figura 504. Histograma de Frecuencias MOR-

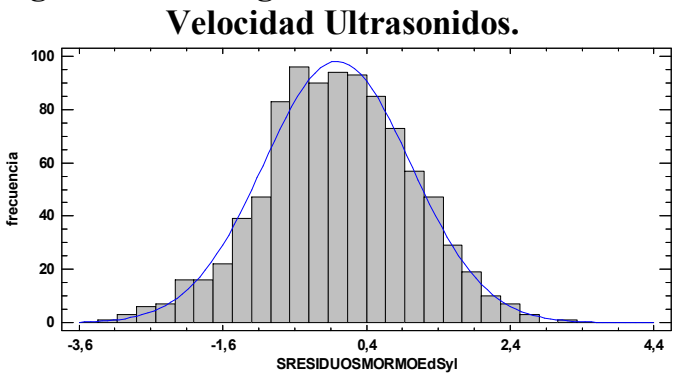

Figura 506. Histograma de Frecuencias MORLOG(Ed) Ultrasonidos.

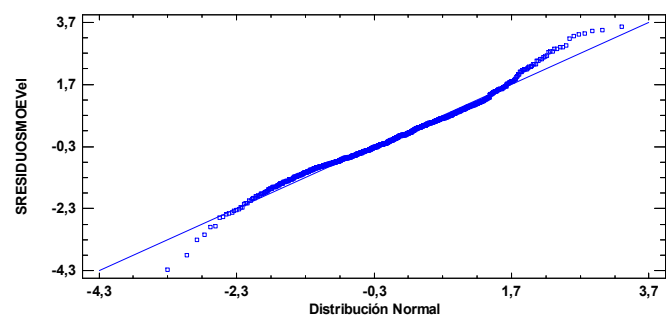

Figura 501. Gráfico probabilidad normal LOG(MOE)-Velocidad Ultrasonidos.

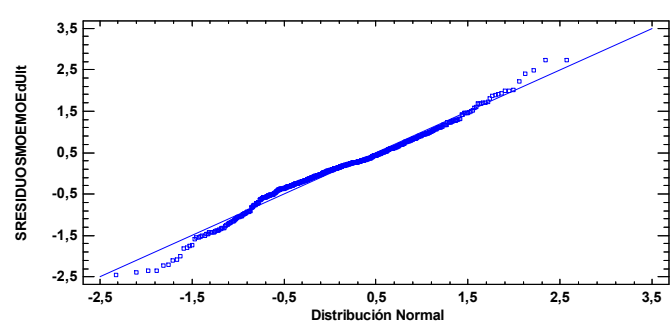

Figura 503. Gráfico probabilidad normal LOG(MOE)-LOG(Ed) Ultrasonidos.

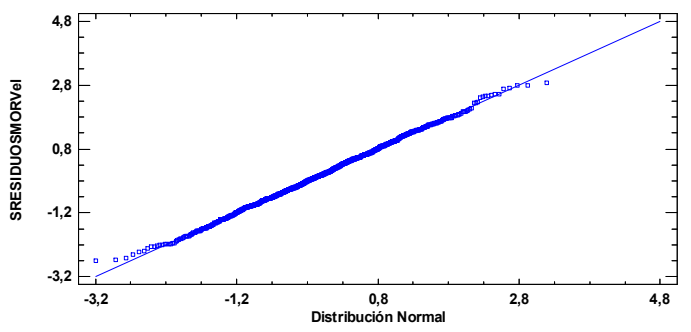

Figura 505. Gráfico probabilidad normal MORVelocidad Ultrasonidos.

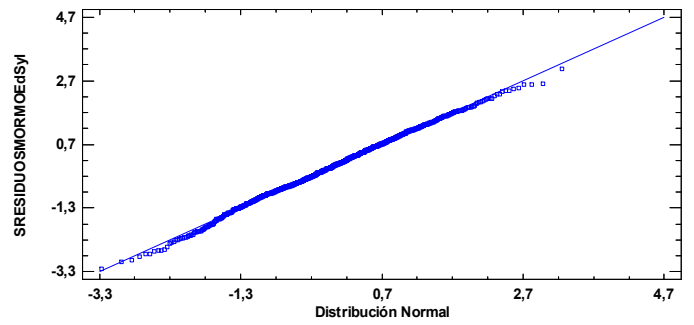

Figura 507. Gráfico probabilidad normal MORUltrasonidos. 


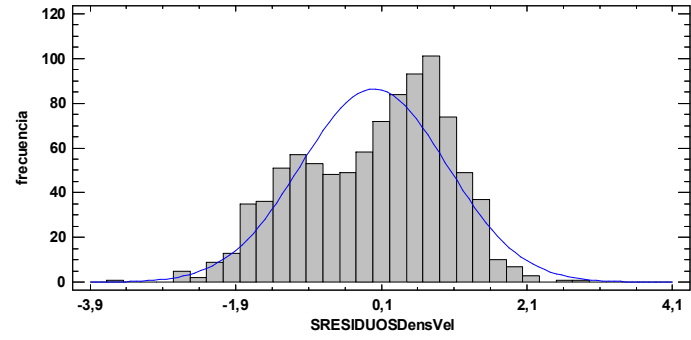

Figura 508. Histograma de Frecuencias 1/(Densidad)-Velocidad Ultrasonidos.

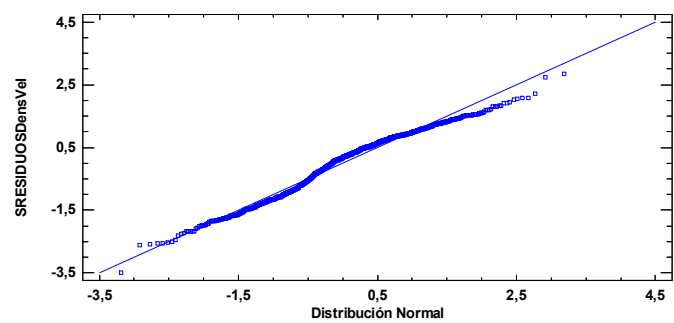

Figura 509. Gráfico probabilidad normal 1/(Densidad)-Velocidad Ultrasonidos.

Los gráficos de regresión entre las variables caracterizadoras y las dinámicas por vibraciones inducidas que presentaron menor eficiencia, se muestran a continuación (Figura 510 a Figura 513).

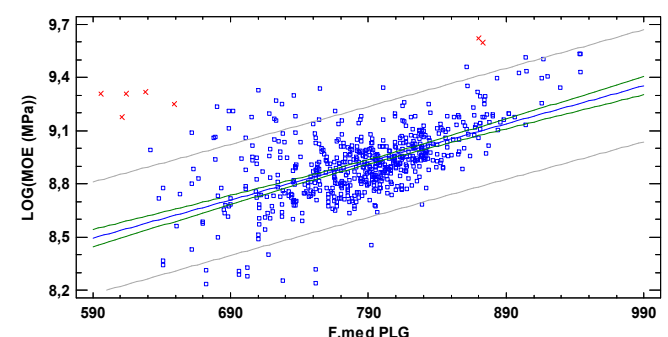

Figura 510.Regresión Simple: LOG(MOE)-Fr. VI

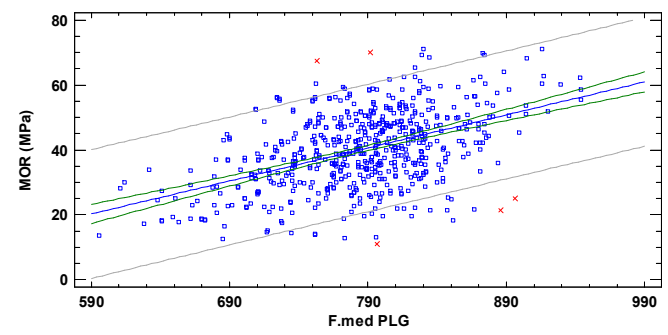

Figura 512.Regresión Simple: MOR-Frecuencia VI

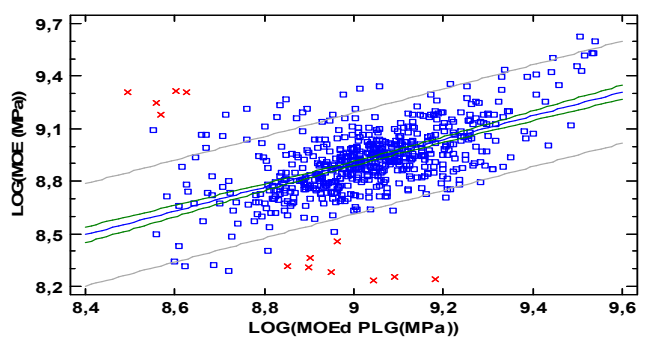

Figura 511. Regresión Simple: LOG(MOE)LOG $(E d)$ VI

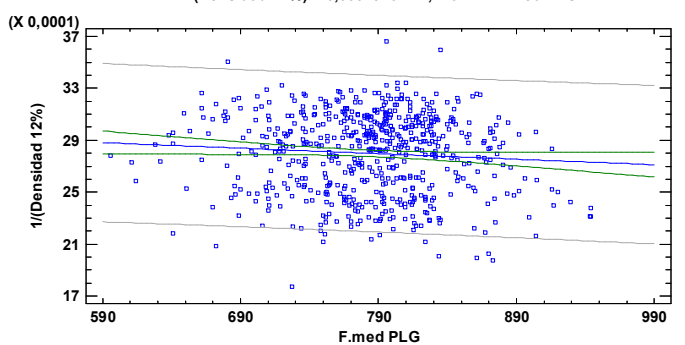

Figura 513. Regresión Simple: 1/(Densidad)-Fr. VI

Los gráficos de regresión entre las variables caracterizadoras y las dinámicas por ultrasonidos que presentaron menor eficiencia, se muestran a continuación (Figura 514 a Figura 517).

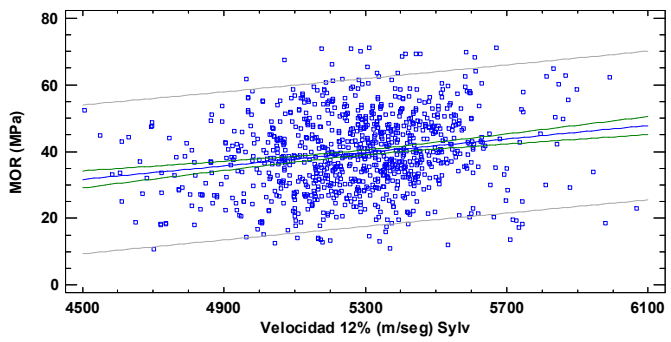

Figura 514. Regresión Simple: MOR-Velocidad Ultrasonidos

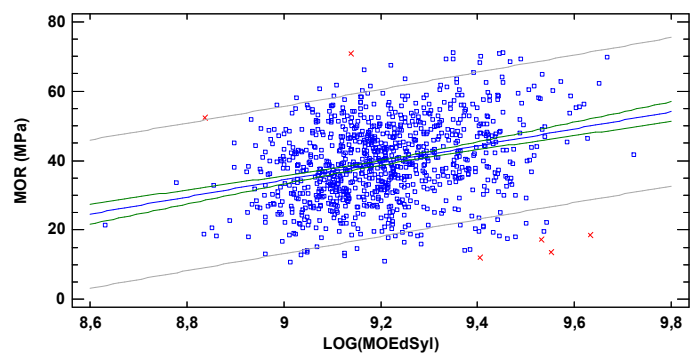

Figura 515. Regresión Simple: MOR-LOG(Ed) Ultrasonidos 


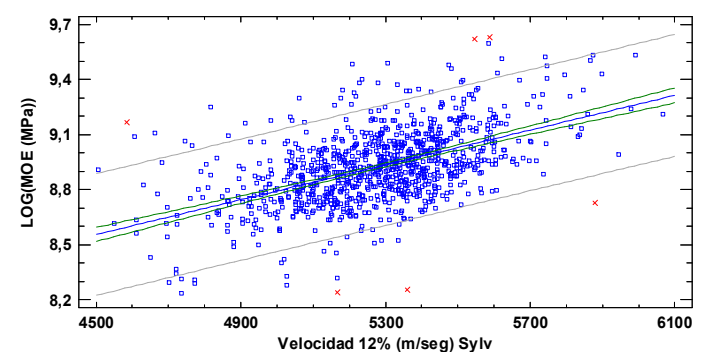

Figura 516. Regresión Simple: LOG(MOE)Velocidad Ultrasonidos

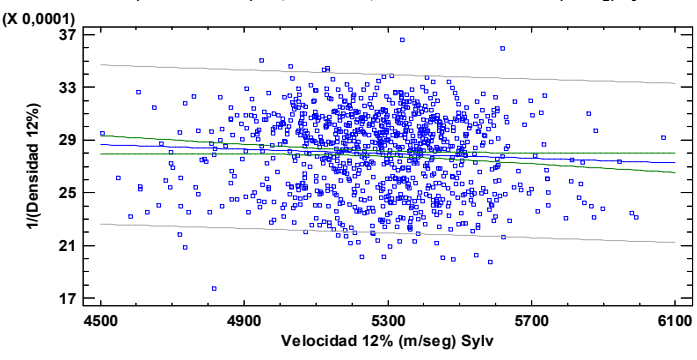

Figura 517. Regresión Simple: 1/(Densidad)Velocidad Ultrasonidos

\subsubsection{Efectividad de los NDT en la estimación de las clases resistentes}

Los ajustes logrados para determinación de la ecuación de regresión estimando el MOE a partir de las variables predictoras velocidad de ultrasonidos y densidad -sin transformar-, se muestran en la Tabla 235 y Figura 518. Con la ecuación de regresión obtenida se determinaron los valores de "corte" de la variable velocidad en la clasificación mediante metodología NDT.

Tabla 235. Ajuste MOE-NDT: determinación de valores de corte para clasificación por variables no destructivas.

\begin{tabular}{|c|c|c|}
\hline \multirow{4}{*}{ Variables predictoras } & \multicolumn{2}{|c|}{ MOE } \\
\hline & $\mathrm{R}^{2}$ ajust. $(\%)$ & P-valor \\
\hline & 42,80 & 0,00 \\
\hline & \multicolumn{2}{|c|}{ P-valor } \\
\hline Velocidad -Ult- & \multicolumn{2}{|c|}{0,00} \\
\hline Densidad & \multicolumn{2}{|c|}{0,00} \\
\hline Ecuación de regresión & \multicolumn{2}{|c|}{$\operatorname{MOE}(\mathrm{MPa})=-16266,3+3,53016 *$ Velocidad $+14,6646 *$ Densidad } \\
\hline
\end{tabular}

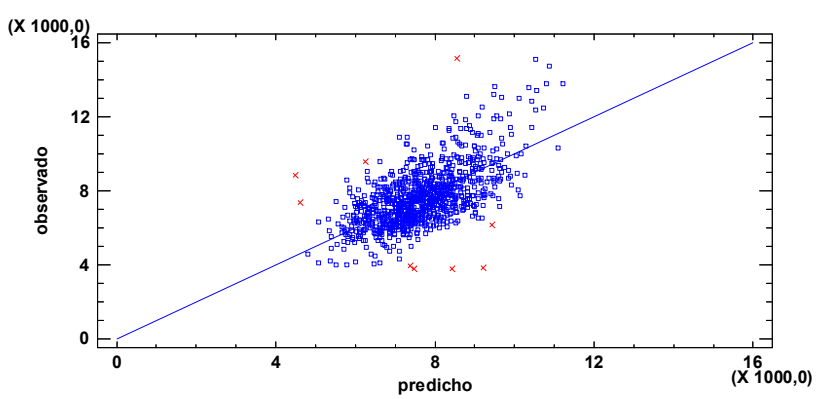

Figura 518. Regresión múltiple: MOE-Velocidad Ultrasonidos-Densidad 


\subsubsection{Influencia de las singularidades en las variables estudiadas.}

\subsubsection{Influencia de defectos en el Módulo de elasticidad (MOE)}

\subsection{Defectos naturales: influencia en el MOE}

Como primer término se presenta el análisis descriptivo de los factores (defectos) cuantitativos: diámetro relativo nudos de cara, diámetro relativo nudos de canto y anchura de anillos, para luego continuar con el análisis de influencia considerando cada categoría establecida.

Tabla 236. Defectos naturales: resumen estadístico

\begin{tabular}{cccccccc}
\hline Variable & $\begin{array}{c}\text { Media } \\
\text { (CV\%) }\end{array}$ & Mínimo & Máximo & IQR & DE* & SE* $^{*}$ & CE* $^{*}$ \\
\hline Diámetro relativo nudos de cara & $\begin{array}{c}35,11 \\
(60,30)\end{array}$ & 4,12 & 158,0 & 27,0 & 21,17 & 14,15 & 11,50 \\
\hline Diámetro relativo nudos de canto & $\begin{array}{c}52,19 \\
(29,02)\end{array}$ & 5,21 & 192,31 & 38,96 & 55,61 & 10,91 & 8,55 \\
\hline Anchura de anillos & 11,09 & 3,8 & 22,0 & 3,4 & 2,70 & 4,75 & 1,60 \\
\hline
\end{tabular}

*IQR: recorrido intercuartílico; DE.: Desvío estándar; SE: sesgo estandarizado; CE: Curtosis estandarizada

Tabla 237. Defectos naturales: pruebas de normalidad

\begin{tabular}{ccccccccc}
\hline & \multicolumn{2}{c}{ Chi-Cuadrado } & \multicolumn{2}{c}{$\begin{array}{c}\text { W de Shapiro- } \\
\text { Wilk }\end{array}$} & \multicolumn{2}{c}{$\begin{array}{c}\text { Valor-Z para } \\
\text { asimetría }\end{array}$} & \multicolumn{2}{c}{$\begin{array}{c}\text { Valor-Z para } \\
\text { curtosis }\end{array}$} \\
\cline { 2 - 9 } & Estad. & P-valor & Estad. & P-valor & Estad. & P-valor & Estad. & P-valor \\
\hline $\begin{array}{c}\text { Diámetro relativo nudos de } \\
\text { cara }\end{array}$ & 337,81 & 0,0 & 0,91 & 0,0 & 8,09 & 0,00 & 6,16 & 0,00 \\
\hline $\begin{array}{c}\text { Diámetro relativo nudo de } \\
\text { canto }\end{array}$ & 234,58 & 0,0 & 0,92 & 0,0 & 6,52 & 0,00 & 5,04 & 0,00 \\
\hline Anchura de anillos & 772,13 & 0,0 & 0,98 & 0,00 & 3,27 & 0,00 & 1,52 & 0,13 \\
\hline
\end{tabular}

En concordancia con el parámetro de Curtosis estandarizada y del P-valor superior a 0,05 en el valor $\mathrm{Z}$ para curtosis, se ha asumido la normalidad del factor anchura de anillos.

La gráfica de dispersión, caja y bigotes, distribución normal y el histograma de frecuencia para los tres factores considerados se muestra a continuación (Figura 519 a Figura $530)$.

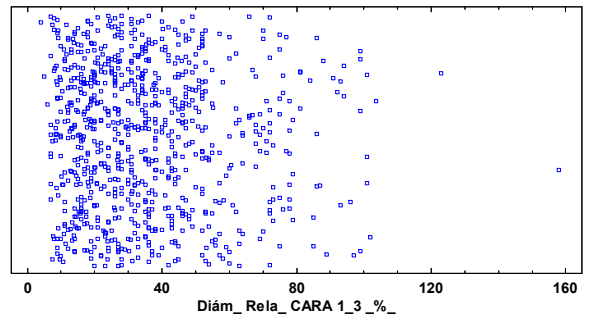

Figura 519. Gráfico de dispersión: diámetro relativo nudo de cara

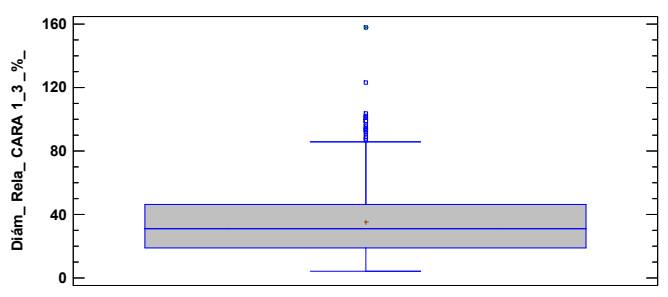

Figura 520. Gráfico de Caja y Bigotes: diámetro relativo nudo de cara 


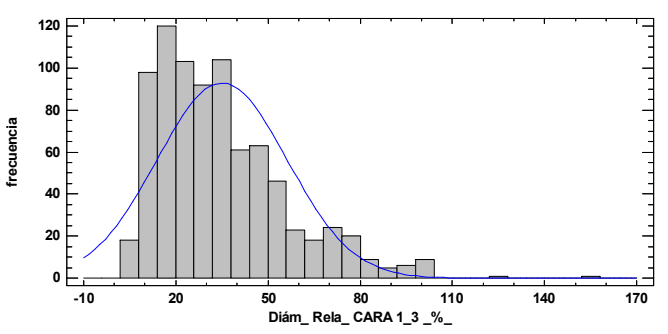

Figura 521. Histograma de frecuencia: diámetro relativo nudo de cara

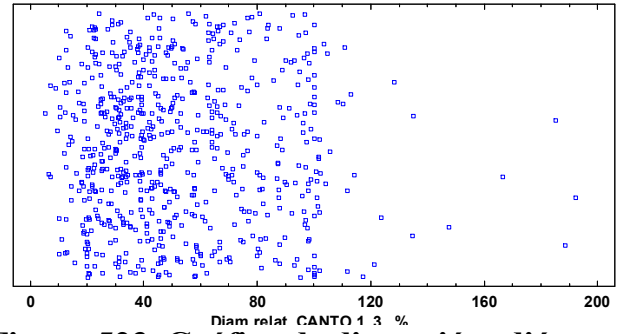

Figura 523. Gráfico de dispersión: diámetro relativo nudo de canto

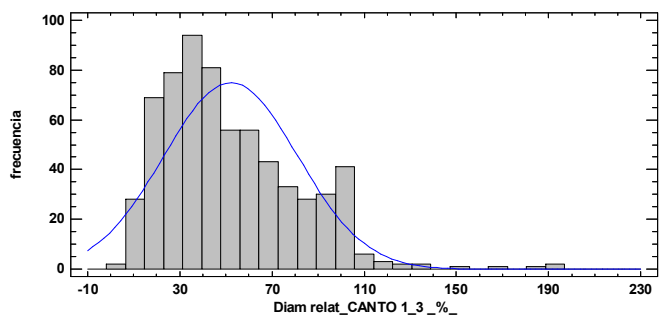

Figura 525. Histograma de frecuencia: diámetro relativo nudo de canto

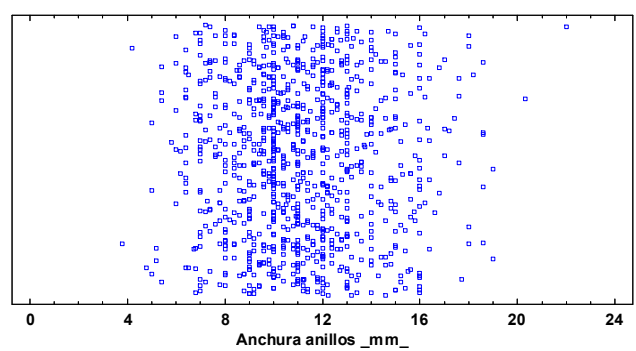

Figura 527. Gráfico de dispersión: Anchura de anillos

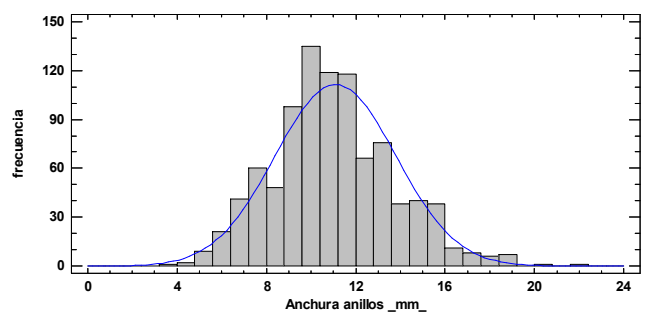

Figura 529. Histograma de frecuencia: Anchura de anillos

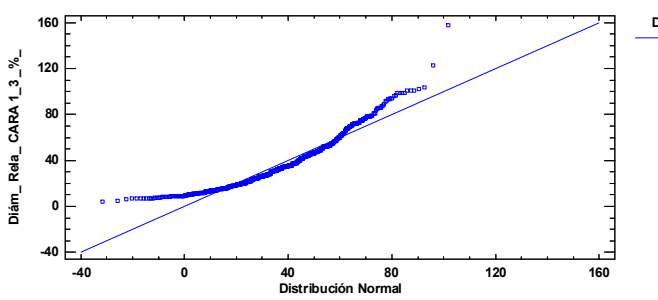

Figura 522. Gráfica de probabilidad normal: diámetro relativo nudo de cara

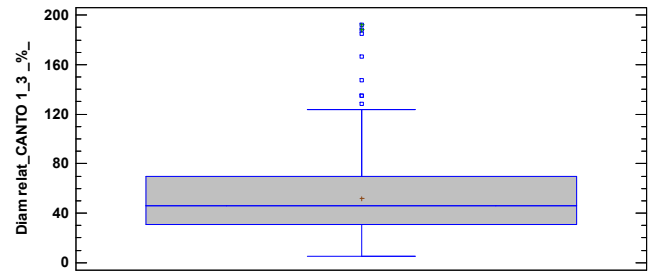

Figura 524. Gráfico de Caja y Bigotes: diámetro relativo nudo de canto

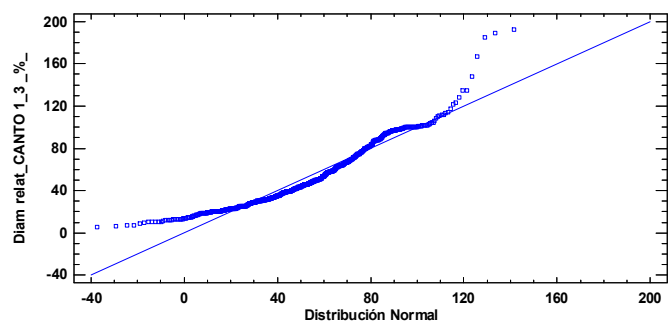

Figura 526. Gráfica de probabilidad normal: diámetro relativo nudo de canto

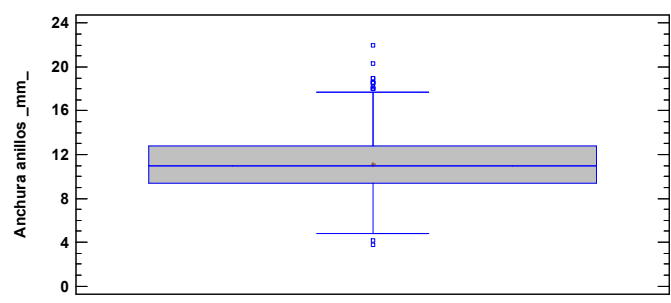

Figura 528. Gráfico de Caja y Bigotes: Anchura de anillos

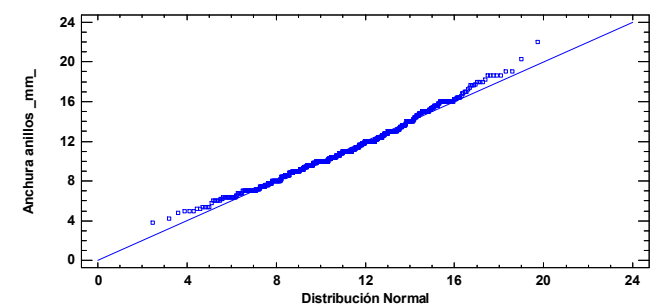

Figura 530. Gráfica de probabilidad normal: Anchura de anillos 


\section{Nudos: consideraciones cualitativas}

\section{Por existencia}

\section{a. Presencia nudos de cara}

En la Tabla 238 se presentan los resultados obtenidos de los análisis de corroboración de los supuestos estadísticos.

Tabla 238. LOG(MOE)-Presencia nudos de cara: prueba de normalidad de residuos y verificación de varianza

\begin{tabular}{|c|c|c|c|c|c|c|c|}
\hline Test de normalidad & Estadístico & $\begin{array}{c}\text { P- } \\
\text { valor }\end{array}$ & $\begin{array}{c}\text { Prueba de bondad de } \\
\text { ajuste }\end{array}$ & $\begin{array}{c}\mathrm{P}- \\
\text { valor }\end{array}$ & $\begin{array}{c}\text { Test de } \\
\text { homocedasticidad }\end{array}$ & Prueba & $\begin{array}{c}\mathrm{P}- \\
\text { valor }\end{array}$ \\
\hline Chi-Cuadrado & 81,90 & 0,01 & \multirow{4}{*}{ Kolmogorov-Smirnov } & \multirow{4}{*}{0,78} & \multirow{4}{*}{ Levene } & \multirow{4}{*}{5,88} & \multirow{4}{*}{0,02} \\
\hline $\begin{array}{c}\text { Estadístico W de } \\
\text { Shapiro-Wilk } \\
\end{array}$ & 0,98 & 0,00 & & & & & \\
\hline Valor-Z para asimetría & 2,44 & 0,01 & & & & & \\
\hline Valor- $\mathrm{Z}$ para curtosis & 3,05 & 0,00 & & & & & \\
\hline
\end{tabular}

\section{b. Presencia nudos de canto}

En la Tabla 239 se presentan los resultados obtenidos de los análisis de corroboración de los supuestos estadísticos.

Tabla 239. LOG(MOE)-Presencia nudos de canto: prueba de normalidad de residuos y verificación de varianza

\begin{tabular}{|c|c|c|c|c|c|c|c|}
\hline Test de normalidad & Estadístico & P-valor & $\begin{array}{c}\text { Prueba de bondad } \\
\text { de ajuste }\end{array}$ & P-valor & $\begin{array}{c}\text { Test de } \\
\text { homocedasticidad }\end{array}$ & Prueba & P-valor \\
\hline Chi-Cuadrado & 63,20 & 0,21 & \multirow{4}{*}{$\begin{array}{l}\text { Kolmogorov- } \\
\text { Smirnov }\end{array}$} & \multirow{4}{*}{0,66} & \multirow{4}{*}{ Levene } & \multirow{4}{*}{4,11} & \multirow{4}{*}{0,04} \\
\hline $\begin{array}{c}\text { Estadístico W de } \\
\text { Shapiro-Wilk } \\
\end{array}$ & 0,98 & 0,00 & & & & & \\
\hline Valor-Z para asimetría & 2,55 & 0,01 & & & & & \\
\hline Valor-Z para curtosis & 3,19 & 0,00 & & & & & \\
\hline
\end{tabular}

\section{Por existencia y ubicación}

\section{a. Nudos}

En la Tabla 240 se presentan los resultados obtenidos de los análisis de corroboración de los supuestos estadísticos.

Tabla 240. LOG(MOE)-Variable nudos: prueba de normalidad de residuos y verificación de varianza

\begin{tabular}{|c|c|c|c|c|c|c|c|}
\hline Test de normalidad & Estadístico & $\begin{array}{c}\text { P- } \\
\text { valor }\end{array}$ & $\begin{array}{c}\text { Prueba de bondad de } \\
\text { ajuste }\end{array}$ & $\begin{array}{c}\mathrm{P}- \\
\text { valor }\end{array}$ & $\begin{array}{c}\text { Test de } \\
\text { homocedasticidad }\end{array}$ & Prueba & $\begin{array}{c}\mathrm{P}- \\
\text { valor }\end{array}$ \\
\hline Chi-Cuadrado & 86,06 & 0,00 & \multirow{4}{*}{ Kolmogorov-Smirnov } & \multirow{4}{*}{0,07} & \multirow{4}{*}{ Levene } & \multirow{4}{*}{5,70} & \multirow{4}{*}{0,00} \\
\hline $\begin{array}{c}\text { Estadístico W de } \\
\text { Shapiro-Wilk } \\
\end{array}$ & 0,98 & 0,00 & & & & & \\
\hline Valor-Z para asimetría & 1,49 & 0,14 & & & & & \\
\hline Valor-Z para curtosis & 4,56 & 0,00 & & & & & \\
\hline
\end{tabular}


Dado que la prueba de Kruskal-Wallis para LOG(MOE) relacionada a la variable "Nudos" presentó significancia estadística, se procedió a realizar el mismo test entre pares de medianas para ver cuáles de ellas eran las responsables de dicha significación (Tabla 241).

Tabla 241. LOG(MOE)-“Nudos": comparación de pares de medianas

\begin{tabular}{|c|c|c|c|c|c|c|c|c|}
\hline Variable nudos & $\begin{array}{l}\text { Tamaño } \\
\text { Muestra } \\
\end{array}$ & $\begin{array}{c}\text { Rango } \\
\text { Promedio } \\
\end{array}$ & $\begin{array}{c}\text { Variable } \\
\text { nudos }\end{array}$ & $\begin{array}{l}\text { Tamaño } \\
\text { Muestra } \\
\end{array}$ & $\begin{array}{c}\text { Rango } \\
\text { Promedio } \\
\end{array}$ & $\begin{array}{c}\text { Variable } \\
\text { nudos }\end{array}$ & $\begin{array}{l}\text { Tamaño } \\
\text { Muestra } \\
\end{array}$ & $\begin{array}{c}\text { Rango } \\
\text { Promedio } \\
\end{array}$ \\
\hline 0 & 110 & 151,92 & 0 & 110 & 424,66 & 1 & 178 & 432,70 \\
\hline 1 & 178 & 139,92 & 3 & 638 & 365,85 & 3 & 638 & 402,03 \\
\hline Estadístico:1,41 & P-va & 0,23 & $\begin{array}{r}\text { Estadíst } \\
6,95 \\
\end{array}$ & & lor $=0,01$ & $\begin{array}{r}\text { Estadís } \\
2,2 \\
\end{array}$ & & alor: 0,14 \\
\hline
\end{tabular}

De la Tabla 241, y en base a los P-valores hallados, se desprende que no existe una diferencia estadísticamente significativa para las medianas del LOG(MOE) entre las categorías 0-1 y 1-3, con un nivel del 95,0\% de confianza; el P-valor inferior a $0,05 \%$ deja establecida la diferencia entre las medianas del LOG(MOE) considerando categoría 0-3.

\section{Nudos: consideraciones cuantitativas}

\section{a. Tamaño nudo de cara}

Los resultados de las pruebas de normalidad y verificación de varianza se indican en la Tabla 242

Tabla 242. LOG(MOE)-Tamaño nudos de cara: prueba de normalidad de residuos y verificación de varianza.

\begin{tabular}{|c|c|c|c|c|c|c|c|}
\hline Test de normalidad & Estadístico & P-valor & $\begin{array}{c}\text { Prueba de bondad de } \\
\text { ajuste }\end{array}$ & $\begin{array}{l}\text { P- } \\
\text { valor }\end{array}$ & $\begin{array}{c}\text { Test de } \\
\text { homocedasticidad }\end{array}$ & Prueba & $\begin{array}{c}\text { P- } \\
\text { valor }\end{array}$ \\
\hline Chi-Cuadrado & 50,69 & 0,64 & \multirow{4}{*}{ Kolmogorov-Smirnov } & \multirow{4}{*}{0,71} & \multirow{4}{*}{ Levene } & \multirow{4}{*}{1,73} & \multirow{4}{*}{0,18} \\
\hline $\begin{array}{l}\text { Estadístico W de } \\
\text { Shapiro-Wilk }\end{array}$ & 0,97 & $\begin{array}{c}1,13 \mathrm{E}- \\
7\end{array}$ & & & & & \\
\hline Valor-Z para asimetría & 2,99 & 0,00 & & & & & \\
\hline Valor-Z para curtosis & 3,31 & 0,00 & & & & & \\
\hline
\end{tabular}

\section{b. Tamaño nudo de canto}

Las pruebas de normalidad y de verificación de varianza se indican en la Tabla 243.

Tabla 243. LOG(MOE)-Tamaño nudos de canto: prueba de normalidad de residuos y verificación de varianza

\begin{tabular}{|c|c|c|c|c|c|c|c|}
\hline Test de normalidad & Estadístico & $\begin{array}{c}\mathrm{P}- \\
\text { valor }\end{array}$ & $\begin{array}{c}\text { Prueba de bondad de } \\
\text { ajuste }\end{array}$ & $\begin{array}{c}\mathrm{P}- \\
\text { valor }\end{array}$ & $\begin{array}{c}\text { Test de } \\
\text { homocedasticidad }\end{array}$ & Prueba & $\begin{array}{c}\mathrm{P}- \\
\text { valor }\end{array}$ \\
\hline Chi-Cuadrado & 56,63 & 0,41 & \multirow{4}{*}{ Kolmogorov-Smirnov } & \multirow{4}{*}{0,80} & \multirow{4}{*}{ Levene } & \multirow{4}{*}{1,75} & \multirow{4}{*}{0,17} \\
\hline $\begin{array}{c}\text { Estadístico W de } \\
\text { Shapiro-Wilk } \\
\end{array}$ & 0,98 & 0,00 & & & & & \\
\hline Valor-Z para asimetría & 2,89 & 0,00 & & & & & \\
\hline Valor-Z para curtosis & 3,17 & 0,00 & & & & & \\
\hline
\end{tabular}




\section{Desviación de las fibras}

Las pruebas de normalidad y de verificación de varianza se indican en la Tabla 244.

Tabla 244. LOG(MOE)-Desviación de las fibras: prueba de normalidad de residuos y verificación de varianza

\begin{tabular}{|c|c|c|c|c|c|c|c|}
\hline Test de normalidad & Estadístico & $\begin{array}{c}\mathrm{P}- \\
\text { valor }\end{array}$ & $\begin{array}{c}\text { Prueba de bondad de } \\
\text { ajuste }\end{array}$ & $\begin{array}{c}\mathrm{P}- \\
\text { valor }\end{array}$ & $\begin{array}{c}\text { Test de } \\
\text { homocedasticidad } \\
\end{array}$ & Prueba & $\begin{array}{c}\mathrm{P}- \\
\text { valor }\end{array}$ \\
\hline Chi-Cuadrado & 58,58 & 0,28 & \multirow{4}{*}{ Kolmogorov-Smirnov } & \multirow{4}{*}{0,99} & \multirow{4}{*}{ Levene } & \multirow{4}{*}{1,07} & \multirow{4}{*}{0,34} \\
\hline $\begin{array}{c}\text { Estadístico W de } \\
\text { Shapiro-Wilk }\end{array}$ & 0,98 & 0,02 & & & & & \\
\hline Valor-Z para asimetría & 1,33 & 0,18 & & & & & \\
\hline Valor-Z para curtosis & 1,12 & 0,26 & & & & & \\
\hline
\end{tabular}

A modo de constatación se presentan los resultados del Test Unequal N HSD para LOG(MOE) considerando la variable "Desviación de fibras" (Tabla 245).

Tabla 245. LOG(MOE) por "Grupo desviación": pruebas Unequal N HSD y test de Tukey HSD.

\begin{tabular}{cccc}
\hline Nivel & Casos & Media & Grupos Homogéneos Tukey HSD \\
\hline 2 & 71 & 8,87 & $\mathrm{~A}$ \\
\hline 0 & 168 & 8,90 & $\mathrm{~A}$ \\
\hline 1 & 591 & 8,92 & $\mathrm{~A}$ \\
\hline
\end{tabular}

\section{$\underline{\text { Entrecasco }}$}

En la Tabla 246 se muestran las pruebas de normalidad y de verificación de varianza.

Tabla 246. LOG(MOE)-Entrecasco: prueba de normalidad de residuos y verificación de varianza

\begin{tabular}{|c|c|c|c|c|c|c|c|}
\hline Test de normalidad & Estadístico & $\begin{array}{c}\text { P- } \\
\text { valor }\end{array}$ & $\begin{array}{c}\text { Prueba de bondad de } \\
\text { ajuste }\end{array}$ & $\begin{array}{c}\text { P- } \\
\text { valor }\end{array}$ & $\begin{array}{c}\text { Test de } \\
\text { homocedasticidad }\end{array}$ & Prueba & $\begin{array}{c}\mathrm{P}- \\
\text { valor }\end{array}$ \\
\hline Chi-Cuadrado & 85,44 & 0,01 & \multirow{4}{*}{ Kolmogorov-Smirnov } & \multirow{4}{*}{0,84} & \multirow{4}{*}{ Levene } & \multirow{4}{*}{3,21} & \multirow{4}{*}{0,07} \\
\hline $\begin{array}{c}\text { Estadístico W de Shapiro- } \\
\text { Wilk } \\
\end{array}$ & 0,98 & 0,01 & & & & & \\
\hline Valor-Z para asimetría & 2,12 & 0,03 & & & & & \\
\hline Valor-Z para curtosis & 2,26 & 0,02 & & & & & \\
\hline
\end{tabular}

\subsection{Defectos de aserrado: influencia en el MOE}

El resumen estadístico y el incumplimiento de los supuestos estadísticos en los factores cuantitativos anchura y longitud de gema, juntos con las correspondientes gráficas de dispersión y distribución, se muestra en la Tabla 247 y Tabla 248 (Figura 543 a Figura 550). Posteriormente se presenta el análisis sobre la influencia de los factores de aserrado (agrupados en las categorías descriptas en Materiales y Métodos) en la determinación del MOE. 
Tabla 247. Anchura y longitud de gemas: resumen estadístico

\begin{tabular}{cccccccc}
\hline Variable & $\begin{array}{c}\text { Media } \\
(\mathrm{CV} \%)\end{array}$ & Mínimo & Máximo & IQR & DE & SE & CE \\
\hline Anchura máxima de gemas & $\begin{array}{c}4,26 \\
(60,04)\end{array}$ & 1,0 & 20,0 & 2,0 & 2,56 & 14,17 & 21,76 \\
\hline Longitud máxima de gemas & $\begin{array}{c}121,57 \\
(55,52)\end{array}$ & 4,5 & 360,5 & 77,2 & 67,49 & 9,15 & 4,94 \\
\hline *IQR: recorrido intercuartílico; DE : Desvío estándar; SE: sesgo estandarizado; CE: Curtosis estandarizada
\end{tabular}

*IQR: recorrido intercuartílico; DE.: Desvío estándar; SE: sesgo estandarizado; CE: Curtosis estandarizada

Tabla 248. Anchura y longitud de gemas: pruebas de normalidad

\begin{tabular}{cccccccccc}
\hline & \multicolumn{2}{c}{ Chi-Cuadrado } & \multicolumn{2}{c}{ W de Shapiro- } & \multicolumn{2}{c}{$\begin{array}{c}\text { Valor-Z para } \\
\text { asimetría }\end{array}$} & \multicolumn{2}{c}{$\begin{array}{c}\text { Valor-Z para } \\
\text { curtosis }\end{array}$} \\
\cline { 2 - 9 } Variable & Estad. & $\begin{array}{c}P \text { - } \\
\text { valor }\end{array}$ & Estad. & P-valor & Estad. & P-valor & Estad. & P-valor \\
\hline $\begin{array}{c}\text { Anchura máxima de } \\
\text { gemas }\end{array}$ & 2148,99 & 0,0 & 0,87 & 0,0 & 7,33 & 0,00 & 7,29 & 0,00 \\
\hline $\begin{array}{c}\text { Longitud máxima de } \\
\text { gemas }\end{array}$ & 134,68 & 0,00 & 0,91 & 0,0 & 5,48 & 0,00 & 3,43 & 0,00 \\
\hline
\end{tabular}

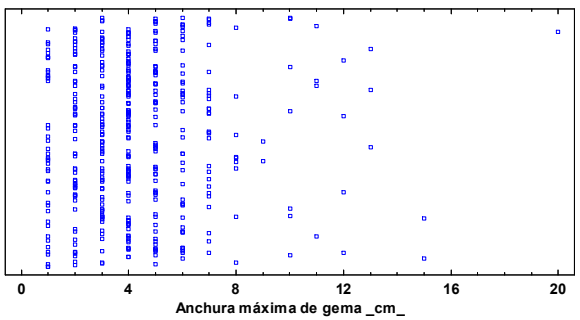

Figura 531. Gráfico de dispersión: Anchura máxima de gemas

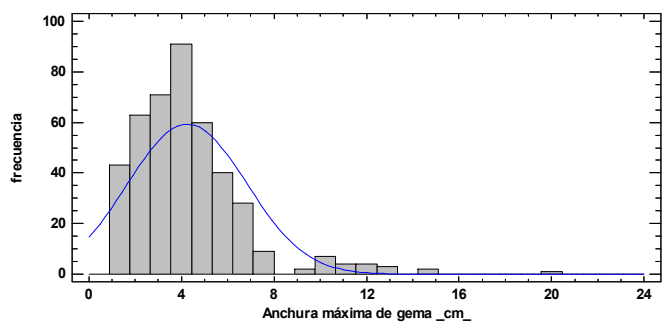

Figura 533. Histograma de frecuencia: Anchura máxima de gemas

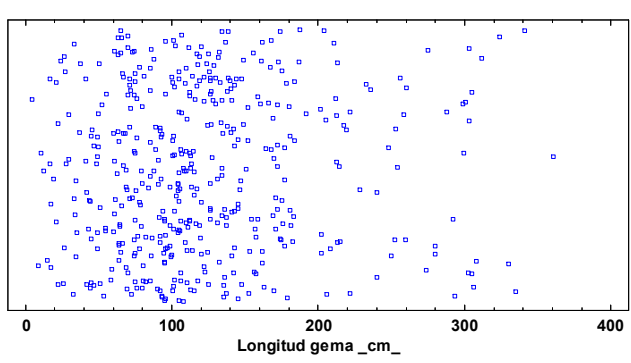

Figura 535. Gráfico de dispersión: Longitud máxima de gemas

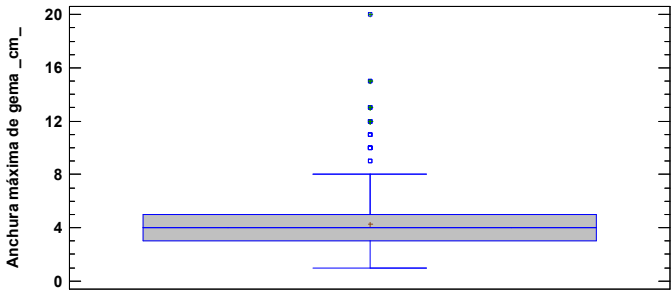

Figura 532. Gráfica de Caja y Bigotes: Anchura máxima de gemas

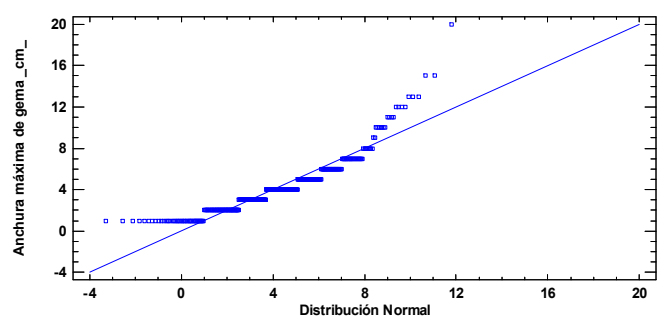

Figura 534. Gráfica de probabilidad normal: Anchura máxima de gemas

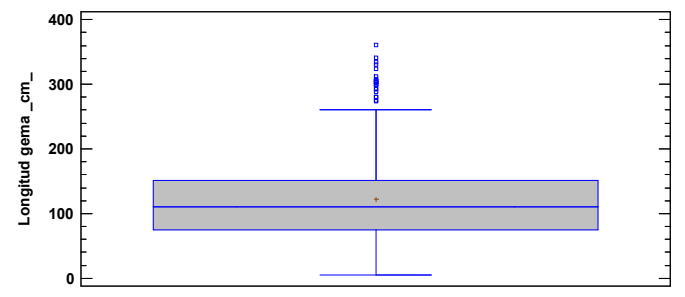

Figura 536. Gráfica de Caja y Bigotes: Longitud máxima de gemas 


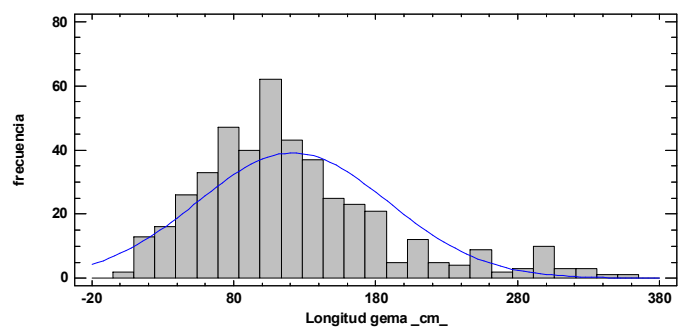

Figura 537. Histograma de frecuencia: Longitud máxima de gemas

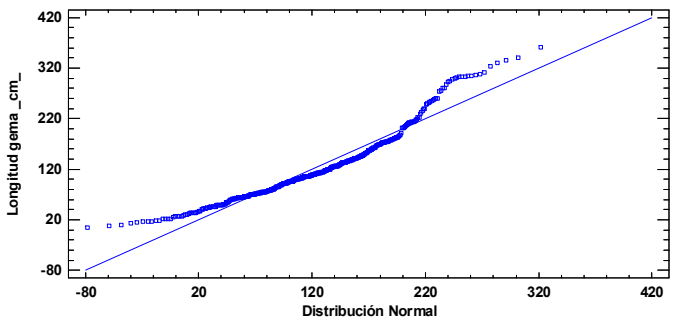

Figura 538. Gráfica de probabilidad normal: Longitud máxima de gemas

\section{$\underline{\text { Gemas }}$}

\section{a. Grupo anchura de gemas}

En la Tabla 249 y Tabla 250 se muestran las pruebas de normalidad (y verificación de varianza) y el test de comparación de medianas, respectivamente.

Tabla 249. LOG(MOE) - Grupo anchura de gemas: prueba de normalidad de residuos y verificación de varianza

\begin{tabular}{|c|c|c|c|c|c|c|c|}
\hline Test de normalidad & Estadístico & $\begin{array}{c}\text { P- } \\
\text { valor }\end{array}$ & $\begin{array}{c}\text { Prueba de bondad de } \\
\text { ajuste }\end{array}$ & $\begin{array}{c}\text { P- } \\
\text { valor }\end{array}$ & $\begin{array}{c}\text { Test de } \\
\text { homocedasticidad }\end{array}$ & Prueba & $\begin{array}{c}\mathrm{P}- \\
\text { valor }\end{array}$ \\
\hline Chi-Cuadrado & 78,41 & 0,02 & \multirow{4}{*}{ Kolmogorov-Smirnov } & \multirow{4}{*}{0,18} & \multirow{4}{*}{ Levene } & \multirow{4}{*}{8,11} & \multirow{4}{*}{0,00} \\
\hline $\begin{array}{c}\text { Estadístico W de } \\
\text { Shapiro-Wilk }\end{array}$ & 0,98 & 0,01 & & & & & \\
\hline Valor-Z para asimetría & 1,35 & 0,18 & & & & & \\
\hline Valor-Z para curtosis & 4,26 & 0,00 & & & & & \\
\hline
\end{tabular}

Tabla 250. LOG(MOE) - Grupo anchura de gemas: comparación de pares de medianas

\begin{tabular}{ccccccccc}
\hline $\begin{array}{c}\text { Variable } \\
\text { nudos }\end{array}$ & $\begin{array}{c}\text { Tamaño } \\
\text { Muestra }\end{array}$ & $\begin{array}{c}\text { Rango } \\
\text { Promedio }\end{array}$ & $\begin{array}{c}\text { Variable } \\
\text { nudos }\end{array}$ & $\begin{array}{c}\text { Tamaño } \\
\text { Muestra }\end{array}$ & $\begin{array}{c}\text { Rango } \\
\text { Promedio }\end{array}$ & $\begin{array}{c}\text { Variable } \\
\text { nudos }\end{array}$ & $\begin{array}{c}\text { Tamaño } \\
\text { Muestra }\end{array}$ & $\begin{array}{c}\text { Rango } \\
\text { Promedio }\end{array}$ \\
\hline 0 & 517 & 375,35 & 0 & 517 & 303,02 & 1 & 300 & 208,14 \\
1 & 300 & 466,99 & 2 & 109 & 363,19 & 2 & 109 & 196,36 \\
\hline $\begin{array}{c}\text { Estadístico: } \\
28,62\end{array}$ & P-valor: 0,00 & $\begin{array}{c}\text { Estadístico: } \\
9,96\end{array}$ & P-valor: 0,00 & Estadístico: 0,79 & P-valor: 0,37 \\
\hline
\end{tabular}

\section{b. Grupo longitud de gemas}

En la Tabla 251 se muestran las pruebas de normalidad y de verificación de varianza.

Tabla 251. LOG(MOE) - Grupo longitud de gemas: prueba de normalidad de residuos y verificación de varianza

\begin{tabular}{|c|c|c|c|c|c|c|c|}
\hline Test de normalidad & Estadístico & $\begin{array}{c}\mathrm{P}- \\
\text { valor }\end{array}$ & $\begin{array}{c}\text { Prueba de bondad de } \\
\text { ajuste }\end{array}$ & $\begin{array}{c}\mathrm{P}- \\
\text { valor }\end{array}$ & $\begin{array}{c}\text { Test de } \\
\text { homocedasticidad }\end{array}$ & Prueba & $\begin{array}{c}\mathrm{P}- \\
\text { valor }\end{array}$ \\
\hline Chi-Cuadrado & 78,82 & 0,02 & \multirow{4}{*}{ Kolmogorov-Smirnov } & \multirow{4}{*}{0,27} & \multirow{4}{*}{ Levene } & \multirow{4}{*}{0,06} & \multirow{4}{*}{0,94} \\
\hline $\begin{array}{c}\text { Estadístico W de } \\
\text { Shapiro-Wilk } \\
\end{array}$ & 0,98 & 0,19 & & & & & \\
\hline Valor-Z para asimetría & 1,13 & 0,26 & & & & & \\
\hline Valor-Z para curtosis & 3,63 & 0,00 & & & & & \\
\hline
\end{tabular}




\section{$\underline{\text { Médula }}$}

Las pruebas de normalidad y de verificación de varianza se muestran en la Tabla 252.

Tabla 252. LOG(MOE) - Médula: prueba de normalidad de residuos y verificación de varianza

\begin{tabular}{|c|c|c|c|c|c|c|c|}
\hline Test de normalidad & Estadístico & $\begin{array}{c}\text { P- } \\
\text { valor }\end{array}$ & $\begin{array}{c}\text { Prueba de bondad de } \\
\text { ajuste }\end{array}$ & $\begin{array}{c}\mathrm{P}- \\
\text { valor }\end{array}$ & $\begin{array}{c}\text { Test de } \\
\text { homocedasticidad }\end{array}$ & Prueba & $\begin{array}{c}\text { P- } \\
\text { valor }\end{array}$ \\
\hline Chi-Cuadrado & 540,88 & 0,0 & \multirow{4}{*}{ Kolmogorov-Smirnov } & \multirow{4}{*}{0,0} & \multirow{4}{*}{ Levene } & \multirow{4}{*}{2,41} & \multirow{4}{*}{0,12} \\
\hline $\begin{array}{c}\text { Estadístico W de } \\
\text { Shapiro-Wilk }\end{array}$ & 0,46 & 0,0 & & & & & \\
\hline Valor-Z para asimetría & 27,89 & 0,0 & & & & & \\
\hline Valor-Z para curtosis & 20,81 & 0,0 & & & & & \\
\hline
\end{tabular}

\subsection{Defectos de secado: influencia en el MOE}

La evaluación de los supuestos estadísticos de las variables curvatura de cara, de canto y alabeo se muestra en la Tabla 253 y Tabla 254 (Figura 539 a Figura 550).

Tabla 253. Variables de secado: resumen estadístico

\begin{tabular}{cccccccc}
\hline Variable & $\begin{array}{c}\text { Media } \\
(\mathrm{CV} \%)\end{array}$ & Mínimo & Máximo & IQR* & DE* $^{*}$ & SE* $^{*}$ & CE* $^{*}$ \\
\hline Curvatura de cara & $\begin{array}{c}0,94 \\
(62,19)\end{array}$ & 0,1 & 3,9 & 0,8 & 0,58 & 15,60 & 18,01 \\
\hline Curvatura de canto & $\begin{array}{c}0,84 \\
(70,77)\end{array}$ & 0,1 & 4,6 & 0,7 & 0,59 & 18,47 & 22,79 \\
\hline Alabeo & $\begin{array}{c}0,60 \\
(74,63)\end{array}$ & 0,04 & 2,9 & 0,4 & 0,45 & 22,41 & 35,80 \\
\hline
\end{tabular}

*IQR: recorrido intercuartílico; DE.: Desvío estándar; SE: sesgo estandarizado; CE: Curtosis estandarizada

Tabla 254. Variables de secado: pruebas de Normalidad

\begin{tabular}{ccccccccc}
\hline \multirow{2}{*}{ Variable } & \multicolumn{2}{c}{ Chi-Cuadrado } & \multicolumn{2}{c}{ W de Shapiro-Wilk } & \multicolumn{2}{c}{ Valor-Z para asimetría } & \multicolumn{2}{c}{ Valor-Z para curtosis } \\
\cline { 2 - 9 } & Estad. & P-valor & Estad. & P-valor & Estad. & P-valor & Estad. & P-valor \\
\hline Curvatura de cara & 1858,28 & 0,00 & 0,90 & 0,00 & 8,62 & 0,00 & 7,68 & 0,00 \\
\hline Curvatura de canto & 1921,6 & 0,00 & 0,87 & 0,00 & 9,52 & 0,00 & 8,40 & 0,00 \\
\hline Alabeo & 1933,9 & 0,00 & 0,77 & 0,00 & 9,88 & 0,00 & 9,04 & 0,00 \\
\hline
\end{tabular}

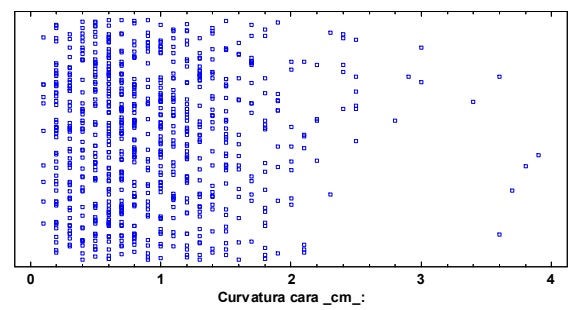

Figura 539. Gráfico de dispersión: Curvatura de cara

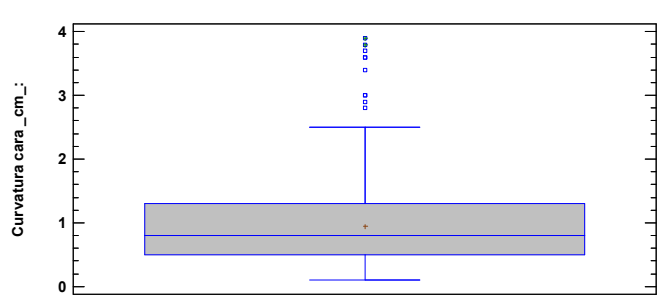

Figura 540. Gráfica de Caja y Bigotes: Curvatura de cara 


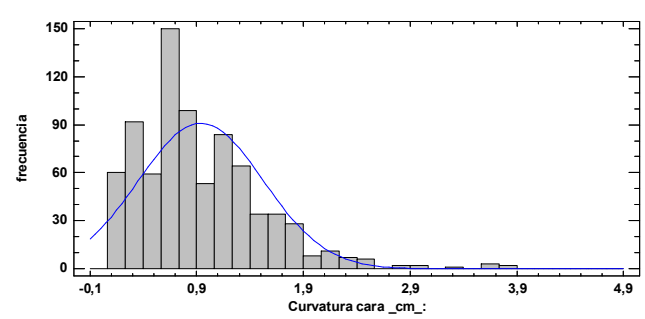

Figura 541. Histograma de frecuencia:

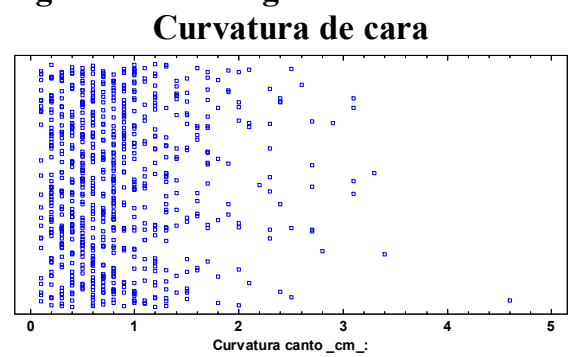

Figura 543. Gráfico de dispersión: Curvatura de canto

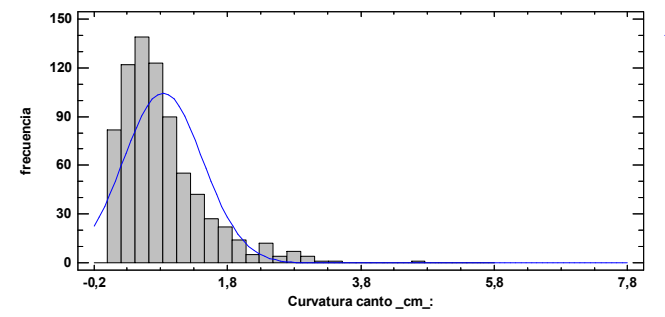

Figura 545. Histograma de frecuencia: Curvatura de canto

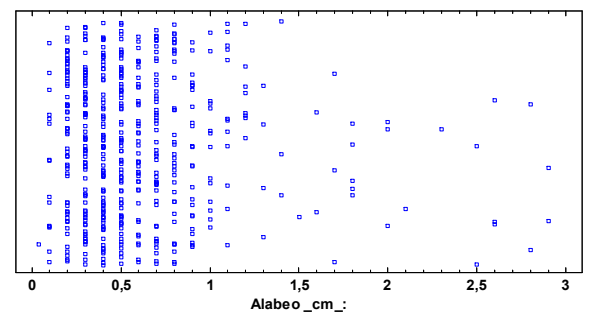

Figura 547. Gráfico de dispersión: Alabeo

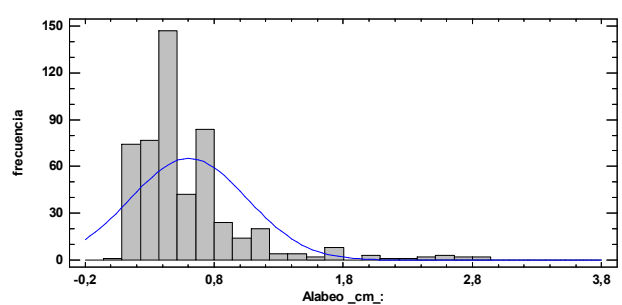

Figura 549. Histograma de frecuencia: Alabeo

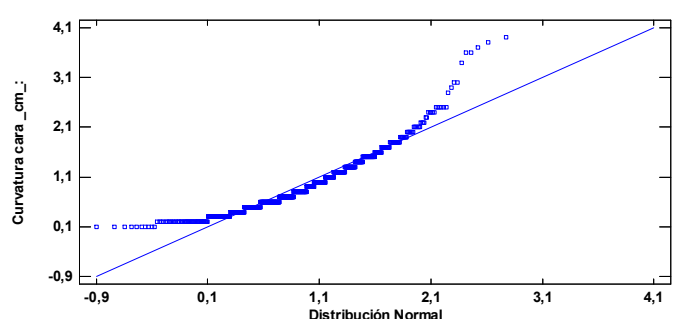

Figura 542. Gráfica de probabilidad normal: Curvatura de cara

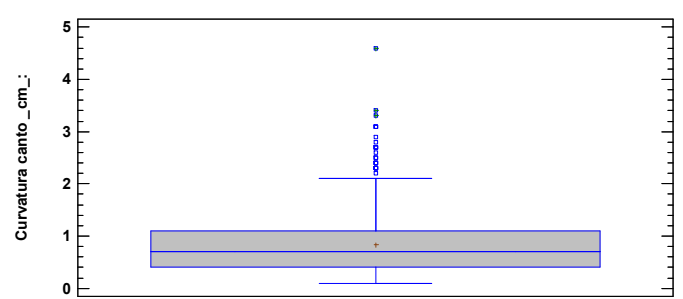

Figura 544. Gráfica de Caja y Bigotes: Curvatura de canto

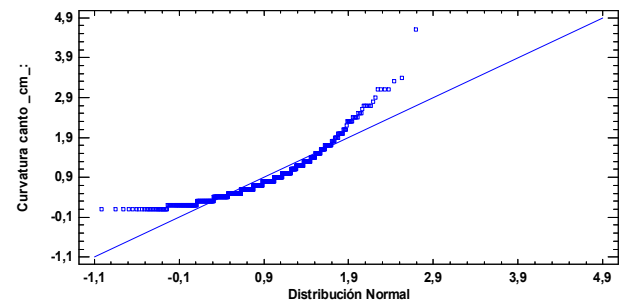

Figura 546. Gráfica de probabilidad normal: Curvatura de canto

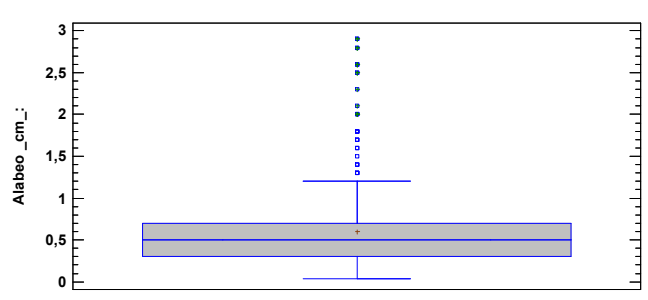

Figura 548. Gráfica de Caja y Bigotes: Alabeo

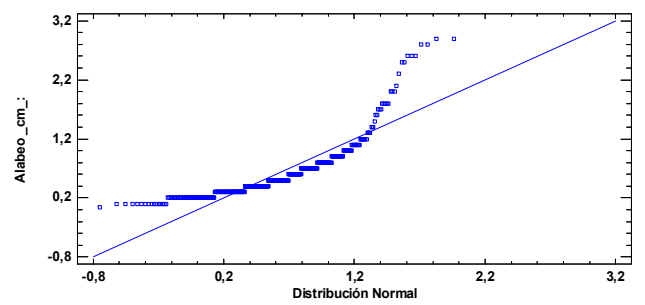

Figura 550. Gráfica de probabilidad normal: Alabeo

Dado el incumplimiento de los mismos, se procedió al análisis de influencia de los defectos utilizando los rangos definidos en Materiales y Métodos. 


\section{Curvatura de cara}

Las pruebas de normalidad y de verificación de varianza se muestran en la Tabla 255.

Tabla 255. LOG(MOE) - Grupo Curvatura de cara: prueba de normalidad de residuos y verificación de varianza

\begin{tabular}{|c|c|c|c|c|c|c|c|}
\hline Test de normalidad & Estadístico & $\begin{array}{c}\mathrm{P}- \\
\text { valor }\end{array}$ & $\begin{array}{l}\text { Prueba de bondad de } \\
\text { ajuste }\end{array}$ & $\begin{array}{c}\text { P- } \\
\text { valor }\end{array}$ & $\begin{array}{c}\text { Test de } \\
\text { homocedasticidad }\end{array}$ & Prueba & $\begin{array}{c}\mathrm{P}- \\
\text { valor }\end{array}$ \\
\hline Chi-Cuadrado & 71,36 & 0,07 & \multirow{4}{*}{ Kolmogorov-Smirnov } & \multirow{4}{*}{0,25} & \multirow{4}{*}{ Levene } & \multirow{4}{*}{1,79} & \multirow{4}{*}{0,17} \\
\hline $\begin{array}{c}\text { Estadístico W de Shapiro- } \\
\text { Wilk } \\
\end{array}$ & 0,98 & 0,00 & & & & & \\
\hline Valor-Z para asimetría & 0,81 & 0,42 & & & & & \\
\hline Valor-Z para curtosis & 4,49 & 0,00 & & & & & \\
\hline
\end{tabular}

\section{Curvatura de canto}

Las pruebas de normalidad y de verificación de varianza se muestran en la Tabla 256.

Tabla 256. LOG(MOE) - Grupo Curvatura de canto: prueba de normalidad de residuos y verificación de varianza

\begin{tabular}{|c|c|c|c|c|c|c|c|}
\hline Test de normalidad & Estadístico & $\begin{array}{c}\mathrm{P}- \\
\text { valor }\end{array}$ & $\begin{array}{l}\text { Prueba de bondad de } \\
\text { ajuste }\end{array}$ & $\begin{array}{c}\mathrm{P}- \\
\text { valor }\end{array}$ & $\begin{array}{c}\text { Test de } \\
\text { homocedasticidad }\end{array}$ & Prueba & $\begin{array}{c}\text { P- } \\
\text { valor }\end{array}$ \\
\hline Chi-Cuadrado & 83,73 & 0,00 & \multirow{4}{*}{ Kolmogorov-Smirnov } & \multirow{4}{*}{0,26} & \multirow{4}{*}{ Levene's } & \multirow{4}{*}{0,99} & \multirow{4}{*}{0,37} \\
\hline $\begin{array}{c}\text { Estadístico W de Shapiro- } \\
\text { Wilk }\end{array}$ & 0,98 & 0,00 & & & & & \\
\hline Valor-Z para asimetría & 1,40 & 0,16 & & & & & \\
\hline Valor-Z para curtosis & 3,94 & 0,00 & & & & & \\
\hline
\end{tabular}

\section{$\underline{\text { Alabeo }}$}

Las pruebas de normalidad y de verificación de varianza se muestran en la Tabla 257.

Tabla 257. LOG(MOE) - Grupo Alabeo: prueba de normalidad de residuos y verificación de varianza

\begin{tabular}{|c|c|c|c|c|c|c|c|}
\hline Test de normalidad & Estadístico & $\begin{array}{c}\mathrm{P}- \\
\text { valor }\end{array}$ & $\begin{array}{c}\text { Prueba de bondad de } \\
\text { ajuste }\end{array}$ & $\begin{array}{l}\mathrm{P}- \\
\text { valor }\end{array}$ & $\begin{array}{c}\text { Test de } \\
\text { homocedasticidad }\end{array}$ & Prueba & $\begin{array}{l}\text { P- } \\
\text { valor }\end{array}$ \\
\hline Chi-Cuadrado & 102,01 & 0,00 & \multirow{4}{*}{ Kolmogorov-Smirnov } & \multirow{4}{*}{0,07} & \multirow{4}{*}{ Levene } & \multirow{4}{*}{0,54} & \multirow{4}{*}{0,58} \\
\hline $\begin{array}{l}\text { Estadístico W de } \\
\text { Shapiro-Wilk }\end{array}$ & 0,98 & 0,00 & & & & & \\
\hline Valor-Z para asimetría & 0,95 & 0,34 & & & & & \\
\hline Valor-Z para curtosis & 4,59 & 0,00 & & & & & \\
\hline
\end{tabular}

\subsubsection{Influencia de defectos en el Módulo de Rotura (MOR)}

\subsection{Defectos naturales: influencia en el MOR}

Del mismo modo que lo planteado en el análisis de influencia de los defectos naturales en el MOE y dado el incumplimiento del supuesto de normalidad de los factores numéricos, se trabajó con los rangos categóricos planteados. 


\section{Nudos: consideraciones cualitativas}

\section{Por existencia}

\section{a. Presencia nudos de cara}

Las pruebas de normalidad y de verificación de varianza se muestran en la Tabla 258.

Tabla 258. MOR - Presencia nudos de cara: prueba de normalidad de residuos y verificación de varianza

\begin{tabular}{|c|c|c|c|c|c|c|c|}
\hline Test de normalidad & Estadístico & $\begin{array}{c}\text { P- } \\
\text { valor }\end{array}$ & $\begin{array}{c}\text { Prueba de bondad de } \\
\text { ajuste }\end{array}$ & $\begin{array}{c}\text { P- } \\
\text { valor }\end{array}$ & $\begin{array}{c}\text { Test de } \\
\text { homocedasticidad }\end{array}$ & Prueba & $\begin{array}{c}\mathrm{P}- \\
\text { valor }\end{array}$ \\
\hline Chi-Cuadrado & 47,88 & 0,77 & \multirow{4}{*}{ Kolmogorov-Smirnov } & \multirow{4}{*}{0,99} & \multirow{4}{*}{ Levene } & \multirow{4}{*}{0,49} & \multirow{4}{*}{0,48} \\
\hline $\begin{array}{c}\text { Estadístico W de } \\
\text { Shapiro-Wilk } \\
\end{array}$ & 0,98 & 0,00 & & & & & \\
\hline Valor-Z para asimetría & 0,76 & 0,45 & & & & & \\
\hline Valor-Z para curtosis & $-1,54$ & 0,12 & & & & & \\
\hline
\end{tabular}

\section{b. Presencia nudo de canto}

Las pruebas de normalidad y de verificación de varianza se muestran en la Tabla 259.

Tabla 259. MOR - Presencia nudos de canto: prueba de normalidad de residuos y verificación de varianza

\begin{tabular}{|c|c|c|c|c|c|c|c|}
\hline Test de normalidad & Estadístico & $\begin{array}{c}\mathrm{P}- \\
\text { valor }\end{array}$ & $\begin{array}{c}\text { Prueba de bondad de } \\
\text { ajuste }\end{array}$ & $\begin{array}{c}\mathrm{P}- \\
\text { valor }\end{array}$ & $\begin{array}{c}\text { Test de } \\
\text { homocedasticidad }\end{array}$ & Prueba & $\begin{array}{c}\mathrm{P}- \\
\text { valor }\end{array}$ \\
\hline Chi-Cuadrado & 45,88 & 0,83 & \multirow{4}{*}{ Kolmogorov-Smirnov } & \multirow{4}{*}{0,96} & \multirow{4}{*}{ Levene } & \multirow{4}{*}{0,04} & \multirow{4}{*}{0,83} \\
\hline $\begin{array}{c}\text { Estadístico W de } \\
\text { Shapiro-Wilk }\end{array}$ & 0,98 & 0,08 & & & & & \\
\hline Valor-Z para asimetría & 0,63 & 0,53 & & & & & \\
\hline Valor-Z para curtosis & $-1,02$ & 0,31 & & & & & \\
\hline
\end{tabular}

\section{Por existencia y ubicación}

\section{a. Nudos}

Las pruebas de normalidad y de verificación de varianza se muestran en la Tabla 260.

Tabla 260. MOR - Variable Nudos: prueba de normalidad de residuos y verificación de varianza

\begin{tabular}{|c|c|c|c|c|c|c|c|}
\hline Test de normalidad & Estadístico & $\begin{array}{c}\mathrm{P}- \\
\text { valor }\end{array}$ & $\begin{array}{c}\text { Prueba de bondad de } \\
\text { ajuste }\end{array}$ & $\begin{array}{c}\mathrm{P}- \\
\text { valor }\end{array}$ & $\begin{array}{c}\text { Test de } \\
\text { homocedasticidad } \\
\end{array}$ & Prueba & $\begin{array}{c}\mathrm{P}- \\
\text { valor }\end{array}$ \\
\hline Chi-Cuadrado & 42,73 & 0,89 & \multirow{4}{*}{ Kolmogorov-Smirnov } & \multirow{4}{*}{0,98} & \multirow{4}{*}{ Levene } & \multirow{4}{*}{2,63} & \multirow{4}{*}{0,07} \\
\hline $\begin{array}{c}\text { Estadístico W de } \\
\text { Shapiro-Wilk } \\
\end{array}$ & 0,98 & 0,13 & & & & & \\
\hline Valor-Z para asimetría & 0,44 & 0,66 & & & & & \\
\hline Valor-Z para curtosis & $-1,19$ & 0,23 & & & & & \\
\hline
\end{tabular}

\section{Nudos: consideraciones cuantitativas}

\section{Por tamaño}

\section{a. Tamaño nudo de cara}

Las pruebas de normalidad y de verificación de varianza se muestran en la Tabla 261. 
Tabla 261. MOR - Tamaño Nudo de cara: prueba de normalidad de residuos y verificación de varianza

\begin{tabular}{|c|c|c|c|c|c|c|c|}
\hline Test de normalidad & Estadístico & $\begin{array}{c}\text { P- } \\
\text { valor }\end{array}$ & $\begin{array}{l}\text { Prueba de bondad de } \\
\text { ajuste }\end{array}$ & $\begin{array}{c}\mathrm{P}- \\
\text { valor }\end{array}$ & $\begin{array}{c}\text { Test de } \\
\text { homocedasticidad }\end{array}$ & Prueba & $\begin{array}{c}\mathrm{P}- \\
\text { valor }\end{array}$ \\
\hline Chi-Cuadrado & 36,25 & 0,98 & \multirow{4}{*}{ Kolmogorov-Smirnov } & \multirow{4}{*}{0,89} & \multirow{4}{*}{ Levene } & \multirow{4}{*}{2,27} & \multirow{4}{*}{0,10} \\
\hline $\begin{array}{c}\text { Estadístico W de } \\
\text { Shapiro-Wilk } \\
\end{array}$ & 0,98 & 0,00 & & & & & \\
\hline Valor-Z para asimetría & 0,41 & 0,68 & & & & & \\
\hline Valor-Z para curtosis & $-2,22$ & 0,03 & & & & & \\
\hline
\end{tabular}

\section{b. Tamaño nudo de canto}

Las pruebas de normalidad y de verificación de varianza se muestran en la Tabla 262.

Tabla 262. MOR - Tamaño Nudo de canto: prueba de normalidad de residuos y verificación de varianza

\begin{tabular}{|c|c|c|c|c|c|c|c|}
\hline Test de normalidad & Estadístico & $\begin{array}{c}\text { P- } \\
\text { valor }\end{array}$ & $\begin{array}{c}\text { Prueba de bondad de } \\
\text { ajuste }\end{array}$ & $\begin{array}{c}\mathrm{P}- \\
\text { valor }\end{array}$ & $\begin{array}{c}\text { Test de } \\
\text { homocedasticidad }\end{array}$ & Prueba & $\begin{array}{c}\mathrm{P}- \\
\text { valor }\end{array}$ \\
\hline Chi-Cuadrado & 45,0 & 0,85 & \multirow{4}{*}{ Kolmogorov-Smirnov } & \multirow{4}{*}{0,85} & \multirow{4}{*}{ Levene } & \multirow{4}{*}{0,24} & \multirow{4}{*}{0,79} \\
\hline $\begin{array}{c}\text { Estadístico W de } \\
\text { Shapiro-Wilk } \\
\end{array}$ & 0,98 & 0,01 & & & & & \\
\hline Valor-Z para asimetría & 0,68 & 0,49 & & & & & \\
\hline Valor-Z para curtosis & $-2,00$ & 0,05 & & & & & \\
\hline
\end{tabular}

\section{Desviación de las fibras}

Las pruebas de normalidad y de verificación de varianza se muestran en la Tabla 263.

Tabla 263. MOR - Desviación de las fibras: prueba de normalidad de residuos y verificación de varianza

\begin{tabular}{|c|c|c|c|c|c|c|c|}
\hline Test de normalidad & Estadístico & $\begin{array}{c}\mathrm{P}- \\
\text { valor }\end{array}$ & $\begin{array}{c}\text { Prueba de bondad de } \\
\text { ajuste }\end{array}$ & $\begin{array}{c}\text { P- } \\
\text { valor }\end{array}$ & $\begin{array}{c}\text { Test de } \\
\text { homocedasticidad }\end{array}$ & Prueba & $\begin{array}{l}\text { P- } \\
\text { valor }\end{array}$ \\
\hline Chi-Cuadrado & 45,33 & 0,79 & \multirow{4}{*}{ Kolmogorov-Smirnov } & \multirow{4}{*}{0,10} & \multirow{4}{*}{ Levene } & \multirow{4}{*}{3,31} & \multirow{4}{*}{0,04} \\
\hline $\begin{array}{c}\text { Estadístico W de } \\
\text { Shapiro-Wilk } \\
\end{array}$ & 0,98 & 0,01 & & & & & \\
\hline Valor-Z para asimetría & 0,90 & 0,37 & & & & & \\
\hline Valor-Z para curtosis & $-0,69$ & 0,49 & & & & & \\
\hline
\end{tabular}

\section{Entrecasco}

Las pruebas de normalidad y de verificación de varianza se muestran en la Tabla 264.

Tabla 264. MOR - Entrecasco: prueba de normalidad de residuos y verificación de varianza

\begin{tabular}{|c|c|c|c|c|c|c|c|}
\hline Test de normalidad & Estadístico & $\begin{array}{c}\mathrm{P}- \\
\text { valor }\end{array}$ & $\begin{array}{c}\text { Prueba de bondad de } \\
\text { ajuste }\end{array}$ & $\begin{array}{c}\mathrm{P}- \\
\text { valor }\end{array}$ & $\begin{array}{c}\text { Test de } \\
\text { homocedasticidad }\end{array}$ & Prueba & $\begin{array}{c}\mathrm{P}- \\
\text { valor }\end{array}$ \\
\hline Chi-Cuadrado & 46,25 & 0,82 & \multirow{4}{*}{ Kolmogorov-Smirnov } & \multirow{4}{*}{0,92} & \multirow{4}{*}{ Levene } & \multirow{4}{*}{7,30} & \multirow{4}{*}{0,00} \\
\hline $\begin{array}{c}\text { Estadístico } \mathrm{W} \mathrm{de} \\
\text { Shapiro-Wilk }\end{array}$ & 0,99 & 0,57 & & & & & \\
\hline Valor-Z para asimetría & 1,63 & 0,10 & & & & & \\
\hline Valor-Z para curtosis & 0,51 & 0,61 & & & & & \\
\hline
\end{tabular}




\subsection{Defectos de aserrado: influencia en el MOR}

Del mismo modo que lo indicado para el MOE, se trabajó con los rangos categóricos planteados en Materiales y Métodos.

\section{$\underline{\text { Gemas }}$}

\section{a. Grupo anchura de gemas}

Las pruebas de normalidad y de verificación de varianza se muestran en la Tabla 265.

Tabla 265. MOR - Grupo anchura de gemas: prueba de normalidad de residuos y verificación de varianza

\begin{tabular}{|c|c|c|c|c|c|c|c|}
\hline Test de normalidad & Estadístico & $\begin{array}{c}\mathrm{P}- \\
\text { valor }\end{array}$ & $\begin{array}{c}\text { Prueba de bondad de } \\
\text { ajuste }\end{array}$ & $\begin{array}{c}\mathrm{P}- \\
\text { valor }\end{array}$ & $\begin{array}{c}\text { Test de } \\
\text { homocedasticidad }\end{array}$ & Prueba & $\begin{array}{c}\mathrm{P}- \\
\text { valor }\end{array}$ \\
\hline Chi-Cuadrado & 43,36 & 0,87 & \multirow{4}{*}{ Kolmogorov-Smirnov } & \multirow{4}{*}{1,00} & \multirow{4}{*}{ Levene } & \multirow{4}{*}{4,10} & \multirow{4}{*}{0,02} \\
\hline $\begin{array}{c}\text { Estadístico W de Shapiro- } \\
\text { Wilk }\end{array}$ & 0,98 & 0,00 & & & & & \\
\hline Valor-Z para asimetría & 0,62 & 0,53 & & & & & \\
\hline Valor-Z para curtosis & $-2,05$ & 0,04 & & & & & \\
\hline
\end{tabular}

\section{b. Grupo longitud de gemas}

Las pruebas de normalidad y de verificación de varianza se muestran en la Tabla 266.

Tabla 266. MOR - Grupo longitud de gemas: prueba de normalidad de residuos y verificación de varianza

\begin{tabular}{|c|c|c|c|c|c|c|c|}
\hline Test de normalidad & Estadístico & $\begin{array}{c}\mathrm{P}- \\
\text { valor }\end{array}$ & $\begin{array}{c}\text { Prueba de bondad de } \\
\text { ajuste }\end{array}$ & $\begin{array}{c}\mathrm{P}- \\
\text { valor }\end{array}$ & $\begin{array}{c}\text { Test de } \\
\text { homocedasticidad } \\
\end{array}$ & Prueba & $\begin{array}{c}\mathrm{P}- \\
\text { valor }\end{array}$ \\
\hline Chi-Cuadrado & 69,80 & 0,09 & \multirow{4}{*}{ Kolmogorov-Smirnov } & \multirow{4}{*}{0,85} & \multirow{4}{*}{ Levene } & \multirow{4}{*}{0,50} & \multirow{4}{*}{0,61} \\
\hline $\begin{array}{c}\text { Estadístico W de } \\
\text { Shapiro-Wilk } \\
\end{array}$ & 0,98 & 0,00 & & & & & \\
\hline Valor-Z para asimetría & 0,88 & 0,38 & & & & & \\
\hline Valor-Z para curtosis & $-2,18$ & 0,03 & & & & & \\
\hline
\end{tabular}

\section{Médula}

Las pruebas de normalidad y de verificación de varianza se muestran en la Tabla 267.

Tabla 267. MOR - Médula: prueba de normalidad de residuos y verificación de Varianza

\begin{tabular}{|c|c|c|c|c|c|c|c|}
\hline Test de normalidad & Estadístico & $\begin{array}{c}\mathrm{P}- \\
\text { valor }\end{array}$ & $\begin{array}{c}\text { Prueba de bondad de } \\
\text { ajuste }\end{array}$ & $\begin{array}{c}\mathrm{P}- \\
\text { valor }\end{array}$ & $\begin{array}{c}\text { Test de } \\
\text { homocedasticidad }\end{array}$ & Prueba & $\begin{array}{c}\mathrm{P}- \\
\text { valor }\end{array}$ \\
\hline Chi-Cuadrado & 40,75 & 0,94 & \multirow{4}{*}{ Kolmogorov-Smirnov } & \multirow{4}{*}{0,99} & \multirow{4}{*}{ Levene } & \multirow{4}{*}{2,50} & \multirow{4}{*}{0,11} \\
\hline $\begin{array}{c}\text { Estadístico W de } \\
\text { Shapiro-Wilk } \\
\end{array}$ & 0,99 & 0,72 & & & & & \\
\hline Valor-Z para asimetría & 1,35 & 0,18 & & & & & \\
\hline Valor-Z para curtosis & 1,37 & 0,17 & & & & & \\
\hline
\end{tabular}




\subsection{Defectos de secado: influencia en el MOR}

\section{Curvatura de cara}

Las pruebas de normalidad y de verificación de varianza se muestran en la Tabla 268.

Tabla 268. MOR - Grupo Curvatura de cara: prueba de normalidad de residuos y verificación de varianza

\begin{tabular}{|c|c|c|c|c|c|c|c|}
\hline Test de normalidad & Estadístico & $\begin{array}{l}\mathrm{P}- \\
\text { valor }\end{array}$ & $\begin{array}{l}\text { Prueba de bondad de } \\
\text { ajuste }\end{array}$ & $\begin{array}{l}\mathrm{P}- \\
\text { valor }\end{array}$ & $\begin{array}{c}\text { Test de } \\
\text { homocedasticidad }\end{array}$ & Prueba & $\begin{array}{l}\mathrm{P}- \\
\text { valor }\end{array}$ \\
\hline Chi-Cuadrado & 68,58 & 0,10 & \multirow{4}{*}{ Kolmogorov-Smirnov } & \multirow{4}{*}{0,82} & \multirow{4}{*}{ Levene } & \multirow{4}{*}{4,02} & \multirow{4}{*}{0,02} \\
\hline $\begin{array}{c}\text { Estadístico W de } \\
\text { Shapiro-Wilk } \\
\end{array}$ & 0,98 & 0,00 & & & & & \\
\hline Valor-Z para asimetría & 0,61 & 0,54 & & & & & \\
\hline Valor-Z para curtosis & $-1,83$ & 0,07 & & & & & \\
\hline
\end{tabular}

De acuerdo con el P-valor obtenido mediante la prueba de Levene, existe una diferencia estadísticamente significativa entre las desviaciones estándar, con un nivel del $95,0 \%$ de confianza, incumpliendo uno de los supuestos importantes subyacentes en el análisis de varianza. Por esa razón se trabajó con la prueba de Kruskal-Wallis. Ante significancia estadística esbozada por esta prueba, se procedió a analizar las medianas de a pares para evaluar entre cuales existía esa diferencia, Tabla 269.

Tabla 269. MOR - Curvatura de cara: prueba de Kruskal-Wallis: comparación de pares de medianas

\begin{tabular}{ccccccccc}
\hline $\begin{array}{c}\text { Variable } \\
\begin{array}{c}\text { Curvatura } \\
\text { cara }\end{array}\end{array}$ & $\begin{array}{c}\text { Tamaño } \\
\text { Muestra }\end{array}$ & $\begin{array}{c}\text { Rango } \\
\text { Promedio }\end{array}$ & $\begin{array}{c}\text { Variable } \\
\text { Curvatura } \\
\text { cara }\end{array}$ & $\begin{array}{c}\text { Tamaño } \\
\text { Muestra }\end{array}$ & $\begin{array}{c}\text { Rango } \\
\text { Promedio }\end{array}$ & $\begin{array}{c}\text { Variable } \\
\text { Curvatura } \\
\text { cara }\end{array}$ & $\begin{array}{c}\text { Tamaño } \\
\text { Muestra }\end{array}$ & $\begin{array}{c}\text { Rango } \\
\text { Promedio }\end{array}$ \\
\hline 0 & 148 & 342,20 & 0 & 148 & 242,33 & 1 & 456 & 367,36 \\
1 & 456 & 289,61 & 2 & 305 & 219,56 & 2 & 305 & 401,40 \\
\hline $\begin{array}{c}\text { Estadístico: } \\
10,15\end{array}$ & \multirow{2}{*}{ P-valor: 0,00} & $\begin{array}{c}\text { Estadístico: } \\
3,01\end{array}$ & P-valor: 0,08 & \multirow{2}{*}{ Estadístico: 4,38 } & \multirow{2}{*}{ P-valor: 0,04} \\
\hline
\end{tabular}

Se consideraron las diferencias significativas establecidas entre la categoría 0 y categoría 1, mientras que las demás comparaciones fueron consideradas no significativas para este análisis

\section{Curvatura de canto}

Las pruebas de normalidad y de verificación de varianza se muestran en la Tabla 270. 
Tabla 270. MOR - Grupo Curvatura de canto: prueba de normalidad de residuos y verificación de varianza

\begin{tabular}{|c|c|c|c|c|c|c|c|}
\hline Test de normalidad & Estadístico & $\begin{array}{c}\mathrm{P}- \\
\text { valor }\end{array}$ & $\begin{array}{l}\text { Prueba de bondad de } \\
\text { ajuste }\end{array}$ & $\begin{array}{c}\text { P- } \\
\text { valor }\end{array}$ & $\begin{array}{c}\text { Test de } \\
\text { homocedasticidad }\end{array}$ & Prueba & $\begin{array}{c}\mathrm{P}- \\
\text { valor }\end{array}$ \\
\hline Chi-Cuadrado & 52,07 & 0,59 & \multirow{4}{*}{ Kolmogorov-Smirnov } & \multirow{4}{*}{0,94} & \multirow{4}{*}{ Levene } & \multirow{4}{*}{3,64} & \multirow{4}{*}{0,03} \\
\hline $\begin{array}{c}\text { Estadístico W de } \\
\text { Shapiro-Wilk } \\
\end{array}$ & 0,98 & 0,00 & & & & & \\
\hline Valor-Z para asimetría & 0,72 & 0,47 & & & & & \\
\hline Valor-Z para curtosis & $-1,80$ & 0,07 & & & & & \\
\hline
\end{tabular}

De acuerdo con el $\mathrm{P}$-valor $<0,05$ del test de Levene, existe una diferencia estadísticamente significativa entre las desviaciones estándar, con un nivel del 95,0\% de confianza, incumpliendo uno de los supuestos subyacentes en el análisis de varianza, por lo que se trabajó con el tes de Kruskal-Wallis.

\section{$\underline{\text { Alabeos }}$}

Las pruebas de normalidad y de verificación de varianza se muestran en la Tabla 271.

Tabla 271. MOR - Alabeos: prueba de normalidad de residuos y verificación de varianza

\begin{tabular}{|c|c|c|c|c|c|c|c|}
\hline Test de normalidad & Estadístico & $\begin{array}{c}\mathrm{P}- \\
\text { valor }\end{array}$ & $\begin{array}{c}\text { Prueba de bondad de } \\
\text { ajuste }\end{array}$ & $\begin{array}{c}\mathrm{P}- \\
\text { valor }\end{array}$ & $\begin{array}{c}\text { Test de } \\
\text { homocedasticidad }\end{array}$ & Prueba & $\begin{array}{c}\mathrm{P}- \\
\text { valor }\end{array}$ \\
\hline Chi-Cuadrado & 55,05 & 0,47 & \multirow{4}{*}{ Kolmogorov-Smirnov } & \multirow{4}{*}{1,00} & \multirow{4}{*}{ Levene } & \multirow{4}{*}{8,30} & \multirow{4}{*}{0,00} \\
\hline $\begin{array}{c}\text { Estadístico W de Shapiro- } \\
\text { Wilk }\end{array}$ & 0,98 & 0,01 & & & & & \\
\hline Valor-Z para asimetría & 0,37 & 0,71 & & & & & \\
\hline Valor-Z para curtosis & $-1,09$ & 0,28 & & & & & \\
\hline
\end{tabular}

Consecuentemente con el $\mathrm{P}$-valor $<0,05$ del test de Levene, existe una diferencia estadísticamente significativa entre las desviaciones estándar, con un nivel del 95,0\% de confianza, incumpliendo uno de los supuestos importantes subyacentes en el análisis de varianza, por lo que se trabajó con el test de Kruskal-Wallis y ante la significancia estadística esbozada, se procedió a analizar las medianas de a pares, Tabla 272.

Tabla 272. MOR - Alabeo: prueba de Kruskal-Wallis: comparación de pares de medianas

\begin{tabular}{ccccccccc}
\hline $\begin{array}{c}\text { Variable } \\
\text { Alabeo }\end{array}$ & $\begin{array}{c}\text { Tamaño } \\
\text { Muestra }\end{array}$ & $\begin{array}{c}\text { Rango } \\
\text { Promedio }\end{array}$ & $\begin{array}{c}\text { Variable } \\
\text { Alabeo }\end{array}$ & $\begin{array}{c}\text { Tamaño } \\
\text { Muestra }\end{array}$ & $\begin{array}{c}\text { Rango } \\
\text { Promedio }\end{array}$ & $\begin{array}{c}\text { Variable } \\
\text { Alabeo }\end{array}$ & $\begin{array}{c}\text { Tamaño } \\
\text { Muestra }\end{array}$ & $\begin{array}{c}\text { Rango } \\
\text { Promedio }\end{array}$ \\
\hline 0 & 419 & 368,14 & 0 & 419 & 318,40 & 1 & 301 & 256,80 \\
1 & 301 & 349,86 & 2 & 184 & 264,66 & 2 & 184 & 220,43 \\
\hline $\begin{array}{c}\text { Estadístico: } \\
\text { 1,35 }\end{array}$ & \multirow{2}{*}{ P-valor: 0,24} & $\begin{array}{c}\text { Estadístico: } \\
12,17\end{array}$ & \multirow{2}{*}{ P-valor: 0,00} & \multirow{2}{*}{ Estadístico: 7,69} & P-valor: 0,01 \\
\hline
\end{tabular}




\subsubsection{Influencia de los defectos en la densidad}

\subsection{Defectos naturales: influencia en la densidad}

Para este análisis se consideraron, al igual que para el MOE y el MOR, los rangos clasificatorios pertenecientes a los factores. Asimismo, dado el incumplimiento del supuesto de la variable densidad, se trabajó con su transformación 1/(Densidad).

\section{Nudos: consideraciones cualitativas}

\section{Por existencia}

\section{a. Presencia nudos de cara}

Las pruebas de normalidad y de verificación de varianza se muestran en la Tabla 273.

Tabla 273. 1/(Densidad) - Presencia nudos de cara: prueba de normalidad de residuos y verificación de varianza

\begin{tabular}{|c|c|c|c|c|c|c|c|}
\hline Test de normalidad & Estadístico & $\begin{array}{c}\mathrm{P}- \\
\text { valor }\end{array}$ & $\begin{array}{c}\text { Prueba de bondad de } \\
\text { ajuste }\end{array}$ & $\begin{array}{c}\mathrm{P}- \\
\text { valor }\end{array}$ & $\begin{array}{c}\text { Test de } \\
\text { homocedasticidad } \\
\end{array}$ & Prueba & $\begin{array}{c}\mathrm{P}- \\
\text { valor }\end{array}$ \\
\hline Chi-Cuadrado & 147,75 & 0,00 & \multirow{4}{*}{ Kolmogorov-Smirnov } & \multirow{4}{*}{0,00} & \multirow{4}{*}{ Levene } & \multirow{4}{*}{23,36} & \multirow{4}{*}{0,00} \\
\hline $\begin{array}{l}\text { Estadístico W de } \\
\text { Shapiro-Wilk } \\
\end{array}$ & 0,97 & 0,00 & & & & & \\
\hline Valor-Z para asimetría & 2,52 & 0,01 & & & & & \\
\hline Valor-Z para curtosis & $-5,57$ & 0,00 & & & & & \\
\hline
\end{tabular}

\section{b. Presencia nudos de canto}

Las pruebas de normalidad y de verificación de varianza se muestran en la Tabla 274.

Tabla 274. 1/(Densidad) - Presencia nudos de canto: prueba de normalidad de residuos y verificación de varianza

\begin{tabular}{|c|c|c|c|c|c|c|c|}
\hline Test de normalidad & Estadístico & $\begin{array}{c}\text { P- } \\
\text { valor }\end{array}$ & $\begin{array}{l}\text { Prueba de bondad de } \\
\text { ajuste }\end{array}$ & $\begin{array}{c}\mathrm{P}- \\
\text { valor }\end{array}$ & $\begin{array}{c}\text { Test de } \\
\text { homocedasticidad }\end{array}$ & Prueba & $\begin{array}{c}\text { P- } \\
\text { valor }\end{array}$ \\
\hline Chi-Cuadrado & 113,31 & 0,00 & \multirow{4}{*}{ Kolmogorov-Smirnov } & \multirow{4}{*}{0,00} & \multirow{4}{*}{ Levene } & \multirow{4}{*}{18,82} & \multirow{4}{*}{0,00} \\
\hline $\begin{array}{c}\text { Estadístico W de } \\
\text { Shapiro-Wilk } \\
\end{array}$ & 0,97 & 0,00 & & & & & \\
\hline Valor-Z para asimetría & 2,60 & 0,01 & & & & & \\
\hline Valor-Z para curtosis & $-4,51$ & 0,00 & & & & & \\
\hline
\end{tabular}

\section{Por existencia y ubicación}

\section{a. Nudos}

Las pruebas de normalidad y de verificación de varianza se muestran en la Tabla 275. 
Tabla 275. 1/(Densidad) - Nudos: prueba de normalidad de residuos y verificación de varianza

\begin{tabular}{|c|c|c|c|c|c|c|c|}
\hline Test de normalidad & Estadístico & $\begin{array}{c}\mathrm{P}- \\
\text { valor }\end{array}$ & $\begin{array}{c}\text { Prueba de bondad de } \\
\text { ajuste }\end{array}$ & $\begin{array}{c}\mathrm{P}- \\
\text { valor }\end{array}$ & $\begin{array}{c}\text { Test de } \\
\text { homocedasticidad } \\
\end{array}$ & Prueba & $\begin{array}{c}\mathrm{P}- \\
\text { valor }\end{array}$ \\
\hline Chi-Cuadrado & 130,30 & 0,00 & \multirow{4}{*}{ Kolmogorov-Smirnov } & \multirow{4}{*}{0,00} & \multirow{4}{*}{ Levene's } & \multirow{4}{*}{14,14} & \multirow{4}{*}{0,00} \\
\hline $\begin{array}{c}\text { Estadístico W de } \\
\text { Shapiro-Wilk } \\
\end{array}$ & 0,97 & 0,00 & & & & & \\
\hline Valor-Z para asimetría & 2,48 & 0,01 & & & & & \\
\hline Valor-Z para curtosis & $-4,64$ & 0,00 & & & & & \\
\hline
\end{tabular}

Dada la significancia estadística obtenida, se procedió a realizar la prueba de KruskalWallis entre pares de medianas para determinar entre cuales de ellas existía la diferencia, Tabla 276.

Tabla 276. 1/(Densidad) - "Nudos": prueba de Kruskal-Wallis: comparación de pares de medianas

\begin{tabular}{ccccccccc}
\hline $\begin{array}{c}\text { Variable } \\
\text { Nudos }\end{array}$ & $\begin{array}{c}\text { Tamaño } \\
\text { Muestra }\end{array}$ & $\begin{array}{c}\text { Rango } \\
\text { Promedio }\end{array}$ & $\begin{array}{c}\text { Variable } \\
\text { Nudos }\end{array}$ & $\begin{array}{c}\text { Tamaño } \\
\text { Muestra }\end{array}$ & $\begin{array}{c}\text { Rango } \\
\text { Promedio }\end{array}$ & $\begin{array}{c}\text { Variable } \\
\text { Nudos }\end{array}$ & $\begin{array}{c}\text { Tamaño } \\
\text { Muestra }\end{array}$ & $\begin{array}{c}\text { Rango } \\
\text { Promedio }\end{array}$ \\
\hline 0 & 111 & 146,76 & 0 & 111 & 438,67 & 1 & 180 & 458,79 \\
1 & 180 & 145,53 & 3 & 641 & 365,73 & 3 & 641 & 397,58 \\
\hline $\begin{array}{c}\text { Estadístico: } \\
0,01\end{array}$ & \multicolumn{2}{c}{ P-valor: 0,90} & $\begin{array}{c}\text { Estadístico: } \\
10,67\end{array}$ & P-valor: 0,00 & Estadístico: 9,36 & P-valor: 0,00 \\
\hline
\end{tabular}

Tal como se observa en la Tabla 276, excepto las categorías 0 y 1 , no se observan diferencias significativas entre las medianas de 1/(Densidad) para las categorías $0-3$ y $1-3$.

\section{Nudos: consideraciones cuantitativas}

\section{Por tamaño}

\section{a. Tamaño nudo de cara}

Las pruebas de normalidad y de verificación de varianza se muestran en la Tabla 277.

Tabla 277. 1/(Densidad) - Tamaño nudo de cara: prueba de normalidad de residuos y verificación de varianza

\begin{tabular}{ccccccc}
\hline Test de normalidad & Estadístico & $\begin{array}{c}\text { P- } \\
\text { valor }\end{array}$ & $\begin{array}{c}\text { Prueba de bondad de } \\
\text { ajuste }\end{array}$ & $\begin{array}{c}\text { P- } \\
\text { valor }\end{array}$ & $\begin{array}{c}\text { Test de } \\
\text { homocedasticidad }\end{array}$ & $\begin{array}{c}\text { Prueba } \\
\begin{array}{c}\text { P- } \\
\text { valor }\end{array}\end{array}$ \\
\hline Chi-Cuadrado & 127,98 & 1,47 & & & & \\
\hline $\begin{array}{c}\text { Estadístico W de } \\
\text { Shapiro-Wilk }\end{array}$ & 0,97 & 0,00 \\
\hline Valor-Z para asimetría & 2,69 & 0,01 \\
\hline Valor-Z para curtosis & $-5,18$ & 0,00 & Levene & 6,43 & 0,00 \\
\hline
\end{tabular}

Dado que no pudo comprobarse el cumplimiento de ambos supuestos, se trabajó con la prueba de Kruskal-Wallis; para evaluar entre que pares de medianas existía diferencias significativas se empleó el mismo test, Tabla 278. 
Tabla 278. 1/(Densidad) - Tamaño nudo de cara: prueba de Kruskal-Wallis: comparación de pares de medianas

\begin{tabular}{ccccccccc}
\hline $\begin{array}{c}\text { Variable } \\
\text { Tamaño } \\
\text { nudo cara }\end{array}$ & $\begin{array}{c}\text { Tamaño } \\
\text { Muestra }\end{array}$ & $\begin{array}{c}\text { Rango } \\
\text { Promedio }\end{array}$ & $\begin{array}{c}\text { Variable } \\
\text { Tamaño } \\
\text { nudo cara }\end{array}$ & $\begin{array}{c}\text { Tamaño } \\
\text { Muestra }\end{array}$ & $\begin{array}{c}\text { Rango } \\
\text { Promedio }\end{array}$ & $\begin{array}{c}\text { Variable } \\
\text { Tamaño } \\
\text { nudo cara }\end{array}$ & $\begin{array}{c}\text { Tamaño } \\
\text { Muestra }\end{array}$ & $\begin{array}{c}\text { Rango } \\
\text { Promedio }\end{array}$ \\
\hline 1 & 571 & 454,32 & 1 & 571 & 333,88 & 2 & 295 & 189,82 \\
2 & 295 & 393,20 & 3 & 83 & 283,61 & 3 & 83 & 188,35 \\
\hline Estadístico: 11,61 & P-valor: 0,00 & Estadístico: 5,13 & P-valor: 0,02 & Estadístico: 0,01 & P-valor: 0,91 \\
\hline
\end{tabular}

De acuerdo a lo planteado en la Tabla 278, las diferencias significativas entre medianas estuvieron representadas por la categoría 1 con respecto a las otras dos categorías, las cuales no se diferenciaron entre sí.

\section{b. Tamaño nudo de canto}

Las pruebas de normalidad y de verificación de varianza se muestran en la Tabla 279.

Tabla 279. 1/(Densidad) - Tamaño nudo de canto: prueba de normalidad de residuos y verificación de varianza

\begin{tabular}{|c|c|c|c|c|c|c|c|}
\hline Test de normalidad & Estadístico & $\begin{array}{c}\text { P- } \\
\text { valor }\end{array}$ & $\begin{array}{c}\text { Prueba de bondad de } \\
\text { ajuste }\end{array}$ & $\begin{array}{c}\text { P- } \\
\text { valor }\end{array}$ & $\begin{array}{c}\text { Test de } \\
\text { homocedasticidad }\end{array}$ & Prueba & $\begin{array}{c}\mathrm{P}- \\
\text { valor }\end{array}$ \\
\hline Chi-Cuadrado & 132,71 & 0,00 & \multirow{4}{*}{ Kolmogorov-Smirnov } & \multirow{4}{*}{0,00} & \multirow{4}{*}{ Levene } & \multirow{4}{*}{3,15} & \multirow{4}{*}{0,04} \\
\hline $\begin{array}{l}\text { Estadístico W de } \\
\text { Shapiro-Wilk }\end{array}$ & 0,97 & 0,00 & & & & & \\
\hline Valor-Z para asimetría & 2,79 & 0,01 & & & & & \\
\hline Valor-Z para curtosis & $-3,30$ & 0,00 & & & & & \\
\hline
\end{tabular}

Dado el incumplimiento del supuesto de normalidad y homocedasticidad, se trabajó con la prueba de Krsukal-Wallis para determinar diferencias entre medianas. De acuerdo con la significancia estadística obtenida mediante dicho test, se realizó la comparación entre pares de medianas, Tabla 280.

Tabla 280. 1/(Densidad) - Tamaño nudo de canto: comparación de pares de medianas

\begin{tabular}{ccccccccc}
\hline $\begin{array}{c}\text { Variable } \\
\text { Tamaño } \\
\text { nudo canto }\end{array}$ & $\begin{array}{c}\text { Tamaño } \\
\text { Muestra }\end{array}$ & $\begin{array}{c}\text { Rango } \\
\text { Promedio }\end{array}$ & $\begin{array}{c}\text { Variable } \\
\text { Tamaño } \\
\text { nudo canto }\end{array}$ & $\begin{array}{c}\text { Tamaño } \\
\text { Muestra }\end{array}$ & $\begin{array}{c}\text { Rango } \\
\text { Promedio }\end{array}$ & $\begin{array}{c}\text { Variable } \\
\text { Tamaño } \\
\text { nudo canto }\end{array}$ & $\begin{array}{c}\text { Tamaño } \\
\text { Muestra }\end{array}$ & $\begin{array}{c}\text { Rango } \\
\text { Promedio }\end{array}$ \\
\hline 1 & 491 & 391,87 & 1 & 491 & 364,95 & 2 & 273 & 247,76 \\
2 & 273 & 365,65 & 3 & 185 & 268,30 & 3 & 185 & 202,55 \\
\hline Estadístico: 2,48 & P-valor: 0,12 & Estadístico: 32,91 & P-valor: $9,65 E-9$ & Estadístico: 12,87 & P-valor: 0,00 \\
\hline
\end{tabular}

Según lo indicado, la diferencia entre medianas de 1/(Densidad) queda indicado por las categoría 3 respecto a las otras dos categorías.

\section{Desviación de las fibras}

Las pruebas de normalidad y de verificación de varianza se muestran en la Tabla 281. 
Tabla 281. 1/(Densidad) - Desviación de fibras: prueba de normalidad de residuos y verificación de varianza

\begin{tabular}{|c|c|c|c|c|c|c|c|}
\hline Test de normalidad & Estadístico & $\begin{array}{c}\mathrm{P}- \\
\text { valor }\end{array}$ & $\begin{array}{l}\text { Prueba de bondad de } \\
\text { ajuste }\end{array}$ & $\begin{array}{c}\mathrm{P}- \\
\text { valor }\end{array}$ & $\begin{array}{c}\text { Test de } \\
\text { homocedasticidad }\end{array}$ & Prueba & $\begin{array}{c}\text { P- } \\
\text { valor }\end{array}$ \\
\hline Chi-Cuadrado & 105,09 & 0,00 & \multirow{4}{*}{ Kolmogorov-Smirnov } & \multirow{4}{*}{0,00} & \multirow{4}{*}{ Levene's } & \multirow{4}{*}{10,23} & \multirow{4}{*}{0,00} \\
\hline $\begin{array}{c}\text { Estadístico W de Shapiro- } \\
\text { Wilk } \\
\end{array}$ & 0,97 & 0,00 & & & & & \\
\hline Valor-Z para asimetría & 3,47 & 0,00 & & & & & \\
\hline Valor-Z para curtosis & $-1,03$ & 0,30 & & & & & \\
\hline
\end{tabular}

De acuerdo con la significancia estadística obtenida mediante la prueba de KruskalWallis, se utilizó el mismo test para determinar entre que pares de medianas existía dicha diferencia, Tabla 282.

Tabla 282. 1/(Densidad) - Desviación de fibras: comparación de pares de medianas

\begin{tabular}{ccccccccc}
\hline $\begin{array}{c}\text { Variable } \\
\begin{array}{c}\text { Desviación } \\
\text { fibras }\end{array}\end{array}$ & $\begin{array}{c}\text { Tamaño } \\
\text { Muestra }\end{array}$ & $\begin{array}{c}\text { Rango } \\
\text { Promedio }\end{array}$ & $\begin{array}{c}\text { Variable } \\
\text { Desviación } \\
\text { fibras }\end{array}$ & $\begin{array}{c}\text { Tamaño } \\
\text { Muestra }\end{array}$ & $\begin{array}{c}\text { Rango } \\
\text { Promedio }\end{array}$ & $\begin{array}{c}\text { Variable } \\
\text { Desviación } \\
\text { fibras }\end{array}$ & $\begin{array}{c}\text { Tamaño } \\
\text { Muestra }\end{array}$ & $\begin{array}{c}\text { Rango } \\
\text { Promedio }\end{array}$ \\
\hline 0 & 172 & 340,82 & 0 & 172 & 110,05 & 1 & 614 & 336,70 \\
1 & 614 & 408,26 & 2 & 73 & 153,52 & 2 & 73 & 405,41 \\
\hline Estadístico: 11,85 & P-valor: 0,00 & Estadístico: 19,29 & P-valor: 0,00 & Estadístico: 7,82 & P-valor: 0,01 \\
\hline
\end{tabular}

De acuerdo con este análisis puede indicarse que la mediana de 1/(Densidad) es significativamente diferente en todas las categorías de desviación de las fibras planteadas.

\section{Entrecasco}

Las pruebas de normalidad y de verificación de varianza se muestran en la Tabla 283.

Tabla 283. 1/(Densidad) - Entrecasco: prueba de normalidad de residuos y verificación de varianza

\begin{tabular}{|c|c|c|c|c|c|c|c|}
\hline Test de normalidad & Estadístico & $\begin{array}{l}\mathrm{P}- \\
\text { valor }\end{array}$ & $\begin{array}{l}\text { Prueba de bondad de } \\
\text { ajuste }\end{array}$ & $\begin{array}{l}\text { P- } \\
\text { valor }\end{array}$ & $\begin{array}{c}\text { Test de } \\
\text { homocedasticidad }\end{array}$ & Prueba & $\begin{array}{l}\mathrm{P}- \\
\text { valor }\end{array}$ \\
\hline Chi-Cuadrado & 153,22 & 0,00 & \multirow{4}{*}{ Kolmogorov-Smirnov } & \multirow{4}{*}{0,00} & \multirow{4}{*}{ Levene's } & \multirow{4}{*}{1,89} & \multirow{4}{*}{0,17} \\
\hline $\begin{array}{c}\text { Estadístico W de } \\
\text { Shapiro-Wilk } \\
\end{array}$ & 0,97 & 0,00 & & & & & \\
\hline Valor-Z para asimetría & 2,67 & 0,01 & & & & & \\
\hline Valor-Z para curtosis & 9,54 & 0,00 & & & & & \\
\hline
\end{tabular}

Dado que no pudo aceptarse el supuesto de normalidad, se trabajó con la prueba de Kruskal-Wallis para determinar diferencias entre medianas.

\subsection{Defectos de aserrado: influencia en la densidad}

\section{$\underline{\text { Gemas }}$}

\section{a. Grupo anchura de gemas}

Las pruebas de normalidad y de verificación de varianza se muestran en la Tabla 284. 
Tabla 284. 1/(Densidad) - Grupo Anchura de gemas: prueba de normalidad de residuos y verificación de varianza

\begin{tabular}{|c|c|c|c|c|c|c|c|}
\hline Test de normalidad & Estadístico & $\begin{array}{c}\text { P- } \\
\text { valor }\end{array}$ & $\begin{array}{c}\text { Prueba de bondad de } \\
\text { ajuste }\end{array}$ & $\begin{array}{c}\mathrm{P}- \\
\text { valor }\end{array}$ & $\begin{array}{c}\text { Test de } \\
\text { homocedasticidad }\end{array}$ & Prueba & $\begin{array}{c}\text { P- } \\
\text { valor } \\
\end{array}$ \\
\hline Chi-Cuadrado & 128,55 & 0,00 & \multirow{4}{*}{ Kolmogorov-Smirnov } & \multirow{4}{*}{0,00} & \multirow{4}{*}{ Levene's } & \multirow{4}{*}{4,19} & \multirow{4}{*}{0,02} \\
\hline $\begin{array}{c}\text { Estadístico W de } \\
\text { Shapiro-Wilk }\end{array}$ & 0,97 & 0,00 & & & & & \\
\hline Valor-Z para asimetría & 2,73 & 0,01 & & & & & \\
\hline Valor-Z para curtosis & $-4,73$ & 0,00 & & & & & \\
\hline
\end{tabular}

Dado el incumplimiento de los supuestos de normalidad y de homogeneidad de la varianza se trabajó con el test de Kruskal-Wallis para determinar diferencias entre medianas; dada la significancia estadística, se realizó el mismo test para determinar entre que pares de medianas se llevaban a cabo esas diferencias, Tabla 285.

Tabla 285. 1/(Densidad) - Grupo Anchura de gemas: prueba de Kruskal-Wallis: comparación de pares de medianas

\begin{tabular}{ccccccccc}
\hline $\begin{array}{c}\text { Variable G. } \\
\begin{array}{c}\text { Anchura } \\
\text { gema }\end{array}\end{array}$ & $\begin{array}{c}\text { Tamaño } \\
\text { Muestra }\end{array}$ & $\begin{array}{c}\text { Rango } \\
\text { Promedio }\end{array}$ & $\begin{array}{c}\text { Variable G. } \\
\text { Anchura } \\
\text { gema }\end{array}$ & $\begin{array}{c}\text { Tamaño } \\
\text { Muestra }\end{array}$ & $\begin{array}{c}\text { Rango } \\
\text { Promedio }\end{array}$ & $\begin{array}{c}\text { Variable G. } \\
\text { Anchura } \\
\text { gema }\end{array}$ & $\begin{array}{c}\text { Tamaño } \\
\text { Muestra }\end{array}$ & $\begin{array}{c}\text { Rango } \\
\text { Promedio }\end{array}$ \\
\hline 0 & 519 & 432,49 & 0 & 519 & 307,77 & 1 & 304 & 192,47 \\
1 & 304 & 377,02 & 2 & 109 & 346,54 & 2 & 109 & 247,53 \\
\hline Estadístico: 10,44 & P-valor: 0,00 & Estadístico: 4,11 & P-valor: 0,04 & Estadístico: 17,07 & P-valor: 0,00 \\
\hline
\end{tabular}

En base a dicho análisis pudo observarse que la mediana de 1/(Densidad) es significativamente diferente en las 3 categorías de anchura de gemas.

\section{b. Grupo longitud de gemas}

Las pruebas de normalidad y de verificación de varianza se muestran en la Tabla 286.

Tabla 286. 1/(Densidad) - Grupo Longitud de gemas: prueba de normalidad de residuos y verificación de varianza

\begin{tabular}{|c|c|c|c|c|c|c|c|}
\hline Test de normalidad & Estadístico & P-valor & $\begin{array}{c}\text { Prueba de bondad de } \\
\text { ajuste }\end{array}$ & $\begin{array}{c}\text { P- } \\
\text { valor }\end{array}$ & $\begin{array}{c}\text { Test de } \\
\text { homocedasticidad }\end{array}$ & Prueba & $\begin{array}{c}\mathrm{P}- \\
\text { valor }\end{array}$ \\
\hline Chi-Cuadrado & 147,74 & $\begin{array}{c}2,01 \mathrm{E}- \\
10\end{array}$ & \multirow{4}{*}{ Kolmogorov-Smirnov } & \multirow{4}{*}{0,00} & \multirow{4}{*}{ Levene's } & \multirow{4}{*}{1,44} & \multirow{4}{*}{0,24} \\
\hline $\begin{array}{c}\text { Estadístico W de } \\
\text { Shapiro-Wilk } \\
\end{array}$ & 0,96 & 0,0 & & & & & \\
\hline Valor-Z para asimetría & 2,70 & 0,01 & & & & & \\
\hline Valor-Z para curtosis & $-5,46$ & $4,80 \mathrm{E}-8$ & & & & & \\
\hline
\end{tabular}

Dado el incumplimiento del supuesto de normalidad se trabajó con la prueba de Kruskal-Wallis para determinar diferencias entre medianas, Tabla 287. 
Tabla 287. 1/(Densidad) - Grupo Longitud de gemas: comparación de pares de medianas

\begin{tabular}{cccccc}
\hline $\begin{array}{c}\text { Variable G. Longitud } \\
\text { gema }\end{array}$ & $\begin{array}{c}\text { Tamaño } \\
\text { Muestra }\end{array}$ & $\begin{array}{c}\text { Rango } \\
\text { Promedio }\end{array}$ & $\begin{array}{c}\text { Variable G. Longitud } \\
\text { gema }\end{array}$ & $\begin{array}{c}\text { Tamaño } \\
\text { Muestra }\end{array}$ & $\begin{array}{c}\text { Rango } \\
\text { Promedio }\end{array}$ \\
\hline 0 & 503 & 366,59 & 1 & 199 & 210,23 \\
2 & 198 & 311,41 & 2 & 198 & 187,72 \\
\hline Estadístico: 10,55 & & P-valor: 0,00 & Estadístico: 3,82 & & P-valor: 0,05 \\
\hline
\end{tabular}

\section{Médula}

Las pruebas de normalidad y de verificación de varianza se muestran en la Tabla 288.

Tabla 288. 1/(Densidad) - Médula: prueba de normalidad de residuos y verificación de varianza

\begin{tabular}{|c|c|c|c|c|c|c|c|}
\hline Test de normalidad & Estadístico & $\begin{array}{c}\text { P- } \\
\text { valor }\end{array}$ & $\begin{array}{c}\text { Prueba de bondad de } \\
\text { ajuste }\end{array}$ & $\begin{array}{c}\text { P- } \\
\text { valor }\end{array}$ & $\begin{array}{c}\text { Test de } \\
\text { homocedasticidad }\end{array}$ & Prueba & $\begin{array}{c}\text { P- } \\
\text { valor }\end{array}$ \\
\hline Chi-Cuadrado & 154,84 & 0,00 & \multirow{4}{*}{ Kolmogorov-Smirnov } & \multirow{4}{*}{0,00} & \multirow{4}{*}{ Levene } & \multirow{4}{*}{0,71} & \multirow{4}{*}{0,40} \\
\hline $\begin{array}{l}\text { Estadístico W de } \\
\text { Shapiro-Wilk }\end{array}$ & 0,97 & 0,00 & & & & & \\
\hline Valor-Z para asimetría & 2,60 & 0,01 & & & & & \\
\hline Valor-Z para curtosis & 9,49 & 0,00 & & & & & \\
\hline
\end{tabular}

Dado el incumplimiento de los supuestos estadísticos se trabajó con la prueba de Kruskal-Wallis de comparación de medianas.

\subsection{Defectos de secado: influencia en la densidad}

\section{Curvatura de cara}

Las pruebas de normalidad y de verificación de varianza se muestran en la Tabla 289.

Tabla 289. 1/(Densidad) - Curvatura de cara: prueba de normalidad de residuos y verificación de varianza.

\begin{tabular}{|c|c|c|c|c|c|c|c|}
\hline Test de normalidad & Estadístico & $\begin{array}{c}\mathrm{P}- \\
\text { valor }\end{array}$ & $\begin{array}{c}\text { Prueba de bondad de } \\
\text { ajuste }\end{array}$ & $\begin{array}{c}\mathrm{P}- \\
\text { valor }\end{array}$ & $\begin{array}{c}\text { Test de } \\
\text { homocedasticidad }\end{array}$ & Prueba & $\begin{array}{c}\mathrm{P}- \\
\text { valor }\end{array}$ \\
\hline Chi-Cuadrado & 127,84 & 0,00 & \multirow{4}{*}{ Kolmogorov-Smirnov } & \multirow{4}{*}{0,00} & \multirow{4}{*}{ Levene } & \multirow{4}{*}{2,86} & \multirow{4}{*}{0,06} \\
\hline $\begin{array}{l}\text { Estadístico W de } \\
\text { Shapiro-Wilk }\end{array}$ & 0,97 & 0,00 & & & & & \\
\hline Valor-Z para asimetría & 3,05 & 0,00 & & & & & \\
\hline Valor-Z para curtosis & $-3,43$ & 0,00 & & & & & \\
\hline
\end{tabular}

En concordancia con la significancia obtenida se trabajó con el test de comparación de medianas; el análisis comparativo entre pares de medianas se muestra en la Tabla 290.

Tabla 290. 1/(Densidad) - Curvatura de cara: comparación de pares de medianas

\begin{tabular}{ccccccccc}
\hline $\begin{array}{c}\text { Variable } \\
\begin{array}{c}\text { Curvatura } \\
\text { cara }\end{array}\end{array}$ & $\begin{array}{c}\text { Tamaño } \\
\text { Muestra }\end{array}$ & $\begin{array}{c}\text { Rango } \\
\text { Promedio }\end{array}$ & $\begin{array}{c}\text { Variable } \\
\text { Curvatura } \\
\text { cara }\end{array}$ & $\begin{array}{c}\text { Tamaño } \\
\text { Muestra }\end{array}$ & $\begin{array}{c}\text { Rango } \\
\text { Promedio }\end{array}$ & $\begin{array}{c}\text { Variable } \\
\text { Curvatura } \\
\text { cara }\end{array}$ & $\begin{array}{c}\text { Tamaño } \\
\text { Muestra }\end{array}$ & $\begin{array}{c}\text { Rango } \\
\text { Promedio }\end{array}$ \\
\hline 0 & 149 & 228,88 & 0 & 149 & 191,03 & 1 & 460 & 394,25 \\
1 & 460 & 329,66 & 2 & 305 & 245,32 & 2 & 305 & 366,04 \\
\hline Estadístico: & 36,92 & P-valor: $1,23 E-9$ & Estadístico: 17,14 & P-valor: 0,00 & Estadístico: 2,99 & P-valor: 0,08 \\
\hline
\end{tabular}


De acuerdo con lo planteado, la diferencia entre medianas para 1/(Densidad) queda establecida entre la categoría 0 y las otras dos categorías, mientras que estas últimas no se diferenciaron entre sí.

\section{Curvatura de canto}

Las pruebas de normalidad y de verificación de varianza se muestran en la Tabla 291.

Tabla 291. 1/(Densidad) - Curvatura de canto: prueba de normalidad de residuos y verificación de varianza.

\begin{tabular}{|c|c|c|c|c|c|c|c|}
\hline Test de normalidad & Estadístico & $\begin{array}{c}\text { P- } \\
\text { valor }\end{array}$ & $\begin{array}{c}\text { Prueba de bondad de } \\
\text { ajuste }\end{array}$ & $\begin{array}{c}\mathrm{P}- \\
\text { valor }\end{array}$ & $\begin{array}{c}\text { Test de } \\
\text { homocedasticidad }\end{array}$ & Prueba & $\begin{array}{c}\mathrm{P}- \\
\text { valor }\end{array}$ \\
\hline Chi-Cuadrado & 117,47 & 0,00 & \multirow{4}{*}{ Kolmogorov-Smirnov } & \multirow{4}{*}{0,00} & \multirow{4}{*}{ Levene } & \multirow{4}{*}{9,57} & \multirow{4}{*}{0,00} \\
\hline $\begin{array}{l}\text { Estadístico W de } \\
\text { Shapiro-Wilk }\end{array}$ & 0,97 & 0,00 & & & & & \\
\hline Valor-Z para asimetría & 2,66 & 0,01 & & & & & \\
\hline Valor-Z para curtosis & $-3,88$ & 0,00 & & & & & \\
\hline
\end{tabular}

En concordancia con la significancia obtenida se trabajó con el test de comparación de medianas; el análisis comparativo entre pares de medianas se indica en la Tabla 292.

Tabla 292. 1/(Densidad) - Curvatura de canto: comparación de pares de medianas

\begin{tabular}{ccccccccc}
\hline $\begin{array}{c}\text { Variable } \\
\begin{array}{c}\text { Curvatura } \\
\text { canto }\end{array}\end{array}$ & $\begin{array}{c}\text { Tamaño } \\
\text { Muestra }\end{array}$ & $\begin{array}{c}\text { Rango } \\
\text { Promedio }\end{array}$ & $\begin{array}{c}\text { Variable } \\
\text { Curvatura } \\
\text { canto }\end{array}$ & $\begin{array}{c}\text { Tamaño } \\
\text { Muestra }\end{array}$ & $\begin{array}{c}\text { Rango } \\
\text { Promedio }\end{array}$ & $\begin{array}{c}\text { Variable } \\
\text { Curvatura } \\
\text { canto }\end{array}$ & $\begin{array}{c}\text { Tamaño } \\
\text { Muestra }\end{array}$ & $\begin{array}{c}\text { Rango } \\
\text { Promedio }\end{array}$ \\
\hline 0 & 197 & 288,43 & 0 & 197 & 189,09 & 1 & 510 & 371,72 \\
1 & 510 & 379,33 & 2 & 206 & 214,34 & 2 & 206 & 325,77 \\
\hline Estadístico: 28,15 & P-valor: 1,12E-7 & Estadístico: 4,73 & P-valor: 0,03 & Estadístico: 7,24 & P-valor: 0,01 \\
\hline
\end{tabular}

\section{Alabeos}

Las pruebas de normalidad y de verificación de varianza se muestran en la Tabla 293.

Tabla 293. 1/(Densidad) - Alabeo: prueba de normalidad de residuos y verificación de varianza.

\begin{tabular}{|c|c|c|c|c|c|c|c|}
\hline Test de normalidad & Estadístico & $\begin{array}{c}\mathrm{P}- \\
\text { valor }\end{array}$ & $\begin{array}{c}\text { Prueba de bondad de } \\
\text { ajuste }\end{array}$ & $\begin{array}{c}\mathrm{P}- \\
\text { valor }\end{array}$ & $\begin{array}{c}\text { Test de } \\
\text { homocedasticidad }\end{array}$ & Prueba & $\begin{array}{c}\mathrm{P}- \\
\text { valor }\end{array}$ \\
\hline Chi-Cuadrado & 126,51 & 0,00 & \multirow{4}{*}{ Kolmogorov-Smirnov } & \multirow{4}{*}{0,00} & \multirow{4}{*}{ Levene's } & \multirow{4}{*}{6,32} & \multirow{4}{*}{0,00} \\
\hline $\begin{array}{c}\text { Estadístico W de } \\
\text { Shapiro-Wilk } \\
\end{array}$ & 0,97 & 0,00 & & & & & \\
\hline Valor-Z para asimetría & 2,61 & 0,01 & & & & & \\
\hline Valor-Z para curtosis & $-3,64$ & 0,00 & & & & & \\
\hline
\end{tabular}

De acuerdo con el incumplimiento de los supuestos estadísticos se trabajó con la prueba de Kruskal-Wallis para comparación de medianas. Dada la significancia obtenida se realizó el análisis comparativo entre pares de medianas tal como se indica en la Tabla 294. 
Tabla 294. 1/(Densidad) - Alabeo: comparación de pares de medianas

\begin{tabular}{ccccccccc}
\hline $\begin{array}{c}\text { Variable } \\
\text { Alabeo }\end{array}$ & $\begin{array}{c}\text { Tamaño } \\
\text { Muestra }\end{array}$ & $\begin{array}{c}\text { Rango } \\
\text { Promedio }\end{array}$ & $\begin{array}{c}\text { Variable } \\
\text { Alabeo }\end{array}$ & $\begin{array}{c}\text { Tamaño } \\
\text { Muestra }\end{array}$ & $\begin{array}{c}\text { Rango } \\
\text { Promedio }\end{array}$ & $\begin{array}{c}\text { Variable } \\
\text { Alabeo }\end{array}$ & $\begin{array}{c}\text { Tamaño } \\
\text { Muestra }\end{array}$ & $\begin{array}{c}\text { Rango } \\
\text { Promedio }\end{array}$ \\
\hline 0 & 421 & 333,54 & 0 & 421 & 283,73 & 1 & 304 & 245,28 \\
1 & 304 & 403,80 & 2 & 184 & 347,09 & 2 & 184 & 243,22 \\
\hline Estadístico: & 19,87 & P-valor: 0,00 & Estadístico: 16,83 & P-valor: 0,00 & Estadístico: 0,02 & P-valor: 0,88 \\
\hline
\end{tabular}

De acuerdo con el análisis comparativo entre pares de medianas puede indicarse que la categoría 0 , es la que establece la diferencia, mientras que las categorías 1 y 2 no se diferencian entre sí.

\subsubsection{Influencia de los defectos (agrupados por tipo) en la predicción de las variables caracterizadoras}

\subsection{Defectos naturales}

La prueba de normalidad de residuos se presenta en la Tabla 295, Tabla 296 y Tabla 297 para el LOG(MOE), MOR y 1/Densidad, respectivamente.

Tabla 295. MOE - Defectos naturales: prueba de normalidad de residuos.

\begin{tabular}{ccccc}
\hline Test de normalidad & Estadístico & P-valor & Prueba de bondad de ajuste & P-valor \\
\hline Chi-Cuadrado & 52,65 & 0,53 & & \\
\cline { 1 - 3 } Estadístico W de Shapiro-Wilk & 0,99 & 0,81 & Kolmogorov-Smirnov & 0,45 \\
\hline Valor-Z para asimetría & 1,849 & 0,07 \\
\hline Valor-Z para curtosis & 2,77 & 0,01 & \\
\hline
\end{tabular}

Tabla 296. MOR - Defectos naturales: prueba de normalidad de residuos.

\begin{tabular}{ccccc}
\hline Test de normalidad & Estadístico & P-valor & Prueba de bondad de ajuste & P-valor \\
\hline Chi-Cuadrado & 69,18 & 0,08 & & \\
\hline Estadístico W de Shapiro-Wilk & 0,98 & 0,20 & \multirow{2}{*}{ Kolmogorov-Smirnov } & 0,84 \\
\hline Valor-Z para asimetría & 0,76 & 0,45 & & \\
\hline Valor-Z para curtosis & 0,18 & 0,86 & \\
\hline
\end{tabular}

Tabla 297. 1/(Densidad) - Defectos naturales: prueba de normalidad de residuos.

\begin{tabular}{ccccc}
\hline Test de normalidad & Estadístico & P-valor & Prueba de bondad de ajuste & P-valor \\
\hline Chi-Cuadrado & 65,31 & 0,14 & & \\
\hline Estadístico W de Shapiro-Wilk & 0,98 & 0,12 & \multirow{2}{*}{ Kolmogorov-Smirnov } & 0,04 \\
\hline Valor-Z para asimetría & 2,56 & 0,01 & & \\
\hline Valor-Z para curtosis & $-0,22$ & 0,83 & \\
\hline
\end{tabular}




\subsection{Defectos de aserrado}

La prueba de normalidad de residuos se presenta en la Tabla 298, Tabla 299 y Tabla 300 para LOG(MOE), MOR y 1/Densidad, respectivamente.

Tabla 298. LOG(MOE) - Defectos de aserrado: prueba de normalidad de residuos.

\begin{tabular}{ccccc}
\hline Test de normalidad & Estadístico & P-valor & Prueba de bondad de ajuste & P-valor \\
\hline Chi-Cuadrado & 66,01 & 0,17 & & \\
\hline Estadístico W de Shapiro-Wilk & 0,98 & 0,02 & \multirow{2}{*}{ Kolmogorov-Smirnov } & 0,21 \\
\hline Valor-Z para asimetría & 0,88 & 0,38 & & \\
\hline Valor-Z para curtosis & 4,71 & 0,00 & \\
\hline
\end{tabular}

Tabla 299. MOR - Defectos de aserrado: prueba de normalidad de residuos.

\begin{tabular}{ccccc}
\hline Test de normalidad & Estadístico & P-valor & Prueba de bondad de ajuste & P-valor \\
\hline Chi-Cuadrado & 40,48 & 0,94 & & \\
\hline Estadístico W de Shapiro-Wilk & 0,99 & 0,29 & \multirow{2}{*}{ Kolmogorov-Smirnov } & 0,98 \\
\hline Valor-Z para asimetría & 0,20 & 0,84 & & \\
\hline Valor-Z para curtosis & $-0,30$ & 0,76 & \\
\hline
\end{tabular}

Tabla 300. 1/(Densidad) - Defectos de aserrado: prueba de normalidad de residuos.

\begin{tabular}{ccccc}
\hline Test de normalidad & Estadístico & P-valor & Prueba de bondad de ajuste & P-valor \\
\hline Chi-Cuadrado & 133,67 & 0,00 & & \\
\cline { 1 - 3 } Estadístico W de Shapiro-Wilk & 0,97 & 0,00 & \multirow{2}{*}{ Kolmogorov-Smirnov } & 0,00 \\
\hline Valor-Z para asimetría & 2,49 & 0,01 & & \\
\hline Valor-Z para curtosis & $-4,32$ & 0,00 & \\
\hline
\end{tabular}

\subsection{Defectos de secado}

La prueba de normalidad de residuos se presenta en la Tabla 301, Tabla 302 y Tabla 303 para LOG(MOE), MOR y 1/Densidad, respectivamente.

Tabla 301. LOG(MOE) - Defectos de secado: prueba de normalidad de residuos.

\begin{tabular}{ccccc}
\hline Test de normalidad & Estadístico & P-valor & Prueba de bondad de ajuste & P-valor \\
\hline Chi-Cuadrado & 69,02 & 0,11 & & \\
\hline Estadístico W de Shapiro-Wilk & 0,98 & 0,03 & \multirow{2}{*}{ Kolmogorov-Smirnov } & 0,15 \\
\hline Valor-Z para asimetría & 0,97 & 0,33 & & \\
\hline Valor-Z para curtosis & 4,15 & 0,00 & \\
\hline
\end{tabular}


Tabla 302. MOR - Defectos de secado: prueba de normalidad de residuos.

\begin{tabular}{ccccc}
\hline Test de normalidad & Estadístico & P-valor & Prueba de bondad de ajuste & P-valor \\
\hline Chi-Cuadrado & 58,12 & 0,40 & & \\
\hline Estadístico W de Shapiro-Wilk & 0,98 & 0,04 & \multirow{2}{*}{ Kolmogorov-Smirnov } & 0,99 \\
\hline Valor-Z para asimetría & 0,28 & 0,78 & & \\
\hline Valor-Z para curtosis & $-0,57$ & 0,57 & \\
\hline
\end{tabular}

Tabla 303. 1/(Densidad) - Defectos de secado: prueba de normalidad de residuos.

\begin{tabular}{ccccc}
\hline Test de normalidad & Estadístico & P-valor & Prueba de bondad de ajuste & P-valor \\
\hline Chi-Cuadrado & 94,21 & 0,00 & & \\
\cline { 1 - 3 } Estadístico W de Shapiro-Wilk & 0,98 & $1,19 \mathrm{E}-7$ & \multirow{2}{*}{ Kolmogorov-Smirnov } & 0,00 \\
\cline { 1 - 3 } Valor-Z para asimetría & 2,65 & 0,01 & & \\
\hline Valor-Z para curtosis & $-2,69$ & 0,01 & & \\
\hline
\end{tabular}

\subsubsection{Influencia de los parámetros no destructivos en la predicción de las} variables caracterizadoras

La prueba de normalidad de residuos para el LOG(MOE), MOR y 1/Densidad con las variables consideradas en el análisis de regresión, para la técnica de vibraciones inducidas, se muestra en la Tabla 304, Tabla 305 y Tabla 306, respectivamente.

Tabla 304. LOG(MOE)-NDT-VI: prueba de normalidad de residuos.

\begin{tabular}{ccccc}
\hline Test de normalidad & Estadístico & P-valor & Prueba de bondad de ajuste & P-valor \\
\hline Chi-Cuadrado & 78,04 & 0,00 & & \\
\cline { 1 - 3 } Estadístico W de Shapiro-Wilk & 0,96 & 0,0 & Kolmogorov-Smirnov & 0,01 \\
\hline Valor-Z para asimetría & 3,64 & 0,00 & & \\
\hline Valor-Z para curtosis & 5,33 & $9,97 \mathrm{E}-8$ & \\
\hline
\end{tabular}

Tabla 305. MOR - NDT-VI-: prueba de normalidad de residuos.

\begin{tabular}{ccccc}
\hline Test de normalidad & Estadístico & P-valor & Prueba de bondad de ajuste & P-valor \\
\hline Chi-Cuadrado & 61,47 & 0,06 & & \\
\cline { 1 - 3 } Estadístico W de Shapiro-Wilk & 0,98 & 0,03 & \multirow{2}{*}{ Kolmogorov-Smirnov } & 0,71 \\
\cline { 1 - 3 } Valor-Z para asimetría & 2,58 & 0,01 & & \\
\cline { 1 - 3 } Valor-Z para curtosis & 1,89 & 0,06 & & \\
\hline
\end{tabular}


Tabla 306. 1/(Densidad) - NDT-VI-: prueba de normalidad de residuos.

\begin{tabular}{ccccc}
\hline Test de normalidad & Estadístico & P-valor & Prueba de bondad de ajuste & P-valor \\
\cline { 1 - 3 } Chi-Cuadrado & 132,81 & $2,33 \mathrm{E}-10$ & & \\
\cline { 1 - 3 } Estadístico W de Shapiro-Wilk & 0,96 & $1,11 \mathrm{E}-15$ & \multirow{2}{*}{ Kolmogorov-Smirnov } & 0,00 \\
\cline { 1 - 3 } Valor-Z para asimetría & 2,65 & 0,01 & & \\
\cline { 1 - 3 } Valor-Z para curtosis & $-3,63$ & 0,00 & & \\
\hline
\end{tabular}

La prueba de normalidad de residuos para el LOG(MOE) y MOR con el $\operatorname{LOG}\left(E_{\mathrm{d}}\right)$ de vibraciones inducidas, se muestra en la Tabla 307 y Tabla 308, respectivamente.

Tabla 307. LOG(MOE) - LOG(Ed) NDT-VI-: prueba de normalidad de residuos.

\begin{tabular}{ccccc}
\hline Test de normalidad & Estadístico & P-valor & Prueba de bondad de ajuste & P-valor \\
\cline { 1 - 3 } Chi-Cuadrado & 116,56 & 0,00 & & \\
\cline { 1 - 3 } Estadístico W de Shapiro-Wilk & 0,96 & 0,00 & \multirow{2}{*}{ Kolmogorov-Smirnov } & 0,00 \\
\cline { 1 - 3 } Valor-Z para asimetría & 0,95 & 0,34 & & \\
\cline { 1 - 2 } Valor-Z para curtosis & 6,67 & 0,00 & \\
\hline
\end{tabular}

Tabla 308. MOR - LOG(Ed) NDT: prueba de normalidad de residuos.

\begin{tabular}{ccccc}
\hline Test de normalidad & Estadístico & P-valor & Prueba de bondad de ajuste & P-valor \\
\cline { 1 - 3 } Chi-Cuadrado & 57,08 & 0,13 & & \\
\cline { 1 - 3 } Estadístico W de Shapiro-Wilk & 0,98 & 0,00 & \multirow{2}{*}{ Kolmogorov-Smirnov } & 0,43 \\
\cline { 1 - 3 } Valor-Z para asimetría & 2,53 & 0,01 & & \\
\cline { 1 - 2 } Valor-Z para curtosis & 2,10 & 0,04 & \\
\hline
\end{tabular}

La prueba de normalidad de residuos para el LOG(MOE), MOR y 1/Densidad con las variables consideradas en el análisis de regresión, para la técnica de ultrasonidos, se muestra en la Tabla 309, Tabla 310 y Tabla 311, respectivamente.

Tabla 309. LOG(MOE) - NDT: prueba de normalidad de residuos.

\begin{tabular}{|c|c|c|c|c|}
\hline Test de normalidad & Estadístico & P-valor & Prueba de bondad de ajuste & P-valor \\
\hline Chi-Cuadrado & 69,76 & 0,10 & \multirow{4}{*}{ Kolmogorov-Smirnov } & \multirow{4}{*}{0,34} \\
\hline Estadístico W de Shapiro-Wilk & 0,98 & 0,00 & & \\
\hline Valor-Z para asimetría & 3,97 & 0,00 & & \\
\hline Valor-Z para curtosis & 6,72 & $1,77 \mathrm{E}-11$ & & \\
\hline
\end{tabular}


Tabla 310. MOR - NDT: prueba de normalidad de residuos.

\begin{tabular}{ccccc}
\hline Test de normalidad & Estadístico & P-valor & Prueba de bondad de ajuste & P-valor \\
\hline Chi-Cuadrado & 51,13 & 0,66 & & \\
\hline Estadístico W de Shapiro-Wilk & 0,98 & 0,13 & \multirow{2}{*}{ Kolmogorov-Smirnov } & 0,96 \\
\hline Valor-Z para asimetría & 0,81 & 0,42 & & \\
\hline Valor-Z para curtosis & $-1,06$ & 0,29 & \\
\hline
\end{tabular}

Tabla 311. 1/(Densidad) - NDT: prueba de normalidad de residuos.

\begin{tabular}{ccccc}
\hline Test de normalidad & Estadístico & P-valor & Prueba de bondad de ajuste & P-valor \\
\hline Chi-Cuadrado & 151,24 & $1,08 \mathrm{E}-10$ & & \\
\cline { 1 - 3 } Estadístico W de Shapiro-Wilk & 0,97 & 0,0 & \multirow{2}{*}{ Kolmogorov-Smirnov } & 0,00 \\
\hline Valor-Z para asimetría & 2,96 & 0,00 & & \\
\hline Valor-Z para curtosis & $-4,92$ & $8,68 \mathrm{E}-7$ & \\
\hline
\end{tabular}

La prueba de normalidad de residuos para el LOG(MOE) y MOR con el $\operatorname{LOG}\left(E_{\mathrm{d}}\right)$ de ultrasonidos, se muestra en la Tabla 307 y Tabla 308, respectivamente.

Tabla 312. LOG(MOE) - LOG( $\left.E_{\mathrm{d}}\right)$ NDT: prueba de normalidad de residuos.

\begin{tabular}{|c|c|c|c|c|}
\hline Test de normalidad & Estadístico & P-valor & Prueba de bondad de ajuste & P-valor \\
\hline Chi-Cuadrado & 54,62 & 0,53 & \multirow{4}{*}{ Kolmogorov-Smirnov } & \multirow{4}{*}{0,48} \\
\hline Estadístico W de Shapiro-Wilk & 0,98 & 0,05 & & \\
\hline Valor-Z para asimetría & 2,92 & 0,00 & & \\
\hline Valor-Z para curtosis & 6,58 & $4,61 \mathrm{E}-11$ & & \\
\hline
\end{tabular}

Tabla 313. MOR - LOG $\left(E_{\mathrm{d}}\right)$ NDT: prueba de normalidad de residuos.

\begin{tabular}{ccccc}
\hline Test de normalidad & Estadístico & P-valor & Prueba de bondad de ajuste & P-valor \\
\hline Chi-Cuadrado & 66,5 & 0,16 & & \\
\hline Estadístico W de Shapiro-Wilk & 0,98 & 0,20 & Kolmogorov-Smirnov & 0,92 \\
\hline Valor-Z para asimetría & 0,86 & 0,39 & & \\
\hline Valor-Z para curtosis & $-0,56$ & 0,57 & \\
\hline
\end{tabular}




\subsection{Piezas macizas estructurales: consideraciones generales}

El análisis de constatación de supuesto estadísticos para el análisis del LOG(MOE), MOR y 1/Densidad, por tipo de corte se muestra en la Tabla 314, Tabla 315 y Tabla 316; el resumen de los test comparativos se muestra en la Tabla 317.

Tabla 314. LOG(MOE) - Tipo de corte: prueba de normalidad de residuos y verificación de varianza

\begin{tabular}{|c|c|c|c|c|c|c|c|}
\hline Test de normalidad & Estadístico & $\begin{array}{c}\text { P- } \\
\text { valor }\end{array}$ & $\begin{array}{c}\text { Prueba de bondad de } \\
\text { ajuste }\end{array}$ & $\begin{array}{c}\text { P- } \\
\text { valor }\end{array}$ & $\begin{array}{c}\text { Test de } \\
\text { homocedasticidad }\end{array}$ & Prueba & $\begin{array}{c}\text { P- } \\
\text { valor }\end{array}$ \\
\hline Chi-Cuadrado & 70,76 & 0,09 & \multirow{4}{*}{ Kolmogorov-Smirnov } & \multirow{4}{*}{0,21} & \multirow{4}{*}{ Levene } & \multirow{4}{*}{2,50} & \multirow{4}{*}{0,08} \\
\hline $\begin{array}{c}\text { Estadístico W de } \\
\text { Shapiro-Wilk } \\
\end{array}$ & 0,98 & 0,00 & & & & & \\
\hline Valor-Z para asimetría & 0,67 & 0,50 & & & & & \\
\hline Valor-Z para curtosis & 3,96 & 0,00 & & & & & \\
\hline
\end{tabular}

Tabla 315. MOR - Tipo de corte: prueba de normalidad de residuos y verificación de varianza

\begin{tabular}{|c|c|c|c|c|c|c|c|}
\hline Test de normalidad & Estadístico & $\begin{array}{c}\mathrm{P}- \\
\text { valor }\end{array}$ & $\begin{array}{c}\text { Prueba de bondad de } \\
\text { ajuste }\end{array}$ & $\begin{array}{c}\mathrm{P}- \\
\text { valor }\end{array}$ & $\begin{array}{c}\text { Test de } \\
\text { homocedasticidad }\end{array}$ & Prueba & $\begin{array}{c}\mathrm{P}- \\
\text { valor }\end{array}$ \\
\hline Chi-Cuadrado & 38,88 & 0,96 & \multirow{4}{*}{ Kolmogorov-Smirnov } & \multirow{4}{*}{0,96} & \multirow{4}{*}{ Levene } & \multirow{4}{*}{0,89} & \multirow{4}{*}{0,41} \\
\hline $\begin{array}{c}\text { Estadístico W de } \\
\text { Shapiro-Wilk }\end{array}$ & 0,98 & 0,00 & & & & & \\
\hline Valor-Z para asimetría & 0,65 & 0,52 & & & & & \\
\hline Valor-Z para curtosis & $-1,93$ & 0,05 & & & & & \\
\hline
\end{tabular}

Tabla 316. 1/(Densidad) - Tipo corte: prueba de normalidad de residuos y verificación de varianza

\begin{tabular}{|c|c|c|c|c|c|c|c|}
\hline Test de normalidad & Estadístico & $\begin{array}{c}\mathrm{P}- \\
\text { valor }\end{array}$ & $\begin{array}{c}\text { Prueba de bondad de } \\
\text { ajuste }\end{array}$ & $\begin{array}{c}\mathrm{P}- \\
\text { valor }\end{array}$ & $\begin{array}{c}\text { Test de } \\
\text { homocedasticidad }\end{array}$ & Prueba & $\begin{array}{c}\mathrm{P}- \\
\text { valor }\end{array}$ \\
\hline Chi-Cuadrado & 150,49 & 0,00 & \multirow{4}{*}{ Kolmogorov-Smirnov } & \multirow{4}{*}{0,00} & \multirow{4}{*}{ Levene } & \multirow{4}{*}{2,42} & \multirow{4}{*}{0,09} \\
\hline $\begin{array}{c}\text { Estadístico W de } \\
\text { Shapiro-Wilk } \\
\end{array}$ & 0,97 & 0,00 & & & & & \\
\hline Valor-Z para asimetría & 2,85 & 0,00 & & & & & \\
\hline Valor-Z para curtosis & $-5,51$ & 0,00 & & & & & \\
\hline
\end{tabular}

Tabla 317. LOG(MOE), MOR y 1/Densidad - Tipos de corte

\begin{tabular}{|c|c|c|c|c|}
\hline \multirow{2}{*}{ ANOVA } & \multirow{2}{*}{ Razón-F } & \multirow{2}{*}{ P-valor } & \multirow{2}{*}{ Tipos de corte } & Grupos Homogéneos** \\
\hline & & & & Unequal N HSD \\
\hline \multirow{3}{*}{ LOG(MOE) - Tipo de corte } & \multirow{3}{*}{18,09} & \multirow{3}{*}{0,00} & Mezcla & $\mathrm{A}$ \\
\hline & & & Radial & $\mathrm{A}$ \\
\hline & & & Tangencial & $\mathrm{B}$ \\
\hline \multirow{3}{*}{ MOR - Tipo de corte } & \multirow{3}{*}{1,88} & \multirow{3}{*}{0,15} & Mezcla & A \\
\hline & & & Radial & A \\
\hline & & & Tangencial & A \\
\hline KW & Estadístico & P-valor & Tipos de corte & Grupos Homogéneos \\
\hline \multirow{3}{*}{ 1/Densidad - Tipo de corte } & \multirow{3}{*}{0,17} & \multirow{3}{*}{0,92} & Mezcla & $\mathrm{A}$ \\
\hline & & & Radial & $\mathrm{A}$ \\
\hline & & & Tangencial & $\mathrm{A}$ \\
\hline
\end{tabular}

*LOG(MOE): logaritmo del módulo de elasticidad; MOR: módulo de rotura; KW: Test de Kruskal-Wallis; **letras diferentes denotan diferencias significativas entre medias o medianas, según Unequal $\mathrm{N}$ HSD ó KW, respectivamente. 


\section{SECCIÓN II: Mejoras tecnológicas}

\subsection{Probetas de pequeñas dimensiones y libres de defectos}

\subsubsection{Termo-modificación}

\subsubsection{Propiedades mecánicas}

\subsection{Dureza superficial}

En la Tabla 318 se detalla el resumen estadístico y los resultados de las pruebas de normalidad para la dureza por tratamiento.

Tabla 318. Dureza - Chopo (España): resumen estadístico y pruebas de normalidad.

\begin{tabular}{|c|c|c|c|c|c|c|c|c|c|c|c|}
\hline \multirow{3}{*}{ Tratamiento* } & \multicolumn{11}{|c|}{ Dureza } \\
\hline & \multirow{2}{*}{$\mathrm{DE}^{*}$} & \multirow{2}{*}{$\mathrm{SE}^{*}$} & \multirow{2}{*}{$\mathrm{CE}^{*}$} & \multicolumn{2}{|c|}{ Chi-Cuadrado } & \multicolumn{2}{|c|}{$\begin{array}{l}\text { W de Shapiro- } \\
\text { Wilk }\end{array}$} & \multicolumn{2}{|c|}{$\begin{array}{l}\text { Valor-Z para } \\
\text { asimetría }\end{array}$} & \multicolumn{2}{|c|}{$\begin{array}{l}\text { Valor-Z para } \\
\text { curtosis }\end{array}$} \\
\hline & & & & Estad. & $\begin{array}{c}P- \\
\text { valor }\end{array}$ & Estad. & $\begin{array}{c}P- \\
\text { valor }\end{array}$ & Estad. & P-valor & Estad. & $\begin{array}{c}P- \\
\text { valor }\end{array}$ \\
\hline \multicolumn{12}{|l|}{ Testigo $(\mathrm{T})^{*}$} \\
\hline TM 80-45 & 1,17 & $\overline{-}, 63$ & $\overline{-}, \overline{38}$ & 12,5 & 0,25 & 0,95 & 0,33 & 0,50 & 0,62 & $-0,29$ & 0,77 \\
\hline TM 80-90 & 0,80 & $\overline{-}, 43$ & 1,69 & 13,8 & 0,18 & 0,93 & 0,15 & 1,09 & 0,27 & 1,65 & 0,10 \\
\hline TM 80-135 & 1,10 & 0,40 & 0,20 & 11,2 & 0,34 & 0,98 & 0,88 & 0,32 & 0,75 & 0,44 & 0,66 \\
\hline TM 80-180 & 1,07 & 1,25 & $-\overline{0}$ & & & & & & & & \\
\hline TM 120-45 & 1,42 & $\begin{array}{l}- \\
0,58 \\
\end{array}$ & $\overline{1,07}$ & 7,3 & 0,70 & 0,93 & 0,15 & 0,46 & 0,65 & $-1,60$ & 0,11 \\
\hline TM 120-90 & 1,01 & 0,48 & 0,37 & 6,0 & 0,82 & 0,99 & 0,99 & 0,38 & 0,70 & 0,62 & 0,53 \\
\hline TM 120-135 & 1,24 & $0, \overline{20}$ & $\overline{-}, 84$ & 8,6 & 0,57 & 0,94 & 0,29 & 0,16 & 0,87 & $-1,07$ & 0,28 \\
\hline TM 120-180 & 0,94 & $\overline{-}, 23$ & 0,22 & 8,6 & 0,57 & 0,96 & 0,54 & 0,95 & 0,34 & 0,47 & 0,64 \\
\hline TM 160-45 & 1,09 & $\overline{2}, \overline{13}$ & 1,34 & 19,0 & 0,04 & 0,88 & 0,02 & 1,56 & 0,12 & 1,42 & 0,15 \\
\hline TM 160-90 & 0,89 & $0, \overline{99}$ & $\overline{-}$ & 12,5 & 0,25 & 0,88 & 0,02 & 0,77 & 0,44 & $-1,82$ & 0,07 \\
\hline TM 160-135 & 0,72 & 0,37 & 1,97 & 6,0 & 0,82 & 0,95 & 0,41 & 0,30 & 0,77 & 1,81 & 0,07 \\
\hline TM 160-180 & 0,95 & 0,04 & $\overline{-}, \overline{54}$ & 6,0 & 0,82 & 0,97 & 0,83 & 0,03 & 0,97 & $-0,53$ & 0,60 \\
\hline TM 200-45 & 1,04 & 0,38 & 0,87 & 11,2 & 0,34 & 0,96 & 0,49 & 0,30 & 0,76 & $-1,13$ & 0,26 \\
\hline TM 200-90 & 1,06 & 0,39 & $\overline{1,43}$ & 8,6 & 0,57 & 0,90 & 0,05 & 0,31 & 0,75 & $-2,68$ & 0,01 \\
\hline TM 200-135 & 0,86 & $\overline{-}, 02$ & 0,22 & 22,9 & 0,01 & 0,93 & 0,14 & 0,80 & 0,42 & 0,47 & 0,64 \\
\hline TM 200-180 & 0,78 & $0, \overline{20}$ & $\begin{array}{c}- \\
1,01 \\
\end{array}$ & 9,9 & 0,45 & 0,95 & 0,34 & 0,16 & 0,88 & $-1,46$ & 0,15 \\
\hline
\end{tabular}

\subsection{Durabilidad natural}

7.1.1.1.2.1. Determinación de la durabilidad natural frente a hongos basidiomicetos xilófagos 


\section{Análisis descriptivo: material termo-modificado expuesto a pudrición blanca}

En la Tabla 319 se resumen los parámetros descriptivos de la pérdida de peso ocasionada por el agente de pudrición fibrosa, Trametes versicolor, en el material termomodificado.

Tabla 319. Pp(\%) Trametes versicolor - Chopo (España): resumen estadístico y pruebas de normalidad.

\begin{tabular}{cccccccc}
\hline & \multicolumn{7}{c}{ Pérdida de peso } \\
\cline { 2 - 5 } Tratamiento* & \multirow{2}{*}{ DE* } & \multirow{2}{*}{ SE* $^{*}$} & \multirow{2}{*}{ CE* } & \multicolumn{2}{c}{ Chi-Cuadrado } & \multicolumn{2}{c}{ W de Shapiro-Wilk } \\
\cline { 5 - 8 } & & & & Estad. & P-valor & Estad. & $P$-valor \\
\hline Testigo (T) & 13,28 & $-0,69$ & $-1,03$ & 14,13 & 0,66 & 0,97 & 0,26 \\
\hline TM 80-45 & 2,29 & $-0,64$ & $-0,55$ & 5,0 & 0,17 & 0,91 & 0,60 \\
\hline TM 80-90 & 7,19 & $-0,64$ & - & 2,0 & 0,37 & 0,97 & 0,65 \\
\hline TM 80-135 & 4,38 & 0,10 & $-2,14$ & 5,0 & 0,17 & 0,83 & 0,31 \\
\hline TM 80-180 & 0,60 & 0,03 & $-2,37$ & 8,0 & 0,05 & 0,78 & 0,16 \\
\hline TM 120-45 & 2,97 & 1,44 & 1,31 & 5,0 & 0,17 & 0,80 & 0,23 \\
\hline TM 120-90 & 0,55 & 1,35 & 1,27 & 5,0 & 0,17 & 0,82 & 0,29 \\
\hline TM 120-135 & 0,35 & 1,18 & - & 5,33 & 0,07 & 0,83 & 0,18 \\
\hline TM 120-180 & 3,78 & $-0,47$ & 0,12 & 2,0 & 0,57 & 0,98 & 0,90 \\
\hline TM 160-45 & 6,67 & $-0,34$ & $-0,47$ & 2,0 & 0,57 & 0,98 & 0,88 \\
\hline TM 160-90 & 2,73 & $-0,76$ & 0,65 & 5,0 & 0,17 & 0,95 & 0,69 \\
\hline TM 160-135 & 6,63 & $-1,41$ & 1,19 & 5,0 & 0,17 & 0,78 & 0,16 \\
\hline TM 160-180 & 8,21 & 0,18 & $-1,86$ & 5,0 & 0,17 & 0,87 & 0,46 \\
\hline TM 200-45 & 19,71 & 0,00 & $-2,44$ & 8,0 & 0,05 & 0,75 & 0,08 \\
\hline TM 200-90 & 22,21 & 0,27 & $-1,17$ & 2,0 & 0,57 & 0,95 & 0,66 \\
\hline TM 200-135 & 17,88 & 0,26 & $-0,74$ & 2,0 & 0,57 & 0,97 & 0,84 \\
\hline TM 200-180 & 1,47 & 0,42 & - & 2,0 & 0,37 & 0,99 & 0,78 \\
\hline
\end{tabular}

*T: material sin termo-modificar: testigo; TM: material termo-modificado (los números indican combinación temperatura-tiempo, respectivamente); DE: desvio estándar; SE: sesgo estandarizado; CE: curtosis estandardizada; Estad: estadístico.

\section{Análisis comparativo: material testigo y termo-modificado expuesto a pudrición blanca}

En la Tabla 320 se muestra el resultado del test de Levene realizado a fin de evaluar la homegeneidad de varianza considerando la pérdida de peso ocasionada por la cepa de pudrición fibrosa en el material sin modificar y termo-modificado.

Tabla 320. Pp (\%) T. versicolor - Material sin modificar/termo-modificado: Chopo (España): test de Levene

\begin{tabular}{ccc}
\hline \multirow{2}{*}{ Levene } & Prueba & P-valor \\
\cline { 2 - 3 } & 80,82 & 0,00 \\
\hline
\end{tabular}

De acuerdo con el incumplimiento del supuesto de homocedasticidad, $\mathrm{P}$-valor $<0,05$, se trabajó con el test no paramétrico de Kruskal-Wallis para la comparación de medianas de Pp $(\%)$ entre material sin modificar y material termo-modificado. 
Dada la variabilidad de los datos, se realizó un análisis multifactorial a fin de evaluar el comportamiento de la pérdida de peso en cada tratamiento ( $\mathrm{T}^{\circ}$ - Tiempos). Con esa finalidad, como primera instancia se realizó la constatación de los supuestos estadísticos de los residuos tal como se muestra en la Tabla 321.

Tabla 321. Pérdida de peso por tratamiento: verificación de supuestos estadísticos de residuos

\begin{tabular}{|c|c|c|c|c|}
\hline Test de normalidad & Estadístico & P-valor & Bondad de ajuste & P-valor \\
\hline Chi-Cuadrado & 21,95 & 0,19 & \multirow{4}{*}{ Kolmogorov-Smirnov } & \multirow{4}{*}{0,28} \\
\hline Estadístico W de Shapiro-Wilk & 0,98 & 0,51 & & \\
\hline Valor-Z para asimetría & 0,84 & 0,40 & & \\
\hline Valor-Z para curtosis & 1,35 & 0,18 & & \\
\hline
\end{tabular}

\section{Análisis descriptivo: material termo-modificado expuesto a pudrición parda}

En la Tabla 322 se resumen los parámetros descriptivos del material termo-modificado expuesto al agente de pudrición parda, Coniophora puteana.

Tabla 322. Deterioro causado por $C$. puteana: resumen estadístico y pruebas de normalidad

\begin{tabular}{|c|c|c|c|c|c|c|c|}
\hline \multirow{3}{*}{ Tratamiento* } & \multicolumn{7}{|c|}{ Pérdida de peso } \\
\hline & \multirow{2}{*}{$\mathrm{DE}^{*}$} & \multirow{2}{*}{$\mathrm{SE}^{*}$} & \multirow{2}{*}{$\mathrm{CE}^{*}$} & \multicolumn{2}{|c|}{ Chi-Cuadrado } & \multicolumn{2}{|c|}{ W de Shapiro-Wilk } \\
\hline & & & & Estad. & $P$-valor & Estad. & $P$-valor \\
\hline Testigo (T) & 8,58 & 2,27 & 0,77 & 13,74 & 0,19 & 0,88 & 0,01 \\
\hline TM 80-45 & 5,60 & $-0,40$ & $-1,07$ & 5,0 & 0,17 & 0,93 & 0,57 \\
\hline TM 80-90 & 2,46 & $-1,22$ & - & 5,33 & 0,07 & 0,77 & 0,04 \\
\hline TM 80-135 & 17,02 & $-1,17$ & - & 5,33 & 0,07 & 0,83 & 0,19 \\
\hline TM 80-180 & 6,21 & $-1,15$ & 0,92 & 5,0 & 0,17 & 0,89 & 0,54 \\
\hline TM 120-45 & 0,89 & 0,18 & $-1,85$ & 5,0 & 0,17 & 0,88 & 0,47 \\
\hline TM 120-90 & 8,77 & $-0,17$ & $-1,89$ & 5,0 & 0,17 & 0,87 & 0,44 \\
\hline TM 120-135 & 0,17 & $-0,69$ & - & 2,0 & 0,37 & 0,96 & 0,62 \\
\hline TM 120-180 & 9,71 & 0,01 & $-1,72$ & 2,0 & 0,57 & 0,92 & 0,62 \\
\hline TM 160-45 & 0,36 & $-0,37$ & - & 2,0 & 0,37 & 0,99 & 0,81 \\
\hline TM 160-90 & 5,79 & 0,09 & $-0,82$ & 2,0 & 0,57 & 0,98 & 0,88 \\
\hline TM 160-135 & 1,22 & $-0,93$ & 0,13 & 5,0 & 0,17 & 0,90 & 0,54 \\
\hline TM 160-180 & 10,48 & $-0,70$ & 0,75 & 5,0 & 0,17 & 0,94 & 0,62 \\
\hline TM 200-45 & 4,45 & $-0,47$ & $-0,92$ & 5,0 & 0,17 & 0,93 & 0,64 \\
\hline TM 200-90 & 5,14 & $-1,32$ & 1,22 & 5,0 & 0,17 & 0,84 & 0,35 \\
\hline TM 200-135 & 3,38 & 0,67 & $-0,59$ & 5,0 & 0,17 & 0,87 & 0,44 \\
\hline TM 200-180 & 0,59 & $-0,61$ & - & 2,0 & 0,37 & 0,97 & 0,67 \\
\hline
\end{tabular}

\section{Análisis comparativo: material testigo y termo-modificado expuesto pudrición parda}

En la Tabla 323 se muestra el resultado del Test de Levene para la pérdida de peso ocasionada por la cepa de pudrición parda comparando material sin modificar y termomodificado. 
Tabla 323. Pp (\%) C. puteana - Material sin modificar/termo-modificado: Chopo (España): test de Levene

\begin{tabular}{ccc}
\hline \multirow{2}{*}{ Levene } & Prueba & P-valor \\
\cline { 2 - 3 } & 17,66 & 0,00 \\
\hline
\end{tabular}

Puesto que el P-valor es inferior a 0,05, existe una diferencia estadísticamente significativa entre las desviaciones estándar, con un nivel del 95\% de confianza, razón por la cual se trabajó con el test no paramétrico de Kruskal-Wallis comparando medianas de pérdida de peso entre material no modificado y material termo-modificado.

Luego del análisis multifactorial y con la finalidad de determinar las diferencias de medias en las pérdidas de peso considerando los tratamientos ( $\mathrm{T}^{\circ}$-Tiempos), se constató el cumplimiento de los supuestos estadísticos en los residuos según se muestra en la Tabla 324.

Tabla 324. Pp (\%) por tratamiento: verificación de supuestos estadísticos de residuos

\begin{tabular}{|c|c|c|c|c|}
\hline Test de normalidad & Estadístico & P-valor & Bondad de ajuste & P-valor \\
\hline Chi-Cuadrado & 40,32 & 0,00 & \multirow{4}{*}{ Kolmogorov-Smirnov } & \multirow{4}{*}{0,28} \\
\hline Estadístico W de Shapiro-Wilk & 0,96 & 0,13 & & \\
\hline Valor-Z para asimetría & 0,73 & 0,46 & & \\
\hline Valor-Z para curtosis & $-0,22$ & 0,83 & & \\
\hline
\end{tabular}

\subsection{Determinación de la durabilidad frente a termitas}

\section{Análisis descriptivo: material termo-modificado expuesto al ataque de termitas}

En la Tabla 325 se resumen los parámetros descriptivos del material termo-modificado expuesto al ataque de termitas. 
Tabla 325. Termo-modificación-supervivencia al ataque de termitas: resumen estadístico y pruebas de normalidad.

\begin{tabular}{|c|c|c|c|c|c|c|c|}
\hline \multirow{3}{*}{ Tratamiento* } & \multicolumn{7}{|c|}{ Supervivencia } \\
\hline & \multirow{2}{*}{$\mathrm{DE}^{*}$} & \multirow{2}{*}{$\mathrm{SE}^{*}$} & \multirow{2}{*}{$\mathrm{CE}^{*}$} & \multicolumn{2}{|c|}{ Chi-Cuadrado } & \multicolumn{2}{|c|}{ W de Shapiro-Wilk } \\
\hline & & & & Estad. & $P$-valor & Estad. & $P$-valor \\
\hline TM 80-45 & 12,03 & $-1,15$ & 0,61 & 5,0 & 0,17 & 0,85 & 0,38 \\
\hline TM 80-90 & 5,69 & $-0,85$ & - & 5,33 & 0,07 & 0,94 & 0,51 \\
\hline TM 120-45 & 24,68 & 21,6 & 73,0 & 11,0 & 0,01 & 0,69 & 0,01 \\
\hline TM 120-90 & 2,54 & 0,17 & $-0,13$ & 2,0 & 0,57 & 1,00 & 0,99 \\
\hline TM 120-135 & 13,65 & 1,41 & 1,28 & 5,0 & 0,17 & 0,82 & 0,28 \\
\hline TM 120-180 & 20,91 & $-0,05$ & $-1,58$ & 2,0 & 0,57 & 0,93 & 0,58 \\
\hline TM 160-45 & 5,43 & $-0,38$ & - & 2,0 & 0,37 & 0,99 & 0,80 \\
\hline TM 200-45 & 7,92 & - & - & - & - & - & - \\
\hline TM 200-90 & 14,52 & 0,84 & 0,86 & 5,0 & 0,17 & 0,91 & 0,59 \\
\hline TM 200-135 & 6,35 & 1,03 & - & 5,33 & 0,07 & 0,89 & 0,36 \\
\hline TM 200-180 & 12,22 & 1,46 & 1,36 & 5,0 & 0,17 & 0,80 & 0,20 \\
\hline
\end{tabular}

*T: material sin termo-modificar: testigo; TM: material termo-modificado (los números indican combinación temperatura-tiempo, respectivamente); DE: desvio estándar; SE: sesgo estandarizado; CE: curtosis estandardizada; Estad: estadístico.

\section{Análisis comparativo: material sin modificar - termo-modificado expuesto a termitas}

En la Tabla 326 se muestra el resultado del test de Levene para la TS al ataque de termitas obtenida entre material sin termo-modificar y termo-modificado.

Tabla 326. TS (\%) R. grassei - material sin-modificar/termo-modificado: test de Levene

\begin{tabular}{ccc}
\hline \multirow{2}{*}{ Levene's } & Prueba & P-valor \\
\cline { 2 - 3 } & 5,13 & 0,03 \\
\hline
\end{tabular}

De acuerdo con el P-valor $<0,05$ hallado en el test de Levene, se utilizó el test no paramétrico de Kruskal-Wallis para evaluar las diferencias de mediantes de TS entre material sin modificar y termo-modificado.

Posteriormente, aceptado el cumplimiento de los supuestos estadísticos para los residuos, se realizó el análisis multifactorial, Tabla 327.

Tabla 327. Tasa de Supervivencia por tratamiento: verificación de supuestos estadísticos de residuos

\begin{tabular}{ccccc}
\hline Test de normalidad & Estadístico & P-valor & Bondad de ajuste & P-valor \\
\hline Chi-Cuadrado & 31,71 & 0,01 & & \\
\cline { 1 - 3 } Estadístico W de Shapiro-Wilk & 0,92 & 0,00 & \multirow{2}{*}{ Kolmogorov-Smirnov } & 0,10 \\
\hline Valor-Z para asimetría & 1,57 & 0,12 & & \\
\hline Valor-Z para curtosis & 1,38 & 0,17 & & \\
\hline
\end{tabular}


7.2. Piezas macizas semi-estructurales (escala 1:5).

\subsubsection{Ensayos no destructivos}

7.2.1.1. Determinación del MOE a través de la frecuencia propia de vibración en piezas en voladizo

\section{Análisis descriptivo: frecuencia de vibración según longitudes libres}

En la Tabla 328 se resumen los parámetros descriptivos de la frecuencia obtenida por vibración libre en piezas con orientación vertical. 
Tabla 328. Frecuencia - longitud libre (orientación vertical): resumen estadístico y pruebas de normalidad.

\begin{tabular}{|c|c|c|c|c|c|c|c|c|c|c|c|}
\hline \multirow{3}{*}{$\begin{array}{l}\text { Longitud } \\
\text { libre }\end{array}$} & \multicolumn{11}{|c|}{ Frecuencia } \\
\hline & \multirow{2}{*}{$\mathrm{DE}^{*}$} & \multirow{2}{*}{$\mathrm{SE}^{*}$} & \multirow{2}{*}{$\mathrm{CE}^{*}$} & \multicolumn{2}{|c|}{ Chi-Cuadrado } & \multicolumn{2}{|c|}{$\begin{array}{c}\text { W de Shapiro- } \\
\text { Wilk } \\
\end{array}$} & \multicolumn{2}{|c|}{$\begin{array}{c}\text { Valor-Z para } \\
\text { asimetría }\end{array}$} & \multicolumn{2}{|c|}{$\begin{array}{c}\text { Valor-Z para } \\
\text { curtosis }\end{array}$} \\
\hline & & & & Estad. & $\begin{array}{c}P \text { - } \\
\text { valor }\end{array}$ & Estad. & $\begin{array}{c}P \text { - } \\
\text { valor }\end{array}$ & Estad. & P-valor & Estad. & $P$-valor \\
\hline 0,500 & 99,15 & $\begin{array}{c}- \\
0,19 \\
\end{array}$ & $\begin{array}{c}- \\
0,09 \\
\end{array}$ & 7,5 & 0,94 & 0,99 & 0,97 & 0,14 & 0,89 & 0,10 & 0,92 \\
\hline 0,525 & 62,96 & $\overline{-}$ & 0,76 & 14,25 & 0,51 & 0,98 & 0,80 & 0,46 & 0,64 & 0,94 & 0,35 \\
\hline 0,550 & 51,06 & $\overline{-}, 02$ & $-\overline{48}$ & 10,5 & 0,79 & 0,99 & 0,90 & 0,02 & 0,99 & $-0,40$ & 0,69 \\
\hline 0,575 & 47,31 & $\overline{1,00}$ & $-\overline{32}$ & 18,0 & 0,26 & 0,98 & 0,63 & 0,75 & 0,45 & $-0,17$ & 0,86 \\
\hline 0,600 & 43,76 & $\overline{-}$ & 0,65 & 15,75 & 0,40 & 0,97 & 0,53 & 1,01 & 0,31 & 0,85 & 0,39 \\
\hline 0,625 & 36,97 & $\overline{-}$ & 0,03 & 11,25 & 0,73 & 0,98 & 0,63 & 0,29 & 0,77 & 0,25 & 0,81 \\
\hline 0,650 & 36,54 & $\overline{-}$ & 0,40 & 15,75 & 0,40 & 0,97 & 0,29 & 0,99 & 0,32 & 0,63 & 0,53 \\
\hline 0,675 & 31,89 & $\begin{array}{c}- \\
0,52 \\
\end{array}$ & $\overline{-}, 85$ & 12,75 & 0,62 & 0,97 & 0,48 & 0,39 & 0,69 & $-1,00$ & 0,32 \\
\hline 0,700 & 32,04 & $\overline{-}$ & 0,97 & 24,75 & 0,05 & 0,96 & 0,11 & 1,05 & 0,29 & 1,11 & 0,27 \\
\hline 0,725 & 27,63 & $\overline{-}$ & 0,28 & 16,5 & 0,35 & 0,98 & 0,50 & 0,99 & 0,32 & 0,51 & 0,61 \\
\hline 0,750 & 87,60 & $-\overline{29}$ & $\begin{array}{c}- \\
1,64 \\
\end{array}$ & 18,75 & 0,23 & 0,94 & 0,03 & 0,22 & 0,83 & $-2,99$ & 0,00 \\
\hline 0,775 & 50,01 & $\overline{-}, \overline{25}$ & $\begin{array}{c}- \\
0,43\end{array}$ & 13,5 & 0,56 & 0,97 & 0,29 & 0,19 & 0,85 & $-0,33$ & 0,74 \\
\hline 0,800 & 32,31 & 0,48 & $\begin{array}{c}- \\
0,63 \\
\end{array}$ & 17,25 & 0,30 & 0,98 & 0,67 & 0,36 & 0,72 & $-0,62$ & 0,54 \\
\hline 0,825 & 29,60 & $\begin{array}{c}- \\
0,71 \\
\end{array}$ & $\begin{array}{c}- \\
0,47 \\
\end{array}$ & 15,0 & 0,45 & 0,98 & 0,61 & 0,54 & 0,59 & $-0,39$ & 0,70 \\
\hline 0,850 & 27,72 & 0,37 & $\overline{-}-\overline{93}$ & 10,5 & 0,79 & 0,97 & 0,35 & 0,28 & 0,78 & $-1,15$ & 0,25 \\
\hline 0,875 & 22,15 & $\overline{-}-$ & $\overline{-}$ & 12,75 & 0,62 & 0,98 & 0,66 & 0,70 & 0,48 & 0,12 & 0,91 \\
\hline 0,900 & 21,75 & $\overline{-}-$ & $\begin{array}{c}- \\
1,60 \\
\end{array}$ & 29,25 & 0,01 & 0,94 & 0,03 & 0,12 & 0,90 & $-2,84$ & 0,00 \\
\hline 0,925 & 22,77 & $\overline{-}$ & $\overline{-}, \overline{29}$ & 12,0 & 0,68 & 0,98 & 0,62 & 0,56 & 0,58 & $-0,14$ & 0,89 \\
\hline 0,950 & 20,39 & $2, \overline{-}$ & 0,15 & 33,0 & 0,00 & 0,95 & 0,06 & 1,44 & 0,15 & 0,38 & 0,71 \\
\hline 0,975 & 18,63 & $\overline{-}, 86$ & 0,01 & 15,75 & 0,40 & 0,97 & 0,49 & 0,65 & 0,51 & 0,22 & 0,82 \\
\hline 1,000 & 33,48 & $\begin{array}{c}- \\
0,47 \\
\end{array}$ & $\begin{array}{c}- \\
1,16 \\
\end{array}$ & 9,75 & 0,84 & 0,96 & 0,14 & 0,36 & 0,72 & $-1,63$ & 0,10 \\
\hline
\end{tabular}

*DE: desvio estándar; SE: sesgo estandarizado; CE: curtosis estandardizada; Estad: estadístico.

Considerando que, al menos uno de los $\mathrm{P}$-valores hallados en las diferentes repeticiones fue superior a 0,05 , no se pudo rechazar la hipótesis de que la frecuencia obtenida en las diferentes longitudes libres proviene de una distribución normal, con un 95\% de confianza.

En la Tabla 329 se resumen los parámetros descriptivos de la frecuencia obtenida por vibración libre en piezas con orientación horizontal. 
Tabla 329. Frecuencia - longitud libre (orientación horizontal): resumen estadístico y pruebas de normalidad.

\begin{tabular}{|c|c|c|c|c|c|c|c|c|c|c|c|}
\hline \multirow{3}{*}{$\begin{array}{l}\text { Longitud } \\
\text { libre }\end{array}$} & \multicolumn{11}{|c|}{ Frecuencia } \\
\hline & \multirow{2}{*}{$\mathrm{DE}^{*}$} & \multirow{2}{*}{$\mathrm{SE}^{*}$} & \multirow{2}{*}{$\mathrm{CE}^{*}$} & \multicolumn{2}{|c|}{ Chi-Cuadrado } & \multicolumn{2}{|c|}{$\begin{array}{c}\text { W de Shapiro- } \\
\text { Wilk } \\
\end{array}$} & \multicolumn{2}{|c|}{$\begin{array}{c}\text { Valor-Z para } \\
\text { asimetría } \\
\end{array}$} & \multicolumn{2}{|c|}{$\begin{array}{c}\text { Valor-Z para } \\
\text { curtosis } \\
\end{array}$} \\
\hline & & & & Estad. & $\begin{array}{c}\mathrm{P}- \\
\text { valor }\end{array}$ & Estad. & $\begin{array}{c}\mathrm{P}- \\
\text { valor }\end{array}$ & Estad. & P-valor & Estad. & P-valor \\
\hline 0,500 & 109,21 & 0,92 & $\overline{-}, 27$ & 19,5 & 0,19 & 0,96 & 0,11 & 0,69 & 0,49 & $-0,11$ & 0,91 \\
\hline 0,525 & 55,18 & 0,07 & $\begin{array}{c}- \\
1,07 \\
\end{array}$ & 13,5 & 0,56 & 0,97 & 0,54 & 0,05 & 0,96 & $-1,43$ & 0,15 \\
\hline 0,550 & 57,70 & 0,73 & $\overline{-}, 32$ & 15,75 & 0,40 & 0,98 & 0,64 & 0,55 & 0,58 & $-0,17$ & 0,86 \\
\hline 0,575 & 41,63 & $\overline{-}$ & $\overline{-}$ & 15,75 & 0,40 & 0,97 & 0,28 & 0,05 & 0,96 & $-1,59$ & 0,11 \\
\hline 0,600 & 36,89 & $\overline{-}$ & $\overline{-}$ & 13,5 & 0,56 & 0,97 & 0,34 & 0,07 & 0,94 & $-0,92$ & 0,36 \\
\hline 0,625 & 36,64 & 0,86 & $-\overline{92}$ & 9,75 & 0,84 & 0,97 & 0,29 & 0,65 & 0,52 & $-1,13$ & 0,26 \\
\hline 0,650 & 34,43 & $\overline{-}$ & $\overline{-}$ & 21,75 & 0,11 & 0,95 & 0,07 & 0,04 & 0,97 & $-2,10$ & 0,04 \\
\hline 0,675 & 32,89 & 0,73 & 0,36 & 9,0 & 0,88 & 0,99 & 0,99 & 0,56 & 0,58 & 0,58 & 0,56 \\
\hline 0,700 & 33,43 & $\overline{-}-\overline{0}$ & $\overline{-}-$ & 6,75 & 0,96 & 0,98 & 0,62 & 0,06 & 0,96 & $-0,93$ & 0,35 \\
\hline 0,725 & 33,19 & 0,26 & $\overline{-}, \overline{98}$ & 24,75 & 0,05 & 0,96 & 0,17 & 0,20 & 0,84 & $-1,24$ & 0,22 \\
\hline 0,750 & 25,90 & $\overline{-}, 24$ & $\overline{-}$ & 12,75 & 0,62 & 0,97 & 0,28 & 0,18 & 0,85 & $-1,72$ & 0,09 \\
\hline 0,775 & 26,09 & $\overline{-}$ & $\begin{array}{c}- \\
1,07 \\
\end{array}$ & 15,0 & 0,45 & 0,97 & 0,32 & 0,32 & 0,75 & $-1,43$ & 0,15 \\
\hline 0,800 & 22,42 & 1,40 & 0,01 & 16,5 & 0,35 & 0,97 & 0,30 & 1,03 & 0,30 & 0,228 & 0,82 \\
\hline 0,825 & 24,54 & 1,08 & $0,-$ & 15,0 & 0,45 & 0,97 & 0,33 & 0,81 & 0,42 & $-0,65$ & 0,51 \\
\hline 0,850 & 20,45 & $\overline{-}$ & $\overline{-}$ & 11,25 & 0,73 & 0,96 & 0,21 & 0,24 & 0,81 & $-0,99$ & 0,32 \\
\hline 0,875 & 19,15 & 0,35 & $\overline{-}$ & 16,5 & 0,35 & 0,97 & 0,27 & 0,26 & 0,79 & $-1,57$ & 0,12 \\
\hline 0,900 & 17,19 & 0,97 & $\overline{-}-$ & 13,5 & 0,56 & 0,97 & 0,47 & 0,73 & 0,46 & $-0,24$ & 0,81 \\
\hline 0,925 & 19,46 & 0,51 & $\overline{-}$, & 15,0 & 0,45 & 0,98 & 0,79 & 0,39 & 0,70 & $-0,07$ & 0,94 \\
\hline 0,950 & 18,89 & $\begin{array}{c}- \\
0,56 \\
\end{array}$ & $\overline{-}, 99$ & 16,5 & 0,35 & 0,97 & 0,41 & 0,42 & 0,67 & $-1,27$ & 0,20 \\
\hline 0,975 & 16,23 & 0,49 & 0,13 & 7,5 & 0,94 & 0,99 & 0,95 & 0,37 & 0,71 & 0,35 & 0,73 \\
\hline 1,000 & 13,40 & $-\overline{62}$ & $\overline{-}-\overline{92}$ & 19,5 & 0,19 & 0,97 & 0,35 & 0,47 & 0,64 & $-1,13$ & 0,26 \\
\hline
\end{tabular}

*DE: desvio estándar; SE: sesgo estandarizado; CE: curtosis estandardizada; Estad: estadístico. 


\section{Análisis predictivo: frecuencia de vibración según longitud libre}

En la Tabla 330 se presentan las rectas de regresión obtenidas para cada pieza a partir de $\mathrm{f}^{2}$ y $1 / \mathrm{L}^{4}$.

Tabla 330. Ecuación de regresión: $\mathrm{f}^{2}-1 / \mathrm{L}^{4}$.

\begin{tabular}{|c|c|c|c|c|}
\hline \multirow[b]{2}{*}{ Pieza $N^{\circ}$} & \multicolumn{2}{|l|}{ Vertical } & \multicolumn{2}{|l|}{ Horizontal } \\
\hline & Ecuación de regresión* & $\mathrm{R}^{2}$ ajustado & Ecuación de regresión* & $\overline{\mathrm{R}^{2} \text { ajustado }}$ \\
\hline 1 & $\mathrm{f} 2=22505,4+87190,7 * \mathrm{~L} 4$ & 99,79 & $\mathrm{f} 2=4927,38+40671,3 * \mathrm{~L} 4$ & 99,51 \\
\hline 2 & $f 2=-9686,16+101744 * L 4$ & 99,71 & $\mathrm{f} 2=3399,1+46015,8 * \mathrm{~L} 4$ & 99,43 \\
\hline 3 & $\mathrm{f} 2=8695,74+94353,9 * \mathrm{~L} 4$ & 99,82 & $\mathrm{f} 2=1851,46+41336,3^{*} \mathrm{~L} 4$ & 99,61 \\
\hline 4 & $\mathrm{f} 2=17171,3+92857,9 * \mathrm{~L} 4$ & 99,63 & $\mathrm{f} 2=3833,66+40346,8^{*} \mathrm{~L} 4$ & 98,79 \\
\hline 5 & $\mathrm{f} 2=15371,8+85676,7 * \mathrm{~L} 4$ & 99,80 & $\mathrm{f} 2=4204,9+40339,6 * \mathrm{~L} 4$ & 99,57 \\
\hline 6 & $\mathrm{f} 2=9194,16+80967,8 * \mathrm{~L} 4$ & 99,61 & $\mathrm{f} 2=4042,23+35298,5^{*} \mathrm{~L} 4$ & 98,03 \\
\hline 7 & $\mathrm{f} 2=4455,2+71963,6^{*} \mathrm{~L} 4$ & 98,98 & $\mathrm{f} 2=3955,52+32081,2 * \mathrm{~L} 4$ & 98,66 \\
\hline 8 & $\mathrm{f} 2=10102,3+84799,6 * \mathrm{~L} 4$ & 99,68 & $\mathrm{f} 2=1857,04+38582,3 * \mathrm{~L} 4$ & 99,41 \\
\hline 9 & $\mathrm{f} 2=6584,66+80212,6 * \mathrm{~L} 4$ & 99,81 & $\mathrm{f} 2=2056,29+35896,4 * \mathrm{~L} 4$ & 99,34 \\
\hline 10 & $\mathrm{f} 2=23017,2+84678 * \mathrm{~L} 4$ & 99,47 & $\mathrm{f} 2=1758,64+39011,2 * \mathrm{~L} 4$ & 99,58 \\
\hline 11 & $\mathrm{f} 2=6851,9+82921 * \mathrm{~L} 4$ & 99,82 & $\mathrm{f} 2=710,423+37743,6^{*} \mathrm{~L} 4$ & 99,16 \\
\hline 12 & $\mathrm{f} 2=3522,71+91323 * \mathrm{~L} 4$ & 99,92 & $\mathrm{f} 2=75,6012+40615,4 * \mathrm{~L} 4$ & 99,84 \\
\hline
\end{tabular}

De acuerdo con los resultados hallados puede indicarse que el modelo ajustado explica eficientemente la variabilidad de la frecuencia, presentando una relación fuerte entre las variables.

En la Tabla 331 se resumen los parámetros correspondientes al análisis descriptivo y a las pruebas de normalidad.

Tabla 331. $E$ en vibración libre y MOE en máquina Universal: resumen estadístico y pruebas de normalidad.

\begin{tabular}{|c|c|c|c|c|c|c|c|c|c|c|c|}
\hline & \multirow{2}{*}{ DE* } & \multirow{2}{*}{$\mathrm{SE}^{*}$} & \multirow{2}{*}{$\mathrm{CE}^{*}$} & \multicolumn{2}{|c|}{ Chi-Cuadrado } & \multicolumn{2}{|c|}{$\begin{array}{l}\text { W de Shapiro- } \\
\text { Wilk }\end{array}$} & \multicolumn{2}{|c|}{$\begin{array}{l}\text { Valor-Z para } \\
\text { asimetría }\end{array}$} & \multicolumn{2}{|c|}{$\begin{array}{c}\text { Valor-Z para } \\
\text { curtosis }\end{array}$} \\
\hline & & & & Estad. & $\begin{array}{c}\mathrm{P}- \\
\text { valor }\end{array}$ & Estad. & $\begin{array}{c}\mathrm{P}- \\
\text { valor }\end{array}$ & Estad. & P-valor & Estad. & $\begin{array}{c}\mathrm{P}- \\
\text { valor }\end{array}$ \\
\hline$E$ (vertical) & 1670,94 & $\overline{-}-$ & 0,29 & 4,67 & 0,70 & 0,96 & 0,84 & 0,45 & 0,65 & - & - \\
\hline $\begin{array}{c}E \\
\text { (horizontal) } \\
\end{array}$ & 1680,72 & $\overline{0}$ & $0, \overline{34}$ & 11,33 & 0,12 & 0,94 & 0,41 & 0,75 & 0,45 & & \\
\hline MOE & 1588,59 & 0,10 & $\begin{array}{c}- \\
0,38\end{array}$ & 4,67 & 0,70 & 0,961 & 0,74 & 0,08 & 0,93 & - & - \\
\hline
\end{tabular}

De acuerdo con el análisis de normalidad, no se puede rechazar la hipótesis de que el $E$, vertical y horizontal, y el MOE provienen de una distribución normal. 
7.2.2. Ensayos destructivos: piezas dúo y trío.

\section{$\underline{\text { Análisis de centralidad y dispersión: material de ambas procedencias }}$}

En la Tabla 332 se describen las dimensiones y contenido de humedad de las piezas "parte" correspondientes a los lotes de madera encolada maciza de ambas procedencias.

Tabla 332. Dimensiones nominales y contenido de humedad de ambos lotes.

\begin{tabular}{|c|c|c|c|c|c|c|c|c|}
\hline \multirow{2}{*}{ Lotes } & \multirow{2}{*}{ Pieza } & \multirow{2}{*}{$\mathrm{n}^{*}$} & \multicolumn{2}{|c|}{$\begin{array}{l}\text { Longitud } \\
(\mathrm{cm})\end{array}$} & \multicolumn{2}{|c|}{$\begin{array}{c}\text { Anchura } \\
(\mathrm{cm})\end{array}$} & \multicolumn{2}{|c|}{$\begin{array}{l}\text { Espesor } \\
(\mathrm{cm})\end{array}$} \\
\hline & & & $\begin{array}{l}\text { Media } \\
(\mathrm{CV} \%)\end{array}$ & $\begin{array}{c}\text { Mín.-Máx. } \\
\text { (IQR) }\end{array}$ & $\begin{array}{l}\text { Media } \\
(\mathrm{CV} \%)\end{array}$ & $\begin{array}{l}\text { Mín.-Máx. } \\
\text { (IQR) }\end{array}$ & $\begin{array}{l}\text { Media } \\
(\mathrm{CV} \%)\end{array}$ & $\begin{array}{c}\text { Mín.-Máx. } \\
\text { (IQR) }\end{array}$ \\
\hline \multirow{2}{*}{ España } & Dúo & 160 & $\begin{array}{l}119,88 \\
(0,15)\end{array}$ & $\begin{array}{c}119,0-120,1 \\
(0,2)\end{array}$ & $\begin{array}{c}6,02 \\
(1,43)\end{array}$ & $\begin{array}{c}5,5-6,17 \\
(0,12)\end{array}$ & $\begin{array}{c}2,00 \\
(4,06)\end{array}$ & $\begin{array}{c}1,54-2,16 \\
(0,1)\end{array}$ \\
\hline & Trío & 135 & $\begin{array}{l}119,84 \\
(0,15)\end{array}$ & $\begin{array}{c}118,5-120,2 \\
(0,1)\end{array}$ & $\begin{array}{c}6,07 \\
(0,74) \\
\end{array}$ & $\begin{array}{c}5,93-6,15 \\
(0,06) \\
\end{array}$ & $\begin{array}{c}1,30 \\
(2,28) \\
\end{array}$ & $\begin{array}{c}1,23-1,6 \\
(0,02)\end{array}$ \\
\hline \multirow{2}{*}{ Argentina } & Dúo & 160 & $\begin{array}{l}120,28 \\
(0,21)\end{array}$ & $\begin{array}{c}119,8-120,8 \\
(0,4)\end{array}$ & $\begin{array}{c}6,39 \\
(1,23)\end{array}$ & $\begin{array}{c}6,1-6,59 \\
(0,10)\end{array}$ & $\begin{array}{c}1,90 \\
(4,86)\end{array}$ & $\begin{array}{c}1,73-2,12 \\
(0,17)\end{array}$ \\
\hline & Trío & 240 & $\begin{array}{l}119,89 \\
(0,31)\end{array}$ & $\begin{array}{c}118,8-120,8 \\
(0,4)\end{array}$ & $\begin{array}{c}6,32 \\
(2,00)\end{array}$ & $\begin{array}{c}6,07-6,73 \\
(0,15)\end{array}$ & $\begin{array}{c}1,22 \\
(6,02)\end{array}$ & $\begin{array}{c}0,98-1,56 \\
(0,08)\end{array}$ \\
\hline
\end{tabular}

*n: número de individuos; CV: coeficiente de variación en \%; IQR: recorrido intercuartílico.

\section{Análisis descriptivo: material de procedencia española}

El resumen estadístico y las pruebas de normalidad para las piezas dúos y tríos son mostrados en la Tabla 333 (Figura 551 a Figura 556, para piezas dúos y Figura 557 a Figura 562 para piezas tríos)

Tabla 333. Propiedades estructurales piezas encoladas (España): resumen estadístico y pruebas de normalidad.

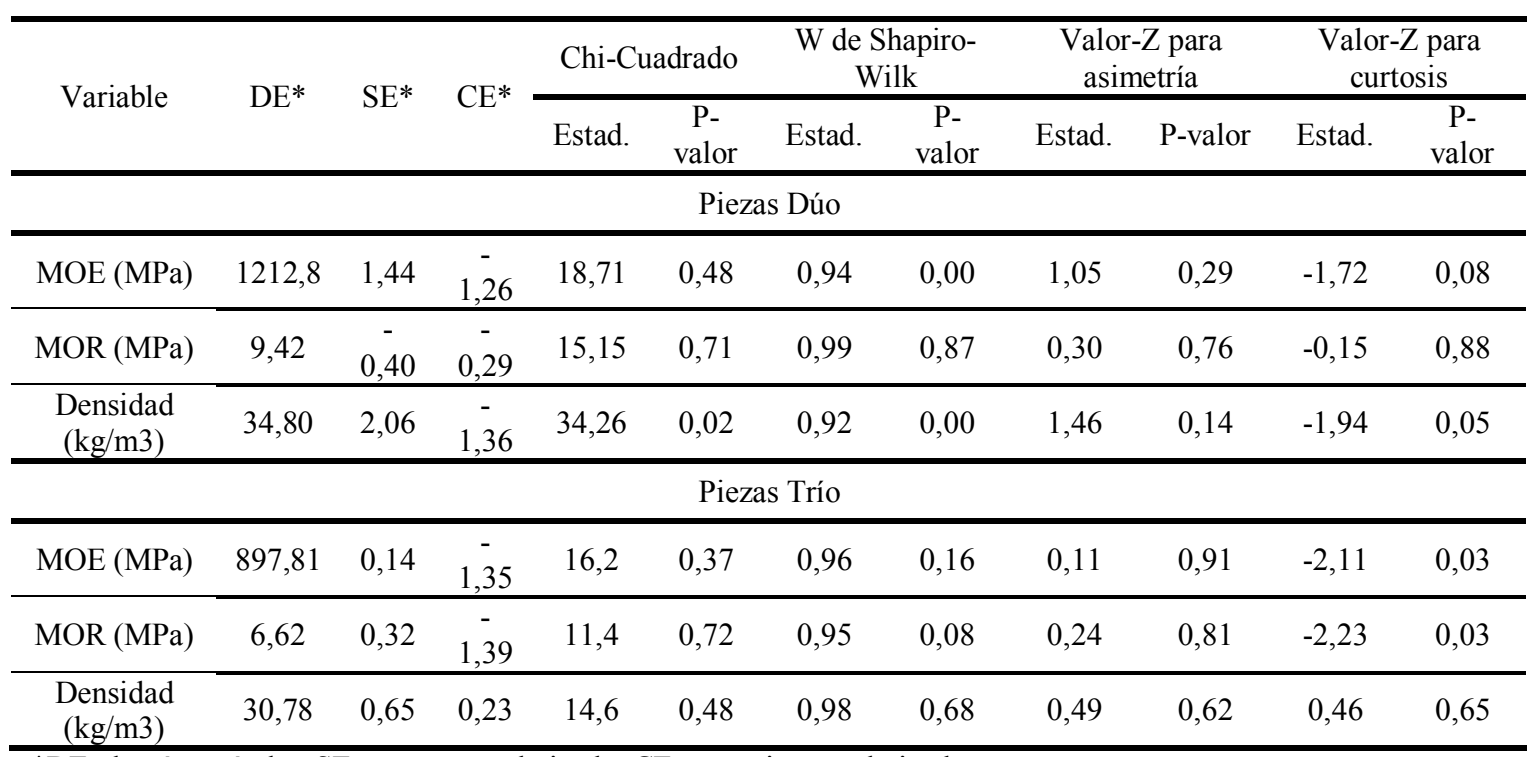

*DE: desvío estándar; SE: sesgo estandarizado; CE: curtosis estandarizada. 


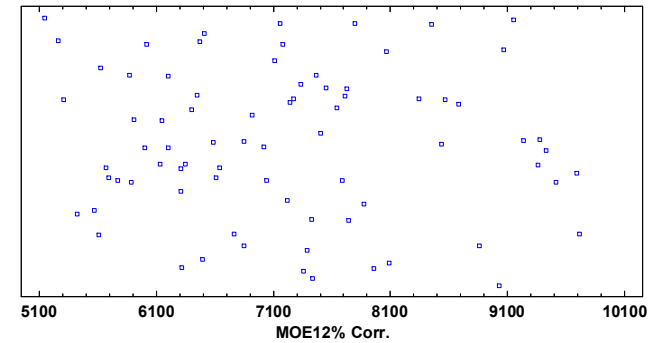

Figura 551. Piezas dúo: Gráfico de dispersión MOE - España

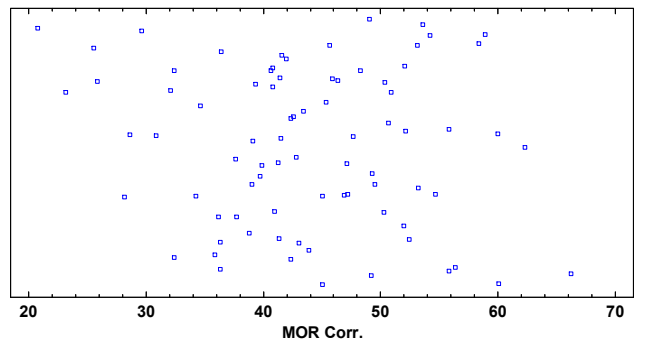

Figura 553. Piezas dúo: Gráfico de dispersión MOR - España

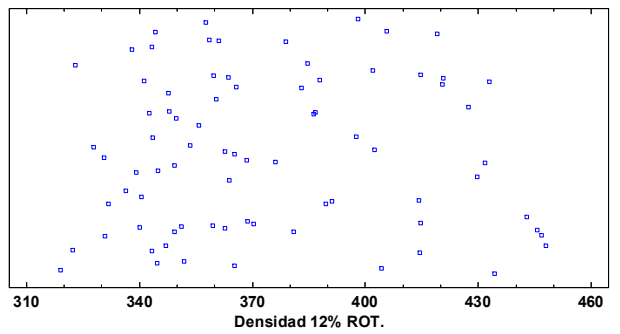

Figura 555. Piezas dúo: Gráfico de dispersión Densidad - España

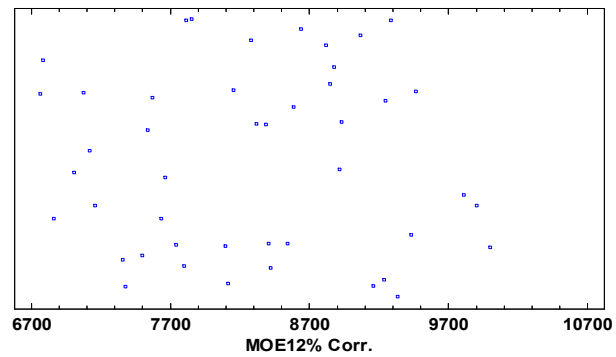

Figura 557. Piezas trío: Gráfico de dispersión MOE - España

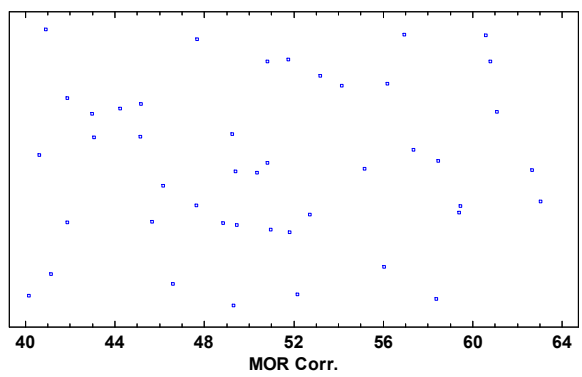

Figura 559. Piezas trío: Gráfico de dispersión MOR - España

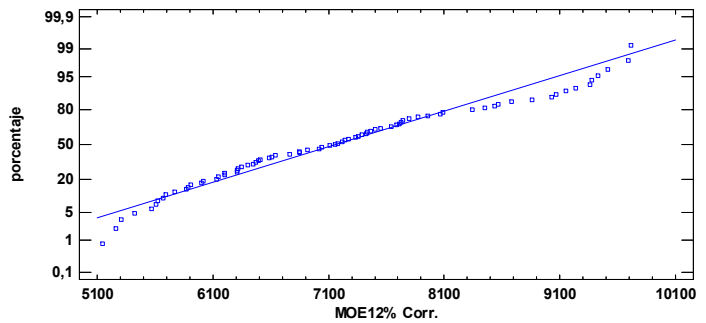

Figura 552. Piezas dúo: Gráfico probabilidad normal MOE - España

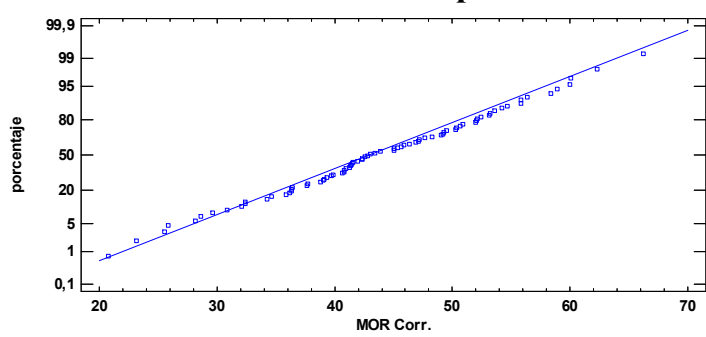

Figura 554. Piezas dúo: Gráfico probabilidad normal MOR - España

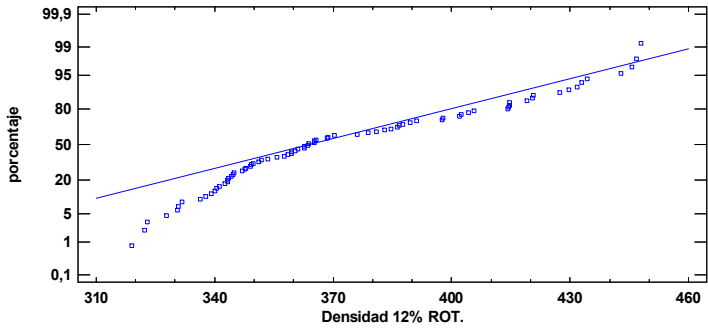

Figura 556. Piezas dúo: Gráfico probabilidad

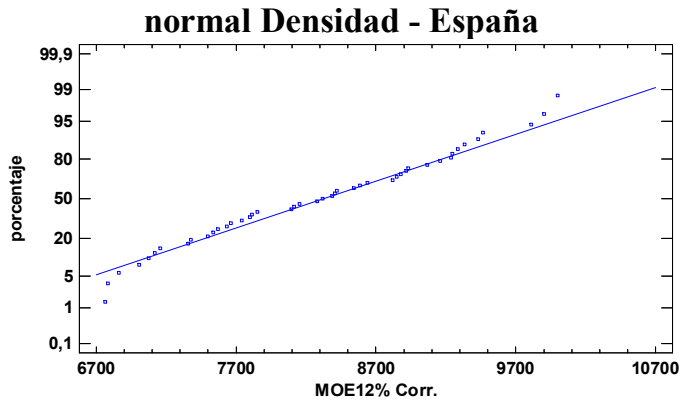

Figura 558. Piezas trío: Gráfico probabilidad normal MOE - España

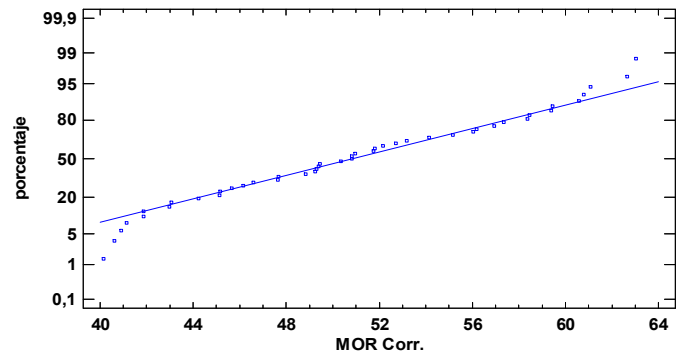

Figura 560. Piezas trío: Gráfico probabilidad normal MOR - España 


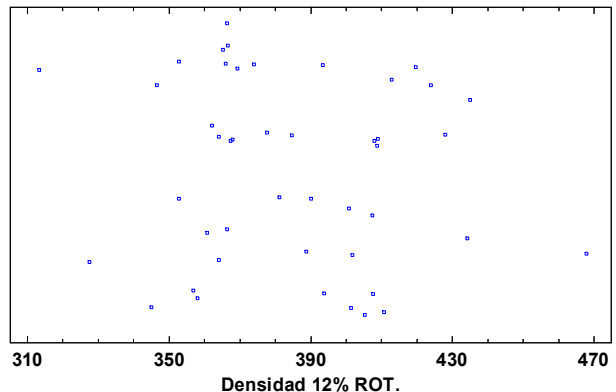

Figura 561. Piezas trío: Gráfico de dispersión Densidad - España

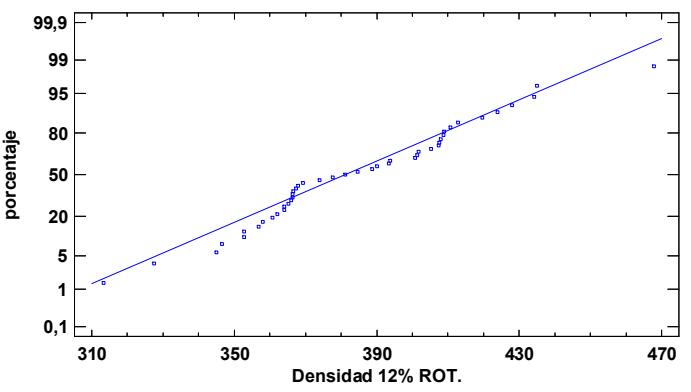

Figura 562. Piezas trío: Gráfico probabilidad normal Densidad - España

\section{Análisis descriptivo: material de procedencia argentina.}

En la Tabla 334 se muestra el resumen estadístico y las pruebas de normalidad para las propiedades estructurales del material dúo y trío (Figura 563 a Figura 568 para piezas dúos y Figura 569 a Figura 574 para piezas tríos).

Tabla 334. Propiedades estructurales piezas encoladas (Argentina): resumen estadístico y pruebas de normalidad.

\begin{tabular}{|c|c|c|c|c|c|c|c|c|c|c|c|}
\hline \multirow{2}{*}{ Variable } & \multirow{2}{*}{$\mathrm{DE}^{*}$} & \multirow{2}{*}{$\mathrm{SE}^{*}$} & \multirow{2}{*}{$\mathrm{CE}^{*}$} & \multicolumn{2}{|c|}{ Chi-Cuadrado } & \multicolumn{2}{|c|}{$\begin{array}{c}\text { W de Shapiro- } \\
\text { Wilk }\end{array}$} & \multicolumn{2}{|c|}{$\begin{array}{c}\text { Valor-Z para } \\
\text { asimetría }\end{array}$} & \multicolumn{2}{|c|}{$\begin{array}{c}\text { Valor-Z para } \\
\text { curtosis }\end{array}$} \\
\hline & & & & Estad. & $\begin{array}{c}\text { P- } \\
\text { valor }\end{array}$ & Estad. & $\begin{array}{c}\mathrm{P}- \\
\text { valor }\end{array}$ & Estad. & P-valor & Estad. & $\begin{array}{c}\mathrm{P}- \\
\text { valor }\end{array}$ \\
\hline \multicolumn{12}{|c|}{ Argentina-Dúo } \\
\hline $\mathrm{MOE}(\mathrm{MPa})$ & 929,80 & $0,-$ & $\overline{-}$ & 10,39 & 0,94 & 0,97 & 0,16 & 0,19 & 0,85 & $-1,81$ & 0,07 \\
\hline MOR (MPa) & 7,44 & $\overline{-}$ & $\overline{-}$ & 19,30 & 0,44 & 0,95 & 0,01 & 0,75 & 0,45 & $-2,37$ & 0,02 \\
\hline $\begin{array}{c}\text { Densidad } \\
\left(\mathrm{kg} / \mathrm{m}^{3}\right)\end{array}$ & 26,40 & 1,48 & $\begin{array}{c}- \\
1,04\end{array}$ & 15,7 & 0,68 & 0,96 & 0,04 & 1,07 & 0,28 & $-1,27$ & 0,20 \\
\hline \multicolumn{12}{|c|}{ Argentina-Trío } \\
\hline $\mathrm{MOE}(\mathrm{MPa})$ & 1338,19 & $\begin{array}{l}- \\
1,54 \\
\end{array}$ & $\overline{-}$ & 27,49 & 0,09 & 0,96 & 0,09 & 1,12 & 0,26 & $-0,35$ & 0,72 \\
\hline MOR (MPa) & 7,13 & $0, \overline{9}$ & $\overline{-}$ & 22,65 & 0,25 & 0,95 & 0,01 & 0,69 & 0,49 & $-2,63$ & 0,01 \\
\hline $\begin{array}{l}\text { Densidad } \\
\left(\mathrm{kg} / \mathrm{m}^{3}\right)\end{array}$ & 20,84 & $\overline{-}$ & $\overline{-}$ & 17,21 & 0,58 & 0,97 & 0,12 & 0,70 & 0,48 & $-0,95$ & 0,34 \\
\hline
\end{tabular}

*DE: desvío estándar; SE: sesgo estandarizado; CE: curtosis estandarizada.

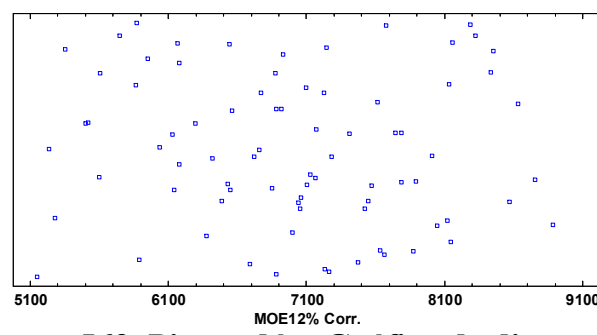

Figura 563. Piezas dúo: Gráfico de dispersión MOE - Argentina

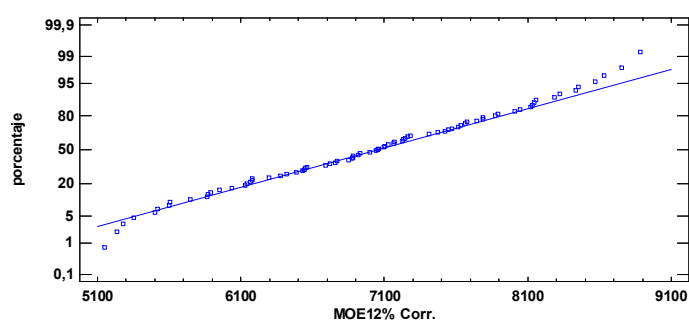

Figura 564. Piezas dúo: Gráfico probabilidad normal MOE - Argentina 


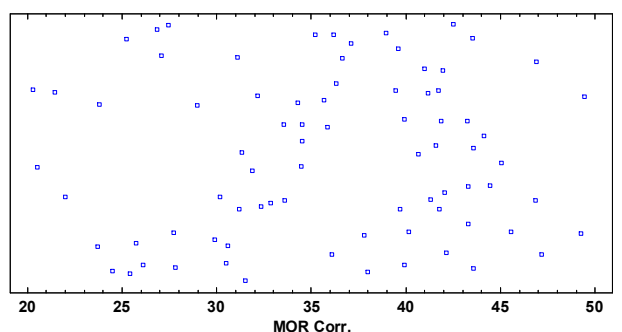

Figura 565. Piezas dúo: Gráfico de dispersión MOR - Argentina

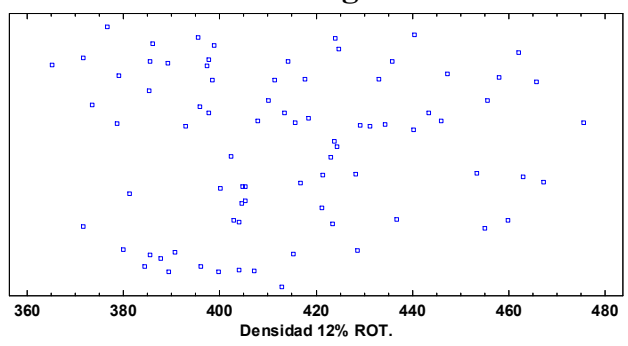

Figura 567. Piezas dúo: Gráfico de dispersión Densidad - Argentina

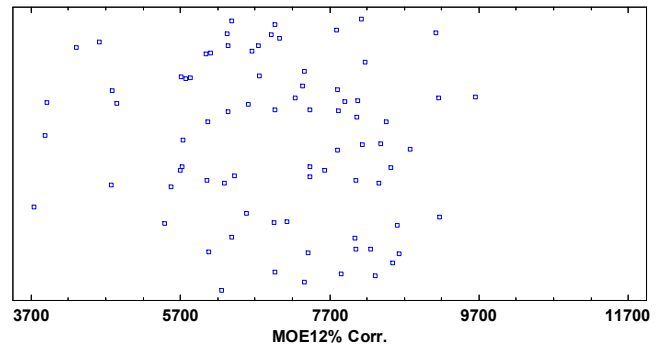

Figura 569. Piezas trío: Gráfico de dispersión MOE - Argentina

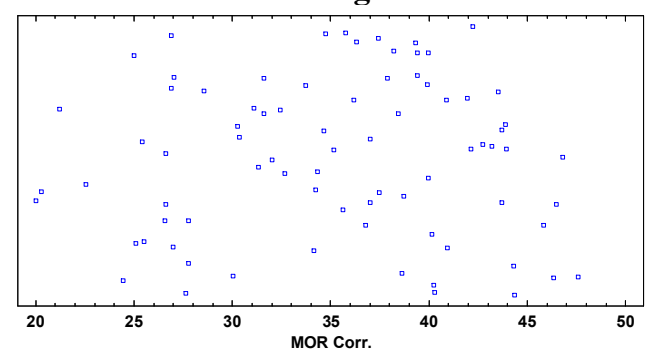

Figura 571. Piezas trío: Gráfico de dispersión MOR - Argentina

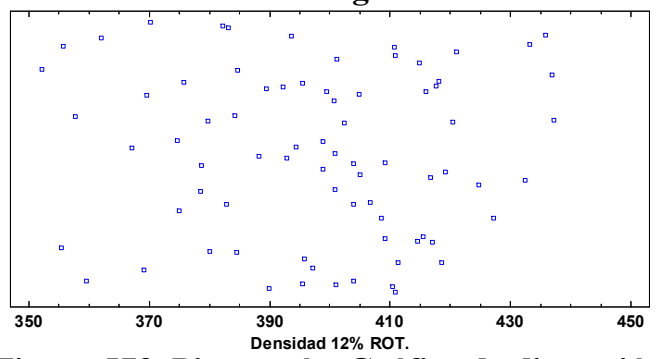

Figura 573. Piezas trío: Gráfico de dispersión Densidad - Argentina

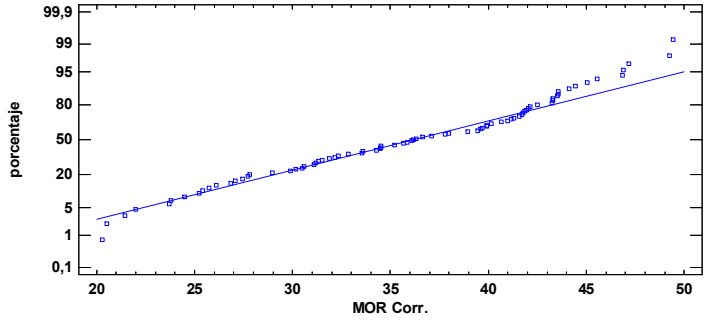

Figura 566. Piezas dúo: Gráfico probabilidad normal MOR - Argentina

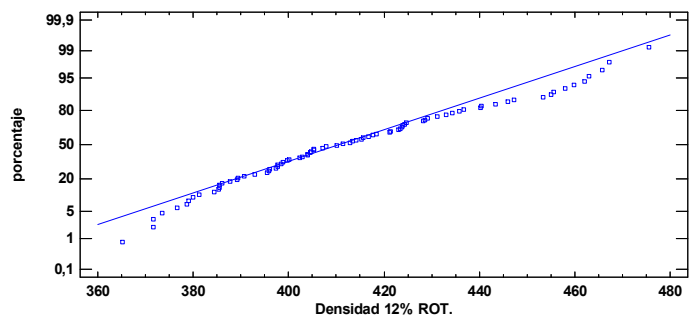

Figura 568. Piezas dúo: Gráfico probabilidad normal Densidad - Argentina

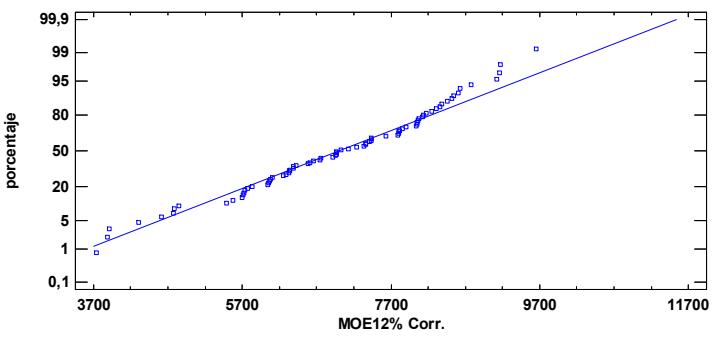

Figura 570. Piezas trío: Gráfico probabilidad normal MOE - Argentina

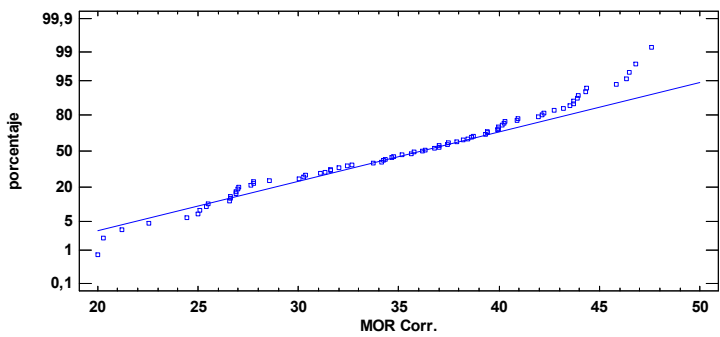

Figura 572. Piezas trío: Gráfico probabilidad normal MOR - Argentina

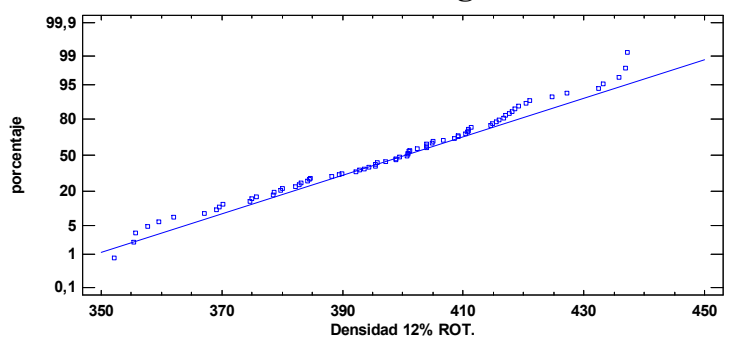

Figura 574. Piezas trío: Gráfico probabilidad normal Densidad - Argentina 


\section{Análisis comparativo: material de procedencia española}

El test de Levene para corroborar la homocedasticidad del análisis sobre MOE por tipo de pieza, se muestra en la Tabla 335.

Tabla 335. MOE - Tipo de pieza: test de Levene.

\begin{tabular}{ccc}
\hline \multirow{2}{*}{ Test de Levene } & Prueba & Valor-P \\
\cline { 2 - 3 } & 16,31 & 0,00 \\
\hline
\end{tabular}

Dado el incumplimiento de la homocedasticidad, P-valor $<0,05$, se realizó el test de Kruskal-Wallis de comparación de medianas, que fue significativo según lo presentado en Resultados y discusión; para evaluar entre que medianas se establecieron las diferencias se aplicó la comparación de a pares mediante Kruskal-Wallis, Tabla 336.

Tabla 336. MOE - Tipo de pieza: comparación de pares de medianas

\begin{tabular}{|c|c|c|c|c|c|c|c|c|}
\hline Tipo pieza & $\begin{array}{l}\text { Tamaño } \\
\text { Muestra }\end{array}$ & $\begin{array}{c}\text { Rango } \\
\text { Promedio }\end{array}$ & $\begin{array}{c}\text { Variable } \\
\text { nudos }\end{array}$ & $\begin{array}{l}\text { Tamaño } \\
\text { Muestra }\end{array}$ & $\begin{array}{c}\text { Rango } \\
\text { Promedio }\end{array}$ & $\begin{array}{l}\text { Variable } \\
\text { nudos }\end{array}$ & $\begin{array}{l}\text { Tamaño } \\
\text { Muestra }\end{array}$ & $\begin{array}{c}\text { Rango } \\
\text { Promedio }\end{array}$ \\
\hline $\bar{D}$ & 80 & 49,78 & $\mathrm{M}$ & 149 & 94,32 & $\mathrm{D}$ & 80 & 94,26 \\
\hline $\mathrm{T}$ & 45 & 81,56 & $\mathrm{~T}$ & 45 & 108,02 & $\mathrm{M}$ & 149 & 123,44 \\
\hline $\begin{array}{c}\text { Estadístico: } \\
22,93\end{array}$ & P-val & 0,00 & Estadístic & 2,06 & lor $=0,15$ & $\begin{array}{r}\text { Estadíst } \\
10,11\end{array}$ & & lor: 0,01 \\
\hline
\end{tabular}

De acuerdo con este análisis, las únicas diferencias están establecidas por las piezas dúos, P-valor $<0,05$.

El test de Levene para corroborar la homocedasticidad del análisis sobre MOR por tipo de pieza, se muestra en la Tabla 337.

Tabla 337. MOR - Tipo de pieza: test de Levene.

\begin{tabular}{ccc}
\hline \multirow{2}{*}{ Test de Levene } & Prueba & Valor-P \\
\cline { 2 - 3 } & 6,71 & 0,00 \\
\hline
\end{tabular}

Dado el incumplimiento de la homocedasticidad, $\mathrm{P}$-valor $<0,05$, se realizó el test de Kruskal-Wallis de comparación de medianas, que fue significativo según lo presentado en Resultados y discusión; para evaluar entre que medianas se establecieron las diferencias se aplicó la comparación de a pares mediante Kruskal-Wallis, Tabla 338.

Tabla 338. MOR - Tipo de pieza: comparación de pares de medianas

\begin{tabular}{|c|c|c|c|c|c|c|c|c|}
\hline Tipo pieza & $\begin{array}{l}\text { Tamaño } \\
\text { Muestra }\end{array}$ & $\begin{array}{c}\text { Rango } \\
\text { Promedio }\end{array}$ & $\begin{array}{c}\text { Variable } \\
\text { nudos }\end{array}$ & $\begin{array}{l}\text { Tamaño } \\
\text { Muestra }\end{array}$ & $\begin{array}{c}\text { Rango } \\
\text { Promedio }\end{array}$ & $\begin{array}{l}\text { Variable } \\
\text { nudos }\end{array}$ & $\begin{array}{l}\text { Tamaño } \\
\text { Muestra }\end{array}$ & $\begin{array}{c}\text { Rango } \\
\text { Promedio }\end{array}$ \\
\hline $\mathrm{D}$ & 80 & 52,75 & $\mathrm{M}$ & 149 & 90,81 & $\mathrm{D}$ & 80 & 107,56 \\
\hline $\mathrm{T}$ & 45 & 81,22 & $\mathrm{~T}$ & 45 & 119,67 & $\mathrm{M}$ & 149 & 118,99 \\
\hline $\begin{array}{c}\text { Estadístico: } \\
17,79\end{array}$ & P-va & 0,00 & Estadístic &, 13 & or $=0,00$ & Estadístic & 1,55 & alor: 0,21 \\
\hline
\end{tabular}


De acuerdo con este análisis, las únicas diferencias están establecidas por las piezas tríos, P-valor $<0,05$.

\section{Análisis comparativo: material de procedencia argentina}

El test de Levene para corroborar la homocedasticidad del análisis sobre MOE por tipo de pieza, y el test de Kruskal-Wallis se muestra en la Tabla 339.

Tabla 339. MOE - Tipo de pieza: test de Levene y test de Kruskal-Wallis

\begin{tabular}{|c|c|c|c|c|c|}
\hline \multirow{5}{*}{ Test de Levene } & Prueba & Valor-P & Tipo de pieza & Tamaño muestra & Rango promedio \\
\hline & \multirow{4}{*}{4,71} & \multirow{4}{*}{0,00} & $\mathrm{D}$ & 80 & 120,11 \\
\hline & & & $\mathrm{M}$ & 92 & 131,16 \\
\hline & & & $\mathrm{T}$ & 80 & 122,68 \\
\hline & & & Estadístico: 1,12 & $\overline{P-v a}$ & 0,57 \\
\hline
\end{tabular}

De acuerdo con el P-valor $>0,05$ del test de comparación de medianas no existen diferencias significativas entre el MOE por tipo de pieza.

El test de Levene para corroborar la homocedasticidad del análisis sobre MOR por tipo de pieza, y el test de Tukey se muestra en la Tabla 340.

Tabla 340. MOR - Tipo de pieza: test de Levene y test de ANOVA

\begin{tabular}{|c|c|c|c|c|c|}
\hline \multirow{4}{*}{ Test de Levene } & Prueba & Valor-P & Tipo de pieza & Razón F & P-valor \\
\hline & \multirow{3}{*}{0,99} & \multirow{3}{*}{0,37} & $\mathrm{D}$ & \multirow{3}{*}{2,38} & \multirow{3}{*}{0,10} \\
\hline & & & $\mathrm{M}$ & & \\
\hline & & & $\mathrm{T}$ & & \\
\hline
\end{tabular}

De acuerdo con el P-valor $>0,05$ del test de comparación de medias no existen diferencias significativas entre el MOR por tipo de pieza.

\section{Análisis comparativo entre procedencias}

El test de Levene para corroborar la homocedasticidad del análisis sobre MOE de piezas dúos por procedencias, y el test de Kruskal-Wallis se muestra en la Tabla 341.

Tabla 341. MOE pieza dúo- procedencia: test de Levene y test de Kruskal-Wallis

\begin{tabular}{|c|c|c|c|c|c|}
\hline \multirow{4}{*}{ Test de Levene } & Prueba & Valor-P & Procedencia & Tamaño muestra & Rango promedio \\
\hline & \multirow{3}{*}{5,66} & \multirow{3}{*}{0,02} & $\mathrm{E}$ & 80 & 80,84 \\
\hline & & & $\mathrm{A}$ & 80 & 76,22 \\
\hline & & & Estadístico: 0,41 & P-va & 0,52 \\
\hline
\end{tabular}

De acuerdo con el P-valor $>0,05$ del test de comparación de medianas no existen diferencias significativas entre procedencias para el MOE obtenido en piezas dúos. 
El test de Levene para corroborar la homocedasticidad del análisis sobre MOR de piezas dúos por procedencias, y el test de ANOVA se muestra en la Tabla 342.

Tabla 342. MOR pieza dúo- procedencia: test de Levene y test de ANOVA

\begin{tabular}{lccccc}
\hline \multirow{2}{*}{ Test de Levene } & Prueba & Valor-P & Procedencia & Razón F & P-valor \\
\cline { 2 - 4 } & 2,53 & 0,11 & 35,49 & 0,00 \\
\hline
\end{tabular}

De acuerdo con el P-valor $<0,05$ del test de ANOVA existen diferencias significativas entre procedencias para el MOR obtenido en piezas dúos.

El test de Levene para corroborar la homocedasticidad del análisis sobre MOE de piezas tríos por procedencias, y el test de Kruskal-Wallis se muestra en la Tabla 343.

Tabla 343. MOE pieza trío- procedencia: test de Levene y test de Kruskal-Wallis

\begin{tabular}{|c|c|c|c|c|c|}
\hline \multirow{4}{*}{ Test de Levene } & Prueba & Valor-P & Procedencia & Tamaño muestra & Rango promedio \\
\hline & \multirow{3}{*}{6,81} & \multirow{3}{*}{0,01} & $\mathrm{E}$ & 45 & 49,14 \\
\hline & & & $\mathrm{A}$ & 80 & 84,29 \\
\hline & & & Estadístico: 27,74 & $\overline{P-v a}$ & 0,00 \\
\hline
\end{tabular}

De acuerdo con el $\mathrm{P}$-valor $<0,05$ del test de comparación de medianas existen diferencias significativas entre procedencias para el MOE obtenido en piezas tríos.

El test de Levene para corroborar la homocedasticidad del análisis sobre MOR de piezas tríos por procedencias, y el test de ANOVAse muestra en la Tabla 344.

Tabla 344. MOR pieza trío- procedencia: test de Levene y test de ANOVA

\begin{tabular}{lccccc}
\hline \multirow{2}{*}{ Test de Levene } & Prueba & Valor-P & Procedencia & Razón F & P-valor \\
\cline { 2 - 4 } & 0,65 & 0,42 & E & 147,24 & 0,00 \\
\hline
\end{tabular}

De acuerdo con el P-valor $<0,05$ del test de ANOVA existen diferencias significativas entre procedencias para el MOE obtenido en piezas tríos.

\subsubsection{Valores elasto-resistentes del material encolado reagrupado por clases visuales}

En la Tabla 345 y Tabla 346 se muestra el resumen estadístico y las pruebas de normalidad para el MOE y MOR, por clases, correspondiente al material dúo de procedencia española y argentina, respectivamente. 
Tabla 345. MOE y MOR por clases (España): resumen estadístico y pruebas de normalidad.

\begin{tabular}{|c|c|c|c|c|c|c|c|c|c|c|c|}
\hline \multirow{2}{*}{ Variable } & \multirow{2}{*}{$\mathrm{DE}^{*}$} & \multirow{2}{*}{$\mathrm{SE}^{*}$} & \multirow{2}{*}{$\mathrm{CE}^{*}$} & \multicolumn{2}{|c|}{ Chi-Cuadrado } & \multicolumn{2}{|c|}{$\begin{array}{c}\text { W de Shapiro- } \\
\text { Wilk } \\
\end{array}$} & \multicolumn{2}{|c|}{$\begin{array}{c}\text { Valor-Z para } \\
\text { asimetría }\end{array}$} & \multicolumn{2}{|c|}{$\begin{array}{c}\text { Valor-Z para } \\
\text { curtosis } \\
\end{array}$} \\
\hline & & & & Estad. & $\begin{array}{c}\mathrm{P}- \\
\text { valor }\end{array}$ & Estad. & $\begin{array}{c}\mathrm{P}- \\
\text { valor }\end{array}$ & Estad. & P-valor & Estad. & P-valor \\
\hline \multicolumn{12}{|c|}{ Piezas Dúo-CS } \\
\hline $\begin{array}{l}\mathrm{MOE} \\
(\mathrm{MPa})\end{array}$ & 1321,5 & 1,53 & $\begin{array}{c}- \\
0,57\end{array}$ & 10,74 & 0,83 & 0,96 & 0,12 & 1,12 & 0,26 & $-0,52$ & 0,60 \\
\hline $\begin{array}{l}\text { MOR } \\
(\mathrm{MPa})\end{array}$ & 8,20 & 0,59 & $\overline{-}-63$ & 11,44 & 0,78 & 0,98 & 0,78 & 0,45 & 0,66 & $-0,62$ & 0,54 \\
\hline \multicolumn{12}{|c|}{ Piezas Dúo-CI } \\
\hline $\begin{array}{l}\mathrm{MOE} \\
(\mathrm{MPa})\end{array}$ & 1145,25 & 0,97 & $\overline{-}, 07$ & 5,57 & 0,35 & 0,91 & 0,42 & - & - & - & - \\
\hline $\begin{array}{l}\text { MOR } \\
(\mathrm{MPa})\end{array}$ & 4,55 & 0,55 & $\begin{array}{c}- \\
0,60\end{array}$ & 5,57 & 0,35 & 0,90 & 0,31 & & & & \\
\hline \multicolumn{12}{|c|}{ Piezas Dúo-R } \\
\hline $\begin{array}{l}\mathrm{MOE} \\
(\mathrm{MPa})\end{array}$ & 1243,91 & 1,06 & 0,25 & 12,67 & 0,18 & 0,94 & 0,28 & 0,83 & 0,40 & - & - \\
\hline $\begin{array}{l}\text { MOR } \\
(\mathrm{MPa})\end{array}$ & 9,84 & 0,67 & $\begin{array}{c}- \\
0,58\end{array}$ & 6,89 & 0,65 & 0,96 & 0,65 & 0,53 & 0,59 & - & - \\
\hline
\end{tabular}

*DE: desvío estándar; SE: sesgo estandarizado; CE: curtosis estandarizada.

Tabla 346. MOE y MOR por clases (Argentina): resumen estadístico y pruebas de normalidad.

\begin{tabular}{|c|c|c|c|c|c|c|c|c|c|c|c|}
\hline \multirow{2}{*}{ Variable } & \multirow{2}{*}{$\mathrm{DE}^{*}$} & \multirow{2}{*}{$\mathrm{SE}^{*}$} & \multirow{2}{*}{$\mathrm{CE}^{*}$} & \multicolumn{2}{|c|}{ Chi-Cuadrado } & \multicolumn{2}{|c|}{$\begin{array}{c}\text { W de Shapiro- } \\
\text { Wilk }\end{array}$} & \multicolumn{2}{|c|}{$\begin{array}{c}\text { Valor-Z para } \\
\text { asimetría }\end{array}$} & \multicolumn{2}{|c|}{$\begin{array}{c}\text { Valor-Z para } \\
\text { curtosis }\end{array}$} \\
\hline & & & & Estad. & $\begin{array}{c}\mathrm{P}- \\
\text { valor }\end{array}$ & Estad. & $\begin{array}{c}\mathrm{P}- \\
\text { valor }\end{array}$ & Estad. & P-valor & Estad. & P-valor \\
\hline \multicolumn{12}{|c|}{ Piezas Dúo-CS } \\
\hline $\begin{array}{l}\mathrm{MOE} \\
(\mathrm{MPa})\end{array}$ & 814,28 & $\overline{-}$ & $\overline{-}$ & 4,89 & 0,98 & 0,97 & 0,45 & 0,42 & 0,68 & $-0,64$ & 0,52 \\
\hline $\begin{array}{l}\text { MOR } \\
(\mathrm{MPa})\end{array}$ & 7,33 & $\overline{-}$ & 0,22 & 20,0 & 0,10 & 0,93 & 0,03 & 1,46 & 0,14 & 0,46 & 0,64 \\
\hline \multicolumn{12}{|c|}{ Piezas Dúo-CI } \\
\hline $\begin{array}{l}\mathrm{MOE} \\
(\mathrm{MPa})\end{array}$ & 319,73 & 0,34 & $\overline{-}$ & 10,14 & 0,07 & 0,82 & 0,06 & - & - & - & - \\
\hline $\begin{array}{l}\text { MOR } \\
(\mathrm{MPa})\end{array}$ & 5,22 & $\overline{-}$ & $\begin{array}{c}- \\
0,52 \\
\end{array}$ & 7,86 & 0,16 & 0,95 & 0,74 & - & - & - & - \\
\hline \multicolumn{12}{|c|}{ Piezas Dúo-R } \\
\hline $\begin{array}{l}\mathrm{MOE} \\
(\mathrm{MPa})\end{array}$ & 890,41 & 1,23 & $\overline{-}$ & 11,11 & 0,60 & 0,95 & 0,13 & 0,93 & 0,35 & $-0,24$ & 0,81 \\
\hline $\begin{array}{l}\text { MOR } \\
(\mathrm{MPa})\end{array}$ & 6,87 & 0,53 & $\begin{array}{c}- \\
1,02\end{array}$ & 13,78 & 0,39 & 0,96 & 0,36 & 0,41 & 0,68 & $-1,38$ & 0,17 \\
\hline
\end{tabular}

*DE: desvío estándar; SE: sesgo estandarizado; CE: curtosis estandarizada.

En la Tabla 347 y Tabla 348 se muestra el resumen estadístico y las pruebas de normalidad para el MOE y MOR, por clases, correspondiente al material trío de procedencia española y argentina, respectivamente. 
Tabla 347. MOE y MOR por clases visuales (España): resumen estadístico y pruebas de normalidad.

\begin{tabular}{|c|c|c|c|c|c|c|c|c|c|c|c|}
\hline \multirow{2}{*}{ Variable } & \multirow{2}{*}{$\mathrm{DE}^{*}$} & \multirow{2}{*}{$\mathrm{SE}^{*}$} & \multirow{2}{*}{$\mathrm{CE}^{*}$} & \multicolumn{2}{|c|}{ Chi-Cuadrado } & \multicolumn{2}{|c|}{$\begin{array}{c}\text { W de Shapiro- } \\
\text { Wilk }\end{array}$} & \multicolumn{2}{|c|}{$\begin{array}{c}\text { Valor-Z para } \\
\text { asimetría }\end{array}$} & \multicolumn{2}{|c|}{$\begin{array}{c}\text { Valor-Z para } \\
\text { curtosis } \\
\end{array}$} \\
\hline & & & & Estad. & $\begin{array}{c}\mathrm{P}- \\
\text { valor }\end{array}$ & Estad. & $\begin{array}{c}\mathrm{P}- \\
\text { valor }\end{array}$ & Estad. & P-valor & Estad. & P-valor \\
\hline \multicolumn{12}{|c|}{ Piezas Trío-CS } \\
\hline $\begin{array}{l}\mathrm{MOE} \\
(\mathrm{MPa})\end{array}$ & 964,20 & 0,40 & $\begin{array}{l}- \\
1,20\end{array}$ & 6,44 & 0,89 & 0,95 & 0,20 & 0,31 & 0,75 & $-1,83$ & 0,07 \\
\hline \multicolumn{12}{|c|}{ Piezas Trío-CI } \\
\hline $\begin{array}{l}\mathrm{MOE} \\
(\mathrm{MPa}) \\
\end{array}$ & 75,74 & - & - & - & - & - & - & - & - & - & - \\
\hline $\begin{array}{l}\mathrm{MOE} \\
(\mathrm{MPa})\end{array}$ & 725,41 & $\begin{array}{c}- \\
1,14 \\
\end{array}$ & 0,04 & 4,45 & 0,73 & 0,93 & 0,43 & 0,92 & 0,36 & - & - \\
\hline $\begin{array}{l}\text { MOR } \\
(\mathrm{MPa})\end{array}$ & 6,11 & 0,08 & $\begin{array}{c}- \\
0,23\end{array}$ & 4,45 & 0,73 & 0,98 & 0,99 & 0,07 & 0,95 & - & - \\
\hline
\end{tabular}

*DE: desvío estándar; SE: sesgo estandarizado; CE: curtosis estandarizada.

Tabla 348. MOE y MOR por clases visuales (Argentina): resumen estadístico y pruebas de normalidad.

\begin{tabular}{|c|c|c|c|c|c|c|c|c|c|c|c|}
\hline \multirow{2}{*}{ Variable } & \multirow{2}{*}{$\mathrm{DE}^{*}$} & \multirow{2}{*}{$\mathrm{SE}^{*}$} & \multirow{2}{*}{$\mathrm{CE}^{*}$} & \multicolumn{2}{|c|}{ Chi-Cuadrado } & \multicolumn{2}{|c|}{$\begin{array}{c}\text { W de Shapiro- } \\
\text { Wilk }\end{array}$} & \multicolumn{2}{|c|}{$\begin{array}{c}\text { Valor-Z para } \\
\text { asimetría } \\
\end{array}$} & \multicolumn{2}{|c|}{$\begin{array}{c}\text { Valor-Z para } \\
\text { curtosis }\end{array}$} \\
\hline & & & & Estad. & $\begin{array}{c}\mathrm{P}- \\
\text { valor }\end{array}$ & Estad. & $\begin{array}{c}\text { P- } \\
\text { valor }\end{array}$ & Estad. & P-valor & Estad. & P-valor \\
\hline \multicolumn{12}{|c|}{ Piezas Trío-CS } \\
\hline $\begin{array}{l}\mathrm{MOE} \\
(\mathrm{MPa})\end{array}$ & 1193,04 & $\overline{2,26}$ & 1,49 & 16,0 & 0,14 & 0,91 & 0,03 & 1,62 & 0,11 & 1,50 & 0,13 \\
\hline $\begin{array}{l}\text { MOR } \\
(\mathrm{MPa})\end{array}$ & 5,91 & $\begin{array}{c}- \\
1,80 \\
\end{array}$ & 0,30 & 7,38 & 0,77 & 0,92 & 0,04 & 1,33 & 0,18 & 0,55 & 0,58 \\
\hline \multicolumn{12}{|c|}{ Piezas Trío-CI } \\
\hline $\begin{array}{l}\mathrm{MOE} \\
(\mathrm{MPa})\end{array}$ & 584,79 & 1,17 & - & 5,33 & 0,07 & 0,83 & 0,18 & - & - & - & - \\
\hline $\begin{array}{l}\text { MOR } \\
(\mathrm{MPa})\end{array}$ & 4,81 & $0,-$ & - & 2,0 & 0,37 & 1,00 & 0,92 & - & - & - & - \\
\hline \multicolumn{12}{|c|}{ Piezas Trío-R } \\
\hline $\begin{array}{l}\text { MOE } \\
(\mathrm{MPa})\end{array}$ & 1509,01 & $\begin{array}{c}- \\
1,26\end{array}$ & 0,65 & 20,56 & 0,15 & 0,98 & 0,81 & 0,94 & 0,35 & 0,85 & 0,40 \\
\hline $\begin{array}{l}\text { MOR } \\
(\mathrm{MPa})\end{array}$ & 7,35 & 0,33 & $\begin{array}{c}- \\
1,29\end{array}$ & 21,28 & 0,13 & 0,96 & 0,17 & 0,25 & 0,80 & $-1,92$ & 0,05 \\
\hline
\end{tabular}

*DE: desvío estándar; SE: sesgo estandarizado; CE: curtosis estandarizada.

\subsection{Piezas macizas estructurales.}

\subsubsection{Evaluación no destructiva}

\subsubsection{Procedimiento para control triboluminiscente de sobrecarga en madera estructural}

La solicitud de la patente P201400866 se presenta en la Figura 575. 


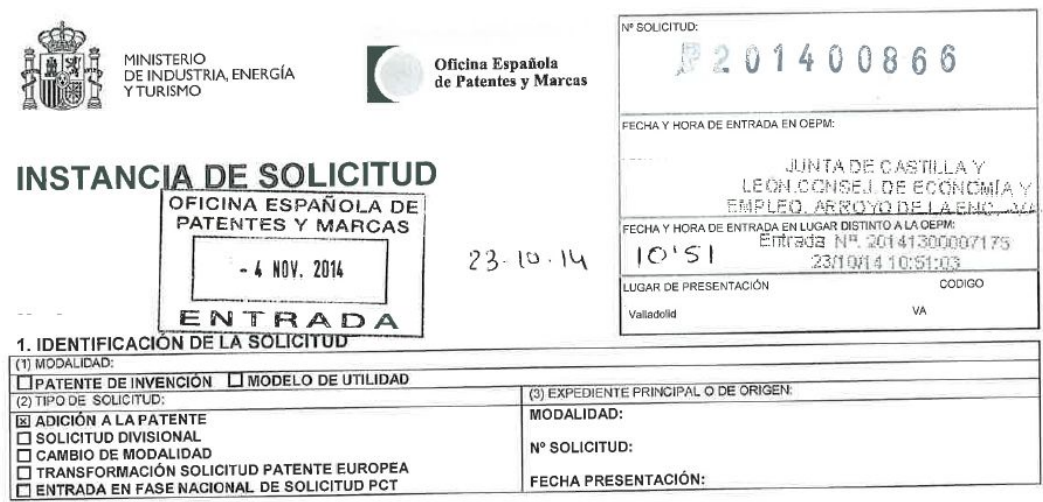

2. TÍTULO DE LA INVENCIÓN (4)

Procedimiento para control triboluminiscente de sobrecarga en madera estructural

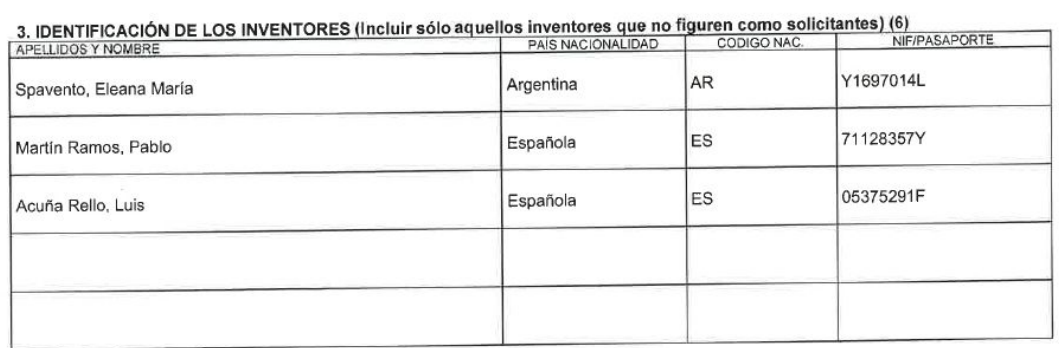

Figura 575. Solicitud de patente 